University of Louisville

ThinkIR: The University of Louisville's Institutional Repository

\title{
Post-diagnosis quality of life and mortality in non-Hispanic White and Hispanic women diagnosed with invasive breast cancer.
}

Delvon T. Mattingly

University of Louisville

Follow this and additional works at: https://ir.library.louisville.edu/etd

Part of the Epidemiology Commons

\section{Recommended Citation}

Mattingly, Delvon T., "Post-diagnosis quality of life and mortality in non-Hispanic White and Hispanic women diagnosed with invasive breast cancer." (2018). Electronic Theses and Dissertations. Paper 3014. https://doi.org/10.18297/etd/3014

This Master's Thesis is brought to you for free and open access by ThinkIR: The University of Louisville's Institutional Repository. It has been accepted for inclusion in Electronic Theses and Dissertations by an authorized administrator of ThinkIR: The University of Louisville's Institutional Repository. This title appears here courtesy of the author, who has retained all other copyrights. For more information, please contact thinkir@louisville.edu. 
POST-DIAGNOSIS QUALITY OF LIFE AND MORTALITY IN NON-HISPANIC WHITE AND HISPANIC WOMEN DIAGNOSED WITH INVASIVE BREAST

\title{
CANCER
}

\section{By}

Delvon T. Mattingly

B.S., University of Louisville, 2016

\begin{abstract}
A Thesis
Submitted to the Faculty of the

School of Public Health and Information Sciences of the University of Louisville in Partial Fulfillment of the Requirements for the Degree of

Master of Science In Epidemiology

Department of Epidemiology and Population Health University of Louisville Louisville, Kentucky
\end{abstract}


Copyright 2018 by Delvon T. Mattingly

All rights reserved 

POST-DIAGNOSIS QUALITY OF LIFE AND MORTALITY IN NON-HISPANIC WHITE AND HISPANIC WOMEN DIAGNOSED WITH INVASIVE BREAST

CANCER

By

Delvon T. Mattingly

B.S., University of Louisville, 2016

A Thesis Approved on

August 6, 2018

by the following Thesis Committee:

Thesis Director

Dr. Stephanie D. Boone

Dr. Kathy B. Baumgartner

Dr. Richard N. Baumgartner 


\section{ACKNOWLEDGEMENTS}

I would like to thank each of my committee members for their mentorship throughout the past few years. I would like to extend a special thanks to my thesis director and academic advisor, Dr. Stephanie Boone, for her personalized guidance during my experiences in the Cancer Education Program and the Master of Science in Epidemiology degree program. I would like to express gratitude to my family, especially those who've consoled me through hardship over the past couple of years. Finally, I would like to thank my biggest role model and inspiration, Thomas S. Mattingly, for his reliable and often needed advice and encouragement. 


\section{ABSTRACT \\ POST-DIAGNOSIS QUALITY OF LIFE AND MORTALITY IN NON-HISPANIC WHITE AND HISPANIC WOMEN DIAGNOSED WITH INVASIVE BREAST \\ CANCER \\ Delvon T. Mattingly \\ August 7, 2018}

The prevalence of breast cancer is increasing, and the health-related quality of life (HRQOL) of breast cancer survivors may help to further understand survivorship. This study evaluated HRQOL as a potential prognostic factor for mortality among NonHispanic White (NHW) and Hispanic women diagnosed with invasive breast cancer. Data were used from the Health, Eating, Activity, and Lifestyle (HEAL) Study. Data for 351 participants were analyzed for associations between HRQOL scores (subscale, component) and mortality. Cox proportional hazards regression was conducted to assess the relationship between HRQOL and mortality outcomes (all-cause, breast cancerspecific, non-cancer). Median follow-up time from HRQOL assessment (approximately 36-months post-diagnosis) to the end of the study period was 11.2 years. There was a statistically significant association between the physical component summary score and all mortality outcome measures for all women and when stratified by race/ethnicity. HRQOL evaluated post-diagnosis was a significant predictor of long-term mortality in this population. 
Menopausal Status.............................................................................15

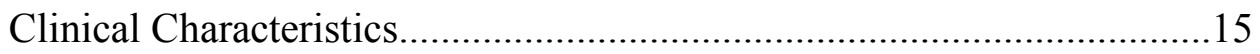

Mental/Psychosocial Characteristics.........................................................16

Lifestyle and Physical Factors...............................................................16

Possible Biological Mechanisms.......................................................................

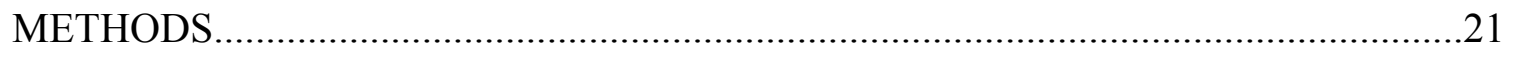

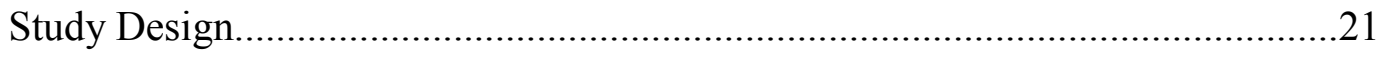

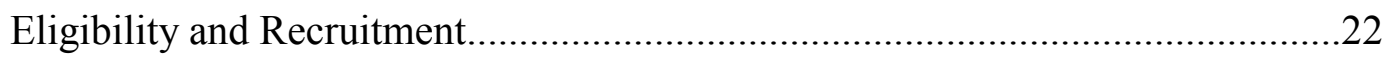

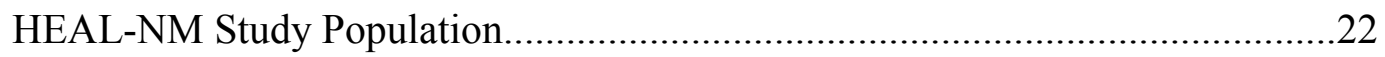

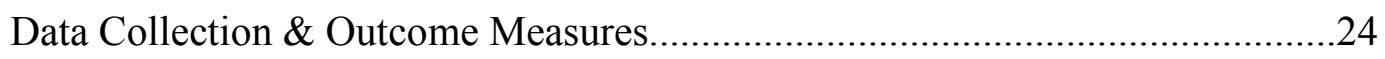

Demographic and Lifestyle Characteristics................................................25

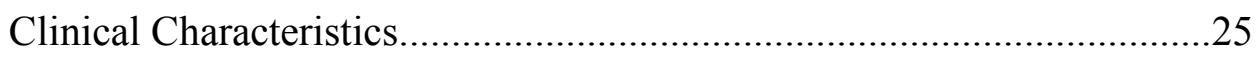

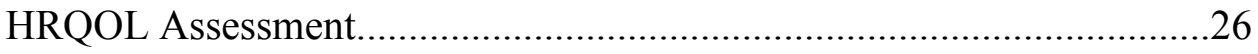

Mortality and Survival Periods.............................................................28

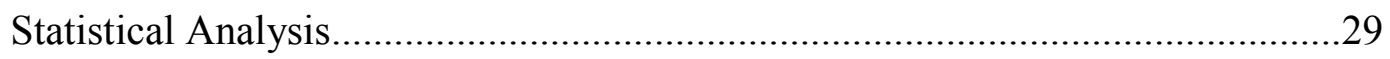

Eligible Analytic Sample Size...........................................................29

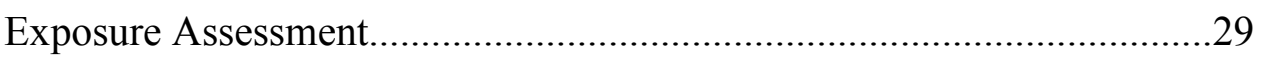

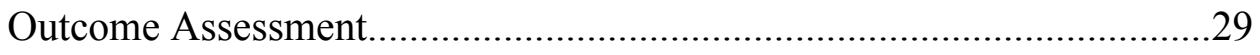

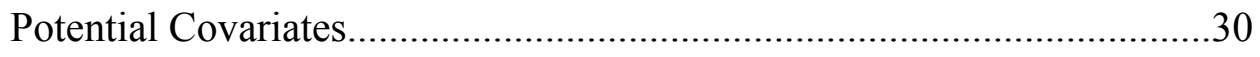

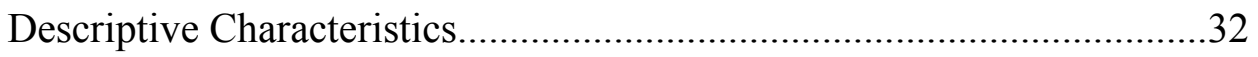

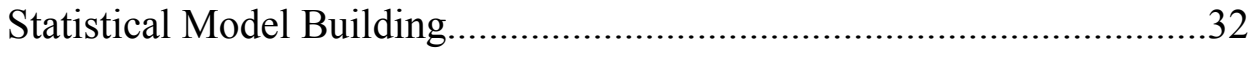

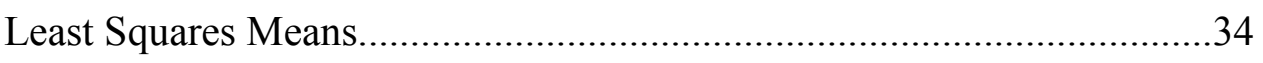

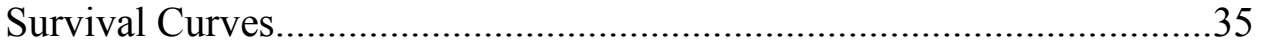


Participant Characteristics.

HRQOL Subscale and Component Summary Scores.

Associations between HRQOL and All-Cause Mortality.

MCS/PCS and All-Cause Mortality

MCS/PCS and All-Cause Mortality by Race/Ethnicity .51

HRQOL Subscales and All-Cause Mortality....

Associations between HRQOL and Breast Cancer-Specific Mortality. .53

MCS/PCS and Breast Cancer-Specific Mortality. .53

MCS/PCS and Breast Cancer-Specific Mortality by Race/Ethnicity........57

HRQOL Subscales and Breast Cancer-Specific Mortality.......................58

Associations between HRQOL and Non-Cancer Mortality................................58

MCS/PCS and Non-Cancer Mortality...............................................58

MCS/PCS and Non-Cancer Mortality by Race/Ethnicity......................62

HRQOL Subscales and Non-Cancer Mortality....................................62

Kaplan-Meier Curves and Survival Rates.....................................................66

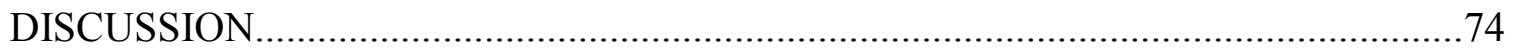

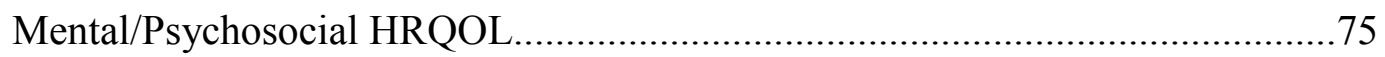

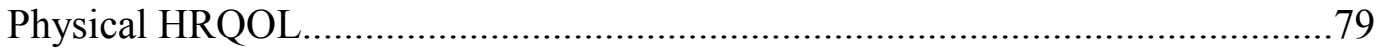

The Role of Chronic Stress and Inflammation.................................................8

HRQOL Evaluated in Other HEAL Studies..................................................82

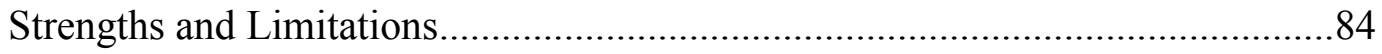


Appendix A: Studies Evaluating Health-Related Quality of Life (HRQOL) as a Predictor of Breast Cancer Prognosis.

Appendix B: Physical Component Summary Score Univariate HR Analysis and Percent Change for All-Cause Mortality when Assessing for Potential

Confounders $(N=351)$.

Appendix C: Percent Change from Crude Model and Model 1 with Each Potential Confounder (PCS \& All-Cause Mortality) $(\mathrm{N}=351)$.

Appendix D: Multivariable Modeling with Physical Component Summary Score as the Predictor and All-Cause Mortality as the Outcome $(\mathrm{N}=351)$...

Appendix E: Mental Component Summary Score Univariate HR Analysis and Percent Change for All-Cause Mortality when Assessing for Potential Confounders $(\mathrm{N}=351)$.

Appendix F: Percent Change from Crude Model and Model 1 with Each Potential Confounder (MCS \& All-Cause Mortality) $(\mathrm{N}=351)$. 155

Appendix G: Multivariable Modeling with Mental Component Summary Score as the Predictor and All-Cause Mortality as the Outcome $(\mathrm{N}=351)$.... 163

Appendix H: Physical Component Summary Score Univariate HR Analysis and Percent Change for Breast Cancer-Specific Mortality when Assessing for

Potential Confounders $(\mathrm{N}=351)$. 178

Appendix I: Mental Component Summary Score Univariate HR Analysis and Percent Change for Breast Cancer-Specific Mortality when Assessing for Potential Confounders $(\mathrm{N}=351)$......

Appendix J: Physical Component Summary Score Univariate HR Analysis and Percent Change for Non-Cancer Mortality when Assessing for Potential Confounders $(\mathrm{N}=351)$. 193

Appendix K: Percent Change from Crude and Model 1 with Each Potential Confounder (PCS \& Non-Cancer Mortality) $(\mathrm{N}=351)$... .200

Appendix L: Multivariable Modeling with Physical Component Summary Score as the Predictor and Non-Cancer Mortality as the Outcome $(\mathrm{N}=351)$ .208 
Appendix M: Mental Component Summary Score Univariate HR Analysis and Percent Change for Non-Cancer Mortality when Assessing for Potential

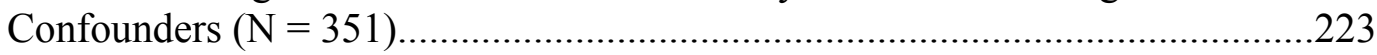

Appendix N: Percent Change from Crude and Model 1 with Each Potential

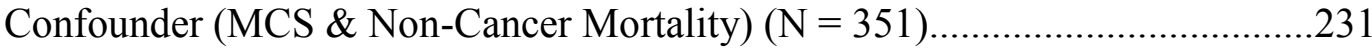

Appendix O: Multivariable Modeling with Mental Component Summary Score as the Predictor and Non-Cancer Mortality as the Outcome $(\mathrm{N}=351) \ldots \ldots \ldots \ldots \ldots . . . .239$

Appendix P: Kaplan-Meier Curves: (All-Cause) Survival Probability Estimates

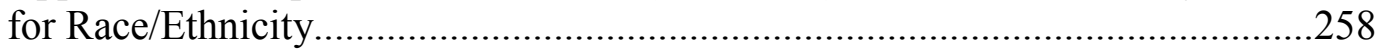

Appendix Q: Kaplan-Meier Curves: (BCS) Survival Probability Estimates for PCS Tertiles. .259

Appendix R: Kaplan-Meier Curves: (BCS) Survival Probability Estimates for

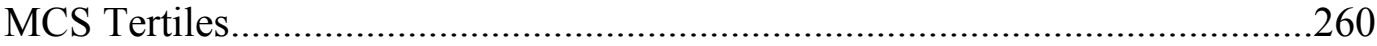

Appendix S: Kaplan-Meier Curves: (BCS) Survival Probability Estimates for Race/Ethnicity. 261

Appendix T: Kaplan-Meier Curves: (Non-Cancer) Survival Probability Estimates for PCS Tertiles. .262

Appendix U: Kaplan-Meier Curves: (Non-Cancer) Survival Probability Estimates for MCS Tertiles. 263

Appendix V: Kaplan-Meier Curves: (Non-Cancer) Survival Probability Estimates for Race/Ethnicity .264

Appendix W: Kaplan-Meier Curves: (All-Cause) Survival Probability Estimates for MCS Tertiles by Race/Ethnicity (NHW Women). .265

Appendix X: Kaplan-Meier Curves: (All-Cause) Survival Probability Estimates for MCS Tertiles by Race/Ethnicity (Hispanic Women). .266

Appendix Y: Kaplan-Meier Curves: (Non-Cancer) Survival Probability Estimates for MCS Tertiles by Race/Ethnicity (NHW Women).

Appendix Z: Kaplan-Meier Curves: (Non-Cancer) Survival Probability Estimates for MCS Tertiles by Race/Ethnicity (Hispanic Women)...................................268 


\section{LIST OF TABLES}

TABLE

PAGE

1. Demographic Characteristics of HEAL Participants Who Completed the HRQOL Assessment Compared to Non-respondents, The HEAL Study New Mexico Site $(N=615)$ 38

2. Demographic Characteristics of HEAL Participants with Invasive Breast Cancer by Vital Status $(N=351)$ .41

3. Comparisons of HRQOL SF-36 Subscale and Component Summary Scores by Vital Status $(N=351)$ .45

4. Comparisons of HRQOL SF-36 Component Summary Score Tertiles by Vital Status $(N=351)$ 48

5. Associations between HRQOL SF-36 Mental \& Physical Component Summary Score Tertiles and All-Cause Mortality $(N=351)$. 50

6. Associations between HRQOL SF-36 Mental \& Physical Component Summary Score Tertiles and All-Cause Mortality by Race/Ethnicity $(N=351)$...... .52

7. Associations between HRQOL SF-36 Subscale Scores and All-Cause Mortality $(N=351)$ .54

8. Associations between HRQOL SF-36 Mental \& Physical Component Summary Score Tertiles and Breast Cancer-Specific Mortality $(N=351)$ .56

9. Associations between HRQOL SF-36 Mental \& Physical Component Summary Score Tertiles and Breast Cancer-Specific Mortality by Race/Ethnicity $(N=351)$

10. Associations between HRQOL SF-36 Subscale Scores and Breast Cancer-Specific Mortality $(N=351)$

11. Associations between HRQOL SF-36 Mental \& Physical Component Summary Score Tertiles at and Non-Cancer Mortality $(N=351)$. .61 
12. Associations between HRQOL SF-36 Mental \& Physical Component Summary Score Tertiles and Non-Cancer Mortality by Race/Ethnicity $(N=$ 351). .63

13. Associations between HRQOL SF-36 Subscale Scores and Non-Cancer Mortality $(N=351)$. .64 


\section{LIST OF FIGURES}

FIGURE

PAGE

1. Study Participation Flow_HEAL Study New Mexico Site................................23

2. HEAL New Mexico Site Follow-Up and Survival Time...................................28

3. Kaplan-Meier Curves: (All-Cause) Survival Probability Estimates for PCS

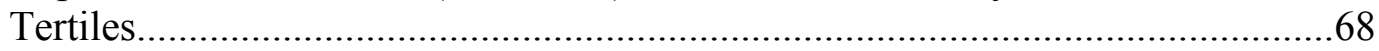

4. Kaplan-Meier Curves: (All-Cause) Survival Probability Estimates for MCS

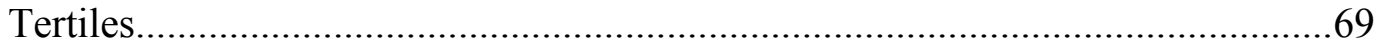

5. Kaplan-Meier Curves: (All-Cause) Survival Probability Estimates for PCS Tertiles by Race/Ethnicity (NHW Women)..................................................70

6. Kaplan-Meier Curves: (All-Cause) Survival Probability Estimates for PCS Tertiles by Race/Ethnicity (Hispanic Women)..................................................71

7. Kaplan-Meier Curves: (Non-Cancer) Survival Probability Estimates for PCS Tertiles by Race/Ethnicity (NHW Women)................................................. 72

8. Kaplan-Meier Curves: (Non-Cancer) Survival Probability Estimates for PCS Tertiles by Race/Ethnicity (Hispanic Women).................................................73 


\title{
INTRODUCTION
}

\begin{abstract}
Summary
Breast cancer remains a leading cause of cancer-related diagnoses and deaths in women (1). The estimated number of breast cancer survivors is rising due to increasing rates of long-term survival, and improving survivorship $(1,2)$. Minority women, most notably African American and Hispanic women, in the United States tend to have poorer breast cancer prognosis and survival outcomes compared to their Non-Hispanic White (NHW) counterparts (3-7). However, recent studies have suggested that this is inconclusive when comparing NHW and Hispanic women (8-10). Measures of healthrelated quality of life (HRQOL) encompass the overall well-being of individuals while assessing areas of interest that may be affected by illness or post-diagnosis treatments (11). While breast cancer survivors are living longer, they may require mental and physical adjustment in response to their diagnosis and treatment (12). Studies assessing HRQOL as a predictor of breast cancer prognosis, including studies evaluating the impact of HRQOL in long-term breast cancer survivor populations are limited $(13,14)$, as well as similar studies of underrepresented populations, such as Hispanic women $(15,16)$.
\end{abstract}




\section{Objective}

Utilizing data from the New Mexico site of the Health Eating Activity and Lifestyle (HEAL) study, the objective of this study is to evaluate Health-Related Quality of Life (HRQOL) at 36-months post-diagnosis and determine its association with mortality among Hispanic and NHW women diagnosed with invasive breast cancer.

\section{Specific Aims}

1. To compute HRQOL subscale and MCS and PCS scores by all-cause, breast cancer-specific, and non-cancer mortality.

2. To determine if survival probabilities differ by HRQOL MCS and PCS scores measured at 36-months post-diagnosis among all women and by ethnic groups.

3. To evaluate the association of HRQOL subscale and MCS and PCS scores at 36months post-diagnosis with all-cause, breast cancer-specific, and non-cancer mortality among all women and by ethnic groups, adjusting for relevant confounders.

\section{Hypotheses}

1. There will be differences in HRQOL subscale and MCS and PCS scores between women who are alive and women who died from all-cause, breast cancer-specific, and non-cancer mortality.

2. Survival probabilities in women with poorer HRQOL will significantly differ from women with better HRQOL overall and by ethnic group. 
3. Women with poorer HRQOL MCS and PCS scores will be at higher risks of dying by all-cause, breast cancer-specific, and non-cancer mortality, compared to their counterparts with better HRQOL. These associations will reflect similarly among a few HRQOL subscales but not all of them. 


\section{LITERATURE REVIEW}

\section{Breast Cancer Survivorship in the U.S.}

Breast cancer remains a leading cause of cancer-related diagnoses and deaths in women with an estimated incidence of 266,120 new diagnoses and 40,920 estimated deaths in 2018 (1). In breast cancer patients receiving treatment, long-term survival is common, with a 5 -year survival rate of nearly $90 \%(1,2), 83 \%$ for 10 -year survival (2), and $78 \%$ for 15 -year survival (2). Survivorship is defined simply as "Living with, through, and beyond cancer," (17). Since long-term survival rates are increasing, breast cancer survivors face a multitude of convoluted barriers when dealing with the implications of their diagnoses and treatments, including pre-existing or developed comorbid conditions, during survivorship (18).

As of January, 2016, the estimated number of breast cancer survivors in the United States is 3,560,570, and this is theorized to increase to 4,571,210 by January, 2026 (2). Post-treatment, breast cancer survivors contend with life-changing responsibilities such as seeking follow-up medical care, developing a wellness plan-which includes ways to take care of physical, emotional, social, and spiritual needs — and staying in contact with a physician or cancer specialist (19). The American Cancer Society recommends a number of guidelines for survivorship care, including the evaluation and management of physical and mental/psychosocial effects of diagnosis and treatment (20). 


\section{HRQOL and Breast Cancer Survivorship}

The burden of breast cancer at diagnosis and throughout survivorship may require mental/psychosocial and physical adjustment, which has often been described as selfreported health-related quality of life (HRQOL) (12). While survivorship increases in breast cancer survivors, so will a variety of health problems, derived from breast cancer or its treatment over short- or long-term survivorship, which may require care. These health problems can exacerbate the well-being of survivors, and studies have suggested that HRQOL is a good indicator of detriments related to breast cancer survivorship (21, 22). Considering the increasing survival rates for women diagnosed with breast cancer, limited research has evaluated the effects of HRQOL measured post-diagnosis on longterm survival or mortality $(14,16,22-24)$. By 2026, the population of breast cancer survivors is expected to increase by approximately $30 \%$ (25). Since HRQOL may have a direct impact on breast cancer outcomes, understanding the relationship between them is important to bolster survivorship research and improve specified developments of interventions and clinical care tactics, including guidelines recommended by the ACS (20).

\section{Breast Cancer Survival and Mortality in Hispanic Women}

The latest SEER cancer registry data estimates that in 2015 incidence of breast cancer in NHW women was 133.8 per 100,000 individuals, compared to 90.3 per 100,000 in Hispanic women (1), a 38.8\% difference between the two populations. 
Although breast cancer incidence is higher in NHW women, Hispanic women tend to have poorer breast cancer prognosis, higher odds of being diagnosed with estrogen-receptor/progesterone-receptor negative (ER-/PR-) breast cancer subtypes, a greater number of positive lymph nodes, higher odds of being diagnosed with more advanced breast cancer, and poorer survival outcomes. These outcomes include a higher risk of breast-cancer specific mortality and a poorer HRQOL compared to NHW cases (3-7). However, recent studies suggest this is inconclusive (8-10). Recent Centers for Disease Control and Prevention (CDC) projections indicated that Hispanic women have a lower rate of breast cancer-related death per 100,000 women (13.6) compared to NHW women (19.8) (9). A 2017 report concluded that 5-year survival by tumor stage is relatively similar between Hispanic and NHW women. When Hispanic women were diagnosed with a distant or unknown tumor stage, their survival was higher than NHW women (10).

Many established risk factors that impact breast cancer prognosis have been compared between NHW and Hispanic women (26-28). Despite growing evidence that breast cancer survival is improving in minorities, due to better cancer screening and treatment strategies, disparities in clinical characteristics and mortality persist and remain unexplained (29). A better understanding of prognosis following a breast cancer diagnosis in diverse populations is important, given that between 2016 and 2017, the Hispanic population accounted for over half of the U.S. population growth (30), and it is projected to almost double from 56 million to 119 million by 2060 (31). A research gap exists evaluating the relationship between HRQOL and breast cancer prognosis in minority populations, including Hispanic women (32). 


\section{Overall HRQOL}

HRQOL is an evolving concept that may have either positive or negative associations with cancer survival depending on the way it is defined. HRQOL is commonly defined in terms of physical and mental responses to illness, as measured from self-reported information on functional, psychological, social, spiritual, and sexual wellbeing $(33,34)$. There are several validated instruments used to measure HRQOL in cancer patients. These include the 36-item Short Form Health Survey (SF-36) $(35,36)$; the Functional Assessment of Cancer Therapy, both the General (FACT-G) version and the Breast Cancer-specific (FACT-B) version $(37,38)$; and the European Organization for Research and Treatment of Cancer Quality of Life Questionnaire (EORTC QLQ-C30) $(39,40)$. Some studies use a combination of psychosocial scales to evaluate HRQOL among women diagnosed with breast cancer (41-43).

The SF-36 instrument, which is used to evaluate physical and mental HRQOL across various chronic diseases and validated among diverse population groups (35), was chosen as the primary instrument used for this thesis study. Eight subscales can be derived from the 36 questions to measure physical and mental domains of HRQOL. Physical functioning, role limitations-physical (role physical), bodily pain, and general health subscales are used to calculate a physical health component summary score; and social functioning, role limitations-emotional (role emotional), vitality, and mental health subscales are used to calculate a mental health component summary score $(44,45)$. Measures of HRQOL summarize the overall well-being of individuals while assessing specific areas of interest that may be affected by an individual's condition of disease as well as by treatment (11). 
Previous studies suggest that Hispanic women diagnosed with breast cancer frequently report lower overall HRQOL compared to NHW cases (32). Additionally, they report a lower socioeconomic status, and are usually diagnosed at a younger age and a later tumor stage (32) Some studies suggest that a disparity exists between NHW and Hispanic women for HRQOL, which may be related to differences in socioeconomic status, treatment, and cultural factors $(32,46)$.

\section{Mental/Psychosocial HRQOL}

Breast cancer survivors experience mental/psychosocial adjustment postdiagnoses and pre- and post-treatment (47-49). Mental HRQOL in breast cancer survivors is primarily associated with age (28), stress (50), anxiety (41), depression (41, 51-53), social support $(54,55)$, coping (56), feelings of helplessness/hopelessness (57), and religiosity/spirituality (58); however, much of the extant research evaluate ethnically homogenous populations, or populations containing one predominant race/ethnicity. Among these factors, declines in mental/psychosocial HRQOL were associated with younger age at diagnosis (28), higher stress (50), higher anxiety (41), higher depression or more depressive symptoms $(41,51-53)$, social isolation (including low levels of social support) $(54,55)$, negative forms of coping (56), feeling helpless/hopeless (57), and lower levels of religiosity/spirituality (58). Some studies have suggested that components of mental HRQOL have been shown to improve over time in breast cancer patients shortly after diagnosis (59) and after short-term treatment (60), while other aspects have suggested some exacerbate HRQOL (61). Mental HRQOL is theorized to be lower in Hispanic women compared to NHW women for all cancers (61). Hispanics may also 
report poorer psychological and emotional well-being compared to other ethnic groups $(15,62)$.

\section{Physical HRQOL}

A breast cancer diagnosis and the effects of breast cancer treatment influence physical HRQOL (59). Factors associated with physical HRQOL in breast cancer survivors include, but may not be limited to, age $(28,63)$, physical activity $(64,65)$, treatment type $(60,66)$ including mastectomy $(52)$, psychological well-being $(63)$, social support $(54,55)$, body mass index $(\mathrm{BMI})(16,67,68)$, fatigue $(53,64,69,70)$, and pain $(69,71)$. Long-term breast cancer survivors usually report good HRQOL, yet these women may still experience some physical-related complications (72). Among these factors, declines in physical HRQOL were associated with younger age at diagnosis (28), yet conversely other studies revealed that younger age was predictive of higher HRQOL (63), lower physical activity $(64,65)$, not receiving treatment $(60,66)$, receiving a mastectomy (52), lower psychological well-being (63), lack of social support (54), obesity $(16,67,68)$, present fatigue $(53,64,69,70)$, and present pain $(69,71)$

In minorities specifically, physical HRQOL is higher when patients are diagnosed with a lower stage of disease, fewer comorbidities, exercise more, and have healthier diets. (51). Compared to other ethnic groups, Hispanic breast cancer survivors report more physical symptoms during survivorship (73), and declines in physical and functional well-being are significantly associated with survival (50). Additional factors, such as sexual functioning, responses to treatments and therapies, pain, and fatigue, impact HRQOL post-breast cancer diagnosis $(46,49)$. In a multi-ethnic sample of breast 
cancer survivors including Europeans, Africans, Latinas, and Asians, socio-ecological factors and health care varied by race/ethnicity, while psychological well-being showed consistency, suggesting a relationship driven by physical components of HRQOL one to five years post-diagnosis (63). In long-term breast cancer survivors, treatment type is predictive of HRQOL, specifically chemotherapy worsening physical-related HRQOL (74).

Clarifying how differences in HRQOL influence mortality is necessary in understanding survival disparities in cancer patients. Studies assessing HRQOL as a predictor of short- and long-term breast cancer survival are limited, especially studies including underrepresented populations, such as Hispanic women $(15,16)$.

\section{HRQOL and Breast Cancer Prognosis}

Previous epidemiologic studies have assessed indicators of poorer HRQOL in breast cancer survivors $(23,28,41,52,58,75-77)$ while other studies have evaluated levels of HRQOL in breast cancer survivors to understand health-related experiences of survivorship $(24,32,46,55,59)$. Of the studies that have assessed HRQOL as a predictor of breast cancer prognosis $(13,14,42,43,50,78-82)$, few have focused on underrepresented populations $(62,83)$. A meta-analysis evaluating HRQOL as a prognostic predicator of cancer survival in patients, using studies assessing HRQOL via the EORTC QLQ-C30, found that HRQOL may be useful in distinguishing survival patterns (81). Research examines the HRQOL status of breast cancer survivors, with fewer studies utilizing HRQOL as a predictor of breast cancer prognosis, as well as longitudinal designs that can evaluate survival over a long-term $(13,14)$. Among these 
longitudinal studies, a report suggested that changes in components of HRQOL may have an impact on survival (14).

Though, the relationship between HRQOL and breast cancer prognosis isn't fully understood, studies evaluating components of HRQOL show that factors are positively and negatively associated with the risk of breast cancer prognosis (84).

\section{$\underline{\text { HRQOL Factors }}$}

Perceived social support, social networks, and marriage are positive indicators of a lower risk of breast cancer mortality $(85,86)$. A study examining the association between post-diagnosis HRQOL in breast cancer patients and breast cancer mortality and recurrence found that social well-being at baseline is a significant indicator of mortality (HR: 0.62, 95\% CI: 0.46, 0.85) and recurrence (HR: $0.52,95 \%$ CI: 0.38, 0.71) (83).

In a study by Goodwin et al., better role functioning and better avoidance significantly $(\mathrm{p}<0.05)$ predicted a lower risk of overall survival $(\mathrm{HR}=0.56$ and 0.48 , respectively), while domestic environment was significantly associated with a 1.5 -fold increased risk of death (42). Other studies have indicated that high scores for anxious preoccupation are associated with poorer distant disease-free survival and overall survival (78). Helplessness or hopelessness also has been reported as an indicator of poorer disease-free survival (HR: 1.53; 95\% CI: 1.11, 2.11), with a significant effect maintained over ten years of follow-up (14). Findings from two studies suggested that better emotional functioning is associated with improved survival (HR: 0.81; 95\% CI: 0.70, $0.95)(13)$ and (HR: $0.49 ; 95 \%$ CI: 0.22, 1.09) (50). However, both studies used different HRQOL measurements and assessed HRQOL at different time points $(13,50)$. In a 
systematic review of studies evaluating the impact of psychosocial factors on breast cancer prognosis, at least $80 \%$ found a significant protective or exacerbating association between one or more psychosocial factors and survival or recurrence (62).

Several studies have shown a significant association between mental HRQOL components and breast cancer prognosis $(13,14,42,43,50,80,83)$. Some reported that higher mental-related functioning predicted lower risk of dying from breast cancer in (83, 87), with hazard ratios ranging from 0.56 to $0.66(83,87)$. However, one study reported that breast cancer survivors with higher cognitive functioning had decreased survival (HR: 1.76, p-value: 0.041) (42). Three studies showed significant associations between physical HRQOL components and breast cancer mortality (87-89). Women who reported higher levels of physical-related health or functioning had decreased risks of mortality, with hazard ratios ranging from 0.42-0.64 $(87,89)$, while women who reported lower levels of physical-related functioning had increased risks of all-cause mortality (HR: 1.49, 95\% CI: 1.17, 1.89) and breast cancer-specific mortality (HR: 1.39, 95\% CI: 1.07, 1.80) (88).

Studies evaluating physical HRQOL as a predictor of breast cancer outcomes (13, 50, 79-82, 87-92) have suggested that better levels of physical and functional HRQOL were associated with decreased risk of all-cause mortality (HR: 0.24; $95 \%$ CI: $0.08,0.70$ and HR: 0.35 ; $95 \%$ CI: $0.14,0.87$, respectively) (50). Physical functioning is also proven to be of significant prognostic value in survivors of multiple cancers (81). Components of physical HRQOL, such as mood, pain, and loss of appetite, were also found to be significant predictors of mortality in breast cancer patients $(81,82,93)$. Nausea/vomiting has been reportedly associated with increased risk of breast cancer recurrence (79). One 
study concluded that fatigue increased risk of recurrence-free mortality (13), and another suggested that severe fatigue led to shorter survival (HR: 1.48; 95\% CI: 1.13, 1.93) (91).

Three studies that utilized the SF-36 indicated that better physical health or physical functioning were predictive of lower risks of mortality (87-89). Saquib et al. found that higher levels of physical health predicted lower additional breast cancer events (p-trend: 0.005) and lower risk of all-cause mortality (p-trend: 0.004) (89). Marinac et al. reported that participants with low physical functioning were more likely to die by allcauses (HR: 1.49, 95\% CI: 1.17, 1.89) and breast cancer-specific causes (HR: 1.39, 95\% CI: 1.07, 1.80). DuMontier et al. found that better levels of physical functioning were predictive of lower mortality (OR: $0.64,95 \%$ CI: $0.44,0.94$ ).

Taken together, the studies have evaluated HRQOL as an indicator of breast cancer prognosis $(13,14,42,43,50,78-81,83,87-95)$ are heterogeneous. Most studies are limited by their sample sizes $(\mathrm{n}<1,000)(14,42,43,78,79,87,90-94)$, and they differed in the use of the specific HRQOL instrument. Out of the 19 studies evaluated, one used the Linear Analog Self-Assessment (LASA) (80), seven used the EORTC QLQC30 (13, 42, 43, 91, 93-95), one used both the Functional Assessment of Cancer Therapy General (FACT-G) and/or the Functional Assessment of Cancer Therapy (FACT-B+4) (50), one used the IBCSG Quality of Life Core Questionnaire (79), one used the General Quality of Life Inventory-74 (83), three used the Medical Outcomes Study (MOS) ShortForm Survey (SF-36) (87-89) and the remaining studies utilized a combination of physical or psychosocial scales to measure $\operatorname{HRQOL}(13,14,42,43,78)$. The majority of studies have been based predominantly on white populations $(62,83)$. Furthermore, the majority of the studies evaluated breast cancer survival as an outcome $(13,14,42,43,50$, 
$78,80,81,83,89-95)$, while four evaluated mortality $(83,87-89)$ and recurrence $(79,83$, $88,89)$

The variance in breast cancer and all-cause mortality that HRQOL might explain could help improve efforts that focus on addressing HRQOL in breast cancer survivors as they deal with survivorship. Further research is necessary to analyze these associations in underrepresented populations to add to extant findings and increase the plausibility of generalizability.

\section{Potential Covariates}

Recognized breast cancer prognostic factors include cancer metastasis, size of tumor, tumor grade, hormone receptor status, lymph node involvement, age at diagnosis, breast cancer recurrence (location of recurrence, time to recurrence), adjuvant therapy, comorbid conditions, family history of breast cancer, age, socioeconomic status (96-98). Many of these factors are associated with HRQOL including adjuvant therapy, cancer metastasis, tumor characteristics, lymph node involvement, comorbid conditions, age at diagnosis, and breast cancer recurrence $(28,60,66,72,83,99-101)$. Additional factors that may impact the relationship between HRQOL and risk of mortality include race/ethnicity, menopausal status, clinical characteristics, psychosocial factors, lifestyle and physical factors.

\section{$\underline{\text { Race/Ethnicity }}$}

Breast cancer mortality and treatment differs by race/ethnicity $(6,29)$. Minority women are diagnosed with more advanced stage breast cancer (102) and usually report 
worse HRQOL $(51,61,103)$. A study has found that race/ethnicity modifies the association between tumor subtype and mortality (104).

\section{$\underline{\text { Menopausal Status }}$}

Menopausal status can modify breast cancer risk and survival, and is usually associated with other factors. For example, post-menopausal breast cancer survivors who are not overweight or obese tend to have better survival rates $(105,106)$. The opposite trend appears to be true for premenopausal women who have better survival rates if they are overweight or obese compared to their normal-weight counterparts (106). A study found an association between high-cognitive fatigue and sever menopause, depressive symptoms, and worsened HRQOL (107).

\section{$\underline{\text { Clinical Characteristics }}$}

Tumor size and lymph node status interact to modify the effect of survival (97). Tumor subtype predicts whether or not breast cancer patients require surgery and any other type of treatment, and tumor size influences the probability of metastasis occurring in breast cancer patients (97). Studies have shown that tumor characteristics impact HRQOL in breast cancer patients $(68,99)$. An increased number of axillary lymph nodes is predictive of breast cancer survival, metastasis, treatment failure, and recurrence (97). Women have reported higher HRQOL after surgical removal of affected lymph nodes (100). Types of adjuvant treatment prescribed are associated with breast cancer node type/tumor subtype. Although breast cancer patients have benefited from adjuvant therapy, regardless of tumor subtype (108), node-negative breast cancer patients do not 
benefit significantly compared to node-positive breast cancer patients (97). HRQOL has been shown to worsen or improve in patients depending on the type of treatment they received $(60,100)$.

\section{$\underline{\text { Mental/Psychosocial Characteristics }}$}

Depression is the most common of all psychiatric disorders (109), and a few studies have evaluated the effects of depression on HRQOL in breast cancer patients (41, 51, 52), and in long-term breast cancer survivors (110). Lower HRQOL scores are associated with depressive symptoms in breast cancer survivors $(41,53)$. Evidence suggests that psychosocial stress plays an important role in the development of cancer growth and metastasis $(62,111)$ and impacts HRQOL (50). Additionally, stress events, anxiety, hopelessness, repressive defensiveness, and denial/avoidance are associated with decreased breast cancer survival, whereas factors such as perceived social support, minimizing adjustment, extroversion, religiosity/spirituality, and marriage are associated with increased survival (62). Generally, many mental/psychosocial factors are associated with HRQOL in breast cancer survivors $(41,50,54,57,58)$.

\section{Lifestyle and Physical Factors:}

An increase in physical activity has been shown to decrease breast cancer mortality overall (112) and in Hispanic women, specifically (113). Higher physical activity is predictive of better HRQOL in women diagnosed with breast cancer $(64,65)$. BMI and waist-hip ratio are associated with breast cancer survival and may differ by race/ethnicity $(114,115)$. Furthermore, other HRQOL and breast cancer survival studies 
have indicated that obesity is associated with a decreased mental health among survivors (16). A study has found that higher BMI and waist-hip ratio were predictive of higher mortality in breast cancer survivors (116).

Lymphedema is a complication of lymph node dissection apart of breast cancer treatment (117). It is defined as the swelling of $100-200 \mathrm{~cm}^{3}$ or $2 \mathrm{~cm}$ by circumference of an affected area in comparison to an unaffected area $(117,118)$. The prevalence of lymphedema in breast cancer survivors rises every year (119). Breast cancer patients who experienced lymphedema had poorer HRQOL $(118,120)$.

The association between diet and breast cancer prognosis is inconclusive (121). Studies have shown that better diet predicts lower all-cause mortality in breast cancer survivors $(122,123)$, while fewer studies have found a similar association between diet and breast cancer-specific mortality (122). Diet quality is associated with mental and physical HRQOL in breast cancer survivors (124). Women who have better diets tend to have higher HRQOL scores (124).

A systematic review found that current smoking increased the risk of all-cause death in breast cancer survivors (125). In a study evaluating breast, colorectal, and endometrial female cancer survivors, persistent smoking predicted increased likelihoods of poorer mental/psychosocial and physical HRQOL (126). In breast cancer survivors, HRQOL is poorer in women who smoke versus women who don't (127).

\section{Possible Biological Mechanisms}

HRQOL measures the overall well-being of breast cancer survivors. Lower scores or decreases in scores may reflect both acute and chronic stress responses to 
cancer diagnosis, treatment, co-morbidity and various negative life changes (e.g. divorce or separation) (128). Evidence indicates that chronic stress is a nervous system response with signaling pathways that may directly impact cancer cells and promote cancer metastasis (111).

The human body responds to stress by activating body systems such as the hypothalamic-pituitary-adrenal (HPA) axis. Levels of norepinephrine and epinephrine are known to increase in people who experience acute or chronic stress (129), while dopamine levels may increase during episodes of acute stress but decrease in people who experience chronic stress $(130,131)$. Norepinephrine and epinephrine are known to induce a 'fight or flight' response from the sympathetic nervous system (SNS). These catecholamines also target $\beta$-adrenergic receptors that mediate their effects on cancer cells, including breast cancer cells (132).

Cortisol, a human glucocorticoid, regulates many cardiovascular, metabolic, immunologic, and homeostatic functions (133), and is secreted by the adrenal cortex in response to stress (134). Studies have shown that cortisol can disrupt neuroendocrine circadian rhythms to support tumor growth and metastasis (135). Chronic stress is involved in inhibiting immune responses, and increased levels of cortisol have been shown to be immunosuppressive (136). On the other hand, studies have shown that acute stress can amplify cellular immunity, increasing resistance to some cancer such as squamous cell carcinoma (137).

Stress also influences cancer metastasis (138). Norepinephrine has shown to stimulate VEGF, an angiogenic molecule that induces neovascularization of malignancy (138). Studies have linked positive and negative psychosocial factors to either an increase 
or decrease of the regulation of VEGF in various cancer patients $(139,140)$. Additionally, the production of IL-6, another angiogenic molecule or cytokine, has been reported to increase or decrease based on the impact of psychosocial factors (141). Although there is limited evidence of the effects of stress on the proliferation of metastatic cancer cells, studies have suggested that the presence of catecholamines may suppress the production of normal or good cells, impacting an immune response to cancer cell proliferation. (142).

Other cytokines, such as IL-1 and TNF- $\alpha$, may work synergistically with IL-6 to stimulate an inflammatory response in response to various stressors (109). The brain can also induce stress-inflammatory responses to perceived social-environmental hazards (109). Inflammation is partly regulated by cortisol, and when stress is high, inflammation can become chronic and promote diseases, such as cardiovascular, autoimmune disorders, and cancers (143). A study concluded that the association between HRQOL and mortality in breast cancer survivors may be contributed to inflammation as the core biological mechanism, where low levels of physical functioning predicts higher risk of mortality (88).

Chronic stress is associated with the pathogenesis of cancer and the development of tumor growth and metastasis (111). Cancers with improving survivorship, such as breast cancer, impact the overall well-being of survivors over short- and long-term periods following a diagnosis. The chronic relationship between stress-responses to what precedes and follows cancer, and the diagnoses of cancer itself, needs to be further evaluated in patients who are living longer with chronic diseases. Even though the association between HRQOL and mortality in breast cancer survivors, and the impact 
stress may have on this association, is not completely understood, studies have found relationships between stress and HRQOL factors. One study found that socially isolated mice were more likely to develop stress via increased corticosterone levels (144), while another showed that exposure to inevitable foot-shock stress in rats reduced the innate activity of natural killer cells (145). Researchers have emphasized the importance of social support on breast cancer survivors, including its impact on reducing stress in these women $(146,147)$. Women who feel that they don't handle stress well tend to have lower HRQOL (50). 


\section{METHODS}

\section{Study Design}

The Health Eating, Activity, and Lifestyle (HEAL) Study is a multicenter prospective cohort of 1,183 enrolled multi-ethnic women diagnosed with first primary insitu or invasive (stages I to III-A) breast cancer between 1994 and 1999 (148). Participants were ascertained from the Surveillance, Epidemiology, and End Results (SEER) cancer registries in New Mexico, Los Angeles County (LA), and Western Washington. Women were initially followed to evaluate how lifestyle factors (physical activity, diet, weight history), hormones, and clinical characteristics had an impact on breast cancer outcomes and prognosis. Participants were evaluated over multiple time periods and each period differed by study site. For New Mexico, participants were evaluated at baseline, 2-year follow-up, 3-year follow-up, 5-year follow-up, and 10-year follow-up (149). Informed consent was obtained during each assessment. Institutional Review Board approvals were obtained at each participating center. Additional study design, recruitment processes, and aims have been previously described in detail (148). This study utilizes data from the New Mexico site only $(\mathrm{N}=616)$. 


\section{Eligibility and Recruitment}

In the HEAL-New Mexico (HEAL-NM) site, women were eligible to be ascertained from SEER New Mexico Tumor Registry (NMTW) for the study if they were diagnosed with in situ to Stage IIIA breast carcinoma between July 1996 and March 1999. Additional eligibility criteria for recruitment included: 1) participants identifying as $\geq 18$ years of age; 2 ) the ability to participate in an interview within 9-months postdiagnosis; 3) residence in Bernalillo, Santa Fe, Sandoval, Valencia, or Taos Counties in New Mexico; and 4) self-reported Hispanic or NHW race/ethnicity.

\section{HEAL-NM Study Population}

Figure 1 provides a description of subject recruitment, participation, and timing of data collection regarding the primary variables used in this thesis. 999 women were eligible. Out of these women, 616 of them completed the baseline survey, on average, six months post-diagnosis. Participants were asked to complete a follow-up assessment approximately 24 months after baseline. Out of the 616 women who participated in the baseline survey, $591(95.9 \%)$ were eligible to participate in the follow-up assessment at 24-months and $496(80.5 \%)$ completed it. Reasons for non-participation in the 24-month follow-up assessment included: refusal to participate $(n=64)$, unable to interview $(n=17)$

or locate $(n=8)$, and leaving the state $(n=6)$. Of the 591 who participated in the 24 -month follow-up, 567 (95.9\%) were eligible to participate in the follow-up assessment at 36months, which included the HRQOL assessment, and 459 (77.7\%) completed it. Reasons for non-participation in the 36-month follow up assessment included: no return $(n=42)$, not chosen $(n=33)$, refusal to participate $(n=22)$, unable to interview $(n=8)$, and unable 


\section{Figure 1. Study Participation Flow-HEAL Study New Mexico Site}

Note: 'never contact' does not mean the women were 'never' contacted but rather somewhere along the way during follow-up these women indicated that they no longer wished to participate.

\begin{tabular}{l}
$\quad$ 6-Month Baseline Assessment \\
Hispanics: 150 \\
Non-Hispanic White: 465 \\
Variables: Demographic characteristics (e.g., age, \\
education, ethnicity, height, menopausal status), \\
Tamoxifen use, and medical record abstraction. \\
$\qquad$ \\
\hline
\end{tabular}

24-Month (post-baseline) Follow-Up Assessment

Hispanics: 109

Non-Hispanic White: 387

Variables: Additional demographic characteristics, such as marital status, employment, income, weight, smoking, menopausal status, the Charlson

Comorbidity Index, Tamoxifen use, and medical record abstraction.

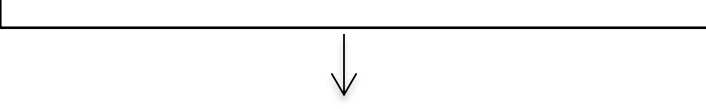

\begin{tabular}{|l|}
\multicolumn{1}{c|}{ HRQOL Assessment } \\
Conducted on average 36 months post-baseline \\
Hispanics: 98 \\
Non-Hispanic White: 361 \\
Variables: Health-related Quality of Life (SF-36) (8 \\
sub-scales \& 2 summary scores), pain, fatigue, \\
general health, social support, fear of recurrence, \\
perceived optimism \& pessimism
\end{tabular}

\begin{tabular}{|c|}
\hline Analytic Sample: \\
351 eligible participants \\
Hispanics: 78 \\
Non-Hispanic White: 273 \\
\end{tabular}

Of the 999 participants who were eligible for the baseline survey, 615 participated in it.

230 refusal, 53 unable to interview, 27 physician refusal, 29 unable to locate, 20 left the state, 12 received late notice, 7 never contact, 3 left the county, 3 unreliable.

Of the 615 who participated in the baseline survey, 590 were eligible for the 24-month follow-up, and 496 completed it.

64 refusal, 25 deaths, 17 unable to interview, 7 unable to locate, 6 left the state.
Of the 590 who participated in the 24month follow-up, 566 were eligible for the 36-month follow-up, and 459 completed it.

49 deaths, 42 no returns, 33 not chosen (based on 24-month follow-up refusal), 22 refusals, 7 unable to interview, 3 unable to locate.

\section{$\underline{\text { Analytic Sample Eligibility Criteria }}$}

-Exclude women with in-situ breast cancer $(\mathrm{n}=85)$

-Exclude women with incomplete HRQOL data $(n=23)$

-Exclude women with missing survival time $(\mathrm{n}=0)$ 
to locate $(n=3)$. (150). Participants were further contacted for 5-year and 10-year followup post-diagnosis; however, data from these assessments are not used for this study. Passive follow-up on all cases occurred by updating survival and cancer diagnosis information regularly through the NMTR. Information on survival and new primaries was available through December 2012 for approximately 12.5 years from baseline assessment.

Participants were eligible for this analysis if they had completed HRQOL assessments and completed data on survival time. Among the 459 women who completed the 36-month HRQOL follow-up, 436 (94.9\%) provided complete HRQOL information. Among these 436 participants, none were missing survival time. The analytic sample was restricted to participants who had invasive breast cancer only (Stage I to Stage IIIa). Thus, women who were diagnosed with in situ breast carcinoma were excluded $(\mathrm{n}=85)$. The final analytic sample size consisted of 351 participants, 78 Hispanic women and 273 NHW women.

\section{Data Collection \& Outcome Measures}

Data used in this thesis originate from HEAL baseline, 24-month, and 36-month (HRQOL) assessments, medical record abstraction, and Surveillance Epidemiology and End Results (SEER) cancer registry records. Baseline interviews occurred, on average, at 6-months post-diagnosis and were conducted at the University of New Mexico Aging and Genetic Epidemiology Program. Questionnaires measured demographics (age, race/ethnicity, education), lifestyle factors covering Tamoxifen use, smoking status, and 
screening practices, as well as anthropometric measurements including BMI, and blood or saliva samples.

At 24-month follow-up, questionnaires measured similar demographics, menstrual status, eating habits, additional breast disease and treatment, medical conditions, hormone replacement therapy, physical activity, smoking habits, and alcohol intake.

At 36-month follow-up, questionnaires measured HRQOL characteristics such as support group experiences, information about breast cancer and surgery, pain, lymphedema, religiosity, optimism, the impact of cancer and changes after cancer, social support, fatigue, sexual activity, life events, fear about recurrence, health status/functioning, perceived stress, and Tamoxifen use.

\section{Demographic and Lifestyle Characteristics}

Demographic data collected at baseline and 24-month follow-up and evaluated in this study include age, self-reported race/ethnicity, education, and marital status. Lifestyle factors evaluated include physical activity, smoking status, and Tamoxifen use. Physical activity was measured only at 24-month follow-up while smoking status and Tamoxifen use were measured at both baseline and 24-month follow-up.

\section{$\underline{\text { Clinical Characteristics }}$}

Data on breast cancer diagnoses and breast cancer stage were ascertained using SEER-NMTR, including additional data on tumor size, lymph node involvement, and tumor subtypes (Luminal A, Luminal B, HER2 Overexpressing, Triple Negative), which 
were obtained via pathology reports. Information on co-morbid conditions and cancer treatment, such as adjuvant therapy, was abstracted from medical record and SEERNMTR registry records. This information includes: radiation and/or chemotherapy, types of surgery, and use of Tamoxifen (medically abstracted and self-reported during the 24month assessment). Participants were passively followed through the SEER NMTR and National Death Index for vital status updates; causes of death, and date of death or date of last contact.

\section{$\underline{\text { HRQOL Assessment }}$}

The following instruments were used to collect HRQOL data at the 36-month follow-up: RAND 36-item Short Form Health Survey (SF-36) (35), Lymphedema Status (added by HEAL investigators), the Life Orientation Test (151), Social Support (152), the Piper Fatigue Scale (153), and Fear of Recurrence Scale (154).

Data from the SF-36 was used to measure eight health components (subscales) and two derived component summary scales (MCS/PCS). Response values from 36 items (questions) were recoded per the scoring key and items in the same scale were averaged to create a measure for each of the eight subscales $(35,155)$. When scoring occurs, items that are left blank are not included in calculating the scale scores, which are calculated by taking an average of only the completed answers (156). There are four mental/psychosocial subscales (Social Functioning, Role-Emotional, Vitality, and Mental Health) and four physical subscales (Physical Functioning, Role-Physical, Bodily Pain, and General Health). Raw subscale scores range from 0 to 100, higher scores indicating a better HRQOL. The MCS and PCS scores were calculated by using weighted Z-scores of 
the eight subscales multiplied by a factor score coefficient and summed over their respective subscales $(35,157)$. Raw scores of the four psychosocial subscales and the four physical subscales as well as the two component summary scores were normalized to the general U.S. population on a T-score metric $($ mean $=50, \mathrm{SD} \pm 10)$ in order to compare across groups. A score change of $1 / 2$ a SD had been used to determine the presence of a clinically meaningful difference $(35,157)$. The SF-36 has been proven reliable with Cronbach's alpha estimates of 0.78 or higher in the $\operatorname{MOS}(155,158)$.

Lymphedema status was determined based on those who ever experienced lymphedema, received treatment for lymphedema, and who were experiencing lymphedema at the time of assessment. The Life Orientation Test provided information on perceived optimism, and conversely, perceived pessimism, both analyzed separately via a 6-item questionnaire (151). Information on the number of types of confidants was utilized from the Social Support aspect of the HRQOL assessment (152). One question pulled from the Piper Fatigue Scale determined current fatigue in participants four weeks prior to assessment (153), and one question about fear of breast cancer recurrence during time of assessment was chosen via the Fear of Recurrence Scale (154).

Optimism, derived from the Life Orientation test, was categorized into two components: perceived pessimism and perceived optimism, based on reverse coding for pessimism in contrast to optimism, and the inherent way the two new concepts differ.

Social support was based on a series of questions about types of confidants at diagnosis and at the time of the interview (i.e., spouse, children, other family members, friends, neighbors, nurses, treating physicians, psychiatrists, psychologists/therapists, priest/rabbis/ministers, support groups, or 'other'). 
Current fatigue (yes/no) in the four weeks before HRQOL assessment was denoted by a preliminary question in the Piper Fatigue Scale (153). Fear of recurrence was defined by participants who indicated that they were afraid of their cancer returning at the time of HRQOL assessment.

\section{Mortality and Survival Periods}

Figure 2 displays a graph of the entire follow-up and survival periods for the population. Mortality, including type of death, of participants was ascertained via the National Death Index. A survival period of one to 12.5 years was used, abstracted from consented passive follow-up through SEER and calculated based on the difference from HRQOL interview to censor date. For this analysis, survival time began at 3-years based on the average completed time for the HRQOL follow-up assessment post-diagnosis. The outcome of interest was mortality, specifically all-cause, breast cancer-specific, and noncancer mortality.

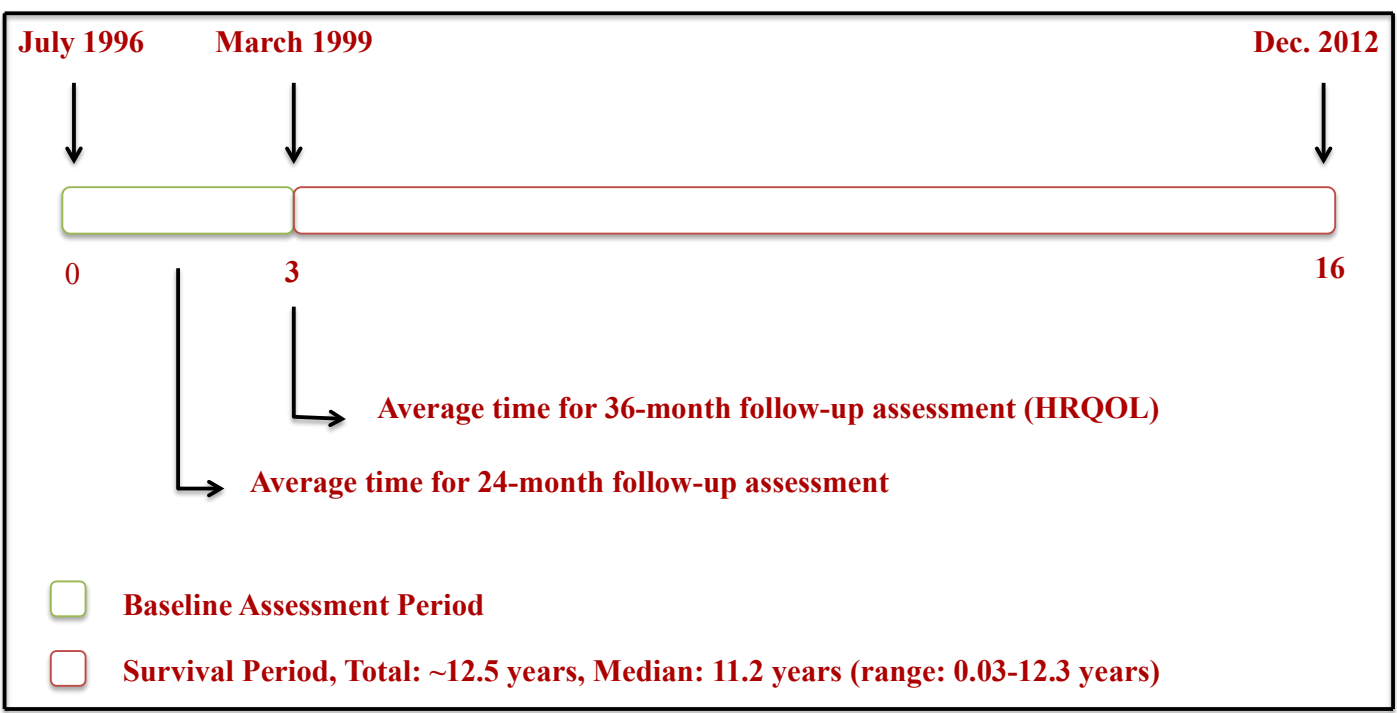

Figure 2. HEAL New Mexico Site Follow-Up and Survival Time. 


\section{Statistical Analysis}

\section{Eligible Analytic Sample Size}

Among the 459 women who completed the 36-month follow-up, 23 were missing complete HRQOL data and 85 were excluded due to a diagnosis in situ disease (stage 0 ). The eligible analytic sample size subsequently consisted of 351 participants ( 78 Hispanic women and $273 \mathrm{NHW)} \mathrm{with} \mathrm{complete} \mathrm{data} \mathrm{on} \mathrm{HRQOL} \mathrm{assessments,} \mathrm{vital} \mathrm{status,} \mathrm{and}$ cause of death, which were diagnosed with invasive breast cancer (Stage I - Stage IIIA) (Figure 1).

\section{Exposure Assessment}

For all-cause and non-cancer mortality, HRQOL subscale and component summary scores were categorized into tertiles with the highest tertile used as the referent group, based on the distribution of the cohort. Because breast cancer-specific mortality had a low number of events, the HRQOL subscale and component summary scores were dichotomized, based on the distribution of the cohort, to increase statistical power.

\section{Outcome Assessment}

Outcomes for analyses included all-cause (death due to any cause), breast cancerspecific, and non-cancer (death due to causes other than cancer) mortality as ascertained from death records. For this analysis, participants were passively followed from date of HRQOL interview (approximately 36-months post-diagnosis) to December 2012. International Classification of Diseases, $10^{\text {th }}$ Revision (ICD-10) codes were used to sort causes of deaths $(159,160)$. For all-cause mortality, the time frame for follow-up was 
initiated from HRQOL assessment to the date of death, and non-deceased participants were censored on December 2012. For breast cancer-specific mortality, women dying of breast cancer-related deaths were the outcome of interest and women dying from other causes were censored on December 2012. For non-cancer mortality, women dying of allcauses with exception to cancer-related deaths were the outcome of interest and women dying from cancer were censored on December 2012. Furthermore, participants were censored if they experienced a death, on their date of last contact, or at the end of the study.

\section{$\underline{\text { Potential Covariates }}$}

Covariates were analyzed as either confounders or effect modifiers in the associations between HRQOL and mortality. Covariates analyzed from the baseline assessment included age, race/ethnicity, education, marital status, and BMI. Clinical characteristics considered included tumor stage, tumor size, tumor subtype, treatment type, lymph node involvement, and comorbidities. At 24-month follow-up, covariates selected were physical activity, smoking status, and Tamoxifen Use. Variables considered from the HRQOL assessment were: current lymphedema, perceived optimism, perceived pessimism, types of confidants, current fatigue, current pain, perceived general health, and fear of recurrence.

Among the self-reported baseline characteristics, age was continuous.

Race/ethnicity were categorized as NHW or Hispanic. Education was classified into four categories: 1) high school or less; 2) some college; 3) college graduate; and 4) graduate 
school. Participants reported whether they were single or married for marital status, and BMI $\left(\mathrm{kg} / \mathrm{m}^{2}\right)$ was categorized into 1) $<25$; 2) $25-29$; and 3) $\geq 30$.

Clinical characteristics were abstracted via medical records or SEER-NMTR. For this analysis, tumor stage was dichotomized into localized (Stage 1) and regional (Stages II-IIIA). Tumor size was dichotomized as $<3$ centimeters and $\geq 3$ centimeters. Tumor subtype was initially classified as luminal A, luminal B, HER2 overexpressing, or triple negative. However, due to a low sample size (missing=51), the covariate was dichotomized as ER+ and ER-. For breast cancer treatment type, there were three categories: any chemotherapy, surgery only, and surgery and radiation. Lymph node involvement was dichotomized as none versus one or more lymph nodes involved, similar to comorbidities, which was categorized as zero versus one or more comorbidity.

For 24-month follow-up covariates, physical activity was categorized as none, light, and moderate or vigorous, and smoking status was classified as never, former smoker, or current smoker. Tamoxifen use was dichotomized as yes/no.

Some of the covariates considered from the HRQOL assessment were dichotomized as yes/no, including current lymphedema, current fatigue, current pain, and fear of recurrence. For perceived optimism/pessimism, identical scores were created based on participants' responses to the three questions for optimism and the three questions for pessimism, categorized as $\leq 10$ or $>10$, or less versus greater perception. These cut points were chosen based on the distribution of the cohort to allow for adequate numbers of participants in each category. A social support variable, types of confidants, was created and categorized based on the distribution of coded responses, similar to the optimism and pessimism variables. In reference to the types of confidants previously 
listed, participants were categorized as having less than four, four to five, or greater or equal to six types of different confidants. Perceived general health, SF-36 item, was dichotomized to include participants who rated their health as fair or poor compared to participants who rated their health as good, very good, or excellent.

\section{Descriptive Characteristics}

Descriptive characteristics of participants who completed the HRQOL assessment were compared to those who did not, and by vital status (alive vs. deceased) at the end of the study period among those with complete HRQOL data. Frequencies and percentages were reported for categorical variables and means (SD), medians (min-max), and ranges were reported for continuous variables. Chi-square tests of independence for categorical variables and student t-tests for continuous variables were calculated to determine whether the distributions of the variables differed among the groups compared. Descriptive characteristics of the analytic sample were computed by vital status, and the same tests were computed to compare alive and deceased participants.

\section{$\underline{\text { Statistical Model Building }}$}

Cox proportional hazards regression models were used to examine the statistical associations of HRQOL component summary scores with mortality. Hazard Ratios (HR) and $95 \%$ Confidence Intervals (CI) were estimated for each outcome. A HR measures how much greater a death rate is in one group compared to another group, using survival times as a comparison between the two groups of participants (161). The time metric in 
all analyses was survival years. The referent group for MCS and PCS scores was tertile 3 (T3) and HR 95\% CIs were estimated for tertile 1 (T1) and tertile 2 (T2).

Crude HRs between the exposure, MCS scores and PCS scores, and mortality outcomes were calculated. To determine potential confounders for consideration in the model building process, each variable was added to the crude model and a percent change was calculated between each adjusted model and crude model to determine the individual magnitude of effect by each covariate.

A base model (Model 1) was established to assess additional associations between the crude model and Model 1, the crude model and Model 1 plus each covariate, and Model 1 and Model 1 plus each covariate. The base model included age, marital status, and tumor stage, and was the same for both MCS scores and PCS scores. Age and marital status was chosen based on their magnitude of effect when added to the crude model for both MCS and PCS scores. Tumor stage was selected to include a clinical characteristic into the model, and this variable was the only one with no missing values.

Purposeful selection of covariates was employed to evaluate potential confounders yielding p-values less than 0.25 during the univariate analyses (162). This is utilized to identify variables that may not show significant associations between the exposure and outcome alone, but may make a relevant contribution alongside other variables (162). For MCS and PCS scores, respectively, covariates were added to the model one at a time to evaluate the change in association between the crude model and Model 1, the crude model and Model 1 plus a group of covariates, and Model 1 and Model 1 plus a group of covariates. For variables with missing data, data subsets were created to include only participants with complete data, and then the same previous 
evaluations were repeated to assess relationships among each model. This step was repeated for each variable with missing data. Final models for associations between MCS scores and all-cause/non-cancer mortality and PCS scores and all-cause/non-cancer mortality were developed depending on the results from the multivariable modeling. These variables were already selected based on the purposeful selection algorithm, and then were further evaluated in conjunction to see their magnitude of effects. Since each variable with missing data (education, lymph node involvement, tumor size, physical activity, Tamoxifen use, smoking status, BMI, and tumor subtype), when considered, did not hold much effect on the associations between the exposures and outcomes, in conjunction with other considered variables, they were excluded. This enabled us to retain a parsimonious model while accounting for covariates that drive the confounding effects. MCS and PCS scores were adjusted for different variables based on their confounding effects in the model building process. Breast cancer-specific multivariable modeling building was not conducted to a low sample of events and no significant results. The final analytic sample size was $(N=351)$ (Figure 1$)$. Tables detailing the statistical modeling process can be found in Appendices (B-O).

\section{$\underline{\text { Least Squares Means }}$}

Means (SD) and adjusted least-squares means (LSMs) for HRQOL subscales and MCS and PCS categories were calculated stratified by mortality outcome. For breast cancer-specific and non-cancer mortality, participants who died from causes other than breast-cancer specific or non-cancer, respectively, were excluded from the analyses. HRQOL subscales were adjusted for covariates associated with either MCS or PCS, and 
these include age, race/ethnicity, tumor stage, education, BMI, treatment type, lymph node involvement, co-morbid conditions, physical activity, current lymphedema, perceived pessimism, number of types of confidants, and fear of recurrence. TukeyKramer p-values were computed to compare HRQOL LSMs between participants who were deemed alive or dead during the study period. Frequencies ( $\mathrm{n} \%)$ and medians (minmax) were reported for MCS and PCS by vital status and Kruskal-Wallis tests were calculated to evaluate differences among participants by vital status (alive, dead) in the study period.

\section{$\underline{\text { Survival Curves }}$}

Kaplan-Meier survival curves were generated to show the survival rates between MCS and all-cause/breast cancer-specific/non-cancer mortality, and PCS and allcause/breast cancer-specific/non-cancer mortality for all women, and by race/ethnicity. Survival curves between MCS/PCS tertiles and the three mortality outcomes were compared via log rank test p-values. The curves show survival times (time-to-event) by each tertile and with each death as the event, respectively. Censored participants, or participants who have the "event" or another censoring characteristics such as date of last contact or the end of the study, were displayed as ticks on each curve.

\section{Cox Proportional Hazards Regression}

Associations from three models were reported: Model 1, the crude associations, Model 2 adjusted for demographic (age, race/ethnicity, marital status) and clinical characteristics (tumor stage, treatment type, co-morbid conditions), and Model 3, 
adjusted for every covariate in Model 2, in addition to variables assessed during the HRQOL follow-up (current lymphedema, perceived optimism/pessimism, types of confidants, bodily pain, perceived general health, and fear of recurrence. P-trends were calculated to test the ordered relationship across the three MCS and PCS tertiles (163).

To evaluate effect modification, Cox Proportional hazard regression models investigated associations between MCS and mortality and PCS and mortality, stratified by race/ethnicity (NHW, Hispanic), and these associations were adjusted for every covariate (Model 3 only). Additional analyses evaluated the associations between individual HRQOL subscales scores and all-cause, breast cancer-specific, and non-cancer mortality, using the three step modeling procedure previously mentioned, adjusted for the same variables for MCS (mental/psychosocial-related) and PCS (physical-related), respectively. Models with breast cancer-specific mortality as the outcome variable were adjusted for the same covariates for all-cause mortality evaluations.

The proportional hazards assumption is that each covariate added to cox proportional hazard models do not vary with time (164). Violation of the proportional hazards assumption was evaluated using Schoenfeld Residuals testing $(164,165)$. Each variable was assessed using a time-dependent covariate method, adding interaction terms to test for their significance (164). P-values were generated for each covariate as well as one for the total model. P-values $<0.05$ were considered significant and as a violation of the proportional hazards assumption.

Data were analyzed using SAS 9.4 (Cary, N.C.). 


\section{RESULTS}

\section{Participant Characteristics}

Demographic and clinical characteristics of the entire HEAL-NM cohort by HRQOL assessment completion status are presented in Table 1. Of those that died prior to the HRQOL assessment, a majority died from breast cancer-specific mortality $(n=47 / 100)$. Among the 615 participants who completed the baseline survey, $436(70.9 \%)$ completed the HRQOL assessment while 179 (29.1\%) did not. The 179 participants who did not complete the HRQOL assessment were either deceased or ineligible by the assessment date, or did not fully complete the HRQOL assessment. Of those who completed the assessment, many were younger (mean age: $58.5 \pm 11.7$ ) compared to their counterparts (mean age: $60.8 \pm 14.6$ ), $\mathrm{p}=0.0390$. Additionally, cause of death significantly differed between the two groups $(\mathrm{p}=0.0019)$. People who completed the HRQOL assessment experienced more all-cause and non-cancer-related deaths but less breast cancer-specific deaths compared to people who did not fully complete the assessment. HRQOL status groups also differed by characteristics at both baseline, including race/ethnicity $(\mathrm{p}=0.0069)$, education $(\mathrm{p}=0.0005)$, marital status $(\mathrm{p}=<0.0001)$, lymph node involvement ( $\mathrm{p}=0.0288$ ); and 24-month follow-up, including Tamoxifen use $(p=0.0206)$, significantly differed.

Table 2 displays demographic, clinical, and HRQOL characteristics of the analytic sample $(\mathrm{N}=351)$ by vital status (all-cause mortality only) at the end of the study 
Table 1. Demographic Characteristics of HEAL Participants Who Completed the HRQOL Assessment Compared to Non-respondents, The HEAL Study New Mexico Site $(N=615)$

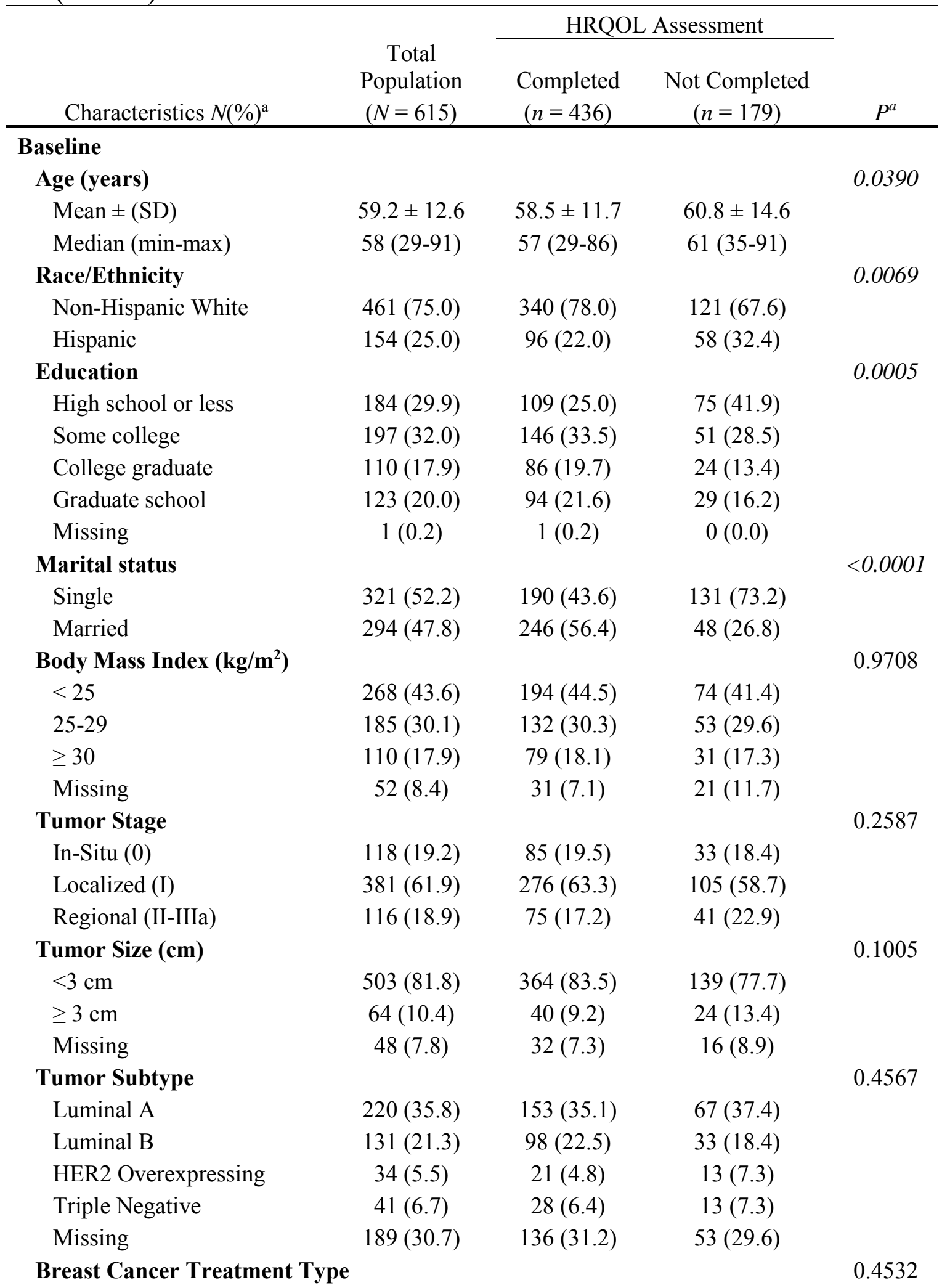




\begin{tabular}{|c|c|c|c|c|}
\hline \multirow[b]{2}{*}{ Characteristics $N(\%)^{\mathrm{a}}$} & \multirow[b]{2}{*}{$\begin{array}{l}\text { Total } \\
\text { Population } \\
(N=615)\end{array}$} & \multicolumn{2}{|c|}{ HRQOL Assessment } & \multirow[b]{2}{*}{$P^{a}$} \\
\hline & & $\begin{array}{c}\text { Completed } \\
(n=436)\end{array}$ & $\begin{array}{l}\text { Not Completed } \\
\quad(n=179)\end{array}$ & \\
\hline Any chemotherapy & $151(24.6)$ & $109(25.0)$ & $42(23.5)$ & \\
\hline Surgery only & $214(34.8)$ & $145(33.3)$ & $69(38.5)$ & \\
\hline Surgery and radiation & $250(40.6)$ & $182(41.7)$ & $68(38.0)$ & \\
\hline Lymph Node Involvement & & & & 0.0288 \\
\hline None & 477 (77.6) & $349(80.0)$ & $128(71.5)$ & \\
\hline$\geq 1$ Lymph Nodes Involved & $122(19.8)$ & $77(17.7)$ & $45(25.1)$ & \\
\hline Missing & $16(2.6)$ & $10(2.3)$ & $6(3.4)$ & \\
\hline Charlson Comorbidity Index & & & & 0.0658 \\
\hline No co-morbid conditions & $508(82.6)$ & $368(84.4)$ & $140(78.2)$ & \\
\hline One or more conditions & $107(17.4)$ & $68(15.6)$ & $39(21.8)$ & \\
\hline \multicolumn{5}{|l|}{ 24-month follow-up } \\
\hline Physical Activity & & & & 0.3176 \\
\hline None & $286(46.5)$ & $229(52.5)$ & $57(31.8)$ & \\
\hline Light & $88(14.3)$ & $74(17.0)$ & $14(7.8)$ & \\
\hline Moderate & $25(4.1)$ & $22(5.0)$ & $3(1.7)$ & \\
\hline Vigorous & $96(15.6)$ & $84(19.3)$ & $12(6.7)$ & \\
\hline Missing & $120(19.5)$ & $27(6.2)$ & $93(52.0)$ & \\
\hline Smoking Status & & & & 0.5858 \\
\hline Never & $222(36.1)$ & $186(42.7)$ & $36(20.1)$ & \\
\hline Former & $212(34.5)$ & $171(39.2)$ & $41(22.9)$ & \\
\hline Current & $61(9.9)$ & $52(11.9)$ & $9(5.0)$ & \\
\hline Missing & $120(19.5)$ & $27(6.2)$ & $93(52.0)$ & \\
\hline Tamoxifen Use & & & & 0.0206 \\
\hline No & $290(47.2)$ & $230(52.7)$ & $60(33.5)$ & \\
\hline Yes & $205(33.3)$ & $179(41.1)$ & $26(14.5)$ & \\
\hline Missing & $120(19.5)$ & $27(6.2)$ & $93(52.0)$ & \\
\hline Vital Status & & & & 0.0019 \\
\hline Alive & $400(65.0)$ & $321(73.6)$ & $79(44.1)$ & \\
\hline Death, Breast cancer-specific & $74(12.0)$ & $27(6.2)$ & $47(26.3)$ & \\
\hline Death, Non-cancer & $123(20.0)$ & $78(17.9)$ & $47(26.3)$ & \\
\hline Death, All-cause & $215(35.0)$ & $115(26.4)$ & $100(55.9)$ & \\
\hline \multicolumn{5}{|c|}{$\begin{array}{l}\text { a. Chi-square p-value for categorical variables or t-test p-values for continuous variables comparing participants } \\
\text { who have completed the HRQOL assessment and participants who have not, excluding missing values. An italic } \\
\text { p-value represents statistically significant differences between comparison groups. }\end{array}$} \\
\hline Note: Reasons for not completing the HR & $\mathrm{DL}$ assessment & refusal and inel & pility (i.e. death). & \\
\hline
\end{tabular}


period. Ninety-nine participants were deceased. 64 died from non-cancer causes, and 26 died from breast cancer-specific causes. The median survival time was 11.2 years (range: 0.03-12.3 years). Several baseline characteristics differed by vital status. Mean age for participants who were alive was significantly younger than those who died $(56.1 \pm 10.4$ vs. $65.2 \pm 12.7$, respectively). Of the total sample, $273(75.4 \%)$ reported NHW race while $78(22.2 \%)$ reported Hispanic origin. The majority of the population indicated having completed some college (32.5\%) and high school or less (26.2\%), similar results were observed by vital status. The distribution of BMI was about the same by vital status. Almost half of the study population had a BMI of less than $25 \mathrm{~kg} / \mathrm{m}^{2}(45.9 \%)$.

Marital status significantly differed by vital status $(\mathrm{p}=0.0004)$, the majority of deceased women were single (60.6\%). Two hundred seventy six participants (78.6\%) presented with localized (I) tumor stage, 75 (21.4\%) were diagnosed with regional (IIIIIa) stages. Most participants had a smaller tumor size $<3 \mathrm{~cm}$ (86.6\%) compared to $\geq 3 \mathrm{~cm}$ $(10.5 \%)$. In terms of tumor subtypes, the majority was diagnosed with ER+ subtypes (71.5\%) compared to ER- (14\%); however, $14.5 \%$ were missing this information. Among all women in the study, most received surgery only $(41.0 \%)$, followed by any chemotherapy (31.1\%) and then surgery and radiation (27.9\%). Furthermore, about 75\% of the population had no lymph node involvement (75.2\%). Tumor stage, size, and subtype, treatment type, and lymph node involvement did not significantly differ by vital status ( $\mathrm{p}=-0.41,0.63,0.81,0.24,0.35$, respectively). Approximately $85 \%$ of the cohort had zero comorbid conditions. The distribution of comorbidities significantly differed by vital status ( $\mathrm{p}=0.0076$ ), those who were deceased were more likely to have $\geq 1$ comorbid condition compared to those who were alive ( $23.2 \%$ vs. $11.9 \%$, respectively). Variables 
ascertained from the 24-month follow-up assessment were physical activity, smoking status, and Tamoxifen use. Twenty one participants were missing these three variables.

Levels of physical activity significantly differed between living and deceased participants

Table 2. Demographic Characteristics of HEAL Participants with Invasive Breast Cancer by Vital Status $(N=351)$

\begin{tabular}{|c|c|c|c|c|}
\hline \multirow[b]{2}{*}{ Characteristics $N(\%)^{\mathrm{a}}$} & \multirow[b]{2}{*}{$\begin{array}{c}\text { Total } \\
\text { Population } \\
(N=351) \\
\end{array}$} & \multicolumn{2}{|c|}{ Vital Status } & \multirow[b]{2}{*}{$P^{a}$} \\
\hline & & $\begin{array}{c}\text { Alive } \\
(n=252)\end{array}$ & $\begin{array}{c}\text { Deceased } \\
(n=99)\end{array}$ & \\
\hline \multicolumn{5}{|l|}{ Baseline } \\
\hline Age (years) & & & & $<0.0001$ \\
\hline Mean $\pm(\mathrm{SD})$ & $58.6 \pm 11.8$ & $56.1 \pm 10.4$ & $65.2 \pm 12.7$ & \\
\hline Median (min-max) & $58(29-86)$ & $55(29-83)$ & $68(32-86)$ & \\
\hline Race/Ethnicity & & & & 0.0869 \\
\hline Non-Hispanic White & $273(77.8)$ & $190(75.4)$ & $83(83.8)$ & \\
\hline Hispanic & $78(22.2)$ & $62(24.6)$ & $16(16.2)$ & \\
\hline Education & & & & 0.0534 \\
\hline High school or less & $92(26.2)$ & $61(24.2)$ & $31(31.3)$ & \\
\hline Some college & $114(32.5)$ & $76(30.2)$ & $38(38.4)$ & \\
\hline College graduate & $70(19.9)$ & $57(22.6)$ & $13(13.1)$ & \\
\hline Graduate school & $74(21.1)$ & $58(23.0)$ & $16(16.2)$ & \\
\hline Missing & $1(0.3)$ & $0(0.0)$ & $1(1.0)$ & \\
\hline Marital status & & & & 0.0004 \\
\hline Single & $160(45.6)$ & $100(39.7)$ & $60(60.6)$ & \\
\hline Married & $191(54.4)$ & $152(60.3)$ & $39(39.4)$ & \\
\hline Body Mass Index $\left(\mathrm{kg} / \mathrm{m}^{2}\right)$ & & & & 0.2450 \\
\hline$<25$ & $161(45.9)$ & $121(48.0)$ & $40(40.4)$ & \\
\hline $25-29$ & $99(28.2)$ & $76(30.2)$ & $23(23.2)$ & \\
\hline$\geq 30$ & $64(18.2)$ & $42(16.7)$ & $22(22.2)$ & \\
\hline Missing & $27(7.7)$ & $13(5.1)$ & $14(1.2)$ & \\
\hline Tumor Stage & & & & 0.4102 \\
\hline Localized (I) & $276(78.6)$ & $201(79.8)$ & $75(75.8)$ & \\
\hline Regional (II-IIIa) & $75(21.4)$ & $51(20.2)$ & $24(24.2)$ & \\
\hline Tumor Size (cm) & & & & 0.6294 \\
\hline$<3 \mathrm{~cm}$ & $304(86.6)$ & $217(86.1)$ & 87 (87.9) & \\
\hline$\geq 3 \mathrm{~cm}$ & $37(10.5)$ & $25(9.9)$ & $12(12.1)$ & \\
\hline Missing & $10(2.9)$ & $10(4.0)$ & $0(0.0)$ & \\
\hline Tumor Subtype & & & & 0.8132 \\
\hline Luminal A & $153(43.6)$ & $109(43.3)$ & $44(44.4)$ & \\
\hline Luminal B & $98(27.9)$ & $71(28.2)$ & $27(27.3)$ & \\
\hline
\end{tabular}




\begin{tabular}{|c|c|c|c|c|}
\hline \multirow[b]{2}{*}{ Characteristics $N(\%)^{\mathrm{a}}$} & \multirow[b]{2}{*}{$\begin{array}{c}\text { Total } \\
\text { Population } \\
(N=351)\end{array}$} & \multicolumn{2}{|c|}{ Vital Status } & \multirow[b]{2}{*}{$P^{a}$} \\
\hline & & $\begin{array}{c}\text { Alive } \\
(n=252)\end{array}$ & $\begin{array}{c}\text { Deceased } \\
(n=99)\end{array}$ & \\
\hline HER2 Overexpressing & $21(6.0)$ & $13(5.2)$ & $8(8.1)$ & \\
\hline Triple Negative & $28(8.0)$ & $20(7.9)$ & $8(8.1)$ & \\
\hline Missing & $51(14.5)$ & $39(15.5)$ & $12(12.1)$ & \\
\hline \multicolumn{2}{|c|}{ Breast Cancer Treatment Type } & & & 0.2433 \\
\hline Any chemotherapy & $109(31.1)$ & $81(32.1)$ & $28(28.3)$ & \\
\hline Surgery only & $144(41.0)$ & $107(42.5)$ & $37(37.4)$ & \\
\hline Surgery and radiation & $98(27.9)$ & $64(25.4)$ & $34(34.3)$ & \\
\hline \multicolumn{2}{|l|}{ Lymph Node Involvement } & & & 0.3466 \\
\hline None & $264(75.2)$ & $196(77.8)$ & $68(68.7)$ & \\
\hline$\geq 1$ & $77(21.9)$ & $53(21.0)$ & $24(24.2)$ & \\
\hline Missing & $10(2.9)$ & $3(1.2)$ & $7(7.1)$ & \\
\hline \multicolumn{2}{|c|}{ Charlson Comorbidity Index } & & & 0.0076 \\
\hline No co-morbid conditions & $298(84.9)$ & $222(88.1)$ & $76(76.8)$ & \\
\hline One or more conditions & $53(15.1)$ & $30(11.9)$ & $23(23.2)$ & \\
\hline \multicolumn{5}{|l|}{ 24-Month follow-up } \\
\hline \multicolumn{2}{|l|}{ Physical Activity } & & & 0.0243 \\
\hline None & $185(52.7)$ & $123(48.8)$ & $62(62.6)$ & \\
\hline Light & $59(16.8)$ & 47 (18.7) & $12(12.1)$ & \\
\hline Moderate/Vigorous & $86(24.5)$ & $69(27.4)$ & $17(17.2)$ & \\
\hline Missing & $21(6.0)$ & $13(5.1)$ & $8(8.1)$ & \\
\hline \multicolumn{2}{|l|}{ Smoking Status } & & & 0.8182 \\
\hline Never & $145(41.3)$ & $106(42.1)$ & $39(39.4)$ & \\
\hline Former & $144(41.0)$ & $105(41.7)$ & $39(39.4)$ & \\
\hline Current & $41(11.7)$ & $28(11.1)$ & $13(13.1$ & \\
\hline Missing & $21(6.0)$ & $13(5.1)$ & $8(8.1)$ & \\
\hline \multicolumn{2}{|l|}{ Tamoxifen Use } & & & 0.4780 \\
\hline No & $160(45.6)$ & $113(44.8)$ & $47(47.5)$ & \\
\hline Yes & $170(48.4)$ & $126(50.0)$ & $44(44.4)$ & \\
\hline Missing & $21(6.0)$ & $13(5.2)$ & $8(8.1)$ & \\
\hline \multicolumn{5}{|c|}{ HRQOL (36-month) follow-up } \\
\hline \multicolumn{2}{|c|}{ Current lymphedema } & & & 0.2219 \\
\hline No & $307(87.5)$ & $217(86.1)$ & $90(90.9)$ & \\
\hline Yes & $44(12.5)$ & 35 (13.9) & $9(9.1)$ & \\
\hline \multicolumn{2}{|l|}{ Perceived Optimism Score } & & & 0.0341 \\
\hline$\leq 10$ & $83(23.7)$ & $52(20.6)$ & $31(31.3)$ & \\
\hline$>10$ & $268(76.3)$ & $200(79.4)$ & $68(68.7)$ & \\
\hline \multicolumn{2}{|l|}{ Perceived Pessimism Score } & & & 0.0176 \\
\hline$\leq 10$ & $255(72.6)$ & $192(76.2)$ & $63(63.6)$ & \\
\hline
\end{tabular}




\begin{tabular}{|c|c|c|c|c|}
\hline \multirow[b]{2}{*}{ Characteristics $N(\%)^{\mathrm{a}}$} & \multirow[b]{2}{*}{$\begin{array}{l}\text { Total } \\
\text { Population } \\
(N=351)\end{array}$} & \multicolumn{2}{|c|}{ Vital Status } & \multirow[b]{2}{*}{$P^{a}$} \\
\hline & & $\begin{array}{c}\text { Alive } \\
(n=252)\end{array}$ & $\begin{array}{c}\text { Deceased } \\
(n=99)\end{array}$ & \\
\hline$>10$ & $96(27.4)$ & $60(23.8)$ & $36(36.4)$ & \\
\hline \multicolumn{2}{|c|}{ Number of Types of Confidants } & & & 0.1021 \\
\hline$<4$ people & $66(18.8)$ & $41(16.3)$ & $25(25.2)$ & \\
\hline 4-5 people & $172(49.0)$ & $124(49.2)$ & $48(48.5)$ & \\
\hline$\geq 6$ people & $113(32.2)$ & $87(34.5)$ & $26(26.3)$ & \\
\hline \multicolumn{2}{|l|}{ Current Fatigue } & & & 0.9304 \\
\hline No & $136(38.8)$ & $98(38.9)$ & $38(38.4)$ & \\
\hline Yes & $215(61.2)$ & $154(61.1)$ & $61(61.6)$ & \\
\hline \multicolumn{2}{|l|}{ Current Pain } & & & 0.0270 \\
\hline No & $93(26.5)$ & $75(29.8)$ & $18(18.2)$ & \\
\hline Yes & $258(73.5)$ & $177(70.2)$ & $81(81.8)$ & \\
\hline \multicolumn{2}{|l|}{ Perceived General Health } & & & $<0.0001$ \\
\hline Fair/Poor & $54(15.4)$ & $26(10.3)$ & $28(28.3)$ & \\
\hline Good/Very Good/Excellent & $297(84.6)$ & $226(89.7)$ & $71(71.7)$ & \\
\hline \multicolumn{2}{|l|}{ Fear of Recurrence } & & & 0.0407 \\
\hline No & $154(43.9)$ & $102(40.5)$ & $52(52.5)$ & \\
\hline Yes & $197(56.1)$ & $150(59.5)$ & $47(47.5)$ & \\
\hline \multicolumn{5}{|l|}{ Cause of Death } \\
\hline \multicolumn{2}{|l|}{ Breast cancer-specific } & -- & $26(26.3)$ & \\
\hline \multicolumn{2}{|l|}{ Other-cancer } & -- & $9(9.1)$ & \\
\hline \multicolumn{2}{|l|}{ Non-cancer } & -- & $64(64.6)$ & \\
\hline \multicolumn{5}{|c|}{$\begin{array}{l}\text { a. Chi-square p-value for categorical variables or t-test p-values for continuous variables comparing participants } \\
\text { who have completed the HRQOL assessment and participants who have not, excluding missing values. An } \\
\text { italicized p-value represents statistically significant differences between comparison groups. }\end{array}$} \\
\hline
\end{tabular}

$(p=0.0243)$, where more women who were alive exercised in moderate or vigorous quantities (27.4\%) compared to their deceased counterparts (17.2\%). Forty-one percent of the population reported never smoked, $41 \%$ reported being a former smoker, $11.7 \%$ were current smokers, and 6\% were missing data for smoking. Approximately half of the cohort reported never using Tamoxifen (48.4\%). Among variables ascertained from HRQOL assessment, perceived optimism score $(\mathrm{p}=0.0341)$, perceived pessimism score $(p=0.0176)$, current pain $(p=0.0270)$, perceived general health $(p=<0.0001)$, and fear of 
recurrence $(p=0.0407)$ significantly differed by vital status. Deceased women had higher proportions of reporting worse aspects of HRQOL variables.

\section{HRQOL Subscale and Component Summary Scores}

Comparisons of HRQOL subscale and component summary scores by vital status by mortality outcomes are presented in Table 3 . When stratified by all-cause mortality, one mental/psychosocial subscale and three physical subscales differed by vital status. The mean $\pm \mathrm{SD}$ (adjusted least square means (LSM)) for the mental subscale, social functioning, was among those who were alive and was higher $50.16 \pm 9.48(47.83)$ compared to those who died 45.68 \pm 11.21 (43.89), $\mathrm{p}=0.0030$. MCS did not differ by vital status and mortality outcomes.

Of the physical subscales that differed by vital status, those who were alive also had significantly higher adjusted LSM compared to those who died: physical functioning (39.27 vs. 35.38 , respectively), role physical (40.55 vs. 37.32 , respectively), and bodily pain (45.89 vs. 42.43, respectively). The PCS significantly differed by vital status (41.97 vs. 38.31, respectively, $p=0.0037)$, but the MCS did not $(p=0.2093)$.

For breast cancer-specific mortality, 73 participants were excluded from the analyses due to dying by other causes. Among participants who were alive and participants who died by breast cancer specific mortality, no significant associations were found. Similarly, 35 participants were excluded from analyses comparing HRQOL subscale and component summary scores by non-cancer mortality. Of the 
Table 3. Comparisons of HRQOL SF-36 Subscale and Component Summary Scores by Vital Status $(N=351)$

\begin{tabular}{|c|c|c|c|c|c|c|c|c|c|c|}
\hline \multirow[b]{2}{*}{ HRQOL SF-36 } & \multirow[b]{2}{*}{$\begin{array}{c}\text { Total } \\
(N=351) \\
\end{array}$} & \multicolumn{2}{|c|}{ All-Cause } & \multirow[b]{2}{*}{$P^{d}$} & $\begin{array}{r}\text { Mortality } \\
\text { Breast Can }\end{array}$ & $\begin{array}{l}\text { Outcomes } \\
\text { er-Specific }\end{array}$ & \multirow[b]{2}{*}{$P^{d}$} & \multicolumn{2}{|c|}{ Non-Cancer ${ }^{b}$} & \multirow[b]{2}{*}{$P^{d}$} \\
\hline & & $\begin{array}{c}\text { Alive } \\
(n=252)\end{array}$ & $\begin{array}{c}\text { Deceased } \\
(n=99) \\
\end{array}$ & & $\begin{array}{c}\text { Alive } \\
(n=252)\end{array}$ & $\begin{array}{c}\text { Deceased } \\
(n=26) \\
\end{array}$ & & $\begin{array}{c}\text { Alive } \\
(n=252)\end{array}$ & $\begin{array}{c}\text { Deceased } \\
(n=64) \\
\end{array}$ & \\
\hline \multicolumn{11}{|l|}{ SF-36 Subscales } \\
\hline Social Functioning & & & & 0.0030 & & & 0.8089 & & & 0.0001 \\
\hline Mean \pm SD & $48.89 \pm 10.18$ & $50.16 \pm 9.48$ & $45.68 \pm 11.21$ & & $50.16 \pm 9.48$ & $49.20 \pm 9.37$ & & $50.16 \pm 9.48$ & $44.24 \pm 11.50$ & \\
\hline $\mathrm{LSM}^{\mathrm{c}}$ & & 47.83 & 43.89 & & 46.80 & 47.29 & & 49.62 & 43.32 & \\
\hline Role Emotional & & & & 0.3707 & & & 0.9736 & & & 0.1772 \\
\hline Mean \pm SD & $45.26 \pm 11.76$ & $46.19 \pm 11.64$ & $42.89 \pm 11.79$ & & $46.19 \pm 11.64$ & $44.40 \pm 11.72$ & & $46.19 \pm 11.64$ & $42.17 \pm 12.02$ & \\
\hline $\mathrm{LSM}^{\mathrm{c}}$ & & 42.66 & 41.28 & & 42.65 & 42.56 & & 45.14 & 42.55 & \\
\hline Vitality & & & & 0.0540 & & & 0.4866 & & & 0.0054 \\
\hline Mean \pm SD & $48.74 \pm 10.22$ & $49.61 \pm 10.33$ & $46.52 \pm 9.64$ & & $49.61 \pm 10.33$ & $49.51 \pm 8.65$ & & $49.61 \pm 10.33$ & $45.39 \pm 10.13$ & \\
\hline $\mathrm{LSM}^{\mathrm{c}}$ & & 43.20 & 40.64 & & 44.28 & 45.76 & & 45.55 & 40.94 & \\
\hline Mental Health & & & & 0.0756 & & & 0.7542 & & & 0.0171 \\
\hline Mean \pm SD & $48.93 \pm 9.73$ & $49.44 \pm 9.81$ & $47.62 \pm 9.46$ & & $49.44 \pm 9.81$ & $48.43 \pm 9.67$ & & $49.44 \pm 9.81$ & $47.28 \pm 9.65$ & \\
\hline $\mathrm{LSM}^{\mathrm{c}}$ & & 42.19 & 40.08 & & 45.55 & 44.93 & & 44.80 & 41.34 & \\
\hline Physical Functioning & & & & 0.0026 & & & 0.4875 & & & 0.0004 \\
\hline Mean $\pm \mathrm{SD}$ & $45.82 \pm 11.27$ & $48.17 \pm 9.66$ & $39.82 \pm 12.80$ & & $48.17 \pm 9.66$ & $46.66 \pm 10.47$ & & $48.17 \pm 9.66$ & $37.34 \pm 13.17$ & \\
\hline $\mathrm{LSM}^{\mathrm{c}}$ & & 39.27 & 35.38 & & 41.22 & 42.57 & & 41.26 & 35.78 & \\
\hline Role Physical & & & & 0.0256 & & & 0.4003 & & & 0.0032 \\
\hline Mean \pm SD & $45.36 \pm 11.35$ & $47.09 \pm 10.79$ & $40.96 \pm 11.60$ & & $47.09 \pm 10.79$ & $46.72 \pm 9.58$ & & $47.09 \pm 10.79$ & $38.78 \pm 11.95$ & \\
\hline $\mathrm{LSM}^{\mathrm{c}}$ & & 40.55 & 37.32 & & 41.43 & 43.34 & & 43.14 & 37.90 & \\
\hline Bodily Pain & & & & 0.0099 & & & 0.5065 & & & 0.0017 \\
\hline Mean $\pm \mathrm{SD}$ & $50.57 \pm 10.49$ & $51.83 \pm 10.17$ & $47.39 \pm 10.66$ & & $51.83 \pm 10.17$ & $51.09 \pm 9.45$ & & $51.83 \pm 10.17$ & $46.18 \pm 11.08$ & \\
\hline $\mathrm{LSM}^{\mathrm{c}}$ & & 45.89 & 42.43 & & 47.40 & 48.83 & & 48.38 & 43.24 & \\
\hline General Health & & & & 0.1588 & & & 0.7916 & & & 0.0110 \\
\hline
\end{tabular}




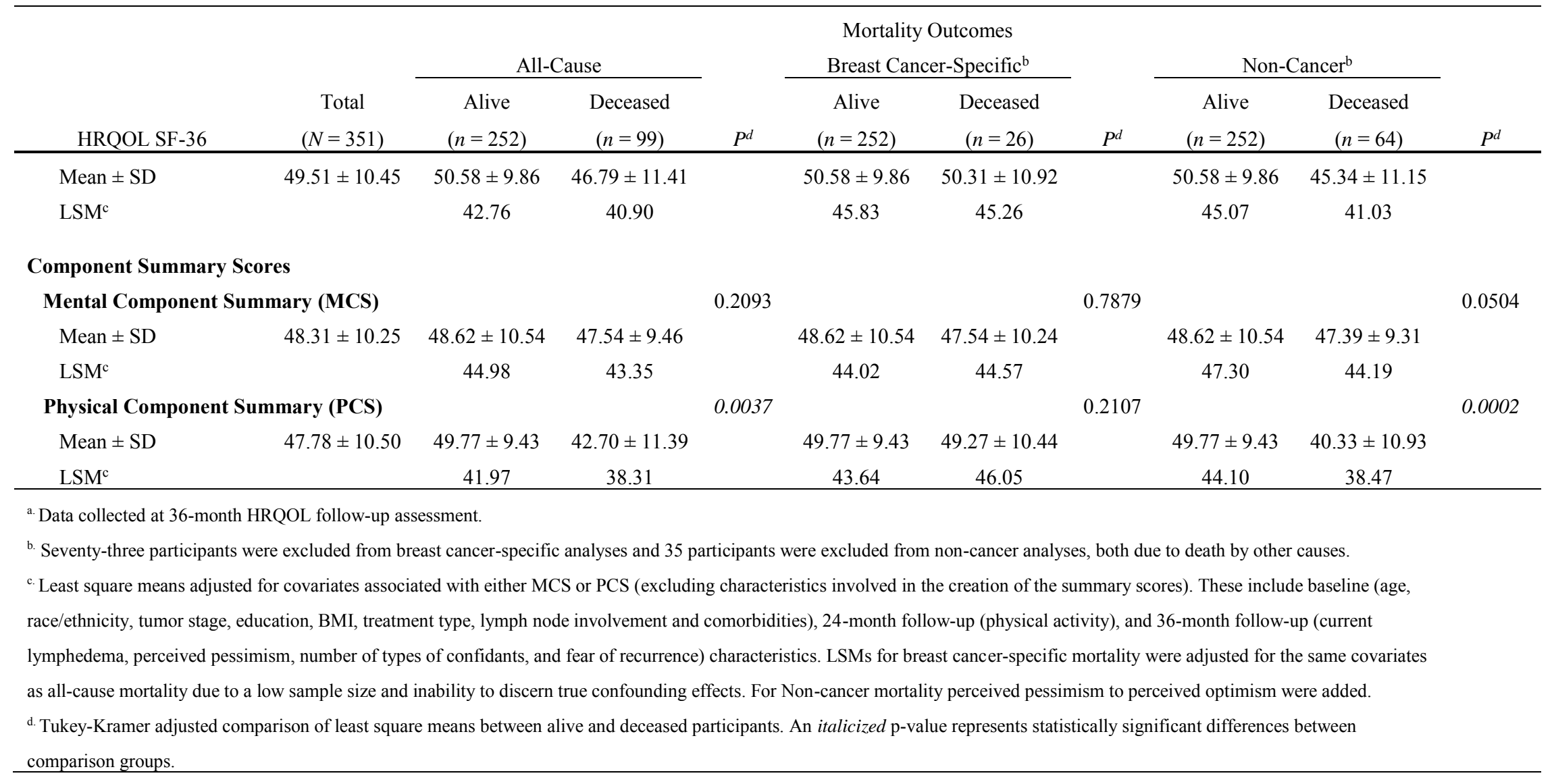


mental/psychosocial subscales that differed by non-cancer mortality, participants who were alive had significantly higher adjusted LSM compared to those who died: social functioning (49.62 vs. 43.32, respectively), vitality (45.55 vs. 40.94, respectively), and mental health (44.80 vs. 41.34, respectively).

All of the physical subscales and the PCS significantly differed by non-cancer mortality. Participants who were alive had higher adjusted LSM compared to those who died: physical functioning (41.26 vs. 35.78, respectively), role physical (43.14 vs. 37.90, respectively), bodily pain (48.38 vs. 43.24, respectively), general health (45.07 vs. 41.03, respectively), and PCS (44.10 vs. 38.47, respectively, $\mathrm{p}=0.0002)$. The MCS did not significantly differ by non-cancer mortality $(\mathrm{p}=0.0504)$.

\section{Associations between HRQOL and All-Cause Mortality $\underline{\text { MCS/PCS and All-Cause Mortality }}$}

Results from multivariable Cox Proportional Hazard regression models assessing the association between PCS and MCS tertiles and the likelihood of dying of any cause can be found in Table 5. For all regression analyses, three models were analyzed. (See Methods Section, Statistical Analysis, Cox Proportional Hazards Regression for covariates included.) Compared to PCS T3, cases in PCS T1 had an almost four-fold increased risk of dying (HR: 3.80, 95\% CI: 2.20, 6.54; p-trend $=<0.0001$ ) of any cause. After adjustment for baseline lifestyle and clinical characteristics, this association attenuated towards the null but remained significant (HR: 2.12, 95\% CI: 1.18, 3.81; ptrend $=0.0053$ ). Furthermore, when adjusted for HRQOL characteristics, the risk of dying of any causes did not change (HR: 2.17, 95\% CI; 1.20, 3.90; p-trend=0.0061). No 
Table 4. Comparisons of HRQOL SF-36 Component Summary Score Tertiles by Vital Status $(N=351)$

\begin{tabular}{|c|c|c|c|c|c|c|c|c|c|c|}
\hline \multirow[b]{3}{*}{ Component Summary Scores ${ }^{\mathrm{a}}$} & \multirow[b]{3}{*}{$\begin{array}{c}\text { Total } \\
(N=351)\end{array}$} & \multicolumn{8}{|c|}{ Mortality Outcomes } & \multirow[b]{3}{*}{$P^{d}$} \\
\hline & & \multicolumn{2}{|c|}{ All-Cause } & \multirow[b]{2}{*}{$P^{d}$} & \multicolumn{2}{|c|}{ Breast Cancer-Specific ${ }^{\mathrm{b}, \mathrm{e}}$} & \multirow[b]{2}{*}{$P^{d}$} & \multicolumn{2}{|c|}{ Non-Cancer ${ }^{\mathrm{b}}$} & \\
\hline & & $\begin{array}{c}\text { Alive } \\
(n=252)\end{array}$ & $\begin{array}{c}\text { Deceased } \\
(n=99)\end{array}$ & & $\begin{array}{c}\text { Alive } \\
(n=252)\end{array}$ & $\begin{array}{c}\text { Deceased } \\
(n=26)\end{array}$ & & $\begin{array}{c}\text { Alive } \\
(n=252)\end{array}$ & $\begin{array}{c}\text { Deceased } \\
(n=64)\end{array}$ & \\
\hline \multicolumn{11}{|c|}{ Mental Component Summary (MCS) } \\
\hline T1 & & & & 0.4933 & & & 0.7324 & & & 0.4640 \\
\hline$n(\%)$ & $117(33.3)$ & $81(32.2)$ & $36(36.4)$ & & $120(47.6)$ & $14(53.8)$ & & $81(32.2)$ & $23(35.9)$ & \\
\hline Median & 37.4 & 36.9 & 38.4 & & 41.8 & 42.2 & & 36.9 & 38.1 & \\
\hline$(\min -\max )^{\mathrm{c}}$ & $(12.8-45.1)$ & $(12.8-45.1)$ & $(21.9-44.0)$ & & $(12.8-50.6)$ & $(26.0-48.7)$ & & $(12.8-45.1)$ & $(21.9-44.0)$ & \\
\hline $\mathbf{T} 2$ & & & & 0.1080 & & & 0.9481 & & & 0.1493 \\
\hline$n(\%)$ & $117(33.3)$ & $82(32.5)$ & $35(35.3)$ & & $132(52.4)$ & $12(46.2)$ & & $82(32.5)$ & $24(37.5)$ & \\
\hline Median & 50.6 & 50.9 & 48.7 & & 56.6 & 57.5 & & 50.9 & 48.5 & \\
\hline$(\min -\max )^{\mathrm{c}}$ & $(45.2-54.4)$ & $(45.2-54.4)$ & $(45.2-54.4)$ & & $(50.7-68.6)$ & $(50.7-59.5)$ & & $(45.2-54.4)$ & $(45.2-54.4)$ & \\
\hline T3 & & & & 0.5313 & & & -- & & & 0.3285 \\
\hline$n(\%)$ & $117(33.3)$ & $89(35.3)$ & $28(28.3)$ & & -- & -- & & $89(35.3)$ & $17(26.6)$ & \\
\hline Median & 57.9 & 57.9 & 57.9 & & -- & -- & & 57.9 & 57.6 & \\
\hline$(\min -\max )^{\mathrm{c}}$ & $(54.4-68.6)$ & $(54.8-68.6)$ & $(54.4-64.9)$ & & & & & $(54.8-68.6)$ & $(54.4-64.9)$ & \\
\hline \multicolumn{11}{|c|}{ Physical Component Summary (PCS) } \\
\hline $\mathbf{T 1}$ & & & & 0.1037 & & & 0.8715 & & & 0.0992 \\
\hline$n(\%)$ & $117(33.3)$ & $62(24.6)$ & $55(55.5)$ & & $109(43.3)$ & $13(50.0)$ & & $62(24.6)$ & $43(67.2)$ & \\
\hline Median & 35.1 & 36.1 & 33.8 & & 43.7 & 44.8 & & 36.1 & 32.8 & \\
\hline$(\min -\max )^{\mathrm{c}}$ & $(19.6-44.8)$ & $(23.1-44.8)$ & $(19.6-44.6)$ & & $(23.1-50.3)$ & $(29.1-48.8)$ & & $(23.1-44.8)$ & $(19.6-44.6)$ & \\
\hline $\mathbf{T 2}$ & & & & 0.9278 & & & 0.8500 & & & 0.1672 \\
\hline$n(\%)$ & $117(33.3)$ & $90(35.7)$ & $27(27.3)$ & & $143(56.7)$ & $13(50.0)$ & & $90(35.7)$ & $12(18.8)$ & \\
\hline Median & 50.3 & 50.2 & 50.3 & & 56.1 & 56.7 & & 50.2 & 51.6 & \\
\hline$(\min -\max )^{c}$ & $(44.8-54.4)$ & $(44.8-54.4)$ & $(44.8-54.1)$ & & $(50.3-66.8)$ & $(50.3-71.4)$ & & $(44.8-54.4)$ & $(48.4-54.1)$ & \\
\hline T3 & & & & 0.9938 & & & -- & & & 0.0693 \\
\hline
\end{tabular}




\begin{tabular}{|c|c|c|c|c|c|c|c|c|c|c|}
\hline \multirow[b]{3}{*}{ Component Summary Scores ${ }^{\mathrm{a}}$} & \multirow[b]{3}{*}{$\begin{array}{c}\text { Total } \\
(N=351)\end{array}$} & \multicolumn{8}{|c|}{ Mortality Outcomes } & \multirow[b]{3}{*}{$P^{d}$} \\
\hline & & \multicolumn{2}{|c|}{ All-Cause } & & \multicolumn{2}{|c|}{ Breast Cancer-Specific ${ }^{\mathrm{b}, \mathrm{e}}$} & & \multicolumn{2}{|c|}{ Non-Cancer ${ }^{\mathrm{b}}$} & \\
\hline & & $\begin{array}{c}\text { Alive } \\
(n=252)\end{array}$ & $\begin{array}{c}\text { Deceased } \\
(n=99)\end{array}$ & $P^{d}$ & $\begin{array}{c}\text { Alive } \\
(n=252) \\
\end{array}$ & $\begin{array}{c}\text { Deceased } \\
(n=26) \\
\end{array}$ & $P^{d}$ & $\begin{array}{c}\text { Alive } \\
(n=252) \\
\end{array}$ & $\begin{array}{c}\text { Deceased } \\
(n=64)\end{array}$ & \\
\hline$n(\%)$ & $117(33.3)$ & $100(39.7)$ & $17(17.2)$ & & -- & -- & & $100(39.7)$ & $9(14.0)$ & \\
\hline $\begin{array}{l}\text { Median } \\
(\min -\max )^{\mathrm{c}}\end{array}$ & $\begin{array}{c}57.3 \\
(54.5-71.4) \\
\end{array}$ & $\begin{array}{c}57.4 \\
(54.6-66.8)\end{array}$ & $\begin{array}{c}57.3 \\
(54.5-71.4)\end{array}$ & & -- & -- & & $\begin{array}{c}57.4 \\
(54.6-66.8)\end{array}$ & $\begin{array}{c}56.2 \\
(54.5-61.5)\end{array}$ & \\
\hline
\end{tabular}

a. Data collected at 36-month HRQOL follow-up assessment.

b. Seventy-three participants were excluded from breast cancer-specific analyses and 35 participants were excluded from non-cancer analyses, both due to death by other causes.

c. Min-max values may overlap due to rounding.

d. Kruskal-Wallis tests comparing median values between alive and deceased.

e. T1/T2 for Breast Cancer-Specific outcomes are dichotomies defined as 'low' and 'high'. HRQOL scores, T3 is defined as 'high' HRQOL scores. 
significant associations between MCS T1 vs. T3 and MCS T2 vs. T3 were observed; however all models were suggestive of an increased risk of dying of any cause.

Table 5. Associations between HRQOL SF-36 Mental \& Physical Component Summary Score Tertiles and All-Cause Mortality $(N=351)$

\begin{tabular}{|c|c|c|c|}
\hline \multirow[b]{2}{*}{$\begin{array}{l}\text { HRQOL Component Summary } \\
\text { Scores }^{\text {a }}\end{array}$} & \multicolumn{3}{|c|}{ Model $1^{\mathrm{c}}$} \\
\hline & $\begin{array}{c}\text { \# of Deaths } \\
\left(^{(\text {Total })^{b}}\right.\end{array}$ & $\operatorname{HR}(95 \% \mathrm{CI})$ & $P$ Trend \\
\hline MCS & & & 0.2238 \\
\hline $\mathrm{T} 1(\leq 45.12)$ & $36(117)$ & $1.36(0.83,2.23)$ & \\
\hline $\mathrm{T} 2(>45.12 \& \leq 54.40)$ & 35 (117) & $1.25(0.76,2.06)$ & \\
\hline $\mathrm{T} 3(>54.40)$ & $28(117)$ & 1.00 (ref) & \\
\hline PCS & & & $<0.0001$ \\
\hline $\mathrm{T} 1(\leq 44.75)$ & $55(117)$ & $3.80(2.20,6.54)$ & \\
\hline T2 $(>44.75 \& \leq 54.39)$ & 27 (117) & $1.67(0.91,3.07)$ & \\
\hline \multirow[t]{3}{*}{$\mathrm{T} 3(>54.39)$} & 17 (117) & $1.00($ ref $)$ & \\
\hline & \multicolumn{3}{|c|}{ Model $2^{\mathrm{d}}$} \\
\hline & \# of Deaths & & \\
\hline $\begin{array}{l}\text { HRQOL Component Summary } \\
\text { Scores }^{\text {a }}\end{array}$ & $(\text { Total })^{\mathrm{b}}$ & $\mathrm{HR}(95 \% \mathrm{CI})$ & $P$ Trend \\
\hline MCS & & & 0.1139 \\
\hline $\mathrm{T} 1(\leq 45.12)$ & $36(117)$ & $1.51(0.90,2.53)$ & \\
\hline $\mathrm{T} 2(>45.12 \& \leq 54.40)$ & 35 (117) & $1.27(0.77,2.10)$ & \\
\hline $\mathrm{T} 3(>54.40)$ & $28(117)$ & $1.00($ ref $)$ & \\
\hline PCS & & & 0.0053 \\
\hline $\mathrm{T} 1(\leq 44.75)$ & 55 (117) & $2.12(1.18,3.81)$ & \\
\hline $\mathrm{T} 2(>44.75 \& \leq 54.39)$ & 27 (117) & $1.26(0.68,2.35)$ & \\
\hline \multirow[t]{3}{*}{$\mathrm{T} 3(>54.39)$} & 17 (117) & $1.00($ ref $)$ & \\
\hline & \multicolumn{3}{|c|}{ Model $3^{\mathrm{e}}$} \\
\hline & \# of Deaths & & \\
\hline $\begin{array}{l}\text { HRQOL Component Summary } \\
\text { Scores }^{\text {a }}\end{array}$ & $(\text { Total })^{\mathrm{b}}$ & $\operatorname{HR}(95 \% \mathrm{CI})$ & $P$ Trend \\
\hline MCS & & & 0.4284 \\
\hline $\mathrm{T} 1(\leq 45.12)$ & $36(117)$ & $1.24(0.72,2.15)$ & \\
\hline $\mathrm{T} 2(>45.12 \& \leq 54.40)$ & 35 (117) & $1.26(0.76,2.10)$ & \\
\hline $\mathrm{T} 3(>54.40)$ & $28(117)$ & $1.00($ ref $)$ & \\
\hline
\end{tabular}


Model $3^{\mathrm{e}}$

\section{HRQOL Component Summary}

\begin{tabular}{lccc} 
Scores $^{\mathbf{a}}$ & (Total) $^{\mathrm{b}}$ & HR $(95 \% \mathrm{CI})$ & $P$ Trend \\
\hline PCS & & & 0.0061 \\
T1 $(\leq 44.75)$ & $55(117)$ & $\mathbf{2 . 1 7}(\mathbf{1 . 2 0}, \mathbf{3 . 9 0})$ & \\
T2 $(>44.75 \& \leq 54.39)$ & $27(117)$ & $1.37(0.74,2.56)$ & \\
T3 $(>54.39)$ & $17(117)$ & $1.00($ ref $)$ & \\
\hline
\end{tabular}

a. Data collected at 36-month HRQOL follow-up assessment.

b. Frequency of \# of events and total number within the category.

c. Model 1, crude.

${ }^{\text {d. }}$ Model 2 adjusted for baseline lifestyle and clinical characteristics. MCS: age, race/ethnicity, marital status, tumor stage, treatment type, and comorbidities; PCS: age, race/ethnicity, marital status, tumor stage, treatment type, and comorbidities.

e. Model 3 adjusted for additional HRQOL characteristics in addition to Model 1. MCS: current lymphedema, perceived pessimism, number of types of confidants, bodily pain, and perceived general health. PCS: current lymphedema, perceived pessimism, number of types of confidants, fear of recurrence.

Abbreviations: HRQOL, Healthy-Related Quality of Life; HR, hazard ratio; CI, confidence interval; MCS, Mental Component Summary Score; PCS, Physical Component Summary Score

\section{MCS/PCS and All-Cause Mortality by Race/Ethnicity}

Associations between MCS and PCS and all-cause mortality stratified by ethnicity is shown in Table 6. Among NHW women, compared to cases in PCS T3, those in PCS T1 were twice as likely to die from any cause (HR: $2.13,95 \%$ CI: $1.10,4.12)$. The number of events was low in the Hispanic population, hence 95\% CI were wide. Hispanics in PCS T1 had a four-fold increased risk of dying due to any cause compared to Hispanics in PCS T3 (HR: 4.05, 95\% CI: 0.82, 20.05, but this association was not statistically significant. All associations between MCS and all-cause mortality we close to the null value and not significant when stratified by race/ethnicity.

\section{$\underline{\text { HRQOL Subscales and All-Cause Mortality }}$}

Table 7 displays results from associations between HRQOL subscales and all-cause mortality. Compared to cases in $\mathrm{T} 3$, cases in $\mathrm{T} 1$ or $\mathrm{T} 2 \mathrm{had}$ an increased risk of death 
Table 6. Associations between HRQOL SF-36 Mental \& Physical Component Summary Score Tertiles and All-Cause Mortality by Race/Ethnicity $(N=351)$

\begin{tabular}{|c|c|c|c|}
\hline \multirow[b]{2}{*}{$\begin{array}{l}\text { HRQOL Component Summary } \\
\text { Scores }^{\text {a }}\end{array}$} & \multicolumn{3}{|c|}{ Non-Hispanic White $(n=273)$} \\
\hline & $\begin{array}{c}\text { \# of Deaths } \\
{\text { (Total })^{b}}\end{array}$ & $\mathrm{HR}(95 \% \mathrm{CI})$ & $P$ Trend \\
\hline $\mathbf{M C S}^{\mathbf{c}}$ & & & 0.8449 \\
\hline $\mathrm{T} 1(\leq 45.12)$ & $28(85)$ & $1.06(0.58,1.92)$ & \\
\hline $\mathrm{T} 2(>45.12 \& \leq 54.40)$ & $29(90)$ & $1.12(0.64,1.95)$ & \\
\hline $\mathrm{T} 3(>54.40)$ & $26(98)$ & 1.00 (ref) & \\
\hline \multicolumn{3}{|l|}{$\operatorname{PCS}^{d}$} & 0.0151 \\
\hline $\mathrm{T} 1(\leq 44.75)$ & $47(90)$ & $2.13(1.10,4.12)$ & \\
\hline $\mathrm{T} 2(>44.75 \& \leq 54.39)$ & $22(90)$ & $1.29(0.64,2.58)$ & \\
\hline \multirow[t]{3}{*}{$\mathrm{T} 3(>54.39)$} & $14(93)$ & 1.00 (ref) & \\
\hline & \multicolumn{3}{|c|}{ Hispanic $(n=78)$} \\
\hline & \multicolumn{3}{|l|}{ \# of Deaths } \\
\hline $\begin{array}{l}\text { HRQOL Component Summary } \\
\text { Scores }^{\text {a }}\end{array}$ & $(\text { Total })^{\mathrm{b}}$ & $\mathrm{HR}(95 \% \mathrm{CI})$ & $P$ Trend \\
\hline \multicolumn{3}{|l|}{$\mathbf{M C S}^{\mathbf{c}}$} & 0.7299 \\
\hline $\mathrm{T} 1(\leq 45.12)$ & $8(32)$ & $0.89 \quad(0.12,6.76)$ & \\
\hline $\mathrm{T} 2(>45.12 \& \leq 54.40)$ & $6(27)$ & $0.47 \quad(0.05,4.42)$ & \\
\hline $\mathrm{T} 3(>54.40)$ & $2(19)$ & 1.00 (ref) & \\
\hline \multicolumn{3}{|l|}{$\mathbf{P C S}^{\mathrm{d}}$} & 0.0661 \\
\hline $\mathrm{T} 1(\leq 44.75)$ & $8(27)$ & $4.05(0.82,20.05)$ & \\
\hline T2 $(>44.75 \& \leq 54.39)$ & $5(27)$ & $1.06(0.21,5.41)$ & \\
\hline $\mathrm{T} 3(>54.39)$ & $3(24)$ & 1.00 (ref) & \\
\hline \multicolumn{3}{|c|}{ a. Data collected at 36-month HRQOL follow-up assessment. } & b. Frequency of \# of events and total number within the category. \\
\hline \multicolumn{4}{|c|}{$\begin{array}{l}\text { c. MCS Model adjusted for age, marital status, tumor stage, treatment type, comorbidities, current lymphedema, perceived } \\
\text { pessimism, number of types of confidants, fear of recurrence, bodily pain, and perceived general health. }\end{array}$} \\
\hline \multicolumn{4}{|c|}{$\begin{array}{l}\text { d. PCS Model adjusted for age, marital status, tumor stage, treatment type, comorbidities, current lymphedema, perceived } \\
\text { pessimism, number of types of confidants, and fear of recurrence. }\end{array}$} \\
\hline \multicolumn{4}{|c|}{$\begin{array}{l}\text { Abbreviations: HRQOL, Health-Related Quality of Life; HR, hazard ratio; CI, confidence interval; MCS, Mental Component } \\
\text { Summary Score; PCS, Physical Component Summary Score. }\end{array}$} \\
\hline
\end{tabular}

due to any cause for the following MSC subscales: social functioning (T1, HR: 2.36, 95\% CI: 1.51, 3.69), role emotional (T1, HR: 1.94, 95\% CI: 1.25, 3.00), role emotional (T1, HR: $1.94,95 \%$ CI: $1.25,3.00$ ), and vitality (T1, HR: 2.16, 95\% CI: 1.25, 3.72; T2, HR: 
$2.11,95 \%$ CI: 1.22, 3.65). Similarly, risk was increased among the following PCS subscales: physical functioning (T1, HR: 4.55, 95\% CI: 2.52, 8.19; T2, HR: 2.11, 95\% CI: $1.12,3.96$ ), role physical (T1, HR: $2.87,95 \%$ CI: 1.75 , 4.69; T2, HR: $2.34,95 \%$ CI: 1.36, 4.04), bodily pain (T1, HR: 2.18, 95\% CI: 1.39, 3.43), and general health (T1, HR: 1.63, 95\% CI: 1.03, 2.59), compared to cases in T3. Additional adjustments in Model 2 attenuated results for social functioning (T1, HR: 1.96, 95\% CI: 1.23, 3.11), vitality (T1, HR: $2.00,95 \%$ CI: $1.15,3.49$; T2, HR: 1.92, 95\% CI: 1.10, 3.36), physical functioning (T1, HR: 2.65, 95\% CI: 1.43, 4.92), role physical (T1, HR: 1.95, 95\% CI: 1.17, 3.26; T2, HR: 1.97, 95\% CI: 1.13, 3.44), and bodily pain (T1, HR: 1.74, 95\% CI: 1.09, 2.77), compared to cases in T3. When adjusted for additional HRQOL characteristics (Model 3), the increased risk of dying from any cause remained significant for the following subscales: vitality (T2, HR: 1.98, 95\% CI: 1.12, 3.50) physical functioning (T1, HR: 2.58, 95\% CI: 1.38, 4.81), role physical (T1, HR: 1.94, 95\% CI: 1.15, 3.25; T2, HR: 1.87, 95\% CI: 1.06, 3.30), and bodily pain (T1, HR: $1.87,95 \%$ CI: 1.15, 3.05).

\section{Associations between HRQOL and Breast Cancer-Specific Mortality $\underline{\text { MCS/PCS and Breast Cancer-Specific Mortality }}$}

Associations between MCS/PCS and breast cancer-specific mortality are presented in Table 8. Compared to cases with high MCS or PCS scores, crude associations among cases with low MCS scores (HR: 1.40, 95\% CI: 0.94, 2.09) or low PCS (HR: 1.09, 95\% CI: 0.51, 2.36), were not statistically significant when comparing cases with high MCS or PCS scores, respectively. However, when adjusted for baseline lifestyle and clinical characteristics, associations between PCS and breast cancer-specific 
Table 7. Associations between HRQOL SF-36 Subscale Scores and All-Cause Mortality $(N=351)$

\begin{tabular}{|c|c|c|c|c|c|c|c|c|c|c|}
\hline & \multirow[b]{3}{*}{ Subscale Scores $^{\mathrm{a}}$} & \multicolumn{3}{|c|}{ Model $1^{\mathrm{c}}$} & \multicolumn{3}{|c|}{ Model $2^{\mathrm{d}}$} & \multicolumn{3}{|c|}{ Model $3^{\mathrm{e}}$} \\
\hline & & Deaths & & & Deaths & & & Deaths & & \\
\hline & & $(\text { Total })^{\mathrm{b}}$ & $\mathrm{HR}(95 \% \mathrm{CI})$ & $P$ Trend & $(\text { Total })^{b}$ & $\mathrm{HR}(95 \% \mathrm{CI})$ & $P$ Trend & $(\text { Total })^{b}$ & $\mathrm{HR}(95 \% \mathrm{CI})$ & $P$ Trend \\
\hline & Social Functioning & & & 0.0002 & & & 0.0046 & & & 0.0593 \\
\hline & $\mathrm{T} 1(\leq 40.86)$ & $43(98)$ & $2.36(1.51,3.69)$ & & $43(98)$ & $1.96(1.23,3.11)$ & & $43(98)$ & $1.65(0.98,2.79)$ & \\
\hline & T2 $(>40.86 \& \leq 51.71)$ & $21(87)$ & $1.18(0.69,2.03)$ & & $21(87)$ & $1.35(0.77,2.35)$ & & $21(87)$ & $1.32(0.75,2.31)$ & \\
\hline & T3 $(>51.71)$ & $35(166)$ & 1.00 (ref) & & 35 (166) & 1.00 (ref) & & $35(166)$ & 1.00 (ref) & \\
\hline & Role Emotional & & & 0.0030 & & & 0.0567 & & & 0.3318 \\
\hline & $\mathrm{T} 1(\leq 34.28)$ & $42(113)$ & $1.94(1.25,3.00)$ & & $42(113)$ & $1.55(0.99,2.44)$ & & $42(113)$ & $1.27(0.78,2.08)$ & \\
\hline & T2 $(>34.28 \& \leq 44.81)$ & $18(61)$ & $1.40(0.80,2.44)$ & & $18(61)$ & $1.28(0.73,2.25)$ & & $18(61)$ & $1.18(0.67,2.11)$ & \\
\hline & $\mathrm{T} 3(>44.81)$ & 39 (177) & 1.00 (ref) & & 39 (177) & 1.00 (ref) & & 39 (177) & 1.00 (ref) & \\
\hline & Vitality & & & 0.0076 & & & 0.0201 & & & 0.1627 \\
\hline & $\mathrm{T} 1(\leq 44.33)$ & $41(121)$ & $2.16(1.25,3.72)$ & & $41(121)$ & $2.00(1.15,3.49)$ & & $41(121)$ & $1.61(0.88,2.96)$ & \\
\hline & T2 $(>44.33 \& \leq 53.79)$ & $39(121)$ & $2.11(1.22,3.65)$ & & $39(121)$ & $1.92(1.10,3.36)$ & & $39(121)$ & $1.98(1.12,3.50)$ & \\
\hline & T3 (>53.79) & 19 (109) & 1.00 (ref) & & 19 (109) & 1.00 (ref) & & 19 (109) & 1.00 (ref) & \\
\hline & Mental Health & & & 0.0982 & & & 0.0543 & & & 0.2250 \\
\hline & $\mathrm{T} 1(\leq 43.63)$ & $35(108)$ & $1.51(0.93,2.46)$ & & 35 (108) & $1.64(0.99,2.71)$ & & $35(108)$ & $1.41(0.81,2.47)$ & \\
\hline & $\mathrm{T} 2(>43.63 \& \leq 52.72)$ & 34 (114) & $1.32(0.81,2.16)$ & & 34 (114) & $1.37(0.83,2.25)$ & & 34 (114) & $1.34(0.80,2.25)$ & \\
\hline & $\mathrm{T} 3(>52.72)$ & $30(129)$ & 1.00 (ref) & & 30 (129) & 1.00 (ref) & & 30 (129) & 1.00 (ref) & \\
\hline & Physical Functioning & & & $<0.0001$ & & & 0.0012 & & & 0.0023 \\
\hline & $\mathrm{T} 1(\leq 43.17)$ & $54(118)$ & $4.55 \quad(2.52,8.19)$ & & $54(118)$ & $2.65(1.43,4.92)$ & & $54(118)$ & $2.58(1.38,4.81)$ & \\
\hline & T2 $(>43.17 \& \leq 52.49)$ & $31(123)$ & $2.11(1.12,3.96)$ & & $31(123)$ & $1.73(0.91,3.28)$ & & $31(123)$ & $1.82(0.96,3.46)$ & \\
\hline & $\mathrm{T} 3(>52.49)$ & $14(110)$ & 1.00 (ref) & & $14(110)$ & 1.00 (ref) & & $14(110)$ & 1.00 (ref) & \\
\hline & Role Physical & & & $<0.0001$ & & & 0.0131 & & & 0.0146 \\
\hline & $\mathrm{T} 1(\leq 35.03)$ & 47 (116) & $2.87 \quad(1.75,4.69)$ & & 47 (116) & $1.95(1.17,3.26)$ & & 47 (116) & $1.94(1.15,3.25)$ & \\
\hline & $\mathrm{T} 2(>35.03 \& \leq 49.18)$ & $28(88)$ & $2.34(1.36,4.04)$ & & $28(88)$ & $1.97(1.13,3.44)$ & & $28(88)$ & $1.87(1.06,3.30)$ & \\
\hline & $\mathrm{T} 3(>49.18)$ & $24(147)$ & 1.00 (ref) & & 24 (147) & 1.00 (ref) & & $24(147)$ & 1.00 (ref) & \\
\hline
\end{tabular}




\begin{tabular}{|c|c|c|c|c|c|c|c|c|c|}
\hline \multirow[b]{2}{*}{ Subscale Scores $^{\mathrm{a}}$} & \multicolumn{3}{|c|}{ Model $1^{\mathrm{c}}$} & \multicolumn{3}{|c|}{ Model $2^{\mathrm{d}}$} & \multicolumn{3}{|c|}{ Model $3^{\mathrm{e}}$} \\
\hline & $\begin{array}{l}\text { Deaths } \\
\left(_{\text {Total })^{b}}\right.\end{array}$ & $\mathrm{HR}(95 \% \mathrm{CI})$ & $P$ Trend & $\begin{array}{l}\text { Deaths } \\
\left(_{\text {Total })^{\mathrm{b}}}\right.\end{array}$ & $\mathrm{HR}(95 \% \mathrm{Cl})$ & $P$ Trend & $\begin{array}{l}\text { Deaths } \\
(\text { Total })^{\mathrm{b}} \\
\end{array}$ & $\mathrm{HR}(95 \% \mathrm{CI})$ & $P$ Trend \\
\hline Bodily Pain & & & 0.0007 & & & 0.0199 & & & 0.0122 \\
\hline $\mathrm{T} 1(\leq 46.05)$ & $44(106)$ & $2.18(1.39,3.43)$ & & $44(106)$ & $1.74(1.09,2.77)$ & & $44(106)$ & $1.87(1.15,3.05)$ & \\
\hline $\mathrm{T} 2(>46.05 \& \leq 54.19)$ & $22(81)$ & $1.38(0.80,2.36)$ & & $22(81)$ & $1.16(0.68,2.01)$ & & $22(81)$ & $1.10(0.63,1.91)$ & \\
\hline $\mathrm{T} 3(>54.19)$ & $33(164)$ & 1.00 (ref) & & $33(164)$ & 1.00 (ref) & & $33(164)$ & 1.00 (ref) & \\
\hline General Health & & & 0.0327 & & & 0.1959 & & & 0.3072 \\
\hline $\mathrm{T} 1(\leq 46.28)$ & $45(123)$ & $1.63(1.03,2.59)$ & & $45(123)$ & $1.33 \quad(0.82,2.16)$ & & $45(123)$ & $1.25(0.76,2.05)$ & \\
\hline $\mathrm{T} 2(>46.28 \& \leq 54.64)$ & $24(104)$ & $0.95 \quad(0.55,1.62)$ & & $24(104)$ & $0.84(0.48,1.45)$ & & $24(104)$ & $0.79(0.45,1.38)$ & \\
\hline $\mathrm{T} 3(>54.64)$ & $30(124)$ & 1.00 (ref) & & $30(124)$ & $1.00(\mathrm{ref})$ & & $30(124)$ & $1.00(\mathrm{ref})$ & \\
\hline
\end{tabular}

a. Data collected at 36-month HRQOL follow-up assessment.

b. Frequency of \# of events and total number within the category.

c. Model 1: crude.

d. Model 2: adjusted for baseline lifestyle and clinical characteristics. Mental-related: age, race/ethnicity, marital status, tumor stage, treatment type, and comorbidities; Physical-related: age, race/ethnicity, marital status, tumor stage, treatment type, and comorbidities.

e. Model 3: adjusted for additional HRQOL characteristics in addition to Model 1. Mental-related: current lymphedema, perceived pessimism, number of types of confidants, bodily pain, and perceived general health. Physical-related: current lymphedema, perceived pessimism, number of types of confidants, fear of recurrence. 
Mortality were significantly increased (HR: 1.71, 95\% CI: 1.10, 2.63), as well as the association adjusted for additional HRQOL characteristics (HR: 1.65, 95\% CI: 1.06, 2.58).

Table 8. Associations between HRQOL SF-36 Mental \& Physical Component Summary Score Tertiles and Breast Cancer-Specific Mortality $(N=351)$

\begin{tabular}{|c|c|c|c|}
\hline \multirow[b]{3}{*}{$\begin{array}{l}\text { HRQOL Component Summary } \\
\text { Scores }^{\text {a }}\end{array}$} & \multicolumn{3}{|c|}{ Model $1^{\mathrm{c}}$} \\
\hline & \multicolumn{3}{|l|}{ \# of Deaths } \\
\hline & $(\text { Total })^{\mathrm{b}}$ & $\operatorname{HR}(95 \% \mathrm{CI})$ & $P$ \\
\hline MCS & & & 0.2238 \\
\hline Low $(\leq 50.70)$ & $14(176)$ & $1.40 \quad(0.94,2.09)$ & \\
\hline $\operatorname{High}(>50.70)$ & $12(175)$ & 1.00 (ref) & \\
\hline PCS & & & 0.8239 \\
\hline Low $(\leq 50.28)$ & $13(176)$ & $1.09 \quad(0.51,2.36)$ & \\
\hline \multirow[t]{3}{*}{$\operatorname{High}(>50.28)$} & $13(175)$ & $1.00($ ref $)$ & \\
\hline & \multicolumn{3}{|c|}{ Model $2^{\mathrm{d}}$} \\
\hline & \# of Deaths & & \\
\hline $\begin{array}{l}\text { HRQOL Component Summary } \\
\text { Scores }^{\text {a }}\end{array}$ & $(\text { Total })^{b}$ & $\mathrm{HR}(95 \% \mathrm{CI})$ & $P$ \\
\hline \multicolumn{3}{|l|}{ MCS } & 0.1139 \\
\hline Low $(\leq 50.70)$ & $14(176)$ & \multirow{2}{*}{\multicolumn{2}{|c|}{$\begin{array}{c}1.39(0.93,2.09) \\
1.00(\text { ref })\end{array}$}} \\
\hline High $(>50.70)$ & $12(175)$ & & \\
\hline \multirow{5}{*}{$\begin{array}{l}\text { PCS } \\
\text { Low }(\leq 50.28) \\
\text { High }(>50.28)\end{array}$} & & \multirow{3}{*}{$\begin{array}{c}1.71(\mathbf{1 . 1 0}, \mathbf{2 . 6 3}) \\
1.00 \text { (ref) }\end{array}$} & \multirow[t]{3}{*}{0.0161} \\
\hline & $13(176)$ & & \\
\hline & $13(175)$ & & \\
\hline & \multicolumn{3}{|c|}{ Model $3^{\mathrm{e}}$} \\
\hline & \multicolumn{2}{|l|}{ \# of Deaths } & \\
\hline $\begin{array}{l}\text { HRQOL Component Summary } \\
\text { Scores }^{\text {a }}\end{array}$ & $(\text { Total })^{b}$ & $\operatorname{HR}(95 \% \mathrm{CI})$ & $P$ \\
\hline \multicolumn{3}{|l|}{ MCS } & 0.4284 \\
\hline Low $(\leq 50.70)$ & $14(176)$ & \multirow{2}{*}{$\begin{array}{c}1.24(0.81,1.91) \\
1.00 \text { (ref) }\end{array}$} & \\
\hline High $(>50.70)$ & $12(175)$ & & \\
\hline \multicolumn{3}{|l|}{ PCS } & 0.0283 \\
\hline Low $(\leq 50.28)$ & $13(176)$ & \multirow{2}{*}{$\begin{array}{c}1.65(\mathbf{1 . 0 6}, \mathbf{2 . 5 8}) \\
1.00 \text { (ref) }\end{array}$} & \\
\hline High $(>50.28)$ & $13(175)$ & & \\
\hline \multicolumn{4}{|c|}{ a: Data collected at 36-month HRQOL follow-up assessment. } \\
\hline \multicolumn{4}{|c|}{$\begin{array}{l}\text { b: frequency of \# of events and total number within the category. } \\
\text { Model 1: crude. }\end{array}$} \\
\hline
\end{tabular}


Model 3: adjusted for additional HRQOL characteristics in addition to Model 1. MCS: current lymphedema, perceived pessimism, number of types of confidants, bodily pain, and perceived general health. PCS: current lymphedema perceived pessimism, number of types of confidants, fear of recurrence;

Abbreviations: HRQOL, Health-Related Quality of Life; HR, hazard ratio; CI, confidence interval; MCS, Mental Component Summary Score; PCS, Physical Component Summary Score.

\section{MCS/PCS and Breast Cancer-Specific Mortality by Race/Ethnicity}

The previous associations were stratified by ethnicity and is presented in Table 9 . Among NHW women, cases in PCS T1 had a two-fold increased risk of dying of breast cancer compared to cases in PCS T3 (HR: 1.93, 95\% CI: 1.16, 3.23). Hispanic women with low MCS scores had a four-fold increased risk of breast cancer-specific mortality compared to Hispanic women with high MCS scores (HR: 4.11, 95\% CI: 0.80, 21.04), though the association was not statistically significant due to the small number of events.

Table 9. Associations between HRQOL SF-36 Mental \& Physical Component Summary Score Tertiles and Breast Cancer-Specific Mortality by Race/Ethnicity ( $N$ =351)

\begin{tabular}{|c|c|c|c|}
\hline \multirow[b]{2}{*}{$\begin{array}{l}\text { HRQOL Component Summary } \\
\text { Scores }^{\text {a }}\end{array}$} & \multicolumn{3}{|c|}{ Non-Hispanic White $(n=273)$} \\
\hline & $\begin{array}{c}\# \text { of Deaths } \\
\left(^{(\text {Total })^{b}}\right. \\
\end{array}$ & $\mathrm{HR}(95 \% \mathrm{CI})$ & $P$-value \\
\hline $\operatorname{MCS}^{\mathbf{c}}$ & & & 0.6568 \\
\hline Low $(\leq 50.70)$ & $11(131)$ & $1.11(0.70,1.77)$ & \\
\hline $\operatorname{High}(>50.70)$ & $10(142)$ & $1.00(\mathrm{ref})$ & \\
\hline $\mathbf{P C S}^{\mathbf{d}}$ & & & 0.0115 \\
\hline Low $(\leq 50.28)$ & $11(137)$ & $1.93(1.16,3.23)$ & \\
\hline \multirow[t]{3}{*}{ High $(>50.28)$} & $10(136)$ & 1.00 (ref) & \\
\hline & & ispanic $(n=78)$ & \\
\hline & \# of Deaths & & \\
\hline $\begin{array}{l}\text { HRQOL Component Summary } \\
\text { Scores }^{\text {a }}\end{array}$ & $(\text { Total })^{\mathrm{b}}$ & $\mathrm{HR}(95 \% \mathrm{CI})$ & $P$-value \\
\hline
\end{tabular}




\begin{tabular}{|c|c|c|c|}
\hline $\begin{array}{l}\text { HRQOL Component Summary } \\
\text { Scores }^{\mathrm{a}}\end{array}$ & $(\text { Total })^{b}$ & $\mathrm{HR}(95 \% \mathrm{CI})$ & $P$-value \\
\hline $\mathbf{M C S}^{\mathbf{c}}$ & & & 0.0900 \\
\hline Low $(\leq 50.70)$ & $3(45)$ & $4.11(0.80,21.04)$ & \\
\hline $\operatorname{High}(>50.70)$ & $2(33)$ & 1.00 (ref) & \\
\hline $\mathbf{P C S}^{\mathbf{d}}$ & & & 0.5070 \\
\hline Low $(\leq 50.28)$ & $2(39)$ & $1.51(0.45,5.05)$ & \\
\hline High $(>50.28)$ & $3(39)$ & 1.00 (ref) & \\
\hline \multicolumn{4}{|c|}{ a. Data collected at 36-month HRQOL follow-up assessment. } \\
\hline \multicolumn{4}{|c|}{$\begin{array}{l}\text { MCS Model adjusted for age, marital status, tumor stage, treatment type, comorbidities, current lymphedema, perceived } \\
\text { pessimism, number of types of confidants, fear of recurrence, bodily pain, and perceived general health. }\end{array}$} \\
\hline \multicolumn{4}{|c|}{$\begin{array}{l}\text { PCS Model adjusted for age, marital status, tumor stage, treatment type, comorbidities, current lymphedema, perceived } \\
\text { pessimism, number of types of confidants, and fear of recurrence. }\end{array}$} \\
\hline \multicolumn{4}{|c|}{ Abbreviations: HRQOL, Health-Related Quality of Life; HR, hazard ratio; CI, confidence interval; } \\
\hline MCS, Mental Component Summary Score; PC & nponent Sum & & \\
\hline
\end{tabular}

\section{$\underline{\text { HRQOL Subscales and Breast Cancer-Specific Mortality }}$}

Associations between each subscale and breast cancer-specific mortality are portrayed in Table 10. There were no significant associations. However, the crude risk of dying was somewhat stronger for certain physical subscales, such as cases with low physical functioning scores (HR: 1.56, 95\% CI: 0.70, 3.51) compared to cases with high physical functioning scores.

\section{Associations between HRQOL and Non-Cancer Mortality \\ $\underline{\text { MCS/PCS and Non-cancer Mortality }}$}

Table 11 presents associations between MCS and PCS component summary scores and risk of death due to non-cancer causes. Similar associations between HRQOL component summary scores and all-cause mortality, there were significant increased risks 
Table 10. Associations between HRQOL SF-36 Subscale Scores and Breast Cancer-Specific Mortality $(N=351)$

\begin{tabular}{|c|c|c|c|c|c|c|c|c|c|}
\hline \multirow[b]{2}{*}{ Subscale Scores ${ }^{\mathrm{a}}$} & \multicolumn{3}{|c|}{ Model $1^{\mathrm{c}}$} & \multicolumn{3}{|c|}{ Model $2^{\mathrm{d}}$} & \multicolumn{3}{|c|}{ Model $3^{\mathrm{e}}$} \\
\hline & $\begin{array}{l}\text { Deaths } \\
\text { (Total) }^{\mathrm{b}}\end{array}$ & $\mathrm{HR}(95 \% \mathrm{CI})$ & $P$ & $\begin{array}{l}\text { Deaths } \\
\text { (Total) }^{\mathrm{b}}\end{array}$ & $\mathrm{HR}(95 \% \mathrm{Cl})$ & $P$ & $\begin{array}{l}\text { Deaths } \\
\left(_{\text {Total })^{b}}\right.\end{array}$ & $\mathrm{HR}(95 \% \mathrm{CI})$ & $P$ \\
\hline Social Functioning & & & 0.7753 & & & 0.9530 & & & 0.7044 \\
\hline Low $(\leq 57.13)$ & $14(185)$ & $1.12(0.52,2.42)$ & & $14(185)$ & $1.03 \quad(0.46,2.31)$ & & $14(185)$ & $0.84 \quad(0.35,2.04)$ & \\
\hline High $(>57.13)$ & $12(166)$ & 1.00 (ref) & & $12(166)$ & 1.00 (ref) & & $12(166)$ & 1.00 (ref) & \\
\hline Role Emotional & & & 0.5111 & & & 0.7636 & & & 0.9997 \\
\hline Low $(\leq 55.34)$ & $14(174)$ & $1.30(0.60,2.80)$ & & $14(174)$ & $1.13(0.51,2.48)$ & & $14(174)$ & $1.00(0.43,2.32)$ & \\
\hline High (>55.34) & 12 (177) & 1.00 (ref) & & 12 (177) & 1.00 (ref) & & $12(177)$ & 1.00 (ref) & \\
\hline Vitality & & & 0.7682 & & & 0.8143 & & & 0.9683 \\
\hline Low $(\leq 51.42)$ & $14(183)$ & $1.12(0.52,2.43)$ & & $14(183)$ & $1.10 \quad(0.49,2.47)$ & & $14(183)$ & $0.98 \quad(0.39,2.45)$ & \\
\hline High $(>51.42)$ & $12(168)$ & 1.00 (ref) & & $12(168)$ & 1.00 (ref) & & $12(168)$ & 1.00 (ref) & \\
\hline Mental Health & & & 0.6757 & & & 0.5060 & & & 0.7049 \\
\hline Low $(\leq 52.71)$ & 14 (177) & $1.18(0.55,2.55)$ & & 14 (177) & $1.31 \quad(0.59,2.90)$ & & 14 (177) & $1.18 \quad(0.50,2.79)$ & \\
\hline High $(>52.71)$ & $12(174)$ & 1.00 (ref) & & $12(174)$ & 1.00 (ref) & & $12(174)$ & 1.00 (ref) & \\
\hline Physical Functioning & & & 0.7614 & & & 0.6906 & & & 0.7223 \\
\hline Low $(\leq 50.15)$ & $12(166)$ & $1.13(0.52,2.44)$ & & $12(166)$ & $1.18 \quad(0.52,2.66)$ & & $12(166)$ & $1.16 \quad(0.51,2.63)$ & \\
\hline High $(>50.15)$ & $14(185)$ & 1.00 (ref) & & $14(185)$ & 1.00 (ref) & & $14(185)$ & 1.00 (ref) & \\
\hline Role Physical & & & 0.2802 & & & 0.5935 & & & 0.6681 \\
\hline Low $(\leq 56.24)$ & $17(204)$ & $1.56(0.70,3.51)$ & & $17(204)$ & $1.26(0.54,2.93)$ & & $17(204)$ & $1.21 \quad(0.51,2.88)$ & \\
\hline High $(>56.24)$ & $9(147)$ & 1.00 (ref) & & $9(147)$ & 1.00 (ref) & & $9(147)$ & 1.00 (ref) & \\
\hline Bodily Pain & & & 0.7762 & & & 0.9850 & & & 0.9208 \\
\hline Low $(\leq 54.18)$ & $14(184)$ & $1.12(0.52,2.42)$ & & $14(184)$ & $1.01 \quad(0.46,2.23)$ & & $14(184)$ & $0.96 \quad(0.43,2.15)$ & \\
\hline High $(>54.18)$ & $12(167)$ & 1.00 (ref) & & $12(167)$ & 1.00 (ref) & & $12(167)$ & $1.00(\mathrm{ref})$ & \\
\hline General Health & & & 0.8683 & & & 0.9954 & & & 0.6920 \\
\hline Low $(\leq 52.29)$ & $13(188)$ & $0.94(0.43,2.02)$ & & $13(188)$ & $1.00 \quad(0.45,2.23)$ & & $13(188)$ & $0.84 \quad(0.25,2.01)$ & \\
\hline High $(>52.29)$ & $13(163)$ & 1.00 (ref) & & $13(163)$ & 1.00 (ref) & & $13(163)$ & 1.00 (ref) & \\
\hline
\end{tabular}




\begin{tabular}{l} 
Subscale Scores ${ }^{\mathrm{a}}$ \\
\cline { 2 - 3 }
\end{tabular}


of cases in PCS T1 compared to cases in PCS T3. Participants had a nearly six-fold increased risk of dying from non-cancer causes if they were in PCS T1 compared to PCS T3 (HR: 5.63, 95\% CI: 2.74, 11.55; p-trend=<0.0001). This association was attenuated by $56.48 \%$ when adjusted for baseline and clinical characteristics (Model 2) (HR: 2.45, 95\% CI: $1.14,5.26$; p-trend $=0.0025)$, and similar (percent change: $54.35 \%$ ) when adjusted for additional HRQOL characteristics (HR: 2.57, 95\% CI: 1.18, 5.61; p-trend=0.0023). No significant associations were discerned for MCS scores and non-cancer mortality.

Table 11. Associations between HRQOL SF-36 Mental \& Physical Component Summary Score Tertiles and Non-Cancer Mortality $(N=351)$

\begin{tabular}{|c|c|c|c|}
\hline \multirow[b]{2}{*}{$\begin{array}{l}\text { HRQOL Component Summary } \\
\text { Scores }^{\mathrm{a}}\end{array}$} & \multicolumn{3}{|c|}{ Model $1^{\mathrm{c}}$} \\
\hline & $\begin{array}{c}\text { \# of Deaths } \\
\left(^{(\text {Total })^{b}}\right. \\
\end{array}$ & $\mathrm{HR}(95 \% \mathrm{CI})$ & $P$ Trend \\
\hline MCS & & & 0.2502 \\
\hline $\mathrm{T} 1(\leq 45.12)$ & $23(117)$ & $1.45(0.78,2.72)$ & \\
\hline $\mathrm{T} 2(>45.12 \& \leq 54.40)$ & $24(117)$ & $1.41 \quad(0.76,2.64)$ & \\
\hline $\mathrm{T} 3(>54.40)$ & 17 (117) & 1.00 (ref) & \\
\hline PCS & & & $<0.0001$ \\
\hline $\mathrm{T} 1(\leq 44.75)$ & 43 (117) & $5.63(2.74,11.55)$ & \\
\hline $\mathrm{T} 2(>44.75 \& \leq 54.39)$ & $12(117)$ & $1.41 \quad(0.59,3.35)$ & \\
\hline \multirow[t]{3}{*}{$\mathrm{T} 3(>54.39)$} & $9(117)$ & 1.00 (ref) & \\
\hline & \multicolumn{3}{|c|}{ Model $2^{\mathrm{d}}$} \\
\hline & \# of Deaths & & \\
\hline $\begin{array}{l}\text { HRQOL Component Summary } \\
\text { Scores }^{\mathrm{a}}\end{array}$ & $(\text { Total })^{\mathrm{b}}$ & $\mathrm{HR}(95 \% \mathrm{CI})$ & $P$ Trend \\
\hline MCS & & & 0.1426 \\
\hline $\mathrm{T} 1(\leq 45.12)$ & $23(117)$ & $1.63(0.84,3.14)$ & \\
\hline $\mathrm{T} 2(>45.12 \& \leq 54.40)$ & 24 (117) & $1.40 \quad(0.74,2.64)$ & \\
\hline $\mathrm{T} 3(>54.40)$ & 17 (117) & 1.00 (ref) & \\
\hline PCS & & & 0.0025 \\
\hline $\mathrm{T} 1(\leq 44.75)$ & 43 (117) & $2.45 \quad(1.14,5.27)$ & \\
\hline $\mathrm{T} 2(>44.75 \& \leq 54.39)$ & $12(117)$ & $0.86 \quad(0.35,2.08)$ & \\
\hline $\mathrm{T} 3(>54.39)$ & $9(117)$ & 1.00 (ref) & \\
\hline & & Model $3^{\mathrm{e}}$ & \\
\hline
\end{tabular}




\begin{tabular}{|c|c|c|c|}
\hline $\begin{array}{l}\text { HRQOL Component Summary } \\
\text { Scores }^{\mathrm{a}}\end{array}$ & $\neq$ of Deaths & $\operatorname{HR}(95 \% \mathrm{CI})$ & $P$ Trend \\
\hline MCS & & & 0.3187 \\
\hline $\mathrm{T} 1(\leq 45.12)$ & $23(117)$ & $1.42(0.70,2.87)$ & \\
\hline $\mathrm{T} 2(>45.12 \& \leq 54.40)$ & $24(117)$ & $1.49(0.77,2.87)$ & \\
\hline $\mathrm{T} 3(>54.40)$ & $17(117)$ & 1.00 (ref) & \\
\hline PCS & & & 0.0023 \\
\hline $\mathrm{T} 1(\leq 44.75)$ & $43(117)$ & $2.57 \quad(1.18,5.61)$ & \\
\hline $\mathrm{T} 2(>44.75 \& \leq 54.39)$ & $12(117)$ & $0.94(0.38,2.32)$ & \\
\hline $\mathrm{T} 3(>54.39)$ & $9(117)$ & 1.00 (ref) & \\
\hline \multicolumn{4}{|c|}{ a. Data collected at 36-month HRQOL follow-up assessment. } \\
\hline \multicolumn{4}{|c|}{ b. frequency of \# of events and total number within the category. } \\
\hline \multicolumn{4}{|c|}{ c. Model 1: crude. } \\
\hline \multicolumn{4}{|c|}{$\begin{array}{l}\text { d. Model 2: adjusted for baseline lifestyle and clinical characteristics. MCS: age, race/ethnicity, marital status, tumor stage, } \\
\text { treatment type; PCS: age, race/ethnicity, marital status, tumor stage, treatment type, and comorbidities. }\end{array}$} \\
\hline \multirow{2}{*}{\multicolumn{4}{|c|}{$\begin{array}{l}\text { e. Model 3: adjusted for additional HRQOL characteristics in addition to Model 1. MCS: current lymphedema, perceived } \\
\text { pessimism, number of types of confidants, bodily pain, and perceived general health. PCS: current lymphedema, perceived }\end{array}$}} \\
\hline & & & \\
\hline \multicolumn{4}{|c|}{ pessimism, number of types of confidants, fear of recurrence; } \\
\hline \multicolumn{4}{|c|}{ Abbreviations: HRQOL, Health-Related Quality of Life; HR, hazard ratio; CI, confidence interval; MCS, Mental Component } \\
\hline Summary Score; PCS, Physical Component Su & & & \\
\hline
\end{tabular}

\section{MCS/PCS and Non-Cancer Mortality by Race/Ethnicity}

Stratification of the previous associations by race/ethnicity is presented in Table 12. There were no significant associations, partly due to a low number of events in NHW and Hispanic women. Even though they were not significant, results were suggestive of increased risk of dying due to non-cancer causes for both NHW (HR: 2.08, 95\% CI: 0.84, 5.16) and Hispanic (HR: 2.62, 95\% CI: 0.38, 18.30) women in PCS T1 vs. PCS T3.

\section{$\underline{\text { HRQOL Subscales and Non-Cancer Mortality }}$}

Associations between HRQOL subscale scores and non-cancer mortality is presented in Table 13. A significant increased risk of death due to non-cancer causes 
Table 12. Associations between HRQOL SF-36 Mental \& Physical Component Summary Score Tertiles and Non-Cancer Mortality by Race/Ethnicity $(N=351)$

\begin{tabular}{|c|c|c|c|}
\hline \multirow[b]{2}{*}{$\begin{array}{l}\text { HRQOL Component Summary } \\
\text { Scores }^{\text {a }}\end{array}$} & \multicolumn{3}{|c|}{ Non-Hispanic White $(n=273)$} \\
\hline & $(\text { Total })^{\mathrm{b}}$ & $\mathrm{HR}(95 \% \mathrm{CI})$ & $P$ Trend \\
\hline $\mathbf{M C S}^{\mathbf{c}}$ & & & 0.6215 \\
\hline $\mathrm{T} 1(\leq 45.12)$ & $18(85)$ & $1.20(0.56,2.54)$ & \\
\hline $\mathrm{T} 2(>45.12 \& \leq 54.40)$ & $21(90)$ & $1.31(0.64,2.65)$ & \\
\hline $\mathrm{T} 3(>54.40)$ & $16(98)$ & 1.00 (ref) & \\
\hline $\mathbf{P C S}^{\mathbf{d}}$ & & & 0.0116 \\
\hline $\mathrm{T} 1(\leq 44.75)$ & $38(90)$ & $2.08 \quad(0.84,5.16)$ & \\
\hline T2 $(>44.75 \& \leq 54.39)$ & $10(90)$ & $0.69(0.24,1.96)$ & \\
\hline \multirow[t]{3}{*}{$\mathrm{T} 3(>54.39)$} & $7(93)$ & 1.00 (ref) & \\
\hline & \multicolumn{3}{|c|}{ Hispanic $(n=78)$} \\
\hline & \multicolumn{3}{|l|}{ \# of Deaths } \\
\hline $\begin{array}{l}\text { HRQOL Component Summary } \\
\text { Scores }^{\mathrm{a}}\end{array}$ & $(\text { Total })^{\mathrm{b}}$ & $\mathrm{HR}(95 \% \mathrm{CI})$ & $P$ Trend \\
\hline $\mathbf{M C S}^{\mathbf{c}}$ & & & 0.9699 \\
\hline $\mathrm{T} 1(\leq 45.12)$ & $5(32)$ & $1.19(0.07,19.20)$ & \\
\hline $\mathrm{T} 2(>45.12 \& \leq 54.40)$ & $3(27)$ & $1.33(0.08,22.14)$ & \\
\hline $\mathrm{T} 3(>54.40)$ & $1(19)$ & 1.00 (ref) & \\
\hline $\mathbf{P C S}^{\mathbf{d}}$ & & & 0.2988 \\
\hline $\mathrm{T} 1(\leq 44.75)$ & $5(27)$ & $2.62(0.38,18.30)$ & \\
\hline T2 (>44.75 \& $\leq 54.39)$ & $2(27)$ & $0.45(0.04,4.59)$ & \\
\hline $\mathrm{T} 3(>54.39)$ & $2(24)$ & 1.00 (ref) & \\
\hline \multicolumn{3}{|c|}{ a. Data collected at 36-month HRQOL follow-up assessment. } & b. frequency of \# of events and total number within the category. \\
\hline \multicolumn{4}{|c|}{$\begin{array}{l}\text { MCS Model adjusted for age, marital status, tumor stage, treatment type, comorbidities, current lymphedema, perceived } \\
\text { optimism, number of types of confidants, fear of recurrence, bodily pain, and perceived general health. }\end{array}$} \\
\hline \multicolumn{4}{|c|}{$\begin{array}{l}\text { d. PCS Model adjusted for age, marital status, tumor stage, treatment type, comorbidities, current lymphedema, perceived } \\
\text { optimism, number of types of confidants, and fear of recurrence. }\end{array}$} \\
\hline Abbreviations: HRQOL, Health-Related Quali & IR, hazard ratio; & lence interval; MCS, Ment & ponent \\
\hline
\end{tabular}

was observed for seven subscales. Specifically, cases in the physical functioning T1, had a 9-fold increased risk (T1, HR: 9.11, 95\% CI: 3.58, 23.15) compared to cases in T3. Cases in T1 for social functioning (T1, HR: 3.27, 95\% CI: 1.85, 5.77), 
Table 13. Associations between HRQOL SF-36 Subscale Scores and Non-Cancer Mortality $(N=351)$

\begin{tabular}{|c|c|c|c|c|c|c|c|c|c|}
\hline \multirow[b]{3}{*}{ Subscale Scores $^{\mathrm{a}}$} & \multicolumn{3}{|c|}{ Model $1^{\mathrm{c}}$} & \multicolumn{3}{|c|}{ Model $2^{\mathrm{d}}$} & \multicolumn{3}{|c|}{ Model $3^{\mathrm{e}}$} \\
\hline & Deaths & & & Deaths & & & Deaths & & \\
\hline & $(\text { Total })^{b}$ & $\mathrm{HR}(95 \% \mathrm{CI})$ & $P$ Trend & $(\text { Total })^{b}$ & $\mathrm{HR}(95 \% \mathrm{CI})$ & $P$ Trend & $(\text { Total })^{\mathrm{b}}$ & $\mathrm{HR}(95 \% \mathrm{CI})$ & $P$ Trend \\
\hline Social Functioning & & & $<0.0001$ & & & 0.0010 & & & 0.0037 \\
\hline $\mathrm{T} 1(\leq 40.86)$ & $32(98)$ & $3.27(1.85,5.77)$ & & $32(98)$ & $2.66(1.48,4.79)$ & & $32(98)$ & $2.62(1.36,5.05)$ & \\
\hline T2 $(>40.86 \& \leq 51.71)$ & $13(87)$ & $1.35(0.67,2.74)$ & & $13(87)$ & $1.64(0.79,3.38)$ & & $13(87)$ & $1.84(0.88,3.85)$ & \\
\hline $\mathrm{T} 3(>51.71)$ & $19(166)$ & 1.00 (ref) & & $19(166)$ & 1.00 (ref) & & $19(166)$ & 1.00 (ref) & \\
\hline Role Emotional & & & 0.0044 & & & 0.0802 & & & 0.1935 \\
\hline $\mathrm{T} 1(\leq 34.28)$ & $29(113)$ & $2.20(1.28,3.78)$ & & $29(113)$ & $1.67(0.94,2.95)$ & & $29(113)$ & $1.50(0.81,2.78)$ & \\
\hline T2 $(>34.28 \& \leq 44.81)$ & $11(61)$ & $1.39(0.68,2.84)$ & & $11(61)$ & $1.32(0.64,2.72)$ & & $11(61)$ & $1.31 \quad(0.62,2.74)$ & \\
\hline $\mathrm{T} 3(>44.81)$ & $24(177)$ & 1.00 (ref) & & $24(177)$ & 1.00 (ref) & & $24(177)$ & 1.00 (ref) & \\
\hline Vitality & & & 0.0041 & & & 0.0098 & & & 0.0427 \\
\hline $\mathrm{T} 1(\leq 44.33)$ & $31(121)$ & $2.61(1.34,5.09)$ & & $31(121)$ & $2.41 \quad(1.22,4.77)$ & & $31(121)$ & $2.18(1.04,4.58)$ & \\
\hline T2 $(>44.33 \& \leq 53.79)$ & $21(121)$ & $1.84(0.90,3.74)$ & & $21(121)$ & $1.70(0.82,3.49)$ & & $21(121)$ & $1.81(0.86,3.80)$ & \\
\hline $\mathrm{T} 3(>53.79)$ & $12(109)$ & 1.00 (ref) & & $12(109)$ & 1.00 (ref) & & $12(109)$ & 1.00 (ref) & \\
\hline Mental Health & & & 0.0990 & & & 0.0631 & & & 0.1205 \\
\hline $\mathrm{T} 1(\leq 43.63)$ & $24(108)$ & $1.66(0.91,3.03)$ & & $24(108)$ & $1.81(0.97,3.38)$ & & $24(108)$ & $1.73(0.86,3.46)$ & \\
\hline $\mathrm{T} 2(>43.63 \& \leq 52.72)$ & $21(114)$ & $1.30(0.70,2.43)$ & & $21(114)$ & $1.29(0.69,2.42)$ & & $21(114)$ & $1.41 \quad(0.73,2.74)$ & \\
\hline $\mathrm{T} 3(>52.72)$ & $19(129)$ & 1.00 (ref) & & $19(129)$ & 1.00 (ref) & & $19(129)$ & 1.00 (ref) & \\
\hline Physical Functioning & & & $<0.0001$ & & & 0.0019 & & & 0.0019 \\
\hline $\mathrm{T} 1(\leq 43.17)$ & $38(118)$ & $9.11(3.58,23.2)$ & & $38(118)$ & $4.36(1.68,11.34)$ & & $38(118)$ & $4.43(1.69,11.7)$ & \\
\hline $\mathrm{T} 2(>43.17 \& \leq 52.49)$ & $21(123)$ & $3.98(1.50,10.6)$ & & $21(123)$ & $3.16(1.19,8.43)$ & & $21(123)$ & $3.17(1.17,8.60)$ & \\
\hline $\mathrm{T} 3(>52.49)$ & $5(110)$ & $1.00(\mathrm{ref})$ & & $5(110)$ & 1.00 (ref) & & $5(110)$ & 1.00 (ref) & \\
\hline Role Physical & & & $<0.0001$ & & & 0.0031 & & & 0.0033 \\
\hline $\mathrm{T} 1(\leq 35.03)$ & $37(116)$ & $3.64(2.00,6.64)$ & & 37 (116) & $2.47(1.33,4.58)$ & & $37(116)$ & $2.51(1.34,4.71)$ & \\
\hline $\mathrm{T} 2(>35.03 \& \leq 49.18)$ & $12(88)$ & $1.64(0.77,3.50)$ & & $12(88)$ & $1.48(0.68,3.23)$ & & $12(88)$ & $1.49(0.67,3.29)$ & \\
\hline T3 (>49.18) & $15(147)$ & 1.00 (ref) & & $15(147)$ & 1.00 (ref) & & $15(147)$ & 1.00 (ref) & \\
\hline
\end{tabular}




\begin{tabular}{|c|c|c|c|c|c|c|c|c|c|}
\hline \multirow[b]{2}{*}{ Subscale Scores $^{\mathrm{a}}$} & \multicolumn{3}{|c|}{ Model $1^{\mathrm{c}}$} & \multicolumn{3}{|c|}{ Model $2^{\mathrm{d}}$} & \multicolumn{3}{|c|}{ Model $3^{\mathrm{e}}$} \\
\hline & $\begin{array}{l}\text { Deaths } \\
\left(_{\text {Total })^{b}}\right.\end{array}$ & $\mathrm{HR}(95 \% \mathrm{CI})$ & $P$ Trend & $\begin{array}{l}\text { Deaths } \\
(\text { Total) }\end{array}$ & $\mathrm{HR}(95 \% \mathrm{Cl})$ & $P$ Trend & $\begin{array}{l}\text { Deaths } \\
(\text { Total })^{\mathrm{b}} \\
\end{array}$ & $\mathrm{HR}(95 \% \mathrm{CI})$ & $P$ Trend \\
\hline Bodily Pain & & & 0.0002 & & & 0.0026 & & & 0.0014 \\
\hline $\mathrm{T} 1(\leq 46.05)$ & $34(106)$ & $2.91(1.66,5.10)$ & & $34(106)$ & $2.33(1.32,4.12)$ & & $34(106)$ & $2.71(1.46,5.03)$ & \\
\hline $\mathrm{T} 2(>46.05 \& \leq 54.19)$ & $11(81)$ & $1.18(0.56,2.49)$ & & $11(81)$ & $0.94(0.44,1.99)$ & & $11(81)$ & $0.94(0.44,2.00)$ & \\
\hline $\mathrm{T} 3(>54.19)$ & $19(164)$ & 1.00 (ref) & & $19(164)$ & 1.00 (ref) & & $19(164)$ & 1.00 (ref) & \\
\hline General Health & & & 0.0035 & & & 0.0125 & & & 0.0146 \\
\hline $\mathrm{T} 1(\leq 46.28)$ & $34(123)$ & $2.31 \quad(1.27,4.18)$ & & $34(123)$ & $2.01 \quad(1.11,3.66)$ & & $34(123)$ & $2.04(1.11,3.76)$ & \\
\hline $\mathrm{T} 2(>46.28 \& \leq 54.64)$ & $14(104)$ & $1.03(0.50,2.11)$ & & $14(104)$ & $0.92(0.45,1.89)$ & & $14(104)$ & $0.97 \quad(0.47,2.01)$ & \\
\hline $\mathrm{T} 3(>54.64)$ & $16(124)$ & 1.00 (ref) & & $16(124)$ & $1.00(\mathrm{ref})$ & & $16(124)$ & $1.00(\mathrm{ref})$ & \\
\hline
\end{tabular}

a. Data collected at 36-month HRQOL follow-up assessment.

b. Frequency of \# of events and total number within the category.

c. Model 1: crude.

G $\quad$ d. Model 2: adjusted for baseline lifestyle and clinical characteristics. Mental-related: age, race/ethnicity, marital status, tumor stage, treatment type, and age, race/ethnicity, comorbidities; Physical-related: marital status, tumor stage, and treatment type.

e. Model 3: adjusted for additional HRQOL characteristics in addition to Model 1. Mental-related: current lymphedema, perceived optimism number of types of confidants, bodily pain, and perceived general health. Physical-related: current lymphedema, perceived optimism, number of types of confidants, fear of recurrence. 
role emotional (T1, HR: 2.20, 95\% CI: 1.28, 3.78), vitality (T1, HR: 2.61, 95\% CI: 1.34, 3.78), role physical (T1, HR: 3.64, 95\% CI: 2.00, 6.64), bodily pain (T1, HR: $2.91,95 \%$ CI: 1.66, 5.10), and general health (T1, HR: 2.31, 95\% CI: $1.27,4.18)$ were at significantly increased risk of dying due to non-cancer causes compared to cases in T3.

When adjusted for baseline lifestyle and clinical characteristics, all of the associations were attenuated for social functioning (T1, HR: $2.66,95 \% \mathrm{CI}: 1.48,4.79$ ), vitality (T1, HR: 2.41, 95\% CI: 1.22, 4.77), physical functioning (T1, HR: 4.36, 95\% CI: 1.68, 11.34), role physical (T1, HR: $2.47,95 \%$ CI: $1.33,4.58)$, bodily pain (T1, HR: 2.33 , 95\% CI: 1.32, 4.12), and general health (T1, HR: 2.01, 95\% CI: 1.11, 3.66).

When further adjusted for additional HRQOL characteristics, subscales significant in Model 2 were also significant in Model 3. Specifically, cases in T1 or T2 compared to $\mathrm{T} 3$ for physical functioning had nearly 4.5 times the increased risk of dying (T1, HR: 4.43, 95\% CI: 1.69, 11.65; T2, HR: 3.17, 95\% CI: 1.17, 8.60). Cases in the T1 of all physical subscales (physical functioning, role physical, bodily pain, and general health) had at least a two-fold increased risk of dying compared to cases in T3.

\section{Kaplan-Meier Curves and Survival Rates}

Seventeen survival curves were constructed to plot the distribution of survival rates by all-cause, breast cancer-specific, and non-cancer mortality for the entire study population. Additional curves were constructed stratified by race/ethnicity for all-cause and non-cancer mortality only because of sample size concerns. In the total population, the five-year survival rate was $89.4 \%$, and $77.7 \%$ for 10 -year survival, when considering death due to any cause. 
For all-cause mortality, survival curves significantly differed by PCS tertiles $(\mathrm{p}=<0.0001)$; however, survival curves did not by MCS tertiles $(\mathrm{p}=0.4643)$. The five-year survival rate for PCS and all participants was higher than $75 \%$. When approaching ten years, cases in T1 had approximately a $60 \%$ survival rate compared to approximately $90 \%$ for cases in T3. Rates continued to decrease for T1 cases, yet remained constant for T2 and T3. Survival rates depicting PCS and non-cancer mortality told a similar story. However, participants in $\mathrm{T} 1$ had a much worse survival rate compared to participants in $\mathrm{T} 2$ and T3. Curves displaying rates for breast cancer-specific mortality did not reveal any significant differences. Figures 3 and 4 display survival curves for all-cause mortality and MCS/PCS.

When stratifying PCS for all-cause and non-cancer by race/ethnicity, the pattern for differences in PCS by tertiles was weighted by the higher number of NHW cases in relation to Hispanic cases. These curves are displayed in Figures 5, 6, 7, and 8. For allcause mortality by race/ethnicity, the survival curves significantly differed by PCS tertiles ( $\mathrm{p}=<0.0001$ ), and the same association can be found for non-cancer mortality $(\mathrm{p}=<0.0001)$. However, this was not true for Hispanic cases for PCS tertiles and all-cause mortality $(\mathrm{p}=0.2415)$ and PCS tertiles and non-cancer mortality $(\mathrm{p}=0.3032)$.At about 11 years post-diagnosis, NHW cases in T1 had a 50\% survival rate compared to NHW cases in T3 ( 90\%). For non-cancer outcomes, the survival rates were similar by tertile. The remaining survival curves are presented in the Appendices section (P-Z). 


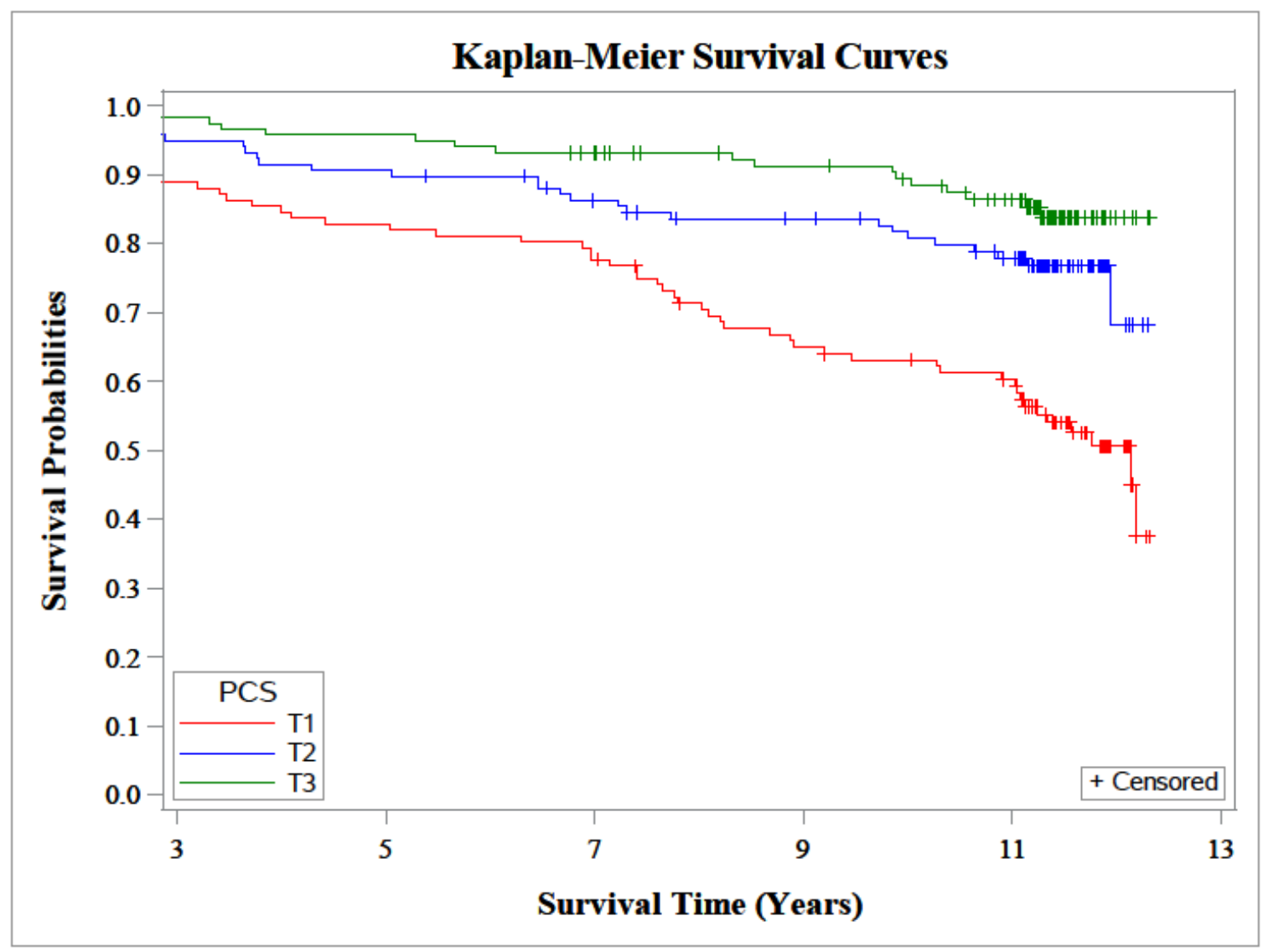

Figure 3. Kaplan-Meier Curves: (All-Cause) Survival Probability Estimates for PCS Tertiles. 


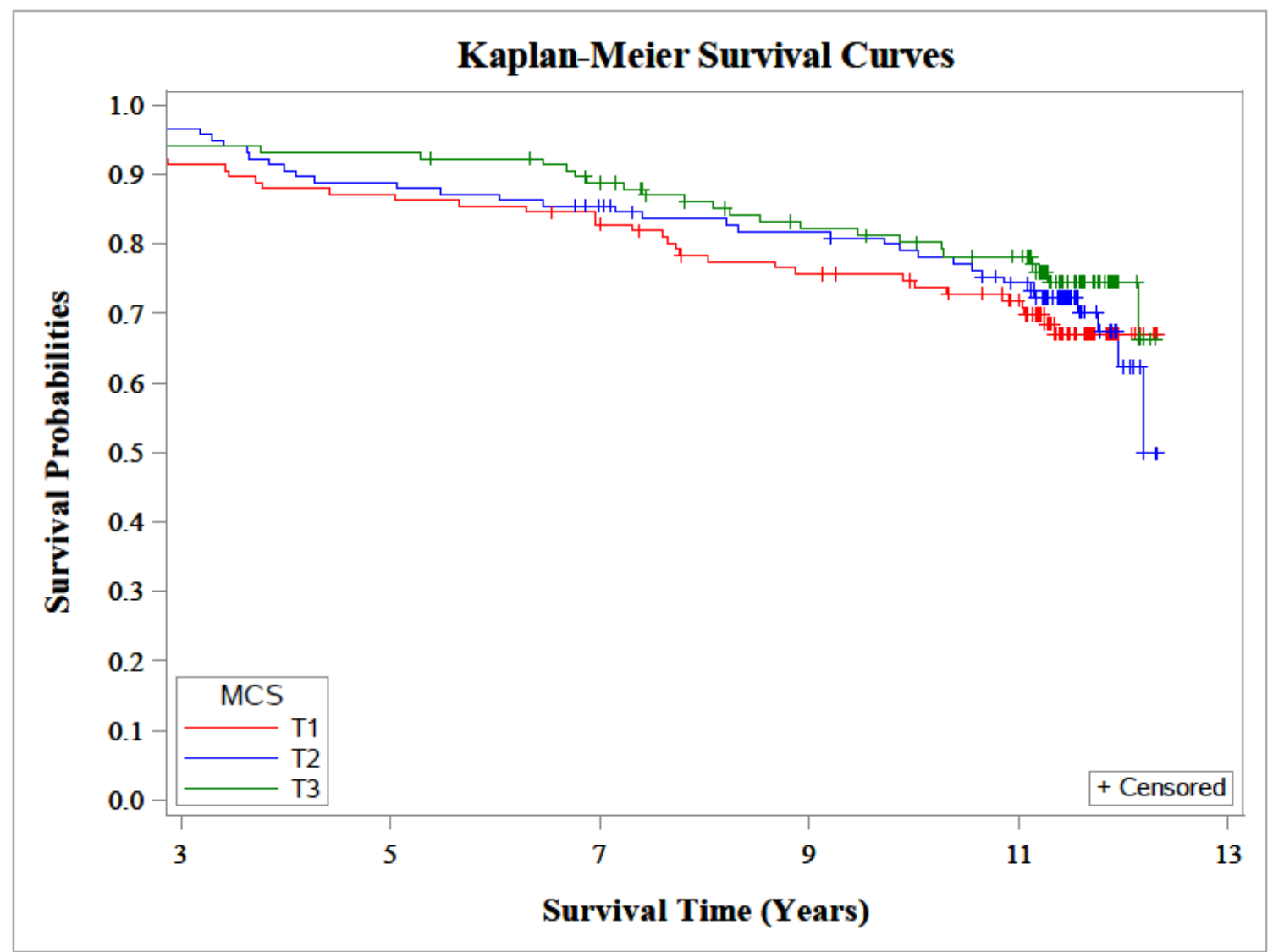

Figure 4. Kaplan-Meier Curves: (All-Cause) Survival Probability Estimates for MCS Tertiles. 


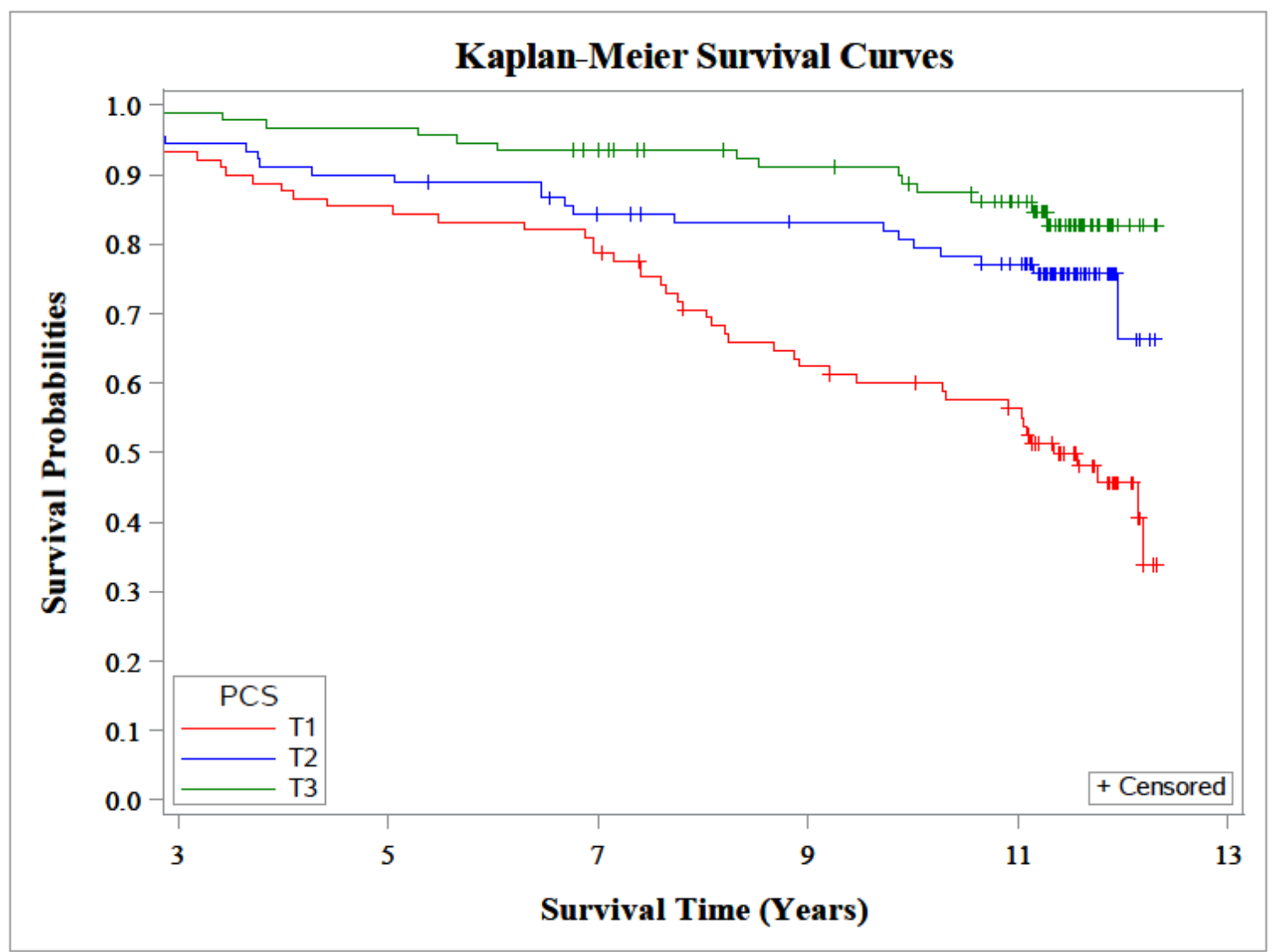

Figure 5. Kaplan-Meier Curves: (All-Cause) Survival Probability Estimates for PCS Tertiles by Race/Ethnicity (NHW Women). 


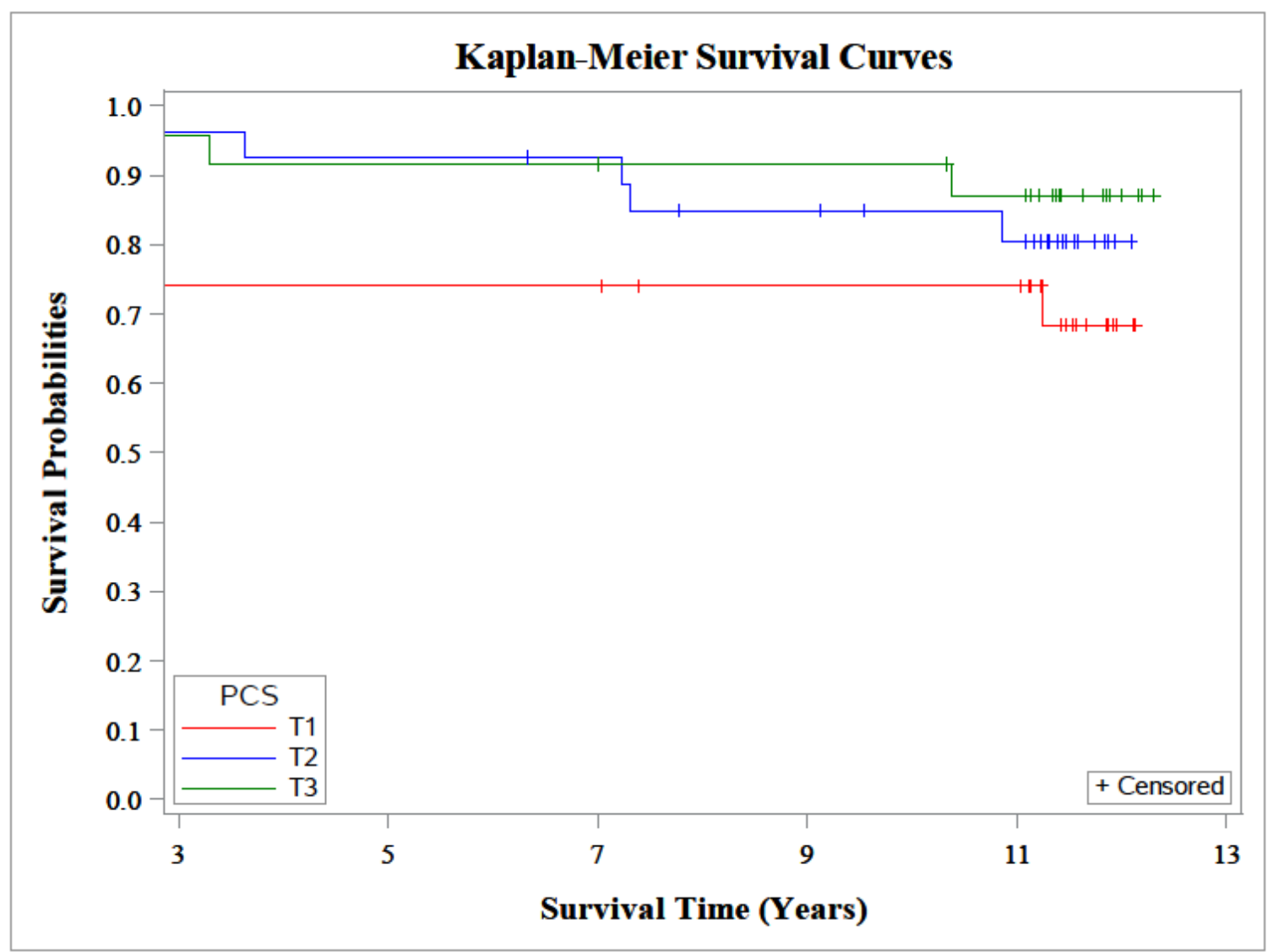

Figure 6. Kaplan-Meier Curves: (All-Cause) Survival Probability Estimates for PCS Tertiles by Race/Ethnicity (Hispanic Women). 


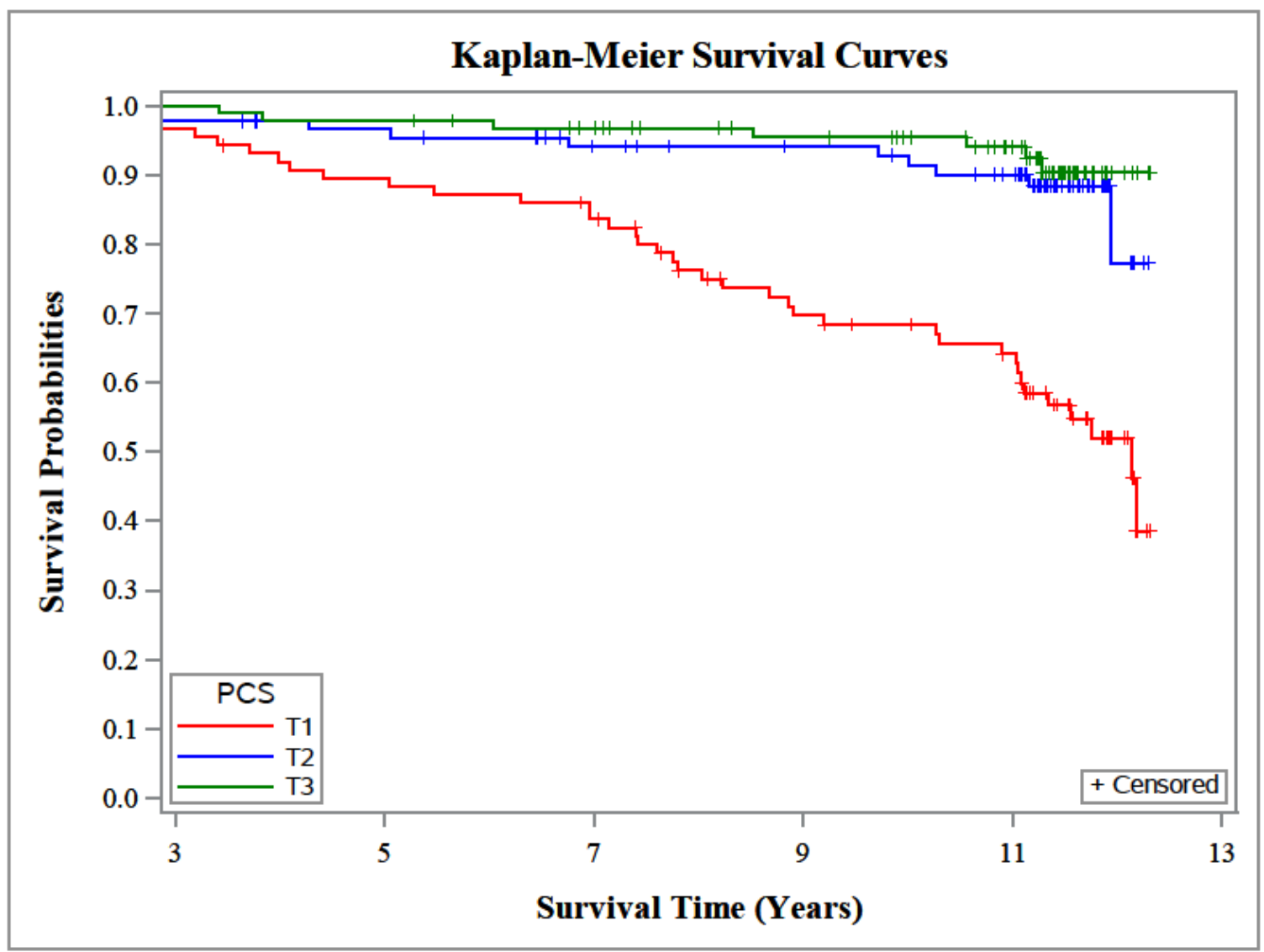

Figure 7. Kaplan-Meier Curves: (Non-Cancer) Survival Probability Estimates for PCS Tertiles by Race/Ethnicity (NHW Women). 


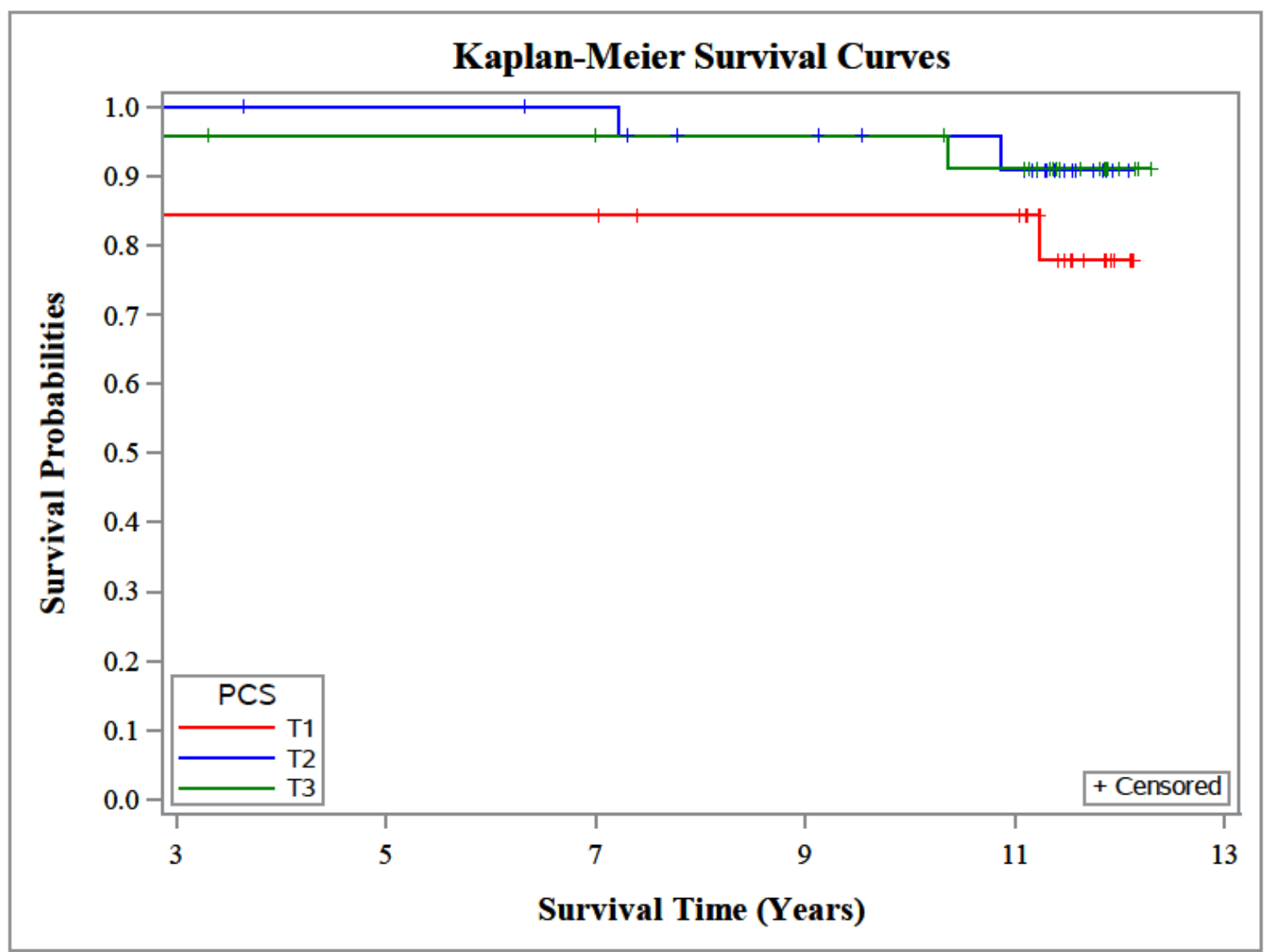

Figure 8. Kaplan-Meier Curves: (Non-Cancer) Survival Probability Estimates for PCS Tertiles by Race/Ethnicity (Hispanic Women). 


\section{DISCUSSION}

To our knowledge, this is the first study to evaluate physical (PCS) and mental (MCS) component summary scores from the SF-36 instrument as a predictor of breast cancer mortality among NHW and Hispanic women. A few other studies evaluating HRQOL via the SF-36 as a predictor of breast cancer prognosis will be discussed later (87-89).

Results from the present study indicate that the physical-related items of HRQOL among women with invasive breast cancer approximately 3 -years post-diagnosis were statistically significantly associated with a decreased risk of all-cause, breast cancerspecific, and non-cancer mortality. Furthermore, these associations were demonstrated in NHW women for all-cause and breast cancer-specific mortality when stratifying the association by ethnicity; however, the association was not observed for non-cancer mortality. There were no significant associations between MCS and mortality outcomes. This finding is in accordance with other studies that have reported no association between overall mental/psychosocial HRQOL and breast cancer prognosis $(42,50,78,89-92,94)$. Although our results did not indicate evidence of an association between the MCS summary score and mortality there were associations present for two subscales (social functioning and vitality).

A comparison between these study findings and those reported in the literature is hindered due to differences in study design, subject characteristics, and the HRQOL 
measures. This study controlled for demographic, clinical, and HRQOL prognostic factors that were found to influence the measure of effect by $10 \%$ or more.

Distinguishing the impact of specific variables based on when they were evaluated is vital to consider. The 36-month follow-up consisted of many of the self-reported variables pertaining to mental/psychosocial or physical HRQOL, in addition to SF-36related assessments. Ultimately, this study found that women who reported their HRQOL negatively had an increased risk of death.

\section{Mental/Psychosocial HRQOL}

Studies have evaluated some form of mental/psychosocial HRQOL as a predictor of survival or mortality in women diagnosed with breast cancer. This analysis found no evidence of association for overall mental/psychosocial HRQOL with mortality, which is consistent with findings reported by previous studies $(42,78-81,89-92)$. However, in keeping with several studies $(13,14,42,43,83,87,95)$ there was evidence of an association between eight mental/psychosocial-related subscales and mortality. In contrast to the finding of this study, Dumontier et al. reported that better mental health was associated with lower mortality in a study testing HRQOL in a predictive model for mortality, utilizing the Mental Health Index (MHI-5) from the SF-36 and 10-year followup data for women diagnosed with breast cancer (87). These results were strengthened with the addition of other HRQOL measures (physical health, mental health, social support) (87). These results suggest prognostic relevancy between HRQOL measures and breast cancer outcomes. Saquib et al. discovered that the mental health summary score in their sample was marginally associated with breast cancer recurrence and all-cause 
mortality when alone, but the associations attenuated towards the null when evaluated via a multivariable model, similar to our study (89).

Seven studies reported significant associations between aspects of mental/psychosocial HRQOL and breast cancer survival or mortality $(13,14,42,43,83$, 87, 95). Goodwin et al. was similar in study size $(\mathrm{N}=397)$ and measured HRQOL postdiagnosis via the European Organization for Research and Treatment of Cancer Quality of Life Questionnaire-Core 30 (EORTC QLQ-C30), as well as other measures of HRQOL factors, with a median of 5.8 years of follow-up. Even though four significant associations were found between mental/psychosocial HRQOL and distant disease-free survival (DDFS) or overall survival, the researchers reported that seven significant associations would've been generated due to chance. They found that women with higher cognitive functioning had lower DDFS; opposite of what was hypothesized, perhaps bolstering their suggestion of deeming the associations inconclusive due to random error. Similarly, although Phillips et al., a quite larger study $(\mathrm{N}=708)$, discovered a connection between anxious preoccupation and worse DDFS and OS, there were no significant associations in the adjusted models, and the aforementioned report was driven more by the confounding of poor prognostic factors rather than a direct relationship (78). The two studies used some of the same surveys to assess mental/psychosocial health $(42,78)$.

Many studies found that out of a variety of evaluated mental/psychosocial prognostic factors, a couple showed significant relationships with breast cancer outcomes. Watson et al. reported that women with higher scores of helplessness/hopelessness were at risk of lower disease-free survival (14). Participants were evaluated via the Mental Adjustment to Cancer Scale (MAC) and for depression 
(HADS) within 4-12 weeks post-diagnosis. Unlike our analysis, these mental/psychosocial factors were assessed immediately after diagnoses, potentially impacting the emotional response to cancer diagnoses, especially in a study evaluating early emotional response on survival. Conversely, participants in our study, who might have undergone treatment, could have reported emotional responses to their health differently if HRQOL evaluations were administered at baseline. De Aguiar et al. used the EORTC QLQ-C30 in a similar sized sample $(\mathrm{N}=549)$ and reported lower survival in participants who had worse future perspective (95). Though, helplessness/hopelessness and future perspective are unrelated, they share commonalities, and further research should explore the idea of the prognostic relevancy behind perceptions of disease burden.

Groenvold et al. reported associations between greater emotional functioning and better recurrence-free survival and overall survival, using the EORTC QLQ-C30 for HRQOL measures (13). The researchers claimed that their study is one of the first to find significant relationships between self-rated psychological factors and breast cancer recurrence and death, contrasting a handful of other studies previously cited (13). Conversely, this study found no associations between role emotional of the SF-36 and mortality. Even then, it's tough to speculate whether the two findings are in any way analogous, given that HRQOL was measured contrarily and distributed at different survivorship periods.

Among the aspects of mental/psychosocial HRQOL, social-related paradigms seemed to have significant relationships with breast cancer prognosis. Lehto et al. suggested that shorter survival was predicted by perceived support, though their classification of support as a covariate was created on the basis of hypothetical support 
rather than support actually received by participants (43). Utilizing the General Quality of Life Inventory-74, Epplein et al. found that women with higher levels of social wellbeing had lower risks of mortality and breast cancer recurrence (83). This association is similar to ours when comparing it to the effects of levels of social functioning and allcause and non-cancer mortality. In our study, participants in $\mathrm{T} 1$ of social functioning subscale had a 2.6 times increased likelihood of dying of non-cancer causes in the fullyadjusted model. Similar associations were found for all-cause mortality, but significance was lost when the relationship was adjusted for additional HRQOL-related characteristics. Another support-related variable, numbers of types of confidants, was adjusted for in the final models to control for social support mainly in associations between component summary scores and mortality. The social functioning subscale isn't built to include this specific concept, so controlling for it is appropriate.

The effects seen in the Epplein et al. study and ours share similarities in methodology and sample. Although the Epplein et al. study was far larger $(\mathrm{N}=2,230)$ (83), the sample contained in-situ cases and a predominant amount of Chinese women, whereas ours was composed of a mix of NHW and Hispanic women. They also categorized their HRQOL predictor variables into tertiles based on the distribution of their population sample (83). Epplein et al. evaluated HRQOL at baseline and 36-month follow-up, contrasting our study only assessing HRQOL-related variables during a follow-up around the same period post-diagnosis. However, Epplein et al. found no significant results between any HRQOL predictors and breast cancer survival or recurrence at 36-month follow-up (83). Additionally, as stated before, the validity of 
comparisons of the two studies originates from how social support and social functioning is classified, defined, and measured.

A variety of factors play a role in the relationship between mental/psychosocial HRQOL and breast cancer prognosis. Among studies evaluating many of these factors, a large proportion of them find at least one significant association between a mental/psychosocial-related predictor and a breast cancer outcome (83). Although, as discussed above, some of these associations were calculated by chance (42), posing a problem with analyses evaluating many variables at once. However, the nature of HRQOL evolves from paradigms of multiple factors influencing health. Considering many aspects of health is essential but can result in analysis containing an oversaturated amount of variables when validated instruments encapsulating HRQOL may be more efficient. The relationship between overall PCS) and mortality remained consistent for all three mortality outcomes. When evaluating similar relationships between each physicalrelated subscale and mortality, several remained significant in fully-adjusted models.

\section{Physical HRQOL}

It has been suggested that poorer physical HRQOL is predictive of poorer breast cancer-related outcomes $(50,79-81,87-94)$. In this study, the relationship between physical-related HRQOL and all-cause, breast cancer-specific, and non-cancer mortality were significant in fully-adjusted models. In fact, the association slightly strengthened for all-cause and non-cancer outcomes, and slightly attenuated for breast cancer-specific mortality. 
Some researchers evaluated the prognostic value of physical-related factors, such as fatigue and pain $(13,91)$, inflammation (94), nausea/vomiting (79), and appetite loss (93) after a diagnosis of breast cancer. Instead of evaluating these factors as separate predictors, they were evaluated all as potential confounders and retained some in the final models (e.g., fatigue and pain) to account for their magnitudes of effects. Some of these factors may serve a proxy of reporting lower physical HRQOL.

Three studies have used SF-36 as the primary HRQOL measurement in breast cancer survivor populations (87-89). Saquib et al. and Marinac et al. both analyzed data from the Women's Healthy Eating and Living (WHEL) Study; both studies reporting analytic sample sizes near 3,000 participants $(88,89)$, majority NHW women, with a mean survival time of 7.3 years) (105). However, the two studies that utilized data from WHEL did adjust their regression models for race/ethnicity. $(88,89)$.

Saquib et al. reported that higher PCS had protective effects against recurrence and all-cause mortality (89). The researchers categorized physical health into quintiles by overall score (0-100), the higher the score, the better HRQOL (89). Even though the categorization of HRQOL differed, the takeaway message remained the same. Our findings parallel their study by comparing higher levels (healthier) of HRQOL to lower levels. Marinac et al. found that lower self-reported physical functioning was significantly associated with all-cause and breast cancer-specific mortality (88).

\section{The Role of Chronic Stress and Inflammation}

Marinac et al. suggested that inflammation might be partly responsible for the increased risk of mortality in women who report lower physical functioning 
characteristics. In their study, BMI, physical activity, and C-reactive protein were all related to physical functioning. Extant research has suggested that stress and the social environment can exacerbate inflammatory responses to diseases (109), and inflammation is partly regulated by cortisol levels, specifically when stress is high, causing erratic increases in inflammation that may promote chronic disease $(109,143)$. Consequently, chronic stress is directly associated with cancer pathogenesis (111).

Stress and inflammation are full-body responses to internal and external factors. When evaluating self-reported data on HRQOL, it is important to consider stress and chronic inflammation as factors that can influence response bias to health-related questions as well as mediate associations between health-related predictors and disease outcomes. Additionally, weighing stress responses may be helpful, especially if they are associated with higher levels of inflammation. In a future study similar to ours where mental/psychosocial and physical HRQOL are evaluated, it would be interesting to see the effects of HRQOL as a whole (e.g., mental/psychosocial \& physical combined) on breast cancer prognosis. Theoretically, since inflammation is associated with poorer HRQOL (94) and stress (143), then psychosocial factors that influence stress may be indicative of inflammatory responses that may worsen physical well-being as well. However, our measure of HRQOL does not account for an overall health status.. Nevertheless, the idea stands that levels of mental/psychosocial and physical HRQOL may be related via biological pathways.

Understanding why participants are answering HRQOL-related parameters as poor compared to healthy is important. Cancer diagnoses can elicit stress responses (111); therefore, it is essential to consider timing of HRQOL assessment during the post- 
diagnosis period and whether assessment occurs pre- or post-treatment. Lower levels of HRQOL are indicative of lower overall well-being and worse survivorship in women previously diagnosed with breast cancer. Research surrounding these domains is vital in improving survivorship and understanding what may be responsible for low HRQOL and poorer prognosis.

\section{HRQOL Evaluated in Other HEAL Studies}

HRQOL has been evaluated in this study population previously; however, none of the previous studies have assessed HRQOL as a predictor of mortality $(124,149,150$, 166-173). The HEAL study was originally designed to examine the relationship between anthropometrics, body composition, lifestyle factors, hormone measurements, clinical characteristics, and other prognostic factors with early stage breast cancer (148).

Although the majority of previous HEAL HRQOL-related analyses have utilized data from all three study sites (New Mexico, Los Angeles County, Western Washington) $(124,149,150,167,168,170-173)$, this analysis is based on New Mexico site data only, which accounts for the majority of Hispanic subjects (148).

In one study, Meeske et al. found that correlates of fatigue were pain, cognitive problems, physical inactivity, weight gain, and antidepressant use (150). Additionally, fatigue and poorer HRQOL were associated (150). In our study, fatigue was analyzed as a confounder. In the univariate models to assess individual effects of covariates on the effect of HRQOL on mortality, fatigue was not significantly associated with MCS (had no effective change between the crude model and additional models) and for all-cause, breast cancer-specific, and non-cancer mortality, and thus was not retained in the 
multivariable models. For PCS, fatigue was not evaluated since questions that compose the PCS contain aspects of fatigue.

Wayne et al. discovered that diet quality was associated with HRQOL, specifically for 3 of the 4 mental subscales and 2 of the 4 physical subscales (124). Though, our study didn't include diet quality, the results of the aforementioned study suggested that factors impacting HRQOL may also effect breast cancer prognosis through mediation. Another HEAL study concluded that better physical activity was associated with better physical HRQOL (166). Additionally, in another HEAL analysis, lack of physical activity and weight gain was associated with risk for pain (149). Unlike fatigue, bodily pain was included in multivariable analyses for MCS and all-cause and non-cancer mortality, attenuating the crude associations. When evaluating MCS and all-cause mortality, pain altered the effects by $38.2 \%$ (T1) and $24.0 \%$ (T2). This may suggest that self-reported pain plays a significant role in the relationship between mental/psychosocial HRQOL and mortality. An issue with self-reported pain falls in its subjectivityparticipants with low mental HRQOL may be more likely to report higher levels of pain related to mental/psychosocial factors rather than physical ones (or vice versa) — and this phenomena is damaging if pain-related assessments presume to be homologous with physiological experiences.

Studies utilizing the HEAL data have found significant prognostic differences between ethnicities $(167,168,173,174)$. Although differences in ethnicity (NHW vs. Hispanic) weren't of main focus in this study, the analyses between HRQOL and mortality were stratified by ethnicity to see if a single group could explain some of the survival disparity. Since the sample size of Hispanics in the present analysis is low 
$(\mathrm{n}=78)$, including only five deaths, it is difficult to determine whether the present findings are due to chance.

Moreover, when stratifying associations between MCS/PCS and mortality by ethnicity, NHW women with poorer physical HRQOL were twice as likely to die compared to NHW women with better physical HRQOL. While a similar relationship was observed for NHW and breast cancer-specific and non-cancer mortality, these associations were not significant. A similar phenomenon was discerned for Hispanic women in the all-cause mortality model. Hispanic women with worse PCS were four times as likely to die by all-causes compared to Hispanics with better PCS, though this association wasn't significant (HR: 4.05, 95\% CI: 0.82, 20.05).

\section{Strengths and Limitations}

This study has several strengths. It utilized a variety of validated and standardized measures for HRQOL and collected data on a number of self-reported HRQOL-related covariates, which allowed for an evaluation of potential confounders (35). Additionally, clinical data were abstracted from medical records and from the SEER registry and used for further evaluation of confounding. Deaths were confirmed via the National Death Index, a reliable approach to validating consistent death counts and survival time. Results were based on a median of 11 years of survival time, which permitted an assessment of long-term survival in relation to HRQOL.

This study has another strength. Since three assessments were of interest, I was able to utilize variables from three time points (baseline, 24-month follow-up, HRQOL 
assessment). Some of these variables, such as demographics, were consistently available at each point of assessment.

Another strength includes the model building process. Accounting for the joint effects of significant covariates created the most parsimonious models. This study also utilized additional HRQOL-related variables that were not included in the construction of the SF-36. If variables were included in the construction of the MCS, and they held relevancy as a confounder in the model building process, then they were adjusted for in the PCS model, and vice versa. For example, bodily pain was controlled for in associations between MCS and mortality, but not PCS and mortality. This was calculated to consider how much of the effect is impacted by physical-related factors in mental/psychosocial models and vice versa.

Utilizing cases with only invasive breast cancer is another strength. Women with in-situ breast cancer experience an approximate 95\% survival rate after five years (1). Thus, it is suggested that these women may undergo different survivorship experiences compared to women diagnosed with higher stages of disease.

Our analysis has several limitations that require thorough consideration. HRQOL was evaluated 36-months post-diagnosis, and cases who died prior to the assessment may or may not of had a poorer HRQOL. Associations between HRQOL and breast cancer mortality may be underestimated in comparison to findings derived from utilizing a HRQOL assessment at baseline. Additionally, one reason why the data has limited breast cancer-specific mortality events is because $63.5 \%(n=47)$ of women who died of breast cancer died before the HRQOL assessment was conducted, and this can create a survival bias. 
Furthermore, data was lacking for of multiple HRQOL measures over time. Measuring HRQOL at baseline and 24-month assessment, in addition to 36-months postdiagnosis, would have presented opportunities to clarify uncertainty behind causal pathways, such as unveiling what factors are correlated with poorer HRQOL during each follow-up. More opportunities to evaluate changes of HRQOL and its impact on breast cancer prognosis would be valuable. Also, I would have had the ability to measure these associations directly after diagnosis in comparison to 36-months post-diagnosis, considering factors such as treatment and the effects of HRQOL on short-term breast cancer survival.

It was difficult to detect the presence of an effect due to small sample size and too few deaths. However, the evaluation of this underrepresented population has added relevant data to the overall literature. Another limitation includes the fact that I may have missed residual confounding by unmeasured measures (e.g., inflammation, stress). Nevertheless, this research question needs to be tested on other populations, especially ones with ethnic demographics.

This study may not indicate a direct causal relationship between HRQOL predictors and breast cancer mortality, but as suggested, the current associations may be representative of additional unmeasured prognostic factors. Physical HRQOL was predictive of all mortality outcomes, and NHW women drove the effect. However, associations with MCS were inconsistent and only remained significant in relationships between few individual subscales and mortality outcomes. Conversely, these findings may elucidate specific relationships between aspects of mental/psychosocial HRQOL and breast cancer prognosis, since a majority of studies evaluating similar associations find at 
least one association between a mental/psychosocial factor and breast cancer prognosis (83). More attention may need to be paid toward the specific factors suggesting poorer prognosis.

\section{Conclusions}

In summary, this analysis has demonstrated a significant prognostic value between items include in a validated HRQOL instrument (mental/psychosocial, physical), and breast cancer-specific mortality in a unique population of women diagnosed with invasive breast cancer. This study also revealed significant associations between HRQOL and mortality in breast cancer survivors by ethnicity. This study appears to be the first to evaluate HRQOL as a predictor of mortality in a population of ethnically diverse breast cancer survivors. Although based on a small sample, study findings suggest that the association between HRQOL and mortality should be addressed in future research, specifically among Hispanic women with breast cancer. Additional research in a larger sample of minority populations will bolster a better understanding of HRQOL as a predictor of breast cancer prognosis (survival, mortality, recurrence). Such research may provide important data for interventions designed to improve overall well-being among breast cancer survivors. 


\section{REFERENCES}

1. Noone AM, Howlader N, Krapcho M, Miller D, Brest A, Yu M, Ruhl J, Tatalovich Z, Mariotto A, Lewis DR, Chen HS, Feuer EJ, Cronin KA (eds). SEER Cancer Statistics Review, 1975-2015, National Cancer Institute. Bethesda, MD, https://seer.cancer.gov/csr/1975_2015/, based on November 2017 SEER data submission, posted to the SEER web site, April 2018.

2. American Cancer Society. Cancer Treatment \& Survivorship Facts \& Figures 2016-2017. Atlanta: American Cancer Society; 2016.

3. Ooi SL, Martinez ME, Li CI. Disparities in breast cancer characteristics and outcomes by race/ethnicity. Breast Cancer Res Treat. 2011;127(3):729-38.

4. Yanez B, McGinty HL, Buitrago D, Ramirez AG, Penedo FJ. Cancer Outcomes in Hispanics/Latinos in the United States: An Integrative Review and Conceptual Model of Determinants of Health. J Lat Psychol. 2016;4(2):114-29.

5. Martinez ME, Nielson CM, Nagle R, Lopez AM, Kim C, Thompson P. Breast cancer among Hispanic and non-Hispanic White women in Arizona. J Health Care Poor Underserved. 2007;18(4 Suppl):130-45.

6. Li CI, Malone KE, Daling JR. Differences in breast cancer stage, treatment, and survival by race and ethnicity. Arch Intern Med. 2003;163(1):49-56.

7. Martinez ME, Gomez SL, Tao L, Cress R, Rodriguez D, Unkart J, et al. Contribution of clinical and socioeconomic factors to differences in breast cancer subtype and mortality between Hispanic and non-Hispanic white women. Breast Cancer Res Treat. 2017;166(1):185-93. 
8. Boone SD, Baumgartner KB, Baumgartner RN, Connor AE, John EM, Giuliano AR, et al. Active and passive cigarette smoking and mortality among Hispanic and nonHispanic white women diagnosed with invasive breast cancer. Ann Epidemiol. 2015;25(11):824-31.

9. U.S. Cancer Statistics Working Group. U.S. Cancer Statistics Data Visualizations Tool, based on November 2017 submission data (1999-2015): U.S. Department of Health and Human Services, Centers for Disease Control and Prevention and National Cancer Institute; http://www.cdc.gov/cancer/dataviz, June 2018.

10. DeSantis CE, Ma J, Goding Sauer A, Newman LA, Jemal A. Breast cancer statistics, 2017, racial disparity in mortality by state. CA Cancer J Clin. 2017;67(6):43948.

11. Cella DF, Bonomi AE. Measuring quality of life: 1995 update. Oncology (Williston Park). 1995;9(11 Suppl):47-60.

12. Perry S, Kowalski TL, Chang CH. Quality of life assessment in women with breast cancer: benefits, acceptability and utilization. Health Qual Life Outcomes. $2007 ; 5: 24$

13. Groenvold M, Petersen MA, Idler E, Bjorner JB, Fayers PM, Mouridsen HT. Psychological distress and fatigue predicted recurrence and survival in primary breast cancer patients. Breast Cancer Res Treat. 2007;105(2):209-19.

14. Watson M, Homewood J, Haviland J, Bliss JM. Influence of psychological response on breast cancer survival: 10-year follow-up of a population-based cohort. Eur J Cancer. 2005;41(12):1710-4. 
15. Lopez-Class M, Gomez-Duarte J, Graves K, Ashing-Giwa K. A contextual approach to understanding breast cancer survivorship among Latinas. Psychooncology. 2012;21(2):115-24.

16. Connor AE, Baumgartner RN, Pinkston CM, Boone SD, Baumgartner KB. Obesity, ethnicity, and quality of life among breast cancer survivors and women without breast cancer: the long-term quality of life follow-up study. Cancer Causes Control. 2016;27(1):115-24.

17. (ASCO) ASoCO. What is Survivorship? 2018 [Available from: https://www.cancer.net/survivorship/what-survivorship.

18. Bodai BI, Tuso P. Breast cancer survivorship: a comprehensive review of longterm medical issues and lifestyle recommendations. Perm J. 2015;19(2):48-79.

19. U.S. Department of Health and Human Services NIoH, National Cancer Institute, Facing Forward: Life After Cancer Treatment. 2018. Available from: https://www.cancer.gov/publications/patient-education/life-after-treatment.pdf. 20. Runowicz CD, Leach CR, Henry NL, Henry KS, Mackey HT, Cowens-Alvarado RL, et al. American Cancer Society/American Society of Clinical Oncology Breast Cancer Survivorship Care Guideline. J Clin Oncol. 2016;34(6):611-35.

21. Gao J, Dizon DS. Preparing for survivorship: quality of life in breast cancer survivors. J Sex Med. 2013;10 Suppl 1:16-20.

22. Hsu T, Ennis M, Hood N, Graham M, Goodwin PJ. Quality of life in long-term breast cancer survivors. J Clin Oncol. 2013;31(28):3540-8. 
23. Carver CS, Smith RG, Petronis VM, Antoni MH. Quality of life among long-term survivors of breast cancer: Different types of antecedents predict different classes of outcomes. Psychooncology. 2006;15(9):749-58.

24. Ganz PA, Desmond KA, Leedham B, Rowland JH, Meyerowitz BE, Belin TR. Quality of life in long-term, disease-free survivors of breast cancer: a follow-up study. J Natl Cancer Inst. 2002;94(1):39-49.

25. American Cancer Society. Cancer Treatment \& Survivorship Facts \& Figures 2016-2017.

26. Hines LM, Risendal B, Slattery ML, Baumgartner KB, Giuliano AR, Sweeney C, et al. Comparative analysis of breast cancer risk factors among Hispanic and nonHispanic white women. Cancer. 2010;116(13):3215-23.

27. Heitz AE, Baumgartner RN, Baumgartner KB, Boone SD. Healthy lifestyle impact on breast cancer-specific and all-cause mortality. Breast Cancer Res Treat. 2017. 28. Kwan ML, Ergas IJ, Somkin CP, Quesenberry CP, Jr., Neugut AI, Hershman DL, et al. Quality of life among women recently diagnosed with invasive breast cancer: the Pathways Study. Breast Cancer Res Treat. 2010;123(2):507-24.

29. Smigal C, Jemal A, Ward E, Cokkinides V, Smith R, Howe HL, et al. Trends in breast cancer by race and ethnicity: update 2006. CA Cancer J Clin. 2006;56(3):168-83. 30. Krogstad JM. U.S. Hispanic population growth has leveled off. Pew Research Center. 2017. [Available from: http://www.pewresearch.org/fact$\operatorname{tank/2017/08/03/u-s-hispanic-population-growth-has-leveled-off/].~}$ 
31. United States Census Bureau. Table 10. Projections of the Population by Sex, Hispanic Origin, and Race for the United States: 2015 to 2060. Microsoft Excel. United States Census Bureau. 2014.

32. Yanez B, Thompson EH, Stanton AL. Quality of life among Latina breast cancer patients: a systematic review of the literature. J Cancer Surviv. 2011;5(2):191-207. 33. Ashing-Giwa KT. The contextual model of HRQoL: a paradigm for expanding the HRQoL framework. Qual Life Res. 2005;14(2):297-307.

34. Donovan K, Sanson-Fisher RW, Redman S. Measuring quality of life in cancer patients. J Clin Oncol. 1989;7(7):959-68.

35. Ware JE, Jr., Sherbourne CD. The MOS 36-item short-form health survey (SF36). I. Conceptual framework and item selection. Med Care. 1992;30(6):473-83.

36. Brazier JE, Harper R, Jones NM, O'Cathain A, Thomas KJ, Usherwood T, et al. Validating the SF-36 health survey questionnaire: new outcome measure for primary care. BMJ. 1992;305(6846):160-4.

37. Cella DF, Tulsky DS, Gray G, Sarafian B, Linn E, Bonomi A, et al. The Functional Assessment of Cancer Therapy scale: development and validation of the general measure. J Clin Oncol. 1993;11(3):570-9.

38. Brady MJ, Cella DF, Mo F, Bonomi AE, Tulsky DS, Lloyd SR, et al. Reliability and validity of the Functional Assessment of Cancer Therapy-Breast quality-of-life instrument. J Clin Oncol. 1997;15(3):974-86.

39. Aaronson NK, Ahmedzai S, Bergman B, Bullinger M, Cull A, Duez NJ, et al. The European Organization for Research and Treatment of Cancer QLQ-C30: a quality-of-life 
instrument for use in international clinical trials in oncology. J Natl Cancer Inst. $1993 ; 85(5): 365-76$.

40. Groenvold M, Klee MC, Sprangers MA, Aaronson NK. Validation of the EORTC QLQ-C30 quality of life questionnaire through combined qualitative and quantitative assessment of patient-observer agreement. J Clin Epidemiol. 1997;50(4):441-50.

41. Hutter N, Vogel B, Alexander T, Baumeister H, Helmes A, Bengel J. Are depression and anxiety determinants or indicators of quality of life in breast cancer patients? Psychol Health Med. 2013;18(4):412-9.

42. Goodwin PJ, Ennis M, Bordeleau LJ, Pritchard KI, Trudeau ME, Koo J, et al. Health-related quality of life and psychosocial status in breast cancer prognosis: analysis of multiple variables. J Clin Oncol. 2004;22(20):4184-92.

43. Lehto US, Ojanen M, Dyba T, Aromaa A, Kellokumpu-Lehtinen P. Baseline psychosocial predictors of survival in localised breast cancer. Br J Cancer. 2006;94(9):1245-52.

44. Kossakowski JJ, Epskamp S, Kieffer JM, van Borkulo CD, Rhemtulla M, Borsboom D. The application of a network approach to Health-Related Quality of Life (HRQoL): introducing a new method for assessing HRQoL in healthy adults and cancer patients. Qual Life Res. 2016;25(4):781-92.

45. McHorney CA, Ware JE, Jr., Raczek AE. The MOS 36-Item Short-Form Health Survey (SF-36): II. Psychometric and clinical tests of validity in measuring physical and mental health constructs. Med Care. 1993;31(3):247-63. 
46. Ashing-Giwa KT, Padilla GV, Bohorquez DE, Tejero JS, Garcia M.

Understanding the breast cancer experience of Latina women. J Psychosoc Oncol. 2006;24(3):19-52.

47. Paraskevi T. Quality of life outcomes in patients with breast cancer. Oncol Rev. 2012;6(1):e2.

48. Stanton AL, Bower JE. Psychological Adjustment in Breast Cancer Survivors. Adv Exp Med Biol. 2015;862:231-42.

49. Montazeri A. Health-related quality of life in breast cancer patients: a bibliographic review of the literature from 1974 to 2007. J Exp Clin Cancer Res. $2008 ; 27: 32$.

50. DiSipio T, Hayes S, Battistutta D, Newman B, Janda M. Patterns, correlates, and prognostic significance of quality of life following breast cancer. Psychooncology. 2011;20(10):1084-91.

51. Miller AM, Ashing KT, Modeste NN, Herring RP, Sealy DA. Contextual factors influencing health-related quality of life in African American and Latina breast cancer survivors. J Cancer Surviv. 2015;9(3):441-9.

52. Rabin EG, Heldt E, Hirakata VN, Fleck MP. Quality of life predictors in breast cancer women. Eur J Oncol Nurs. 2008;12(1):53-7.

53. Kim SH, Son BH, Hwang SY, Han W, Yang JH, Lee S, et al. Fatigue and depression in disease-free breast cancer survivors: prevalence, correlates, and association with quality of life. J Pain Symptom Manage. 2008;35(6):644-55. 
54. Michael YL, Berkman LF, Colditz GA, Holmes MD, Kawachi I. Social networks and health-related quality of life in breast cancer survivors: a prospective study. $\mathrm{J}$ Psychosom Res. 2002;52(5):285-93.

55. Leung J, Pachana NA, McLaughlin D. Social support and health-related quality of life in women with breast cancer: a longitudinal study. Psychooncology. 2014;23(9):1014-20.

56. Yoo GJ LEPR. Breast cancer and coping among women of color: a systematic review of the literature. Support Care Cancer. 2014;22(3):811-24.

57. Cotton SP, Levine EG, Fitzpatrick CM, Dold KH, Targ E. Exploring the relationships among spiritual well-being, quality of life, and psychological adjustment in women with breast cancer. Psychooncology. 1999;8(5):429-38.

58. Wildes KA, Miller AR, de Majors SS, Ramirez AG. The religiosity/spirituality of Latina breast cancer survivors and influence on health-related quality of life. Psychooncology. 2009;18(8):831-40.

59. DiSipio T, Hayes S, Newman B, Janda M. Health-related quality of life 18 months after breast cancer: comparison with the general population of Queensland, Australia. Support Care Cancer. 2008;16(10):1141-50.

60. Ganz PA, Kwan L, Stanton AL, Bower JE, Belin TR. Physical and psychosocial recovery in the year after primary treatment of breast cancer. J Clin Oncol. 2011;29(9):1101-9.

61. Luckett T, Goldstein D, Butow PN, Gebski V, Aldridge LJ, McGrane J, et al. Psychological morbidity and quality of life of ethnic minority patients with cancer: a systematic review and meta-analysis. Lancet Oncol. 2011;12(13):1240-8. 
62. Falagas ME, Zarkadoulia EA, Ioannidou EN, Peppas G, Christodoulou C, Rafailidis PI. The effect of psychosocial factors on breast cancer outcome: a systematic review. Breast Cancer Res. 2007;9(4):R44.

63. Ashing-Giwa KT, Lim JW. Predicting physical quality of life among a multiethnic sample of breast cancer survivors. Qual Life Res. 2010;19(6):789-802. 64. Canario AC, Cabral PU, de Paiva LC, Florencio GL, Spyrides MH, Goncalves AK. Physical activity, fatigue and quality of life in breast cancer patients. Rev Assoc Med Bras (1992). 2016;62(1):38-44.

65. Valenti M, Porzio G, Aielli F, Verna L, Cannita K, Manno R, et al. Physical exercise and quality of life in breast cancer survivors. Int J Med Sci. 2008;5(1):24-8. 66. Coates A, Gebski V, Bishop JF, Jeal PN, Woods RL, Snyder R, et al. Improving the quality of life during chemotherapy for advanced breast cancer. A comparison of intermittent and continuous treatment strategies. N Engl J Med. 1987;317(24):1490-5.

67. Fang P, Tan KS, Troxel AB, Rengan R, Freedman G, Lin LL. High body mass index is associated with worse quality of life in breast cancer patients receiving radiotherapy. Breast Cancer Res Treat. 2013;141(1):125-33.

68. Xiao C, Miller AH, Felger J, Mister D, Liu T, Torres MA. A prospective study of quality of life in breast cancer patients undergoing radiation therapy. Adv Radiat Oncol. 2016;1(1):10-6.

69. Ferrell BR, Grant M, Funk B, Garcia N, Otis-Green S, Schaffner ML. Quality of life in breast cancer. Cancer Pract. 1996;4(6):331-40. 
70. Byar KL, Berger AM, Bakken SL, Cetak MA. Impact of adjuvant breast cancer chemotherapy on fatigue, other symptoms, and quality of life. Oncol Nurs Forum. 2006;33(1):E18-26.

71. Avis NE, Crawford S, Manuel J. Quality of life among younger women with breast cancer. J Clin Oncol. 2005;23(15):3322-30.

72. Mols F, Vingerhoets AJ, Coebergh JW, van de Poll-Franse LV. Quality of life among long-term breast cancer survivors: a systematic review. Eur J Cancer. 2005;41(17):2613-9.

73. Giedzinska AS, Meyerowitz BE, Ganz PA, Rowland JH. Health-related quality of life in a multiethnic sample of breast cancer survivors. Ann Behav Med. 2004;28(1):3951.

74. Ahles TA, Saykin AJ, Furstenberg CT, Cole B, Mott LA, Titus-Ernstoff L, et al. Quality of life of long-term survivors of breast cancer and lymphoma treated with standard-dose chemotherapy or local therapy. J Clin Oncol. 2005;23(19):4399-405.

75. Shim EJ, Mehnert A, Koyama A, Cho SJ, Inui H, Paik NS, et al. Health-related quality of life in breast cancer: A cross-cultural survey of German, Japanese, and South Korean patients. Breast Cancer Res Treat. 2006;99(3):341-50.

76. Maly RC, Stein JA, Umezawa Y, Leake B, Anglin MD. Racial/ethnic differences in breast cancer outcomes among older patients: effects of physician communication and patient empowerment. Health Psychol. 2008;27(6):728-36.

77. Ashing-Giwa KT, Tejero JS, Kim J, Padilla GV, Hellemann G. Examining predictive models of HRQOL in a population-based, multiethnic sample of women with breast carcinoma. Qual Life Res. 2007;16(3):413-28. 
78. Phillips KA, Osborne RH, Giles GG, Dite GS, Apicella C, Hopper JL, et al. Psychosocial factors and survival of young women with breast cancer: a populationbased prospective cohort study. J Clin Oncol. 2008;26(28):4666-71.

79. Kenne Sarenmalm E, Oden A, Ohlen J, Gaston-Johansson F, Holmberg SB. Changes in health-related quality of life may predict recurrent breast cancer. Eur J Oncol Nurs. 2009;13(5):323-9.

80. Coates AS, Hurny C, Peterson HF, Bernhard J, Castiglione-Gertsch M, Gelber $\mathrm{RD}$, et al. Quality-of-life scores predict outcome in metastatic but not early breast cancer. International Breast Cancer Study Group. J Clin Oncol. 2000;18(22):3768-74.

81. Quinten C, Coens C, Mauer M, Comte S, Sprangers MA, Cleeland C, et al. Baseline quality of life as a prognostic indicator of survival: a meta-analysis of individual patient data from EORTC clinical trials. Lancet Oncol. 2009;10(9):865-71.

82. Coates A, Gebski V, Signorini D, Murray P, McNeil D, Byrne M, et al. Prognostic value of quality-of-life scores during chemotherapy for advanced breast cancer. Australian New Zealand Breast Cancer Trials Group. J Clin Oncol. 1992;10(12):1833-8.

83. Epplein M, Zheng Y, Zheng W, Chen Z, Gu K, Penson D, et al. Quality of life after breast cancer diagnosis and survival. J Clin Oncol. 2011;29(4):406-12.

84. Montazeri A. Quality of life data as prognostic indicators of survival in cancer patients: an overview of the literature from 1982 to 2008. Health Qual Life Outcomes. 2009;7:102.

85. Pinquart M, Duberstein PR. Associations of social networks with cancer mortality: a meta-analysis. Crit Rev Oncol Hematol. 2010;75(2):122-37. 
86. Kroenke CH, Quesenberry C, Kwan ML, Sweeney C, Castillo A, Caan BJ. Social networks, social support, and burden in relationships, and mortality after breast cancer diagnosis in the Life After Breast Cancer Epidemiology (LACE) study. Breast Cancer Res Treat. 2013;137(1):261-71.

87. DuMontier C, Clough-Gorr KM, Silliman RA, Stuck AE, Moser A. HealthRelated Quality of Life in a Predictive Model for Mortality in Older Breast Cancer Survivors. J Am Geriatr Soc. 2018.

88. Marinac C, Patterson RE, Villasenor A, Flatt SW, Pierce JP. Mechanisms of association between physical functioning and breast cancer mortality: evidence from the Women's Healthy Eating and Living Study. J Cancer Surviv. 2014;8(3):402-9.

89. Saquib N, Pierce JP, Saquib J, Flatt SW, Natarajan L, Bardwell WA, et al. Poor physical health predicts time to additional breast cancer events and mortality in breast cancer survivors. Psychooncology. 2011;20(3):252-9.

90. Shimozuma K, Sonoo H, Ichihara K, Tanaka K. The prognostic value of qualityof-life scores: preliminary results of an analysis of patients with breast cancer. Surg Today. 2000;30(3):255-61.

91. Luoma ML, Hakamies-Blomqvist L, Sjostrom J, Pluzanska A, Ottoson S, Mouridsen $\mathrm{H}$, et al. Prognostic value of quality of life scores for time to progression (TTP) and overall survival time (OS) in advanced breast cancer. Eur J Cancer. 2003;39(10):1370-6.

92. Gupta D, Granick J, Grutsch JF, Lis CG. The prognostic association of healthrelated quality of life scores with survival in breast cancer. Support Care Cancer. 2007;15(4):387-93. 
93. Bredal IS, Sandvik L, Karesen R, Ekeberg O. Prognostic value of health-related quality-of-life parameters in early-stage breast cancer: an 8-year follow-up study. Psychooncology. 2011;20(10):1102-7.

94. Efficace F, Therasse P, Piccart MJ, Coens C, van Steen K, Welnicka-Jaskiewicz M, et al. Health-related quality of life parameters as prognostic factors in a nonmetastatic breast cancer population: an international multicenter study. J Clin Oncol. 2004;22(16):3381-8.

95. De Aguiar SS, Bergmann A, Mattos IE. Quality of life as a predictor of overall survival after breast cancer treatment. Qual Life Res. 2014;23(2):627-37.

96. Cianfrocca M, Goldstein LJ. Prognostic and predictive factors in early-stage breast cancer. Oncologist. 2004;9(6):606-16.

97. Masood S. Prognostic/predictive factors in breast cancer. Clin Lab Med. 2005;25(4):809-25, viii.

98. Soerjomataram I, Louwman MW, Ribot JG, Roukema JA, Coebergh JW. An overview of prognostic factors for long-term survivors of breast cancer. Breast Cancer Res Treat. 2008;107(3):309-30.

99. Weitzner MA, Meyers CA, Stuebing KK, Saleeba AK. Relationship between quality of life and mood in long-term survivors of breast cancer treated with mastectomy. Support Care Cancer. 1997;5(3):241-8.

100. Kootstra J, Hoekstra-Weebers JE, Rietman H, de Vries J, Baas P, Geertzen JH, et al. Quality of life after sentinel lymph node biopsy or axillary lymph node dissection in stage I/II breast cancer patients: a prospective longitudinal study. Ann Surg Oncol. 2008;15(9):2533-41. 
101. Wyatt G, Sikorskii A, Tamkus D, You M. Quality of life among advanced breast cancer patients with and without distant metastasis. Eur J Cancer Care (Engl). $2013 ; 22(2): 272-80$.

102. Ashing-Giwa KT, Padilla G, Tejero J, Kraemer J, Wright K, Coscarelli A, et al. Understanding the breast cancer experience of women: a qualitative study of African American, Asian American, Latina and Caucasian cancer survivors. Psychooncology. 2004;13(6):408-28.

103. Paskett ED, Alfano CM, Davidson MA, Andersen BL, Naughton MJ, Sherman A, et al. Breast cancer survivors' health-related quality of life : racial differences and comparisons with noncancer controls. Cancer. 2008;113(11):3222-30.

104. O'Brien KM, Cole SR, Tse CK, Perou CM, Carey LA, Foulkes WD, et al. Intrinsic breast tumor subtypes, race, and long-term survival in the Carolina Breast Cancer Study. Clin Cancer Res. 2010;16(24):6100-10.

105. Zhang S, Folsom AR, Sellers TA, Kushi LH, Potter JD. Better breast cancer survival for postmenopausal women who are less overweight and eat less fat. The Iowa Women's Health Study. Cancer. 1995;76(2):275-83.

106. Chang S, Alderfer JR, Asmar L, Buzdar AU. Inflammatory breast cancer survival: the role of obesity and menopausal status at diagnosis. Breast Cancer Res Treat. 2000;64(2):157-63.

107. Miura K, Ando S, Imai T. The association of cognitive fatigue with menopause, depressive symptoms, and quality of life in ambulatory breast cancer patients. Breast Cancer. 2016;23(3):407-14. 
108. Early Breast Cancer Trialists' Collaborative Group. Effects of chemotherapy and hormonal therapy for early breast cancer on recurrence and 15-year survival: an overview of the randomised trials. Lancet. 2005;365(9472):1687-717.

109. Slavich GM, Irwin MR. From stress to inflammation and major depressive disorder: a social signal transduction theory of depression. Psychol Bull. 2014;140(3):774-815.

110. Ashing-Giwa K, Rosales M, Lai L, Weitzel J. Depressive symptomatology among Latina breast cancer survivors. Psychooncology. 2013;22(4):845-53.

111. Moreno-Smith M, Lutgendorf SK, Sood AK. Impact of stress on cancer metastasis. Future Oncol. 2010;6(12):1863-81.

112. Bradshaw PT, Ibrahim JG, Khankari N, Cleveland RJ, Abrahamson PE, Stevens J, et al. Post-diagnosis physical activity and survival after breast cancer diagnosis: the Long Island Breast Cancer Study. Breast Cancer Res Treat. 2014;145(3):735-42.

113. Pinkston CM, Baumgartner RN, Connor AE, Boone SD, Baumgartner KB. Physical activity and survival among Hispanic and non-Hispanic white long-term breast cancer survivors and population-based controls. J Cancer Surviv. 2015;9(4):650-9. 114. Kwan ML, John EM, Caan BJ, Lee VS, Bernstein L, Cheng I, et al. Obesity and mortality after breast cancer by race/ethnicity: The California Breast Cancer Survivorship Consortium. Am J Epidemiol. 2014;179(1):95-111.

115. Kroenke CH, Chen WY, Rosner B, Holmes MD. Weight, weight gain, and survival after breast cancer diagnosis. J Clin Oncol. 2005;23(7):1370-8. 
116. Dal Maso L, Zucchetto A, Talamini R, Serraino D, Stocco CF, Vercelli M, et al. Effect of obesity and other lifestyle factors on mortality in women with breast cancer. Int J Cancer. 2008;123(9):2188-94.

117. Szuba A, Shin WS, Strauss HW, Rockson S. The third circulation: radionuclide lymphoscintigraphy in the evaluation of lymphedema. J Nucl Med. 2003;44(1):43-57. 118. Ahmed RL, Prizment A, Lazovich D, Schmitz KH, Folsom AR. Lymphedema and quality of life in breast cancer survivors: the Iowa Women's Health Study. J Clin Oncol. 2008;26(35):5689-96.

119. Brayton KM, Hirsch AT, PJ OB, Cheville A, Karaca-Mandic P, Rockson SG. Lymphedema prevalence and treatment benefits in cancer: impact of a therapeutic intervention on health outcomes and costs. PLoS One. 2014;9(12):e114597.

120. Velanovich V, Szymanski W. Quality of life of breast cancer patients with lymphedema. Am J Surg. 1999;177(3):184-7; discussion 8.

121. Ellsworth RE, Valente AL, Shriver CD, Bittman B, Ellsworth DL. Impact of lifestyle factors on prognosis among breast cancer survivors in the USA. Expert Rev Pharmacoecon Outcomes Res. 2012;12(4):451-64.

122. George SM, Irwin ML, Smith AW, Neuhouser ML, Reedy J, McTiernan A, et al. Postdiagnosis diet quality, the combination of diet quality and recreational physical activity, and prognosis after early-stage breast cancer. Cancer Causes Control. $2011 ; 22(4): 589-98$.

123. Kwan ML, Weltzien E, Kushi LH, Castillo A, Slattery ML, Caan BJ. Dietary patterns and breast cancer recurrence and survival among women with early-stage breast cancer. J Clin Oncol. 2009;27(6):919-26. 
124. Wayne SJ, Baumgartner K, Baumgartner RN, Bernstein L, Bowen DJ, BallardBarbash R. Diet quality is directly associated with quality of life in breast cancer survivors. Breast Cancer Res Treat. 2006;96(3):227-32.

125. Sollie M, Bille C. Smoking and mortality in women diagnosed with breast cancera systematic review with meta-analysis based on 400,944 breast cancer cases. Gland Surg. 2017;6(4):385-93.

126. Jang S, Prizment A, Haddad T, Robien K, Lazovich D. Smoking and quality of life among female survivors of breast, colorectal and endometrial cancers in a prospective cohort study. J Cancer Surviv. 2011;5(2):115-22.

127. Pinheiro LC, Tan X, Olshan AF, Wheeler SB, Reeder-Hayes KE, Samuel CA, et al. Examining health-related quality of life patterns in women with breast cancer. Qual Life Res. 2017;26(7):1733-43.

128. Sapolsky R.M. Why Zebras Don't Get Ulcers: A Guide to Stress, Stress-Related Diseases, and Coping. NY, USA: WH Freeman and Co.; 1998.

129. Schmidt C, Kraft K. Beta-endorphin and catecholamine concentrations during chronic and acute stress in intensive care patients. Eur J Med Res. 1996;1(11):528-32. 130. Puglisi-Allegra S, Imperato A, Angelucci L, Cabib S. Acute stress induces timedependent responses in dopamine mesolimbic system. Brain Res. 1991;554(1-2):217-22. 131. Imperato A, Angelucci L, Casolini P, Zocchi A, Puglisi-Allegra S. Repeated stressful experiences differently affect limbic dopamine release during and following stress. Brain Res. 1992;577(2):194-9.

132. Badino GR, Novelli A, Girardi C, Di Carlo F. Evidence for functional betaadrenoceptor subtypes in CG-5 breast cancer cell. Pharmacol Res. 1996;33(4-5):255-60. 
133. Rhen T, Cidlowski JA. Antiinflammatory action of glucocorticoids--new mechanisms for old drugs. N Engl J Med. 2005;353(16):1711-23.

134. Chrousos GP, Gold PW. The concepts of stress and stress system disorders. Overview of physical and behavioral homeostasis. JAMA. 1992;267(9):1244-52.

135. Sephton S, Spiegel D. Circadian disruption in cancer: a neuroendocrine-immune pathway from stress to disease? Brain Behav Immun. 2003;17(5):321-8.

136. Vedhara K, Cox NK, Wilcock GK, Perks P, Hunt M, Anderson S, et al. Chronic stress in elderly carers of dementia patients and antibody response to influenza vaccination. Lancet. 1999;353(9153):627-31.

137. Dhabhar FS, Saul AN, Daugherty C, Holmes TH, Bouley DM, Oberyszyn TM. Short-term stress enhances cellular immunity and increases early resistance to squamous cell carcinoma. Brain Behav Immun. 2010;24(1):127-37.

138. Fredriksson JM, Lindquist JM, Bronnikov GE, Nedergaard J. Norepinephrine induces vascular endothelial growth factor gene expression in brown adipocytes through a beta -adrenoreceptor/cAMP/protein kinase A pathway involving Src but independently of Erk1/2. J Biol Chem. 2000;275(18):13802-11.

139. Sharma A, Greenman J, Sharp DM, Walker LG, Monson JR. Vascular endothelial growth factor and psychosocial factors in colorectal cancer. Psychooncology. 2008;17(1):66-73.

140. Lutgendorf SK, Johnsen EL, Cooper B, Anderson B, Sorosky JI, Buller RE, et al. Vascular endothelial growth factor and social support in patients with ovarian carcinoma. Cancer. 2002;95(4):808-15. 
141. Costanzo ES, Lutgendorf SK, Sood AK, Anderson B, Sorosky J, Lubaroff DM. Psychosocial factors and interleukin-6 among women with advanced ovarian cancer. Cancer. 2005;104(2):305-13.

142. Flaxman BA, Harper RA. In vitro analysis of the control of keratinocyte proliferation in human epidermis by physiologic and pharmacologic agents. J Invest Dermatol. 1975;65(1):52-9.

143. Cohen S, Janicki-Deverts D, Doyle WJ, Miller GE, Frank E, Rabin BS, et al. Chronic stress, glucocorticoid receptor resistance, inflammation, and disease risk. Proc Natl Acad Sci U S A. 2012;109(16):5995-9.

144. Williams JB, Pang D, Delgado B, Kocherginsky M, Tretiakova M, Krausz T, et al. A model of gene-environment interaction reveals altered mammary gland gene expression and increased tumor growth following social isolation. Cancer Prev Res (Phila). 2009;2(10):850-61.

145. Shavit Y, Lewis JW, Terman GW, Gale RP, Liebeskind JC. Opioid peptides mediate the suppressive effect of stress on natural killer cell cytotoxicity. Science. 1984;223(4632):188-90.

146. Reynolds P, Boyd PT, Blacklow RS, Jackson JS, Greenberg RS, Austin DF, et al. The relationship between social ties and survival among black and white breast cancer patients. National Cancer Institute Black/White Cancer Survival Study Group. Cancer Epidemiol Biomarkers Prev. 1994;3(3):253-9.

147. Chou AF, Stewart SL, Wild RC, Bloom JR. Social support and survival in young women with breast carcinoma. Psychooncology. 2012;21(2):125-33. 
148. Irwin ML, Crumley D, McTiernan A, Bernstein L, Baumgartner R, Gilliland FD, et al. Physical activity levels before and after a diagnosis of breast carcinoma: the Health, Eating, Activity, and Lifestyle (HEAL) study. Cancer. 2003;97(7):1746-57.

149. Forsythe LP, Alfano CM, George SM, McTiernan A, Baumgartner KB, Bernstein L, et al. Pain in long-term breast cancer survivors: the role of body mass index, physical activity, and sedentary behavior. Breast Cancer Res Treat. 2013;137(2):617-30.

150. Meeske K, Smith AW, Alfano CM, McGregor BA, McTiernan A, Baumgartner $\mathrm{KB}$, et al. Fatigue in breast cancer survivors two to five years post diagnosis: a HEAL Study report. Qual Life Res. 2007;16(6):947-60.

151. Scheier MF, Carver CS, Bridges MW. Distinguishing optimism from neuroticism (and trait anxiety, self-mastery, and self-esteem): a reevaluation of the Life Orientation Test. J Pers Soc Psychol. 1994;67(6):1063-78.

152. Maunsell E, Brisson J, Deschenes L. Social support and survival among women with breast cancer. Cancer. 1995;76(4):631-7.

153. Piper BF, Dibble SL, Dodd MJ, Weiss MC, Slaughter RE, Paul SM. The revised Piper Fatigue Scale: psychometric evaluation in women with breast cancer. Oncol Nurs Forum. 1998;25(4):677-84.

154. Northouse LL. Mastectomy patients and the fear of cancer recurrence. Cancer Nurs. 1981;4(3):213-20.

155. Hays RD, Shapiro MF. An overview of generic health-related quality of life measures for HIV research. Qual Life Res. 1992;1(2):91-7. 
156. RAND Corporation. 36-Item Short Form Survey (SF-36) Scoring Instructions N.A. [Available from: https://www.rand.org/health/surveys_tools/mos/36-itemshort-form/scoring.html.

157. Bjorner JB, Wallenstein GV, Martin MC, Lin P, Blaisdell-Gross B, Tak Piech C, et al. Interpreting score differences in the SF-36 Vitality scale: using clinical conditions and functional outcomes to define the minimally important difference. Curr Med Res Opin. 2007;23(4):731-9.

158. Alfano CM, McGregor BA, Kuniyuki A, Reeve BB, Bowen DJ, Baumgartner $\mathrm{KB}$, et al. Psychometric properties of a tool for measuring hormone-related symptoms in breast cancer survivors. Psychooncology. 2006;15(11):985-1000.

159. Bramer GR. International statistical classification of diseases and related health problems. Tenth revision. World Health Stat Q. 1988;41(1):32-6.

160. Villasenor A, Ballard-Barbash R, Baumgartner K, Baumgartner R, Bernstein L, McTiernan A, et al. Prevalence and prognostic effect of sarcopenia in breast cancer survivors: the HEAL Study. J Cancer Surviv. 2012;6(4):398-406.

161. Zwiener I, Blettner M, Hommel G. Survival analysis: part 15 of a series on evaluation of scientific publications. Dtsch Arztebl Int. 2011;108(10):163-9.

162. Bursac Z, Gauss CH, Williams DK, Hosmer DW. Purposeful selection of variables in logistic regression. Source Code Biol Med. 2008;3:17.

163. Patino CM, Ferreira JC. Test for trend: evaluating dose-response effects in association studies. J Bras Pneumol. 2016;42(4):240.

164. Ng'andu NH. An empirical comparison of statistical tests for assessing the proportional hazards assumption of Cox's model. Stat Med. 1997;16(6):611-26. 
165. Schoenfeld D. Partial Residuals for the Proportional Hazards Regression Model. Biometrika. 1982;69(1):239-41.

166. Alfano CM, Smith AW, Irwin ML, Bowen DJ, Sorensen B, Reeve BB, et al. Physical activity, long-term symptoms, and physical health-related quality of life among breast cancer survivors: a prospective analysis. J Cancer Surviv. 2007;1(2):116-28.

167. Bowen DJ, Alfano CM, McGregor BA, Kuniyuki A, Bernstein L, Meeske K, et al. Possible socioeconomic and ethnic disparities in quality of life in a cohort of breast cancer survivors. Breast Cancer Res Treat. 2007;106(1):85-95.

168. Bellizzi KM, Smith AW, Reeve BB, Alfano CM, Bernstein L, Meeske K, et al. Posttraumatic growth and health-related quality of life in a racially diverse cohort of breast cancer survivors. J Health Psychol. 2010;15(4):615-26.

169. Alfano CM, Lichstein KL, Vander Wal GS, Smith AW, Reeve BB, McTiernan A, et al. Sleep duration change across breast cancer survivorship: associations with symptoms and health-related quality of life. Breast Cancer Res Treat. 2011;130(1):24354.

170. Ma H, Sullivan-Halley J, Smith AW, Neuhouser ML, Alfano CM, Meeske K, et al. Estrogenic botanical supplements, health-related quality of life, fatigue, and hormonerelated symptoms in breast cancer survivors: a HEAL study report. BMC Complement Altern Med. 2011;11:109.

171. Stover AM, Reeve BB, Piper BF, Alfano CM, Smith AW, Mitchell SA, et al. Deriving clinically meaningful cut-scores for fatigue in a cohort of breast cancer survivors: a Health, Eating, Activity, and Lifestyle (HEAL) Study. Qual Life Res. 2013;22(9):2279-92. 
172. George SM, Alfano CM, Neuhouser ML, Smith AW, Baumgartner RN, Baumgartner KB, et al. Better postdiagnosis diet quality is associated with less cancerrelated fatigue in breast cancer survivors. J Cancer Surviv. 2014;8(4):680-7.

173. Smith AW, Alfano CM, Reeve BB, Irwin ML, Bernstein L, Baumgartner K, et al. Race/ethnicity, physical activity, and quality of life in breast cancer survivors. Cancer Epidemiol Biomarkers Prev. 2009;18(2):656-63.

174. Boone SD, Baumgartner KB, Joste NE, Pinkston CM, Yang D, Baumgartner RN. The joint contribution of tumor phenotype and education to breast cancer survival disparity between Hispanic and non-Hispanic white women. Cancer Causes Control. 2014;25(3):273-82. 


\section{APPENDICES}

Appendix A: Studies Evaluating Health-Related Quality of Life (HRQOL) as a Predictor of Breast Cancer Prognosis

Appendix B: Physical Component Summary Score Univariate HR Analysis and Percent Change for All-Cause Mortality when Assessing for Potential Confounders $(N=351)$

Appendix C: Percent Change from Crude Model and Model 1 with Each Potential Confounder (PCS \& All-Cause Mortality) $(\mathrm{N}=351)$

Appendix D: Multivariable Modeling with Physical Component Summary Score as the Predictor and All-Cause Mortality as the Outcome $(\mathrm{N}=351)$

Appendix E: Mental Component Summary Score Univariate HR Analysis and Percent Change for All-Cause Mortality when Assessing for Potential Confounders $(\mathrm{N}=351)$

Appendix F: Percent Change from Crude Model and Model 1 with Each Potential Confounder (MCS \& All-Cause Mortality) $(\mathrm{N}=351)$

Appendix G: Multivariable Modeling with Mental Component Summary Score as the Predictor and All-Cause Mortality as the Outcome $(\mathrm{N}=351)$

Appendix H: Physical Component Summary Score Univariate HR Analysis and Percent Change for Breast Cancer-Specific Mortality when Assessing for Potential Confounders $(\mathrm{N}=351)$

Appendix I: Mental Component Summary Score Univariate HR Analysis and Percent Change for Breast Cancer-Specific Mortality when Assessing for Potential Confounders $(\mathrm{N}=351)$

Appendix J: Physical Component Summary Score Univariate HR Analysis and Percent Change for Non-Cancer Mortality when Assessing for Potential Confounders $(\mathrm{N}=351)$

Appendix K: Percent Change from Crude and Model 1 with Each Potential Confounder (PCS \& Non-Cancer Mortality) $(\mathrm{N}=351)$

Appendix L: Multivariable Modeling with Physical Component Summary Score as the Predictor and Non-Cancer Mortality as the Outcome $(\mathrm{N}=351)$ 
Appendix M: Mental Component Summary Score Univariate HR Analysis and Percent Change for Non-Cancer Mortality when Assessing for Potential Confounders $(\mathrm{N}=351)$

Appendix N: Percent Change from Crude and Model 1 with Each Potential Confounder (MCS \& Non-Cancer Mortality) $(\mathrm{N}=351)$

Appendix O: Multivariable Modeling with Mental Component Summary Score as the Predictor and Non-Cancer Mortality as the Outcome $(\mathrm{N}=351)$

Appendix P: Kaplan-Meier Curves: (All-Cause) Survival Probability Estimates for Race/Ethnicity

Appendix Q: Kaplan-Meier Curves: (BCS) Survival Probability Estimates for PCS Tertiles

Appendix R: Kaplan-Meier Curves: (BCS) Survival Probability Estimates for MCS Tertiles

Appendix S: Kaplan-Meier Curves: (BCS) Survival Probability Estimates for Race/Ethnicity

Appendix T: Kaplan-Meier Curves: (Non-Cancer) Survival Probability Estimates for PCS Tertiles

Appendix U: Kaplan-Meier Curves: (Non-Cancer) Survival Probability Estimates for MCS Tertiles

Appendix V: Kaplan-Meier Curves: (Non-Cancer) Survival Probability Estimates for Race/Ethnicity

Appendix W: Kaplan-Meier Curves: (All-Cause) Survival Probability Estimates for MCS Tertiles by Race/Ethnicity (NHW Women)

Appendix X: Kaplan-Meier Curves: (All-Cause) Survival Probability Estimates for MCS Tertiles by Race/Ethnicity (Hispanic Women)

Appendix Y: Kaplan-Meier Curves: (Non-Cancer) Survival Probability Estimates for MCS Tertiles by Race/Ethnicity (NHW Women)

Appendix Z: Kaplan-Meier Curves: (Non-Cancer) Survival Probability Estimates for MCS Tertiles by Race/Ethnicity (Hispanic Women) 


\section{Appendix A. Studies Evaluating Health-Related Quality of Life (HRQOL) as a Predictor of Breast Cancer Prognosis}

\begin{tabular}{|c|c|c|c|c|c|c|c|}
\hline \# & Authors & Study Sample & Study Measures & Date(s) Assessed & $\begin{array}{l}\text { Outcome } \\
\text { Measures }\end{array}$ & Survival Time & Findings \\
\hline 1 & $\begin{array}{l}\text { Coates et } \\
\text { al., } 2000\end{array}$ & $\begin{array}{l}\text { Participants: Trial } \\
\text { VI }(n=1,262) \text { and } \\
\text { Trial VII }(n=1,008) \\
\text { at baseline; }(n=869) \\
\text { of Trial VI and } \\
(n=742) \text { of Trial VII } \\
\text { at } 18 \text { months. At } 1 \\
\text { month after relapse: } \\
(n=203) \text { Trial VI } \\
\text { and }(n=149) \text { Trial } \\
\text { VII. At } 6 \text { months } \\
\text { after relapse: } \\
(n=219) \text { Trial VI } \\
\text { and }(n=162) \text { Trial } \\
\text { VII }\end{array}$ & $\begin{array}{l}\text { Linear Analog Self- } \\
\text { Assessment (LASA) }\end{array}$ & $\begin{array}{l}\text { Regular intervals } \\
\text { for } 6 \text { years after } \\
\text { randomization or } \\
\text { until relapse; } 1 \text { - } \\
\text { and 6-months } \\
\text { post-disease } \\
\text { relapse }\end{array}$ & $\begin{array}{l}\text { Disease-free } \\
\text { survival (DFS) } \\
\text { and overall } \\
\text { survival }\end{array}$ & 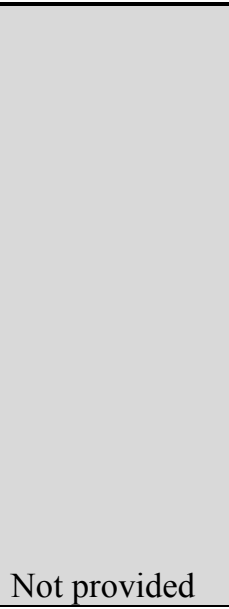 & $\begin{array}{l}\text { Six months after relapse: } \\
\text { Better physical well-being in } \\
\text { premenopausal women (HR: } \\
0.91, \text { p-value: } 0.03 \text { ) and } \\
\text { postmenopausal women (HR: } \\
0.85, \text { p-value: }<0.0001) \\
\text { predicted longer survival. } \\
\text { Mood (HR: } 0.88 \text {, p-value: } \\
0.002) \text { and coping (HR: } 0.85 \text {, } \\
\text { p-value: } 0.0001) \text { predicted } \\
\text { longer survival in } \\
\text { postmenopausal women. }\end{array}$ \\
\hline 2 & $\begin{array}{l}\text { Shimozuma } \\
\text { et al., } 2000\end{array}$ & $(n=19)$ & $\begin{array}{l}\text { Quality of Life } \\
\text { Questionnaire for } \\
\text { Cancer Patients } \\
\text { Treated with } \\
\text { Anticancer Drugs } \\
\text { (QOL-ACD) }\end{array}$ & $\begin{array}{l}\text { Baseline and } \\
\text { once a month }\end{array}$ & Overall survival & $\begin{array}{l}\text { After first } \\
\text { assessment: } 14 \\
\text { months (range: } \\
1-37 \text { months); } \\
\text { after last } \\
\text { assessment: } 4 \\
\text { months (range: } \\
0-21 \text { months) }\end{array}$ & $\begin{array}{l}\text { Physical elements of quality of } \\
\text { life predicted survival, but } \\
\text { psychosocial elements did not. }\end{array}$ \\
\hline 3 & $\begin{array}{l}\text { Luoma et } \\
\text { al., } 2003\end{array}$ & $(n=283)$ & EORTC QLQ-C30 & Not provided & $\begin{array}{l}\text { Time to } \\
\text { progression (TTP) } \\
\text { and overall } \\
\text { survival (OS) }\end{array}$ & $\begin{array}{l}\text { T group: } 10.4 \\
\text { months; MF } \\
\text { group: } 11.4 \\
\text { months (range: } \\
6 \text { days to } 29 \\
\text { months for } \\
\text { both) }\end{array}$ & $\begin{array}{l}\text { More severe fatigue (HR: } 1.48 \text {, } \\
95 \% \text { CI: } 1.13-1.93 \text {, p-value: } \\
0.0044 \text { ) and pain (HR: } 1.46 \text {, } \\
95 \% \text { CI: } 1.10-1.94, \mathrm{p} \text {-value: } \\
0.008 \text { ) were associated with } \\
\text { shorter overall survival. }\end{array}$ \\
\hline
\end{tabular}




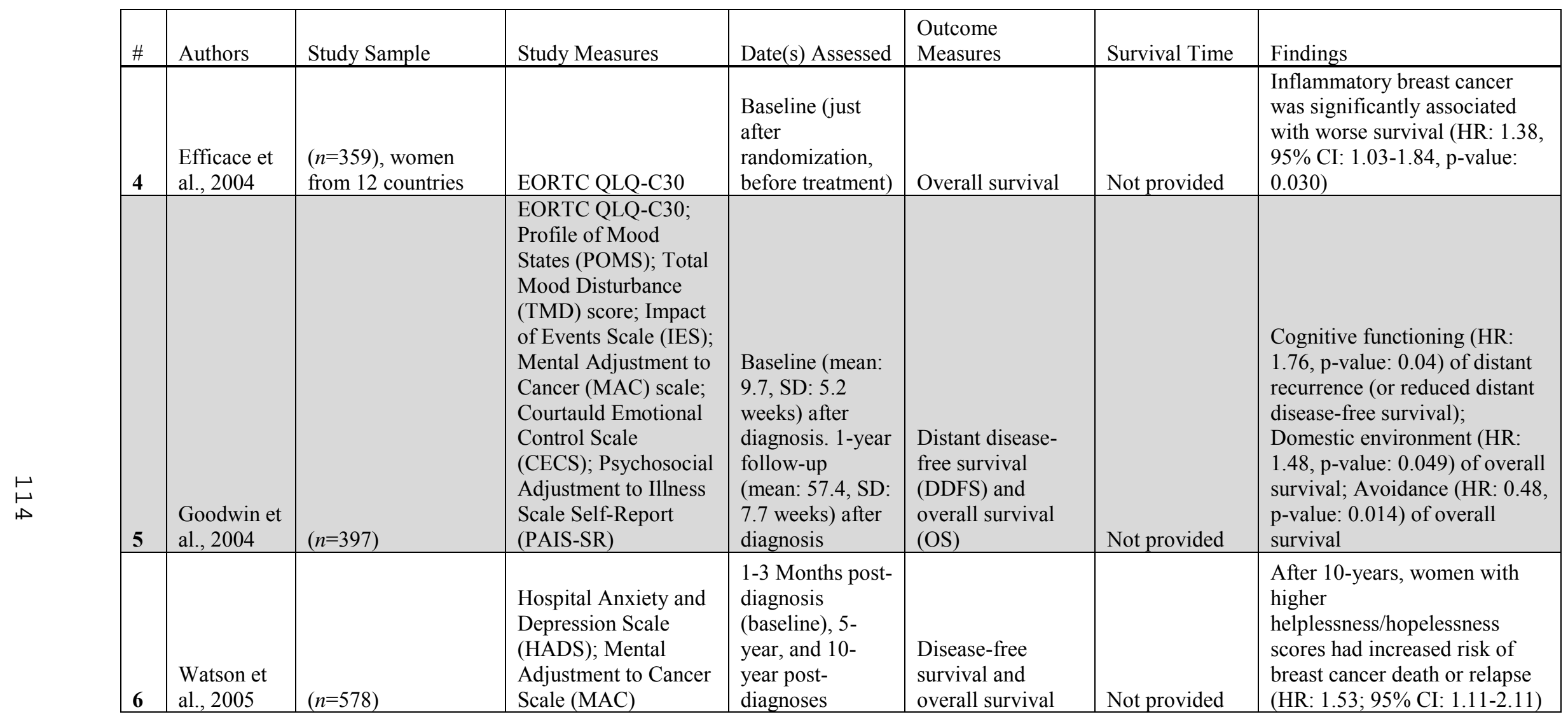




\begin{tabular}{|c|c|c|c|c|c|c|c|}
\hline \# & Authors & Study Sample & Study Measures & Date(s) Assessed & $\begin{array}{l}\text { Outcome } \\
\text { Measures }\end{array}$ & Survival Time & Findings \\
\hline 7 & $\begin{array}{l}\text { Lehto et al., } \\
2006\end{array}$ & $(n=102)$ & $\begin{array}{l}\text { Chronic Strains } \\
\text { Survey (CSS), the } \\
\text { Rotterdamn Symptom } \\
\text { Checklist (RSCL), } \\
\text { 10-item Depression } \\
\text { Scale (DEPS), } \\
\text { EORTC-breast 23. }\end{array}$ & $\begin{array}{l}\text { 3-4 Months post- } \\
\text { diagnosis }\end{array}$ & Overall survival & Not provided & $\begin{array}{l}\text { High education and distancing } \\
\text { predicted better overall } \\
\text { survival (HR: } 0.08 \text {, p-value: } \\
0.003) \text {; (HR: } 0.78 \text {; p-value: } \\
0.034 \text { ). Behavioral escape- } \\
\text { avoidance (HR: } 1.38 \text {, p-value: } \\
0.008 \text { ), emotional } \\
\text { defensiveness (HR: } 1.31, p- \\
\text { value: } 0.007 \text { ) and perceived } \\
\text { support (HR: } 5.19 ; \text { p-value: } \\
0.009 \text { ) predicted worse } \\
\text { survival. }\end{array}$ \\
\hline 8 & $\begin{array}{l}\text { Groenvold } \\
\text { et al., } 2007\end{array}$ & $(n=1,588)$ & $\begin{array}{l}\text { EORTC QLQ-C30; } \\
\text { Hospital Anxiety and } \\
\text { Depression Scale } \\
\text { (HADS) }\end{array}$ & $\begin{array}{l}\text { Approximately } \\
\text { 4-months post- } \\
\text { diagnosis }\end{array}$ & $\begin{array}{l}\text { Recurrence-free } \\
\text { survival (RFS) } \\
\text { and overall } \\
\text { survival (OS) } \\
\end{array}$ & Not provided & $\begin{array}{l}\text { Higher levels of emotional } \\
\text { functioning predicted better } \\
\text { recurrence-free survival (RFS) } \\
\text { (RR: } 0.80 \text {; } 95 \% \text { CI: } 0.69-0.93) \\
\text { and overall survival (OS) (RR: } \\
0.81 ; 95 \% \text { CI: } 0.70-0.95 \text { ). } \\
\text { Higher levels of fatigue } \\
\text { predicted worse RFS (RR: } \\
1.32 ; 95 \% \text { CI: } 1.13-1.54 \text { ) and } \\
\text { OS (RR: } 1.23 ; 95 \% \text { CI: } 1.05- \\
1.44 \text { ). }\end{array}$ \\
\hline 9 & $\begin{array}{l}\text { Gupta et } \\
\text { al., } 2007\end{array}$ & $(n=251)$ & $\begin{array}{l}\text { Ferrans and Powers } \\
\text { quality of life index } \\
\text { (QLI) }\end{array}$ & $\begin{array}{l}\text { At time of } \\
\text { diagnosis }\end{array}$ & Overall survival & Not provided & $\begin{array}{l}\text { Higher scores in the health and } \\
\text { physical subscale (RR: } 0.91 \text {, } \\
95 \% \text { CI: } 0.86-0.96 \text {, p-value: } \\
<0.001) \text { and overall HRQOL } \\
\text { (RR: } 0.90,95 \% \text { CI: } 0.85-0.95 \text {, } \\
\text { p-value: }<0.0011) \text { were } \\
\text { associated with better survival. }\end{array}$ \\
\hline
\end{tabular}




\begin{tabular}{|c|c|c|c|c|c|c|c|}
\hline$\#$ & Authors & Study Sample & Study Measures & Date(s) Assessed & $\begin{array}{l}\text { Outcome } \\
\text { Measures }\end{array}$ & Survival Time & Findings \\
\hline 10 & $\begin{array}{l}\text { Phillips et } \\
\text { al., } 2008\end{array}$ & $(n=708)$ & $\begin{array}{l}\text { Hospital Anxiety and } \\
\text { Depression Scale } \\
\text { (HADS), Mental } \\
\text { Adjustment to Cancer } \\
\text { Scale (MAC), } \\
\text { Courtauld Emotional } \\
\text { Control Scale } \\
\text { (CECS), and the } \\
\text { Duke-University of } \\
\text { North Carolina } \\
\text { Functional Social } \\
\text { Support (DUFSS) } \\
\text { questionnaire }\end{array}$ & $\begin{array}{l}\text { 2-42-Months } \\
\text { post-diagnosis } \\
\text { (median: } 11 \\
\text { months) }\end{array}$ & $\begin{array}{l}\text { Distant disease- } \\
\text { free survival } \\
\text { (DDFS) and } \\
\text { overall survival } \\
\text { (OS) }\end{array}$ & Not provided & $\begin{array}{l}\text { There were no statistically } \\
\text { significant associations } \\
\text { between the } \\
\text { HRQOL/psychosocial } \\
\text { variables and DDFS and OS } \\
\text { when adjusted for known } \\
\text { prognostic factors. }\end{array}$ \\
\hline 11 & $\begin{array}{l}\text { Quinten et } \\
\text { al., } 2009\end{array}$ & $\begin{array}{l}(n=30) \text { randomized } \\
\text { control trials, } \\
(n=7,417) \text { HRQOL } \\
\text { present at baseline }\end{array}$ & EORTC QLQ-C30 & N/A & Overall survival & $\begin{array}{l}\text { Median: } 18.77 \\
\text { months }(95 \% \\
\text { CI: } 17.42 \\
19.98)\end{array}$ & $\begin{array}{l}\text { Physical functioning (HR: } \\
0.94 ; 95 \% \text { CI: } 0.92,0.96) \text {, pain } \\
\text { (HR: } 1.04 ; 95 \% \text { CI: } 1.02-1.06 \text { ), } \\
\text { and appetite loss (HR: } 1.05 \text {; } \\
95 \% \text { CI: } 1.03-1.06 \text { ) were } \\
\text { significant prognostic factors } \\
\text { of overall cancer survival. }\end{array}$ \\
\hline 12 & $\begin{array}{l}\text { Sarenmalm } \\
\text { et al., } 2009\end{array}$ & $\begin{array}{l}(n=67) \text { Trial } 12-93, \\
(n=74) \text { Trial } 14-93\end{array}$ & $\begin{array}{l}\text { IBCSG Quality of } \\
\text { Life Core } \\
\text { Questionnaire }\end{array}$ & $\begin{array}{l}\text { Performed } \\
\text { during the trials } \\
\text { at } \\
\text { randomization, } \\
\text { and at } 3,6,9,12 \text {, } \\
\text { and } 18 \text { months, } \\
\text { followed by } \\
\text { annual follow- } \\
\text { ups over 6-years } \\
\text { post- } \\
\text { randomization }\end{array}$ & $\begin{array}{l}\text { Breast cancer } \\
\text { recurrence }\end{array}$ & Not provided & $\begin{array}{l}\text { Nausea/vomiting ( } \beta:-0.006, \mathrm{p}- \\
\text { value: } 0.013) \text { and physical } \\
\text { well-being ( } \beta \text { : } 0.004, \mathrm{p} \text {-value: } \\
\text { 0.047) predict breast cancer } \\
\text { recurrence. }\end{array}$ \\
\hline
\end{tabular}




\begin{tabular}{|c|c|c|c|c|c|c|c|}
\hline \# & Authors & Study Sample & Study Measures & Date(s) Assessed & $\begin{array}{l}\text { Outcome } \\
\text { Measures }\end{array}$ & Survival Time & Findings \\
\hline 13 & $\begin{array}{l}\text { Bredal et } \\
\text { al., } 2011\end{array}$ & $(n=195)$ & $\begin{array}{l}\text { EORTC QLQ-C30; } \\
\text { Hospital Anxiety and } \\
\text { Depression Scale } \\
\text { (HADS) }\end{array}$ & $\begin{array}{l}\text { At time of } \\
\text { diagnosis and 1- } \\
\text { year post- } \\
\text { diagnosis }\end{array}$ & $\begin{array}{l}\text { Disease-free } \\
\text { survival (DFS) }\end{array}$ & $\begin{array}{l}\text { Median: } 2.5 \\
\text { years (range: } \\
0.9-7.4 \text { years) }\end{array}$ & $\begin{array}{l}\text { Appetite loss was significantly } \\
\text { associated with worse survival } \\
\text { (HR: } 2.92,95 \% \text { CI: } 1.50-5.66 \text {, } \\
\text { p-value: } 0.002 \text { ) }\end{array}$ \\
\hline 14 & $\begin{array}{l}\text { Disipio et } \\
\text { al, 2011 }\end{array}$ & $(n=287)$ & $\begin{array}{l}\text { Functional } \\
\text { Assessment of Cancer } \\
\text { Therapy, General } \\
\text { (FACT-G) \& Breast } \\
\text { (FACT-B+4) }\end{array}$ & $\begin{array}{l}\text { HRQOL } \\
\text { assessed at 6-, } \\
12-, \text { and 18- } \\
\text { months post- } \\
\text { diagnosis }\end{array}$ & $\begin{array}{l}\text { Overall survival } \\
\text { (OS), changes } \\
\text { over time }\end{array}$ & $\begin{array}{l}\text { Overall } \\
\text { survival time } \\
\text { not provided. } \\
\text { However, } \\
\text { mean survival } \\
\text { times by } \\
\text { associations } \\
\text { were. }\end{array}$ & $\begin{array}{l}\text { Physical well-being, emotional } \\
\text { well-being, functional well- } \\
\text { being, breast cancer concerns, } \\
\text { FACT-G, and FACT-B+4 } 4 \text { all } \\
\text { showed significant changes } \\
\text { over time ( } 6 \text { to } 12 \text { to } 18 \\
\text { months post-diagnosis). } \\
\text { Women who reported } \\
\text { stable/improving physical } \\
\text { well-being had better survival } \\
\text { than women who reported } \\
\text { declining physical well-being } \\
\text { (HR: } 0.24 ; 95 \% \text { CI: } 0.08-0.70 \text { ). } \\
\text { The same applied to functional } \\
\text { well-being (HR: } 0.35 ; 95 \% \text { CI: } \\
0.14-0.87) \text {. }\end{array}$ \\
\hline
\end{tabular}




\begin{tabular}{|c|c|c|c|c|c|c|c|}
\hline \# & Authors & Study Sample & Study Measures & Date(s) Assessed & $\begin{array}{l}\text { Outcome } \\
\text { Measures }\end{array}$ & Survival Time & Findings \\
\hline 15 & $\begin{array}{l}\text { Epplein et } \\
\text { al., } 2011\end{array}$ & $\begin{array}{l}(\mathrm{n}=2,230) \text { baseline, } \\
(\mathrm{n}=1,845) 36- \\
\text { months post- } \\
\text { diagnosis }\end{array}$ & $\begin{array}{l}\text { General Quality of } \\
\text { Life Inventory- } 74\end{array}$ & $\begin{array}{l}\text { At 6-months and } \\
\text { 36-months post- } \\
\text { diagnosis }\end{array}$ & $\begin{array}{l}\text { All-cause } \\
\text { mortality and } \\
\text { breast cancer } \\
\text { recurrence }\end{array}$ & $\begin{array}{l}\text { From 6-month } \\
\text { survey: } 4.9 \\
\text { years for } \\
\text { women who } \\
\text { lived and } 2.3 \\
\text { years for } \\
\text { women who } \\
\text { died. From } 36- \\
\text { month follow- } \\
\text { up: } 2.4 \text { years } \\
\text { for women } \\
\text { who lived and } \\
1.2 \text { years for } \\
\text { women who } \\
\text { died. }\end{array}$ & $\begin{array}{l}\text { At baseline, a higher } \\
\text { psychological well-being and a } \\
\text { higher social well-being were } \\
\text { associated with better mortality } \\
\text { (HR: } 0.66 ; 95 \% \text { CI: } 0.49-0.88 \text { ) } \\
\text { (HR: } 0.52 ; 95 \% \text { CI } 0.38-0.71 \text { ). } \\
\text { There were no significant } \\
\text { associations at follow-up. }\end{array}$ \\
\hline 16 & $\begin{array}{l}\text { Saquib et } \\
\text { al., } 2011\end{array}$ & $(n=2,967)$ & $\begin{array}{l}\text { Thoughts and } \\
\text { Feelings } \\
\text { Questionnaire } \\
\text { (included the Medical } \\
\text { Outcomes Study } \\
\text { (MOS) Short-Form } \\
\text { Survey (SF-36)) }\end{array}$ & Baseline & $\begin{array}{l}\text { Additional breast } \\
\text { cancer events and } \\
\text { all-cause mortality }\end{array}$ & Not provided & $\begin{array}{l}\text { Higher levels of physical } \\
\text { health predicted lower } \\
\text { additional breast cancer events } \\
\text { (p-trend: } 0.005 \text { ) and lower risk } \\
\text { of all-cause mortality (p-trend: } \\
0.004 \text { ) }\end{array}$ \\
\hline 17 & $\begin{array}{l}\text { De Aguiar } \\
\text { et al., } 2014\end{array}$ & $\begin{array}{l}(n=1,002) \text { beginning } \\
\text { of the follow-up, } \\
(n=766) 4 \text {-year } \\
\text { follow-up, }(\mathrm{n}=549) \\
\text { QOL evaluation }\end{array}$ & $\begin{array}{l}\text { EORTC QLQ-C30 } \\
\text { and the BR23 module }\end{array}$ & $\begin{array}{l}\text { About } 4 \text { years } \\
\text { after surgery }\end{array}$ & Overall survival & $\begin{array}{l}\text { Mean: } 23 \\
\text { months, SD: } \\
3.9 \text { months }\end{array}$ & $\begin{array}{l}\text { Worse future perspective was } \\
\text { associated with a higher } \\
\text { likelihood of death (HR: } 3.46 \text {, } \\
95 \% \text { CI: } 1.36-8.79 \text {, p-value: } \\
0.009 \text { ). }\end{array}$ \\
\hline
\end{tabular}




\begin{tabular}{|c|c|c|c|c|c|c|c|}
\hline \# & Authors & Study Sample & Study Measures & Date(s) Assessed & $\begin{array}{l}\text { Outcome } \\
\text { Measures }\end{array}$ & Survival Time & Findings \\
\hline 18 & $\begin{array}{l}\text { Marinac et } \\
\text { al., } 2014\end{array}$ & $(n=2,892)$ & $\begin{array}{l}\text { 10-item physical } \\
\text { function subscale (PF- } \\
\text { 10) of the Medical } \\
\text { Outcomes Study } \\
\text { (MOS) Short Form-36 } \\
\text { (SF-36) }\end{array}$ & Baseline & $\begin{array}{l}\text { All-cause } \\
\text { mortality and } \\
\text { breast cancer- } \\
\text { specific mortality }\end{array}$ & Not provided & $\begin{array}{l}\text { Compared to adequate and } \\
\text { high physical functioning, } \\
\text { participants with low physical } \\
\text { functioning were more likely } \\
\text { to die by all-causes (HR: } 1.49 \text {, } \\
95 \% \text { CI: } 1.17-1.89 \text { ) and breast } \\
\text { cancer-specific-causes (HR: } \\
1.39,95 \% \text { CI: } 1.07-1.80 \text { ) }\end{array}$ \\
\hline 19 & $\begin{array}{l}\text { DuMontier } \\
\text { et al., } 2018\end{array}$ & $(n=660)$ & $\begin{array}{l}\text { Medical Outcomes } \\
\text { Study (MOS) 36-item } \\
\text { Short-Form Survey } \\
\text { (SF-36) and MOS } \\
\text { Social Support Survey } \\
\text { (mMOS-SSS) }\end{array}$ & $\begin{array}{l}\text { Within the year } \\
\text { post-surgery }\end{array}$ & $\begin{array}{l}\text { All-cause } \\
\text { mortality }\end{array}$ & 10 -years & $\begin{array}{l}\text { In the fully adjusted model, } \\
\text { better levels of mental health } \\
\text { (OR: } 0.56,95 \% \text { CI: } 0.37-0.83 \text { ) } \\
\text { and physical functioning (OR: } \\
0.64,95 \% \text { CI: } 0.44-0.94 \text { ) were } \\
\text { associated with lower } \\
\text { mortality. }\end{array}$ \\
\hline
\end{tabular}


Appendix B. Physical Component Summary Score Univariate HR Analysis and Percent Change for All-Cause Mortality when Assessing for Potential Confounders $(N=351)$

\begin{tabular}{|c|c|c|c|c|c|c|c|c|c|}
\hline Model & Variable(s) in model & Categories & $\begin{array}{l}\text { Total in } \\
\text { categories } \\
\text { (n) }\end{array}$ & $\begin{array}{l}\text { Total } \\
\text { in } \\
\text { model } \\
\text { (n); } \\
\text { dead } \\
\text { (d) } \\
\end{array}$ & Missing & Univariate-Cox HR (95\% CI) & p-values* & $\begin{array}{l}\text { PCS HR }(95 \% \mathrm{CI}) \text { and } \mathrm{p}- \\
\text { values }\end{array}$ & $\begin{array}{l}\% \text { change } \\
\text { from crude } \\
\text { model }\end{array}$ \\
\hline Crude & $\begin{array}{l}\text { Physical Component } \\
\text { Summary Score (PCS) }\end{array}$ & $\begin{array}{l}0: \leq 44.75 \\
1:>44.75 \& \leq 54.39 \\
2:>54.39(\mathrm{REF})\end{array}$ & $\begin{array}{l}0: 117 \\
1: 117 \\
2: 117\end{array}$ & $\begin{array}{l}\mathrm{n}=351 \\
\mathrm{~d}=99\end{array}$ & 0 & $\begin{array}{l}0: H R=3.80(2.20-6.54) \\
1: H R=1.67(0.91-3.07)\end{array}$ & $\mathrm{p}=<0.0001$ & $\begin{array}{l}0: \mathrm{HR}=3.80(2.20-6.54) \\
\mathrm{p}(\mathrm{PCS})=<0.0001 \\
1: \mathrm{HR}=1.67(0.91-3.07) \\
\mathrm{p}(\mathrm{PCS})=0.0963\end{array}$ & -- \\
\hline 1 & Age & Continuous & -- & $\begin{array}{l}\mathrm{n}=351 \\
\mathrm{~d}=99\end{array}$ & 0 & $\mathrm{HR}=1.06(1.04-1.08)$ & $\mathrm{p}=<0.0001$ & $\begin{array}{l}0: \mathrm{HR}=2.37(1.34-4.19) \\
\mathrm{p}(\mathrm{PCS})=0.0030 \\
1: \mathrm{HR}=1.29(0.69-2.39) \\
\mathrm{p}(\mathrm{PCS})=0.4138 \\
\mathrm{p}(\mathrm{Age})=<0.0001\end{array}$ & $\begin{array}{l}0: 37.63 \% \\
1: 29.46 \%\end{array}$ \\
\hline 2 & Race/Ethnicity & $\begin{array}{l}\text { 0: Non-Hispanic } \\
\text { White (REF) } \\
\text { Hispanic }\end{array}$ & $\begin{array}{l}0: 273 \\
1: 78\end{array}$ & $\begin{array}{l}\mathrm{n}=351 \\
\mathrm{~d}=99\end{array}$ & 0 & $\begin{array}{l}0: H R=1.00 \\
1: H R=0.66(0.38-1.12)\end{array}$ & $p=0.1231$ & $\begin{array}{l}0: \mathrm{HR}=3.80(2.21-6.56) \\
\mathrm{p}(\mathrm{PCS})=<0.0001 \\
1: \mathrm{HR}=1.68(0.92-3.08) \\
\mathrm{p}(\mathrm{PCS})=0.0944 \\
\mathrm{p}(\text { Ethnicity })=0.1231\end{array}$ & $\begin{array}{l}0: 0.00 \% \\
1: 0.60 \%\end{array}$ \\
\hline 3 & Marital Status & $\begin{array}{l}\text { 0: Single } \\
\text { 1: Married (REF) }\end{array}$ & $\begin{array}{l}0: 160 \\
1: 191\end{array}$ & $\begin{array}{l}\mathrm{n}=351 \\
\mathrm{~d}=99\end{array}$ & 0 & $\begin{array}{l}0: H R=1.75(1.17-2.64) \\
1: H R=1.00\end{array}$ & $p=0.0067$ & $\begin{array}{l}0: \mathrm{HR}=3.52(2.04-6.09) \\
\mathrm{p}(\mathrm{PCS})=<0.0001 \\
1: \mathrm{HR}=1.66(0.91-3.05) \\
\mathrm{p}(\mathrm{PCS})=0.1003 \\
\mathrm{p}(\text { Marital })=0.0067\end{array}$ & $\begin{array}{l}0: 7.37 \% \\
1: 0.60 \%\end{array}$ \\
\hline
\end{tabular}




\begin{tabular}{|c|c|c|c|c|c|c|c|c|c|}
\hline Model & Variable(s) in model & Categories & $\begin{array}{l}\text { Total in } \\
\text { categories } \\
\text { (n) }\end{array}$ & $\begin{array}{l}\text { Total } \\
\text { in } \\
\text { model } \\
\text { (n); } \\
\text { dead } \\
\text { (d) } \\
\end{array}$ & Missing & Univariate-Cox HR (95\% CI) & p-values* & $\begin{array}{l}\text { PCS HR }(95 \% \mathrm{CI}) \text { and } \mathrm{p}- \\
\text { values }\end{array}$ & $\begin{array}{l}\% \text { change } \\
\text { from crude } \\
\text { model }\end{array}$ \\
\hline 4 & Tumor Stage & $\begin{array}{l}\text { 0: Localized (I) } \\
\text { 1: Regional (II-IIIa) }\end{array}$ & $\begin{array}{l}0: 276 \\
1: 75\end{array}$ & $\begin{array}{l}\mathrm{n}=351 \\
\mathrm{~d}=99\end{array}$ & 0 & $\begin{array}{l}0: \mathrm{HR}=1.00 \\
1: \mathrm{HR}=1.25(0.79-1.98)\end{array}$ & $\mathrm{p}=0.3405$ & $\begin{array}{l}0: \mathrm{HR}=3.84(2.23-6.63) \\
\mathrm{p}(\mathrm{PCS})=<0.0001 \\
1: \mathrm{HR}=1.69(0.92-3.10) \\
\mathrm{p}(\mathrm{PCS})=0.0904 \\
\mathrm{p}(\mathrm{Stage})=0.3405\end{array}$ & $\begin{array}{l}0: 1.05 \% \\
1: 1.20 \%\end{array}$ \\
\hline 5 & $\begin{array}{l}\text { Breast Cancer Treatment } \\
\text { Type }\end{array}$ & $\begin{array}{l}0: \text { Surgery only (REF) } \\
\text { 1: Any chemotherapy } \\
\text { 2: Surgery and } \\
\text { radiation }\end{array}$ & $\begin{array}{l}0: 98 \\
1: 109 \\
2: 144\end{array}$ & $\begin{array}{l}\mathrm{n}=351 \\
\mathrm{~d}=99\end{array}$ & 0 & $\begin{array}{l}0: H R=1.00 \\
1: H R=0.80(0.48-1.32) \\
2: H R=0.73(0.46-1.16)\end{array}$ & $\mathrm{p}=0.3937$ & $\begin{array}{l}0: \mathrm{HR}=3.73(2.16-6.44) \\
\mathrm{p}(\mathrm{PCS})=<0.0001 \\
1: \mathrm{HR}=1.66(0.90-3.04) \\
\mathrm{p}(\mathrm{PCS})=0.1023 \\
\mathrm{p}(\text { Treatment } 1)=0.3827 \\
\mathrm{p}(\text { Treatment } 2)=0.1795\end{array}$ & $\begin{array}{l}0: 1.84 \% \\
1: 0.60 \%\end{array}$ \\
\hline 6 & Comorbidities & $\begin{array}{l}0: \text { Zero (REF) } \\
1: \text { One or more }\end{array}$ & $\begin{array}{l}0: 298 \\
1: 53\end{array}$ & $\begin{array}{l}\mathrm{n}=351 \\
\mathrm{~d}=99\end{array}$ & 0 & $\begin{array}{l}0: \mathrm{HR}=1.00 \\
1: \mathrm{HR}=1.52(0.94-2.45)\end{array}$ & $p=0.0864$ & $\begin{array}{l}0: \mathrm{HR}=3.50(2.01-6.09) \\
\mathrm{p}(\mathrm{PCS})=<0.0001 \\
1: \mathrm{HR}=1.61(0.87-2.96) \\
\mathrm{p}(\mathrm{PCS})=0.1266 \\
\mathrm{p}(\text { Comorbidities })=0.0864\end{array}$ & $\begin{array}{l}0: 7.89 \% \\
1: 3.59 \%\end{array}$ \\
\hline 7 & Current Lymphedema & $\begin{array}{l}0: \text { No (REF) } \\
\text { 1: Yes }\end{array}$ & $\begin{array}{l}0: 307 \\
1: 44\end{array}$ & $\begin{array}{l}\mathrm{n}=351 \\
\mathrm{~d}=99\end{array}$ & 0 & $\begin{array}{l}0: \mathrm{HR}=1.00 \\
1: \mathrm{HR}=0.55(0.28-1.09)\end{array}$ & $\mathrm{p}=\mathbf{0 . 0 5 2 4}$ & $\begin{array}{l}0: \mathrm{HR}=4.08(2.36-7.05) \\
\mathrm{p}(\mathrm{PCS})=<0.0001 \\
1: \mathrm{HR}=1.74(0.95-3.20) \\
\mathrm{p}(\mathrm{PCS})=0.0731 \\
\mathrm{p}(\text { Lymphedema })=0.0524\end{array}$ & $\begin{array}{l}0: 7.37 \% \\
1: 4.19 \%\end{array}$ \\
\hline
\end{tabular}




\begin{tabular}{|c|c|c|c|c|c|c|c|c|c|}
\hline Model & Variable(s) in model & Categories & $\begin{array}{l}\text { Total in } \\
\text { categories } \\
\text { (n) }\end{array}$ & $\begin{array}{l}\text { Total } \\
\text { in } \\
\text { model } \\
\text { (n); } \\
\text { dead } \\
\text { (d) } \\
\end{array}$ & Missing & Univariate-Cox HR (95\% CI) & p-values* & $\begin{array}{l}\text { PCS HR }(95 \% \mathrm{CI}) \text { and } \mathrm{p}- \\
\text { values }\end{array}$ & $\begin{array}{l}\% \text { change } \\
\text { from crude } \\
\text { model }\end{array}$ \\
\hline 8 & Perceived Optimism & $\begin{array}{l}0: \leq 10 \\
1:>10(\mathrm{REF})\end{array}$ & $\begin{array}{l}0: 83 \\
1: 268\end{array}$ & $\begin{array}{l}n=351 \\
d=99\end{array}$ & 0 & $\begin{array}{l}0: \mathrm{HR}=1.25(0.81-1.93) \\
1: \mathrm{HR}=1.00\end{array}$ & $\mathrm{p}=0.3160$ & $\begin{array}{l}0: \mathrm{HR}=3.61(2.07-6.28) \\
\mathrm{p}(\mathrm{PCS})=<0.0001 \\
1: \mathrm{HR}=1.64(0.90-3.02) \\
\mathrm{p}(\mathrm{PCS})=0.1093 \\
\mathrm{p}(\text { Optimism })=0.3160\end{array}$ & $\begin{array}{l}0: 5.00 \% \\
1: 1.80 \%\end{array}$ \\
\hline 9 & Perceived Pessimism & $\begin{array}{l}0: \leq 10(\mathrm{REF}) \\
1:>10\end{array}$ & $\begin{array}{l}0: 255 \\
1: 96\end{array}$ & $\begin{array}{l}\mathrm{n}=351 \\
\mathrm{~d}=99\end{array}$ & 0 & $\begin{array}{l}0: \mathrm{HR}=1.00 \\
1: \mathrm{HR}=1.42(0.93-2.15)\end{array}$ & $p=0.1009$ & $\begin{array}{l}0: \mathrm{HR}=3.54(2.04-6.14) \\
\mathrm{p}(\mathrm{PCS})=<0.0001 \\
1: \mathrm{HR}=1.64(0.89-3.01) \\
\mathrm{p}(\mathrm{PCS})=0.1114 \\
\mathrm{p}(\mathrm{Pessimism})=0.1009\end{array}$ & $\begin{array}{l}0: 6.84 \% \\
1: 1.80 \%\end{array}$ \\
\hline 10 & $\begin{array}{l}\text { Number of Types of } \\
\text { Confidants }\end{array}$ & $\begin{array}{l}0:<3 \\
1: 4-5 \\
2:>5(\mathrm{REF})\end{array}$ & $\begin{array}{l}0: 66 \\
1: 172 \\
2: 113\end{array}$ & $\begin{array}{l}n=351 \\
d=99\end{array}$ & 0 & $\begin{array}{l}0: \mathrm{HR}=1.78(1.02-3.08) \\
1: \mathrm{HR}=1.28(0.79-2.06) \\
2: \mathrm{HR}=1.00\end{array}$ & $p=0.1226$ & $\begin{array}{l}0: \mathrm{HR}=3.84(2.23-6.62) \\
\mathrm{p}(\mathrm{PCS})=<0.0001 \\
1: \mathrm{HR}=1.73(0.94-3.18) \\
\mathrm{p}(\mathrm{PCS})=0.0761 \\
\mathrm{p}(\text { Confidant } 0)=0.0412 \\
\mathrm{p}(\text { Confidant } 1)=0.3118\end{array}$ & $\begin{array}{l}0: 1.05 \% \\
1: 3.59 \%\end{array}$ \\
\hline 11 & Fear of Recurrence & $\begin{array}{l}0: \text { No (REF) } \\
1: \text { Yes }\end{array}$ & $\begin{array}{l}0: 154 \\
1: 197\end{array}$ & $\begin{array}{l}\mathrm{n}=351 \\
\mathrm{~d}=99\end{array}$ & 0 & $\begin{array}{l}0: \mathrm{HR}=1.00 \\
1: \mathrm{HR}=0.69(0.47-1.03)\end{array}$ & $p=0.0674$ & $\begin{array}{l}0: \mathrm{HR}=3.78(2.19-6.52) \\
\mathrm{p}(\mathrm{PCS})=<0.0001 \\
1: \mathrm{HR}=1.68(0.92-3.09) \\
\mathrm{p}(\mathrm{PCS})=0.0935 \\
\mathrm{p}(\mathrm{Fear})=0.0674\end{array}$ & $\begin{array}{l}0: 0.53 \% \\
1: 0.60 \%\end{array}$ \\
\hline
\end{tabular}




\begin{tabular}{|c|c|c|c|c|c|c|c|c|c|}
\hline Model & Variable(s) in model & Categories & $\begin{array}{l}\text { Total in } \\
\text { categories } \\
\text { (n) }\end{array}$ & $\begin{array}{l}\text { Total } \\
\text { in } \\
\text { model } \\
\text { (n); } \\
\text { dead } \\
\text { (d) } \\
\end{array}$ & Missing & Univariate-Cox HR (95\% CI) & p-values* & $\begin{array}{l}\text { PCS HR }(95 \% \mathrm{CI}) \text { and } \mathrm{p}- \\
\text { values }\end{array}$ & $\begin{array}{l}\% \text { change } \\
\text { from crude } \\
\text { model }\end{array}$ \\
\hline Crude & $\begin{array}{l}\text { PCS (restricted to those } \\
\text { with education) }\end{array}$ & & $\begin{array}{l}0: 116 \\
1: 117 \\
2: 117\end{array}$ & $\begin{array}{l}\mathrm{n}=350 \\
\mathrm{~d}=98\end{array}$ & & $\begin{array}{l}0: \mathrm{HR}=3.74(2.17-6.45) \\
1: \mathrm{HR}=1.67(0.91-3.07)\end{array}$ & $\mathrm{p}=<0.0001$ & $\begin{array}{l}0: \mathrm{HR}=3.74(2.17-6.45) \\
\mathrm{p}(\mathrm{PCS})=<0.0001 \\
1: \mathrm{HR}=1.67(0.91-3.07) \\
\mathrm{p}(\mathrm{PCS})=0.0963\end{array}$ & -- \\
\hline 12 & Education & $\begin{array}{l}\text { 0: High school or less } \\
\text { 1: Some college } \\
\text { 2: College graduate } \\
\text { 3: Graduate school } \\
\text { (REF) }\end{array}$ & $\begin{array}{l}0: 92 \\
1: 114 \\
2: 70 \\
3: 74\end{array}$ & $\begin{array}{l}\mathrm{n}=350 \\
\mathrm{~d}=98\end{array}$ & 1 & $\begin{array}{l}0: \mathrm{HR}=1.65(0.90-3.02) \\
1: \mathrm{HR}=1.28(0.71-2.32) \\
2: \mathrm{HR}=0.92(0.44-1.91) \\
3: \mathrm{HR}=1.00\end{array}$ & $\mathrm{p}=\mathbf{0 . 2 3 5 2}$ & $\begin{array}{l}0: \mathrm{HR}=3.43(1.97-5.98) \\
\mathrm{p}(\mathrm{PCS})=<0.0001 \\
1: \mathrm{HR}=1.55(0.84-2.86) \\
\mathrm{p}(\mathrm{PCS})=0.1587 \\
\mathrm{p}(\text { Education} 0)=0.1087 \\
\mathrm{p}(\text { Education } 1)=0.4054 \\
\mathrm{p}(\text { Education } 2)=0.8174\end{array}$ & $\begin{array}{l}0: 8.29 \% \\
1: 7.19 \%\end{array}$ \\
\hline Crude & $\begin{array}{l}\text { PCS (restricted to those } \\
\text { with tumor size) }\end{array}$ & & $\begin{array}{l}0: 116 \\
1: 114 \\
2: 111\end{array}$ & $\begin{array}{l}\mathrm{n}=341 \\
\mathrm{~d}=99\end{array}$ & & $\begin{array}{l}0: \mathrm{HR}=3.66(2.12-6.30) \\
1: \mathrm{HR}=1.65(0.90-3.02)\end{array}$ & $\mathrm{p}=<0.0001$ & $\begin{array}{l}0: \mathrm{HR}=3.66(2.12-6.30) \\
\mathrm{p}(\mathrm{PCS})=<0.0001 \\
1: \mathrm{HR}=1.65(0.90-3.02) \\
\mathrm{p}(\mathrm{PCS})=0.1069\end{array}$ & -- \\
\hline 13 & Tumor Size & $\begin{array}{l}0:<3 \mathrm{~cm}(\mathrm{REF}) \\
1: \geq 3 \mathrm{~cm}\end{array}$ & $\begin{array}{l}0: 304 \\
1: 37\end{array}$ & $\begin{array}{l}n=341 \\
d=99\end{array}$ & 10 & $\begin{array}{l}0: \mathrm{HR}=1.00 \\
1: \mathrm{HR}=1.25(0.68-2.29)\end{array}$ & $\mathrm{p}=0.4712$ & $\begin{array}{l}0: \mathrm{HR}=3.66(2.12-6.30) \\
\mathrm{p}(\mathrm{PCS})=<0.0001 \\
1: \mathrm{HR}=1.63(0.89-3.00) \\
\mathrm{p}(\mathrm{PCS})=0.1142 \\
\mathrm{p}(\mathrm{Size})=0.4712\end{array}$ & $\begin{array}{l}0: 0.00 \% \\
1: 1.21 \%\end{array}$ \\
\hline
\end{tabular}




\begin{tabular}{|c|c|c|c|c|c|c|c|c|c|}
\hline Model & Variable(s) in model & Categories & $\begin{array}{l}\text { Total in } \\
\text { categories } \\
\text { (n) }\end{array}$ & $\begin{array}{l}\text { Total } \\
\text { in } \\
\text { model } \\
\text { (n); } \\
\text { dead } \\
\text { (d) } \\
\end{array}$ & Missing & Univariate-Cox HR $(95 \%$ CI) & p-values* & $\begin{array}{l}\text { PCS HR }(95 \% \mathrm{CI}) \text { and } \mathrm{p} \text { - } \\
\text { values }\end{array}$ & $\begin{array}{l}\% \text { change } \\
\text { from crude } \\
\text { model }\end{array}$ \\
\hline Crude & $\begin{array}{l}\text { PCS (restricted to those } \\
\text { with lymph node } \\
\text { involvement) }\end{array}$ & & $\begin{array}{l}0: 113 \\
1: 112 \\
2: 116\end{array}$ & $\begin{array}{l}\mathrm{n}=341 \\
\mathrm{~d}=92\end{array}$ & & $\begin{array}{l}0: \mathrm{HR}=3.96(2.26-6.94) \\
\text { 1: } \mathrm{HR}=1.63(0.87-3.07)\end{array}$ & $\mathrm{p}=<0.0001$ & $\begin{array}{l}0: \mathrm{HR}=3.96(2.26-6.94) \\
\mathrm{p}(\mathrm{PCS})=<0.0001 \\
1: \mathrm{HR}=1.63(0.87-3.07) \\
\mathrm{p}(\mathrm{PCS})=0.1308\end{array}$ & -- \\
\hline 14 & $\begin{array}{l}\text { Lymph Node } \\
\text { Involvement }\end{array}$ & $\begin{array}{l}0: \text { None }(\mathrm{REF}) \\
1: \geq 1 \text { lymph node } \\
\text { involved }\end{array}$ & $\begin{array}{l}0: 264 \\
1: 77\end{array}$ & $\begin{array}{l}n=341 \\
d=92\end{array}$ & 10 & $\begin{array}{l}0: \mathrm{HR}=1.00 \\
\text { 1: } \mathrm{HR}=1.32(0.83-2.10)\end{array}$ & $\mathrm{p}=0.2435$ & $\begin{array}{l}\text { 0: } \mathrm{HR}=4.02(2.29-7.05) \\
\mathrm{p}(\mathrm{PCS})=<0.0001 \\
\text { 1: } \mathrm{HR}=1.64(0.87-3.10) \\
\mathrm{p}(\mathrm{PCS})=0.1239 \\
\mathrm{p}(\mathrm{Lymph} \text { node })=0.6706\end{array}$ & $\begin{array}{l}0: 1.52 \% \\
1: 0.61 \%\end{array}$ \\
\hline Crude & $\begin{array}{l}\text { PCS (restricted to those } \\
\text { with Tamoxifen use, } \\
\text { smoking status, and } \\
\text { physical activity) }\end{array}$ & & $\begin{array}{l}0: 107 \\
1: 110 \\
2: 113\end{array}$ & $\begin{array}{l}n=330 \\
d=91\end{array}$ & & $\begin{array}{l}0: \mathrm{HR}=3.55(2.04-6.17) \\
1: \mathrm{HR}=1.56(0.84-2.90)\end{array}$ & $\mathrm{p}=<0.0001$ & $\begin{array}{l}0: \mathrm{HR}=3.55(2.04-6.17) \\
\mathrm{p}(\mathrm{PCS})=<0.0001 \\
\text { 1: HR }=1.56(0.84-2.90) \\
\mathrm{p}(\mathrm{PCS})=0.1556\end{array}$ & -- \\
\hline 15 & Tamoxifen Use & $\begin{array}{l}\text { 0: No } \\
1 \text { : Yes (REF) }\end{array}$ & $\begin{array}{l}0: 160 \\
1: 170\end{array}$ & $\begin{array}{l}n=330 \\
d=91\end{array}$ & 21 & $\begin{array}{l}0: \mathrm{HR}=1.18(0.78-1.79) \\
1: \mathrm{HR}=1.00\end{array}$ & $\mathrm{p}=0.4226$ & $\begin{array}{l}0: \mathrm{HR}=3.56(2.05-6.19) \\
\mathrm{p}(\mathrm{PCS})=<0.0001 \\
1: \mathrm{HR}=1.55(0.84-2.87) \\
\text { p(PCS)=0.1659 } \\
\text { p(Tamoxifen) }=0.4226\end{array}$ & $\begin{array}{l}0: 0.28 \% \\
1: 0.64 \%\end{array}$ \\
\hline
\end{tabular}




\begin{tabular}{|c|c|c|c|c|c|c|c|c|c|}
\hline Model & Variable(s) in model & Categories & $\begin{array}{l}\text { Total in } \\
\text { categories } \\
\text { (n) }\end{array}$ & $\begin{array}{l}\text { Total } \\
\text { in } \\
\text { model } \\
\text { (n); } \\
\text { dead } \\
\text { (d) } \\
\end{array}$ & Missing & Univariate-Cox HR $(95 \%$ CI) & p-values* & $\begin{array}{l}\text { PCS HR }(95 \% \mathrm{Cl}) \text { and } \mathrm{p} \text { - } \\
\text { values }\end{array}$ & $\begin{array}{l}\% \text { change } \\
\text { from crude } \\
\text { model }\end{array}$ \\
\hline 16 & Smoking Status & $\begin{array}{l}0: \text { Never (REF) } \\
\text { 1: Former } \\
\text { 2: Current }\end{array}$ & $\begin{array}{l}0: 145 \\
1: 144 \\
2: 41\end{array}$ & $\begin{array}{l}n=330 \\
d=91\end{array}$ & 21 & $\begin{array}{l}0: \mathrm{HR}=1.00 \\
1: \mathrm{HR}=1.02(0.66-1.60) \\
2: \mathrm{HR}=1.25(0.66-2.34)\end{array}$ & $\mathrm{p}=0.7825$ & $\begin{array}{l}\text { 0: HR=3.51 (2.02-6.11) } \\
\text { p(PCS)=<0.0001 } \\
\text { 1: HR }=1.55(0.83-2.87) \\
\text { p(PCS)=0.1671 } \\
\text { p(Smoker1) })=0.9169 \\
\text { p(Smoker2) }=0.4933\end{array}$ & $\begin{array}{l}0: 1.13 \% \\
1: 0.64 \%\end{array}$ \\
\hline 17 & Physical Activity & $\begin{array}{l}\text { 0: None } \\
\text { 1: Low } \\
\text { 2: Moderate/Vigorous } \\
\text { (REF) }\end{array}$ & $\begin{array}{l}0: 185 \\
1: 59 \\
2: 86\end{array}$ & $\begin{array}{l}n=330 \\
d=91\end{array}$ & 21 & $\begin{array}{l}0: \mathrm{HR}=1.48(0.86-2.56) \\
1: \mathrm{HR}=0.80(0.38-1.68) \\
2: \mathrm{HR}=1.00\end{array}$ & $\mathrm{p}=0.0842$ & $\begin{array}{l}0: \mathrm{HR}=3.35(1.90-5.88) \\
\text { p(PCS) }=<0.0001 \\
\text { 1: } \mathrm{HR}=1.49(0.80-2.77) \\
\text { p(PS) }=0.2065 \\
\text { p(PA0)=0.1621 } \\
\text { p(PA1) }=0.5513\end{array}$ & $\begin{array}{l}0: 5.63 \% \\
1: 4.49 \%\end{array}$ \\
\hline Crude & $\begin{array}{l}\text { PCS (restricted to those } \\
\text { with BMI) }\end{array}$ & & $\begin{array}{l}0: 106 \\
1: 110 \\
2: 108\end{array}$ & $\begin{array}{l}n=324 \\
d=85\end{array}$ & & $\begin{array}{l}0: \mathrm{HR}=3.48(1.94-6.24) \\
1: \mathrm{HR}=1.71(0.90-3.24)\end{array}$ & $\mathrm{p}=<0.0001$ & $\begin{array}{l}0: \mathrm{HR}=3.48(1.94-6.24) \\
\mathrm{p}(\mathrm{PCS})=<0.0001 \\
1: \mathrm{HR}=1.71(0.90-3.24) \\
\mathrm{p}(\mathrm{PCS})=0.1011\end{array}$ & -- \\
\hline
\end{tabular}




\begin{tabular}{|c|c|c|c|c|c|c|c|c|c|}
\hline Model & Variable(s) in model & Categories & $\begin{array}{l}\text { Total in } \\
\text { categories } \\
\text { (n) }\end{array}$ & $\begin{array}{l}\text { Total } \\
\text { in } \\
\text { model } \\
\text { (n); } \\
\text { dead } \\
\text { (d) } \\
\end{array}$ & Missing & Univariate-Cox HR $(95 \% \mathrm{CI})$ & p-values* & $\begin{array}{l}\text { PCS HR }(95 \% \mathrm{CI}) \text { and } \mathrm{p}- \\
\text { values }\end{array}$ & $\begin{array}{l}\% \text { change } \\
\text { from crude } \\
\text { model }\end{array}$ \\
\hline 18 & Body Mass Index (BMI) & $\begin{array}{l}0:<25 \text { (REF) } \\
1: 25-29 \\
2: \geq 30\end{array}$ & $\begin{array}{l}0: 161 \\
1: 99 \\
2: 64\end{array}$ & $\begin{array}{l}\mathrm{n}=324 \\
\mathrm{~d}=85\end{array}$ & 27 & $\begin{array}{l}0: H R=1.00 \\
1: H R=0.80(0.48-1.34) \\
2: H R=1.15(0.68-1.95)\end{array}$ & $\mathrm{p}=0.4604$ & $\begin{array}{l}0: \mathrm{HR}=3.43(1.89-6.23) \\
\mathrm{p}(\mathrm{PCS})=<0.0001 \\
\text { 1: HR=1.71 (0.90-3.25) } \\
\text { p(PCS)=0.1028 } \\
\text { p(BMI) }=0.3879 \\
\mathrm{p}(\mathrm{BM} 2)=0.6073\end{array}$ & $\begin{array}{l}0: 1.44 \% \\
1: 0.00 \%\end{array}$ \\
\hline Crude & $\begin{array}{l}\text { PCS (restricted to those } \\
\text { tumor subtype) }\end{array}$ & & $\begin{array}{l}0: 102 \\
1: 101 \\
2: 97\end{array}$ & $\begin{array}{l}n=300 \\
d=87\end{array}$ & & $\begin{array}{l}0: H R=3.37(1.88-6.04) \\
1: H R=1.79(0.95-3.38)\end{array}$ & $\mathrm{p}=<\mathbf{0 . 0 0 0 1}$ & $\begin{array}{l}0: \mathrm{HR}=3.37(1.88-6.04) \\
\mathrm{p}(\mathrm{PCS})=<0.0001 \\
1: \mathrm{HR}=1.79(0.95-3.38) \\
\mathrm{p}(\mathrm{PCS})=0.0733\end{array}$ & -- \\
\hline 19 & Tumor Subtype & $\begin{array}{l}0: \mathrm{ER}+(\mathrm{REF}) \\
\text { 1: ER- }\end{array}$ & $\begin{array}{l}0: 251 \\
1: 49\end{array}$ & $\begin{array}{l}n=300 \\
d=87\end{array}$ & 51 & $\begin{array}{l}0: H R=1.00 \\
1: H R=1.29(0.75-2.23)\end{array}$ & $\mathrm{p}=0.3553$ & $\begin{array}{l}0: \mathrm{HR}=3.43(1.91-6.15) \\
\mathrm{p}(\mathrm{PCS})=<0.0001 \\
1: \mathrm{HR}=1.78(0.94-3.37) \\
\mathrm{p}(\mathrm{PCS})=0.0745 \\
\mathrm{p}(\mathrm{Subtype})=0.3553\end{array}$ & $\begin{array}{l}0: 1.78 \% \\
1: 0.56 \%\end{array}$ \\
\hline
\end{tabular}


Appendix C. Percent Change from Crude Model and Model 1 with Each Potential Confounder (PCS \& All-Cause Mortality) $(N=351)$

\begin{tabular}{|c|c|c|c|c|c|c|}
\hline Model & Variable(s) in model & $\begin{array}{l}\text { Physical Component Summary } \\
\text { Score (PCS) HR ( } 95 \% \text { CI) }\end{array}$ & $\begin{array}{l}\text { Difference in } \\
\text { ' } \mathrm{N}^{\prime}\end{array}$ & $\begin{array}{l}\text { Total in model (n) } \\
\text { and total dead (d) }\end{array}$ & $\begin{array}{l}\% \text { change from } \\
\text { Crude }\end{array}$ & $\begin{array}{l}\% \text { change from } \\
\text { model } 1\end{array}$ \\
\hline \multicolumn{7}{|c|}{ Dataset restricted to those diagnosed with invasive breast cancer who have HRQOL and baseline covariates data } \\
\hline Crude & Physical Component Summary Score (PCS) & $\begin{array}{l}0: \mathrm{HR}=3.80(2.20-6.54) \\
1: \mathrm{HR}=1.67(0.91-3.07) \\
2: \mathrm{HR}=1.00(\mathrm{REF}) \\
\mathrm{p}=<0.0001\end{array}$ & 0 & $\begin{array}{l}\mathrm{n}=351 \\
\mathrm{~d}=99\end{array}$ & -- & -- \\
\hline 1 & Age, Marital Status, \& Tumor Stage & $\begin{array}{l}0: \mathrm{HR}=2.32(1.30-4.11) \\
1: \mathrm{HR}=1.34(0.72-2.47) \\
2: \mathrm{HR}=1.00(\mathrm{REF}) \\
\mathrm{p}=0.0052\end{array}$ & 0 & $\begin{array}{l}\mathrm{n}=351 \\
\mathrm{~d}=99\end{array}$ & $\begin{array}{l}0: 38.95 \% \\
1: 19.76 \%\end{array}$ & -- \\
\hline 2 & Model $1+$ Race/Ethnicity & $\begin{array}{l}0: \mathrm{HR}=2.34(1.32-4.15) \\
1: \mathrm{HR}=1.34(0.72-2.48) \\
2: \mathrm{HR}=1.00(\mathrm{REF}) \\
\mathrm{p}=0.0048\end{array}$ & 0 & $\begin{array}{l}\mathrm{n}=351 \\
\mathrm{~d}=99\end{array}$ & $\begin{array}{l}0: 38.42 \% \\
1: 19.76 \%\end{array}$ & $\begin{array}{l}0: 0.86 \% \\
1: 0.00 \%\end{array}$ \\
\hline 3 & Model $1+$ Treatment Type & $\begin{array}{l}0: \mathrm{HR}=2.25(1.27-3.98) \\
1: \mathrm{HR}=1.29(0.69-2.40) \\
2: \mathrm{HR}=1.00(\mathrm{REF}) \\
\mathrm{p}=0.0065\end{array}$ & 0 & $\begin{array}{l}\mathrm{n}=351 \\
\mathrm{~d}=99\end{array}$ & $\begin{array}{l}0: 40.79 \% \\
1: 22.75 \%\end{array}$ & $\begin{array}{l}0: 3.02 \% \\
1: 3.73 \%\end{array}$ \\
\hline
\end{tabular}




\begin{tabular}{|c|c|c|c|c|c|c|}
\hline Model & Variable(s) in model & $\begin{array}{l}\text { Physical Component Summary } \\
\text { Score (PCS) HR }(95 \% \text { CI })\end{array}$ & $\begin{array}{l}\text { Difference in } \\
\text { ' }{ }^{\prime}\end{array}$ & $\begin{array}{l}\text { Total in model (n) } \\
\text { and total dead (d) }\end{array}$ & $\begin{array}{l}\% \text { change from } \\
\text { Crude }\end{array}$ & $\begin{array}{l}\% \text { change from } \\
\text { model } 1\end{array}$ \\
\hline 4 & Model $1+$ Comorbidities & $\begin{array}{l}0: \mathrm{HR}=2.21(1.24-3.95) \\
1: \mathrm{HR}=1.31(0.71-2.43) \\
2: \mathrm{HR}=1.00(\mathrm{REF}) \\
\mathrm{p}=0.0109\end{array}$ & 0 & $\begin{array}{l}\mathrm{n}=351 \\
\mathrm{~d}=99\end{array}$ & $\begin{array}{l}0: 41.84 \% \\
1: 21.56 \%\end{array}$ & $\begin{array}{l}0: 4.74 \% \\
1: 2.24 \%\end{array}$ \\
\hline 5 & Model 1 + Current Lymphedema & $\begin{array}{l}0: \mathrm{HR}=2.45(1.37-4.37) \\
1: \mathrm{HR}=1.37(0.74-2.55) \\
2: \mathrm{HR}=1.00 \text { (REF) } \\
\mathrm{p}=0.0033\end{array}$ & 0 & $\begin{array}{l}\mathrm{n}=351 \\
\mathrm{~d}=99\end{array}$ & $\begin{array}{l}0: 35.53 \% \\
1: 17.76 \%\end{array}$ & $\begin{array}{l}0: 5.60 \% \\
1: 2.24 \%\end{array}$ \\
\hline 6 & Model $1+$ Optimism & $\begin{array}{l}0: \mathrm{HR}=2.23(1.25-3.97) \\
1: \mathrm{HR}=1.32(0.71-2.44) \\
2: \mathrm{HR}=1.00(\mathrm{REF}) \\
\mathrm{p}=0.0099\end{array}$ & 0 & $\begin{array}{l}\mathrm{n}=351 \\
\mathrm{~d}=99\end{array}$ & $\begin{array}{l}0: 41.32 \% \\
1: 20.96 \%\end{array}$ & $\begin{array}{l}0: 3.88 \% \\
1: 1.49 \%\end{array}$ \\
\hline 7 & Model $1+$ Pessimism & $\begin{array}{l}0: \mathrm{HR}=2.17(1.23-3.83) \\
1: \mathrm{HR}=1.36(0.74-2.51) \\
2: \mathrm{HR}=1.00(\mathrm{REF}) \\
\mathrm{p}=0.0156\end{array}$ & 0 & $\begin{array}{l}\mathrm{n}=351 \\
\mathrm{~d}=99\end{array}$ & $\begin{array}{l}0: 42.89 \% \\
1: 18.56 \%\end{array}$ & $\begin{array}{l}0: 6.47 \% \\
1: 1.49 \%\end{array}$ \\
\hline 8 & Model $1+$ Number of Types of Confidants & $\begin{array}{l}0: \mathrm{HR}=2.34(1.32-4.15) \\
1: \mathrm{HR}=1.36(0.73-2.51) \\
2: \mathrm{HR}=1.00(\mathrm{REF}) \\
\mathrm{p}=0.0051\end{array}$ & 0 & $\begin{array}{l}\mathrm{n}=351 \\
\mathrm{~d}=99\end{array}$ & $\begin{array}{l}0: 38.42 \% \\
1: 18.56 \%\end{array}$ & $\begin{array}{l}0: 0.86 \% \\
1: 1.49 \%\end{array}$ \\
\hline
\end{tabular}




\begin{tabular}{|c|c|c|c|c|c|c|}
\hline Model & Variable(s) in model & $\begin{array}{l}\text { Physical Component Summary } \\
\text { Score (PCS) HR }(95 \% \mathrm{CI})\end{array}$ & $\begin{array}{l}\text { Difference in } \\
\text { ' } \mathrm{N} \text { ' }\end{array}$ & $\begin{array}{l}\text { Total in model (n) } \\
\text { and total dead (d) }\end{array}$ & $\begin{array}{l}\% \text { change from } \\
\text { Crude }\end{array}$ & $\begin{array}{l}\% \text { change from } \\
\text { model } 1\end{array}$ \\
\hline 9 & Model $1+$ Fear of Recurrence & $\begin{array}{l}0: \mathrm{HR}=2.34(1.32-4.16) \\
1: \mathrm{HR}=1.34(0.72-2.49) \\
2: \mathrm{HR}=1.00(\mathrm{REF}) \\
\mathrm{p}=0.0047\end{array}$ & 0 & $\begin{array}{l}\mathrm{n}=351 \\
\mathrm{~d}=99\end{array}$ & $\begin{array}{l}0: 38.42 \% \\
1: 19.76 \%\end{array}$ & $\begin{array}{l}0: 0.86 \% \\
1: 0.00 \%\end{array}$ \\
\hline \multicolumn{7}{|c|}{ Subset--Restricted to participants with Education variable } \\
\hline Crude & Physical Component Summary Score (PCS) & $\begin{array}{l}0: H R=3.74(2.17-6.45) \\
1: H R=1.67(0.91-3.07) \\
2: H R=1.00(R E F) \\
p=<0.0001\end{array}$ & 1 & $\begin{array}{l}\mathrm{n}=350 \\
\mathrm{~d}=98\end{array}$ & -- & -- \\
\hline 1 & Age, Marital Status, \& Tumor Stage & $\begin{array}{l}0: \mathrm{HR}=2.29(1.29-4.07) \\
\text { 1: } \mathrm{HR}=1.33(0.72-2.47) \\
2: \mathrm{HR}=1.00 \text { (REF) } \\
\mathrm{p}=0.0063\end{array}$ & 1 & $\begin{array}{l}\mathrm{n}=350 \\
\mathrm{~d}=98\end{array}$ & $\begin{array}{l}\text { 0: } 38.77 \% \\
\text { 1: } 20.36 \%\end{array}$ & -- \\
\hline 10 & Model $1+$ Education & $\begin{array}{l}0: \mathrm{HR}=2.26(1.28-4.02) \\
1: \mathrm{HR}=1.31(0.71-2.43) \\
2: \mathrm{HR}=1.00(\mathrm{REF}) \\
\mathrm{p}=0.0076\end{array}$ & 1 & $\begin{array}{l}\mathrm{n}=350 \\
\mathrm{~d}=98\end{array}$ & $\begin{array}{l}0: 39.57 \% \\
1: 21.56 \%\end{array}$ & $\begin{array}{l}0: 1.31 \% \\
1: 1.50 \%\end{array}$ \\
\hline & & tricted to participants with the $\mathrm{Tu}$ & Size variable & & & \\
\hline
\end{tabular}




\begin{tabular}{|c|c|c|c|c|c|c|}
\hline Model & Variable(s) in model & $\begin{array}{l}\text { Physical Component Summary } \\
\text { Score (PCS) HR }(95 \% \mathrm{CI})\end{array}$ & $\begin{array}{l}\text { Difference in } \\
\text { ' } \mathrm{N} \text { ' }\end{array}$ & $\begin{array}{l}\text { Total in model (n) } \\
\text { and total dead (d) }\end{array}$ & $\begin{array}{l}\% \text { change from } \\
\text { Crude }\end{array}$ & $\begin{array}{l}\% \text { change from } \\
\text { model } 1\end{array}$ \\
\hline Crude & Physical Component Summary Score (PCS) & $\begin{array}{l}0: H R=3.66(2.12-6.30) \\
1: H R=1.65(0.90-3.02) \\
2: H R=1.00(R E F) \\
p=<0.0001\end{array}$ & 10 & $\begin{array}{l}\mathrm{n}=341 \\
\mathrm{~d}=99\end{array}$ & -- & -- \\
\hline 1 & Age, Marital Status, \& Tumor Stage & $\begin{array}{l}0: H R=2.30(1.30-4.07) \\
1: H R=1.34(0.73-2.49) \\
2: H R=1.00(R E F) \\
p=0.0059\end{array}$ & 10 & $\begin{array}{l}\mathrm{n}=341 \\
\mathrm{~d}=99\end{array}$ & $\begin{array}{l}0: 37.16 \% \\
1: 18.79 \%\end{array}$ & -- \\
\hline 11 & Model $1+$ Tumor Size & $\begin{array}{l}0: \mathrm{HR}=2.25(1.28-3.98) \\
1: \mathrm{HR}=1.30(0.70-2.41) \\
2: \mathrm{HR}=1.00(\mathrm{REF}) \\
\mathrm{p}=0.0064\end{array}$ & 10 & $\begin{array}{l}\mathrm{n}=341 \\
\mathrm{~d}=99\end{array}$ & $\begin{array}{l}\text { 0: } 38.52 \% \\
1: 21.21 \%\end{array}$ & $\begin{array}{l}0: 2.17 \% \\
1: 2.99 \%\end{array}$ \\
\hline \multicolumn{7}{|c|}{ Subset--Restricted to participants with Lymph Node Involvement variable } \\
\hline Crude & Physical Component Summary Score (PCS) & $\begin{array}{l}0: \mathrm{HR}=3.96(2.26-6.94) \\
\text { 1: } \mathrm{HR}=1.63(0.87-3.07) \\
\text { 2: } \mathrm{HR}=1.00(\mathrm{REF}) \\
\mathrm{p}=<0.0001\end{array}$ & 10 & $\begin{array}{l}n=341 \\
d=92\end{array}$ & -- & -- \\
\hline
\end{tabular}




\begin{tabular}{|c|c|c|c|c|c|c|}
\hline Model & Variable(s) in model & $\begin{array}{l}\text { Physical Component Summary } \\
\text { Score (PCS) HR ( } 95 \% \text { CI) }\end{array}$ & $\begin{array}{l}\text { Difference in } \\
\text { ' } \mathrm{N} \text { ' }\end{array}$ & $\begin{array}{l}\text { Total in model (n) } \\
\text { and total dead (d) }\end{array}$ & $\begin{array}{l}\% \text { change from } \\
\text { Crude }\end{array}$ & $\begin{array}{l}\% \text { change from } \\
\text { model } 1\end{array}$ \\
\hline 1 & Age, Marital Status, \& Tumor Stage & $\begin{array}{l}0: \mathrm{HR}=2.36(1.30-4.25) \\
1: \mathrm{HR}=1.35(0.71-2.56) \\
2: \mathrm{HR}=1.00(\mathrm{REF}) \\
\mathrm{p}=0.0071\end{array}$ & 10 & $\begin{array}{l}\mathrm{n}=341 \\
\mathrm{~d}=92\end{array}$ & $\begin{array}{l}0: 40.40 \% \\
1: 17.18 \%\end{array}$ & -- \\
\hline 12 & Model $1+$ Lymph Node Involvement & $\begin{array}{l}0: \mathrm{HR}=2.34(1.30-4.24) \\
1: \mathrm{HR}=1.34(0.71-2.55) \\
2: \mathrm{HR}=1.00(\mathrm{REF}) \\
\mathrm{p}=0.0076\end{array}$ & 10 & $\begin{array}{l}\mathrm{n}=341 \\
\mathrm{~d}=92\end{array}$ & $\begin{array}{l}0: 40.91 \% \\
1: 17.79 \%\end{array}$ & $\begin{array}{l}0: 0.85 \% \\
1: 0.74 \%\end{array}$ \\
\hline \multicolumn{7}{|c|}{ Subset--Restricted to participants with Tamoxifen Use, Smoking Status, \& Physical Activity variables (24-month follow-up) } \\
\hline Crude & Physical Component Summary Score (PCS) & $\begin{array}{l}0: \mathrm{HR}=3.55(2.04-6.17) \\
1: \mathrm{HR}=1.56(0.84-2.90) \\
2: \mathrm{HR}=1.00(\mathrm{REF}) \\
\mathrm{p}=<0.0001\end{array}$ & 21 & $\begin{array}{l}\mathrm{n}=330 \\
\mathrm{~d}=91\end{array}$ & -- & -- \\
\hline 1 & Age, Marital Status, \& Tumor Stage & $\begin{array}{l}0: \mathrm{HR}=2.18(1.22-3.91) \\
1: \mathrm{HR}=1.24(0.66-2.34) \\
2: \mathrm{HR}=1.00(\mathrm{REF}) \\
\mathrm{p}=0.0107\end{array}$ & 21 & $\begin{array}{l}\mathrm{n}=330 \\
\mathrm{~d}=91\end{array}$ & $\begin{array}{l}0: 38.59 \% \\
1: 20.51 \%\end{array}$ & -- \\
\hline
\end{tabular}




\begin{tabular}{|c|c|c|c|c|c|c|}
\hline Model & Variable(s) in model & $\begin{array}{l}\text { Physical Component Summary } \\
\text { Score (PCS) HR ( } 95 \% \text { CI) }\end{array}$ & $\begin{array}{l}\text { Difference in } \\
\text { ' } \mathrm{N} \text { ' }\end{array}$ & $\begin{array}{l}\text { Total in model (n) } \\
\text { and total dead (d) }\end{array}$ & $\begin{array}{l}\% \text { change from } \\
\text { Crude }\end{array}$ & $\begin{array}{l}\% \text { change from } \\
\text { model } 1\end{array}$ \\
\hline 13 & Model 1 + Tamoxifen Use & $\begin{array}{l}0: \mathrm{HR}=2.21(1.24-3.95) \\
1: \mathrm{HR}=1.23(0.66-2.29) \\
2: \mathrm{HR}=1.00(\mathrm{REF}) \\
\mathrm{p}=0.0079\end{array}$ & 21 & $\begin{array}{l}\mathrm{n}=330 \\
\mathrm{~d}=91\end{array}$ & $\begin{array}{l}0: 37.75 \% \\
1: 21.15 \%\end{array}$ & $\begin{array}{l}0: 1.38 \% \\
1: 0.81 \%\end{array}$ \\
\hline 14 & Model $1+$ Smoking Status & $\begin{array}{l}0: \mathrm{HR}=2.13(1.20-3.81) \\
1: \mathrm{HR}=1.22(0.65-2.29) \\
2: \mathrm{HR}=1.00(\mathrm{REF}) \\
\mathrm{p}=0.0128\end{array}$ & 21 & $\begin{array}{l}\mathrm{n}=330 \\
\mathrm{~d}=91\end{array}$ & $\begin{array}{l}0: 40.00 \% \\
1: 21.79 \%\end{array}$ & $\begin{array}{l}0: 2.29 \% \\
1: 1.61 \%\end{array}$ \\
\hline 15 & Model $1+$ Physical Activity & $\begin{array}{l}0: \mathrm{HR}=2.13(1.18-3.82) \\
1: \mathrm{HR}=1.22(0.65-2.28) \\
2: \mathrm{HR}=1.00(\mathrm{REF}) \\
\mathrm{p}=0.0143\end{array}$ & 21 & $\begin{array}{l}\mathrm{n}=330 \\
\mathrm{~d}=91\end{array}$ & $\begin{array}{l}0: 40.00 \% \\
1: 21.79 \%\end{array}$ & $\begin{array}{l}0: 2.29 \% \\
1: 1.61 \%\end{array}$ \\
\hline \multicolumn{7}{|c|}{ Subset--Restricted to participants with BMI variable } \\
\hline Crude & Physical Component Summary Score (PCS) & $\begin{array}{l}0: \mathrm{HR}=3.48(1.94-6.24) \\
1: \mathrm{HR}=1.71(0.90-3.24) \\
2: \mathrm{HR}=1.00(\mathrm{REF}) \\
\mathrm{p}=<0.0001\end{array}$ & 27 & $\begin{array}{l}\mathrm{n}=324 \\
\mathrm{~d}=85\end{array}$ & -- & -- \\
\hline
\end{tabular}




\begin{tabular}{|c|c|c|c|c|c|c|}
\hline Model & Variable(s) in model & $\begin{array}{l}\text { Physical Component Summary } \\
\text { Score (PCS) HR }(95 \% \text { CI) }\end{array}$ & $\begin{array}{l}\text { Difference in } \\
\text { ' } \mathrm{N} \text { ' }\end{array}$ & $\begin{array}{l}\text { Total in model (n) } \\
\text { and total dead (d) }\end{array}$ & $\begin{array}{l}\% \text { change from } \\
\text { Crude }\end{array}$ & $\begin{array}{l}\% \text { change from } \\
\text { model } 1\end{array}$ \\
\hline 1 & Age, Marital Status, \& Tumor Stage & $\begin{array}{l}0: \mathrm{HR}=2.19(1.19-4.04) \\
1: \mathrm{HR}=1.44(0.75-2.76) \\
2: \mathrm{HR}=1.00(\mathrm{REF}) \\
\mathrm{p}=0.0300\end{array}$ & 27 & $\begin{array}{l}\mathrm{n}=324 \\
\mathrm{~d}=85\end{array}$ & $\begin{array}{l}0: 37.07 \% \\
1: 15.79 \%\end{array}$ & -- \\
\hline 16 & Model $1+$ BMI & $\begin{array}{l}0: \mathrm{HR}=2.17(1.16-4.07) \\
1: \mathrm{HR}=1.45(0.75-2.78) \\
2: \mathrm{HR}=1.00(\mathrm{REF}) \\
\mathrm{p}=0.0402\end{array}$ & 27 & $\begin{array}{l}\mathrm{n}=324 \\
\mathrm{~d}=85\end{array}$ & $\begin{array}{l}0: 37.64 \% \\
1: 15.20 \%\end{array}$ & $\begin{array}{l}0: 0.91 \% \\
1: 0.69 \%\end{array}$ \\
\hline \multicolumn{7}{|c|}{ Subset--Restricted to participants with Tumor Subtype variable } \\
\hline Crude & Physical Component Summary Score (PCS) & $\begin{array}{l}0: H R=3.37(1.88-6.04) \\
1: H R=1.79(0.95-3.38) \\
2: H R=1.00(R E F) \\
p=<0.0001\end{array}$ & 51 & $\begin{array}{l}n=300 \\
d=87\end{array}$ & -- & -- \\
\hline 1 & Age, Marital Status, \& Tumor Stage & $\begin{array}{l}0: \mathrm{HR}=2.11(1.15-3.89) \\
1: \mathrm{HR}=1.46(0.76-2.77) \\
2: \mathrm{HR}=1.00(\mathrm{REF}) \\
\mathrm{p}=0.0435\end{array}$ & 51 & $\begin{array}{l}\mathrm{n}=300 \\
\mathrm{~d}=87\end{array}$ & $\begin{array}{l}0: 37.39 \% \\
1: 18.44 \%\end{array}$ & -- \\
\hline
\end{tabular}




\begin{tabular}{|c|c|c|c|c|c|c|}
\hline Model & Variable(s) in model & $\begin{array}{l}\text { Physical Component Summary } \\
\text { Score (PCS) HR ( } 95 \% \text { CI) }\end{array}$ & $\begin{array}{l}\text { Difference in } \\
\text { ' } \mathrm{N} \text { ' }\end{array}$ & $\begin{array}{l}\text { Total in model (n) } \\
\text { and total dead (d) }\end{array}$ & $\begin{array}{l}\% \text { change from } \\
\text { Crude }\end{array}$ & $\begin{array}{l}\% \text { change from } \\
\text { model } 1\end{array}$ \\
\hline 17 & Model $1+$ Tumor Subtype & $\begin{array}{l}0: \mathrm{HR}=2.14(1.16-3.95) \\
1: \mathrm{HR}=1.45(0.76-2.77) \\
2: \mathrm{HR}=1.00(\mathrm{REF}) \\
\mathrm{p}=0.0371\end{array}$ & 51 & $\begin{array}{l}\mathrm{n}=300 \\
\mathrm{~d}=87\end{array}$ & $\begin{array}{l}0: 36.50 \% \\
1: 18.99 \%\end{array}$ & $\begin{array}{l}0: 1.42 \% \\
1: 0.68 \%\end{array}$ \\
\hline
\end{tabular}


Appendix D. Multivariable Modeling with Physical Component Summary Score as the Predictor and All-Cause Mortality as the Outcome $(N=351)$

\begin{tabular}{|c|c|c|c|c|c|c|c|}
\hline Model & Variable(s) in model & $\begin{array}{l}\text { Physical Component } \\
\text { Summary Score (PCS) HR } \\
(95 \% \text { CI })\end{array}$ & $\begin{array}{l}\text { Difference in } \\
\text { ' } \mathrm{N} \text { ' }\end{array}$ & $\begin{array}{l}\text { Total in model } \\
\text { (n) and total } \\
\text { dead (d) }\end{array}$ & $\begin{array}{l}\% \text { change } \\
\text { from Crude }\end{array}$ & $\begin{array}{l}\% \text { change } \\
\text { from model } \\
1\end{array}$ & $\begin{array}{l}\% \text { change } \\
\text { from } \\
\text { previous } \\
\text { model }\end{array}$ \\
\hline Crude & Physical Component Summary Score (PCS) & $\begin{array}{l}0: H R=3.80(2.20-6.54) \\
1: H R=1.67(0.91-3.07) \\
2: H R=1.00(R E F) \\
p=<0.0001\end{array}$ & 0 & $\begin{array}{l}\mathrm{n}=351 \\
\mathrm{~d}=99\end{array}$ & -- & -- & -- \\
\hline 1 & Age, Marital Status, \& Tumor Stage & $\begin{array}{l}0: \mathrm{HR}=2.32(1.29-4.11) \\
1: \mathrm{HR}=1.34(0.72-2.47) \\
2: \mathrm{HR}=1.00(\mathrm{REF}) \\
\mathrm{p}=0.0052\end{array}$ & 0 & $\begin{array}{l}\mathrm{n}=351 \\
\mathrm{~d}=99\end{array}$ & $\begin{array}{l}0: 38.95 \% \\
1: 19.76 \%\end{array}$ & -- & -- \\
\hline 2 & Model $1+$ Race/Ethnicity & $\begin{array}{l}0: \mathrm{HR}=2.34(1.32-4.15) \\
1: \mathrm{HR}=1.34(0.72-2.48) \\
2: \mathrm{HR}=1.00(\mathrm{REF}) \\
\mathrm{p}=0.0048\end{array}$ & 0 & $\begin{array}{l}\mathrm{n}=351 \\
\mathrm{~d}=99\end{array}$ & $\begin{array}{l}0: 38.42 \% \\
1: 19.76 \%\end{array}$ & $\begin{array}{l}0: 0.86 \% \\
1: 0.00 \%\end{array}$ & -- \\
\hline 3 & Model $1+$ Race/Ethnicity + Treatment Type & $\begin{array}{l}0: \mathrm{HR}=2.26(1.27-4.00) \\
1: \mathrm{HR}=1.29(0.70-2.40) \\
2: \mathrm{HR}=1.00(\mathrm{REF}) \\
\mathrm{p}=0.0062\end{array}$ & 0 & $\begin{array}{l}\mathrm{n}=351 \\
\mathrm{~d}=99\end{array}$ & $\begin{array}{l}0: 40.53 \% \\
1: 22.75 \%\end{array}$ & $\begin{array}{l}0: 2.59 \% \\
1: 3.73 \%\end{array}$ & $\begin{array}{l}0: 3.42 \% \\
1: 3.73 \%\end{array}$ \\
\hline 4 & $\begin{array}{l}\text { Model } 1+\text { Race/Ethnicity }+ \text { Treatment Type }+ \\
\text { Comorbidities }\end{array}$ & $\begin{array}{l}0: \mathrm{HR}=2.12(1.18-3.81) \\
1: \mathrm{HR}=1.26(0.68-2.35) \\
2: \mathrm{HR}=1.00(\mathrm{REF}) \\
\mathrm{p}=0.0152\end{array}$ & 0 & $\begin{array}{l}\mathrm{n}=351 \\
\mathrm{~d}=99\end{array}$ & $\begin{array}{l}0: 44.21 \% \\
1: 24.55 \%\end{array}$ & $\begin{array}{l}0: 8.62 \% \\
1: 5.97 \%\end{array}$ & $\begin{array}{l}0: 6.19 \% \\
1: 2.33 \%\end{array}$ \\
\hline
\end{tabular}




\begin{tabular}{|c|c|c|c|c|c|c|c|}
\hline Model & Variable(s) in model & $\begin{array}{l}\text { Physical Component } \\
\text { Summary Score (PCS) HR } \\
(95 \% \mathrm{CI})\end{array}$ & $\begin{array}{l}\text { Difference in } \\
\text { ' } \mathrm{N} \text { ' }\end{array}$ & $\begin{array}{l}\text { Total in model } \\
\text { (n) and total } \\
\text { dead (d) }\end{array}$ & $\begin{array}{l}\% \text { change } \\
\text { from Crude }\end{array}$ & $\begin{array}{l}\% \text { change } \\
\text { from model } \\
1\end{array}$ & $\begin{array}{l}\% \text { change } \\
\text { from } \\
\text { previous } \\
\text { model } \\
\end{array}$ \\
\hline 5 & $\begin{array}{l}\text { Model } 1+\text { Race/Ethnicity + Treatment Type + } \\
\text { Comorbidities + Current Lymphedema }\end{array}$ & $\begin{array}{l}0: \mathrm{HR}=2.26(1.26-4.06) \\
1: \mathrm{HR}=1.31(0.70-2.44) \\
2: \mathrm{HR}=1.00(\mathrm{REF}) \\
\mathrm{p}=0.0086\end{array}$ & 0 & $\begin{array}{l}n=351 \\
d=99\end{array}$ & $\begin{array}{l}0: 40.53 \% \\
1: 21.56 \%\end{array}$ & $\begin{array}{l}0: 2.59 \% \\
1: 2.24 \%\end{array}$ & $\begin{array}{l}0: 6.60 \% \\
1: 3.97 \%\end{array}$ \\
\hline 6 & $\begin{array}{l}\text { Model } 1+\text { Race/Ethnicity + Treatment Type }+ \\
\text { Comorbidities + Current Lymphedema + Pessimism }\end{array}$ & $\begin{array}{l}0: \mathrm{HR}=2.14(1.19-3.85) \\
1: \mathrm{HR}=1.34(0.72-2.48) \\
2: \mathrm{HR}=1.00(\mathrm{REF}) \\
\mathrm{p}=0.0205\end{array}$ & 0 & $\begin{array}{l}\mathrm{n}=351 \\
\mathrm{~d}=99\end{array}$ & $\begin{array}{l}0: 43.68 \% \\
1: 19.76 \%\end{array}$ & $\begin{array}{l}0: 7.76 \% \\
1: 0.00 \%\end{array}$ & $\begin{array}{l}0: 5.31 \% \\
1: 2.29 \%\end{array}$ \\
\hline 7 & $\begin{array}{l}\text { Model } 1+\text { Race/Ethnicity }+ \text { Treatment Type }+ \\
\text { Comorbidities }+ \text { Current Lymphedema }+ \text { Pessimism }+ \\
\text { Number of Types of Confidants (Confide) }\end{array}$ & $\begin{array}{l}0: \mathrm{HR}=2.17(1.21-3.90) \\
1: \mathrm{HR}=1.36(0.73-2.54) \\
2: \mathrm{HR}=1.00(\mathrm{REF}) \\
\mathrm{p}=0.0201\end{array}$ & 0 & $\begin{array}{l}\mathrm{n}=351 \\
\mathrm{~d}=99\end{array}$ & $\begin{array}{l}0: 42.89 \% \\
1: 18.56 \%\end{array}$ & $\begin{array}{l}0: 6.47 \% \\
1: 1.49 \%\end{array}$ & $\begin{array}{l}0: 1.40 \% \\
1: 1.49 \%\end{array}$ \\
\hline 8 & $\begin{array}{l}\text { Model } 1+\text { Race/Ethnicity }+ \text { Treatment Type }+ \\
\text { Comorbidities + Current Lymphedema + Pessimism + } \\
\text { Confide + Fear of Recurrence }\end{array}$ & $\begin{array}{l}0: \mathrm{HR}=2.17(1.20-3.90) \\
1: \mathrm{HR}=1.37(0.74-2.56) \\
2: \mathrm{HR}=1.00(\mathrm{REF}) \\
\mathrm{p}=0.0209\end{array}$ & 0 & $\begin{array}{l}\mathrm{n}=351 \\
\mathrm{~d}=99\end{array}$ & $\begin{array}{l}0: 17.96 \% \\
1: 21.56 \%\end{array}$ & $\begin{array}{l}0: 6.47 \% \\
1: 2.24 \%\end{array}$ & $\begin{array}{l}0: 0.00 \% \\
1: 0.74 \%\end{array}$ \\
\hline \multicolumn{8}{|c|}{ Subset--Restricted to participants with Education variable } \\
\hline Crude & Physical Component Summary Score (PCS) & $\begin{array}{l}0: \mathrm{HR}=3.74(2.17-6.45) \\
1: \mathrm{HR}=1.67(0.91-3.07) \\
2: \mathrm{HR}=1.00(\mathrm{REF}) \\
\mathrm{p}=<0.0001\end{array}$ & 1 & $\begin{array}{l}n=350 \\
d=98\end{array}$ & -- & -- & -- \\
\hline
\end{tabular}




\begin{tabular}{|c|c|c|c|c|c|c|c|}
\hline Model & Variable(s) in model & $\begin{array}{l}\text { Physical Component } \\
\text { Summary Score (PCS) HR } \\
(95 \% \mathrm{CI})\end{array}$ & $\begin{array}{l}\text { Difference in } \\
\text { ' } \mathrm{N} \text { ' }\end{array}$ & $\begin{array}{l}\text { Total in model } \\
\text { (n) and total } \\
\text { dead (d) }\end{array}$ & $\begin{array}{l}\% \text { change } \\
\text { from Crude }\end{array}$ & $\begin{array}{l}\% \text { change } \\
\text { from model } \\
1\end{array}$ & $\begin{array}{l}\% \text { change } \\
\text { from } \\
\text { previous } \\
\text { model } \\
\end{array}$ \\
\hline 1 & Age, Marital Status, \& Tumor Stage & $\begin{array}{l}0: \mathrm{HR}=2.30(1.29-4.07) \\
1: \mathrm{HR}=1.33(0.72-2.47) \\
2: \mathrm{HR}=1.00(\mathrm{REF}) \\
\mathrm{p}=0.0063\end{array}$ & 1 & $\begin{array}{l}\mathrm{n}=350 \\
\mathrm{~d}=98\end{array}$ & $\begin{array}{l}0: 38.50 \% \\
1: 20.36 \%\end{array}$ & -- & -- \\
\hline 9 & Model $1+$ Education & $\begin{array}{l}0: \mathrm{HR}=2.26(1.28-4.02) \\
1: \mathrm{HR}=1.31(0.71-2.43) \\
2: \mathrm{HR}=1.00(\mathrm{REF}) \\
\mathrm{p}=0.0076\end{array}$ & 1 & $\begin{array}{l}\mathrm{n}=350 \\
\mathrm{~d}=98\end{array}$ & $\begin{array}{l}0: 39.57 \% \\
1: 21.56 \%\end{array}$ & $\begin{array}{l}0: 1.74 \% \\
1: 1.50 \%\end{array}$ & -- \\
\hline 10 & Model $1+$ Education + Race/Ethnicity & $\begin{array}{l}0: \mathrm{HR}=2.27(1.28-4.04) \\
1: \mathrm{HR}=1.31(0.71-2.43) \\
2: \mathrm{HR}=1.00(\mathrm{REF}) \\
\mathrm{p}=0.0071\end{array}$ & 1 & $\begin{array}{l}n=350 \\
d=98\end{array}$ & $\begin{array}{l}0: 39.30 \% \\
1: 21.56 \%\end{array}$ & $\begin{array}{l}0: 1.30 \% \\
1: 1.50 \%\end{array}$ & $\begin{array}{l}0: 0.44 \% \\
1: 0.00 \%\end{array}$ \\
\hline 11 & Model $1+$ Education + Race/Ethnicity + Treatment Type & $\begin{array}{l}0: H R=2.18(1.23-3.87) \\
1: H R=1.28(0.69-2.37) \\
2: H R=1.00(\text { REF }) \\
p=0.0100\end{array}$ & 1 & $\begin{array}{l}n=350 \\
d=98\end{array}$ & $\begin{array}{l}0: 41.71 \% \\
1: 23.35 \%\end{array}$ & $\begin{array}{l}0: 5.22 \% \\
1: 3.76 \%\end{array}$ & $\begin{array}{l}0: 3.96 \% \\
1: 2.29 \%\end{array}$ \\
\hline 12 & $\begin{array}{l}\text { Model } 1+\text { Education + Race/Ethnicity + Treatment Type } \\
+ \text { Comorbidities }\end{array}$ & $\begin{array}{l}0: \mathrm{HR}=2.08(1.16-3.72) \\
1: \mathrm{HR}=1.25(0.67-2.32) \\
2: \mathrm{HR}=1.00(\mathrm{REF}) \\
\mathrm{p}=0.0204\end{array}$ & 1 & $\begin{array}{l}n=350 \\
d=98\end{array}$ & $\begin{array}{l}0: 44.39 \% \\
1: 25.15 \%\end{array}$ & $\begin{array}{l}0: 9.57 \% \\
1: 6.02 \%\end{array}$ & $\begin{array}{l}0: 4.59 \% \\
1: 2.34 \%\end{array}$ \\
\hline
\end{tabular}




\begin{tabular}{|c|c|c|c|c|c|c|c|}
\hline Model & Variable(s) in model & $\begin{array}{l}\text { Physical Component } \\
\text { Summary Score (PCS) HR } \\
(95 \% \mathrm{CI})\end{array}$ & $\begin{array}{l}\text { Difference in } \\
\text { ' } \mathrm{N} \text { ' }\end{array}$ & $\begin{array}{l}\text { Total in model } \\
\text { (n) and total } \\
\text { dead (d) }\end{array}$ & $\begin{array}{l}\% \text { change } \\
\text { from Crude }\end{array}$ & $\begin{array}{l}\% \text { change } \\
\text { from model } \\
1\end{array}$ & $\begin{array}{l}\text { \% change } \\
\text { from } \\
\text { previous } \\
\text { model }\end{array}$ \\
\hline 13 & $\begin{array}{l}\text { Model } 1+\text { Education + Race/Ethnicity + Treatment Type } \\
\text { + Comorbidities + Current Lymphedema }\end{array}$ & $\begin{array}{l}0: \mathrm{HR}=2.21(1.23-3.97) \\
1: \mathrm{HR}=1.30(0.70-2.42) \\
2: \mathrm{HR}=1.00(\mathrm{REF}) \\
\mathrm{p}=0.0119\end{array}$ & 1 & $\begin{array}{l}\mathrm{n}=350 \\
\mathrm{~d}=98\end{array}$ & $\begin{array}{l}0: 40.91 \% \\
1: 22.16 \%\end{array}$ & $\begin{array}{l}0: 3.91 \% \\
1: 2.26 \%\end{array}$ & $\begin{array}{l}0: 6.25 \% \\
1: 4.00 \%\end{array}$ \\
\hline 14 & $\begin{array}{l}\text { Model } 1+\text { Education + Race/Ethnicity + Treatment Type } \\
+ \text { Comorbidities + Current Lymphedema + Pessimism }\end{array}$ & $\begin{array}{l}0: \mathrm{HR}=2.09(1.16-3.75) \\
1: \mathrm{HR}=1.34(0.72-2.49) \\
2: \mathrm{HR}=1.00(\mathrm{REF}) \\
\mathrm{p}=0.0296\end{array}$ & 1 & $\begin{array}{l}\mathrm{n}=350 \\
\mathrm{~d}=98\end{array}$ & $\begin{array}{l}0: 44.12 \% \\
1: 19.76 \%\end{array}$ & $\begin{array}{l}0: 9.13 \% \\
1: 0.75 \%\end{array}$ & $\begin{array}{l}0: 5.43 \% \\
1: 3.08 \%\end{array}$ \\
\hline 15 & $\begin{array}{l}\text { Model } 1+\text { Education }+ \text { Race/Ethnicity }+ \text { Treatment Type } \\
+ \text { Comorbidities + Current Lymphedema + Pessimism }+ \\
\text { Confide }\end{array}$ & $\begin{array}{l}0: H R=2.11(1.17-3.80) \\
1: H R=1.37(0.73-2.54) \\
2: H R=1.00(\mathrm{REF}) \\
\mathrm{p}=0.0289\end{array}$ & 1 & $\begin{array}{l}\mathrm{n}=350 \\
\mathrm{~d}=98\end{array}$ & $\begin{array}{l}0: 43.58 \% \\
1: 17.96 \%\end{array}$ & $\begin{array}{l}0: 8.26 \% \\
1: 3.01 \%\end{array}$ & $\begin{array}{l}0: 0.96 \% \\
1: 2.24 \%\end{array}$ \\
\hline 16 & $\begin{array}{l}\text { Model } 1+\text { Education + Race/Ethnicity + Treatment Type } \\
+ \text { Comorbidities + Current Lymphedema + Pessimism + } \\
\text { Confide + Fear of Recurrence }\end{array}$ & $\begin{array}{l}0: \mathrm{HR}=2.11(1.18-3.80) \\
1: \mathrm{HR}=1.38(0.74-2.57) \\
2: \mathrm{HR}=1.00(\mathrm{REF}) \\
\mathrm{p}=0.0293\end{array}$ & 1 & $\begin{array}{l}\mathrm{n}=350 \\
\mathrm{~d}=98\end{array}$ & $\begin{array}{l}0: 43.58 \% \\
1: 17.37 \%\end{array}$ & $\begin{array}{l}0: 8.26 \% \\
1: 3.76 \%\end{array}$ & $\begin{array}{l}0: 0.00 \% \\
1: 0.73 \%\end{array}$ \\
\hline \multicolumn{8}{|c|}{ Subset--Restricted to participants with Lymph Node Involvement variable } \\
\hline Crude & Physical Component Summary Score (PCS) & $\begin{array}{l}0: \mathrm{HR}=3.96(2.26-6.94) \\
1: \mathrm{HR}=1.63(0.87-3.07) \\
2: \mathrm{HR}=1.00(\mathrm{REF}) \\
\mathrm{p}=<0.0001\end{array}$ & 10 & $\begin{array}{l}\mathrm{n}=341 \\
\mathrm{~d}=92\end{array}$ & -- & -- & -- \\
\hline
\end{tabular}




\begin{tabular}{|c|c|c|c|c|c|c|c|}
\hline Model & Variable(s) in model & $\begin{array}{l}\text { Physical Component } \\
\text { Summary Score (PCS) HR } \\
(95 \% \mathrm{CI})\end{array}$ & $\begin{array}{l}\text { Difference in } \\
\text { ' } \mathrm{N} \text { ' }\end{array}$ & $\begin{array}{l}\text { Total in model } \\
\text { (n) and total } \\
\text { dead (d) }\end{array}$ & $\begin{array}{l}\% \text { change } \\
\text { from Crude }\end{array}$ & $\begin{array}{l}\% \text { change } \\
\text { from model } \\
1\end{array}$ & $\begin{array}{l}\text { \% change } \\
\text { from } \\
\text { previous } \\
\text { model }\end{array}$ \\
\hline 1 & Age, Marital Status, \& Tumor Stage & $\begin{array}{l}0: \mathrm{HR}=2.36(1.30-4.25) \\
1: \mathrm{HR}=1.35(0.71-2.56) \\
2: \mathrm{HR}=1.00(\mathrm{REF}) \\
\mathrm{p}=0.0071\end{array}$ & 10 & $\begin{array}{l}n=341 \\
d=92\end{array}$ & $\begin{array}{l}0: 40.40 \% \\
1: 17.18 \%\end{array}$ & -- & -- \\
\hline 17 & Model 1 + Lymph Node Involvement (LNI) & $\begin{array}{l}0: \mathrm{HR}=2.34(1.30-4.24) \\
1: \mathrm{HR}=1.34(0.71-2.55) \\
2: \mathrm{HR}=1.00(\mathrm{REF}) \\
\mathrm{p}=0.0076\end{array}$ & 10 & $\begin{array}{l}n=341 \\
d=92\end{array}$ & $\begin{array}{l}0: 40.91 \% \\
1: 17.79 \%\end{array}$ & $\begin{array}{l}0: 0.85 \% \\
1: 0.74 \%\end{array}$ & -- \\
\hline 18 & Model 1 + LNI + Race/Ethnicity & $\begin{array}{l}0: H R=2.36(1.31-4.28) \\
1: H R=1.35(0.71-2.56) \\
2: H R=1.00(\text { REF }) \\
p=0.0070\end{array}$ & 10 & $\begin{array}{l}n=341 \\
d=92\end{array}$ & $\begin{array}{l}0: 40.40 \% \\
1: 17.18 \%\end{array}$ & $\begin{array}{l}0: 0.00 \% \\
1: 0.00 \%\end{array}$ & $\begin{array}{l}0: 0.85 \% \\
1: 0.75 \%\end{array}$ \\
\hline 19 & Model $1+$ LNI + Race/Ethnicity + Treatment Type & $\begin{array}{l}0: H R=2.28(1.26-4.13) \\
1: H R=1.33(0.70-2.52) \\
2: H R=1.00(\text { REF }) \\
p=0.0102\end{array}$ & 10 & $\begin{array}{l}n=341 \\
d=92\end{array}$ & $\begin{array}{l}0: 42.42 \% \\
1: 18.40 \%\end{array}$ & $\begin{array}{l}0: 3.39 \% \\
1: 1.48 \%\end{array}$ & $\begin{array}{l}0: 3.39 \% \\
1: 1.48 \%\end{array}$ \\
\hline 20 & $\begin{array}{l}\text { Model } 1+\text { LNI }+ \text { Race/Ethnicity }+ \text { Treatment Type }+ \\
\text { Comorbidities }\end{array}$ & $\begin{array}{l}0: \mathrm{HR}=2.19(1.20-4.01) \\
1: \mathrm{HR}=1.30(0.68-2.48) \\
2: \mathrm{HR}=1.00(\mathrm{REF}) \\
\mathrm{p}=0.0174\end{array}$ & 10 & $\begin{array}{l}n=341 \\
d=92\end{array}$ & $\begin{array}{l}0: 44.70 \% \\
1: 20.25 \%\end{array}$ & $\begin{array}{l}0: 7.20 \% \\
1: 3.70 \%\end{array}$ & $\begin{array}{l}0: 3.95 \% \\
1: 2.26 \%\end{array}$ \\
\hline
\end{tabular}




\begin{tabular}{|c|c|c|c|c|c|c|c|}
\hline Model & Variable(s) in model & $\begin{array}{l}\text { Physical Component } \\
\text { Summary Score (PCS) HR } \\
(95 \% \mathrm{CI})\end{array}$ & $\begin{array}{l}\text { Difference in } \\
\text { ' } \mathrm{N} \text { ' }\end{array}$ & $\begin{array}{l}\text { Total in model } \\
\text { (n) and total } \\
\text { dead (d) }\end{array}$ & $\begin{array}{l}\% \text { change } \\
\text { from Crude }\end{array}$ & $\begin{array}{l}\% \text { change } \\
\text { from model } \\
1\end{array}$ & $\begin{array}{l}\% \text { change } \\
\text { from } \\
\text { previous } \\
\text { model } \\
\end{array}$ \\
\hline 21 & $\begin{array}{l}\text { Model } 1+\text { LNI + Race/Ethnicity + Treatment Type + } \\
\text { Comorbidities + Current Lymphedema }\end{array}$ & $\begin{array}{l}0: \mathrm{HR}=2.32(1.27-4.26) \\
1: \mathrm{HR}=1.35(0.71-2.58) \\
2: \mathrm{HR}=1.00(\mathrm{REF}) \\
\mathrm{p}=0.0109\end{array}$ & 10 & $\begin{array}{l}n=341 \\
d=92\end{array}$ & $\begin{array}{l}0: 41.41 \% \\
1: 17.18 \%\end{array}$ & $\begin{array}{l}0: 1.69 \% \\
1: 0.00 \%\end{array}$ & $\begin{array}{l}0: 5.94 \% \\
1: 3.85 \%\end{array}$ \\
\hline 22 & $\begin{array}{l}\text { Model } 1 \text { + LNI + Race/Ethnicity + Treatment Type + } \\
\text { Comorbidities + Current Lymphedema + Pessimism }\end{array}$ & $\begin{array}{l}0: \mathrm{HR}=2.20(1.20-4.04) \\
1: \mathrm{HR}=1.37(0.72-2.61) \\
2: \mathrm{HR}=1.00(\mathrm{REF}) \\
\mathrm{p}=0.0222\end{array}$ & 10 & $\begin{array}{l}n=341 \\
d=92\end{array}$ & $\begin{array}{l}0: 44.44 \% \\
1: 15.95 \%\end{array}$ & $\begin{array}{l}0: 6.78 \% \\
1: 1.48 \%\end{array}$ & $\begin{array}{l}0: 5.17 \% \\
1: 1.48 \%\end{array}$ \\
\hline 23 & $\begin{array}{l}\text { Model } 1+\text { LNI }+ \text { Race/Ethnicity + Treatment Type }+ \\
\text { Comorbidities + Current Lymphedema + Pessimism }+ \\
\text { Confide }\end{array}$ & $\begin{array}{l}0: \mathrm{HR}=2.24(1.22-4.11) \\
1: \mathrm{HR}=1.40(0.74-2.68) \\
2: \mathrm{HR}=1.00(\mathrm{REF}) \\
\mathrm{p}=0.0206\end{array}$ & 10 & $\begin{array}{l}n=341 \\
d=92\end{array}$ & $\begin{array}{l}0: 43.43 \% \\
1: 14.11 \%\end{array}$ & $\begin{array}{l}0: 5.08 \% \\
1: 3.70 \%\end{array}$ & $\begin{array}{l}0: 1.82 \% \\
1: 2.19 \%\end{array}$ \\
\hline 24 & $\begin{array}{l}\text { Model } 1+\text { LNI + Race/Ethnicity + Treatment Type + } \\
\text { Comorbidities + Current Lymphedema + Pessimism }+ \\
\text { Confide + Fear of Recurrence }\end{array}$ & $\begin{array}{l}0: \mathrm{HR}=2.25(1.23-4.11) \\
1: \mathrm{HR}=1.42(0.74-2.70) \\
2: \mathrm{HR}=1.00(\mathrm{REF}) \\
\mathrm{p}=0.0207\end{array}$ & 10 & $\begin{array}{l}n=341 \\
d=92\end{array}$ & $\begin{array}{l}0: 43.18 \% \\
1: 12.88 \%\end{array}$ & $\begin{array}{l}0: 4.66 \% \\
1: 5.19 \%\end{array}$ & $\begin{array}{l}0: 0.45 \% \\
1: 1.43 \%\end{array}$ \\
\hline \multicolumn{8}{|c|}{ Subset--Restricted to participants with Education and LNI variables (24-month follow-up) } \\
\hline Crude & Physical Component Summary Score (PCS) & $\begin{array}{l}0: \mathrm{HR}=3.90(2.22-6.84) \\
1: \mathrm{HR}=1.63(0.87-3.07) \\
2: \mathrm{HR}=1.00(\mathrm{REF}) \\
\mathrm{p}=<0.0001\end{array}$ & 11 & $\begin{array}{l}n=340 \\
d=91\end{array}$ & -- & -- & -- \\
\hline
\end{tabular}




\begin{tabular}{|c|c|c|c|c|c|c|c|}
\hline Model & Variable(s) in model & $\begin{array}{l}\text { Physical Component } \\
\text { Summary Score (PCS) HR } \\
(95 \% \mathrm{CI})\end{array}$ & $\begin{array}{l}\text { Difference in } \\
\text { ' } \mathrm{N} \text { ' }\end{array}$ & $\begin{array}{l}\text { Total in model } \\
\text { (n) and total } \\
\text { dead (d) }\end{array}$ & $\begin{array}{l}\% \text { change } \\
\text { from Crude }\end{array}$ & $\begin{array}{l}\% \text { change } \\
\text { from model } \\
1\end{array}$ & $\begin{array}{l}\text { \% change } \\
\text { from } \\
\text { previous } \\
\text { model }\end{array}$ \\
\hline 1 & Age, Marital Status, \& Tumor Stage & $\begin{array}{l}0: \mathrm{HR}=2.33(1.29-4.21) \\
1: \mathrm{HR}=1.35(0.71-2.56) \\
2: \mathrm{HR}=1.00(\mathrm{REF}) \\
\mathrm{p}=0.0085\end{array}$ & 11 & $\begin{array}{l}n=340 \\
d=91\end{array}$ & $\begin{array}{l}0: 40.26 \% \\
1: 17.18 \%\end{array}$ & -- & -- \\
\hline 25 & Model $1+$ Education + LNI & $\begin{array}{l}0: \mathrm{HR}=2.31(1.27-4.18) \\
1: \mathrm{HR}=1.31(0.69-2.49) \\
2: \mathrm{HR}=1.00(\mathrm{REF}) \\
\mathrm{p}=0.0093\end{array}$ & 11 & $\begin{array}{l}n=340 \\
d=91\end{array}$ & $\begin{array}{l}0: 40.77 \% \\
1: 19.63 \%\end{array}$ & $\begin{array}{l}0: 0.86 \% \\
1: 2.96 \%\end{array}$ & -- \\
\hline 26 & Model 1 Education + LNI + Race/Ethnicity & $\begin{array}{l}0: H R=2.32(1.28-4.20) \\
1: H R=1.32(0.69-2.50) \\
2: H R=1.00(\text { REF }) \\
p=0.0086\end{array}$ & 11 & $\begin{array}{l}n=340 \\
d=91\end{array}$ & $\begin{array}{l}0: 40.51 \% \\
1: 19.02 \%\end{array}$ & $\begin{array}{l}0: 0.43 \% \\
1: 2.22 \%\end{array}$ & $\begin{array}{l}0: 0.43 \% \\
1: 0.76 \%\end{array}$ \\
\hline 27 & $\begin{array}{l}\text { Model } 1+\text { Education }+ \text { LNI + Race/Ethnicity }+ \text { Treatment } \\
\text { Type }\end{array}$ & $\begin{array}{l}0: \mathrm{HR}=2.23(1.23-4.04) \\
1: \mathrm{HR}=1.30(0.69-2.47) \\
2: \mathrm{HR}=1.00(\mathrm{REF}) \\
\mathrm{p}=0.0129\end{array}$ & 11 & $\begin{array}{l}n=340 \\
d=91\end{array}$ & $\begin{array}{l}0: 42.82 \% \\
1: 20.25 \%\end{array}$ & $\begin{array}{l}0: 4.29 \% \\
1: 3.70 \%\end{array}$ & $\begin{array}{l}0: 3.88 \% \\
1: 1.52 \%\end{array}$ \\
\hline 28 & $\begin{array}{l}\text { Model } 1+\text { Education }+ \text { LNI + Race/Ethnicity }+ \text { Treatment } \\
\text { Type }+ \text { Comorbidities }\end{array}$ & $\begin{array}{l}0: \mathrm{HR}=2.16(1.18-3.95) \\
1: \mathrm{HR}=1.28(0.67-2.43) \\
2: \mathrm{HR}=1.00(\mathrm{REF}) \\
\mathrm{p}=0.0202\end{array}$ & 11 & $\begin{array}{l}n=340 \\
d=91\end{array}$ & $\begin{array}{l}0: 44.62 \% \\
1: 21.47 \%\end{array}$ & $\begin{array}{l}0: 7.30 \% \\
1: 5.19 \%\end{array}$ & $\begin{array}{l}0: 7.30 \% \\
1: 1.54 \%\end{array}$ \\
\hline
\end{tabular}




\begin{tabular}{|c|c|c|c|c|c|c|c|}
\hline Model & Variable(s) in model & $\begin{array}{l}\text { Physical Component } \\
\text { Summary Score (PCS) HR } \\
(95 \% \mathrm{CI})\end{array}$ & $\begin{array}{l}\text { Difference in } \\
\text { ' } \mathrm{N} \text { ' }\end{array}$ & $\begin{array}{l}\text { Total in model } \\
\text { (n) and total } \\
\text { dead (d) }\end{array}$ & $\begin{array}{l}\% \text { change } \\
\text { from Crude }\end{array}$ & $\begin{array}{l}\% \text { change } \\
\text { from model } \\
1\end{array}$ & $\begin{array}{l}\% \text { change } \\
\text { from } \\
\text { previous } \\
\text { model }\end{array}$ \\
\hline 29 & $\begin{array}{l}\text { Model } 1+\text { Education + LNI + Race/Ethnicity + Treatment } \\
\text { Type + Comorbidities + Current Lymphedema }\end{array}$ & $\begin{array}{l}0: \mathrm{HR}=2.29(1.25-4.20) \\
1: \mathrm{HR}=1.34(0.70-2.55) \\
2: \mathrm{HR}=1.00(\mathrm{REF}) \\
\mathrm{p}=0.0128\end{array}$ & 11 & $\begin{array}{l}n=340 \\
d=91\end{array}$ & $\begin{array}{l}0: 41.28 \% \\
1: 17.79 \%\end{array}$ & $\begin{array}{l}0: 1.72 \% \\
1: 0.74 \%\end{array}$ & $\begin{array}{l}0: 6.02 \% \\
1: 4.69 \%\end{array}$ \\
\hline 30 & $\begin{array}{l}\text { Model } 1+\text { Education }+ \text { LNI + Race/Ethnicity }+ \text { Treatment } \\
\text { Type + Comorbidities + Current Lymphedema }+ \\
\text { Pessimism }\end{array}$ & $\begin{array}{l}0: \mathrm{HR}=2.16(1.18-3.95) \\
1: \mathrm{HR}=1.37(0.72-2.61) \\
2: \mathrm{HR}=1.00(\mathrm{REF}) \\
\mathrm{p}=0.0298\end{array}$ & 11 & $\begin{array}{l}\mathrm{n}=340 \\
\mathrm{~d}=91\end{array}$ & $\begin{array}{l}0: 44.62 \% \\
1: 15.95 \%\end{array}$ & $\begin{array}{l}0: 7.30 \% \\
1: 1.48 \%\end{array}$ & $\begin{array}{l}0: 5.68 \% \\
1: 2.24 \%\end{array}$ \\
\hline 31 & $\begin{array}{l}\text { Model } 1+\text { Education + LNI + Race/Ethnicity + Treatment } \\
\text { Type + Comorbidities + Current Lymphedema }+ \\
\text { Pessimism + Confide }\end{array}$ & $\begin{array}{l}0: H R=2.19(1.20-4.02) \\
1: H R=1.40(0.74-2.68) \\
2: H R=1.00(\text { REF }) \\
p=0.0274\end{array}$ & 11 & $\begin{array}{l}\mathrm{n}=340 \\
\mathrm{~d}=91\end{array}$ & $\begin{array}{l}0: 43.85 \% \\
1: 14.11 \%\end{array}$ & $\begin{array}{l}0: 6.01 \% \\
1: 3.70 \%\end{array}$ & $\begin{array}{l}0: 0.44 \% \\
1: 2.19 \%\end{array}$ \\
\hline 32 & $\begin{array}{l}\text { Model } 1+\text { Education + LNI + Race/Ethnicity + Treatment } \\
\text { Type + Comorbidities + Current Lymphedema }+ \\
\text { Pessimism + Confide + Fear of Recurrence }\end{array}$ & $\begin{array}{l}0: \mathrm{HR}=2.21(1.20-4.05) \\
1: \mathrm{HR}=1.42(0.74-2.72) \\
2: \mathrm{HR}=1.00(\mathrm{REF}) \\
\mathrm{p}=0.0268\end{array}$ & 11 & $\begin{array}{l}\mathrm{n}=340 \\
\mathrm{~d}=91\end{array}$ & $\begin{array}{l}0: 43.33 \% \\
1: 12.88 \%\end{array}$ & $\begin{array}{l}0: 5.15 \% \\
1: 5.19 \%\end{array}$ & $\begin{array}{l}0: 0.91 \% \\
1: 1.43 \%\end{array}$ \\
\hline \multicolumn{8}{|c|}{ Subset--Restricted to participants with Physical Activity variable (24-month follow-up) } \\
\hline Crude & Physical Component Summary Score (PCS) & $\begin{array}{l}0: \mathrm{HR}=3.55(2.04-6.17) \\
1: \mathrm{HR}=1.56(0.84-2.90) \\
2: \mathrm{HR}=1.00(\mathrm{REF}) \\
\mathrm{p}=<0.0001\end{array}$ & 21 & $\begin{array}{l}n=330 \\
d=91\end{array}$ & -- & -- & -- \\
\hline
\end{tabular}




\begin{tabular}{|c|c|c|c|c|c|c|c|}
\hline Model & Variable(s) in model & $\begin{array}{l}\text { Physical Component } \\
\text { Summary Score (PCS) HR } \\
(95 \% \mathrm{CI})\end{array}$ & $\begin{array}{l}\text { Difference in } \\
\text { ' } \mathrm{N} \text { ' }\end{array}$ & $\begin{array}{l}\text { Total in model } \\
\text { (n) and total } \\
\text { dead (d) }\end{array}$ & $\begin{array}{l}\% \text { change } \\
\text { from Crude }\end{array}$ & $\begin{array}{l}\% \text { change } \\
\text { from model } \\
1\end{array}$ & $\begin{array}{l}\% \text { change } \\
\text { from } \\
\text { previous } \\
\text { model } \\
\end{array}$ \\
\hline 1 & Age, Marital Status, \& Tumor Stage & $\begin{array}{l}0: \mathrm{HR}=2.18(1.22-3.91) \\
1: \mathrm{HR}=1.24(0.66-2.33) \\
2: \mathrm{HR}=1.00(\mathrm{REF}) \\
\mathrm{p}=0.0107\end{array}$ & 21 & $\begin{array}{l}\mathrm{n}=330 \\
\mathrm{~d}=91\end{array}$ & $\begin{array}{l}0: 38.59 \% \\
1: 20.51 \%\end{array}$ & -- & -- \\
\hline 33 & Model $1+$ Physical Activity & $\begin{array}{l}0: \mathrm{HR}=2.13(1.18-3.82) \\
1: \mathrm{HR}=1.22(0.65-2.28) \\
2: \mathrm{HR}=1.00(\mathrm{REF}) \\
\mathrm{p}=0.0143\end{array}$ & 21 & $\begin{array}{l}n=330 \\
d=91\end{array}$ & $\begin{array}{l}0: 40.00 \% \\
1: 21.79 \%\end{array}$ & $\begin{array}{l}0: 2.29 \% \\
1: 1.61 \%\end{array}$ & -- \\
\hline 34 & Model $1+$ Physical Activity + Race/Ethnicity & $\begin{array}{l}0: \mathrm{HR}=2.14(1.19-3.85) \\
1: \mathrm{HR}=1.21(0.65-2.27) \\
2: \mathrm{HR}=1.00(\mathrm{REF}) \\
\mathrm{p}=0.0130\end{array}$ & 21 & $\begin{array}{l}n=330 \\
d=91\end{array}$ & $\begin{array}{l}0: 39.72 \% \\
1: 22.44 \%\end{array}$ & $\begin{array}{l}0: 1.83 \% \\
1: 2.42 \%\end{array}$ & $\begin{array}{l}0: 0.47 \% \\
1: 0.82 \%\end{array}$ \\
\hline 35 & $\begin{array}{l}\text { Model } 1+\text { Physical Activity }+ \text { Race/Ethnicity }+ \text { Treatment } \\
\text { Type }\end{array}$ & $\begin{array}{l}0: \mathrm{HR}=2.03(1.13-3.64) \\
1: \mathrm{HR}=1.19(0.63-2.22) \\
2: \mathrm{HR}=1.00(\mathrm{REF}) \\
\mathrm{p}=0.0224\end{array}$ & 21 & $\begin{array}{l}n=330 \\
d=91\end{array}$ & $\begin{array}{l}0: 42.82 \% \\
1: 23.72 \%\end{array}$ & $\begin{array}{l}0: 6.88 \% \\
1: 4.03 \%\end{array}$ & $\begin{array}{l}0: 5.14 \% \\
1: 1.65 \%\end{array}$ \\
\hline 36 & $\begin{array}{l}\text { Model } 1+\text { Physical Activity }+ \text { Race/Ethnicity }+ \text { Treatment } \\
\text { Type }+ \text { Comorbidities }\end{array}$ & $\begin{array}{l}0: \mathrm{HR}=1.90(1.04-3.45) \\
1: \mathrm{HR}=1.17(0.62-2.20) \\
2: \mathrm{HR}=1.00(\mathrm{REF}) \\
\mathrm{p}=0.0549\end{array}$ & 21 & $\begin{array}{l}n=330 \\
d=91\end{array}$ & $\begin{array}{l}0: 46.48 \% \\
1: 25.00 \%\end{array}$ & $\begin{array}{l}\mathbf{0 :} \mathbf{1 2 . 8 4 \%} \\
1: 5.65 \%\end{array}$ & $\begin{array}{l}0: 6.40 \% \\
1: 1.68 \%\end{array}$ \\
\hline
\end{tabular}




\begin{tabular}{|c|c|c|c|c|c|c|c|}
\hline Model & Variable(s) in model & $\begin{array}{l}\text { Physical Component } \\
\text { Summary Score (PCS) HR } \\
(95 \% \mathrm{CI})\end{array}$ & $\begin{array}{l}\text { Difference in } \\
\text { ' } \mathrm{N}^{\prime}\end{array}$ & $\begin{array}{l}\text { Total in model } \\
\text { (n) and total } \\
\text { dead (d) }\end{array}$ & $\begin{array}{l}\% \text { change } \\
\text { from Crude }\end{array}$ & $\begin{array}{l}\% \text { change } \\
\text { from model } \\
1\end{array}$ & $\begin{array}{l}\% \text { change } \\
\text { from } \\
\text { previous } \\
\text { model }\end{array}$ \\
\hline 37 & $\begin{array}{l}\text { Model } 1+\text { Physical Activity + Race/Ethnicity + Treatment } \\
\text { Type + Comorbidities + Current Lymphedema }\end{array}$ & $\begin{array}{l}0: \mathrm{HR}=2.00(1.09-3.64) \\
1: \mathrm{HR}=1.21(0.65-2.28) \\
2: \mathrm{HR}=1.00(\mathrm{REF}) \\
\mathrm{p}=0.0386\end{array}$ & 21 & $\begin{array}{l}\mathrm{n}=330 \\
\mathrm{~d}=91\end{array}$ & $\begin{array}{l}0: 43.66 \% \\
1: 22.44 \%\end{array}$ & $\begin{array}{l}0: 8.26 \% \\
1: 2.42 \%\end{array}$ & $\begin{array}{l}0: 5.26 \% \\
1: 3.42 \%\end{array}$ \\
\hline 38 & $\begin{array}{l}\text { Model } 1+\text { Physical Activity }+ \text { Race/Ethnicity }+ \text { Treatment } \\
\text { Type }+ \text { Comorbidities }+ \text { Current Lymphedema }+ \\
\text { Pessimism }\end{array}$ & $\begin{array}{l}0: \mathrm{HR}=1.96(1.08-3.57) \\
1: \mathrm{HR}=1.24(0.66-2.32) \\
2: \mathrm{HR}=1.00(\mathrm{REF}) \\
\mathrm{p}=0.0523\end{array}$ & 21 & $\begin{array}{l}\mathrm{n}=330 \\
\mathrm{~d}=91\end{array}$ & $\begin{array}{l}0: 44.79 \% \\
1: 20.51 \%\end{array}$ & $\begin{array}{l}\mathbf{0 :} \mathbf{1 0 . 0 9 \%} \\
1: 0.00 \%\end{array}$ & $\begin{array}{l}0: 2.00 \% \\
1: 2.48 \%\end{array}$ \\
\hline 39 & $\begin{array}{l}\text { Model } 1+\text { Physical Activity + Race/Ethnicity + Treatment } \\
\text { Type + Comorbidities + Current Lymphedema }+ \\
\text { Pessimism + Confide }\end{array}$ & $\begin{array}{l}0: \mathrm{HR}=1.98(1.08-4.08) \\
1: \mathrm{HR}=1.26(0.67-2.36) \\
2: \mathrm{HR}=1.00(\mathrm{REF}) \\
\mathrm{p}=0.0521\end{array}$ & 21 & $\begin{array}{l}\mathrm{n}=330 \\
\mathrm{~d}=91\end{array}$ & $\begin{array}{l}0: 44.23 \% \\
1: 19.23 \%\end{array}$ & $\begin{array}{l}0: 9.17 \% \\
1: 1.61 \%\end{array}$ & $\begin{array}{l}0: 1.02 \% \\
1: 1.61 \%\end{array}$ \\
\hline 40 & $\begin{array}{l}\text { Model } 1+\text { Physical Activity }+ \text { Race/Ethnicity }+ \text { Treatment } \\
\text { Type }+ \text { Comorbidities }+ \text { Current Lymphedema }+ \\
\text { Pessimism + Confide + Fear of Recurrence }\end{array}$ & $\begin{array}{l}0: \mathrm{HR}=1.98(1.08-3.63) \\
1: \mathrm{HR}=1.26(0.67-2.36) \\
\text { 2: } \mathrm{HR}=1.00(\mathrm{REF}) \\
\mathrm{p}=0.0521\end{array}$ & 21 & $\begin{array}{l}\mathrm{n}=330 \\
\mathrm{~d}=91\end{array}$ & $\begin{array}{l}0: 44.23 \% \\
1: 19.23 \%\end{array}$ & $\begin{array}{l}0: 9.17 \% \\
1: 1.61 \%\end{array}$ & $\begin{array}{l}0: 0.00 \% \\
1: 0.00 \%\end{array}$ \\
\hline \multicolumn{8}{|c|}{ Subset--Restricted to participants with Education, LNI, and Physical Activity variables } \\
\hline Crude & Physical Component Summary Score (PCS) & $\begin{array}{l}0: \mathrm{HR}=3.62(2.05-6.41) \\
1: \mathrm{HR}=1.51(0.79-2.87) \\
\text { 2: } \mathrm{HR}=1.00(\mathrm{REF}) \\
\mathrm{p}=<0.0001\end{array}$ & 32 & $\begin{array}{l}n=319 \\
d=83\end{array}$ & -- & -- & -- \\
\hline
\end{tabular}




\begin{tabular}{|c|c|c|c|c|c|c|c|}
\hline Model & Variable(s) in model & $\begin{array}{l}\text { Physical Component } \\
\text { Summary Score (PCS) HR } \\
(95 \% \mathrm{CI})\end{array}$ & $\begin{array}{l}\text { Difference in } \\
\text { ' } \mathrm{N} \text { ' }\end{array}$ & $\begin{array}{l}\text { Total in model } \\
\text { (n) and total } \\
\text { dead (d) }\end{array}$ & $\begin{array}{l}\% \text { change } \\
\text { from Crude }\end{array}$ & $\begin{array}{l}\% \text { change } \\
\text { from model } \\
1\end{array}$ & $\begin{array}{l}\% \text { change } \\
\text { from } \\
\text { previous } \\
\text { model } \\
\end{array}$ \\
\hline 1 & Age, Marital Status, \& Tumor Stage & $\begin{array}{l}0: H R=2.17(1.19-3.98) \\
1: H R=1.25(0.65-2.40) \\
2: H R=1.00(\text { REF }) \\
p=0.0186\end{array}$ & 32 & $\begin{array}{l}n=319 \\
d=83\end{array}$ & $\begin{array}{l}0: 40.06 \% \\
1: 17.22 \%\end{array}$ & -- & -- \\
\hline 41 & Model $1+$ Education + LNI + Physical Activity & $\begin{array}{l}0: \mathrm{HR}=2.13(1.15-3.93) \\
1: \mathrm{HR}=1.23(0.64-2.36) \\
2: \mathrm{HR}=1.00(\mathrm{REF}) \\
\mathrm{p}=0.0258\end{array}$ & 32 & $\begin{array}{l}n=319 \\
d=83\end{array}$ & $\begin{array}{l}0: 41.16 \% \\
1: 18.54 \%\end{array}$ & $\begin{array}{l}0: 1.84 \% \\
1: 1.60 \%\end{array}$ & -- \\
\hline 42 & $\begin{array}{l}\text { Model } 1+\text { Education + LNI + Physical Activity + } \\
\text { Race/Ethnicity }\end{array}$ & $\begin{array}{l}0: \mathrm{HR}=2.14(1.16-3.95) \\
1: \mathrm{HR}=1.23(0.64-2.35) \\
2: \mathrm{HR}=1.00(\mathrm{REF}) \\
\mathrm{p}=0.0241\end{array}$ & 32 & $\begin{array}{l}n=319 \\
d=83\end{array}$ & $\begin{array}{l}0: 40.88 \% \\
1: 18.54 \%\end{array}$ & $\begin{array}{l}0: 1.38 \% \\
1: 1.60 \%\end{array}$ & $\begin{array}{l}0: 0.47 \% \\
1: 0.00 \%\end{array}$ \\
\hline 43 & $\begin{array}{l}\text { Model } 1+\text { Education + LNI + Physical Activity + } \\
\text { Race/Ethnicity + Treatment Type }\end{array}$ & $\begin{array}{l}0: \mathrm{HR}=2.01(1.09-3.71) \\
1: \mathrm{HR}=1.22(0.64-2.34) \\
2: \mathrm{HR}=1.00(\mathrm{REF}) \\
\mathrm{p}=0.0444\end{array}$ & 32 & $\begin{array}{l}n=319 \\
d=83\end{array}$ & $\begin{array}{l}0: 44.48 \% \\
1: 19.21 \%\end{array}$ & $\begin{array}{l}0: 7.37 \% \\
1: 2.40 \%\end{array}$ & $\begin{array}{l}0: 6.07 \% \\
1: 0.81 \%\end{array}$ \\
\hline 44 & $\begin{array}{l}\text { Model } 1+\text { Education }+ \text { LNI }+ \text { Physical Activity }+ \\
\text { Race/Ethnicity }+ \text { Treatment Type + Comorbidities }\end{array}$ & $\begin{array}{l}0: \mathrm{HR}=1.93(1.04-3.61) \\
1: \mathrm{HR}=1.21(0.63-2.32) \\
2: \mathrm{HR}=1.00(\mathrm{REF}) \\
\mathrm{p}=0.0707\end{array}$ & 32 & $\begin{array}{l}n=319 \\
d=83\end{array}$ & $\begin{array}{l}0: 46.69 \% \\
1: 19.87 \%\end{array}$ & $\begin{array}{l}\mathbf{0 :} \mathbf{1 1 . 0 6 \%} \\
1: 3.20 \%\end{array}$ & $\begin{array}{l}0: 3.98 \% \\
1: 0.82 \%\end{array}$ \\
\hline
\end{tabular}




\begin{tabular}{|c|c|c|c|c|c|c|c|}
\hline Model & Variable(s) in model & $\begin{array}{l}\text { Physical Component } \\
\text { Summary Score (PCS) HR } \\
(95 \% \text { CI) }\end{array}$ & $\begin{array}{l}\text { Difference in } \\
\text { ' } \mathrm{N} \text { ' }\end{array}$ & $\begin{array}{l}\text { Total in model } \\
\text { (n) and total } \\
\text { dead (d) }\end{array}$ & $\begin{array}{l}\% \text { change } \\
\text { from Crude }\end{array}$ & $\begin{array}{l}\% \text { change } \\
\text { from model } \\
1\end{array}$ & $\begin{array}{l}\% \text { change } \\
\text { from } \\
\text { previous } \\
\text { model }\end{array}$ \\
\hline 45 & $\begin{array}{l}\text { Model } 1+\text { Education }+ \text { LNI }+ \text { Physical Activity }+ \\
\text { Race/Ethnicity + Treatment Type + Comorbidities + } \\
\text { Current Lymphedema }\end{array}$ & $\begin{array}{l}0: \mathrm{HR}=2.05(1.09-3.83) \\
1: \mathrm{HR}=1.26(0.65-2.42) \\
\text { 2: } \mathrm{HR}=1.00(\mathrm{REF}) \\
\mathrm{p}=0.0504\end{array}$ & 32 & $\begin{array}{l}n=319 \\
d=83\end{array}$ & $\begin{array}{l}0: 43.37 \% \\
1: 16.56 \%\end{array}$ & $\begin{array}{l}0: 5.53 \% \\
1: 0.80 \%\end{array}$ & $\begin{array}{l}0: 6.22 \% \\
1: 4.13 \%\end{array}$ \\
\hline 46 & $\begin{array}{l}\text { Model } 1+\text { Education }+ \text { LNI + Physical Activity }+ \\
\text { Race/Ethnicity + Treatment Type + Comorbidities + } \\
\text { Current Lymphedema + Pessimism }\end{array}$ & $\begin{array}{l}0: \mathrm{HR}=2.00(1.07-3.74) \\
\text { 1: } \mathrm{HR}=1.29(0.67-2.48) \\
\text { 2: } \mathrm{HR}=1.00(\mathrm{REF}) \\
\mathrm{p}=0.0666\end{array}$ & 32 & $\begin{array}{l}n=319 \\
d=83\end{array}$ & $\begin{array}{l}0: 44.75 \% \\
1: 14.57 \%\end{array}$ & $\begin{array}{l}0: 7.83 \% \\
1: 3.20 \%\end{array}$ & $\begin{array}{l}0: 2.44 \% \\
1: 2.38 \%\end{array}$ \\
\hline 47 & $\begin{array}{l}\text { Model } 1+\text { Education }+ \text { LNI + Physical Activity }+ \\
\text { Race/Ethnicity + Treatment Type + Comorbidities + } \\
\text { Current Lymphedema + Pessimism + Confide }\end{array}$ & $\begin{array}{l}0: \mathrm{HR}=2.05(1.09-3.85) \\
1: \mathrm{HR}=1.31(0.68-2.54) \\
\text { 2: } \mathrm{HR}=1.00(\mathrm{REF}) \\
\mathrm{p}=0.0617\end{array}$ & 32 & $\begin{array}{l}n=319 \\
d=83\end{array}$ & $\begin{array}{l}\text { 0: } 43.37 \% \\
1: 13.25 \%\end{array}$ & $\begin{array}{l}0: 5.53 \% \\
1: 4.80 \%\end{array}$ & $\begin{array}{l}0: 2.50 \% \\
1: 1.55 \%\end{array}$ \\
\hline 48 & $\begin{array}{l}\text { Model } 1 \text { + Education + LNI + Physical Activity + } \\
\text { Race/Ethnicity + Treatment Type + Comorbidities + } \\
\text { Current Lymphedema + Pessimism + Confide + Fear of } \\
\text { Recurrence }\end{array}$ & $\begin{array}{l}0: \mathrm{HR}=2.05(1.09-3.86) \\
\text { 1: } \mathrm{HR}=1.32(0.68-2.56) \\
\text { 2: } \mathrm{HR}=1.00 \text { (REF) } \\
\mathrm{p}=0.0622\end{array}$ & 32 & $\begin{array}{l}n=319 \\
d=83\end{array}$ & $\begin{array}{l}0: 43.37 \% \\
1: 12.58 \%\end{array}$ & $\begin{array}{l}0: 5.53 \% \\
1: 5.60 \%\end{array}$ & $\begin{array}{l}0: 0.00 \% \\
1: 0.76 \%\end{array}$ \\
\hline
\end{tabular}


Appendix E. Mental Component Summary Score Univariate HR Analysis and Percent Change for All-Cause Mortality when Assessing for Potential Confounders $(N=351)$

\begin{tabular}{|c|c|c|c|c|c|c|c|c|c|}
\hline Model & Variable(s) in model & Categories & $\begin{array}{l}\text { Total in } \\
\text { categories } \\
\text { (n) }\end{array}$ & $\begin{array}{l}\text { Total } \\
\text { in } \\
\text { model } \\
(\mathrm{n}) ; \\
\text { dead } \\
\text { (d) } \\
\end{array}$ & Missing & Univariate-Cox HR (95\% CI) & p-values* & $\begin{array}{l}\text { MCS HR }(95 \% \mathrm{CI}) \text { and p- } \\
\text { values }\end{array}$ & $\begin{array}{l}\% \text { change } \\
\text { from crude } \\
\text { model }\end{array}$ \\
\hline Crude & $\begin{array}{l}\text { Mental Component } \\
\text { Summary Score (MCS) }\end{array}$ & $\begin{array}{l}0: \leq 45.12 \\
1:>45.12 \& \leq 54.40 \\
2:>54.40(\mathrm{REF})\end{array}$ & $\begin{array}{l}0: 117 \\
1: 117 \\
2: 117\end{array}$ & $\begin{array}{l}n=351 \\
d=99\end{array}$ & 0 & $\begin{array}{l}0: \mathrm{HR}=1.36(0.83-2.23) \\
1: \mathrm{HR}=1.25(0.76-2.06)\end{array}$ & $\mathrm{p}=0.4590$ & $\begin{array}{l}0: H R=1.36(0.83-2.23) \\
p(M C S)=0.4590 \\
1: H R=1.25(0.76-2.06) \\
p(M C S)=0.3760\end{array}$ & -- \\
\hline 1 & Age & Continuous & -- & $\begin{array}{l}\mathrm{n}=351 \\
\mathrm{~d}=99\end{array}$ & 0 & $\mathrm{HR}=1.07(1.05-1.09)$ & $\mathrm{p}=<0.0001$ & $\begin{array}{l}0: \mathrm{HR}=1.66(1.01-2.72) \\
\mathrm{p}(\mathrm{MCS})=0.0461 \\
1: \mathrm{HR}=1.34(0.81-2.20) \\
\mathrm{p}(\mathrm{MCS})=0.2496 \\
\mathrm{p}(\mathrm{Age})=<0.0001\end{array}$ & $\begin{array}{l}0: 22.06 \% \\
1: 7.20 \%\end{array}$ \\
\hline 2 & Race/Ethnicity & $\begin{array}{l}\text { 0: Non-Hispanic } \\
\text { White (REF) } \\
\text { Hispanic }\end{array}$ & $\begin{array}{l}0: 273 \\
1: 78\end{array}$ & $\begin{array}{l}\mathrm{n}=351 \\
\mathrm{~d}=99\end{array}$ & 0 & $\begin{array}{l}0: \mathrm{HR}=1.00 \\
1: \mathrm{HR}=0.64(0.37-1.09)\end{array}$ & $p=0.1015$ & $\begin{array}{l}0: \mathrm{HR}=1.41(0.86-2.32) \\
\mathrm{p}(\mathrm{MCS})=0.1720 \\
1: \mathrm{HR}=1.28(0.78-2.11) \\
\mathrm{p}(\mathrm{MCS})=0.3275 \\
\mathrm{p}(\text { Ethnicity })=0.1015\end{array}$ & $\begin{array}{l}0: 3.68 \% \\
1: 2.40 \%\end{array}$ \\
\hline 3 & Marital Status & $\begin{array}{l}0 \text { : Single } \\
\text { 1: Married (REF) }\end{array}$ & $\begin{array}{l}0: 160 \\
1: 191\end{array}$ & $\begin{array}{l}\mathrm{n}=351 \\
\mathrm{~d}=99\end{array}$ & 0 & $\begin{array}{l}0: \mathrm{HR}=1.99(1.33-2.98) \\
1: \mathrm{HR}=1.00\end{array}$ & $p=0.0008$ & $\begin{array}{l}0: \mathrm{HR}=1.35(0.83-2.22) \\
\mathrm{p}(\mathrm{MCS})=0.2290 \\
1: \mathrm{HR}=1.29(0.78-2.12) \\
\mathrm{p}(\mathrm{MCS})=0.3201 \\
\mathrm{p}(\text { Marital })=0.0008\end{array}$ & $\begin{array}{l}0: 0.74 \% \\
1: 3.20 \%\end{array}$ \\
\hline
\end{tabular}




\begin{tabular}{|c|c|c|c|c|c|c|c|c|c|}
\hline Model & Variable(s) in model & Categories & $\begin{array}{l}\text { Total in } \\
\text { categories } \\
\text { (n) }\end{array}$ & $\begin{array}{l}\text { Total } \\
\text { in } \\
\text { model } \\
\text { (n); } \\
\text { dead } \\
\text { (d) } \\
\end{array}$ & Missing & Univariate-Cox HR $(95 \% \mathrm{CI})$ & p-values* & $\begin{array}{l}\text { MCS HR }(95 \% \mathrm{CI}) \text { and } \mathrm{p}- \\
\text { values }\end{array}$ & $\begin{array}{l}\% \text { change } \\
\text { from crude } \\
\text { model }\end{array}$ \\
\hline 4 & Tumor Stage & $\begin{array}{l}\text { 0: Localized (I) } \\
\text { 1: Regional (II-IIIa) }\end{array}$ & $\begin{array}{l}0: 276 \\
1: 75\end{array}$ & $\begin{array}{l}\mathrm{n}=351 \\
\mathrm{~d}=99\end{array}$ & 0 & $\begin{array}{l}0: H R=1.00 \\
1: H R=1.20(0.76-1.90)\end{array}$ & $\mathrm{p}=0.4442$ & $\begin{array}{l}0: \mathrm{HR}=1.38(0.84-2.26) \\
\mathrm{p}(\mathrm{MCS})=0.2050 \\
1: \mathrm{HR}=1.26(0.76-2.07) \\
\mathrm{p}(\mathrm{MCS})=0.3682 \\
\mathrm{p}(\mathrm{Stage})=0.4442\end{array}$ & $\begin{array}{l}0: 1.47 \% \\
1: 0.80 \%\end{array}$ \\
\hline 5 & $\begin{array}{l}\text { Breast Cancer Treatment } \\
\text { Type }\end{array}$ & $\begin{array}{l}0: \text { Surgery only (REF) } \\
\text { 1: Any chemotherapy } \\
\text { 2: Surgery and } \\
\text { radiation }\end{array}$ & $\begin{array}{l}0: 98 \\
1: 109 \\
2: 144\end{array}$ & $\begin{array}{l}\mathrm{n}=351 \\
\mathrm{~d}=99\end{array}$ & 0 & $\begin{array}{l}0: H R=1.00 \\
1: H R=0.69(0.42-1.14) \\
2: H R=0.69(0.43-1.10)\end{array}$ & $\mathrm{p}=0.2202$ & $\begin{array}{l}0: \mathrm{HR}=1.37(0.84-2.25) \\
\mathrm{p}(\mathrm{MCS}=0.2111 \\
1: \mathrm{HR}=1.25(0.76-2.06) \\
\mathrm{p}(\mathrm{MCS})=0.3777 \\
\mathrm{p}(\text { Treatment1 } 1=0.1492 \\
\mathrm{p}(\text { Treatment2) }=0.1211\end{array}$ & $\begin{array}{l}0: 0.74 \% \\
1: 0.00 \%\end{array}$ \\
\hline 6 & Comorbidities & $\begin{array}{l}0: \text { Zero (REF) } \\
\text { 1: One or more }\end{array}$ & $\begin{array}{l}0: 298 \\
1: 53\end{array}$ & $\begin{array}{l}n=351 \\
d=99\end{array}$ & 0 & $\begin{array}{l}0: H R=1.00 \\
1: H R=1.96(1.22-3.14)\end{array}$ & $\mathrm{p}=\mathbf{0 . 0 0 5 6}$ & $\begin{array}{l}0: \mathrm{HR}=1.25(0.76-2.05) \\
\mathrm{p}(\mathrm{MCS})=0.3898 \\
1: \mathrm{HR}=1.23(0.75-2.03) \\
\mathrm{p}(\mathrm{MCS})=0.4095 \\
\mathrm{p}(\text { Comorbidities })=0.0056\end{array}$ & $\begin{array}{l}0: 8.09 \% \\
1: 1.60 \%\end{array}$ \\
\hline 7 & Current Lymphedema & $\begin{array}{l}0: \text { No (REF) } \\
1: \text { Yes }\end{array}$ & $\begin{array}{l}0: 307 \\
1: 44\end{array}$ & $\begin{array}{l}\mathrm{n}=351 \\
\mathrm{~d}=99\end{array}$ & 0 & $\begin{array}{l}0: H R=1.00 \\
1: H R=0.61(0.31-1.21)\end{array}$ & $p=0.1586$ & $\begin{array}{l}0: \mathrm{HR}=1.43(0.87-2.35) \\
\mathrm{p}(\mathrm{MCS})=0.1612 \\
1: \mathrm{HR}=1.27(0.77-2.09) \\
\mathrm{p}(\mathrm{MCS})=0.3417 \\
\mathrm{p}(\text { Lymphedema })=0.0524\end{array}$ & $\begin{array}{l}0: 5.15 \% \\
1: 1.57 \%\end{array}$ \\
\hline
\end{tabular}




\begin{tabular}{|c|c|c|c|c|c|c|c|c|c|}
\hline Model & Variable(s) in model & Categories & $\begin{array}{l}\text { Total in } \\
\text { categories } \\
\text { (n) }\end{array}$ & $\begin{array}{l}\text { Total } \\
\text { in } \\
\text { model } \\
\text { (n); } \\
\text { dead } \\
\text { (d) } \\
\end{array}$ & Missing & Univariate-Cox HR $(95 \% \mathrm{CI})$ & p-values* & $\begin{array}{l}\text { MCS HR }(95 \% \mathrm{CI}) \text { and p- } \\
\text { values }\end{array}$ & $\begin{array}{l}\% \text { change } \\
\text { from crude } \\
\text { model }\end{array}$ \\
\hline 8 & Perceived Optimism & $\begin{array}{l}0: \leq 10 \\
1:>10 \text { (REF) }\end{array}$ & $\begin{array}{l}0: 83 \\
1: 268\end{array}$ & $\begin{array}{l}n=351 \\
d=99\end{array}$ & 0 & $\begin{array}{l}0: \mathrm{HR}=1.51(0.99-2.41) \\
1: \mathrm{HR}=1.00\end{array}$ & $\mathrm{p}=0.0519$ & $\begin{array}{l}0: \mathrm{HR}=1.20(0.72-2.00) \\
\mathrm{p}(\mathrm{MCS})=0.4913 \\
1: \mathrm{HR}=1.17(0.71-1.94) \\
\mathrm{p}(\mathrm{MCS})=0.5348 \\
\mathrm{p}(\text { Optimism })=0.0519\end{array}$ & $\begin{array}{l}\mathbf{0 :} \mathbf{1 1 . 7 6 \%} \\
1: 6.40 \%\end{array}$ \\
\hline 9 & Perceived Pessimism & $\begin{array}{l}0: \leq 10 \text { (REF) } \\
1:>10\end{array}$ & $\begin{array}{l}0: 255 \\
1: 96\end{array}$ & $\begin{array}{l}n=351 \\
d=99\end{array}$ & 0 & $\begin{array}{l}0: \mathrm{HR}=1.00 \\
1: \mathrm{HR}=1.69(1.10-2.58)\end{array}$ & $p=0.0146$ & $\begin{array}{l}0: H R=1.19(0.71-1.97) \\
p(M C S)=0.5096 \\
1: H R=1.17(0.71-1.94) \\
p(M C S)=0.5330 \\
p(\text { Pessimism })=0.0146\end{array}$ & $\begin{array}{l}\mathbf{0 :} \mathbf{1 2 . 5 0 \%} \\
1: 6.40 \%\end{array}$ \\
\hline 10 & Current Fatigue & $\begin{array}{l}0: \text { No (REF) } \\
\text { 1: Yes }\end{array}$ & $\begin{array}{l}0: 136 \\
1: 215\end{array}$ & $\begin{array}{l}n=351 \\
d=99\end{array}$ & 0 & $\begin{array}{l}0: \mathrm{HR}=1.00 \\
1: \mathrm{HR}=0.86(0.55-1.35)\end{array}$ & $\mathrm{p}=0.5080$ & $\begin{array}{l}0: H R=1.47(0.85-2.54) \\
\mathrm{p}(\mathrm{MCS})=0.1664 \\
1: \mathrm{HR}=1.29(0.78-2.14) \\
\mathrm{p}(\mathrm{MCS})=0.3237 \\
\mathrm{p}(\text { Fatigue })=0.5080\end{array}$ & $\begin{array}{l}0: 8.09 \% \\
1: 3.20 \%\end{array}$ \\
\hline 11 & Fear of Recurrence & $\begin{array}{l}0: \text { No (REF) } \\
1: \text { Yes }\end{array}$ & $\begin{array}{l}0: 154 \\
1: 197\end{array}$ & $\begin{array}{l}n=351 \\
d=99\end{array}$ & 0 & $\begin{array}{l}0: \mathrm{HR}=1.00 \\
1: \mathrm{HR}=0.64(0.43-0.96)\end{array}$ & $\mathrm{p}=\mathbf{0 . 0 3 1 3}$ & $\begin{array}{l}0: \mathrm{HR}=1.49(0.90-2.46) \\
\mathrm{p}(\mathrm{MCS})=0.1177 \\
1: \mathrm{HR}=1.34(0.81-2.21) \\
\mathrm{p}(\mathrm{MCS})=0.2528 \\
\mathrm{p}(\text { Fear })=0.0313\end{array}$ & $\begin{array}{l}0: 9.56 \% \\
1: 7.20 \%\end{array}$ \\
\hline
\end{tabular}




\begin{tabular}{|c|c|c|c|c|c|c|c|c|c|}
\hline Model & Variable(s) in model & Categories & $\begin{array}{l}\text { Total in } \\
\text { categories } \\
\text { (n) }\end{array}$ & $\begin{array}{l}\text { Total } \\
\text { in } \\
\text { model } \\
\text { (n); } \\
\text { dead } \\
\text { (d) } \\
\end{array}$ & Missing & Univariate-Cox HR $(95 \% \mathrm{CI})$ & p-values* & $\begin{array}{l}\text { MCS HR }(95 \% \mathrm{CI}) \text { and p- } \\
\text { values }\end{array}$ & $\begin{array}{l}\% \text { change } \\
\text { from crude } \\
\text { model }\end{array}$ \\
\hline 12 & $\begin{array}{l}\text { Number of Types of } \\
\text { Confidants }\end{array}$ & $\begin{array}{l}0:<3 \\
1: 4-5 \\
2:>5(\mathrm{REF})\end{array}$ & $\begin{array}{l}0: 66 \\
1: 172 \\
2: 113\end{array}$ & $\begin{array}{l}\mathrm{n}=351 \\
\mathrm{~d}=99\end{array}$ & 0 & $\begin{array}{l}0: H R=1.76(1.01-3.04) \\
1: H R=1.23(0.76-1.98) \\
2: H R=1.00\end{array}$ & $\mathrm{p}=0.1241$ & $\begin{array}{l}\text { 0: } \mathrm{HR}=1.35(0.82-2.22) \\
\mathrm{p}(\mathrm{MCS})=0.2328 \\
\text { 1: } \mathrm{HR}=1.26(0.76-2.06) \\
\mathrm{p}(\mathrm{MCS})=0.3710 \\
\mathrm{p}(\text { Confidant } 0)=0.0444 \\
\mathrm{p}(\text { Confidant } 1)=0.4031\end{array}$ & $\begin{array}{l}0: 0.74 \% \\
1: 0.80 \%\end{array}$ \\
\hline 13 & Bodily Pain & $\begin{array}{l}\text { 0: No Pain } \\
\text { 1: Experienced Pain } \\
\text { (REF) }\end{array}$ & $\begin{array}{l}0: 180 \\
1: 171\end{array}$ & $\begin{array}{l}\mathrm{n}=351 \\
\mathrm{~d}=99\end{array}$ & 0 & $\begin{array}{l}0: \mathrm{HR}=1.00 \\
1: \mathrm{HR}=1.60(0.96-2.67)\end{array}$ & $p=0.0746$ & $\begin{array}{l}0: H R=0.84(0.36-1.96) \\
\mathrm{p}(\mathrm{MCS})=0.6864 \\
1: \mathrm{HR}=0.95(0.49-1.84) \\
\mathrm{p}(\mathrm{MCS})=0.8795 \\
\mathrm{p}(\text { Pain })=0.0746\end{array}$ & $\begin{array}{l}0: 38.24 \% \\
1: 24.00 \%\end{array}$ \\
\hline 14 & $\begin{array}{l}\text { Perceived General } \\
\text { Health }\end{array}$ & $\begin{array}{l}\text { 0: "Poor" \& "Fair" } \\
\text { 1: "Good", "Very } \\
\text { Good", \& "Excellent" } \\
\text { (REF) }\end{array}$ & $\begin{array}{l}0: 54 \\
1: 297\end{array}$ & $\begin{array}{l}\mathrm{n}=351 \\
\mathrm{~d}=99\end{array}$ & 0 & $\begin{array}{l}0: \mathrm{HR}=2.43(1.53-3.85) \\
1: \mathrm{HR}=1.00\end{array}$ & $\mathrm{p}=\mathbf{0 . 0 0 0 2}$ & $\begin{array}{l}0: H R=1.08(0.64-1.80) \\
p(M C S)=0.7809 \\
1: \text { HR }=1.21(0.73-1.98) \\
p(\text { MCS })=0.4627 \\
\text { p(Health })=0.0797\end{array}$ & $\begin{array}{l}\mathbf{0 : 2 0 . 5 9 \%} \\
1: 3.20 \%\end{array}$ \\
\hline Crude & $\begin{array}{l}\text { MCS (restricted to those } \\
\text { with education) }\end{array}$ & & $\begin{array}{l}0: 117 \\
1: 116 \\
2: 117\end{array}$ & $\begin{array}{l}\mathrm{n}=350 \\
\mathrm{~d}=98\end{array}$ & & $\begin{array}{l}0: \mathrm{HR}=1.36(0.83-2.23) \\
1: \mathrm{HR}=1.22(0.74-2.01)\end{array}$ & $\mathrm{p}=0.4697$ & $\begin{array}{l}0: \mathrm{HR}=1.36(0.83-2.23) \\
\mathrm{p}(\mathrm{MCS})=0.2210 \\
1: \mathrm{HR}=1.22(0.74-2.01) \\
\mathrm{p}(\mathrm{MCS})=0.4374\end{array}$ & -- \\
\hline
\end{tabular}




\begin{tabular}{|c|c|c|c|c|c|c|c|c|c|}
\hline Model & Variable(s) in model & Categories & $\begin{array}{l}\text { Total in } \\
\text { categories } \\
\text { (n) }\end{array}$ & $\begin{array}{l}\text { Total } \\
\text { in } \\
\text { model } \\
\text { (n); } \\
\text { dead } \\
\text { (d) } \\
\end{array}$ & Missing & Univariate-Cox HR $(95 \%$ CI) & p-values* & $\begin{array}{l}\text { MCS HR }(95 \% \mathrm{CI}) \text { and } \mathrm{p}- \\
\text { values }\end{array}$ & $\begin{array}{l}\% \text { change } \\
\text { from crude } \\
\text { model }\end{array}$ \\
\hline 15 & Education & $\begin{array}{l}\text { 0: High school or less } \\
\text { 1: Some college } \\
\text { 2: College graduate } \\
\text { 3: Graduate school } \\
\text { (REF) }\end{array}$ & $\begin{array}{l}0: 92 \\
1: 114 \\
2: 70 \\
3: 74\end{array}$ & $\begin{array}{l}\mathrm{n}=350 \\
\mathrm{~d}=98\end{array}$ & 1 & $\begin{array}{l}0: H R=1.88(1.03-3.45) \\
1: H R=1.55(0.86-2.78) \\
2: H R=0.87(0.42-1.81) \\
3: H R=1.00\end{array}$ & $\mathrm{p}=0.0504$ & $\begin{array}{l}0: \mathrm{HR}=1.33(0.81-2.19) \\
\mathrm{p}(\mathrm{MCS})=0.2554 \\
1: \mathrm{HR}=1.27(0.77-2.11) \\
\mathrm{p}(\mathrm{MCS})=0.3461 \\
\mathrm{p}(\text { Education} 0)=0.0408 \\
\mathrm{p}(\text { Education } 1)=0.1415 \\
\mathrm{p}(\text { Education} 2)=0.7046\end{array}$ & $\begin{array}{l}0: 2.21 \% \\
1: 4.10 \%\end{array}$ \\
\hline Crude & $\begin{array}{l}\text { MCS (restricted to those } \\
\text { with tumor size) }\end{array}$ & & $\begin{array}{l}0: 113 \\
1: 114 \\
2: 114\end{array}$ & $\begin{array}{l}\mathrm{n}=341 \\
\mathrm{~d}=99\end{array}$ & & $\begin{array}{l}0: \mathrm{HR}=1.38(0.84-2.27) \\
1: \mathrm{HR}=1.26(0.78-2.07)\end{array}$ & $\mathrm{p}=0.4244$ & $\begin{array}{l}0: \mathrm{HR}=1.38(0.84-2.27) \\
\mathrm{p}(\mathrm{MCS})=0.1979 \\
1: \mathrm{HR}=1.26(0.78-2.07) \\
\mathrm{p}(\mathrm{MCS})=0.3593\end{array}$ & -- \\
\hline 16 & Tumor Size & $\begin{array}{l}0:<3 \mathrm{~cm} \text { (REF) } \\
1: \geq 3 \mathrm{~cm}\end{array}$ & $\begin{array}{l}0: 304 \\
1: 37\end{array}$ & $\begin{array}{l}\mathrm{n}=341 \\
\mathrm{~d}=99\end{array}$ & 10 & $\begin{array}{l}0: \mathrm{HR}=1.00 \\
1: \mathrm{HR}=1.21(0.66-2.21)\end{array}$ & $\mathrm{p}=0.5424$ & $\begin{array}{l}0: \mathrm{HR}=1.38(0.84-2.26) \\
\mathrm{p}(\mathrm{MCS})=0.2021 \\
1: \mathrm{HR}=1.27(0.77-2.08) \\
\mathrm{p}(\mathrm{MCS})=0.3527 \\
\mathrm{p}(\text { Size })=0.5424\end{array}$ & $\begin{array}{l}0: 0.00 \% \\
1: 0.79 \%\end{array}$ \\
\hline Crude & $\begin{array}{l}\text { MCS (restricted to those } \\
\text { with lymph node } \\
\text { involvement) }\end{array}$ & & $\begin{array}{l}0: 112 \\
1: 114 \\
2: 115\end{array}$ & $\begin{array}{l}\mathrm{n}=341 \\
\mathrm{~d}=92\end{array}$ & & $\begin{array}{l}0: \mathrm{HR}=1.18(0.71-1.96) \\
1: \mathrm{HR}=1.19(0.72-1.97)\end{array}$ & $\mathrm{p}=0.7579$ & $\begin{array}{l}0: \mathrm{HR}=1.18(0.71-1.96) \\
\mathrm{p}(\mathrm{MCS})=0.5337 \\
1: \mathrm{HR}=1.19(0.72-1.97) \\
\mathrm{p}(\mathrm{MCS})=0.4980\end{array}$ & -- \\
\hline
\end{tabular}




\begin{tabular}{|c|c|c|c|c|c|c|c|c|c|}
\hline Model & Variable(s) in model & Categories & $\begin{array}{l}\text { Total in } \\
\text { categories } \\
\text { (n) }\end{array}$ & $\begin{array}{l}\text { Total } \\
\text { in } \\
\text { model } \\
(\mathrm{n}) ; \\
\text { dead } \\
\text { (d) } \\
\end{array}$ & Missing & Univariate-Cox HR $(95 \% \mathrm{CI})$ & p-values* & $\begin{array}{l}\text { MCS HR }(95 \% \mathrm{CI}) \text { and p- } \\
\text { values }\end{array}$ & $\begin{array}{l}\% \text { change } \\
\text { from crude } \\
\text { model }\end{array}$ \\
\hline 17 & $\begin{array}{l}\text { Lymph Node } \\
\text { Involvement }\end{array}$ & $\begin{array}{l}0: \text { None }(\mathrm{REF}) \\
1: \geq 1 \text { lymph node } \\
\text { involved }\end{array}$ & $\begin{array}{l}0: 264 \\
1: 77\end{array}$ & $\begin{array}{l}\mathrm{n}=341 \\
\mathrm{~d}=92\end{array}$ & 10 & $\begin{array}{l}0: \mathrm{HR}=1.00 \\
1: \mathrm{HR}=1.25(0.78-1.99)\end{array}$ & $\mathrm{p}=0.3564$ & $\begin{array}{l}0: \mathrm{HR}=1.19(0.71-1.99) \\
\mathrm{p}(\mathrm{MCS})=0.5050 \\
1: \mathrm{HR}=1.19(0.72-1.98) \\
\mathrm{p}(\mathrm{MCS})=0.4916 \\
\mathrm{p}(\text { Lymph node })=0.3564\end{array}$ & $\begin{array}{l}0: 0.85 \% \\
1: 0.00 \%\end{array}$ \\
\hline Crude & $\begin{array}{l}\text { MCS (restricted to those } \\
\text { with Tamoxifen use, } \\
\text { smoking status, and } \\
\text { physical activity) }\end{array}$ & & $\begin{array}{l}0: 110 \\
1: 109 \\
2: 111\end{array}$ & $\begin{array}{l}\mathrm{n}=330 \\
\mathrm{~d}=91\end{array}$ & & $\begin{array}{l}0: \mathrm{HR}=1.42(0.85-2.36) \\
1: \mathrm{HR}=1.21(0.72-2.03)\end{array}$ & $p=0.4106$ & $\begin{array}{l}0: \mathrm{HR}=1.42(0.85-2.36) \\
\mathrm{p}(\mathrm{MCS})=0.1824 \\
1: \mathrm{HR}=1.21(0.72-2.03) \\
\mathrm{p}(\mathrm{MCS})=0.4824\end{array}$ & -- \\
\hline 18 & Tamoxifen Use & $\begin{array}{l}0: \text { No } \\
1: \text { Yes (REF) }\end{array}$ & $\begin{array}{l}0: 160 \\
1: 170\end{array}$ & $\begin{array}{l}\mathrm{n}=330 \\
\mathrm{~d}=91\end{array}$ & 21 & $\begin{array}{l}0: H R=1.13(0.75-1.70) \\
1: H R=1.00\end{array}$ & $\mathrm{p}=0.5755$ & $\begin{array}{l}0: \text { HR }=1.41(0.84-2.35) \\
p(M C S)=0.1916 \\
1: \text { HR }=1.19(0.71-2.01) \\
p(\text { MCS })=0.5088 \\
p(\text { Tamoxifen })=0.5755\end{array}$ & $\begin{array}{l}0: 0.70 \% \\
1: 1.65 \%\end{array}$ \\
\hline 19 & Smoking Status & $\begin{array}{l}0: \text { Never (REF) } \\
\text { 1: Former } \\
2 \text { : Current }\end{array}$ & $\begin{array}{l}0: 145 \\
1: 144 \\
2: 41\end{array}$ & $\begin{array}{l}\mathrm{n}=330 \\
\mathrm{~d}=91\end{array}$ & 21 & $\begin{array}{l}0: \mathrm{HR}=1.00 \\
1: \mathrm{HR}=0.98(0.62-1.51) \\
2: \mathrm{HR}=1.27(0.68-2.40)\end{array}$ & $\mathrm{p}=0.6859$ & $\begin{array}{l}0: \mathrm{HR}=1.39(0.83-2.33) \\
\mathrm{p}(\mathrm{MCS})=0.2090 \\
1: \mathrm{HR}=1.20(0.71-2.03) \\
\mathrm{p}(\mathrm{MCS})=0.1671 \\
\mathrm{p}(\text { Smoker1 })=0.8821 \\
\mathrm{p}(\text { Smoker2) }=0.4551\end{array}$ & $\begin{array}{l}0: 2.11 \% \\
1: 0.83 \%\end{array}$ \\
\hline
\end{tabular}




\begin{tabular}{|c|c|c|c|c|c|c|c|c|c|}
\hline Model & Variable(s) in model & Categories & $\begin{array}{l}\text { Total in } \\
\text { categories } \\
\text { (n) }\end{array}$ & $\begin{array}{l}\text { Total } \\
\text { in } \\
\text { model } \\
\text { (n); } \\
\text { dead } \\
\text { (d) } \\
\end{array}$ & Missing & Univariate-Cox HR (95\% CI) & p-values* & $\begin{array}{l}\text { MCS HR }(95 \% \mathrm{CI}) \text { and p- } \\
\text { values }\end{array}$ & $\begin{array}{l}\% \text { change } \\
\text { from crude } \\
\text { model }\end{array}$ \\
\hline 20 & Physical Activity & $\begin{array}{l}0: \text { None } \\
\text { 1: Low } \\
\text { 2: Moderate/Vigorous } \\
\text { (REF) }\end{array}$ & $\begin{array}{l}0: 185 \\
1: 59 \\
2: 86\end{array}$ & $\begin{array}{l}\mathrm{n}=330 \\
\mathrm{~d}=91\end{array}$ & 21 & $\begin{array}{l}0: \mathrm{HR}=1.99(1.16-3.41) \\
1: \mathrm{HR}=1.05(0.50-2.19) \\
2: \mathrm{HR}=1.00\end{array}$ & $p=0.0132$ & $\begin{array}{l}0: \mathrm{HR}=1.54(0.92-2.57) \\
\mathrm{p}(\mathrm{MCS})=0.0995 \\
1: \mathrm{HR}=1.34(0.79-2.27) \\
\mathrm{p}(\mathrm{MCS})=0.2729 \\
\mathrm{p}(\mathrm{PA} 0)=0.0130 \\
\mathrm{p}(\mathrm{PA} 1)=0.9068\end{array}$ & $\begin{array}{l}0: 8.45 \% \\
\mathbf{1}: \mathbf{1 0 . 7 4 \%}\end{array}$ \\
\hline Crude & $\begin{array}{l}\text { MCS (restricted to those } \\
\text { with BMI) }\end{array}$ & & $\begin{array}{l}0: 110 \\
1: 108 \\
2: 106\end{array}$ & $\begin{array}{l}n=324 \\
d=85\end{array}$ & & $\begin{array}{l}0: \mathrm{HR}=1.42(0.83-2.43) \\
1: \mathrm{HR}=1.27(0.74-2.18)\end{array}$ & $\mathrm{p}=0.4304$ & $\begin{array}{l}0: H R=1.42(0.83-2.43) \\
p(M C S)=0.1963 \\
1: H R=1.27(0.74-2.18) \\
p(M C S)=0.3968\end{array}$ & -- \\
\hline 21 & Body Mass Index (BMI) & $\begin{array}{l}0:<25(\mathrm{REF}) \\
1: 25-29 \\
2: \geq 30\end{array}$ & $\begin{array}{l}0: 161 \\
1: 99 \\
2: 64\end{array}$ & $\begin{array}{l}n=324 \\
d=85\end{array}$ & 27 & $\begin{array}{l}0: H R=1.00 \\
1: H R=0.91(0.54-1.52) \\
2: H R=1.52(0.89-2.59)\end{array}$ & $p=0.1846$ & $\begin{array}{l}0: \mathrm{HR}=1.42(0.83-2.42) \\
\mathrm{p}(\mathrm{MCS})=0.2046 \\
1: \mathrm{HR}=1.35(0.78-2.33) \\
\mathrm{p}(\mathrm{MCS})=0.2913 \\
\mathrm{p}(\mathrm{BMI})=0.7102 \\
\mathrm{p}(\mathrm{BMI})=0.1235\end{array}$ & $\begin{array}{l}0: 0.00 \% \\
1: 6.30 \%\end{array}$ \\
\hline Crude & $\begin{array}{l}\text { MCS (restricted to those } \\
\text { tumor subtype) }\end{array}$ & & $\begin{array}{l}0: 99 \\
1: 99 \\
2: 102\end{array}$ & $\begin{array}{l}n=300 \\
d=87\end{array}$ & & $\begin{array}{l}0: \mathrm{HR}=1.16(0.69-1.94) \\
1: \mathrm{HR}=1.06(0.63-1.78)\end{array}$ & $\mathrm{p}=0.8474$ & $\begin{array}{l}0: H R=1.16(0.69-1.94) \\
p(M C S)=0.5696 \\
1: H R=1.06(0.63-1.78) \\
p(M C S)=0.8290\end{array}$ & -- \\
\hline
\end{tabular}




\begin{tabular}{|c|c|c|c|c|c|c|c|c|c|}
\hline Model & Variable(s) in model & Categories & $\begin{array}{l}\text { Total in } \\
\text { categories } \\
\text { (n) }\end{array}$ & $\begin{array}{l}\text { Total } \\
\text { in } \\
\text { model } \\
(\mathrm{n}) ; \\
\text { dead } \\
\text { (d) } \\
\end{array}$ & Missing & Univariate-Cox HR $(95 \% \mathrm{CI})$ & p-values* & $\begin{array}{l}\text { MCS HR }(95 \% \mathrm{CI}) \text { and } \mathrm{p}- \\
\text { values }\end{array}$ & $\begin{array}{l}\% \text { change } \\
\text { from crude } \\
\text { model }\end{array}$ \\
\hline 22 & Tumor Subtype & $\begin{array}{l}\text { 0: } \mathrm{ER}+(\mathrm{REF}) \\
\text { 1: ER- }\end{array}$ & $\begin{array}{l}0: 251 \\
1: 49\end{array}$ & $\begin{array}{l}n=300 \\
d=87\end{array}$ & 51 & $\begin{array}{l}0: \mathrm{HR}=1.00 \\
1: \mathrm{HR}=1.17(0.68-2.02)\end{array}$ & $\mathrm{p}=0.5712$ & $\begin{array}{l}0: \mathrm{HR}=1.16(0.69-1.94) \\
\mathrm{p}(\mathrm{MCS})=0.5832 \\
1: \mathrm{HR}=1.05(0.62-1.76) \\
\mathrm{p}(\mathrm{MCS})=0.8604 \\
\mathrm{p}(\text { Subtype })=0.5712\end{array}$ & $\begin{array}{l}0: 0.00 \% \\
1: 0.94 \%\end{array}$ \\
\hline
\end{tabular}


Appendix F. Percent Change from Crude Model and Model 1 with Each Potential Confounder (MCS \& All-Cause Mortality) $(N=351)$

\begin{tabular}{|c|c|c|c|c|c|c|}
\hline Model & Variable(s) in model & $\begin{array}{l}\text { Mental Component Summary } \\
\text { Score (MCS) }(95 \% \text { CI })\end{array}$ & $\begin{array}{l}\text { Difference in } \\
\text { ' } \mathrm{N} \text { ' }\end{array}$ & $\begin{array}{l}\text { Total in model (n) } \\
\text { and total dead (d) }\end{array}$ & $\begin{array}{l}\text { \% change from } \\
\text { Crude }\end{array}$ & $\begin{array}{l}\% \text { change from } \\
\text { model } 1\end{array}$ \\
\hline \multicolumn{7}{|c|}{ Dataset restricted to those with full HRQOL data and baseline covariates } \\
\hline Crude & Mental Component Summary Score (MCS) & $\begin{array}{l}0: \mathrm{HR}=1.36(0.83-2.23) \\
1: \mathrm{HR}=1.25(0.76-2.06) \\
2: \mathrm{HR}=1.00(\mathrm{REF}) \\
\mathrm{p}=0.4590\end{array}$ & 0 & $\begin{array}{l}\mathrm{n}=351 \\
\mathrm{~d}=99\end{array}$ & -- & -- \\
\hline 1 & Age, Marital Status, \& Tumor Stage & $\begin{array}{l}0: H R=1.67(1.01-2.75) \\
1: H R=1.32(0.80-2.18) \\
2: H R=1.00(\mathrm{REF}) \\
\mathrm{p}=0.1319\end{array}$ & 0 & $\begin{array}{l}\mathrm{n}=351 \\
\mathrm{~d}=99\end{array}$ & $\begin{array}{l}\mathbf{0 :} \mathbf{2 2 . 7 9 \%} \\
1: 5.60 \%\end{array}$ & -- \\
\hline 2 & Model 1 + Race/Ethnicity & $\begin{array}{l}0: H R=1.69(1.03-2.79) \\
1: H R=1.33(0.81-2.19) \\
2: H R=1.00(\mathrm{REF}) \\
\mathrm{p}=0.1208\end{array}$ & 0 & $\begin{array}{l}\mathrm{n}=351 \\
\mathrm{~d}=99\end{array}$ & $\begin{array}{l}\mathbf{0 :} \mathbf{2 4 . 2 6 \%} \\
1: 6.40 \%\end{array}$ & $\begin{array}{l}0: 1.20 \% \\
1: 0.76 \%\end{array}$ \\
\hline 3 & Model $1+$ Treatment Type & $\begin{array}{l}0: \mathrm{HR}=1.63(0.99-2.68) \\
1: \mathrm{HR}=1.27(0.77-2.09) \\
2: \mathrm{HR}=1.00(\mathrm{REF}) \\
\mathrm{p}=0.1560\end{array}$ & 0 & $\begin{array}{l}\mathrm{n}=351 \\
\mathrm{~d}=99\end{array}$ & $\begin{array}{l}\mathbf{0 :} \mathbf{1 9 . 8 5 \%} \\
1: 1.60 \%\end{array}$ & $\begin{array}{l}0: 2.40 \% \\
1: 3.79 \%\end{array}$ \\
\hline
\end{tabular}




\begin{tabular}{|c|c|c|c|c|c|c|}
\hline Model & Variable(s) in model & $\begin{array}{l}\text { Mental Component Summary } \\
\text { Score (MCS) }(95 \% \mathrm{CI})\end{array}$ & $\begin{array}{l}\text { Difference in } \\
\text { ' } \mathrm{N} \text { ' }\end{array}$ & $\begin{array}{l}\text { Total in model (n) } \\
\text { and total dead (d) }\end{array}$ & $\begin{array}{l}\% \text { change from } \\
\text { Crude }\end{array}$ & $\begin{array}{l}\% \text { change from } \\
\text { model } 1\end{array}$ \\
\hline 4 & Model $1+$ Comorbidities & $\begin{array}{l}0: \mathrm{HR}=1.56(0.93-2.59) \\
1: \mathrm{HR}=1.33(0.81-2.19) \\
2: \mathrm{HR}=1.00(\mathrm{REF}) \\
\mathrm{p}=0.2308\end{array}$ & 0 & $\begin{array}{l}\mathrm{n}=351 \\
\mathrm{~d}=99\end{array}$ & $\begin{array}{l}\mathbf{0 :} \mathbf{1 4 . 7 1 \%} \\
1: 2.21 \%\end{array}$ & $\begin{array}{l}0: 6.59 \% \\
1: 0.76 \%\end{array}$ \\
\hline 5 & Model $1+$ Current Lymphedema & $\begin{array}{l}0: \mathrm{HR}=1.71(1.03-2.82) \\
1: \mathrm{HR}=1.33(0.81-2.19) \\
2: \mathrm{HR}=1.00(\mathrm{REF}) \\
\mathrm{p}=0.1137\end{array}$ & 0 & $\begin{array}{l}\mathrm{n}=351 \\
\mathrm{~d}=99\end{array}$ & $\begin{array}{l}\mathbf{0 :} \mathbf{2 5 . 7 4 \%} \\
1: 6.40 \%\end{array}$ & $\begin{array}{l}0: 2.40 \% \\
1: 0.76 \%\end{array}$ \\
\hline 6 & Model $1+$ Optimism & $\begin{array}{l}0: H R=1.57(0.94-2.62) \\
1: H R=1.26(0.76-2.09) \\
2: H R=1.00(\mathrm{REF}) \\
\mathrm{p}=0.2271\end{array}$ & 0 & $\begin{array}{l}\mathrm{n}=351 \\
\mathrm{~d}=99\end{array}$ & $\begin{array}{l}\text { 0: } \mathbf{1 5 . 4 4 \%} \\
1: 0.80 \%\end{array}$ & $\begin{array}{l}0: 5.99 \% \\
1: 4.55 \%\end{array}$ \\
\hline 7 & Model $1+$ Pessimism & $\begin{array}{l}0: H R=1.47(0.88-2.45) \\
1: H R=1.25(0.75-2.06) \\
2: H R=1.00(R E F) \\
p=0.3316\end{array}$ & 0 & $\begin{array}{l}\mathrm{n}=351 \\
\mathrm{~d}=99\end{array}$ & $\begin{array}{l}0: 8.09 \% \\
1: 0.00 \%\end{array}$ & $\begin{array}{l}\mathbf{0 :} \mathbf{1 1 . 9 8 \%} \\
1: 5.30 \%\end{array}$ \\
\hline 8 & Model $1+$ Current Fatigue & $\begin{array}{l}0: \mathrm{HR}=1.78(1.01-3.14) \\
1: \mathrm{HR}=1.35(0.81-2.25) \\
2: \mathrm{HR}=1.00(\mathrm{REF}) \\
\mathrm{p}=0.1358\end{array}$ & 0 & $\begin{array}{l}n=351 \\
d=99\end{array}$ & $\begin{array}{l}\mathbf{0 :} \mathbf{3 0 . 8 8 \%} \\
1: 8.00 \%\end{array}$ & $\begin{array}{l}0: 6.59 \% \\
1: 2.27 \%\end{array}$ \\
\hline
\end{tabular}




\begin{tabular}{|c|c|c|c|c|c|c|}
\hline Model & Variable(s) in model & $\begin{array}{l}\text { Mental Component Summary } \\
\text { Score (MCS) }(95 \% \text { CI) }\end{array}$ & $\begin{array}{l}\text { Difference in } \\
\text { ' } N \text { ' }\end{array}$ & $\begin{array}{l}\text { Total in model (n) } \\
\text { and total dead (d) }\end{array}$ & $\begin{array}{l}\% \text { change from } \\
\text { Crude }\end{array}$ & $\begin{array}{l}\% \text { change from } \\
\text { model } 1\end{array}$ \\
\hline 9 & Model $1+$ Fear of Recurrence & $\begin{array}{l}0: \mathrm{HR}=1.71(1.04-2.83) \\
1: \mathrm{HR}=1.35(0.82-2.22) \\
2: \mathrm{HR}=1.00(\mathrm{REF}) \\
\mathrm{p}=0.1111\end{array}$ & 0 & $\begin{array}{l}\mathrm{n}=351 \\
\mathrm{~d}=99\end{array}$ & $\begin{array}{l}\mathbf{0 :} \mathbf{2 5 . 7 4 \%} \\
1: 8.00 \%\end{array}$ & $\begin{array}{l}0: 2.40 \% \\
1: 2.27 \%\end{array}$ \\
\hline 10 & Model $1+$ Number of Types of Confidants & $\begin{array}{l}0: \mathrm{HR}=1.67(1.02-2.76) \\
1: \mathrm{HR}=1.34(0.81-2.21) \\
2: \mathrm{HR}=1.00(\mathrm{REF}) \\
\mathrm{p}=0.1295\end{array}$ & 0 & $\begin{array}{l}\mathrm{n}=351 \\
\mathrm{~d}=99\end{array}$ & $\begin{array}{l}\mathbf{0 :} \mathbf{2 2 . 7 9 \%} \\
1: 7.20 \%\end{array}$ & $\begin{array}{l}0: 0.00 \% \\
1: 1.52 \%\end{array}$ \\
\hline 11 & Model 1 + Bodily Pain & $\begin{array}{l}0: \mathrm{HR}=1.58(0.96-2.62) \\
1: \mathrm{HR}=1.28(0.78-2.11) \\
2: \mathrm{HR}=1.00(\mathrm{REF}) \\
\mathrm{p}=0.2053\end{array}$ & 0 & $\begin{array}{l}\mathrm{n}=351 \\
\mathrm{~d}=99\end{array}$ & $\begin{array}{l}\mathbf{0 :} \mathbf{1 6 . 1 8 \%} \\
1: 2.40 \%\end{array}$ & $\begin{array}{l}0: 5.39 \% \\
1: 3.03 \%\end{array}$ \\
\hline 12 & Model $1+$ Perceived General Health & $\begin{array}{l}0: \mathrm{HR}=1.41(0.83-2.37) \\
1: \mathrm{HR}=1.31(0.80-2.16) \\
2: \mathrm{HR}=1.00(\mathrm{REF}) \\
\mathrm{p}=0.5532\end{array}$ & 0 & $\begin{array}{l}\mathrm{n}=351 \\
\mathrm{~d}=99\end{array}$ & $\begin{array}{l}0: 3.68 \% \\
1: 4.80 \%\end{array}$ & $\begin{array}{l}\mathbf{0}: \mathbf{1 5 . 5 7 \%} \\
1: 0.76 \%\end{array}$ \\
\hline \multicolumn{7}{|c|}{ Subset--Restricted to participants with Education variable } \\
\hline
\end{tabular}




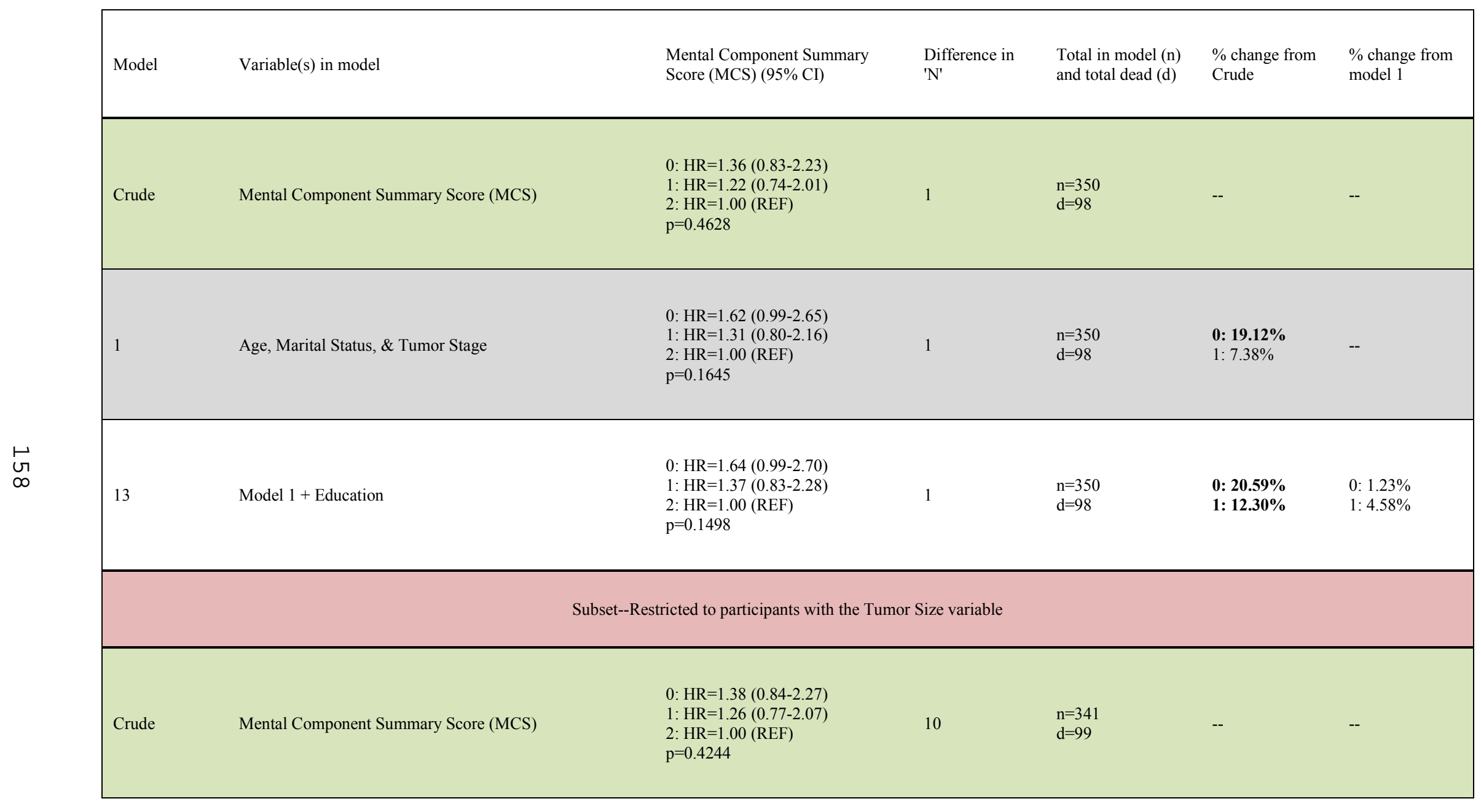




\begin{tabular}{|c|c|c|c|c|c|c|}
\hline Model & Variable(s) in model & $\begin{array}{l}\text { Mental Component Summary } \\
\text { Score (MCS) }(95 \% \text { CI })\end{array}$ & $\begin{array}{l}\text { Difference in } \\
\text { ' } \mathrm{N} \text { ' }\end{array}$ & $\begin{array}{l}\text { Total in model (n) } \\
\text { and total dead (d) }\end{array}$ & $\begin{array}{l}\% \text { change from } \\
\text { Crude }\end{array}$ & $\begin{array}{l}\% \text { change from } \\
\text { model } 1\end{array}$ \\
\hline 1 & Age, Marital Status, \& Tumor Stage & $\begin{array}{l}0: H R=1.66(1.01-2.73) \\
1: H R=1.32(0.80-2.17) \\
2: H R=1.00(\mathrm{REF}) \\
\mathrm{p}=0.1392\end{array}$ & 10 & $\begin{array}{l}\mathrm{n}=341 \\
\mathrm{~d}=99\end{array}$ & $\begin{array}{l}\mathbf{0 :} \mathbf{2 0 . 2 9 \%} \\
1: 4.76 \%\end{array}$ & -- \\
\hline 14 & Model $1+$ Tumor Size & $\begin{array}{l}0: H R=1.64(1.00-2.70) \\
1: H R=1.36(0.82-2.24) \\
2: H R=1.00(\mathrm{REF}) \\
\mathrm{p}=0.1496\end{array}$ & 10 & $\begin{array}{l}\mathrm{n}=341 \\
\mathrm{~d}=99\end{array}$ & $\begin{array}{l}\mathbf{0 :} \mathbf{1 8 . 8 4 \%} \\
1: 7.94 \%\end{array}$ & $\begin{array}{l}0: 1.20 \% \\
1: 3.03 \%\end{array}$ \\
\hline \multicolumn{7}{|c|}{ Subset--Restricted to participants with Lymph Node Involvement variable } \\
\hline Crude & Mental Component Summary Score (MCS) & $\begin{array}{l}0: H R=1.18(0.71-1.96) \\
1: H R=1.19(0.72-1.97) \\
2: H R=1.00(\mathrm{REF}) \\
\mathrm{p}=0.7579\end{array}$ & 10 & $\begin{array}{l}\mathrm{n}=341 \\
\mathrm{~d}=92\end{array}$ & -- & -- \\
\hline 1 & Age, Marital Status, \& Tumor Stage & $\begin{array}{l}0: \mathrm{HR}=1.49(0.89-2.49) \\
1: \mathrm{HR}=1.33(0.80-2.21) \\
2: \mathrm{HR}=1.00(\mathrm{REF}) \\
\mathrm{p}=0.2946\end{array}$ & 10 & $\begin{array}{l}\mathrm{n}=341 \\
\mathrm{~d}=92\end{array}$ & $\begin{array}{l}0: 26.27 \% \\
1: 11.76 \%\end{array}$ & -- \\
\hline
\end{tabular}




\begin{tabular}{|c|c|c|c|c|c|c|}
\hline Model & Variable(s) in model & $\begin{array}{l}\text { Mental Component Summary } \\
\text { Score (MCS) }(95 \% \mathrm{CI})\end{array}$ & $\begin{array}{l}\text { Difference in } \\
\text { ' } \mathrm{N}^{\prime}\end{array}$ & $\begin{array}{l}\text { Total in model (n) } \\
\text { and total dead (d) }\end{array}$ & $\begin{array}{l}\% \text { change from } \\
\text { Crude }\end{array}$ & $\begin{array}{l}\% \text { change from } \\
\text { model } 1\end{array}$ \\
\hline 15 & Model $1+$ Lymph Node Involvement & $\begin{array}{l}0: \mathrm{HR}=1.48(0.88-2.48) \\
1: \mathrm{HR}=1.32(0.80-2.20) \\
2: \mathrm{HR}=1.00(\mathrm{REF}) \\
\mathrm{p}=0.3132\end{array}$ & 10 & $\begin{array}{l}\mathrm{n}=341 \\
\mathrm{~d}=92\end{array}$ & $\begin{array}{l}0: 25.42 \% \\
1: 10.92 \%\end{array}$ & $\begin{array}{l}0: 0.67 \% \\
1: 0.75 \%\end{array}$ \\
\hline \multicolumn{7}{|c|}{ Subset--Restricted to participants with Tamoxifen Use, Smoking Status, \& Physical Activity variables (24-month follow-up) } \\
\hline Crude & Mental Component Summary Score (MCS) & $\begin{array}{l}0: \mathrm{HR}=1.42(0.85-2.36) \\
1: \mathrm{HR}=1.21(0.72-2.03) \\
2: \mathrm{HR}=1.00(\mathrm{REF}) \\
\mathrm{p}=0.4071\end{array}$ & 21 & $\begin{array}{l}\mathrm{n}=330 \\
\mathrm{~d}=91\end{array}$ & -- & -- \\
\hline 1 & Age, Marital Status, \& Tumor Stage & $\begin{array}{l}0: \mathrm{HR}=1.69(1.01-2.83) \\
1: \mathrm{HR}=1.32(0.78-2.23) \\
2: \mathrm{HR}=1.00(\mathrm{REF}) \\
\mathrm{p}=0.1360\end{array}$ & 21 & $\begin{array}{l}\mathrm{n}=330 \\
\mathrm{~d}=91\end{array}$ & $\begin{array}{l}\mathbf{0 :} \mathbf{1 9 . 0 1 \%} \\
1: 9.09 \%\end{array}$ & -- \\
\hline 16 & Model $1+$ Tamoxifen Use & $\begin{array}{l}0: \mathrm{HR}=1.74(1.04-2.92) \\
1: \mathrm{HR}=1.28(0.76-2.17) \\
2: \mathrm{HR}=1.00(\mathrm{REF}) \\
\mathrm{p}=0.1046\end{array}$ & 21 & $\begin{array}{l}\mathrm{n}=330 \\
\mathrm{~d}=91\end{array}$ & $\begin{array}{l}\mathbf{0 :} \mathbf{2 2 . 5 4 \%} \\
1: 5.79 \%\end{array}$ & $\begin{array}{l}0: 2.96 \% \\
1: 3.03 \%\end{array}$ \\
\hline
\end{tabular}




\begin{tabular}{|c|c|c|c|c|c|c|}
\hline Model & Variable(s) in model & $\begin{array}{l}\text { Mental Component Summary } \\
\text { Score (MCS) }(95 \% \text { CI) }\end{array}$ & $\begin{array}{l}\text { Difference in } \\
\text { ' } \mathrm{N} \text { ' }\end{array}$ & $\begin{array}{l}\text { Total in model (n) } \\
\text { and total dead (d) }\end{array}$ & $\begin{array}{l}\% \text { change from } \\
\text { Crude }\end{array}$ & $\begin{array}{l}\% \text { change from } \\
\text { model } 1\end{array}$ \\
\hline 17 & Model $1+$ Smoking Status & $\begin{array}{l}0: \mathrm{HR}=1.64(0.98-2.75) \\
1: \mathrm{HR}=1.32(0.78-2.22) \\
2: \mathrm{HR}=1.00(\mathrm{REF}) \\
\mathrm{p}=0.1753\end{array}$ & 21 & $\begin{array}{l}\mathrm{n}=330 \\
\mathrm{~d}=91\end{array}$ & $\begin{array}{l}\mathbf{0 :} \mathbf{1 5 . 4 9 \%} \\
1: 9.09 \%\end{array}$ & $\begin{array}{l}0: 2.96 \% \\
1: 0.00 \%\end{array}$ \\
\hline 18 & Model $1+$ Physical Activity & $\begin{array}{l}0: \mathrm{HR}=1.71(1.02-2.87) \\
1: \mathrm{HR}=1.41(0.83-2.39) \\
2: \mathrm{HR}=1.00(\mathrm{REF}) \\
\mathrm{p}=0.1230\end{array}$ & 21 & $\begin{array}{l}\mathrm{n}=330 \\
\mathrm{~d}=91\end{array}$ & $\begin{array}{l}0: 20.42 \% \\
1: 16.53 \%\end{array}$ & $\begin{array}{l}0: 1.18 \% \\
1: 6.82 \%\end{array}$ \\
\hline \multicolumn{7}{|c|}{ Subset--Restricted to participants with BMI variable } \\
\hline Crude & Mental Component Summary Score (MCS) & $\begin{array}{l}0: \mathrm{HR}=1.42(0.83-2.43) \\
1: \mathrm{HR}=1.27(0.74-2.18) \\
2: \mathrm{HR}=1.00(\mathrm{REF}) \\
\mathrm{p}=0.4304\end{array}$ & 27 & $\begin{array}{l}\mathrm{n}=324 \\
\mathrm{~d}=85\end{array}$ & -- & -- \\
\hline 1 & Age, Marital Status, \& Tumor Stage & $\begin{array}{l}0: \mathrm{HR}=1.73(1.01-2.97) \\
1: \mathrm{HR}=1.27(0.74-2.20) \\
2: \mathrm{HR}=1.00(\mathrm{REF}) \\
\mathrm{p}=0.1335\end{array}$ & 27 & $\begin{array}{l}\mathrm{n}=324 \\
\mathrm{~d}=85\end{array}$ & $\begin{array}{l}\mathbf{0 :} \mathbf{2 1 . 8 3 \%} \\
1: 0.00 \%\end{array}$ & -- \\
\hline
\end{tabular}




\begin{tabular}{|c|c|c|c|c|c|c|}
\hline Model & Variable(s) in model & $\begin{array}{l}\text { Mental Component Summary } \\
\text { Score (MCS) }(95 \% \text { CI) }\end{array}$ & $\begin{array}{l}\text { Difference in } \\
\text { ' } \mathrm{N} \text { ' }\end{array}$ & $\begin{array}{l}\text { Total in model (n) } \\
\text { and total dead (d) }\end{array}$ & $\begin{array}{l}\% \text { change from } \\
\text { Crude }\end{array}$ & $\begin{array}{l}\% \text { change from } \\
\text { model } 1\end{array}$ \\
\hline 19 & Model $1+$ BMI & $\begin{array}{l}0: \mathrm{HR}=1.72(1.00-2.96) \\
1: \mathrm{HR}=1.32(0.76-2.28) \\
2: \mathrm{HR}=1.00(\mathrm{REF}) \\
\mathrm{p}=0.1492\end{array}$ & 27 & $\begin{array}{l}\mathrm{n}=324 \\
\mathrm{~d}=85\end{array}$ & $\begin{array}{l}\mathbf{0 :} \mathbf{2 1 . 1 3 \%} \\
1: 3.94 \%\end{array}$ & $\begin{array}{l}0: 0.58 \% \\
1: 3.94 \%\end{array}$ \\
\hline \multicolumn{7}{|c|}{ Subset--Restricted to participants with Tumor Subtype variable } \\
\hline Crude & Mental Component Summary Score (MCS) & $\begin{array}{l}0: \mathrm{HR}=1.16(0.69-1.94) \\
1: \mathrm{HR}=1.06(0.63-1.78) \\
2: \mathrm{HR}=1.00(\mathrm{REF}) \\
\mathrm{p}=0.8481\end{array}$ & 51 & $\begin{array}{l}\mathrm{n}=300 \\
\mathrm{~d}=87\end{array}$ & -- & -- \\
\hline 1 & Age, Marital Status, \& Tumor Stage & $\begin{array}{l}0: \mathrm{HR}=1.39(0.83-2.34) \\
1: \mathrm{HR}=1.12(0.67-1.89) \\
2: \mathrm{HR}=1.00(\mathrm{REF}) \\
\mathrm{p}=0.4426\end{array}$ & 51 & $\begin{array}{l}\mathrm{n}=300 \\
\mathrm{~d}=87\end{array}$ & $\begin{array}{l}\mathbf{0 :} \mathbf{1 9 . 8 3 \%} \\
1: 5.66 \%\end{array}$ & -- \\
\hline 20 & Model $1+$ Tumor Subtype & $\begin{array}{l}0: \mathrm{HR}=1.42(0.85-2.39) \\
1: \mathrm{HR}=1.12(0.66-1.88) \\
2: \mathrm{HR}=1.00(\mathrm{REF}) \\
\mathrm{p}=0.3926\end{array}$ & 51 & $\begin{array}{l}\mathrm{n}=300 \\
\mathrm{~d}=87\end{array}$ & $\begin{array}{l}\mathbf{0 :} \mathbf{2 2 . 4 1 \%} \\
1: 5.66 \%\end{array}$ & $\begin{array}{l}0: 2.16 \% \\
1: 0.00 \%\end{array}$ \\
\hline
\end{tabular}


Appendix G. Multivariable Modeling with Mental Component Summary Score as the Predictor and All-Cause Mortality as the Outcome $(N=351)$

\begin{tabular}{|c|c|c|c|c|c|c|c|}
\hline Model & Variable(s) in model & $\begin{array}{l}\text { Mental Component Summary } \\
\text { Score (MCS) HR }(95 \% \mathrm{CI})\end{array}$ & $\begin{array}{l}\text { Difference in } \\
\text { ' } \mathrm{N} \text { ' }\end{array}$ & $\begin{array}{l}\text { Total in model } \\
\text { (n) and total } \\
\text { dead (d) }\end{array}$ & $\begin{array}{l}\% \text { change } \\
\text { from Crude }\end{array}$ & $\begin{array}{l}\% \text { change } \\
\text { from model } \\
1\end{array}$ & $\begin{array}{l}\text { \% change } \\
\text { from } \\
\text { previous } \\
\text { model } \\
\end{array}$ \\
\hline Crude & Mental Component Summary Score (MCS) & $\begin{array}{l}0: \mathrm{HR}=1.36(0.83-2.23) \\
1: \mathrm{HR}=1.25(0.76-2.06) \\
2: \mathrm{HR}=1.00(\mathrm{REF}) \\
\mathrm{p}=0.4590\end{array}$ & 0 & $\begin{array}{l}\mathrm{n}=351 \\
\mathrm{~d}=99\end{array}$ & -- & -- & -- \\
\hline 1 & Age, Marital Status, \& Tumor Stage & $\begin{array}{l}0: \mathrm{HR}=1.67(1.01-2.75) \\
1: \mathrm{HR}=1.32(0.80-2.18) \\
2: \mathrm{HR}=1.00(\mathrm{REF}) \\
\mathrm{p}=0.1319\end{array}$ & 0 & $\begin{array}{l}\mathrm{n}=351 \\
\mathrm{~d}=99\end{array}$ & $\begin{array}{l}\mathbf{0}: \mathbf{2 2 . 7 9 \%} \\
1: 5.60 \%\end{array}$ & -- & -- \\
\hline 2 & Model $1+$ Race/Ethnicity & $\begin{array}{l}0: \mathrm{HR}=1.69(1.03-2.79) \\
1: \mathrm{HR}=1.33(0.81-2.19) \\
2: \mathrm{HR}=1.00(\mathrm{REF}) \\
\mathrm{p}=0.1208\end{array}$ & 0 & $\begin{array}{l}\mathrm{n}=351 \\
\mathrm{~d}=99\end{array}$ & $\begin{array}{l}\mathbf{0 :} \mathbf{2 4 . 2 6 \%} \\
1: 6.40 \%\end{array}$ & $\begin{array}{l}0: 1.20 \% \\
1: 0.76 \%\end{array}$ & -- \\
\hline 3 & Model $1+$ Race/Ethnicity + Treatment Type & $\begin{array}{l}0: \mathrm{HR}=1.64(1.00-2.71) \\
1: \mathrm{HR}=1.27(0.77-2.10) \\
2: \mathrm{HR}=1.00(\mathrm{REF}) \\
\mathrm{p}=0.1468\end{array}$ & 0 & $\begin{array}{l}\mathrm{n}=351 \\
\mathrm{~d}=99\end{array}$ & $\begin{array}{l}\mathbf{0}: \mathbf{2 0 . 5 9 \%} \\
1: 1.60 \%\end{array}$ & $\begin{array}{l}0: 1.80 \% \\
1: 3.79 \%\end{array}$ & $\begin{array}{l}0: 2.96 \% \\
1: 4.51 \%\end{array}$ \\
\hline 4 & $\begin{array}{l}\text { Model } 1+\text { Race/Ethnicity }+ \text { Treatment Type }+ \\
\text { Comorbidities }\end{array}$ & $\begin{array}{l}0: \mathrm{HR}=1.51(0.90-2.53) \\
1: \mathrm{HR}=1.27(0.77-2.10) \\
2: \mathrm{HR}=1.00(\mathrm{REF}) \\
\mathrm{p}=0.2871\end{array}$ & 0 & $\begin{array}{l}\mathrm{n}=351 \\
\mathrm{~d}=99\end{array}$ & $\begin{array}{l}\mathbf{0 :} \mathbf{1 1 . 0 3 \%} \\
1: 1.60 \%\end{array}$ & $\begin{array}{l}0: 9.58 \% \\
1: 3.79 \%\end{array}$ & $\begin{array}{l}0: 7.93 \% \\
1: 0.00 \%\end{array}$ \\
\hline
\end{tabular}




\begin{tabular}{|c|c|c|c|c|c|c|c|}
\hline Model & Variable(s) in model & $\begin{array}{l}\text { Mental Component Summary } \\
\text { Score (MCS) HR }(95 \% \text { CI) }\end{array}$ & $\begin{array}{l}\text { Difference in } \\
\text { ' } \mathrm{N} \text { ' }\end{array}$ & $\begin{array}{l}\text { Total in model } \\
\text { (n) and total } \\
\text { dead (d) }\end{array}$ & $\begin{array}{l}\% \text { change } \\
\text { from Crude }\end{array}$ & $\begin{array}{l}\% \text { change } \\
\text { from model } \\
1\end{array}$ & $\begin{array}{l}\% \text { change } \\
\text { from } \\
\text { previous } \\
\text { model }\end{array}$ \\
\hline 5 & $\begin{array}{l}\text { Model } 1+\text { Race/Ethnicity }+ \text { Treatment Type }+ \\
\text { Comorbidities + Current Lymphedema }\end{array}$ & $\begin{array}{l}0: \mathrm{HR}=1.56(0.93-2.61) \\
1: \mathrm{HR}=1.30(0.79-2.14) \\
\text { 2: } \mathrm{HR}=1.00(\mathrm{REF}) \\
\mathrm{p}=0.2397\end{array}$ & 0 & $\begin{array}{l}\mathrm{n}=351 \\
\mathrm{~d}=99\end{array}$ & $\begin{array}{l}\mathbf{0 :} \mathbf{1 4 . 7 1 \%} \\
1: 4.00 \%\end{array}$ & $\begin{array}{l}0: 6.59 \% \\
1: 1.52 \%\end{array}$ & $\begin{array}{l}0: 3.31 \% \\
1: 2.36 \%\end{array}$ \\
\hline 6 & $\begin{array}{l}\text { Model } 1+\text { Race/Ethnicity + Treatment Type }+ \\
\text { Comorbidities + Current Lymphedema + Pessimism }\end{array}$ & $\begin{array}{l}0: \mathrm{HR}=1.41(0.83-2.37) \\
\text { 1: } \mathrm{HR}=1.24(0.75-2.06) \\
\text { 2: } \mathrm{HR}=1.00(\mathrm{REF}) \\
\mathrm{p}=0.4326\end{array}$ & 0 & $\begin{array}{l}\mathrm{n}=351 \\
\mathrm{~d}=99\end{array}$ & $\begin{array}{l}0: 3.68 \% \\
1: 0.80 \%\end{array}$ & $\begin{array}{l}\mathbf{0 :} \mathbf{1 5 . 5 7 \%} \\
1: 6.06 \%\end{array}$ & $\begin{array}{l}0: 9.62 \% \\
1: 4.62 \%\end{array}$ \\
\hline 7 & $\begin{array}{l}\text { Model } 1+\text { Race/Ethnicity }+ \text { Treatment Type }+ \\
\text { Comorbidities + Current Lymphedema + Pessimism }+ \\
\text { Fear of Recurrence }\end{array}$ & $\begin{array}{l}0: \mathrm{HR}=1.44(0.85-2.42) \\
1: \mathrm{HR}=1.27(0.76-2.11) \\
\text { 2: } \mathrm{HR}=1.00 \text { (REF) } \\
\mathrm{p}=0.3898\end{array}$ & 0 & $\begin{array}{l}\mathrm{n}=351 \\
\mathrm{~d}=99\end{array}$ & $\begin{array}{l}0: 5.88 \% \\
1: 1.60 \%\end{array}$ & $\begin{array}{l}\mathbf{0 :} \mathbf{1 3 . 7 7 \%} \\
1: 3.79 \%\end{array}$ & $\begin{array}{l}0: 2.13 \% \\
1: 2.42 \%\end{array}$ \\
\hline 8 & $\begin{array}{l}\text { Model } 1+\text { Race/Ethnicity }+ \text { Treatment Type }+ \\
\text { Comorbidities }+ \text { Current Lymphedema + Pessimism }+ \\
\text { Fear of Recurrence }+ \text { Number of Types of Confidants } \\
\text { (Confide) }\end{array}$ & $\begin{array}{l}0: \mathrm{HR}=1.45(0.86-2.46) \\
1: \mathrm{HR}=1.29(0.78-2.15) \\
\text { 2: } \mathrm{HR}=1.00(\mathrm{REF}) \\
\mathrm{p}=0.3664\end{array}$ & 0 & $\begin{array}{l}\mathrm{n}=351 \\
\mathrm{~d}=99\end{array}$ & $\begin{array}{l}0: 6.62 \% \\
1: 3.20 \%\end{array}$ & $\begin{array}{l}\mathbf{0 :} \mathbf{1 3 . 1 7 \%} \\
1: 2.27 \%\end{array}$ & $\begin{array}{l}0: 0.69 \% \\
1: 1.57 \%\end{array}$ \\
\hline 9 & $\begin{array}{l}\text { Model } 1+\text { Race/Ethnicity + Treatment Type + } \\
\text { Comorbidities + Current Lymphedema + Pessimism + } \\
\text { Fear of Recurrence + Confide + Bodily Pain }\end{array}$ & $\begin{array}{l}0: \mathrm{HR}=1.40(0.82-2.38) \\
\text { 1: } \mathrm{HR}=1.26(0.76-2.11) \\
\text { 2: } \mathrm{HR}=1.00(\mathrm{REF}) \\
\mathrm{p}=0.4499\end{array}$ & 0 & $\begin{array}{l}\mathrm{n}=351 \\
\mathrm{~d}=99\end{array}$ & $\begin{array}{l}0: 2.94 \% \\
1: 0.80 \%\end{array}$ & $\begin{array}{l}\mathbf{0 :} \mathbf{1 6 . 1 7 \%} \\
1: 4.55 \%\end{array}$ & $\begin{array}{l}0: 3.45 \% \\
1: 2.33 \%\end{array}$ \\
\hline
\end{tabular}




\begin{tabular}{|c|c|c|c|c|c|c|c|}
\hline Model & Variable(s) in model & $\begin{array}{l}\text { Mental Component Summary } \\
\text { Score (MCS) HR }(95 \% \mathrm{CI})\end{array}$ & $\begin{array}{l}\text { Difference in } \\
\text { ' } \mathrm{N} \text { ' }\end{array}$ & $\begin{array}{l}\text { Total in model } \\
\text { (n) and total } \\
\text { dead (d) }\end{array}$ & $\begin{array}{l}\% \text { change } \\
\text { from Crude }\end{array}$ & $\begin{array}{l}\% \text { change } \\
\text { from model } \\
1\end{array}$ & $\begin{array}{l}\text { \% change } \\
\text { from } \\
\text { previous } \\
\text { model }\end{array}$ \\
\hline 10 & $\begin{array}{l}\text { Model } 1+\text { Race/Ethnicity }+ \text { Treatment Type }+ \\
\text { Comorbidities }+ \text { Current Lymphedema }+ \text { Pessimism }+ \\
\text { Fear of Recurrence }+ \text { Confide }+ \text { Bodily Pain }+ \text { Perceived } \\
\text { General Health }\end{array}$ & $\begin{array}{l}0: \mathrm{HR}=1.24(0.72-2.15) \\
1: \mathrm{HR}=1.26(0.76-2.10) \\
2: \mathrm{HR}=1.00(\mathrm{REF}) \\
\mathrm{p}=0.6340\end{array}$ & 0 & $\begin{array}{l}n=351 \\
d=99\end{array}$ & $\begin{array}{l}0: 8.82 \% \\
1: 0.80 \%\end{array}$ & $\begin{array}{l}\mathbf{0}: \mathbf{2 5 . 7 5 \%} \\
1: 4.55 \%\end{array}$ & $\begin{array}{l}\mathbf{0 :} \mathbf{1 1 . 4 3 \%} \\
1: 0.00 \%\end{array}$ \\
\hline \multicolumn{8}{|c|}{ Subset--Restricted to participants with Education variable } \\
\hline Crude & Mental Component Summary Score (MCS) & $\begin{array}{l}0: \mathrm{HR}=1.36(0.83-2.23) \\
1: \mathrm{HR}=1.22(0.74-2.01) \\
2: \mathrm{HR}=1.00(\mathrm{REF}) \\
\mathrm{p}=0.4628\end{array}$ & 1 & $\begin{array}{l}n=350 \\
d=98\end{array}$ & -- & -- & -- \\
\hline 1 & Age, Marital Status, \& Tumor Stage & $\begin{array}{l}0: \mathrm{HR}=1.66(1.01-2.74) \\
1: \mathrm{HR}=1.30(0.79-2.14) \\
2: \mathrm{HR}=1.00(\mathrm{REF}) \\
\mathrm{p}=0.1352\end{array}$ & 1 & $\begin{array}{l}\mathrm{n}=350 \\
\mathrm{~d}=98\end{array}$ & $\begin{array}{l}\mathbf{0 :} \mathbf{2 2 . 0 6 \%} \\
1: 6.56 \%\end{array}$ & -- & -- \\
\hline 11 & Model 1 + Education & $\begin{array}{l}0: \mathrm{HR}=1.64(1.00-2.70) \\
1: \mathrm{HR}=1.37(0.83-2.28) \\
2: \mathrm{HR}=1.00(\mathrm{REF}) \\
\mathrm{p}=0.1498\end{array}$ & 1 & $\begin{array}{l}\mathrm{n}=350 \\
\mathrm{~d}=98\end{array}$ & $\begin{array}{l}0: 20.59 \% \\
1: 12.30 \%\end{array}$ & $\begin{array}{l}0: 1.20 \% \\
1: 5.38 \%\end{array}$ & -- \\
\hline
\end{tabular}




\begin{tabular}{|c|c|c|c|c|c|c|c|}
\hline Model & Variable(s) in model & $\begin{array}{l}\text { Mental Component Summary } \\
\text { Score (MCS) HR }(95 \% \text { CI) }\end{array}$ & $\begin{array}{l}\text { Difference in } \\
\text { ' } \mathrm{N} \text { ' }\end{array}$ & $\begin{array}{l}\text { Total in model } \\
\text { (n) and total } \\
\text { dead (d) }\end{array}$ & $\begin{array}{l}\% \text { change } \\
\text { from Crude }\end{array}$ & $\begin{array}{l}\% \text { change } \\
\text { from model } \\
1\end{array}$ & $\begin{array}{l}\% \text { change } \\
\text { from } \\
\text { previous } \\
\text { model }\end{array}$ \\
\hline 12 & Model 1 + Education + Race/Ethnicity & $\begin{array}{l}0: \mathrm{HR}=1.66(1.01-4.04) \\
1: \mathrm{HR}=1.40(0.84-2.34) \\
2: \mathrm{HR}=1.00(\mathrm{REF}) \\
\mathrm{p}=0.1333\end{array}$ & 1 & $\begin{array}{l}\mathrm{n}=350 \\
\mathrm{~d}=98\end{array}$ & $\begin{array}{l}0: 22.06 \% \\
1: 14.75 \%\end{array}$ & $\begin{array}{l}0: 0.00 \% \\
1: 7.69 \%\end{array}$ & $\begin{array}{l}0: 1.22 \% \\
1: 2.19 \%\end{array}$ \\
\hline 13 & Model $1+$ Education + Race/Ethnicity + Treatment Type & $\begin{array}{l}0: \mathrm{HR}=1.61(0.98-2.65) \\
1: \mathrm{HR}=1.35(0.81-2.25) \\
\text { 2: } \mathrm{HR}=1.00(\mathrm{REF}) \\
\mathrm{p}=0.1714\end{array}$ & 1 & $\begin{array}{l}\mathrm{n}=350 \\
\mathrm{~d}=98\end{array}$ & $\begin{array}{l}0: 18.38 \% \\
1: 10.66 \%\end{array}$ & $\begin{array}{l}0: 3.01 \% \\
1: 3.85 \%\end{array}$ & $\begin{array}{l}0: 3.01 \% \\
1: 3.57 \%\end{array}$ \\
\hline 14 & $\begin{array}{l}\text { Model } 1+\text { Education + Race/Ethnicity + Treatment Type } \\
\text { + Comorbidities }\end{array}$ & $\begin{array}{l}0: \mathrm{HR}=1.50(0.90-2.51) \\
1: \mathrm{HR}=1.33(0.80-2.22) \\
2: \mathrm{HR}=1.00 \text { (REF) } \\
\mathrm{p}=0.2847\end{array}$ & 1 & $\begin{array}{l}\mathrm{n}=350 \\
\mathrm{~d}=98\end{array}$ & $\begin{array}{l}\mathbf{0 :} \mathbf{1 0 . 2 9 \%} \\
1: 9.02 \%\end{array}$ & $\begin{array}{l}0: 9.64 \% \\
1: 2.31 \%\end{array}$ & $\begin{array}{l}0: 6.83 \% \\
1: 1.48 \%\end{array}$ \\
\hline 15 & $\begin{array}{l}\text { Model } 1+\text { Education + Race/Ethnicity + Treatment Type } \\
+ \text { Comorbidities + Current Lymphedema }\end{array}$ & $\begin{array}{l}0: \mathrm{HR}=1.54(0.92-2.58) \\
1: \mathrm{HR}=1.34(0.81-2.24) \\
\text { 2: } \mathrm{HR}=1.00(\mathrm{REF}) \\
\mathrm{p}=0.2447\end{array}$ & 1 & $\begin{array}{l}\mathrm{n}=350 \\
\mathrm{~d}=98\end{array}$ & $\begin{array}{l}0: 13.24 \% \\
1: 9.84 \%\end{array}$ & $\begin{array}{l}\mathbf{0 :} \mathbf{1 8 . 4 6 \%} \\
1: 3.08 \%\end{array}$ & $\begin{array}{l}0: 2.67 \% \\
1: 0.75 \%\end{array}$ \\
\hline 16 & $\begin{array}{l}\text { Model } 1+\text { Education + Race/Ethnicity + Treatment Type } \\
+ \text { Comorbidities + Current Lymphedema + Pessimism }\end{array}$ & $\begin{array}{l}0: \mathrm{HR}=1.39(0.83-2.35) \\
\text { 1: } \mathrm{HR}=1.28(0.76-2.13) \\
\text { 2: } \mathrm{HR}=1.00(\mathrm{REF}) \\
\mathrm{p}=0.4368\end{array}$ & 1 & $\begin{array}{l}\mathrm{n}=350 \\
\mathrm{~d}=98\end{array}$ & $\begin{array}{l}0: 2.21 \% \\
1: 4.92 \%\end{array}$ & $\begin{array}{l}\mathbf{0 :} \mathbf{1 6 . 2 7 \%} \\
1: 1.54 \%\end{array}$ & $\begin{array}{l}0: 9.74 \% \\
1: 4.48 \%\end{array}$ \\
\hline
\end{tabular}




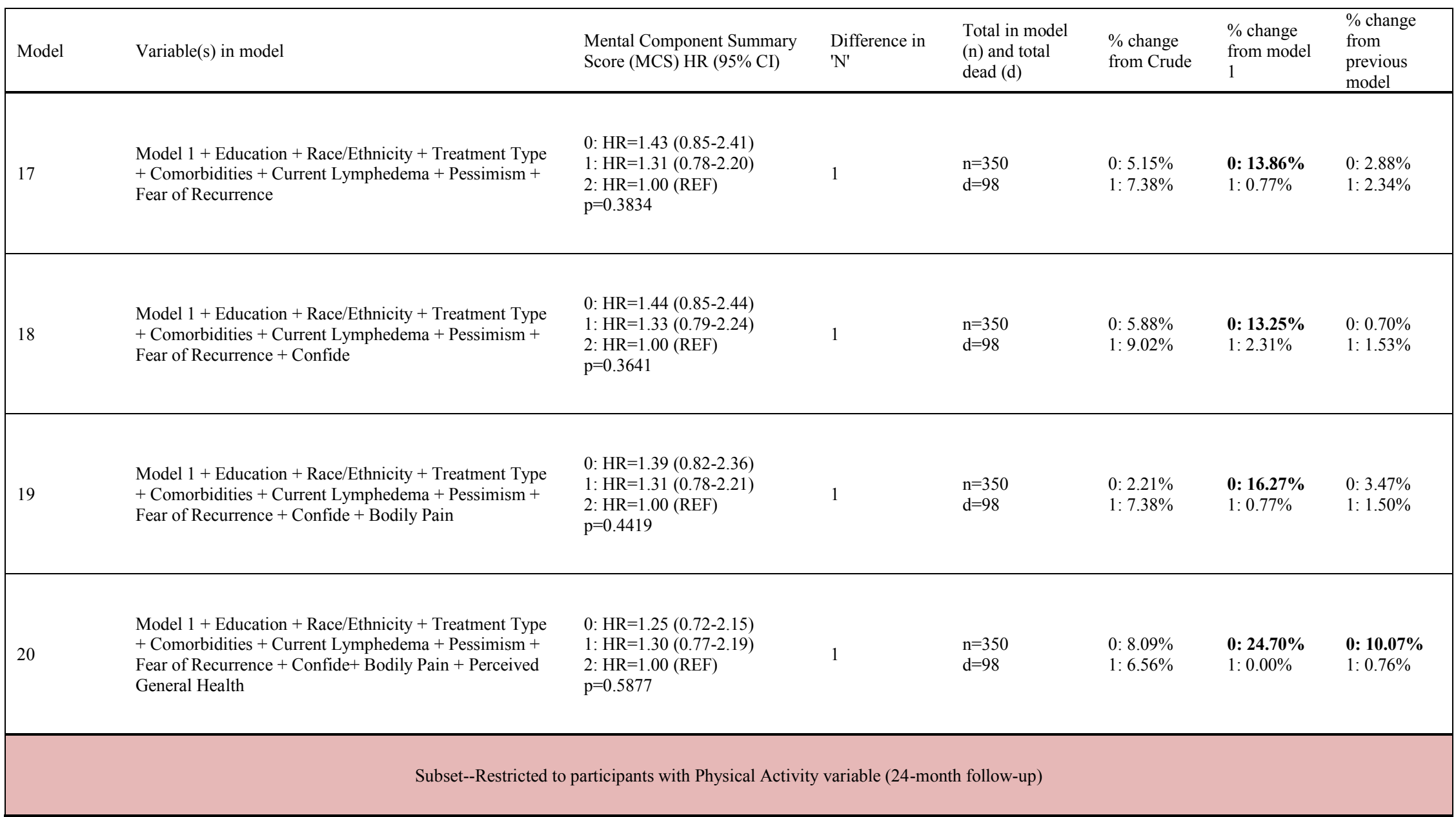




\begin{tabular}{|c|c|c|c|c|c|c|c|}
\hline Model & Variable(s) in model & $\begin{array}{l}\text { Mental Component Summary } \\
\text { Score (MCS) HR }(95 \% \mathrm{Cl})\end{array}$ & $\begin{array}{l}\text { Difference in } \\
\text { ' } \mathrm{N} \text { ' }\end{array}$ & $\begin{array}{l}\text { Total in model } \\
\text { (n) and total } \\
\text { dead (d) }\end{array}$ & $\begin{array}{l}\% \text { change } \\
\text { from Crude }\end{array}$ & $\begin{array}{l}\% \text { change } \\
\text { from model } \\
1\end{array}$ & $\begin{array}{l}\% \text { change } \\
\text { from } \\
\text { previous } \\
\text { model } \\
\end{array}$ \\
\hline Crude & Mental Component Summary Score (MCS) & $\begin{array}{l}0: \mathrm{HR}=1.42(0.85-2.36) \\
\text { 1: } \mathrm{HR}=1.21(0.72-2.03) \\
\text { 2: } \mathrm{HR}=1.00 \text { (REF) } \\
\mathrm{p}=0.4106\end{array}$ & 21 & $\begin{array}{l}\mathrm{n}=330 \\
\mathrm{~d}=91\end{array}$ & -- & -- & -- \\
\hline 1 & Age, Marital Status, \& Tumor Stage & $\begin{array}{l}0: \mathrm{HR}=1.69(1.01-2.83) \\
1: \mathrm{HR}=1.32(0.78-2.23) \\
\text { 2: } \mathrm{HR}=1.00 \text { (REF) } \\
\mathrm{p}=0.1360\end{array}$ & 21 & $\begin{array}{l}n=330 \\
d=91\end{array}$ & $\begin{array}{l}\text { 0: } \mathbf{1 9 . 0 1 \%} \\
1: 9.09 \%\end{array}$ & -- & -- \\
\hline 21 & Model $1+$ Physical Activity & $\begin{array}{l}0: \mathrm{HR}=1.71(1.02-2.87) \\
1: \mathrm{HR}=1.41(0.83-2.39) \\
\text { 2: } \mathrm{HR}=1.00(\mathrm{REF}) \\
\mathrm{p}=0.1230\end{array}$ & 21 & $\begin{array}{l}\mathrm{n}=330 \\
\mathrm{~d}=91\end{array}$ & $\begin{array}{l}0: 20.42 \% \\
1: 16.53 \%\end{array}$ & $\begin{array}{l}0: 1.18 \% \\
1: 6.82 \%\end{array}$ & -- \\
\hline 22 & Model $1+$ Physical Activity + Race/Ethnicity & $\begin{array}{l}0: \mathrm{HR}=1.74(1.04-2.93) \\
\text { 1: } \mathrm{HR}=1.41(0.83-2.40) \\
\text { 2: } \mathrm{HR}=1.00 \text { (REF) } \\
\mathrm{p}=0.1084\end{array}$ & 21 & $\begin{array}{l}n=330 \\
d=91\end{array}$ & $\begin{array}{l}0: 22.54 \% \\
1: 16.53 \%\end{array}$ & $\begin{array}{l}0: 2.96 \% \\
1: 6.82 \%\end{array}$ & $\begin{array}{l}0: 1.75 \% \\
1: 0.00 \%\end{array}$ \\
\hline 23 & $\begin{array}{l}\text { Model } 1+\text { Physical Activity + Race/Ethnicity + Treatment } \\
\text { Type }\end{array}$ & $\begin{array}{l}0: \mathrm{HR}=1.72(1.03-2.88) \\
\text { 1: } \mathrm{HR}=1.37(0.80-2.33) \\
\text { 2: } \mathrm{HR}=1.00 \text { (REF) } \\
\mathrm{p}=0.1216\end{array}$ & 21 & $\begin{array}{l}\mathrm{n}=330 \\
\mathrm{~d}=91\end{array}$ & $\begin{array}{l}0: 21.13 \% \\
1: 13.22 \%\end{array}$ & $\begin{array}{l}0: 1.78 \% \\
1: 3.79 \%\end{array}$ & $\begin{array}{l}0: 1.15 \% \\
1: 2.84 \%\end{array}$ \\
\hline
\end{tabular}




\begin{tabular}{|c|c|c|c|c|c|c|c|}
\hline Model & Variable(s) in model & $\begin{array}{l}\text { Mental Component Summary } \\
\text { Score (MCS) HR ( } 95 \% \text { CI) }\end{array}$ & $\begin{array}{l}\text { Difference in } \\
\text { ' } \mathrm{N} \text { ' }\end{array}$ & $\begin{array}{l}\text { Total in model } \\
\text { (n) and total } \\
\text { dead (d) }\end{array}$ & $\begin{array}{l}\% \text { change } \\
\text { from Crude }\end{array}$ & $\begin{array}{l}\% \text { change } \\
\text { from model } \\
1\end{array}$ & $\begin{array}{l}\% \text { change } \\
\text { from } \\
\text { previous } \\
\text { model }\end{array}$ \\
\hline 24 & $\begin{array}{l}\text { Model } 1+\text { Physical Activity }+ \text { Race/Ethnicity }+ \text { Treatment } \\
\text { Type }+ \text { Comorbidities }\end{array}$ & $\begin{array}{l}0: \mathrm{HR}=1.59(0.94-2.70) \\
1: \mathrm{HR}=1.37(0.80-2.34) \\
2: \mathrm{HR}=1.00(\mathrm{REF}) \\
\mathrm{p}=0.2217\end{array}$ & 21 & $\begin{array}{l}\mathrm{n}=330 \\
\mathrm{~d}=91\end{array}$ & $\begin{array}{l}0: 46.48 \% \\
1: 25.00 \%\end{array}$ & $\begin{array}{l}\mathbf{0 :} \mathbf{1 2 . 8 4 \%} \\
1: 5.65 \%\end{array}$ & $\begin{array}{l}0: 6.40 \% \\
1: 1.68 \%\end{array}$ \\
\hline 25 & $\begin{array}{l}\text { Model } 1+\text { Physical Activity + Race/Ethnicity }+ \text { Treatment } \\
\text { Type + Comorbidities + Current Lymphedema }\end{array}$ & $\begin{array}{l}0: \mathrm{HR}=1.60(0.94-2.73) \\
1: \mathrm{HR}=1.40(0.82-2.39) \\
\text { 2: } \mathrm{HR}=1.00(\mathrm{REF}) \\
\mathrm{p}=0.2048\end{array}$ & 21 & $\begin{array}{l}\mathrm{n}=330 \\
\mathrm{~d}=91\end{array}$ & $\begin{array}{l}0: 12.68 \% \\
1: 15.70 \%\end{array}$ & $\begin{array}{l}0: 5.33 \% \\
1: 6.06 \%\end{array}$ & $\begin{array}{l}0: 0.63 \% \\
1: 2.19 \%\end{array}$ \\
\hline 26 & $\begin{array}{l}\text { Model } 1+\text { Physical Activity + Race/Ethnicity }+ \text { Treatment } \\
\text { Type + Comorbidities + Current Lymphedema }+ \\
\text { Pessimism }\end{array}$ & $\begin{array}{l}0: \mathrm{HR}=1.50(0.88-2.57) \\
\text { 1: } \mathrm{HR}=1.38(0.81-2.37) \\
\text { 2: } \mathrm{HR}=1.00(\mathrm{REF}) \\
\mathrm{p}=0.3011\end{array}$ & 21 & $\begin{array}{l}n=330 \\
d=91\end{array}$ & $\begin{array}{l}0: 5.63 \% \\
1: 14.05 \%\end{array}$ & $\begin{array}{l}\mathbf{0 :} \mathbf{1 1 . 2 4 \%} \\
1: 4.55 \%\end{array}$ & $\begin{array}{l}0: 6.25 \% \\
1: 1.43 \%\end{array}$ \\
\hline 27 & $\begin{array}{l}\text { Model } 1+\text { Physical Activity + Race/Ethnicity + Treatment } \\
\text { Type + Comorbidities + Current Lymphedema + } \\
\text { Pessimism + Fear of Recurrence }\end{array}$ & $\begin{array}{l}0: H R=1.51(0.88-2.59) \\
1: H R=1.39(0.81-2.38) \\
\text { 2: } \mathrm{HR}=1.00(\mathrm{REF}) \\
\mathrm{p}=0.2958\end{array}$ & 21 & $\begin{array}{l}\mathrm{n}=330 \\
\mathrm{~d}=91\end{array}$ & $\begin{array}{l}0: 6.34 \% \\
1: 14.88 \%\end{array}$ & $\begin{array}{l}\mathbf{0 :} \mathbf{1 0 . 6 5 \%} \\
1: 5.30 \%\end{array}$ & $\begin{array}{l}0: 0.67 \% \\
1: 0.72 \%\end{array}$ \\
\hline 28 & $\begin{array}{l}\text { Model } 1+\text { Physical Activity + Race/Ethnicity + Treatment } \\
\text { Type + Comorbidities + Current Lymphedema + } \\
\text { Pessimism + Fear of Recurrence + Confide }\end{array}$ & $\begin{array}{l}0: H R=1.55(0.89-2.68) \\
\text { 1: } \mathrm{HR}=1.41(0.82-2.42) \\
\text { 2: } \mathrm{HR}=1.00 \text { (REF) } \\
\mathrm{p}=0.2686\end{array}$ & 21 & $\begin{array}{l}n=330 \\
d=91\end{array}$ & $\begin{array}{l}0: 9.15 \% \\
1: 16.53 \%\end{array}$ & $\begin{array}{l}0: 8.28 \% \\
1: 6.82 \%\end{array}$ & $\begin{array}{l}0: 2.65 \% \\
1: 1.44 \%\end{array}$ \\
\hline
\end{tabular}




\begin{tabular}{|c|c|c|c|c|c|c|c|}
\hline Model & Variable(s) in model & $\begin{array}{l}\text { Mental Component Summary } \\
\text { Score (MCS) HR ( } 95 \% \text { CI) }\end{array}$ & $\begin{array}{l}\text { Difference in } \\
\text { ' } \mathrm{N} \text { ' }\end{array}$ & $\begin{array}{l}\text { Total in model } \\
\text { (n) and total } \\
\text { dead (d) }\end{array}$ & $\begin{array}{l}\% \text { change } \\
\text { from Crude }\end{array}$ & $\begin{array}{l}\% \text { change } \\
\text { from model } \\
1\end{array}$ & $\begin{array}{l}\text { \% change } \\
\text { from } \\
\text { previous } \\
\text { model }\end{array}$ \\
\hline 29 & $\begin{array}{l}\text { Model } 1+\text { Physical Activity }+ \text { Race/Ethnicity }+ \text { Treatment } \\
\text { Type }+ \text { Comorbidities + Current Lymphedema }+ \\
\text { Pessimism + Fear of Recurrence + Confide + Bodily Pain }\end{array}$ & $\begin{array}{l}0: \mathrm{HR}=1.48(0.85-2.59) \\
1: \mathrm{HR}=1.38(0.80-2.38) \\
2: \mathrm{HR}=1.00(\mathrm{REF}) \\
\mathrm{p}=0.3478\end{array}$ & 21 & $\begin{array}{l}\mathrm{n}=330 \\
\mathrm{~d}=91\end{array}$ & $\begin{array}{l}0: 4.23 \% \\
\mathbf{1}: \mathbf{1 4 . 0 5 \%}\end{array}$ & $\begin{array}{l}\mathbf{0 :} \mathbf{1 2 . 4 3 \%} \\
1: 4.55 \%\end{array}$ & $\begin{array}{l}0: 4.52 \% \\
1: 2.13 \%\end{array}$ \\
\hline 30 & $\begin{array}{l}\text { Model } 1+\text { Physical Activity }+ \text { Race/Ethnicity }+ \text { Treatment } \\
\text { Type }+ \text { Comorbidities + Current Lymphedema }+ \\
\text { Pessimism + Fear of Recurrence + Confide + Bodily Pain } \\
+ \text { Perceived General Health }\end{array}$ & $\begin{array}{l}0: \mathrm{HR}=1.31(0.73-2.33) \\
1: \mathrm{HR}=1.34(0.78-2.31) \\
2: \mathrm{HR}=1.00(\mathrm{REF}) \\
\mathrm{p}=0.5299\end{array}$ & 21 & $\begin{array}{l}\mathrm{n}=330 \\
\mathrm{~d}=91\end{array}$ & $\begin{array}{l}0: 7.75 \% \\
1: 10.74 \%\end{array}$ & $\begin{array}{l}\mathbf{0 :} \mathbf{2 2 . 4 9 \%} \\
1: 1.52 \%\end{array}$ & $\begin{array}{l}\mathbf{0 :} \mathbf{1 1 . 4 9 \%} \\
1: 2.90 \%\end{array}$ \\
\hline \multicolumn{8}{|c|}{ Subset--Restricted to participants with Education and Physical Activity variables } \\
\hline Crude & Mental Component Summary Score (MCS) & $\begin{array}{l}0: \mathrm{HR}=1.42(0.85-2.36) \\
1: \mathrm{HR}=1.17(0.69-1.98) \\
2: \mathrm{HR}=1.00(\mathrm{REF}) \\
\mathrm{p}=0.4045\end{array}$ & 22 & $\begin{array}{l}\mathrm{n}=329 \\
\mathrm{~d}=90\end{array}$ & -- & -- & -- \\
\hline 1 & Age, Marital Status, \& Tumor Stage & $\begin{array}{l}0: H R=1.68(1.01-2.82) \\
1: H R=1.29(0.76-2.18) \\
2: H R=1.00(\text { REF }) \\
p=0.1388\end{array}$ & 22 & $\begin{array}{l}\mathrm{n}=329 \\
\mathrm{~d}=90\end{array}$ & $\begin{array}{l}0: 18.31 \% \\
1: 10.26 \%\end{array}$ & -- & -- \\
\hline
\end{tabular}




\begin{tabular}{|c|c|c|c|c|c|c|c|}
\hline Model & Variable(s) in model & $\begin{array}{l}\text { Mental Component Summary } \\
\text { Score (MCS) HR }(95 \% \text { CI) }\end{array}$ & $\begin{array}{l}\text { Difference in } \\
\text { ' } \mathrm{N} \text { ' }\end{array}$ & $\begin{array}{l}\text { Total in model } \\
\text { (n) and total } \\
\text { dead (d) }\end{array}$ & $\begin{array}{l}\% \text { change } \\
\text { from Crude }\end{array}$ & $\begin{array}{l}\% \text { change } \\
\text { from model } \\
1\end{array}$ & $\begin{array}{l}\% \text { change } \\
\text { from } \\
\text { previous } \\
\text { model }\end{array}$ \\
\hline 31 & Model 1 + Education + Physical Activity & $\begin{array}{l}0: \mathrm{HR}=1.66(0.99-2.78) \\
1: \mathrm{HR}=1.40(0.82-2.39) \\
2: \mathrm{HR}=1.00(\mathrm{REF}) \\
\mathrm{p}=0.1535\end{array}$ & 22 & $\begin{array}{l}\mathrm{n}=329 \\
\mathrm{~d}=90\end{array}$ & $\begin{array}{l}0: 16.90 \% \\
1: 19.66 \%\end{array}$ & $\begin{array}{l}0: 1.19 \% \\
1: 8.53 \%\end{array}$ & -- \\
\hline 32 & $\begin{array}{l}\text { Model } 1 \text { + Education + Physical Activity + } \\
\text { Race/Ethnicity }\end{array}$ & $\begin{array}{l}0: \mathrm{HR}=1.69(1.01-2.83) \\
\text { 1: } \mathrm{HR}=1.42(0.83-2.43) \\
\text { 2: } \mathrm{HR}=1.00 \text { (REF) } \\
\mathrm{p}=0.1362\end{array}$ & 22 & $\begin{array}{l}\mathrm{n}=329 \\
\mathrm{~d}=90\end{array}$ & $\begin{array}{l}0: 19.01 \% \\
1: 21.37 \%\end{array}$ & $\begin{array}{l}0: 0.60 \% \\
1: 10.08 \%\end{array}$ & $\begin{array}{l}0: 1.81 \% \\
1: 1.43 \%\end{array}$ \\
\hline 33 & $\begin{array}{l}\text { Model } 1 \text { + Education + Physical Activity + } \\
\text { Race/Ethnicity + Treatment Type }\end{array}$ & $\begin{array}{l}0: \mathrm{HR}=1.66(0.99-2.78) \\
\text { 1: } \mathrm{HR}=1.38(0.80-2.38) \\
\text { 2: } \mathrm{HR}=1.00(\mathrm{REF}) \\
\mathrm{p}=0.1584\end{array}$ & 22 & $\begin{array}{l}\mathrm{n}=329 \\
\mathrm{~d}=90\end{array}$ & $\begin{array}{l}0: 16.90 \% \\
1: 17.95 \%\end{array}$ & $\begin{array}{l}0: 1.19 \% \\
1: 6.98 \%\end{array}$ & $\begin{array}{l}0: 1.78 \% \\
1: 2.82 \%\end{array}$ \\
\hline 34 & $\begin{array}{l}\text { Model } 1+\text { Education }+ \text { Physical Activity }+ \\
\text { Race/Ethnicity }+ \text { Treatment Type }+ \text { Comorbidities }\end{array}$ & $\begin{array}{l}0: \mathrm{HR}=1.54(0.91-2.62) \\
1: \mathrm{HR}=1.37(0.80-2.36) \\
\text { 2: } \mathrm{HR}=1.00(\mathrm{REF}) \\
\mathrm{p}=0.2578\end{array}$ & 22 & $\begin{array}{l}\mathrm{n}=329 \\
\mathrm{~d}=90\end{array}$ & $\begin{array}{l}0: 8.45 \% \\
1: 17.09 \%\end{array}$ & $\begin{array}{l}0: 8.33 \% \\
1: 6.20 \%\end{array}$ & $\begin{array}{l}0: 7.23 \% \\
1: 0.72 \%\end{array}$ \\
\hline 35 & $\begin{array}{l}\text { Model } 1+\text { Education }+ \text { Physical Activity }+ \text { Race/Ethnicity } \\
+ \text { Treatment Type }+ \text { Comorbidities + Current } \\
\text { Lymphedema }\end{array}$ & $\begin{array}{l}0: H R=1.56(0.92-2.65) \\
\text { 1: } \mathrm{HR}=1.39(0.81-2.39) \\
\text { 2: } \mathrm{HR}=1.00(\mathrm{REF}) \\
\mathrm{p}=0.2404\end{array}$ & 22 & $\begin{array}{l}\mathrm{n}=329 \\
\mathrm{~d}=90\end{array}$ & $\begin{array}{l}0: 9.86 \% \\
1: 18.80 \%\end{array}$ & $\begin{array}{l}0: 7.14 \% \\
1: 7.75 \%\end{array}$ & $\begin{array}{l}0: 1.30 \% \\
1: 1.46 \%\end{array}$ \\
\hline
\end{tabular}




\begin{tabular}{|c|c|c|c|c|c|c|c|}
\hline Model & Variable(s) in model & $\begin{array}{l}\text { Mental Component Summary } \\
\text { Score (MCS) HR }(95 \% \mathrm{Cl})\end{array}$ & $\begin{array}{l}\text { Difference in } \\
\text { ' } \mathrm{N} \text { ' }\end{array}$ & $\begin{array}{l}\text { Total in model } \\
\text { (n) and total } \\
\text { dead (d) }\end{array}$ & $\begin{array}{l}\% \text { change } \\
\text { from Crude }\end{array}$ & $\begin{array}{l}\% \text { change } \\
\text { from model } \\
1\end{array}$ & $\begin{array}{l}\% \text { change } \\
\text { from } \\
\text { previous } \\
\text { model }\end{array}$ \\
\hline 36 & $\begin{array}{l}\text { Model } 1 \text { + Education + Physical Activity + Race/Ethnicity } \\
+ \text { Treatment Type + Comorbidities + Current } \\
\text { Lymphedema + Pessimism }\end{array}$ & $\begin{array}{l}0: \mathrm{HR}=1.46(0.85-2.50) \\
\text { 1: } \mathrm{HR}=1.37(0.79-2.36) \\
\text { 2: } \mathrm{HR}=1.00 \text { (REF) } \\
\mathrm{p}=0.3446\end{array}$ & 22 & $\begin{array}{l}\mathrm{n}=329 \\
\mathrm{~d}=90\end{array}$ & $\begin{array}{l}0: 2.82 \% \\
1: 17.09 \%\end{array}$ & $\begin{array}{l}\mathbf{0 :} \mathbf{1 3 . 1 \%} \\
1: 6.20 \%\end{array}$ & $\begin{array}{l}0: 6.41 \% \\
1: 1.44 \%\end{array}$ \\
\hline 37 & $\begin{array}{l}\text { Model } 1+\text { Education }+ \text { Physical Activity }+ \\
\text { Race/Ethnicity + Treatment Type + Comorbidities + } \\
\text { Current Lymphedema + Pessimism + Fear of Recurrence }\end{array}$ & $\begin{array}{l}0: \mathrm{HR}=1.47(0.86-2.52) \\
1: \mathrm{HR}=1.37(0.80-2.37) \\
\text { 2: } \mathrm{HR}=1.00 \text { (REF) } \\
\mathrm{p}=0.3356\end{array}$ & 22 & $\begin{array}{l}\mathrm{n}=329 \\
\mathrm{~d}=90\end{array}$ & $\begin{array}{l}0: 3.52 \% \\
1: 17.09 \%\end{array}$ & $\begin{array}{l}\mathbf{0 :} \mathbf{1 2 . 5 0 \%} \\
1: 6.20 \%\end{array}$ & $\begin{array}{l}0: 0.68 \% \\
1: 0.00 \%\end{array}$ \\
\hline 38 & $\begin{array}{l}\text { Model 1 + Education + Physical Activity + } \\
\text { Race/Ethnicity + Treatment Type + Comorbidities + } \\
\text { Current Lymphedema + Pessimism + Fear of Recurrence } \\
\text { + Confide }\end{array}$ & $\begin{array}{l}0: \mathrm{HR}=1.50(0.86-2.59) \\
1: \mathrm{HR}=1.39(0.80-2.40) \\
2: \mathrm{HR}=1.00(\mathrm{REF}) \\
\mathrm{p}=0.3178\end{array}$ & 22 & $\begin{array}{l}\mathrm{n}=329 \\
\mathrm{~d}=90\end{array}$ & $\begin{array}{l}0: 5.63 \% \\
1: 18.80 \%\end{array}$ & $\begin{array}{l}\mathbf{0 :} \mathbf{1 0 . 7 1 \%} \\
1: 7.75 \%\end{array}$ & $\begin{array}{l}0: 2.04 \% \\
1: 1.46 \%\end{array}$ \\
\hline 39 & $\begin{array}{l}\text { Model } 1+\text { Education + Physical Activity }+ \\
\text { Race/Ethnicity + Treatment Type + Comorbidities + } \\
\text { Current Lymphedema + Pessimism + Fear of Recurrence } \\
+ \text { Confide + Bodily Pain }\end{array}$ & $\begin{array}{l}0: \mathrm{HR}=1.43(0.82-2.51) \\
1: \mathrm{HR}=1.37(0.79-2.37) \\
\text { 2: } \mathrm{HR}=1.00 \text { (REF) } \\
\mathrm{p}=0.3985\end{array}$ & 22 & $\begin{array}{l}\mathrm{n}=329 \\
\mathrm{~d}=90\end{array}$ & $\begin{array}{l}0: 0.70 \% \\
1: 17.09 \%\end{array}$ & $\begin{array}{l}\mathbf{0 :} \mathbf{1 4 . 8 8 \%} \\
1: 6.20 \%\end{array}$ & $\begin{array}{l}0: 4.67 \% \\
1: 1.44 \%\end{array}$ \\
\hline 40 & $\begin{array}{l}\text { Model } 1 \text { + Education + Physical Activity + } \\
\text { Race/Ethnicity + Treatment Type + Comorbidities + } \\
\text { Current Lymphedema + Pessimism + Fear of Recurrence } \\
\text { + Confide + Bodily Pain + Perceived General Health }\end{array}$ & $\begin{array}{l}0: \mathrm{HR}=1.28(0.72-2.29) \\
\text { 1: } \mathrm{HR}=1.33(0.76-2.31) \\
\text { 2: } \mathrm{HR}=1.00(\mathrm{REF}) \\
\mathrm{p}=0.5655\end{array}$ & 22 & $\begin{array}{l}\mathrm{n}=329 \\
\mathrm{~d}=90\end{array}$ & $\begin{array}{l}0: 9.86 \% \\
1: \mathbf{1 3 . 6 8} \%\end{array}$ & $\begin{array}{l}\mathbf{0 :} \mathbf{2 3 . 8 1} \% \\
1: 3.10 \%\end{array}$ & $\begin{array}{l}\mathbf{0}: \mathbf{1 0 . 4 9 \%} \\
1: 2.92 \%\end{array}$ \\
\hline
\end{tabular}




\begin{tabular}{|c|c|c|c|c|c|c|c|}
\hline Model & Variable(s) in model & $\begin{array}{l}\text { Mental Component Summary } \\
\text { Score (MCS) HR }(95 \% \text { CI) }\end{array}$ & $\begin{array}{l}\text { Difference in } \\
\text { ' } \mathrm{N} \text { ' }\end{array}$ & $\begin{array}{l}\text { Total in model } \\
\text { (n) and total } \\
\text { dead (d) }\end{array}$ & $\begin{array}{l}\% \text { change } \\
\text { from Crude }\end{array}$ & $\begin{array}{l}\% \text { change } \\
\text { from model } \\
1\end{array}$ & $\begin{array}{l}\text { \% change } \\
\text { from } \\
\text { previous } \\
\text { model }\end{array}$ \\
\hline \multicolumn{8}{|c|}{ Subset--Restricted to participants with BMI variable } \\
\hline Crude & Mental Component Summary Score (MCS) & $\begin{array}{l}0: H R=1.42(0.83-2.43) \\
1: H R=1.27(0.74-2.18) \\
2: H R=1.00(\mathrm{REF}) \\
\mathrm{p}=0.4304\end{array}$ & 27 & $\begin{array}{l}\mathrm{n}=324 \\
\mathrm{~d}=85\end{array}$ & -- & -- & -- \\
\hline 1 & Age, Marital Status, \& Tumor Stage & $\begin{array}{l}0: \mathrm{HR}=1.73(1.01-2.97) \\
1: \mathrm{HR}=1.27(0.74-2.20) \\
2: \mathrm{HR}=1.00(\mathrm{REF}) \\
\mathrm{p}=0.1335\end{array}$ & 27 & $\begin{array}{l}\mathrm{n}=324 \\
\mathrm{~d}=85\end{array}$ & $\begin{array}{l}\mathbf{0 :} \mathbf{2 1 . 8 3 \%} \\
1: 0.00 \%\end{array}$ & -- & -- \\
\hline 41 & Model $1+$ Education + BMI & $\begin{array}{l}0: H R=1.72(1.00-2.96) \\
1: H R=1.32(0.76-2.28) \\
2: H R=1.00(\mathrm{REF}) \\
\mathrm{p}=0.1492\end{array}$ & 27 & $\begin{array}{l}\mathrm{n}=324 \\
\mathrm{~d}=85\end{array}$ & $\begin{array}{l}\mathbf{0}: \mathbf{2 1 . 1 3 \%} \\
1: 3.94 \%\end{array}$ & $\begin{array}{l}0: 0.58 \% \\
1: 3.94 \%\end{array}$ & -- \\
\hline 42 & Model 1 + Education + BMI + Race/Ethnicity & $\begin{array}{l}0: \mathrm{HR}=1.75(1.01-3.02) \\
1: \mathrm{HR}=1.33(0.77-2.32) \\
2: \mathrm{HR}=1.00(\mathrm{REF}) \\
\mathrm{p}=0.1360\end{array}$ & 27 & $\begin{array}{l}\mathrm{n}=324 \\
\mathrm{~d}=85\end{array}$ & $\begin{array}{l}\mathbf{0 :} \mathbf{2 3 . 2 4 \%} \\
1: 4.72 \%\end{array}$ & $\begin{array}{l}0: 1.16 \% \\
1: 4.72 \%\end{array}$ & $\begin{array}{l}0: 1.74 \% \\
1: 0.76 \%\end{array}$ \\
\hline 43 & $\begin{array}{l}\text { Model } 1+\text { Education + BMI + Race/Ethnicity + Treatment } \\
\text { Type }\end{array}$ & $\begin{array}{l}0: \mathrm{HR}=1.67(0.97-2.89) \\
1: \mathrm{HR}=1.23(0.70-2.15) \\
2: \mathrm{HR}=1.00(\mathrm{REF}) \\
\mathrm{p}=0.1739\end{array}$ & 27 & $\begin{array}{l}\mathrm{n}=324 \\
\mathrm{~d}=85\end{array}$ & $\begin{array}{l}\mathbf{0 :} \mathbf{1 7 . 6 1 \%} \\
1: 3.15 \%\end{array}$ & $\begin{array}{l}\mathbf{0 :} \mathbf{3 1 . 5 0 \%} \\
1: 3.15 \%\end{array}$ & $\begin{array}{l}0: 4.57 \% \\
1: 7.52 \%\end{array}$ \\
\hline
\end{tabular}




\begin{tabular}{|c|c|c|c|c|c|c|c|}
\hline Model & Variable(s) in model & $\begin{array}{l}\text { Mental Component Summary } \\
\text { Score (MCS) HR }(95 \% \text { CI) }\end{array}$ & $\begin{array}{l}\text { Difference in } \\
\text { ' } \mathrm{N} \text { ' }\end{array}$ & $\begin{array}{l}\text { Total in model } \\
\text { (n) and total } \\
\text { dead (d) }\end{array}$ & $\begin{array}{l}\% \text { change } \\
\text { from Crude }\end{array}$ & $\begin{array}{l}\% \text { change } \\
\text { from model } \\
1\end{array}$ & $\begin{array}{l}\% \text { change } \\
\text { from } \\
\text { previous } \\
\text { model }\end{array}$ \\
\hline 44 & $\begin{array}{l}\text { Model } 1+\text { Education + BMI + Race/Ethnicity + Treatment } \\
\text { Type + Comorbidities }\end{array}$ & $\begin{array}{l}0: \mathrm{HR}=1.61(0.92-2.82) \\
1: \mathrm{HR}=1.22(0.70-2.14) \\
\text { 2: } \mathrm{HR}=1.00(\mathrm{REF}) \\
\mathrm{p}=0.2370\end{array}$ & 27 & $\begin{array}{l}n=324 \\
d=85\end{array}$ & $\begin{array}{l}\mathbf{0 :} \mathbf{1 3 . 3 8 \%} \\
1: 3.94 \%\end{array}$ & $\begin{array}{l}0: 6.94 \% \\
1: 3.94 \%\end{array}$ & $\begin{array}{l}0: 3.59 \% \\
1: 0.81 \%\end{array}$ \\
\hline 45 & $\begin{array}{l}\text { Model } 1+\text { Education + BMI + Race/Ethnicity + Treatment } \\
\text { Type + Comorbidities + Current Lymphedema }\end{array}$ & $\begin{array}{l}0: \mathrm{HR}=1.69(0.96-2.95) \\
\text { 1: } \mathrm{HR}=1.25(0.71-2.20) \\
\text { 2: } \mathrm{HR}=1.00(\mathrm{REF}) \\
\mathrm{p}=0.1838\end{array}$ & 27 & $\begin{array}{l}n=324 \\
d=85\end{array}$ & $\begin{array}{l}\mathbf{0 :} \mathbf{1 9 . 0 1 \%} \\
1: 1.57 \%\end{array}$ & $\begin{array}{l}0: 2.31 \% \\
1: 1.57 \%\end{array}$ & $\begin{array}{l}0: 4.97 \% \\
1: 2.46 \%\end{array}$ \\
\hline 46 & $\begin{array}{l}\text { Model } 1 \text { + Education + BMI + Race/Ethnicity + Treatment } \\
\text { Type + Comorbidities + Current Lymphedema + } \\
\text { Pessimism }\end{array}$ & $\begin{array}{l}0: \mathrm{HR}=1.52(0.86-2.67) \\
\text { 1: } \mathrm{HR}=1.19(0.68-2.08) \\
\text { 2: } \mathrm{HR}=1.00(\mathrm{REF}) \\
\mathrm{p}=0.3423\end{array}$ & 27 & $\begin{array}{l}n=324 \\
d=85\end{array}$ & $\begin{array}{l}0: 7.04 \% \\
1: 6.30 \%\end{array}$ & $\begin{array}{l}\mathbf{0 :} \mathbf{1 2 . 1 4 \%} \\
1: 6.30 \%\end{array}$ & $\begin{array}{l}\mathbf{0 :} \mathbf{1 0 . 0 6 \%} \\
1: 4.80 \%\end{array}$ \\
\hline 47 & $\begin{array}{l}\text { Model } 1 \text { + Education + BMI + Race/Ethnicity + Treatment } \\
\text { Type + Comorbidities + Current Lymphedema + } \\
\text { Pessimism + Fear of Recurrence }\end{array}$ & $\begin{array}{l}0: \mathrm{HR}=1.54(0.88-2.71) \\
\text { 1: } \mathrm{HR}=1.21(0.69-2.14) \\
\text { 2: } \mathrm{HR}=1.00(\mathrm{REF}) \\
\mathrm{p}=0.3206\end{array}$ & 27 & $\begin{array}{l}n=324 \\
d=85\end{array}$ & $\begin{array}{l}0: 8.45 \% \\
1: 4.72 \%\end{array}$ & $\begin{array}{l}\mathbf{0 :} \mathbf{1 0 . 9 8 \%} \\
1: 4.72 \%\end{array}$ & $\begin{array}{l}0: 1.32 \% \\
1: 1.68 \%\end{array}$ \\
\hline 48 & $\begin{array}{l}\text { Model } 1 \text { + Education + BMI + Race/Ethnicity + Treatment } \\
\text { Type + Comorbidities + Current Lymphedema + } \\
\text { Pessimism + Fear of Recurrence + Confide }\end{array}$ & $\begin{array}{l}0: \mathrm{HR}=1.56(0.88-2.74) \\
\text { 1: } \mathrm{HR}=1.22(0.69-2.14) \\
\text { 2: } \mathrm{HR}=1.00 \text { (REF) } \\
\mathrm{p}=0.3061\end{array}$ & 27 & $\begin{array}{l}n=324 \\
d=85\end{array}$ & $\begin{array}{l}0: 9.86 \% \\
1: 3.94 \%\end{array}$ & $\begin{array}{l}0: 9.83 \% \\
1: 3.94 \%\end{array}$ & $\begin{array}{l}0: 1.30 \% \\
1: 0.83 \%\end{array}$ \\
\hline
\end{tabular}




\begin{tabular}{|c|c|c|c|c|c|c|c|}
\hline Model & Variable(s) in model & $\begin{array}{l}\text { Mental Component Summary } \\
\text { Score (MCS) HR }(95 \% \mathrm{CI})\end{array}$ & $\begin{array}{l}\text { Difference in } \\
\text { ' } \mathrm{N} \text { ' }\end{array}$ & $\begin{array}{l}\text { Total in model } \\
\text { (n) and total } \\
\text { dead (d) }\end{array}$ & $\begin{array}{l}\% \text { change } \\
\text { from Crude }\end{array}$ & $\begin{array}{l}\% \text { change } \\
\text { from model } \\
1\end{array}$ & $\begin{array}{l}\text { \% change } \\
\text { from } \\
\text { previous } \\
\text { model }\end{array}$ \\
\hline 49 & $\begin{array}{l}\text { Model } 1+\text { Education }+ \text { BMI + Race/Ethnicity }+ \text { Treatment } \\
\text { Type }+ \text { Comorbidities }+ \text { Current Lymphedema }+ \\
\text { Pessimism + Fear of Recurrence + Confide + Bodily Pain }\end{array}$ & $\begin{array}{l}0: \mathrm{HR}=1.54(0.87-2.71) \\
1: \mathrm{HR}=1.20(0.68-2.12) \\
2: \mathrm{HR}=1.00(\mathrm{REF}) \\
\mathrm{p}=0.3289\end{array}$ & 27 & $\begin{array}{l}\mathrm{n}=324 \\
\mathrm{~d}=85\end{array}$ & $\begin{array}{l}0: 8.45 \% \\
1: 5.51 \%\end{array}$ & $\begin{array}{l}\mathbf{0 :} \mathbf{1 0 . 9 8 \%} \\
1: 5.51 \%\end{array}$ & $\begin{array}{l}0: 1.28 \% \\
1: 1.64 \%\end{array}$ \\
\hline 50 & $\begin{array}{l}\text { Model } 1+\text { Education }+ \text { BMI + Race/Ethnicity }+ \text { Treatment } \\
\text { Type }+ \text { Comorbidities }+ \text { Current Lymphedema }+ \\
\text { Pessimism }+ \text { Fear of Recurrence + Confide + Bodily Pain } \\
+ \text { Perceived General Health }\end{array}$ & $\begin{array}{l}0: \mathrm{HR}=1.37(0.76-2.46) \\
1: \mathrm{HR}=1.18(0.67-2.08) \\
2: \mathrm{HR}=1.00(\mathrm{REF}) \\
\mathrm{p}=0.5805\end{array}$ & 27 & $\begin{array}{l}n=324 \\
d=85\end{array}$ & $\begin{array}{l}0: 3.52 \% \\
1: 7.09 \%\end{array}$ & $\begin{array}{l}\mathbf{0 :} \mathbf{2 0 . 8 1 \%} \\
1: 7.09 \%\end{array}$ & $\begin{array}{l}\mathbf{0 :} \mathbf{1 1 . 0 4 \%} \\
1: 1.67 \%\end{array}$ \\
\hline \multicolumn{8}{|c|}{ Subset--Restricted to participants with Education, Physical Activity, and BMI variables } \\
\hline Crude & Mental Component Summary Score (MCS) & $\begin{array}{l}0: \mathrm{HR}=1.51(0.87-2.64) \\
1: \mathrm{HR}=1.21(0.68-2.15) \\
2: \mathrm{HR}=1.00(\mathrm{REF}) \\
\mathrm{p}=0.3415\end{array}$ & 46 & $\begin{array}{l}n=305 \\
d=77\end{array}$ & -- & -- & -- \\
\hline 1 & Age, Marital Status, \& Tumor Stage & $\begin{array}{l}0: H R=1.84(1.05-3.22) \\
1: H R=1.31(0.74-2.33) \\
2: H R=1.00(R E F) \\
p=0.1006\end{array}$ & 46 & $\begin{array}{l}n=305 \\
d=77\end{array}$ & $\begin{array}{l}\mathbf{0 :} \mathbf{2 1 . 8 5 \%} \\
1: 8.26 \%\end{array}$ & -- & -- \\
\hline
\end{tabular}




\begin{tabular}{|c|c|c|c|c|c|c|c|}
\hline Model & Variable(s) in model & $\begin{array}{l}\text { Mental Component Summary } \\
\text { Score (MCS) HR }(95 \% \text { CI) }\end{array}$ & $\begin{array}{l}\text { Difference in } \\
\text { ' } \mathrm{N} \text { ' }\end{array}$ & $\begin{array}{l}\text { Total in model } \\
\text { (n) and total } \\
\text { dead (d) }\end{array}$ & $\begin{array}{l}\% \text { change } \\
\text { from Crude }\end{array}$ & $\begin{array}{l}\% \text { change } \\
\text { from model } \\
1\end{array}$ & $\begin{array}{l}\% \text { change } \\
\text { from } \\
\text { previous } \\
\text { model }\end{array}$ \\
\hline 51 & Model $1+$ Education + Physical Activity + BMI & $\begin{array}{l}0: H R=1.78(1.01-3.14) \\
1: H R=1.46(0.81-2.64) \\
2: H R=1.00(\mathrm{REF}) \\
\mathrm{p}=0.1317\end{array}$ & 46 & $\begin{array}{l}\mathrm{n}=305 \\
\mathrm{~d}=77\end{array}$ & $\begin{array}{l}0: 17.88 \% \\
1: 20.66 \%\end{array}$ & $\begin{array}{l}0: 3.26 \% \\
1: 11.45 \%\end{array}$ & -- \\
\hline 52 & $\begin{array}{l}\text { Model } 1+\text { Education + Physical Activity + BMI + } \\
\text { Race/Ethnicity }\end{array}$ & $\begin{array}{l}0: \mathrm{HR}=1.84(1.04-3.26) \\
1: \mathrm{HR}=1.51(0.83-2.73) \\
2: \mathrm{HR}=1.00(\mathrm{REF}) \\
\mathrm{p}=0.1064\end{array}$ & 46 & $\begin{array}{l}\mathrm{n}=305 \\
\mathrm{~d}=77\end{array}$ & $\begin{array}{l}0: 21.85 \% \\
1: 24.79 \%\end{array}$ & $\begin{array}{l}0: 0.00 \% \\
1: 15.27 \%\end{array}$ & $\begin{array}{l}0: 3.37 \% \\
1: 3.42 \%\end{array}$ \\
\hline 53 & $\begin{array}{l}\text { Model } 1+\text { Education + Physical Activity + BMI + } \\
\text { Race/Ethnicity + Treatment Type }\end{array}$ & $\begin{array}{l}0: \mathrm{HR}=1.81(1.02-3.19) \\
1: \mathrm{HR}=1.46(0.80-2.66) \\
2: \mathrm{HR}=1.00(\mathrm{REF}) \\
\mathrm{p}=0.1246\end{array}$ & 46 & $\begin{array}{l}n=305 \\
d=77\end{array}$ & $\begin{array}{l}0: 19.87 \% \\
1: 20.66 \%\end{array}$ & $\begin{array}{l}0: 1.63 \% \\
1: \mathbf{1 1 . 4 5 \%}\end{array}$ & $\begin{array}{l}0: 1.63 \% \\
1: 3.31 \%\end{array}$ \\
\hline 54 & $\begin{array}{l}\text { Model } 1+\text { Education + Physical Activity + BMI + } \\
\text { Race/Ethnicity + Treatment Type + Comorbidities }\end{array}$ & $\begin{array}{l}0: \mathrm{HR}=1.75(0.98-3.12) \\
1: \mathrm{HR}=1.44(0.79-2.64) \\
2: \mathrm{HR}=1.00(\mathrm{REF}) \\
\mathrm{p}=0.1618\end{array}$ & 46 & $\begin{array}{l}n=305 \\
d=77\end{array}$ & $\begin{array}{l}0: 15.89 \% \\
1: 19.01 \%\end{array}$ & $\begin{array}{l}0: 4.89 \% \\
1: 9.92 \%\end{array}$ & $\begin{array}{l}0: 3.31 \% \\
1: 1.37 \%\end{array}$ \\
\hline 55 & $\begin{array}{l}\text { Model } 1+\text { Education }+ \text { Physical Activity }+ \text { BMI }+ \\
\text { Race/Ethnicity }+ \text { Treatment Type + Comorbidities }+ \\
\text { Current Lymphedema }\end{array}$ & $\begin{array}{l}0: H R=1.78(1.00-3.17) \\
1: H R=1.46(0.80-2.67) \\
2: H R=1.00(\text { REF }) \\
p=0.1471\end{array}$ & 46 & $\begin{array}{l}\mathrm{n}=305 \\
\mathrm{~d}=77\end{array}$ & $\begin{array}{l}0: 17.88 \% \\
1: 20.66 \%\end{array}$ & $\begin{array}{l}0: 3.26 \% \\
1: 11.45 \%\end{array}$ & $\begin{array}{l}0: 1.71 \% \\
1: 1.39 \%\end{array}$ \\
\hline
\end{tabular}




\begin{tabular}{|c|c|c|c|c|c|c|c|}
\hline Model & Variable(s) in model & $\begin{array}{l}\text { Mental Component Summary } \\
\text { Score (MCS) HR }(95 \% \text { CI) }\end{array}$ & $\begin{array}{l}\text { Difference in } \\
\text { ' } \mathrm{N} \text { ' }\end{array}$ & $\begin{array}{l}\text { Total in model } \\
\text { (n) and total } \\
\text { dead (d) }\end{array}$ & $\begin{array}{l}\% \text { change } \\
\text { from Crude }\end{array}$ & $\begin{array}{l}\% \text { change } \\
\text { from model } \\
1\end{array}$ & $\begin{array}{l}\text { \% change } \\
\text { from } \\
\text { previous } \\
\text { model }\end{array}$ \\
\hline 56 & $\begin{array}{l}\text { Model } 1+\text { Education + Physical Activity + BMI + } \\
\text { Race/Ethnicity + Treatment Type + Comorbidities + } \\
\text { Current Lymphedema + Pessimism }\end{array}$ & $\begin{array}{l}0: \mathrm{HR}=1.65(0.92-2.96) \\
1: \mathrm{HR}=1.43(0.78-2.62) \\
2: \mathrm{HR}=1.00(\mathrm{REF}) \\
\mathrm{p}=0.2391\end{array}$ & 46 & $\begin{array}{l}\mathrm{n}=305 \\
\mathrm{~d}=77\end{array}$ & $\begin{array}{l}0: 9.27 \% \\
1: \mathbf{1 8 . 1 8 \%}\end{array}$ & $\begin{array}{l}\mathbf{0 :} \mathbf{1 0 . 3 3 \%} \\
1: 9.16 \%\end{array}$ & $\begin{array}{l}0: 7.30 \% \\
1: 2.05 \%\end{array}$ \\
\hline 57 & $\begin{array}{l}\text { Model } 1+\text { Education }+ \text { Physical Activity }+ \text { BMI }+ \\
\text { Race/Ethnicity }+ \text { Treatment Type }+ \text { Comorbidities }+ \\
\text { Current Lymphedema }+ \text { Pessimism }+ \text { Fear of Recurrence }\end{array}$ & $\begin{array}{l}0: H R=1.65(0.92-2.97) \\
1: H R=1.43(0.78-2.63) \\
2: H R=1.00(\text { REF }) \\
p=0.2384\end{array}$ & 46 & $\begin{array}{l}\mathrm{n}=305 \\
\mathrm{~d}=77\end{array}$ & $\begin{array}{l}0: 9.27 \% \\
1: \mathbf{1 8 . 1 8 \%}\end{array}$ & $\begin{array}{l}\mathbf{0 :} \mathbf{1 0 . 3 3 \%} \\
1: 9.16 \%\end{array}$ & $\begin{array}{l}0: 0.00 \% \\
1: 0.00 \%\end{array}$ \\
\hline 58 & $\begin{array}{l}\text { Model } 1+\text { Education + Physical Activity + BMI + } \\
\text { Race/Ethnicity }+ \text { Treatment Type }+ \text { Comorbidities }+ \\
\text { Current Lymphedema + Pessimism + Fear of Recurrence } \\
+ \text { Confide }\end{array}$ & $\begin{array}{l}0: \mathrm{HR}=1.68(0.93-3.05) \\
1: \mathrm{HR}=1.44(0.78-2.64) \\
2: \mathrm{HR}=1.00(\mathrm{REF}) \\
\mathrm{p}=0.2213\end{array}$ & 46 & $\begin{array}{l}\mathrm{n}=305 \\
\mathrm{~d}=77\end{array}$ & $\begin{array}{l}0: 11.26 \% \\
1: 19.01 \%\end{array}$ & $\begin{array}{l}0: 8.70 \% \\
1: 9.92 \%\end{array}$ & $\begin{array}{l}0: 1.82 \% \\
1: 0.70 \%\end{array}$ \\
\hline 59 & $\begin{array}{l}\text { Model } 1+\text { Education + Physical Activity + BMI + } \\
\text { Race/Ethnicity + Treatment Type + Comorbidities }+ \\
\text { Current Lymphedema + Pessimism + Fear of Recurrence } \\
+ \text { Confide + Bodily Pain }\end{array}$ & $\begin{array}{l}0: \mathrm{HR}=1.66(0.91-3.03) \\
1: \mathrm{HR}=1.43(0.78-2.63) \\
2: \mathrm{HR}=1.00(\mathrm{REF}) \\
\mathrm{p}=0.2449\end{array}$ & 46 & $\begin{array}{l}\mathrm{n}=305 \\
\mathrm{~d}=77\end{array}$ & $\begin{array}{l}0: 9.93 \% \\
\mathbf{1}: \mathbf{1 8 . 1 8 \%}\end{array}$ & $\begin{array}{l}0: 9.78 \% \\
1: 9.16 \%\end{array}$ & $\begin{array}{l}0: 1.19 \% \\
1: 0.69 \%\end{array}$ \\
\hline 60 & $\begin{array}{l}\text { Model } 1+\text { Education + Physical Activity + BMI + } \\
\text { Race/Ethnicity + Treatment Type + Comorbidities + } \\
\text { Current Lymphedema + Pessimism + Fear of Recurrence } \\
+ \text { Confide + Bodily Pain + Perceived General Health }\end{array}$ & $\begin{array}{l}0: \mathrm{HR}=1.46(0.79-2.71) \\
1: \mathrm{HR}=1.35(0.73-2.50) \\
2: \mathrm{HR}=1.00(\mathrm{REF}) \\
\mathrm{p}=0.4553\end{array}$ & 46 & $\begin{array}{l}\mathrm{n}=305 \\
\mathrm{~d}=77\end{array}$ & $\begin{array}{l}0: 3.31 \% \\
1: \mathbf{1 1 . 5 7 \%}\end{array}$ & $\begin{array}{l}\mathbf{0 :} \mathbf{2 0 . 6 5 \%} \\
1: 3.05 \%\end{array}$ & $\begin{array}{l}\mathbf{0}: \mathbf{1 2 . 0 5 \%} \\
1: 5.59 \%\end{array}$ \\
\hline
\end{tabular}


Appendix H. Physical Component Summary Score Univariate HR Analysis and Percent Change for Breast Cancer-Specific Mortality when Assessing for Potential Confounders $(N=351)$

\begin{tabular}{|c|c|c|c|c|c|c|c|c|c|c|}
\hline Model & Variable(s) in model & Categories & & $\begin{array}{l}\text { Total in } \\
\text { categories } \\
\text { (n) }\end{array}$ & $\begin{array}{l}\text { Total } \\
\text { in } \\
\text { model } \\
(\mathrm{n}) ; \\
\text { dead } \\
\text { (d) } \\
\end{array}$ & Missing & Univariate-Cox HR $(95 \% \mathrm{CI})$ & p-values* & $\begin{array}{l}\text { PCS HR }(95 \% \mathrm{CI}) \text { and } \mathrm{p}- \\
\text { values }\end{array}$ & $\begin{array}{l}\% \text { change } \\
\text { from crude } \\
\text { model }\end{array}$ \\
\hline Crude & $\begin{array}{l}\text { Physical Component } \\
\text { Summary Score (PCS) }\end{array}$ & $\begin{array}{l}0: \leq 50.28 \\
1:>50.28(\mathrm{REF})\end{array}$ & & $\begin{array}{l}0: 176 \\
1: 175\end{array}$ & $\begin{array}{l}n=351 \\
d=26\end{array}$ & 0 & $0: H R=1.09(0.51-2.36)$ & $\mathrm{p}=0.8239$ & $\begin{array}{l}0: \mathrm{HR}=1.09(0.51-2.36) \\
\mathrm{p}(\mathrm{PCS})=0.8239\end{array}$ & -- \\
\hline 1 & Age & Continuous & & -- & $\begin{array}{l}\mathrm{n}=351 \\
\mathrm{~d}=26\end{array}$ & 0 & $\mathrm{HR}=1.00(0.97-1.04)$ & $\mathrm{p}=0.8950$ & $\begin{array}{l}0: \mathrm{HR}=1.08(0.49-2.37) \\
\mathrm{p}(\mathrm{PCS})=0.8473 \\
\mathrm{p}(\mathrm{Age})=0.8950\end{array}$ & $0: 0.92 \%$ \\
\hline 2 & Race/Ethnicity & $\begin{array}{l}0: \text { Non-Hispanic } \\
\text { White (REF) } \\
\text { Hispanic }\end{array}$ & 1: & $\begin{array}{l}0: 273 \\
1: 78\end{array}$ & $\begin{array}{l}\mathrm{n}=351 \\
\mathrm{~d}=26\end{array}$ & 0 & $\begin{array}{l}0: H R=1.00 \\
1: H R=0.84(0.32-2.23)\end{array}$ & $\mathrm{p}=0.7292$ & $\begin{array}{l}0: \mathrm{HR}=1.09(0.51-2.36) \\
\mathrm{p}(\mathrm{PCS})=0.8230 \\
\mathrm{p}(\text { Ethnicity })=0.7292\end{array}$ & $0: 0.00 \%$ \\
\hline 3 & Marital Status & $\begin{array}{l}\text { 0: Single } \\
1 \text { : Married (REF) }\end{array}$ & & $\begin{array}{l}0: 160 \\
1: 191\end{array}$ & $\begin{array}{l}\mathrm{n}=351 \\
\mathrm{~d}=26\end{array}$ & 0 & $\begin{array}{l}0: \mathrm{HR}=1.10(0.51-2.40) \\
1: \mathrm{HR}=1.00\end{array}$ & $\mathrm{p}=0.8040$ & $\begin{array}{l}0: \mathrm{HR}=1.08(0.50-2.34) \\
\mathrm{p}(\mathrm{PCS})=0.8454 \\
\mathrm{p}(\text { Marital })=0.8040\end{array}$ & $0: 0.92 \%$ \\
\hline
\end{tabular}




\begin{tabular}{|c|c|c|c|c|c|c|c|c|c|}
\hline Model & Variable(s) in model & Categories & $\begin{array}{l}\text { Total in } \\
\text { categories } \\
\text { (n) }\end{array}$ & $\begin{array}{l}\text { Total } \\
\text { in } \\
\text { model } \\
\text { (n); } \\
\text { dead } \\
\text { (d) } \\
\end{array}$ & Missing & Univariate-Cox HR $(95 \% \mathrm{CI})$ & p-values* & $\begin{array}{l}\text { PCS HR }(95 \% \mathrm{CI}) \text { and } \mathrm{p} \text { - } \\
\text { values }\end{array}$ & $\begin{array}{l}\% \text { change } \\
\text { from crude } \\
\text { model }\end{array}$ \\
\hline 4 & Tumor Stage & $\begin{array}{l}\text { 0: Localized (I) } \\
\text { 1: Regional (II-IIIa) }\end{array}$ & $\begin{array}{l}0: 276 \\
1: 75\end{array}$ & $\begin{array}{l}n=351 \\
d=26\end{array}$ & 0 & $\begin{array}{l}0: \mathrm{HR}=1.00 \\
1: \mathrm{HR}=2.75(1.26-5.99)\end{array}$ & $\mathrm{p}=\mathbf{0 . 0 1 1 0}$ & $\begin{array}{l}0: \mathrm{HR}=1.14(0.53-2.46) \\
\mathrm{p}(\mathrm{PCS})=0.7388 \\
\mathrm{p}(\mathrm{Stage})=0.0110\end{array}$ & $0: 4.59 \%$ \\
\hline 5 & $\begin{array}{l}\text { Breast Cancer Treatment } \\
\text { Type }\end{array}$ & $\begin{array}{l}0 \text { : Surgery only (REF) } \\
\text { 1: Any chemotherapy } \\
\text { 2: Surgery and } \\
\text { radiation }\end{array}$ & $\begin{array}{l}0: 98 \\
1: 109 \\
2: 144\end{array}$ & $\begin{array}{l}n=351 \\
d=26\end{array}$ & 0 & $\begin{array}{l}0: \mathrm{HR}=1.00 \\
1: \mathrm{HR}=6.83(1.56-29.79) \\
2: \mathrm{HR}=2.56(0.54-12.04)\end{array}$ & $\mathrm{p}=\mathbf{0 . 0 0 7 6}$ & $\begin{array}{l}0: \mathrm{HR}=1.24(0.57-2.68) \\
\mathrm{p}(\mathrm{PCS})=0.5852 \\
\mathrm{p}(\text { Treatment } 1)=0.0106 \\
\mathrm{p}(\text { Treatment } 2)=0.2354\end{array}$ & $0: 13.76 \%$ \\
\hline 6 & Comorbidities & $\begin{array}{l}\text { 0: Zero (REF) } \\
1: \text { One or more }\end{array}$ & $\begin{array}{l}0: 298 \\
1: 53\end{array}$ & $\begin{array}{l}n=351 \\
d=26\end{array}$ & 0 & $\begin{array}{l}0: \mathrm{HR}=1.00 \\
1: \mathrm{HR}=1.49(0.55-4.01)\end{array}$ & $\mathrm{p}=0.4335$ & $\begin{array}{l}0: \mathrm{HR}=1.04(0.47-2.27) \\
\mathrm{p}(\mathrm{PCS})=0.9274 \\
\mathrm{p}(\text { Comorbidities })=0.4335\end{array}$ & $0: 4.59 \%$ \\
\hline 7 & Current Lymphedema & $\begin{array}{l}0: \text { No (REF) } \\
1: \text { Yes }\end{array}$ & $\begin{array}{l}0: 307 \\
1: 44\end{array}$ & $\begin{array}{l}n=351 \\
d=26\end{array}$ & 0 & $\begin{array}{l}0: \mathrm{HR}=1.00 \\
1: \mathrm{HR}=0.83(0.25-2.81)\end{array}$ & $\mathrm{p}=0.7685$ & $\begin{array}{l}0: \mathrm{HR}=1.11(0.51-2.42) \\
\text { p(PCS) }=0.7910 \\
\text { p(Lymphedema })=0.7685\end{array}$ & $0: 1.83 \%$ \\
\hline
\end{tabular}




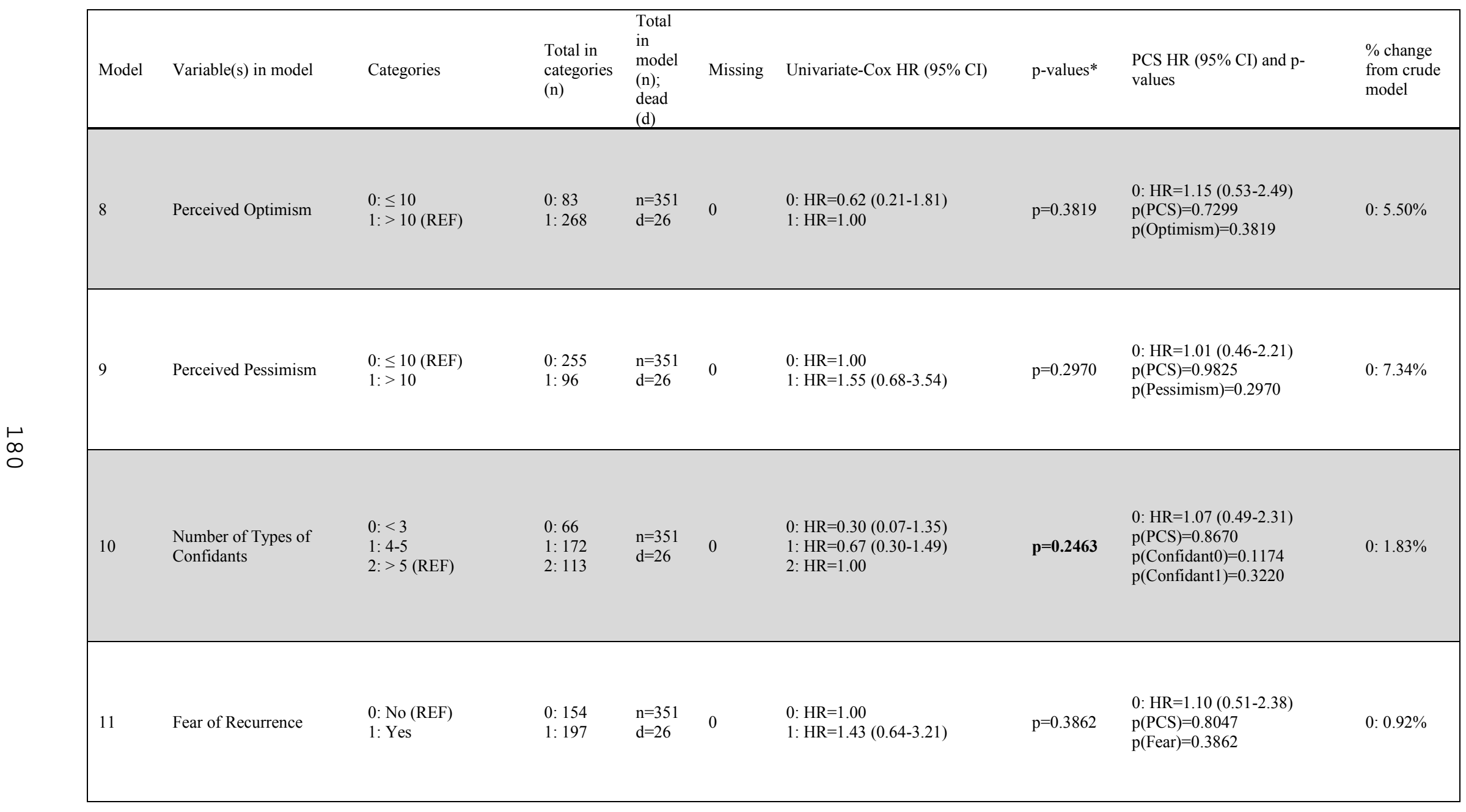




\begin{tabular}{|c|c|c|c|c|c|c|c|c|c|}
\hline Model & Variable(s) in model & Categories & $\begin{array}{l}\text { Total in } \\
\text { categories } \\
\text { (n) }\end{array}$ & $\begin{array}{l}\text { Total } \\
\text { in } \\
\text { model } \\
\text { (n); } \\
\text { dead } \\
\text { (d) } \\
\end{array}$ & Missing & Univariate-Cox HR $(95 \%$ Cl) & p-values* & $\begin{array}{l}\text { PCS HR }(95 \% \mathrm{CI}) \text { and p- } \\
\text { values }\end{array}$ & $\begin{array}{l}\% \text { change } \\
\text { from crude } \\
\text { model }\end{array}$ \\
\hline Crude & $\begin{array}{l}\text { PCS (restricted to those } \\
\text { with education) }\end{array}$ & & $\begin{array}{l}0: 175 \\
1: 175\end{array}$ & $\begin{array}{l}n=350 \\
d=26\end{array}$ & & $0: \mathrm{HR}=1.09(0.51-2.36)$ & $\mathrm{p}=0.8183$ & $\begin{array}{l}0: \mathrm{HR}=1.09(0.51-2.36) \\
\mathrm{p}(\mathrm{PCS})=0.8183\end{array}$ & -- \\
\hline 12 & Education & $\begin{array}{l}\text { 0: High school or less } \\
\text { 1: Some college } \\
\text { 2: College graduate } \\
\text { 3: Graduate school } \\
\text { (REF) }\end{array}$ & $\begin{array}{l}0: 92 \\
1: 114 \\
2: 70 \\
3: 74\end{array}$ & $\begin{array}{l}n=350 \\
d=26\end{array}$ & 1 & $\begin{array}{l}0: \mathrm{HR}=1.36(0.48-3.85) \\
1: \mathrm{HR}=1.10(0.39-3.05) \\
\text { 2: } \mathrm{HR}=0.17(0.02-1.44) \\
3: \mathrm{HR}=1.00\end{array}$ & $\mathrm{p}=0.2800$ & $\begin{array}{l}\text { 0: HR=0.99 }(0.45-2.15) \\
\text { p(PCS) }=0.9735 \\
\text { p(Education } 0=0.5647 \\
\text { p(Education } 1)=0.8616 \\
\text { p(Education } 2)=0.1047\end{array}$ & $0: 9.17 \%$ \\
\hline Crude & $\begin{array}{l}\text { PCS (restricted to those } \\
\text { with tumor size) }\end{array}$ & & $\begin{array}{l}0: 173 \\
1: 168\end{array}$ & $\begin{array}{l}\mathrm{n}=341 \\
\mathrm{~d}=26\end{array}$ & & $0: \mathrm{HR}=1.07(0.50-2.31)$ & $\mathrm{p}=0.8631$ & $\begin{array}{l}0: \mathrm{HR}=1.07(0.50-2.31) \\
\mathrm{p}(\mathrm{PCS})=0.8631\end{array}$ & -- \\
\hline 13 & Tumor Size & $\begin{array}{l}0:<3 \mathrm{~cm}(\mathrm{REF}) \\
1: \geq 3 \mathrm{~cm}\end{array}$ & $\begin{array}{l}0: 304 \\
1: 37\end{array}$ & $\begin{array}{l}\mathrm{n}=341 \\
\mathrm{~d}=26\end{array}$ & 10 & $\begin{array}{l}0: H R=1.00 \\
1: H R=3.88(1.69-8.94)\end{array}$ & $p=0.0014$ & $\begin{array}{l}0: \mathrm{HR}=1.11(0.51-2.39) \\
\mathrm{p}(\mathrm{PCS})=0.7997 \\
\mathrm{p}(\mathrm{Size})=0.0014\end{array}$ & $0: 3.74 \%$ \\
\hline
\end{tabular}




\begin{tabular}{|c|c|c|c|c|c|c|c|c|c|}
\hline Model & Variable(s) in model & Categories & $\begin{array}{l}\text { Total in } \\
\text { categories } \\
\text { (n) }\end{array}$ & $\begin{array}{l}\text { Total } \\
\text { in } \\
\text { model } \\
\text { (n); } \\
\text { dead } \\
\text { (d) } \\
\end{array}$ & Missing & Univariate-Cox HR $(95 \%$ CI) & p-values* & $\begin{array}{l}\text { PCS HR }(95 \% \mathrm{CI}) \text { and } \mathrm{p} \text { - } \\
\text { values }\end{array}$ & $\begin{array}{l}\% \text { change } \\
\text { from crude } \\
\text { model }\end{array}$ \\
\hline Crude & $\begin{array}{l}\text { PCS (restricted to those } \\
\text { with lymph node } \\
\text { involvement) }\end{array}$ & & $\begin{array}{l}0: 170 \\
1: 171\end{array}$ & $\begin{array}{l}n=341 \\
d=24\end{array}$ & & $0: \mathrm{HR}=0.94(0.42-2.09)$ & $\mathrm{p}=0.8715$ & $\begin{array}{l}0: \mathrm{HR}=0.94(0.42-2.09) \\
\mathrm{p}(\mathrm{PCS})=0.8715\end{array}$ & -- \\
\hline 14 & $\begin{array}{l}\text { Lymph Node } \\
\text { Involvement }\end{array}$ & $\begin{array}{l}0: \text { None (REF) } \\
1: \geq 1 \text { lymph node } \\
\text { involved }\end{array}$ & $\begin{array}{l}0: 264 \\
1: 77\end{array}$ & $\begin{array}{l}n=341 \\
d=24\end{array}$ & 10 & $\begin{array}{l}0: \mathrm{HR}=1.00 \\
1: \mathrm{HR}=2.97(0.83-2.10)\end{array}$ & $\mathrm{p}=\mathbf{0 . 0 0 8 0}$ & $\begin{array}{l}0: \mathrm{HR}=0.99(0.44-2.22) \\
\mathrm{p}(\mathrm{PCS})=0.9865 \\
\mathrm{p}(\text { Lymph node })=0.0080\end{array}$ & $0: 5.32 \%$ \\
\hline Crude & $\begin{array}{l}\text { PCS (restricted to those } \\
\text { with Tamoxifen use, } \\
\text { smoking status, and } \\
\text { physical activity) }\end{array}$ & & $\begin{array}{l}0: 165 \\
1: 165\end{array}$ & $\begin{array}{l}n=330 \\
d=24\end{array}$ & & $0: \mathrm{HR}=1.31(0.59-2.93)$ & $\mathrm{p}=0.5088$ & $\begin{array}{l}0: \mathrm{HR}=1.31(0.59-2.93) \\
\mathrm{p}(\mathrm{PCS})=0.5088\end{array}$ & -- \\
\hline 15 & Tamoxifen Use & $\begin{array}{l}0: \text { No } \\
1: \text { Yes (REF) }\end{array}$ & $\begin{array}{l}0: 160 \\
1: 170\end{array}$ & $\begin{array}{l}\mathrm{n}=330 \\
\mathrm{~d}=24\end{array}$ & 21 & $\begin{array}{l}0: \mathrm{HR}=0.88(0.39-1.97) \\
1: \mathrm{HR}=1.00\end{array}$ & $\mathrm{p}=0.7580$ & $\begin{array}{l}0: \mathrm{HR}=1.32(0.59-2.95) \\
\mathrm{p}(\mathrm{PCS})=0.4990 \\
\mathrm{p}(\text { Tamoxifen })=0.7580\end{array}$ & $0: 0.76 \%$ \\
\hline
\end{tabular}




\begin{tabular}{|c|c|c|c|c|c|c|c|c|c|}
\hline Model & Variable(s) in model & Categories & $\begin{array}{l}\text { Total in } \\
\text { categories } \\
\text { (n) }\end{array}$ & $\begin{array}{l}\text { Total } \\
\text { in } \\
\text { model } \\
\text { (n); } \\
\text { dead } \\
\text { (d) } \\
\end{array}$ & Missing & Univariate-Cox HR $(95 \% \mathrm{CI})$ & p-values* & $\begin{array}{l}\text { PCS HR }(95 \% \mathrm{CI}) \text { and } \mathrm{p} \text { - } \\
\text { values }\end{array}$ & $\begin{array}{l}\% \text { change } \\
\text { from crude } \\
\text { model }\end{array}$ \\
\hline 16 & Smoking Status & $\begin{array}{l}0: \text { Never (REF) } \\
\text { 1: Former } \\
2: \text { Current }\end{array}$ & $\begin{array}{l}0: 145 \\
1: 144 \\
2: 41\end{array}$ & $\begin{array}{l}n=330 \\
d=24\end{array}$ & 21 & $\begin{array}{l}0: H R=1.00 \\
\text { 1: } \mathrm{HR}=0.91(0.37-2.23) \\
2: \mathrm{HR}=1.86(0.63-5.44)\end{array}$ & $\mathrm{p}=0.4113$ & $\begin{array}{l}0: \mathrm{HR}=1.24(0.55-2.79) \\
\text { p(PCS) }=0.6020 \\
\text { p(Smokerl })=0.8280 \\
\text { p(Smoker2) }=0.2600\end{array}$ & $0: 5.34 \%$ \\
\hline 17 & Physical Activity & $\begin{array}{l}\text { 0: None } \\
\text { 1: Low } \\
\text { 2: Moderate/Vigorous } \\
\text { (REF) }\end{array}$ & $\begin{array}{l}0: 185 \\
1: 59 \\
2: 86\end{array}$ & $\begin{array}{l}\mathrm{n}=330 \\
\mathrm{~d}=24\end{array}$ & 21 & $\begin{array}{l}0: H R=1.27(0.44-3.60) \\
1: H R=1.64(0.49-5.44) \\
\text { 2: } H R=1.00\end{array}$ & $\mathrm{p}=0.7216$ & $\begin{array}{l}0: \mathrm{HR}=1.25(0.55-2.82) \\
\text { p(PCS) }=0.5970 \\
\text { p(PA0) }=0.6600 \\
\text { p(PA1) }=0.4222\end{array}$ & $0: 4.58 \%$ \\
\hline Crude & $\begin{array}{l}\text { PCS (restricted to those } \\
\text { with BMI) }\end{array}$ & & $\begin{array}{l}0: 161 \\
1: 163\end{array}$ & $\begin{array}{l}\mathrm{n}=324 \\
\mathrm{~d}=24\end{array}$ & & $0: \mathrm{HR}=1.09(0.49-2.42)$ & $\mathrm{p}=0.8385$ & $\begin{array}{l}0: \mathrm{HR}=1.09(0.49-2.42) \\
\mathrm{p}(\mathrm{PCS})=0.8385\end{array}$ & -- \\
\hline 18 & Body Mass Index (BMI) & $\begin{array}{l}0:<25 \text { (REF) } \\
1: 25-29 \\
2: \geq 30\end{array}$ & $\begin{array}{l}0: 161 \\
1: 99 \\
2: 64\end{array}$ & $\begin{array}{l}\mathrm{n}=324 \\
\mathrm{~d}=24\end{array}$ & 27 & $\begin{array}{l}0: H R=1.00 \\
1: H R=1.77(0.72-4.39) \\
2: H R=1.48(0.49-4.45)\end{array}$ & $\mathrm{p}=0.4574$ & $\begin{array}{l}0: \mathrm{HR}=1.02(0.45-2.28) \\
\mathrm{p}(\mathrm{PCS})=0.9684 \\
\text { p(BMI1) }=0.2149 \\
\mathrm{p}(\mathrm{BMI})=0.4887\end{array}$ & $0: 6.42 \%$ \\
\hline
\end{tabular}




\begin{tabular}{|c|c|c|c|c|c|c|c|c|c|}
\hline Model & Variable(s) in model & Categories & $\begin{array}{l}\text { Total in } \\
\text { categories } \\
\text { (n) }\end{array}$ & $\begin{array}{l}\text { Total } \\
\text { in } \\
\text { model } \\
\text { (n); } \\
\text { dead } \\
\text { (d) }\end{array}$ & Missing & Univariate-Cox HR $(95 \%$ CI) & p-values* & $\begin{array}{l}\text { PCS HR }(95 \% \mathrm{CI}) \text { and } \mathrm{p} \text { - } \\
\text { values }\end{array}$ & $\begin{array}{l}\% \text { change } \\
\text { from crude } \\
\text { model }\end{array}$ \\
\hline Crude & $\begin{array}{l}\text { PCS (restricted to those } \\
\text { tumor subtype) }\end{array}$ & & $\begin{array}{l}0: 155 \\
1: 145\end{array}$ & $\begin{array}{l}\mathrm{n}=300 \\
\mathrm{~d}=22\end{array}$ & & $0: \mathrm{HR}=1.02(0.44-2.35)$ & $\mathrm{p}=0.9667$ & $\begin{array}{l}0: \mathrm{HR}=1.02(0.44-2.35) \\
\mathrm{p}(\mathrm{PCS})=0.9667\end{array}$ & -- \\
\hline 19 & Tumor Subtype & $\begin{array}{l}0: \mathrm{ER}+(\mathrm{REF}) \\
1: \mathrm{ER}-\end{array}$ & $\begin{array}{l}0: 251 \\
1: 49\end{array}$ & $\begin{array}{l}n=300 \\
d=22\end{array}$ & 51 & $\begin{array}{l}0: \mathrm{HR}=1.00 \\
1: \mathrm{HR}=1.55(0.57-4.19)\end{array}$ & $\mathrm{p}=0.3926$ & $\begin{array}{l}0: \mathrm{HR}=1.02(0.44-2.35) \\
\mathrm{p}(\mathrm{PCS})=0.9659 \\
\mathrm{p}(\text { Subtype })=0.3926\end{array}$ & $0: 0.00 \%$ \\
\hline olde & values are $<0.25$. & & & & & & & & \\
\hline
\end{tabular}


Appendix I. Mental Component Summary Score Univariate HR Analysis and Percent Change for Breast Cancer-Specific Mortality when Assessing for Potential Confounders $(N=351)$

\begin{tabular}{|c|c|c|c|c|c|c|c|c|c|c|}
\hline Model & Variable(s) in model & Categories & & $\begin{array}{l}\text { Total in } \\
\text { categories } \\
\text { (n) }\end{array}$ & $\begin{array}{l}\text { Total } \\
\text { in } \\
\text { model } \\
(\mathrm{n}) ; \\
\text { dead } \\
\text { (d) } \\
\end{array}$ & Missing & Univariate-Cox HR $(95 \%$ CI $)$ & p-values* & $\begin{array}{l}\text { MCS HR }(95 \% \mathrm{CI}) \text { and } \mathrm{p}- \\
\text { values }\end{array}$ & $\begin{array}{l}\% \text { change } \\
\text { from crude } \\
\text { model }\end{array}$ \\
\hline Crude & $\begin{array}{l}\text { Mental Component } \\
\text { Summary Score (MCS) }\end{array}$ & $\begin{array}{l}0: \leq 50.70 \\
1:>50.70(\mathrm{REF})\end{array}$ & & $\begin{array}{l}0: 176 \\
1: 175\end{array}$ & $\begin{array}{l}\mathrm{n}=351 \\
\mathrm{~d}=26\end{array}$ & 0 & $0: \mathrm{HR}=1.22(0.57-2.65)$ & $\mathrm{p}=0.6082$ & $\begin{array}{l}0: \mathrm{HR}=1.22(0.57-2.65) \\
\mathrm{p}(\mathrm{MCS})=0.6082\end{array}$ & -- \\
\hline 1 & Age & Continuous & & -- & $\begin{array}{l}\mathrm{n}=351 \\
\mathrm{~d}=26\end{array}$ & 0 & $\mathrm{HR}=1.00(0.97-1.04)$ & $\mathrm{p}=0.8186$ & $\begin{array}{l}0: H R=1.24(0.57-2.68) \\
p(M C S)=0.5928 \\
p(\text { Age })=0.8186\end{array}$ & $0: 1.64 \%$ \\
\hline 2 & Race/Ethnicity & $\begin{array}{l}\text { 0: Non-Hispanic } \\
\text { White (REF) } \\
\text { Hispanic }\end{array}$ & 1: & $\begin{array}{l}0: 273 \\
1: 78\end{array}$ & $\begin{array}{l}\mathrm{n}=351 \\
\mathrm{~d}=26\end{array}$ & 0 & $\begin{array}{l}0: H R=1.00 \\
1: H R=0.83(0.31-2.20)\end{array}$ & $\mathrm{p}=0.7047$ & $\begin{array}{l}0: \mathrm{HR}=1.24(0.57-2.68) \\
\mathrm{p}(\mathrm{MCS})=0.5910 \\
\mathrm{p}(\text { Ethnicity })=0.7047\end{array}$ & $0: 1.64 \%$ \\
\hline 3 & Marital Status & $\begin{array}{l}0: \text { Single } \\
\text { 1: Married (REF) }\end{array}$ & & $\begin{array}{l}0: 160 \\
1: 191\end{array}$ & $\begin{array}{l}\mathrm{n}=351 \\
\mathrm{~d}=26\end{array}$ & 0 & $\begin{array}{l}0: \mathrm{HR}=1.11(0.51-2.40) \\
1: \mathrm{HR}=1.00\end{array}$ & $\mathrm{p}=0.7902$ & $\begin{array}{l}0: \mathrm{HR}=1.22(0.57-2.64) \\
\mathrm{p}(\mathrm{MCS})=0.6094 \\
\mathrm{p}(\text { Marital })=0.7902\end{array}$ & $0: 0.00 \%$ \\
\hline
\end{tabular}




\begin{tabular}{|c|c|c|c|c|c|c|c|c|c|}
\hline Model & Variable(s) in model & Categories & $\begin{array}{l}\text { Total in } \\
\text { categories } \\
\text { (n) }\end{array}$ & $\begin{array}{l}\text { Total } \\
\text { in } \\
\text { model } \\
(\mathrm{n}) ; \\
\text { dead } \\
\text { (d) } \\
\end{array}$ & Missing & Univariate-Cox HR $(95 \%$ CI) & p-values* & $\begin{array}{l}\text { MCS HR }(95 \% \mathrm{CI}) \text { and p- } \\
\text { values }\end{array}$ & $\begin{array}{l}\% \text { change } \\
\text { from crude } \\
\text { model }\end{array}$ \\
\hline 4 & Tumor Stage & $\begin{array}{l}\text { 0: Localized (I) } \\
\text { 1: Regional (II-IIIa) }\end{array}$ & $\begin{array}{l}0: 276 \\
1: 75\end{array}$ & $\begin{array}{l}n=351 \\
d=26\end{array}$ & 0 & $\begin{array}{l}0: H R=1.00 \\
1: H R=2.77(1.27-6.05)\end{array}$ & $p=0.0104$ & $\begin{array}{l}0: \mathrm{HR}=1.29(0.60-2.80) \\
\mathrm{p}(\mathrm{MCS})=0.5165 \\
\mathrm{p}(\text { Stage })=0.0104\end{array}$ & $0: 5.74 \%$ \\
\hline 5 & $\begin{array}{l}\text { Breast Cancer Treatment } \\
\text { Type }\end{array}$ & $\begin{array}{l}0: \text { Surgery only (REF) } \\
\text { 1: Any chemotherapy } \\
2 \text { : Surgery and } \\
\text { radiation }\end{array}$ & $\begin{array}{l}0: 98 \\
1: 109 \\
2: 144\end{array}$ & $\begin{array}{l}\mathrm{n}=351 \\
\mathrm{~d}=26\end{array}$ & 0 & $\begin{array}{l}0: \mathrm{HR}=1.00 \\
1: \mathrm{HR}=6.61(1.52-28.74) \\
2: \mathrm{HR}=2.54(0.54-11.97)\end{array}$ & $\mathrm{p}=\mathbf{0 . 0 0 9 2}$ & $\begin{array}{l}0: \mathrm{HR}=1.14(0.53-2.47) \\
\mathrm{p}(\mathrm{MCS})=0.2111 \\
\mathrm{p}(\text { Treatment } 1)=0.0119 \\
\mathrm{p}(\text { Treatment } 2)=0.2383\end{array}$ & $0: 6.56 \%$ \\
\hline 6 & Comorbidities & $\begin{array}{l}0: \text { Zero (REF) } \\
1: \text { One or more }\end{array}$ & $\begin{array}{l}0: 298 \\
1: 53\end{array}$ & $\begin{array}{l}n=351 \\
d=26\end{array}$ & 0 & $\begin{array}{l}0: \mathrm{HR}=1.00 \\
1: \mathrm{HR}=1.45(0.54-3.90)\end{array}$ & $\mathrm{p}=0.4574$ & $\begin{array}{l}0: H R=1.18(0.54-2.57) \\
p(M C S)=0.6824 \\
p(\text { Comorbidities })=0.4574\end{array}$ & $0: 3.28 \%$ \\
\hline 7 & Current Lymphedema & $\begin{array}{l}0: \text { No (REF) } \\
\text { 1: Yes }\end{array}$ & $\begin{array}{l}0: 307 \\
1: 44\end{array}$ & $\begin{array}{l}\mathrm{n}=351 \\
\mathrm{~d}=26\end{array}$ & 0 & $\begin{array}{l}0: \mathrm{HR}=1.00 \\
1: \mathrm{HR}=0.84(0.25-2.79)\end{array}$ & $\mathrm{p}=0.7688$ & $\begin{array}{l}0: \mathrm{HR}=1.23(0.57-2.67) \\
\mathrm{p}(\mathrm{MCS})=0.5942 \\
\mathrm{p}(\text { Lymphedema })=0.7688\end{array}$ & $0: 0.82 \%$ \\
\hline
\end{tabular}




\begin{tabular}{|c|c|c|c|c|c|c|c|c|c|}
\hline Model & Variable(s) in model & Categories & $\begin{array}{l}\text { Total in } \\
\text { categories } \\
\text { (n) }\end{array}$ & $\begin{array}{l}\text { Total } \\
\text { in } \\
\text { model } \\
\text { (n); } \\
\text { dead } \\
\text { (d) } \\
\end{array}$ & Missing & Univariate-Cox HR $(95 \% \mathrm{CI})$ & p-values* & $\begin{array}{l}\text { MCS HR }(95 \% \mathrm{CI}) \text { and p- } \\
\text { values }\end{array}$ & $\begin{array}{l}\% \text { change } \\
\text { from crude } \\
\text { model }\end{array}$ \\
\hline 8 & Perceived Optimism & $\begin{array}{l}0: \leq 10 \\
1:>10 \text { (REF) }\end{array}$ & $\begin{array}{l}0: 83 \\
1: 268\end{array}$ & $\begin{array}{l}n=351 \\
d=26\end{array}$ & 0 & $\begin{array}{l}0: \mathrm{HR}=0.60(0.20-1.75) \\
1: \mathrm{HR}=1.00\end{array}$ & $\mathrm{p}=0.3460$ & $\begin{array}{l}0: \mathrm{HR}=1.32(0.60-2.88) \\
\mathrm{p}(\mathrm{MCS})=0.4909 \\
\mathrm{p}(\text { Optimism })=0.3460\end{array}$ & $0: 8.20 \%$ \\
\hline 9 & Perceived Pessimism & $\begin{array}{l}0: \leq 10 \text { (REF) } \\
1:>10\end{array}$ & $\begin{array}{l}0: 255 \\
1: 96\end{array}$ & $\begin{array}{l}n=351 \\
d=26\end{array}$ & 0 & $\begin{array}{l}0: \mathrm{HR}=1.00 \\
1: \mathrm{HR}=1.51(0.66-3.46)\end{array}$ & $\mathrm{p}=0.3280$ & $\begin{array}{l}0: \mathrm{HR}=1.13(0.51-2.49) \\
\mathrm{p}(\mathrm{MCS})=0.7593 \\
\mathrm{p}(\mathrm{Pessimism})=0.3280\end{array}$ & $0: 7.38 \%$ \\
\hline 10 & Current Fatigue & $\begin{array}{l}\text { 0: No (REF) } \\
1: \text { Yes }\end{array}$ & $\begin{array}{l}0: 136 \\
1: 215\end{array}$ & $\begin{array}{l}n=351 \\
d=26\end{array}$ & 0 & $\begin{array}{l}0: \mathrm{HR}=1.00 \\
1: \mathrm{HR}=0.75(0.55-1.35)\end{array}$ & $\mathrm{p}=0.5085$ & $\begin{array}{l}0: \mathrm{HR}=1.36(0.59-3.12) \\
\mathrm{p}(\mathrm{MCS})=0.4728 \\
\mathrm{p}(\text { Fatigue })=0.5085\end{array}$ & 0: $11.48 \%$ \\
\hline 11 & Fear of Recurrence & $\begin{array}{l}0: \text { No (REF) } \\
\text { 1: Yes }\end{array}$ & $\begin{array}{l}0: 154 \\
1: 197\end{array}$ & $\begin{array}{l}n=351 \\
d=26\end{array}$ & 0 & $\begin{array}{l}0: \mathrm{HR}=1.00 \\
1: \mathrm{HR}=1.39(0.61-3.15)\end{array}$ & $\mathrm{p}=0.4284$ & $\begin{array}{l}0: \mathrm{HR}=1.16(0.53-2.54) \\
\mathrm{p}(\mathrm{MCS})=0.7029 \\
\mathrm{p}(\mathrm{Fear})=0.4284\end{array}$ & $0: 4.92 \%$ \\
\hline
\end{tabular}




\begin{tabular}{|c|c|c|c|c|c|c|c|c|c|}
\hline Model & Variable(s) in model & Categories & $\begin{array}{l}\text { Total in } \\
\text { categories } \\
\text { (n) }\end{array}$ & $\begin{array}{l}\text { Total } \\
\text { in } \\
\text { model } \\
\text { (n); } \\
\text { dead } \\
\text { (d) } \\
\end{array}$ & Missing & Univariate-Cox HR (95\% CI) & p-values* & $\begin{array}{l}\text { MCS HR }(95 \% \mathrm{CI}) \text { and p- } \\
\text { values }\end{array}$ & $\begin{array}{l}\% \text { change } \\
\text { from crude } \\
\text { model }\end{array}$ \\
\hline 12 & $\begin{array}{l}\text { Number of Types of } \\
\text { Confidants }\end{array}$ & $\begin{array}{l}0:<3 \\
1: 4-5 \\
2:>5(\mathrm{REF})\end{array}$ & $\begin{array}{l}0: 66 \\
1: 172 \\
2: 113\end{array}$ & $\begin{array}{l}n=351 \\
d=26\end{array}$ & 0 & $\begin{array}{l}0: \mathrm{HR}=0.30(0.07-1.32) \\
1: \mathrm{HR}=0.65(0.29-1.46) \\
2: \mathrm{HR}=1.00\end{array}$ & $p=0.2284$ & $\begin{array}{l}0: \mathrm{HR}=1.28(0.59-2.78) \\
\mathrm{p}(\mathrm{MCS})=0.5283 \\
\mathrm{p}(\text { Confidant } 0)=0.1105 \\
\mathrm{p}(\text { Confidant } 1)=0.2964\end{array}$ & $0: 4.92 \%$ \\
\hline 13 & Bodily Pain & $\begin{array}{l}\text { 0: No Pain } \\
\text { 1: Experienced Pain } \\
\text { (REF) }\end{array}$ & $\begin{array}{l}0: 180 \\
1: 171\end{array}$ & $\begin{array}{l}\mathrm{n}=351 \\
\mathrm{~d}=26\end{array}$ & 0 & $\begin{array}{l}0: \mathrm{HR}=1.00 \\
1: \mathrm{HR}=1.20(0.48-3.02)\end{array}$ & $\mathrm{p}=0.6965$ & $\begin{array}{l}0: \mathrm{HR}=1.20(0.55-2.61) \\
\mathrm{p}(\mathrm{MCS})=0.6517 \\
\mathrm{p}(\text { Pain })=0.6965\end{array}$ & $0: 1.64 \%$ \\
\hline 14 & $\begin{array}{l}\text { Perceived General } \\
\text { Health }\end{array}$ & $\begin{array}{l}\text { 0: "Poor" \& "Fair" } \\
\text { 1: "Good", "Very } \\
\text { Good", \& "Excellent" } \\
\text { (REF) }\end{array}$ & $\begin{array}{l}0: 54 \\
1: 297\end{array}$ & $\begin{array}{l}n=351 \\
d=26\end{array}$ & 0 & $\begin{array}{l}0: \mathrm{HR}=1.42(0.52-3.83) \\
1: \mathrm{HR}=1.00\end{array}$ & $\mathrm{p}=0.4930$ & $\begin{array}{l}0: \mathrm{HR}=1.17(0.53-2.56) \\
\mathrm{p}(\mathrm{MCS})=0.7027 \\
\mathrm{p}(\text { Health })=0.4930\end{array}$ & $0: 4.10 \%$ \\
\hline Crude & $\begin{array}{l}\text { MCS (restricted to those } \\
\text { with education) }\end{array}$ & & $\begin{array}{l}0: 176 \\
1: 174\end{array}$ & $\begin{array}{l}n=350 \\
d=26\end{array}$ & & $0: \mathrm{HR}=1.22(0.56-2.64)$ & $\mathrm{p}=0.6131$ & $\begin{array}{l}0: \mathrm{HR}=1.22(0.56-2.64) \\
\mathrm{p}(\mathrm{MCS})=0.6131\end{array}$ & -- \\
\hline
\end{tabular}




\begin{tabular}{|c|c|c|c|c|c|c|c|c|c|}
\hline Model & Variable(s) in model & Categories & $\begin{array}{l}\text { Total in } \\
\text { categories } \\
\text { (n) }\end{array}$ & $\begin{array}{l}\text { Total } \\
\text { in } \\
\text { model } \\
\text { (n); } \\
\text { dead } \\
\text { (d) } \\
\end{array}$ & Missing & Univariate-Cox HR (95\% CI) & p-values* & $\begin{array}{l}\text { MCS HR }(95 \% \mathrm{CI}) \text { and } \mathrm{p}- \\
\text { values }\end{array}$ & $\begin{array}{l}\% \text { change } \\
\text { from crude } \\
\text { model }\end{array}$ \\
\hline 15 & Education & $\begin{array}{l}\text { 0: High school or less } \\
\text { 1: Some college } \\
\text { 2: College graduate } \\
\text { 3: Graduate school } \\
\text { (REF) }\end{array}$ & $\begin{array}{l}0: 92 \\
1: 114 \\
2: 70 \\
3: 74\end{array}$ & $\begin{array}{l}n=350 \\
d=26\end{array}$ & 1 & $\begin{array}{l}0: H R=1.37(0.49-3.85) \\
1: H R=1.09(0.40-3.01) \\
2: H R=0.18(0.02-1.48) \\
3: H R=1.00\end{array}$ & $\mathrm{p}=0.2833$ & $\begin{array}{l}0: \mathrm{HR}=1.12(0.52-2.42) \\
\mathrm{p}(\mathrm{MCS})=0.7803 \\
\mathrm{p}(\text { Education} 0)=0.5539 \\
\mathrm{p}(\text { Education} 1)=0.8640 \\
\mathrm{p}(\text { Education} 2)=0.1095\end{array}$ & $0: 8.20 \%$ \\
\hline Crude & $\begin{array}{l}\text { MCS (restricted to those } \\
\text { with tumor size) }\end{array}$ & & $\begin{array}{l}0: 170 \\
1: 171\end{array}$ & $\begin{array}{l}n=341 \\
d=26\end{array}$ & & $0: \mathrm{HR}=1.24(0.58-2.69)$ & $\mathrm{p}=0.5804$ & $\begin{array}{l}0: \mathrm{HR}=1.24(0.58-2.69) \\
\mathrm{p}(\mathrm{MCS})=0.5804\end{array}$ & -- \\
\hline 16 & Tumor Size & $\begin{array}{l}0:<3 \mathrm{~cm} \text { (REF) } \\
1: \geq 3 \mathrm{~cm}\end{array}$ & $\begin{array}{l}0: 304 \\
1: 37\end{array}$ & $\begin{array}{l}n=341 \\
d=26\end{array}$ & 10 & $\begin{array}{l}0: \mathrm{HR}=1.00 \\
1: \mathrm{HR}=3.88(1.69-8.93)\end{array}$ & $\mathrm{p}=0.0014$ & $\begin{array}{l}0: \mathrm{HR}=1.26(0.58-2.72) \\
\mathrm{p}(\mathrm{MCS})=0.5608 \\
\mathrm{p}(\mathrm{Siz})=0.0014\end{array}$ & $0: 1.61 \%$ \\
\hline Crude & $\begin{array}{l}\text { MCS (restricted to those } \\
\text { with lymph node } \\
\text { involvement) }\end{array}$ & & $\begin{array}{l}0: 170 \\
1: 171\end{array}$ & $\begin{array}{l}n=341 \\
d=24\end{array}$ & & $0: \mathrm{HR}=1.05(0.47-2.33)$ & $\mathrm{p}=0.9126$ & $\begin{array}{l}0: \mathrm{HR}=1.05(0.47-2.33) \\
\mathrm{p}(\mathrm{MCS})=0.9126\end{array}$ & -- \\
\hline
\end{tabular}




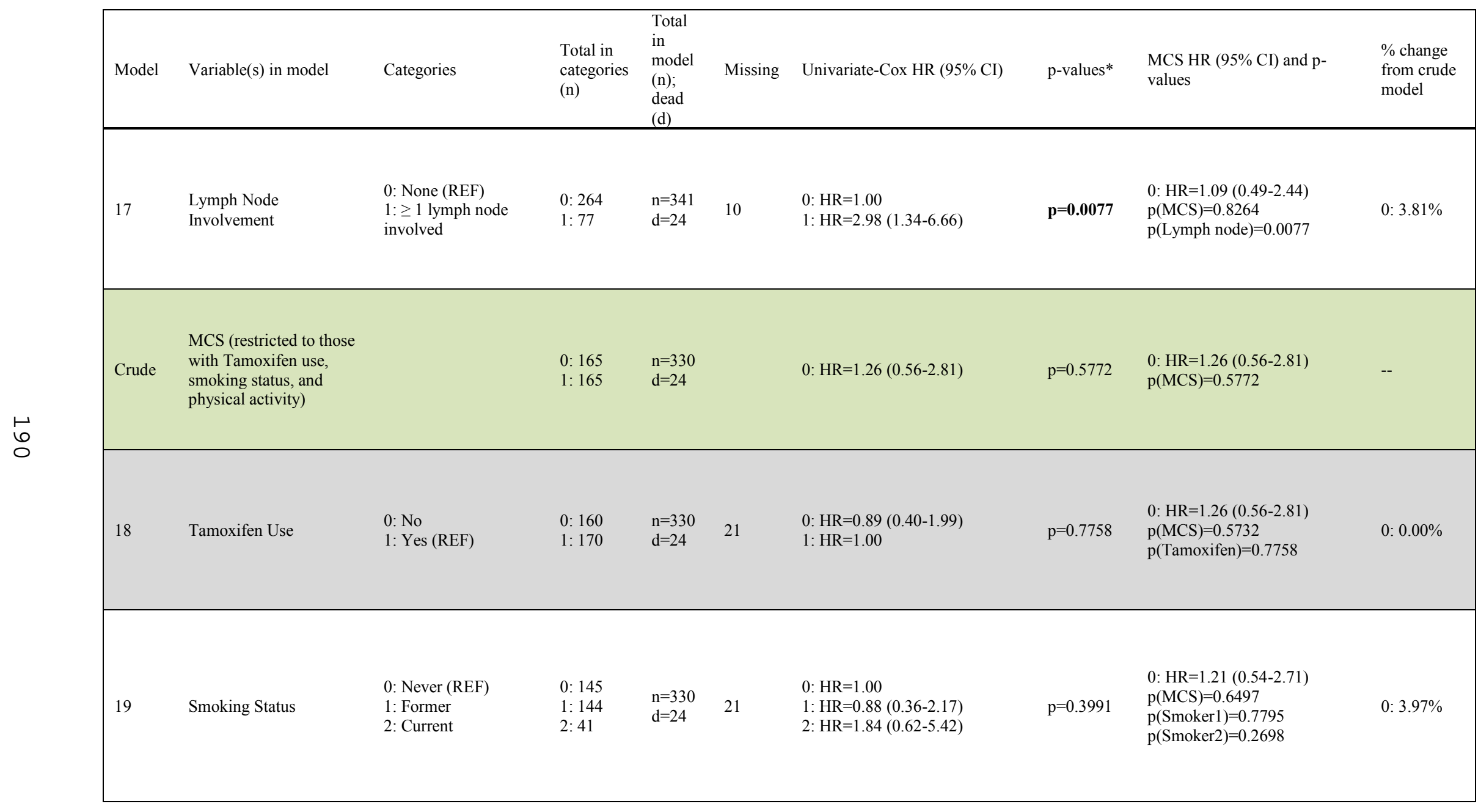




\begin{tabular}{|c|c|c|c|c|c|c|c|c|c|}
\hline Model & Variable(s) in model & Categories & $\begin{array}{l}\text { Total in } \\
\text { categories } \\
\text { (n) }\end{array}$ & $\begin{array}{l}\text { Total } \\
\text { in } \\
\text { model } \\
\text { (n); } \\
\text { dead } \\
\text { (d) }\end{array}$ & Missing & Univariate-Cox HR (95\% CI) & p-values* & $\begin{array}{l}\text { MCS HR }(95 \% \mathrm{CI}) \text { and } \mathrm{p}- \\
\text { values }\end{array}$ & $\begin{array}{l}\% \text { change } \\
\text { from crude } \\
\text { model }\end{array}$ \\
\hline 20 & Physical Activity & $\begin{array}{l}0: \text { None } \\
\text { 1: Low } \\
\text { 2: Moderate/Vigorous } \\
\text { (REF) }\end{array}$ & $\begin{array}{l}0: 185 \\
1: 59 \\
2: 86\end{array}$ & $\begin{array}{l}n=330 \\
d=24\end{array}$ & 21 & $\begin{array}{l}0: \mathrm{HR}=1.37(0.49-3.87) \\
1: \mathrm{HR}=1.76(0.54-5.78) \\
2: \mathrm{HR}=1.00\end{array}$ & $\mathrm{p}=0.6484$ & $\begin{array}{l}0: H R=1.29(0.58-2.90) \\
\text { p(MCS })=0.5332 \\
\text { p(PA0) }=0.5499 \\
\text { p(PA1 })=0.3520\end{array}$ & $0: 2.38 \%$ \\
\hline Crude & $\begin{array}{l}\text { MCS (restricted to those } \\
\text { with BMI) }\end{array}$ & & $\begin{array}{l}0: 167 \\
1: 157\end{array}$ & $\begin{array}{l}n=324 \\
d=24\end{array}$ & & $0: \mathrm{HR}=1.40(0.62-3.16)$ & $\mathrm{p}=0.4144$ & $\begin{array}{l}0: \mathrm{HR}=1.40(0.62-3.16) \\
\mathrm{p}(\mathrm{MCS})=0.4144\end{array}$ & -- \\
\hline 21 & Body Mass Index (BMI) & $\begin{array}{l}0:<25(\mathrm{REF}) \\
1: 25-29 \\
2: \geq 30\end{array}$ & $\begin{array}{l}0: 161 \\
1: 99 \\
2: 64\end{array}$ & $\begin{array}{l}\mathrm{n}=324 \\
\mathrm{~d}=24\end{array}$ & 27 & $\begin{array}{l}0: H R=1.00 \\
1: H R=1.75(0.71-4.31) \\
2: H R=1.46(0.49-4.35)\end{array}$ & $\mathrm{p}=0.4729$ & $\begin{array}{l}0: \mathrm{HR}=1.36(0.61-3.08) \\
\mathrm{p}(\mathrm{MCS})=0.4539 \\
\mathrm{p}(\mathrm{BMI1})=0.2250 \\
\mathrm{p}(\mathrm{BMI})=0.5021\end{array}$ & $0: 2.86 \%$ \\
\hline Crude & $\begin{array}{l}\text { MCS (restricted to those } \\
\text { tumor subtype) }\end{array}$ & & $\begin{array}{l}0: 150 \\
1: 150\end{array}$ & $\begin{array}{l}n=300 \\
d=22\end{array}$ & & $0: \mathrm{HR}=1.05(0.45-2.42)$ & $\mathrm{p}=0.9132$ & $\begin{array}{l}0: \mathrm{HR}=1.05(0.45-2.42) \\
\mathrm{p}(\mathrm{MCS})=0.9132\end{array}$ & -- \\
\hline
\end{tabular}




\begin{tabular}{|c|c|c|c|c|c|c|c|c|c|}
\hline Model & Variable(s) in model & Categories & $\begin{array}{l}\text { Total in } \\
\text { categories } \\
\text { (n) }\end{array}$ & $\begin{array}{l}\text { Total } \\
\text { in } \\
\text { model } \\
\text { (n); } \\
\text { dead } \\
\text { (d) }\end{array}$ & Missing & Univariate-Cox HR $(95 \% \mathrm{Cl})$ & p-values* & $\begin{array}{l}\text { MCS HR }(95 \% \mathrm{CI}) \text { and p- } \\
\text { values }\end{array}$ & $\begin{array}{l}\% \text { change } \\
\text { from crude } \\
\text { model }\end{array}$ \\
\hline 22 & Tumor Subtype & $\begin{array}{l}0: \mathrm{ER}+(\mathrm{REF}) \\
\text { 1: ER- }\end{array}$ & $\begin{array}{l}0: 251 \\
1: 49\end{array}$ & $\begin{array}{l}n=300 \\
d=22\end{array}$ & 51 & $\begin{array}{l}0: H R=1.00 \\
1: H R=1.54(0.57-4.18)\end{array}$ & $\mathrm{p}=0.3945$ & $\begin{array}{l}\text { 0: } \mathrm{HR}=1.04(0.45-2.39) \\
\mathrm{p}(\mathrm{MCS})=0.9342 \\
\mathrm{p}(\text { Subtype })=0.3945\end{array}$ & $0: 0.95 \%$ \\
\hline
\end{tabular}


Appendix J. Physical Component Summary Score Univariate HR Analysis and Percent Change for Non-Cancer Mortality when Assessing for Potential Confounders $(N=351)$

\begin{tabular}{|c|c|c|c|c|c|c|c|c|c|}
\hline Model & Variable(s) in model & Categories & $\begin{array}{l}\text { Total in } \\
\text { categories } \\
\text { (n) }\end{array}$ & $\begin{array}{l}\text { Total } \\
\text { in } \\
\text { model } \\
\text { (n); } \\
\text { dead } \\
\text { (d) } \\
\end{array}$ & Missing & Univariate-Cox HR $(95 \% \mathrm{CI})$ & p-values* & $\begin{array}{l}\text { PCS HR }(95 \% \mathrm{CI}) \text { and } \mathrm{p}- \\
\text { values }\end{array}$ & $\begin{array}{l}\% \text { change } \\
\text { from crude } \\
\text { model }\end{array}$ \\
\hline Crude & $\begin{array}{l}\text { Physical Component } \\
\text { Summary Score (PCS) }\end{array}$ & $\begin{array}{l}0: \leq 44.75 \\
1:>44.75 \& \leq 54.39 \\
2:>54.39(\mathrm{REF})\end{array}$ & $\begin{array}{l}0: 117 \\
1: 117 \\
2: 117\end{array}$ & $\begin{array}{l}n=351 \\
d=64\end{array}$ & 0 & $\begin{array}{l}0: H R=5.63(2.74-11.55) \\
1: H R=1.41(0.59-3.35)\end{array}$ & $\mathrm{p}=<0.0001$ & $\begin{array}{l}0: H R=5.63(2.74-11.55) \\
p(P C S)=<0.0001 \\
1: H R=1.41(0.59-3.35) \\
p(P C S)=0.4366\end{array}$ & -- \\
\hline 1 & Age & Continuous & -- & $\begin{array}{l}\mathrm{n}=351 \\
\mathrm{~d}=64\end{array}$ & 0 & $\mathrm{HR}=1.10(1.07-1.13)$ & $\mathrm{p}=<\mathbf{0 . 0 0 0 1}$ & $\begin{array}{l}0: \mathrm{HR}=2.71(1.28-5.74) \\
\mathrm{p}(\mathrm{PCS})=0.0090 \\
1: \mathrm{HR}=0.92(0.38-2.27) \\
\mathrm{p}(\mathrm{PCS})=0.8539 \\
\mathrm{p}(\mathrm{Age})=<0.0001\end{array}$ & $\begin{array}{l}0: 51.87 \% \\
1: 34.75 \%\end{array}$ \\
\hline 2 & Race/Ethnicity & $\begin{array}{l}\text { 0: Non-Hispanic } \\
\text { White (REF) } \\
\text { Hispanic }\end{array}$ & $\begin{array}{l}0: 273 \\
1: 78\end{array}$ & $\begin{array}{l}\mathrm{n}=351 \\
\mathrm{~d}=64\end{array}$ & 0 & $\begin{array}{l}0: H R=1.00 \\
1: H R=0.55(0.27-1.11)\end{array}$ & $p=0.0941$ & $\begin{array}{l}0: \mathrm{HR}=5.63(2.74-11.57) \\
\mathrm{p}(\mathrm{PCS})=<0.0001 \\
1: \mathrm{HR}=1.41(0.59-3.34) \\
\mathrm{p}(\mathrm{PCS})=0.0944 \\
\mathrm{p}(\text { Ethnicity })=0.0941\end{array}$ & $\begin{array}{l}0: 0.00 \% \\
1: 0.00 \%\end{array}$ \\
\hline 3 & Marital Status & $\begin{array}{l}\text { 0: Single } \\
\text { 1: Married (REF) }\end{array}$ & $\begin{array}{l}0: 160 \\
1: 191\end{array}$ & $\begin{array}{l}\mathrm{n}=351 \\
\mathrm{~d}=64\end{array}$ & 0 & $\begin{array}{l}0: \mathrm{HR}=2.23(1.32-3.77) \\
1: \mathrm{HR}=1.00\end{array}$ & $p=0.0028$ & $\begin{array}{l}0: \mathrm{HR}=5.10(2.48-10.49) \\
\mathrm{p}(\mathrm{PCS})=<0.0001 \\
1: \mathrm{HR}=1.39(0.59-3.31) \\
\mathrm{p}(\mathrm{PCS})=0.4514 \\
\mathrm{p}(\mathrm{Marital})=0.0028\end{array}$ & $\begin{array}{l}0: 9.41 \% \\
1: 1.42 \%\end{array}$ \\
\hline
\end{tabular}




\begin{tabular}{|c|c|c|c|c|c|c|c|c|c|}
\hline Model & Variable(s) in model & Categories & $\begin{array}{l}\text { Total in } \\
\text { categories } \\
\text { (n) }\end{array}$ & $\begin{array}{l}\text { Total } \\
\text { in } \\
\text { model } \\
(\mathrm{n}) ; \\
\text { dead } \\
\text { (d) } \\
\end{array}$ & Missing & Univariate-Cox HR $(95 \%$ CI) & p-values* & $\begin{array}{l}\text { PCS HR }(95 \% \mathrm{CI}) \text { and } \mathrm{p}- \\
\text { values }\end{array}$ & $\begin{array}{l}\% \text { change } \\
\text { from crude } \\
\text { model }\end{array}$ \\
\hline 4 & Tumor Stage & $\begin{array}{l}\text { 0: Localized (I) } \\
\text { 1: Regional (II-IIIa) }\end{array}$ & $\begin{array}{l}0: 276 \\
1: 75\end{array}$ & $\begin{array}{l}\mathrm{n}=351 \\
\mathrm{~d}=64\end{array}$ & 0 & $\begin{array}{l}0: \mathrm{HR}=1.00 \\
1: \mathrm{HR}=0.81(0.42-1.55)\end{array}$ & $\mathrm{p}=0.5227$ & $\begin{array}{l}0: \mathrm{HR}=5.58(2.72-11.45) \\
\mathrm{p}(\mathrm{PCS})=<0.0001 \\
1: \mathrm{HR}=1.40(0.59-3.32) \\
\mathrm{p}(\mathrm{PCS})=0.4485 \\
\mathrm{p}(\text { Stage })=0.5227\end{array}$ & $\begin{array}{l}0: 0.89 \% \\
1: 0.71 \%\end{array}$ \\
\hline 5 & $\begin{array}{l}\text { Breast Cancer Treatment } \\
\text { Type }\end{array}$ & $\begin{array}{l}0: \text { Surgery only (REF) } \\
1: \text { Any chemotherapy } \\
2: \text { Surgery and } \\
\text { radiation }\end{array}$ & $\begin{array}{l}0: 98 \\
1: 109 \\
2: 144\end{array}$ & $\begin{array}{l}\mathrm{n}=351 \\
\mathrm{~d}=64\end{array}$ & 0 & $\begin{array}{l}0: H R=1.00 \\
1: H R=0.43(0.21-0.87) \\
2: H R=0.69(0.40-1.19)\end{array}$ & $p=0.0556$ & $\begin{array}{l}0: \mathrm{HR}=5.31(2.58-10.92) \\
\mathrm{p}(\mathrm{PCS})=<0.0001 \\
1: \mathrm{HR}=1.39(0.58-3.29) \\
\mathrm{p}(\mathrm{PCS})=0.4594 \\
\mathrm{p}(\text { Treatment } 1)=0.0181 \\
\mathrm{p}(\text { Treatment } 2)=0.1819\end{array}$ & $\begin{array}{l}0: 5.68 \% \\
1: 1.42 \%\end{array}$ \\
\hline 6 & Comorbidities & $\begin{array}{l}0: \text { Zero }(\mathrm{REF}) \\
1: \text { One or more }\end{array}$ & $\begin{array}{l}0: 298 \\
1: 53\end{array}$ & $\begin{array}{l}\mathrm{n}=351 \\
\mathrm{~d}=64\end{array}$ & 0 & $\begin{array}{l}0: \mathrm{HR}=1.00 \\
1: \mathrm{HR}=1.31(0.72-2.40)\end{array}$ & $\mathrm{p}=0.3799$ & $\begin{array}{l}0: \mathrm{HR}=5.36(2.58-11.11) \\
\mathrm{p}(\mathrm{PCS})=<0.0001 \\
1: \mathrm{HR}=1.38(0.58-3.27) \\
\mathrm{p}(\mathrm{PCS})=0.4704 \\
\mathrm{p}(\text { Comorbidities })=0.3799\end{array}$ & $\begin{array}{l}0: 4.80 \% \\
1: 2.13 \%\end{array}$ \\
\hline 7 & Current Lymphedema & $\begin{array}{l}0: \text { No (REF) } \\
1: \text { Yes }\end{array}$ & $\begin{array}{l}0: 307 \\
1: 44\end{array}$ & $\begin{array}{l}\mathrm{n}=351 \\
\mathrm{~d}=64\end{array}$ & 0 & $\begin{array}{l}0: \mathrm{HR}=1.00 \\
1: \mathrm{HR}=0.48(0.21-1.12)\end{array}$ & $p=0.0875$ & $\begin{array}{l}0: \mathrm{HR}=6.09(2.96-12.54) \\
\mathrm{p}(\mathrm{PCS})=<0.0001 \\
1: \mathrm{HR}=1.47(0.62-3.49) \\
\mathrm{p}(\mathrm{PCS})=0.3823 \\
\mathrm{p}(\text { Lymphedema })=0.0875\end{array}$ & $\begin{array}{l}0: 8.17 \% \\
1: 4.26 \%\end{array}$ \\
\hline
\end{tabular}




\begin{tabular}{|c|c|c|c|c|c|c|c|c|c|}
\hline Model & Variable(s) in model & Categories & $\begin{array}{l}\text { Total in } \\
\text { categories } \\
\text { (n) }\end{array}$ & $\begin{array}{l}\text { Total } \\
\text { in } \\
\text { model } \\
(\mathrm{n}) ; \\
\text { dead } \\
\text { (d) } \\
\end{array}$ & Missing & Univariate-Cox HR $(95 \% \mathrm{CI})$ & p-values* & $\begin{array}{l}\text { PCS HR }(95 \% \mathrm{CI}) \text { and } \mathrm{p}- \\
\text { values }\end{array}$ & $\begin{array}{l}\% \text { change } \\
\text { from crude } \\
\text { model }\end{array}$ \\
\hline 8 & Perceived Optimism & $\begin{array}{l}0: \leq 10 \\
1:>10(\mathrm{REF})\end{array}$ & $\begin{array}{l}0: 83 \\
1: 268\end{array}$ & $\begin{array}{l}n=351 \\
d=64\end{array}$ & 0 & $\begin{array}{l}0: \mathrm{HR}=1.50(0.90-2.53) \\
1: \mathrm{HR}=1.00\end{array}$ & $p=0.1227$ & $\begin{array}{l}0: \mathrm{HR}=5.09(2.44-10.58) \\
\mathrm{p}(\mathrm{PCS})=<0.0001 \\
1: \mathrm{HR}=1.36(0.57-3.23) \\
\mathrm{p}(\mathrm{PCS})=0.4895 \\
\mathrm{p}(\text { Optimism })=0.1227\end{array}$ & $\begin{array}{l}0: 9.59 \% \\
1: 3.55 \%\end{array}$ \\
\hline 9 & Perceived Pessimism & $\begin{array}{l}0: \leq 10(\mathrm{REF}) \\
1:>10\end{array}$ & $\begin{array}{l}0: 255 \\
1: 96\end{array}$ & $\begin{array}{l}n=351 \\
d=64\end{array}$ & 0 & $\begin{array}{l}0: \mathrm{HR}=1.00 \\
1: \mathrm{HR}=1.39(0.83-2.33)\end{array}$ & $p=0.2062$ & $\begin{array}{l}0: \mathrm{HR}=5.26(2.54-10.89) \\
\mathrm{p}(\mathrm{PCS})=<0.0001 \\
1: \mathrm{HR}=1.38(0.58-3.28) \\
\mathrm{p}(\mathrm{PCS})=0.4664 \\
\mathrm{p}(\text { Pessimism })=0.2062\end{array}$ & $\begin{array}{l}0: 6.57 \% \\
1: 2.13 \%\end{array}$ \\
\hline 10 & $\begin{array}{l}\text { Number of Types of } \\
\text { Confidants }\end{array}$ & $\begin{array}{l}0:<3 \\
1: 4-5 \\
2:>5 \text { (REF) }\end{array}$ & $\begin{array}{l}0: 66 \\
1: 172 \\
2: 113\end{array}$ & $\begin{array}{l}n=351 \\
d=64\end{array}$ & 0 & $\begin{array}{l}0: H R=2.85(1.41-5.74) \\
1: H R=1.67(0.87-3.20) \\
2: H R=1.00\end{array}$ & $p=0.0123$ & $\begin{array}{l}0: \mathrm{HR}=5.77(2.81-11.86) \\
\mathrm{p}(\mathrm{PCS})=<0.0001 \\
1: \mathrm{HR}=1.50(0.63-3.57) \\
\mathrm{p}(\mathrm{PCS})=0.3575 \\
\mathrm{p}(\text { Confidant } 0)=0.0034 \\
\mathrm{p}(\text { Confidant } 1)=0.1212\end{array}$ & $\begin{array}{l}0: 2.49 \% \\
1: 6.38 \%\end{array}$ \\
\hline 11 & Fear of Recurrence & $\begin{array}{l}0: \text { No (REF) } \\
1: \text { Yes }\end{array}$ & $\begin{array}{l}0: 154 \\
1: 197\end{array}$ & $\begin{array}{l}n=351 \\
d=64\end{array}$ & 0 & $\begin{array}{l}0: \mathrm{HR}=1.00 \\
1: \mathrm{HR}=0.49(0.30-0.81)\end{array}$ & $\mathrm{p}=\mathbf{0 . 0 0 5 3}$ & $\begin{array}{l}0: \mathrm{HR}=5.63(2.74-11.56) \\
\mathrm{p}(\mathrm{PCS})=<0.0001 \\
1: \mathrm{HR}=1.43(0.60-3.39) \\
\mathrm{p}(\mathrm{PCS})=0.4191 \\
\mathrm{p}(\mathrm{Fear})=0.0053\end{array}$ & $\begin{array}{l}0: 0.00 \% \\
1: 1.42 \%\end{array}$ \\
\hline
\end{tabular}




\begin{tabular}{|c|c|c|c|c|c|c|c|c|c|}
\hline Model & Variable(s) in model & Categories & $\begin{array}{l}\text { Total in } \\
\text { categories } \\
\text { (n) }\end{array}$ & $\begin{array}{l}\text { Total } \\
\text { in } \\
\text { model } \\
\text { (n); } \\
\text { dead } \\
\text { (d) } \\
\end{array}$ & Missing & Univariate-Cox HR $(95 \% \mathrm{CI})$ & p-values* & $\begin{array}{l}\text { PCS HR }(95 \% \mathrm{Cl}) \text { and p- } \\
\text { values }\end{array}$ & $\begin{array}{l}\% \text { change } \\
\text { from crude } \\
\text { model }\end{array}$ \\
\hline Crude & $\begin{array}{l}\text { PCS (restricted to those } \\
\text { with education) }\end{array}$ & & $\begin{array}{l}0: 116 \\
1: 117 \\
2: 117\end{array}$ & $\begin{array}{l}n=350 \\
d=63\end{array}$ & & $\begin{array}{l}0: \mathrm{HR}=5.51(2.68-11.33) \\
1: \mathrm{HR}=1.41(0.59-3.35)\end{array}$ & $\mathrm{p}=<0.0001$ & $\begin{array}{l}0: \mathrm{HR}=5.51(2.68-11.33) \\
\mathrm{p}(\mathrm{PCS})=<0.0001 \\
1: \mathrm{HR}=1.41(0.59-3.35) \\
\mathrm{p}(\mathrm{PCS})=0.4365\end{array}$ & -- \\
\hline 12 & Education & $\begin{array}{l}\text { 0: High school or less } \\
\text { 1: Some college } \\
\text { 2: College graduate } \\
\text { 3: Graduate school } \\
\text { (REF) }\end{array}$ & $\begin{array}{l}0: 92 \\
1: 114 \\
2: 70 \\
3: 74\end{array}$ & $\begin{array}{l}n=350 \\
d=63\end{array}$ & 1 & $\begin{array}{l}0: \mathrm{HR}=2.50(1.05-5.94) \\
1: \mathrm{HR}=1.73(0.74-4.04) \\
2: \mathrm{HR}=2.05(0.81-5.22) \\
3: \mathrm{HR}=1.00\end{array}$ & $\mathrm{p}=0.2047$ & $\begin{array}{l}0: \mathrm{HR}=5.34(2.56-11.12) \\
\mathrm{p}(\mathrm{PCS})=<0.0001 \\
1: \mathrm{HR}=1.33(0.56-3.17) \\
\mathrm{p}(\mathrm{PCS})=0.5231 \\
\mathrm{p}(\text { Education } 0)=0.0386 \\
\mathrm{p}(\text { Education } 1)=0.2037 \\
\mathrm{p}(\text { Education2 })=0.1319\end{array}$ & $\begin{array}{l}0: 3.09 \% \\
1: 5.67 \%\end{array}$ \\
\hline Crude & $\begin{array}{l}\text { PCS (restricted to those } \\
\text { with tumor size) }\end{array}$ & & $\begin{array}{l}0: 116 \\
1: 114 \\
2: 111\end{array}$ & $\begin{array}{l}\mathrm{n}=341 \\
\mathrm{~d}=64\end{array}$ & & $\begin{array}{l}0: H R=5.43(2.64-11.14) \\
1: H R=1.39(0.59-3.30)\end{array}$ & $\mathrm{p}=<0.0001$ & $\begin{array}{l}0: \mathrm{HR}=5.43(2.64-11.14) \\
\mathrm{p}(\mathrm{PCS})=<0.0001 \\
1: \mathrm{HR}=1.39(0.59-3.30) \\
\mathrm{p}(\mathrm{PCS})=0.4544\end{array}$ & -- \\
\hline 13 & Tumor Size & $\begin{array}{l}0:<3 \mathrm{~cm} \text { (REF) } \\
1: \geq 3 \mathrm{~cm}\end{array}$ & $\begin{array}{l}0: 304 \\
1: 37\end{array}$ & $\begin{array}{l}\mathrm{n}=341 \\
\mathrm{~d}=64\end{array}$ & 10 & $\begin{array}{l}0: H R=1.00 \\
1: H R=0.45(0.14-1.45)\end{array}$ & $\mathrm{p}=\mathbf{0 . 1 8 2 8}$ & $\begin{array}{l}0: \mathrm{HR}=5.44(2.65-11.16) \\
\mathrm{p}(\mathrm{PCS})=<0.0001 \\
1: \mathrm{HR}=1.42(0.60-3.38) \\
\mathrm{p}(\mathrm{PCS})=0.4238 \\
\mathrm{p}(\mathrm{Size})=0.1828\end{array}$ & $\begin{array}{l}0: 0.18 \% \\
1: 4.51 \%\end{array}$ \\
\hline
\end{tabular}




\begin{tabular}{|c|c|c|c|c|c|c|c|c|c|}
\hline Model & Variable(s) in model & Categories & $\begin{array}{l}\text { Total in } \\
\text { categories } \\
\text { (n) }\end{array}$ & $\begin{array}{l}\text { Total } \\
\text { in } \\
\text { model } \\
\text { (n); } \\
\text { dead } \\
\text { (d) } \\
\end{array}$ & Missing & Univariate-Cox HR $(95 \%$ CI) & p-values* & $\begin{array}{l}\text { PCS HR }(95 \% \mathrm{CI}) \text { and } \mathrm{p} \text { - } \\
\text { values }\end{array}$ & $\begin{array}{l}\% \text { change } \\
\text { from crude } \\
\text { model }\end{array}$ \\
\hline Crude & $\begin{array}{l}\text { PCS (restricted to those } \\
\text { with lymph node } \\
\text { involvement) }\end{array}$ & & $\begin{array}{l}0: 113 \\
\text { 1: } 112 \\
2: 116\end{array}$ & $\begin{array}{l}\mathrm{n}=341 \\
\mathrm{~d}=59\end{array}$ & & $\begin{array}{l}0: H R=6.29(2.95-13.41) \\
1: H R=1.36(0.54-3.45)\end{array}$ & $\mathrm{p}=<0.0001$ & $\begin{array}{l}0: \mathrm{HR}=6.29(2.95-13.41) \\
\mathrm{p}(\mathrm{PCS})=<0.0001 \\
1: \mathrm{HR}=1.36(0.54-3.45) \\
\mathrm{p}(\mathrm{PCS})=0.5161\end{array}$ & -- \\
\hline 14 & $\begin{array}{l}\text { Lymph Node } \\
\text { Involvement }\end{array}$ & $\begin{array}{l}0: \text { None }(\mathrm{REF}) \\
1: \geq 1 \text { lymph node } \\
\text { involved }\end{array}$ & $\begin{array}{l}0: 264 \\
1: 77\end{array}$ & $\begin{array}{l}\mathrm{n}=341 \\
\mathrm{~d}=59\end{array}$ & 10 & $\begin{array}{l}0: \mathrm{HR}=1.00 \\
1: \mathrm{HR}=0.86(0.45-1.66)\end{array}$ & $\mathrm{p}=0.6606$ & $\begin{array}{l}0: \mathrm{HR}=6.25(2.93-13.34) \\
\mathrm{p}(\mathrm{PCS})=<0.0001 \\
1: \mathrm{HR}=1.36(0.53-3.43) \\
\mathrm{p}(\mathrm{PCS})=0.5225 \\
\mathrm{p}(\text { Lymph node })=0.6606\end{array}$ & $\begin{array}{l}0: 0.64 \% \\
1: 0.00 \%\end{array}$ \\
\hline Crude & $\begin{array}{l}\text { PCS (restricted to those } \\
\text { with Tamoxifen use, } \\
\text { smoking status, and } \\
\text { physical activity) }\end{array}$ & & $\begin{array}{l}0: 107 \\
1: 110 \\
2: 113\end{array}$ & $\begin{array}{l}n=330 \\
d=59\end{array}$ & & $\begin{array}{l}0: \mathrm{HR}=5.19(2.51-10.74) \\
1: \mathrm{HR}=1.42(0.60-3.37)\end{array}$ & $\mathrm{p}=<\mathbf{0 . 0 0 0 1}$ & $\begin{array}{l}0: \mathrm{HR}=5.19(2.51-10.74) \\
\mathrm{p}(\mathrm{PCS})=<0.0001 \\
1: \mathrm{HR}=1.42(0.60-3.37) \\
\mathrm{p}(\mathrm{PCS})=0.4276\end{array}$ & -- \\
\hline 15 & Tamoxifen Use & $\begin{array}{l}0: \text { No } \\
1: \text { Yes (REF) }\end{array}$ & $\begin{array}{l}0: 160 \\
1: 170\end{array}$ & $\begin{array}{l}n=330 \\
d=59\end{array}$ & 21 & $\begin{array}{l}0: \mathrm{HR}=1.36(0.81-2.26) \\
1: \mathrm{HR}=1.00\end{array}$ & $p=0.2465$ & $\begin{array}{l}0: \mathrm{HR}=5.22(2.52-10.81) \\
\mathrm{p}(\mathrm{PCS})=<0.0001 \\
1: \mathrm{HR}=1.39(0.59-3.31) \\
\mathrm{p}(\mathrm{PCS})=0.4522 \\
\mathrm{p}(\text { Tamoxifen })=0.2465\end{array}$ & $\begin{array}{l}0: 0.58 \% \\
1: 2.11 \%\end{array}$ \\
\hline
\end{tabular}




\begin{tabular}{|c|c|c|c|c|c|c|c|c|c|}
\hline Model & Variable(s) in model & Categories & $\begin{array}{l}\text { Total in } \\
\text { categories } \\
\text { (n) }\end{array}$ & $\begin{array}{l}\text { Total } \\
\text { in } \\
\text { model } \\
\text { (n); } \\
\text { dead } \\
\text { (d) } \\
\end{array}$ & Missing & Univariate-Cox HR $(95 \% \mathrm{Cl})$ & p-values* & $\begin{array}{l}\text { PCS HR }(95 \% \mathrm{CI}) \text { and } \mathrm{p}- \\
\text { values }\end{array}$ & $\begin{array}{l}\% \text { change } \\
\text { from crude } \\
\text { model }\end{array}$ \\
\hline 16 & Smoking Status & $\begin{array}{l}0: \text { Never (REF) } \\
\text { 1: Former } \\
\text { 2: Current }\end{array}$ & $\begin{array}{l}0: 145 \\
1: 144 \\
2: 41\end{array}$ & $\begin{array}{l}\mathrm{n}=330 \\
\mathrm{~d}=59\end{array}$ & 21 & $\begin{array}{l}0: \mathrm{HR}=1.00 \\
\text { 1: } \mathrm{HR}=1.07(0.62-1.86) \\
2: \mathrm{HR}=1.20(0.54-2.67)\end{array}$ & $\mathrm{p}=0.8981$ & $\begin{array}{l}0: \mathrm{HR}=5.16(2.49-10.70) \\
\mathrm{p}(\mathrm{PCS})=<0.0001 \\
1: \mathrm{HR}=1.41(0.59-3.34) \\
\mathrm{p}(\mathrm{PCS})=0.4393 \\
\mathrm{p}(\mathrm{Smoker} 1)=0.7983 \\
\mathrm{p}(\mathrm{Smoker} 2)=0.6515\end{array}$ & $\begin{array}{l}0: 0.58 \% \\
1: 0.70 \%\end{array}$ \\
\hline 17 & Physical Activity & $\begin{array}{l}\text { 0: None } \\
\text { 1: Low } \\
\text { 2: Moderate/Vigorous } \\
\text { (REF) }\end{array}$ & $\begin{array}{l}0: 185 \\
1: 59 \\
2: 86\end{array}$ & $\begin{array}{l}\mathrm{n}=330 \\
\mathrm{~d}=59\end{array}$ & 21 & $\begin{array}{l}0: \mathrm{HR}=1.51(0.77-2.97) \\
1: \mathrm{HR}=0.37(0.12-1.81) \\
2: \mathrm{HR}=1.00\end{array}$ & $\mathrm{p}=0.0191$ & $\begin{array}{l}0: \mathrm{HR}=4.99(2.38-10.48) \\
\mathrm{p}(\mathrm{PCS})=<0.0001 \\
1: \mathrm{HR}=1.35(0.57-3.23) \\
\mathrm{p}(\mathrm{PCS})=0.4965 \\
\mathrm{p}(\mathrm{PA} 0)=0.2314 \\
\mathrm{p}(\mathrm{PA} 1)=0.0936\end{array}$ & $\begin{array}{l}0: 3.85 \% \\
1: 4.93 \%\end{array}$ \\
\hline Crude & $\begin{array}{l}\text { PCS (restricted to those } \\
\text { with BMI) }\end{array}$ & & $\begin{array}{l}0: 106 \\
\text { 1: } 110 \\
\text { 2: } 108\end{array}$ & $\begin{array}{l}\mathrm{n}=324 \\
\mathrm{~d}=54\end{array}$ & & $\begin{array}{l}0: \mathrm{HR}=5.09(2.36-10.99) \\
1: \mathrm{HR}=1.41(0.57-3.51)\end{array}$ & $\mathrm{p}=<0.0001$ & $\begin{array}{l}0: \mathrm{HR}=5.09(2.36-10.99) \\
\mathrm{p}(\mathrm{PCS})=<0.0001 \\
1: \mathrm{HR}=1.41(0.57-3.51) \\
\mathrm{p}(\mathrm{PCS})=0.4585\end{array}$ & -- \\
\hline
\end{tabular}




\begin{tabular}{|c|c|c|c|c|c|c|c|c|c|}
\hline Model & Variable(s) in model & Categories & $\begin{array}{l}\text { Total in } \\
\text { categories } \\
\text { (n) }\end{array}$ & $\begin{array}{l}\text { Total } \\
\text { in } \\
\text { model } \\
\text { (n); } \\
\text { dead } \\
\text { (d) }\end{array}$ & Missing & Univariate-Cox HR $(95 \% \mathrm{CI})$ & p-values* & $\begin{array}{l}\text { PCS HR }(95 \% \mathrm{Cl}) \text { and } \mathrm{p}- \\
\text { values }\end{array}$ & $\begin{array}{l}\% \text { change } \\
\text { from crude } \\
\text { model }\end{array}$ \\
\hline 18 & Body Mass Index (BMI) & $\begin{array}{l}0:<25 \text { (REF) } \\
1: 25-29 \\
2: \geq 30\end{array}$ & $\begin{array}{l}0: 161 \\
1: 99 \\
2: 64\end{array}$ & $\begin{array}{l}\mathrm{n}=324 \\
\mathrm{~d}=54\end{array}$ & 27 & $\begin{array}{l}0: H R=1.00 \\
1: H R=0.51(0.25-1.04) \\
2: H R=1.03(0.54-1.95)\end{array}$ & $\mathrm{p}=0.1354$ & $\begin{array}{l}0: \mathrm{HR}=5.25(2.40-11.49) \\
\mathrm{p}(\mathrm{PCS})=<0.0001 \\
\text { 1: } \mathrm{HR}=1.46(0.58-3.64) \\
\mathrm{p}(\mathrm{PCS})=0.4199 \\
\mathrm{p}(\mathrm{BMI1})=0.0622 \\
\mathrm{p}(\mathrm{BMI} 2)=0.9382\end{array}$ & $\begin{array}{l}0: 3.14 \% \\
1: 3.55 \%\end{array}$ \\
\hline Crude & $\begin{array}{l}\text { PCS (restricted to those } \\
\text { tumor subtype) }\end{array}$ & & $\begin{array}{l}0: 102 \\
1: 101 \\
2: 97\end{array}$ & $\begin{array}{l}\mathrm{n}=300 \\
\mathrm{~d}=56\end{array}$ & & $\begin{array}{l}0: \mathrm{HR}=4.43(2.13-9.20) \\
1: \mathrm{HR}=1.27(0.53-3.07)\end{array}$ & $\mathrm{p}=<\mathbf{0 . 0 0 0 1}$ & $\begin{array}{l}0: \mathrm{HR}=4.43(2.13-9.20) \\
\mathrm{p}(\mathrm{PCS})=<0.0001 \\
1: \mathrm{HR}=1.27(0.53-3.07) \\
\mathrm{p}(\mathrm{PCS})=0.5912\end{array}$ & -- \\
\hline 19 & Tumor Subtype & $\begin{array}{l}\text { 0: ER+ (REF) } \\
\text { 1: ER- }\end{array}$ & $\begin{array}{l}0: 251 \\
1: 49\end{array}$ & $\begin{array}{l}\mathrm{n}=300 \\
\mathrm{~d}=56\end{array}$ & 51 & $\begin{array}{l}0: \mathrm{HR}=1.00 \\
1: \mathrm{HR}=1.47(0.76-2.85)\end{array}$ & $\mathrm{p}=0.2578$ & $\begin{array}{l}0: \mathrm{HR}=4.53(2.18-9.43) \\
\mathrm{p}(\mathrm{PCS})=<0.0001 \\
1: \mathrm{HR}=1.27(0.53-3.06) \\
\text { p(PCS) }=0.5963 \\
\mathrm{p}(\mathrm{Subtype})=0.2578\end{array}$ & $\begin{array}{l}0: 2.26 \% \\
1: 0.00 \%\end{array}$ \\
\hline
\end{tabular}


Appendix K. Percent Change from Crude and Model 1 with Each Potential Confounder (PCS \& Non-Cancer Mortality) $(N=$ 351)

\begin{tabular}{|c|c|c|c|c|c|c|}
\hline Model & Variable(s) in model & $\begin{array}{l}\text { Physical Component Summary } \\
\text { Score (PCS) HR }(95 \% \text { CI) }\end{array}$ & $\begin{array}{l}\text { Difference in } \\
\text { ' } \mathrm{N} \text { ' }\end{array}$ & $\begin{array}{l}\text { Total in model (n) } \\
\text { and total dead (d) }\end{array}$ & $\begin{array}{l}\% \text { change from } \\
\text { Crude }\end{array}$ & $\begin{array}{l}\% \text { change from } \\
\text { model } 1\end{array}$ \\
\hline \multicolumn{7}{|c|}{ Dataset restricted to those diagnosed with invasive breast cancer who have HRQOL and baseline covariates data } \\
\hline Crude & Physical Component Summary Score (PCS) & $\begin{array}{l}0: H R=5.63(2.74-11.55) \\
1: H R=1.41(0.59-3.35) \\
2: H R=1.00(R E F) \\
p=<0.0001\end{array}$ & 0 & $\begin{array}{l}\mathrm{n}=351 \\
\mathrm{~d}=64\end{array}$ & -- & -- \\
\hline 1 & Age, Marital Status, \& Tumor Size & $\begin{array}{l}0: H R=2.53(1.19-5.40) \\
1: H R=0.91(0.38-2.19) \\
2: H R=1.00(R E F) \\
p=0.0016\end{array}$ & 0 & $\begin{array}{l}\mathrm{n}=351 \\
\mathrm{~d}=64\end{array}$ & $\begin{array}{l}0: 55.06 \% \\
1: 35.46 \%\end{array}$ & -- \\
\hline 2 & Model $1+$ Race/Ethnicity & $\begin{array}{l}0: H R=2.53(1.18-5.39) \\
1: H R=0.90(0.37-2.18) \\
2: H R=1.00(\mathrm{REF}) \\
\mathrm{p}=0.0016\end{array}$ & 0 & $\begin{array}{l}\mathrm{n}=351 \\
\mathrm{~d}=64\end{array}$ & $\begin{array}{l}0: 55.06 \% \\
1: 36.17 \%\end{array}$ & $\begin{array}{l}0: 0.00 \% \\
1: 1.10 \%\end{array}$ \\
\hline 3 & Model $1+$ Treatment Type & $\begin{array}{l}0: \mathrm{HR}=2.51(1.18-5.35) \\
1: \mathrm{HR}=0.87(0.36-2.11) \\
2: \mathrm{HR}=1.00(\mathrm{REF}) \\
\mathrm{p}=0.0013\end{array}$ & 0 & $\begin{array}{l}\mathrm{n}=351 \\
\mathrm{~d}=64\end{array}$ & $\begin{array}{l}0: 55.42 \% \\
1: 38.30 \%\end{array}$ & $\begin{array}{l}0: 0.79 \% \\
1: 4.40 \%\end{array}$ \\
\hline
\end{tabular}




\begin{tabular}{|c|c|c|c|c|c|c|}
\hline Model & Variable(s) in model & $\begin{array}{l}\text { Physical Component Summary } \\
\text { Score (PCS) HR }(95 \% \text { CI) }\end{array}$ & $\begin{array}{l}\text { Difference in } \\
\text { ' }{ }^{\prime}\end{array}$ & $\begin{array}{l}\text { Total in model (n) } \\
\text { and total dead (d) }\end{array}$ & $\begin{array}{l}\% \text { change from } \\
\text { Crude }\end{array}$ & $\begin{array}{l}\% \text { change from } \\
\text { model } 1\end{array}$ \\
\hline 4 & Model $1+$ Comorbidities & $\begin{array}{l}0: \mathrm{HR}=2.50(1.16-5.37) \\
1: \mathrm{HR}=0.90(0.37-2.18) \\
2: \mathrm{HR}=1.00(\mathrm{REF}) \\
\mathrm{p}=0.0024\end{array}$ & 0 & $\begin{array}{l}\mathrm{n}=351 \\
\mathrm{~d}=64\end{array}$ & $\begin{array}{l}0: 55.60 \% \\
1: 36.17 \%\end{array}$ & $\begin{array}{l}0: 1.19 \% \\
1: 1.10 \%\end{array}$ \\
\hline 5 & Model 1 + Current Lymphedema & $\begin{array}{l}0: \mathrm{HR}=2.62(1.22-5.64) \\
1: \mathrm{HR}=0.92(0.38-2.23) \\
2: \mathrm{HR}=1.00(\mathrm{REF}) \\
\mathrm{p}=0.0014\end{array}$ & 0 & $\begin{array}{l}\mathrm{n}=351 \\
\mathrm{~d}=64\end{array}$ & $\begin{array}{l}0: 53.46 \% \\
1: 34.75 \%\end{array}$ & $\begin{array}{l}0: 3.56 \% \\
1: 1.10 \%\end{array}$ \\
\hline 6 & Model $1+$ Optimism & $\begin{array}{l}0: \mathrm{HR}=2.40(1.20-5.14) \\
1: \mathrm{HR}=0.88(0.36-2.14) \\
2: \mathrm{HR}=1.00(\mathrm{REF}) \\
\mathrm{p}=0.0028\end{array}$ & 0 & $\begin{array}{l}\mathrm{n}=351 \\
\mathrm{~d}=64\end{array}$ & $\begin{array}{l}0: 57.37 \% \\
1: 37.59 \%\end{array}$ & $\begin{array}{l}0: 5.14 \% \\
1: 3.30 \%\end{array}$ \\
\hline 7 & Model $1+$ Pessimism & $\begin{array}{l}0: \mathrm{HR}=2.48(1.17-5.26) \\
1: \mathrm{HR}=0.97(0.40-2.35) \\
2: \mathrm{HR}=1.00(\mathrm{REF}) \\
\mathrm{p}=0.0042\end{array}$ & 0 & $\begin{array}{l}\mathrm{n}=351 \\
\mathrm{~d}=64\end{array}$ & $\begin{array}{l}0: 55.95 \% \\
1: 31.21 \%\end{array}$ & $\begin{array}{l}0: 1.98 \% \\
1: 6.59 \%\end{array}$ \\
\hline 8 & Model $1+$ Number of Types of Confidants & $\begin{array}{l}0: \mathrm{HR}=2.62(1.23-5.59) \\
1: \mathrm{HR}=0.96(0.40-2.32) \\
2: \mathrm{HR}=1.00(\mathrm{REF}) \\
\mathrm{p}=0.0017\end{array}$ & 0 & $\begin{array}{l}\mathrm{n}=351 \\
\mathrm{~d}=64\end{array}$ & $\begin{array}{l}0: 53.46 \% \\
1: 31.91 \%\end{array}$ & $\begin{array}{l}0: 3.56 \% \\
1: 5.49 \%\end{array}$ \\
\hline
\end{tabular}




\begin{tabular}{|c|c|c|c|c|c|c|}
\hline Model & Variable(s) in model & $\begin{array}{l}\text { Physical Component Summary } \\
\text { Score (PCS) HR }(95 \% \text { CI })\end{array}$ & $\begin{array}{l}\text { Difference in } \\
\text { ' } \mathrm{N} \text { ' }\end{array}$ & $\begin{array}{l}\text { Total in model (n) } \\
\text { and total dead (d) }\end{array}$ & $\begin{array}{l}\% \text { change from } \\
\text { Crude }\end{array}$ & $\begin{array}{l}\% \text { change from } \\
\text { model } 1\end{array}$ \\
\hline 9 & Model $1+$ Fear of Recurrence & $\begin{array}{l}0: \mathrm{HR}=2.58(1.21-5.51) \\
1: \mathrm{HR}=0.91(0.38-2.20) \\
2: \mathrm{HR}=1.00 \text { (REF) } \\
\mathrm{p}=0.0013\end{array}$ & 0 & $\begin{array}{l}\mathrm{n}=351 \\
\mathrm{~d}=64\end{array}$ & $\begin{array}{l}0: 54.17 \% \\
1: 35.46 \%\end{array}$ & $\begin{array}{l}0: 1.98 \% \\
1: 0.00 \%\end{array}$ \\
\hline \multicolumn{7}{|c|}{ Subset--Restricted to participants with Education variable } \\
\hline Crude & Physical Component Summary Score (PCS) & $\begin{array}{l}0: \mathrm{HR}=5.51(2.68-11.33) \\
1: \mathrm{HR}=1.41(0.59-3.35) \\
2: \mathrm{HR}=1.00(\mathrm{REF}) \\
\mathrm{p}=<0.0001\end{array}$ & 1 & $\begin{array}{l}\mathrm{n}=350 \\
\mathrm{~d}=63\end{array}$ & -- & -- \\
\hline 1 & Age, Marital Status, \& Tumor Stage & $\begin{array}{l}0: \mathrm{HR}=2.48(1.16-5.29) \\
1: \mathrm{HR}=0.90(0.37-2.17) \\
\text { 2: } \mathrm{HR}=1.00 \text { (REF) } \\
\mathrm{p}=0.0022\end{array}$ & 1 & $\begin{array}{l}\mathrm{n}=350 \\
\mathrm{~d}=63\end{array}$ & $\begin{array}{l}0: 54.99 \% \\
1: 36.17 \%\end{array}$ & -- \\
\hline 10 & Model 1 + Education & $\begin{array}{l}0: \mathrm{HR}=2.59(1.21-5.54) \\
1: \mathrm{HR}=0.90(0.37-2.17) \\
2: \mathrm{HR}=1.00(\mathrm{REF}) \\
\mathrm{p}=0.0016\end{array}$ & 1 & $\begin{array}{l}\mathrm{n}=350 \\
\mathrm{~d}=63\end{array}$ & $\begin{array}{l}0: 52.99 \% \\
1: 36.17 \%\end{array}$ & $\begin{array}{l}0: 4.44 \% \\
1: 0.00 \%\end{array}$ \\
\hline & & tricted to participants with the $\mathrm{Tu}$ & Size variable & & & \\
\hline
\end{tabular}




\begin{tabular}{|c|c|c|c|c|c|c|}
\hline Model & Variable(s) in model & $\begin{array}{l}\text { Physical Component Summary } \\
\text { Score (PCS) HR }(95 \% \text { CI) }\end{array}$ & $\begin{array}{l}\text { Difference in } \\
\text { ' } \mathrm{N}^{\prime}\end{array}$ & $\begin{array}{l}\text { Total in model (n) } \\
\text { and total dead (d) }\end{array}$ & $\begin{array}{l}\% \text { change from } \\
\text { Crude }\end{array}$ & $\begin{array}{l}\% \text { change from } \\
\text { model } 1\end{array}$ \\
\hline Crude & Physical Component Summary Score (PCS) & $\begin{array}{l}0: H R=5.43(2.64-11.14) \\
1: H R=1.39(0.59-3.30) \\
2: H R=1.00(\text { REF }) \\
p=<0.0001\end{array}$ & 10 & $\begin{array}{l}\mathrm{n}=341 \\
\mathrm{~d}=64\end{array}$ & -- & -- \\
\hline 1 & Age, Marital Status, \& Tumor Stage & $\begin{array}{l}0: \mathrm{HR}=2.53(1.19-5.39) \\
1: \mathrm{HR}=0.92(0.38-2.22) \\
2: \mathrm{HR}=1.00(\mathrm{REF}) \\
\mathrm{p}=0.0018\end{array}$ & 10 & $\begin{array}{l}n=341 \\
d=64\end{array}$ & $\begin{array}{l}0: 53.41 \% \\
1: 33.81 \%\end{array}$ & -- \\
\hline 11 & Model $1+$ Tumor Size & $\begin{array}{l}0: \mathrm{HR}=2.53(1.19-5.39) \\
1: \mathrm{HR}=0.91(0.38-2.21) \\
2: \mathrm{HR}=1.00(\mathrm{REF}) \\
\mathrm{p}=0.0018\end{array}$ & 10 & $\begin{array}{l}\mathrm{n}=341 \\
\mathrm{~d}=64\end{array}$ & $\begin{array}{l}0: 53.41 \% \\
1: 34.53 \%\end{array}$ & $\begin{array}{l}0: 0.00 \% \\
1: 1.09 \%\end{array}$ \\
\hline \multicolumn{7}{|c|}{ Subset--Restricted to participants with Lymph Node Involvement variable } \\
\hline Crude & Physical Component Summary Score (PCS) & $\begin{array}{l}0: H R=6.29(2.95-13.41) \\
1: H R=1.36(0.54-3.45) \\
2: H R=1.00(\text { REF }) \\
p=<0.0001\end{array}$ & 10 & $\begin{array}{l}\mathrm{n}=341 \\
\mathrm{~d}=59\end{array}$ & -- & -- \\
\hline
\end{tabular}




\begin{tabular}{|c|c|c|c|c|c|c|}
\hline Model & Variable(s) in model & $\begin{array}{l}\text { Physical Component Summary } \\
\text { Score (PCS) HR }(95 \% \text { CI) }\end{array}$ & $\begin{array}{l}\text { Difference in } \\
\text { ' } \mathrm{N} \text { ' }\end{array}$ & $\begin{array}{l}\text { Total in model (n) } \\
\text { and total dead (d) }\end{array}$ & $\begin{array}{l}\% \text { change from } \\
\text { Crude }\end{array}$ & $\begin{array}{l}\% \text { change from } \\
\text { model } 1\end{array}$ \\
\hline 1 & Age, Marital Status, \& Tumor Stage & $\begin{array}{l}0: \mathrm{HR}=2.71(1.22-6.02) \\
1: \mathrm{HR}=0.96(0.38-2.46) \\
2: \mathrm{HR}=1.00(\mathrm{REF}) \\
\mathrm{p}=0.0029\end{array}$ & 10 & $\begin{array}{l}\mathrm{n}=341 \\
\mathrm{~d}=59\end{array}$ & $\begin{array}{l}\text { 0: } 56.92 \% \\
1: 29.41 \%\end{array}$ & -- \\
\hline 12 & Model $1+$ Lymph Node Involvement & $\begin{array}{l}0: \mathrm{HR}=2.69(1.21-5.97) \\
1: \mathrm{HR}=0.95(0.37-2.45) \\
2: \mathrm{HR}=1.00(\mathrm{REF}) \\
\mathrm{p}=0.0030\end{array}$ & 10 & $\begin{array}{l}\mathrm{n}=341 \\
\mathrm{~d}=59\end{array}$ & $\begin{array}{l}0: 57.23 \% \\
1: 30.15 \%\end{array}$ & $\begin{array}{l}0: 0.74 \% \\
1: 1.04 \%\end{array}$ \\
\hline \multicolumn{7}{|c|}{ Subset--Restricted to participants with Tamoxifen Use, Smoking Status, \& Physical Activity variables (24-month follow-up) } \\
\hline Crude & Physical Component Summary Score (PCS) & $\begin{array}{l}0: \mathrm{HR}=5.19(2.51-10.74) \\
1: \mathrm{HR}=1.42(0.60-3.37) \\
2: \mathrm{HR}=1.00 \text { (REF) } \\
\mathrm{p}=<0.0001\end{array}$ & 21 & $\begin{array}{l}n=330 \\
d=59\end{array}$ & -- & -- \\
\hline 1 & Age, Marital Status, \& Tumor Stage & $\begin{array}{l}0: \mathrm{HR}=2.40(1.12-5.16) \\
1: \mathrm{HR}=0.94(0.39-2.27) \\
2: \mathrm{HR}=1.00(\mathrm{REF}) \\
\mathrm{p}=0.0054\end{array}$ & 21 & $\begin{array}{l}\mathrm{n}=330 \\
\mathrm{~d}=59\end{array}$ & $\begin{array}{l}0: 53.76 \% \\
1: 33.80 \%\end{array}$ & -- \\
\hline
\end{tabular}




\begin{tabular}{|c|c|c|c|c|c|c|}
\hline Model & Variable(s) in model & $\begin{array}{l}\text { Physical Component Summary } \\
\text { Score (PCS) HR }(95 \% \text { CI) }\end{array}$ & $\begin{array}{l}\text { Difference in } \\
\text { ' }{ }^{\prime} \text { ' }\end{array}$ & $\begin{array}{l}\text { Total in model (n) } \\
\text { and total dead (d) }\end{array}$ & $\begin{array}{l}\% \text { change from } \\
\text { Crude }\end{array}$ & $\begin{array}{l}\% \text { change from } \\
\text { model } 1\end{array}$ \\
\hline 13 & Model 1 + Tamoxifen Use & $\begin{array}{l}0: \mathrm{HR}=2.51(1.18-5.37) \\
1: \mathrm{HR}=0.93(0.38-2.24) \\
\text { 2: } \mathrm{HR}=1.00 \text { (REF) } \\
\mathrm{p}=0.0027\end{array}$ & 21 & $\begin{array}{l}\mathrm{n}=330 \\
\mathrm{~d}=59\end{array}$ & $\begin{array}{l}0: 51.64 \% \\
1: 34.51 \%\end{array}$ & $\begin{array}{l}0: 4.58 \% \\
1: 1.06 \%\end{array}$ \\
\hline 14 & Model $1+$ Smoking Status & $\begin{array}{l}\text { 0: } \mathrm{HR}=2.38(1.11-5.09) \\
\text { 1: } \mathrm{HR}=0.93(0.38-2.25) \\
\text { 2: } \mathrm{HR}=1.00 \text { (REF) } \\
\mathrm{p}=0.0057\end{array}$ & 21 & $\begin{array}{l}\mathrm{n}=330 \\
\mathrm{~d}=59\end{array}$ & $\begin{array}{l}0: 54.14 \% \\
1: 34.51 \%\end{array}$ & $\begin{array}{l}0: 0.83 \% \\
1: 1.06 \%\end{array}$ \\
\hline 15 & Model $1+$ Physical Activity & $\begin{array}{l}\text { 0: } \mathrm{HR}=2.45(1.13-5.28) \\
\text { 1: } \mathrm{HR}=0.94(0.39-2.27) \\
\text { 2: } \mathrm{HR}=1.00(\mathrm{REF}) \\
\mathrm{p}=0.0049\end{array}$ & 21 & $\begin{array}{l}\mathrm{n}=330 \\
\mathrm{~d}=59\end{array}$ & $\begin{array}{l}\text { 0: } 52.79 \% \\
1: 33.80 \%\end{array}$ & $\begin{array}{l}0: 2.08 \% \\
1: 0.00 \%\end{array}$ \\
\hline \multicolumn{7}{|c|}{ Subset--Restricted to participants with BMI variable } \\
\hline Crude & Physical Component Summary Score (PCS) & $\begin{array}{l}0: \mathrm{HR}=5.09(2.36-10.99) \\
1: \mathrm{HR}=1.41(0.57-3.51) \\
2: \mathrm{HR}=1.00(\mathrm{REF}) \\
\mathrm{p}=<0.0001\end{array}$ & 27 & $\begin{array}{l}\mathrm{n}=324 \\
\mathrm{~d}=54\end{array}$ & -- & -- \\
\hline
\end{tabular}




\begin{tabular}{|c|c|c|c|c|c|c|}
\hline Model & Variable(s) in model & $\begin{array}{l}\text { Physical Component Summary } \\
\text { Score (PCS) HR }(95 \% \text { CI) }\end{array}$ & $\begin{array}{l}\text { Difference in } \\
\text { ' } \mathrm{N}^{\prime}\end{array}$ & $\begin{array}{l}\text { Total in model (n) } \\
\text { and total dead (d) }\end{array}$ & $\begin{array}{l}\% \text { change from } \\
\text { Crude }\end{array}$ & $\begin{array}{l}\% \text { change from } \\
\text { model } 1\end{array}$ \\
\hline 1 & Age, Marital Status, \& Tumor Stage & $\begin{array}{l}0: \mathrm{HR}=2.41(1.07-5.41) \\
1: \mathrm{HR}=1.00(0.39-2.52) \\
2: \mathrm{HR}=1.00(\mathrm{REF}) \\
\mathrm{p}=0.0129\end{array}$ & 27 & $\begin{array}{l}\mathrm{n}=324 \\
\mathrm{~d}=54\end{array}$ & $\begin{array}{l}0: 52.65 \% \\
1: 29.08 \%\end{array}$ & -- \\
\hline 16 & Model $1+$ BMI & $\begin{array}{l}0: \mathrm{HR}=2.54(1.11-5.83) \\
1: \mathrm{HR}=1.07(0.42-2.72) \\
2: \mathrm{HR}=1.00(\mathrm{REF}) \\
\mathrm{p}=0.0147\end{array}$ & 27 & $\begin{array}{l}\mathrm{n}=324 \\
\mathrm{~d}=54\end{array}$ & $\begin{array}{l}0: 50.10 \% \\
1: 24.11 \%\end{array}$ & $\begin{array}{l}0: 5.12 \% \\
1: 7.00 \%\end{array}$ \\
\hline \multicolumn{7}{|c|}{ Subset--Restricted to participants with Tumor Subtype variable } \\
\hline Crude & Physical Component Summary Score (PCS) & $\begin{array}{l}0: \mathrm{HR}=4.43(2.13-9.20) \\
1: \mathrm{HR}=1.27(0.53-3.07) \\
2: \mathrm{HR}=1.00(\mathrm{REF}) \\
\mathrm{p}=<0.0001\end{array}$ & 51 & $\begin{array}{l}\mathrm{n}=300 \\
\mathrm{~d}=56\end{array}$ & -- & -- \\
\hline 1 & Age, Marital Status, \& Tumor Stage & $\begin{array}{l}0: \mathrm{HR}=2.09(0.97-4.52) \\
1: \mathrm{HR}=0.86(0.35-2.13) \\
2: \mathrm{HR}=1.00(\mathrm{REF}) \\
\mathrm{p}=0.0172\end{array}$ & 51 & $\begin{array}{l}\mathrm{n}=300 \\
\mathrm{~d}=56\end{array}$ & $\begin{array}{l}0: 52.82 \% \\
1: 32.28 \%\end{array}$ & -- \\
\hline
\end{tabular}




\begin{tabular}{|c|c|c|c|c|c|c|}
\hline Model & Variable(s) in model & $\begin{array}{l}\text { Physical Component Summary } \\
\text { Score (PCS) HR ( } 95 \% \text { CI) }\end{array}$ & $\begin{array}{l}\text { Difference in } \\
\text { ' } \mathrm{N} \text { ' }\end{array}$ & $\begin{array}{l}\text { Total in model (n) } \\
\text { and total dead (d) }\end{array}$ & $\begin{array}{l}\% \text { change from } \\
\text { Crude }\end{array}$ & $\begin{array}{l}\% \text { change from } \\
\text { model } 1\end{array}$ \\
\hline 17 & Model $1+$ Tumor Subtype & $\begin{array}{l}0: \mathrm{HR}=2.17(1.01-4.71) \\
1: \mathrm{HR}=0.88(0.36-2.16) \\
2: \mathrm{HR}=1.00(\mathrm{REF}) \\
\mathrm{p}=0.0132\end{array}$ & 51 & $\begin{array}{l}\mathrm{n}=300 \\
\mathrm{~d}=56\end{array}$ & $\begin{array}{l}0: 51.02 \% \\
1: 30.71 \%\end{array}$ & $\begin{array}{l}0: 3.83 \% \\
1: 2.33 \%\end{array}$ \\
\hline
\end{tabular}


Appendix L. Multivariable Modeling with Physical Component Summary Score as the Predictor and Non-Cancer Mortality as the Outcome $(N=351)$

\begin{tabular}{|c|c|c|c|c|c|c|c|}
\hline Model & Variable(s) in model & $\begin{array}{l}\text { Physical Component } \\
\text { Summary Score (PCS) HR } \\
(95 \% \mathrm{CI})\end{array}$ & $\begin{array}{l}\text { Difference in } \\
\text { ' } \mathrm{N} \text { ' }\end{array}$ & $\begin{array}{l}\text { Total in model } \\
\text { (n) and total } \\
\text { dead (d) }\end{array}$ & $\begin{array}{l}\% \text { change } \\
\text { from Crude }\end{array}$ & $\begin{array}{l}\% \text { change } \\
\text { from model } \\
1\end{array}$ & $\begin{array}{l}\% \text { change } \\
\text { from } \\
\text { previous } \\
\text { model } \\
\end{array}$ \\
\hline Crude & Physical Component Summary Score (PCS) & $\begin{array}{l}0: H R=5.63(2.74-11.55) \\
1: H R=1.41(0.59-3.35) \\
2: H R=1.00(R E F) \\
p=<0.0001\end{array}$ & 0 & $\begin{array}{l}\mathrm{n}=351 \\
\mathrm{~d}=64\end{array}$ & -- & -- & -- \\
\hline 1 & Age, Marital Status, \& Tumor Stage & $\begin{array}{l}0: H R=2.53(1.19-5.40) \\
1: H R=0.91(0.38-2.19) \\
2: H R=1.00(\mathrm{REF}) \\
\mathrm{p}=0.0016\end{array}$ & 0 & $\begin{array}{l}\mathrm{n}=351 \\
\mathrm{~d}=64\end{array}$ & $\begin{array}{l}0: 55.06 \% \\
1: 35.46 \%\end{array}$ & -- & -- \\
\hline 2 & Model 1 + Race/Ethnicity & $\begin{array}{l}0: \mathrm{HR}=2.53(1.18-5.39) \\
1: \mathrm{HR}=0.90(0.37-2.18) \\
2: \mathrm{HR}=1.00(\mathrm{REF}) \\
\mathrm{p}=0.0016\end{array}$ & 0 & $\begin{array}{l}\mathrm{n}=351 \\
\mathrm{~d}=64\end{array}$ & $\begin{array}{l}0: 55.06 \% \\
1: 36.17 \%\end{array}$ & $\begin{array}{l}0: 0.00 \% \\
1: 1.10 \%\end{array}$ & -- \\
\hline 3 & Model $1+$ Race/Ethnicity + Treatment Type & $\begin{array}{l}0: \mathrm{HR}=2.50(1.17-5.32) \\
1: \mathrm{HR}=0.86(0.35-2.09) \\
2: \mathrm{HR}=1.00(\mathrm{REF}) \\
\mathrm{p}=0.0013\end{array}$ & 0 & $\begin{array}{l}\mathrm{n}=351 \\
\mathrm{~d}=64\end{array}$ & $\begin{array}{l}0: 55.60 \% \\
1: 39.01 \%\end{array}$ & $\begin{array}{l}0: 1.19 \% \\
1: 5.49 \%\end{array}$ & $\begin{array}{l}0: 1.19 \% \\
1: 4.44 \%\end{array}$ \\
\hline 4 & $\begin{array}{l}\text { Model } 1+\text { Race/Ethnicity }+ \text { Treatment Type }+ \text { Current } \\
\text { Lymphedema }\end{array}$ & $\begin{array}{l}0: \mathrm{HR}=2.60(1.21-5.60) \\
1: \mathrm{HR}=0.88(0.36-2.15) \\
2: \mathrm{HR}=1.00(\mathrm{REF}) \\
\mathrm{p}=0.0010\end{array}$ & 0 & $\begin{array}{l}\mathrm{n}=351 \\
\mathrm{~d}=64\end{array}$ & $\begin{array}{l}0: 53.82 \% \\
1: 37.59 \%\end{array}$ & $\begin{array}{l}0: 2.77 \% \\
1: 3.30 \%\end{array}$ & $\begin{array}{l}0: 4.00 \% \\
1: 2.33 \%\end{array}$ \\
\hline
\end{tabular}




\begin{tabular}{|c|c|c|c|c|c|c|c|}
\hline Model & Variable(s) in model & $\begin{array}{l}\text { Physical Component } \\
\text { Summary Score (PCS) HR } \\
(95 \% \mathrm{CI})\end{array}$ & $\begin{array}{l}\text { Difference in } \\
\text { ' } \mathrm{N} \text { ' }\end{array}$ & $\begin{array}{l}\text { Total in model } \\
\text { (n) and total } \\
\text { dead (d) }\end{array}$ & $\begin{array}{l}\% \text { change } \\
\text { from Crude }\end{array}$ & $\begin{array}{l}\% \text { change } \\
\text { from model } \\
1\end{array}$ & $\begin{array}{l}\% \text { change } \\
\text { from } \\
\text { previous } \\
\text { model } \\
\end{array}$ \\
\hline 7 & $\begin{array}{l}\text { Model } 1+\text { Race/Ethnicity }+ \text { Treatment Type }+ \text { Current } \\
\text { Lymphedema }+ \text { Optimism }+ \text { Confide }+ \text { Fear of Recurrence }\end{array}$ & $\begin{array}{l}0: H R=2.65(1.22-5.74) \\
1: H R=0.95(0.38-2.33) \\
2: H R=1.00(R E F) \\
p=0.0015\end{array}$ & 0 & $\begin{array}{l}\mathrm{n}=351 \\
\mathrm{~d}=64\end{array}$ & $\begin{array}{l}0: 52.93 \% \\
1: 32.62 \%\end{array}$ & $\begin{array}{l}0: 4.74 \% \\
1: 4.40 \%\end{array}$ & $\begin{array}{l}0: 0.75 \% \\
1: 1.06 \%\end{array}$ \\
\hline Crude & Physical Component Summary Score (PCS) & $\begin{array}{l}0: \mathrm{HR}=5.51(2.68-11.33) \\
1: \mathrm{HR}=1.41(0.59-3.35) \\
2: \mathrm{HR}=1.00(\mathrm{REF}) \\
\mathrm{p}=<0.0001\end{array}$ & 1 & $\begin{array}{l}\mathrm{n}=350 \\
\mathrm{~d}=63\end{array}$ & -- & -- & -- \\
\hline 1 & Age, Marital Status, \& Tumor Stage & $\begin{array}{l}0: \mathrm{HR}=2.48(1.16-5.29) \\
1: \mathrm{HR}=0.90(0.37-2.17) \\
2: \mathrm{HR}=1.00(\mathrm{REF}) \\
\mathrm{p}=0.0022\end{array}$ & 1 & $\begin{array}{l}\mathrm{n}=350 \\
\mathrm{~d}=63\end{array}$ & $\begin{array}{l}0: 54.99 \% \\
1: 36.17 \%\end{array}$ & -- & -- \\
\hline
\end{tabular}




\begin{tabular}{|c|c|c|c|c|c|c|c|}
\hline Model & Variable(s) in model & $\begin{array}{l}\text { Physical Component } \\
\text { Summary Score (PCS) HR } \\
(95 \% \text { CI) }\end{array}$ & $\begin{array}{l}\text { Difference in } \\
\text { ' } \mathrm{N} \text { ' }\end{array}$ & $\begin{array}{l}\text { Total in model } \\
\text { (n) and total } \\
\text { dead (d) }\end{array}$ & $\begin{array}{l}\% \text { change } \\
\text { from Crude }\end{array}$ & $\begin{array}{l}\% \text { change } \\
\text { from model } \\
1\end{array}$ & $\begin{array}{l}\% \text { change } \\
\text { from } \\
\text { previous } \\
\text { model } \\
\end{array}$ \\
\hline 10 & Model $1+$ Education + Race/Ethnicity + Treatment Type & $\begin{array}{l}0: \mathrm{HR}=2.51(1.17-5.37) \\
1: \mathrm{HR}=0.85(0.35-2.07) \\
2: \mathrm{HR}=1.00(\mathrm{REF}) \\
\mathrm{p}=0.0014\end{array}$ & 1 & $\begin{array}{l}\mathrm{n}=350 \\
\mathrm{~d}=63\end{array}$ & $\begin{array}{l}0: 54.45 \% \\
1: 39.72 \%\end{array}$ & $\begin{array}{l}0: 1.21 \% \\
1: 5.56 \%\end{array}$ & $\begin{array}{l}0: 2.33 \% \\
1: 5.56 \%\end{array}$ \\
\hline 11 & $\begin{array}{l}\text { Model } 1+\text { Education + Race/Ethnicity + Treatment Type } \\
\text { + Current Lymphedema }\end{array}$ & $\begin{array}{l}0: \mathrm{HR}=2.71(1.25-5.84) \\
1: \mathrm{HR}=0.88(0.36-2.15) \\
2: \mathrm{HR}=1.00(\mathrm{REF}) \\
\mathrm{p}=0.0008\end{array}$ & 1 & $\begin{array}{l}n=350 \\
d=63\end{array}$ & $\begin{array}{l}0: 50.82 \% \\
1: 37.59 \%\end{array}$ & $\begin{array}{l}0: 9.27 \% \\
1: 2.22 \%\end{array}$ & $\begin{array}{l}0: 7.97 \% \\
1: 3.53 \%\end{array}$ \\
\hline 12 & $\begin{array}{l}\text { Model } 1+\text { Education + Race/Ethnicity + Treatment Type } \\
+ \text { Current Lymphedema + Optimism }\end{array}$ & $\begin{array}{l}0: \mathrm{HR}=2.61(1.20-5.65) \\
1: \mathrm{HR}=0.87(0.36-2.11) \\
2: \mathrm{HR}=1.00(\mathrm{REF}) \\
\mathrm{p}=0.0012\end{array}$ & 1 & $\begin{array}{l}\mathrm{n}=350 \\
\mathrm{~d}=63\end{array}$ & $\begin{array}{l}0: 52.63 \% \\
1: 38.30 \%\end{array}$ & $\begin{array}{l}0: 5.24 \% \\
1: 3.33 \%\end{array}$ & $\begin{array}{l}0: 3.69 \% \\
1: 1.14 \%\end{array}$ \\
\hline
\end{tabular}




\begin{tabular}{|c|c|c|c|c|c|c|c|}
\hline Model & Variable(s) in model & $\begin{array}{l}\text { Physical Component } \\
\text { Summary Score (PCS) HR } \\
(95 \% \mathrm{CI})\end{array}$ & $\begin{array}{l}\text { Difference in } \\
\text { ' } \mathrm{N} \text { ' }\end{array}$ & $\begin{array}{l}\text { Total in model } \\
\text { (n) and total } \\
\text { dead (d) }\end{array}$ & $\begin{array}{l}\% \text { change } \\
\text { from Crude }\end{array}$ & $\begin{array}{l}\% \text { change } \\
\text { from model } \\
1\end{array}$ & $\begin{array}{l}\% \text { change } \\
\text { from } \\
\text { previous } \\
\text { model } \\
\end{array}$ \\
\hline 13 & $\begin{array}{l}\text { Model } 1+\text { Education + Race/Ethnicity + Treatment Type } \\
+ \text { Current Lymphedema + Optimism + Confide }\end{array}$ & $\begin{array}{l}0: \mathrm{HR}=2.71(1.25-5.89) \\
1: \mathrm{HR}=0.93(0.38-2.28) \\
2: \mathrm{HR}=1.00(\mathrm{REF}) \\
\mathrm{p}=0.0013\end{array}$ & 1 & $\begin{array}{l}n=350 \\
d=63\end{array}$ & $\begin{array}{l}0: 50.82 \% \\
1: 34.04 \%\end{array}$ & $\begin{array}{l}0: 9.27 \% \\
1: 3.33 \%\end{array}$ & $\begin{array}{l}0: 3.83 \% \\
1: 6.90 \%\end{array}$ \\
\hline 14 & $\begin{array}{l}\text { Model } 1+\text { Education + Race/Ethnicity + Treatment Type } \\
+ \text { Current Lymphedema + Optimism + Confide + Fear of } \\
\text { Recurrence }\end{array}$ & $\begin{array}{l}0: \mathrm{HR}=2.69(1.24-5.84) \\
1: \mathrm{HR}=0.93(0.38-2.30) \\
2: \mathrm{HR}=1.00(\mathrm{REF}) \\
\mathrm{p}=0.0014\end{array}$ & 1 & $\begin{array}{l}n=350 \\
d=63\end{array}$ & $\begin{array}{l}0: 51.18 \% \\
1: 34.04 \%\end{array}$ & $\begin{array}{l}0: 8.47 \% \\
1: 3.33 \%\end{array}$ & $\begin{array}{l}0: 0.74 \% \\
1: 0.00 \%\end{array}$ \\
\hline \multicolumn{8}{|c|}{ Subset--Restricted to participants with Tumor Size variable } \\
\hline Crude & Physical Component Summary Score (PCS) & $\begin{array}{l}0: H R=5.43(2.64-11.14) \\
1: H R=1.39(0.59-3.30) \\
2: H R=1.00(R E F) \\
p=<0.0001\end{array}$ & 10 & $\begin{array}{l}n=341 \\
d=64\end{array}$ & -- & -- & -- \\
\hline 1 & Age, Marital Status, \& Tumor Stage & $\begin{array}{l}0: \mathrm{HR}=2.53(1.19-5.39) \\
1: \mathrm{HR}=0.92(0.38-2.22) \\
2: \mathrm{HR}=1.00(\mathrm{REF}) \\
\mathrm{p}=0.0018\end{array}$ & 10 & $\begin{array}{l}n=341 \\
d=64\end{array}$ & $\begin{array}{l}0: 53.41 \% \\
1: 33.81 \%\end{array}$ & -- & -- \\
\hline 15 & Model $1+$ Tumor Size & $\begin{array}{l}0: \mathrm{HR}=2.53(1.19-5.39) \\
1: \mathrm{HR}=0.91(0.38-2.21) \\
2: \mathrm{HR}=1.00(\mathrm{REF}) \\
\mathrm{p}=0.0018\end{array}$ & 10 & $\begin{array}{l}n=341 \\
d=64\end{array}$ & $\begin{array}{l}0: 53.41 \% \\
1: 34.53 \%\end{array}$ & $\begin{array}{l}0: 0.00 \% \\
1: 1.09 \%\end{array}$ & -- \\
\hline
\end{tabular}




\begin{tabular}{|c|c|c|c|c|c|c|c|}
\hline Model & Variable(s) in model & $\begin{array}{l}\text { Physical Component } \\
\text { Summary Score (PCS) HR } \\
(95 \% \mathrm{CI})\end{array}$ & $\begin{array}{l}\text { Difference in } \\
\text { ' } \mathrm{N} \text { ' }\end{array}$ & $\begin{array}{l}\text { Total in model } \\
\text { (n) and total } \\
\text { dead (d) }\end{array}$ & $\begin{array}{l}\% \text { change } \\
\text { from Crude }\end{array}$ & $\begin{array}{l}\% \text { change } \\
\text { from model } \\
1\end{array}$ & $\begin{array}{l}\% \text { change } \\
\text { from } \\
\text { previous } \\
\text { model }\end{array}$ \\
\hline 16 & Model 1 + Tumor Size + Race/Ethnicity & $\begin{array}{l}0: \mathrm{HR}=2.52(1.19-5.38) \\
1: \mathrm{HR}=0.91(0.38-2.20) \\
2: \mathrm{HR}=1.00(\mathrm{REF}) \\
\mathrm{p}=0.0018\end{array}$ & 10 & $\begin{array}{l}n=341 \\
d=64\end{array}$ & $\begin{array}{l}0: 53.59 \% \\
1: 34.53 \%\end{array}$ & $\begin{array}{l}0: 0.40 \% \\
1: 1.09 \%\end{array}$ & $\begin{array}{l}0: 0.40 \% \\
1: 0.00 \%\end{array}$ \\
\hline 17 & Model $1+$ Tumor Size + Race/Ethnicity + Treatment Type & $\begin{array}{l}0: \mathrm{HR}=2.50(1.17-5.32) \\
1: \mathrm{HR}=0.87(0.36-2.11) \\
2: \mathrm{HR}=1.00(\mathrm{REF}) \\
\mathrm{p}=0.0013\end{array}$ & 10 & $\begin{array}{l}n=341 \\
d=64\end{array}$ & $\begin{array}{l}0: 53.96 \% \\
1: 37.41 \%\end{array}$ & $\begin{array}{l}0: 1.19 \% \\
1: 5.43 \%\end{array}$ & $\begin{array}{l}0: 0.79 \% \\
1: 4.40 \%\end{array}$ \\
\hline 18 & $\begin{array}{l}\text { Model } 1+\text { Tumor Size + Race/Ethnicity + Treatment Type } \\
+ \text { Current Lymphedema }\end{array}$ & $\begin{array}{l}0: \mathrm{HR}=2.61(1.22-5.61) \\
1: \mathrm{HR}=0.89(0.36-2.17) \\
2: \mathrm{HR}=1.00(\mathrm{REF}) \\
\mathrm{p}=0.0011\end{array}$ & 10 & $\begin{array}{l}n=341 \\
d=64\end{array}$ & $\begin{array}{l}0: 51.93 \% \\
1: 35.97 \%\end{array}$ & $\begin{array}{l}0: 3.16 \% \\
1: 3.26 \%\end{array}$ & $\begin{array}{l}0: 4.40 \% \\
1: 2.30 \%\end{array}$ \\
\hline 19 & $\begin{array}{l}\text { Model } 1+\text { Tumor Size + Race/Ethnicity + Treatment Type } \\
+ \text { Current Lymphedema + Optimism }\end{array}$ & $\begin{array}{l}0: \mathrm{HR}=2.50(1.16-5.39) \\
1: \mathrm{HR}=0.86(0.35-2.11) \\
2: \mathrm{HR}=1.00(\mathrm{REF}) \\
\mathrm{p}=0.0016\end{array}$ & 10 & $\begin{array}{l}n=341 \\
d=64\end{array}$ & $\begin{array}{l}0: 53.96 \% \\
1: 38.13 \%\end{array}$ & $\begin{array}{l}0: 1.19 \% \\
1: 6.52 \%\end{array}$ & $\begin{array}{l}0: 4.21 \% \\
1: 3.37 \%\end{array}$ \\
\hline 20 & $\begin{array}{l}\text { Model } 1+\text { Tumor Size + Race/Ethnicity + Treatment Type } \\
+ \text { Current Lymphedema + Optimism + Confide }\end{array}$ & $\begin{array}{l}0: \mathrm{HR}=2.67(1.23-5.78) \\
1: \mathrm{HR}=0.95(0.39-2.34) \\
2: \mathrm{HR}=1.00(\mathrm{REF}) \\
\mathrm{p}=0.0016\end{array}$ & 10 & $\begin{array}{l}\mathrm{n}=341 \\
\mathrm{~d}=64\end{array}$ & $\begin{array}{l}0: 50.83 \% \\
1: 31.65 \%\end{array}$ & $\begin{array}{l}0: 5.53 \% \\
1: 3.26 \%\end{array}$ & $\begin{array}{l}0: 6.80 \% \\
1: \mathbf{1 0 . 4 7 \%}\end{array}$ \\
\hline
\end{tabular}




\begin{tabular}{|c|c|c|c|c|c|c|c|}
\hline Model & Variable(s) in model & $\begin{array}{l}\text { Physical Component } \\
\text { Summary Score (PCS) HR } \\
(95 \% \mathrm{CI})\end{array}$ & $\begin{array}{l}\text { Difference in } \\
\text { ' } N \text { ' }\end{array}$ & $\begin{array}{l}\text { Total in model } \\
\text { (n) and total } \\
\text { dead (d) }\end{array}$ & $\begin{array}{l}\% \text { change } \\
\text { from Crude }\end{array}$ & $\begin{array}{l}\% \text { change } \\
\text { from model } \\
1\end{array}$ & $\begin{array}{l}\% \text { change } \\
\text { from } \\
\text { previous } \\
\text { model }\end{array}$ \\
\hline 21 & $\begin{array}{l}\text { Model } 1+\text { Tumor Size }+ \text { Race/Ethnicity + Treatment Type } \\
+ \text { Current Lymphedema + Optimism + Confide + Fear of } \\
\text { Recurrence }\end{array}$ & $\begin{array}{l}0: H R=2.66(1.23-5.76) \\
1: H R=0.96(0.39-2.36) \\
2: H R=1.00(\text { REF }) \\
p=0.0016\end{array}$ & 10 & $\begin{array}{l}n=341 \\
d=64\end{array}$ & $\begin{array}{l}0: 51.01 \% \\
1: 30.94 \%\end{array}$ & $\begin{array}{l}0: 5.14 \% \\
1: 4.35 \%\end{array}$ & $\begin{array}{l}0: 0.37 \% \\
1: 1.05 \%\end{array}$ \\
\hline \multicolumn{8}{|c|}{ Subset--Restricted to participants with Education and Tumor Size variables (24-month follow-up) } \\
\hline Crude & Physical Component Summary Score (PCS) & $\begin{array}{l}0: H R=5.31(2.59-10.92) \\
1: H R=1.39(0.59-3.30) \\
2: H R=1.00(R E F) \\
p=<0.0001\end{array}$ & 11 & $\begin{array}{l}n=340 \\
d=63\end{array}$ & -- & -- & -- \\
\hline 1 & Age, Marital Status, \& Tumor Stage & $\begin{array}{l}0: \mathrm{HR}=2.48(1.16-5.28) \\
1: \mathrm{HR}=0.91(0.38-2.20) \\
2: \mathrm{HR}=1.00(\mathrm{REF}) \\
\mathrm{p}=0.0024\end{array}$ & 11 & $\begin{array}{l}n=340 \\
d=63\end{array}$ & $\begin{array}{l}0: 53.30 \% \\
1: 34.53 \%\end{array}$ & -- & -- \\
\hline 22 & Model $1+$ Education + Tumor Size & $\begin{array}{l}0: \mathrm{HR}=2.57(1.20-5.50) \\
1: \mathrm{HR}=0.91(0.69-2.49) \\
2: \mathrm{HR}=1.00(\mathrm{REF}) \\
\mathrm{p}=0.0018\end{array}$ & 11 & $\begin{array}{l}\mathrm{n}=340 \\
\mathrm{~d}=63\end{array}$ & $\begin{array}{l}0: 51.60 \% \\
1: 34.53 \%\end{array}$ & $\begin{array}{l}0: 3.63 \% \\
1: 0.00 \%\end{array}$ & -- \\
\hline 23 & Model 1 Education + Tumor Size + Race/Ethnicity & $\begin{array}{l}0: \mathrm{HR}=2.56(1.20-5.48) \\
1: \mathrm{HR}=0.90(0.37-2.18) \\
2: \mathrm{HR}=1.00(\mathrm{REF}) \\
\mathrm{p}=0.0018\end{array}$ & 11 & $\begin{array}{l}n=340 \\
d=63\end{array}$ & $\begin{array}{l}0: 51.79 \% \\
1: 35.25 \%\end{array}$ & $\begin{array}{l}0: 3.23 \% \\
1: 1.10 \%\end{array}$ & $\begin{array}{l}0: 0.39 \% \\
1: 1.10 \%\end{array}$ \\
\hline
\end{tabular}




\begin{tabular}{|c|c|c|c|c|c|c|c|}
\hline Model & Variable(s) in model & $\begin{array}{l}\text { Physical Component } \\
\text { Summary Score (PCS) HR } \\
(95 \% \mathrm{CI})\end{array}$ & $\begin{array}{l}\text { Difference in } \\
\text { ' } \mathrm{N} \text { ' }\end{array}$ & $\begin{array}{l}\text { Total in model } \\
\text { (n) and total } \\
\text { dead (d) }\end{array}$ & $\begin{array}{l}\% \text { change } \\
\text { from Crude }\end{array}$ & $\begin{array}{l}\% \text { change } \\
\text { from model } \\
1\end{array}$ & $\begin{array}{l}\text { \% change } \\
\text { from } \\
\text { previous } \\
\text { model }\end{array}$ \\
\hline 24 & $\begin{array}{l}\text { Model } 1+\text { Education }+ \text { Tumor Size }+ \text { Race/Ethnicity }+ \\
\text { Treatment Type }\end{array}$ & $\begin{array}{l}0: \mathrm{HR}=2.49(1.18-5.33) \\
1: \mathrm{HR}=0.86(0.36-2.10) \\
2: \mathrm{HR}=1.00(\mathrm{REF}) \\
\mathrm{p}=0.0016\end{array}$ & 11 & $\begin{array}{l}n=340 \\
d=63\end{array}$ & $\begin{array}{l}0: 53.11 \% \\
1: 38.13 \%\end{array}$ & $\begin{array}{l}0: 0.40 \% \\
1: 5.49 \%\end{array}$ & $\begin{array}{l}0: 2.73 \% \\
1: 4.44 \%\end{array}$ \\
\hline 25 & $\begin{array}{l}\text { Model } 1+\text { Education + Tumor Size + Race/Ethnicity + } \\
\text { Treatment Type + Current Lymphedema }\end{array}$ & $\begin{array}{l}0: \mathrm{HR}=2.70(1.25-5.83) \\
1: \mathrm{HR}=0.89(0.37-2.18) \\
2: \mathrm{HR}=1.00(\mathrm{REF}) \\
\mathrm{p}=0.0009\end{array}$ & 11 & $\begin{array}{l}n=340 \\
d=63\end{array}$ & $\begin{array}{l}0: 49.15 \% \\
1: 35.97 \%\end{array}$ & $\begin{array}{l}0: 8.87 \% \\
1: 2.20 \%\end{array}$ & $\begin{array}{l}0: 8.43 \% \\
1: 3.49 \%\end{array}$ \\
\hline 26 & $\begin{array}{l}\text { Model } 1+\text { Education + Tumor Size + Race/Ethnicity + } \\
\text { Treatment Type + Current Lymphedema + Optimism }\end{array}$ & $\begin{array}{l}0: \mathrm{HR}=2.60(1.20-5.64) \\
1: \mathrm{HR}=0.88(0.36-2.14) \\
2: \mathrm{HR}=1.00(\mathrm{REF}) \\
\mathrm{p}=0.0014\end{array}$ & 11 & $\begin{array}{l}n=340 \\
d=63\end{array}$ & $\begin{array}{l}0: 51.04 \% \\
1: 36.69 \%\end{array}$ & $\begin{array}{l}0: 4.84 \% \\
1: 3.30 \%\end{array}$ & $\begin{array}{l}0: 3.70 \% \\
1: 1.12 \%\end{array}$ \\
\hline 27 & $\begin{array}{l}\text { Model } 1+\text { Education + Tumor Size + Race/Ethnicity + } \\
\text { Treatment Type + Current Lymphedema + Optimism + } \\
\text { Confide }\end{array}$ & $\begin{array}{l}0: \mathrm{HR}=2.72(1.25-5.91) \\
1: \mathrm{HR}=0.95(0.39-2.33) \\
2: \mathrm{HR}=1.00(\mathrm{REF}) \\
\mathrm{p}=0.0015\end{array}$ & 11 & $\begin{array}{l}n=340 \\
d=63\end{array}$ & $\begin{array}{l}0: 48.78 \% \\
1: 31.65 \%\end{array}$ & $\begin{array}{l}0: 9.68 \% \\
1: 4.40 \%\end{array}$ & $\begin{array}{l}0: 4.62 \% \\
1: 7.95 \%\end{array}$ \\
\hline 28 & $\begin{array}{l}\text { Model } 1+\text { Education + Tumor Size + Race/Ethnicity + } \\
\text { Treatment Type + Current Lymphedema + Optimism + } \\
\text { Confide + Fear of Recurrence }\end{array}$ & $\begin{array}{l}0: \mathrm{HR}=2.69(1.24-5.85) \\
1: \mathrm{HR}=0.95(0.38-2.35) \\
2: \mathrm{HR}=1.00(\mathrm{REF}) \\
\mathrm{p}=0.0016\end{array}$ & 11 & $\begin{array}{l}n=340 \\
d=63\end{array}$ & $\begin{array}{l}0: 49.34 \% \\
1: 31.65 \%\end{array}$ & $\begin{array}{l}0: 8.47 \% \\
1: 4.40 \%\end{array}$ & $\begin{array}{l}0: 1.10 \% \\
1: 0.00 \%\end{array}$ \\
\hline
\end{tabular}




\begin{tabular}{|c|c|c|c|c|c|c|c|}
\hline Model & Variable(s) in model & $\begin{array}{l}\text { Physical Component } \\
\text { Summary Score (PCS) HR } \\
(95 \% \text { CI) }\end{array}$ & $\begin{array}{l}\text { Difference in } \\
\text { ' } \mathrm{N} \text { ' }\end{array}$ & $\begin{array}{l}\text { Total in model } \\
\text { (n) and total } \\
\text { dead (d) }\end{array}$ & $\begin{array}{l}\% \text { change } \\
\text { from Crude }\end{array}$ & $\begin{array}{l}\% \text { change } \\
\text { from model } \\
1\end{array}$ & $\begin{array}{l}\% \text { change } \\
\text { from } \\
\text { previous } \\
\text { model }\end{array}$ \\
\hline Crude & Physical Component Summary Score (PCS) & $\begin{array}{l}0: \mathrm{HR}=5.19(2.51-10.74) \\
1: \mathrm{HR}=1.42(0.60-3.37) \\
2: \mathrm{HR}=1.00(\mathrm{REF}) \\
\mathrm{p}=<0.0001\end{array}$ & 21 & $\begin{array}{l}n=330 \\
d=59\end{array}$ & -- & -- & -- \\
\hline 1 & Age, Marital Status, \& Tumor Stage & $\begin{array}{l}0: \mathrm{HR}=2.40(1.12-5.16) \\
\text { 1: } \mathrm{HR}=0.94(0.39-2.27) \\
\text { 2: } \mathrm{HR}=1.00 \text { (REF) } \\
\mathrm{p}=0.0054\end{array}$ & 21 & $\begin{array}{l}n=330 \\
d=59\end{array}$ & $\begin{array}{l}0: 53.76 \% \\
1: 33.80 \%\end{array}$ & -- & -- \\
\hline 29 & Model $1+$ Tamoxifen Use + Physical Activity & $\begin{array}{l}0: \mathrm{HR}=2.56(1.19-5.48) \\
1: \mathrm{HR}=0.93(0.39-2.24) \\
\text { 2: } \mathrm{HR}=1.00(\mathrm{REF}) \\
\mathrm{p}=0.0025\end{array}$ & 21 & $\begin{array}{l}\mathrm{n}=330 \\
\mathrm{~d}=59\end{array}$ & $\begin{array}{l}0: 50.67 \% \\
1: 34.51 \%\end{array}$ & $\begin{array}{l}0: 6.67 \% \\
1: 1.06 \%\end{array}$ & -- \\
\hline 30 & $\begin{array}{l}\text { Model } 1+\text { Tamoxifen Use + Physical Activity + } \\
\text { Race/Ethnicity }\end{array}$ & $\begin{array}{l}0: \mathrm{HR}=2.55(1.19-5.47) \\
1: \mathrm{HR}=0.92(0.38-2.23) \\
\text { 2: } \mathrm{HR}=1.00 \text { (REF) } \\
\mathrm{p}=0.0025\end{array}$ & 21 & $\begin{array}{l}n=330 \\
d=59\end{array}$ & $\begin{array}{l}0: 50.87 \% \\
1: 35.21 \%\end{array}$ & $\begin{array}{l}0: 6.25 \% \\
1: 2.13 \%\end{array}$ & $\begin{array}{l}0: 0.39 \% \\
1: 1.08 \%\end{array}$ \\
\hline 31 & $\begin{array}{l}\text { Model } 1+\text { Tamoxifen Use + Physical Activity }+ \\
\text { Race/Ethnicity + Treatment Type }\end{array}$ & $\begin{array}{l}0: \mathrm{HR}=2.47(1.15-5.30) \\
\text { 1: } \mathrm{HR}=0.89(0.37-2.16) \\
\text { 2: } \mathrm{HR}=1.00 \text { (REF) } \\
\mathrm{p}=0.0029\end{array}$ & 21 & $\begin{array}{l}\mathrm{n}=330 \\
\mathrm{~d}=59\end{array}$ & $\begin{array}{l}0: 52.41 \% \\
1: 37.32 \%\end{array}$ & $\begin{array}{l}0: 2.92 \% \\
1: 5.32 \%\end{array}$ & $\begin{array}{l}0: 3.14 \% \\
1: 3.26 \%\end{array}$ \\
\hline
\end{tabular}




\begin{tabular}{|c|c|c|c|c|c|c|c|}
\hline Model & Variable(s) in model & $\begin{array}{l}\text { Physical Component } \\
\text { Summary Score (PCS) HR } \\
(95 \% \mathrm{CI})\end{array}$ & $\begin{array}{l}\text { Difference in } \\
\text { 'N' }\end{array}$ & $\begin{array}{l}\text { Total in model } \\
\text { (n) and total } \\
\text { dead (d) }\end{array}$ & $\begin{array}{l}\% \text { change } \\
\text { from Crude }\end{array}$ & $\begin{array}{l}\% \text { change } \\
\text { from model } \\
1\end{array}$ & $\begin{array}{l}\% \text { change } \\
\text { from } \\
\text { previous } \\
\text { model }\end{array}$ \\
\hline 32 & $\begin{array}{l}\text { Model } 1+\text { Tamoxifen Use + Physical Activity }+ \\
\text { Race/Ethnicity + Treatment Type + Current Lymphedema }\end{array}$ & $\begin{array}{l}0: H R=2.44(1.12-5.31) \\
1: H R=0.90(0.37-2.19) \\
2: H R=1.00(R E F) \\
p=0.0050\end{array}$ & 21 & $\begin{array}{l}n=330 \\
d=59\end{array}$ & $\begin{array}{l}0: 52.99 \% \\
1: 36.62 \%\end{array}$ & $\begin{array}{l}0: 1.67 \% \\
1: 4.26 \%\end{array}$ & $\begin{array}{l}0: 1.21 \% \\
1: 1.12 \%\end{array}$ \\
\hline 33 & $\begin{array}{l}\text { Model } 1+\text { Tamoxifen Use }+ \text { Physical Activity }+ \\
\text { Race/Ethnicity }+ \text { Treatment Type }+ \text { Current Lymphedema } \\
+ \text { Optimism }\end{array}$ & $\begin{array}{l}0: H R=2.45(1.14-5.29) \\
1: H R=0.88(0.36-2.15) \\
2: H R=1.00(\mathrm{REF}) \\
\mathrm{p}=0.0031\end{array}$ & 21 & $\begin{array}{l}\mathrm{n}=330 \\
\mathrm{~d}=59\end{array}$ & $\begin{array}{l}0: 52.79 \% \\
1: 38.03 \%\end{array}$ & $\begin{array}{l}0: 2.08 \% \\
1: 6.38 \%\end{array}$ & $\begin{array}{l}0: 0.41 \% \\
1: 2.22 \%\end{array}$ \\
\hline 34 & $\begin{array}{l}\text { Model } 1+\text { Tamoxifen Use + Physical Activity }+ \\
\text { Race/Ethnicity + Treatment Type + Current Lymphedema } \\
+ \text { Optimism + Confide }\end{array}$ & $\begin{array}{l}0: \mathrm{HR}=2.60(1.19-5.68) \\
1: \mathrm{HR}=0.94(0.38-2.33) \\
\text { 2: } \mathrm{HR}=1.00(\mathrm{REF}) \\
\mathrm{p}=0.0027\end{array}$ & 21 & $\begin{array}{l}\mathrm{n}=330 \\
\mathrm{~d}=59\end{array}$ & $\begin{array}{l}0: 49.90 \% \\
1: 33.80 \%\end{array}$ & $\begin{array}{l}0: 8.33 \% \\
1: 0.00 \%\end{array}$ & $\begin{array}{l}0: 6.12 \% \\
1: 6.82 \%\end{array}$ \\
\hline 35 & $\begin{array}{l}\text { Model } 1+\text { Tamoxifen Use + Physical Activity }+ \\
\text { Race/Ethnicity + Treatment Type + Current Lymphedema } \\
+ \text { Optimism + Confide + Fear of Recurrence }\end{array}$ & $\begin{array}{l}0: \mathrm{HR}=2.60(1.19-5.69) \\
1: \mathrm{HR}=0.96(0.39-2.38) \\
2: \mathrm{HR}=1.00(\mathrm{REF}) \\
\mathrm{p}=0.0029\end{array}$ & 21 & $\begin{array}{l}\mathrm{n}=330 \\
\mathrm{~d}=59\end{array}$ & $\begin{array}{l}0: 49.90 \% \\
1: 32.39 \%\end{array}$ & $\begin{array}{l}0: 8.33 \% \\
1: 2.13 \%\end{array}$ & $\begin{array}{l}0: 0.00 \% \\
1: 2.13 \%\end{array}$ \\
\hline \multicolumn{8}{|c|}{ Subset--Restricted to participants with Education, Tumor Size, Tamoxifen Use, and Physical Activity variables } \\
\hline Crude & Physical Component Summary Score (PCS) & $\begin{array}{l}0: \mathrm{HR}=4.88(2.35-10.12) \\
1: \mathrm{HR}=1.40(0.59-3.33) \\
2: \mathrm{HR}=1.00(\mathrm{REF}) \\
\mathrm{p}=<0.0001\end{array}$ & 32 & $\begin{array}{l}\mathrm{n}=319 \\
\mathrm{~d}=58\end{array}$ & -- & -- & -- \\
\hline
\end{tabular}




\begin{tabular}{|c|c|c|c|c|c|c|c|}
\hline Model & Variable(s) in model & $\begin{array}{l}\text { Physical Component } \\
\text { Summary Score (PCS) HR } \\
(95 \% \mathrm{CI})\end{array}$ & $\begin{array}{l}\text { Difference in } \\
\text { ' } \mathrm{N} \text { ' }\end{array}$ & $\begin{array}{l}\text { Total in model } \\
\text { (n) and total } \\
\text { dead (d) }\end{array}$ & $\begin{array}{l}\% \text { change } \\
\text { from Crude }\end{array}$ & $\begin{array}{l}\% \text { change } \\
\text { from model } \\
1\end{array}$ & $\begin{array}{l}\% \text { change } \\
\text { from } \\
\text { previous } \\
\text { model }\end{array}$ \\
\hline 1 & Age, Marital Status, \& Tumor Stage & $\begin{array}{l}0: \mathrm{HR}=2.35(1.09-5.05) \\
1: \mathrm{HR}=0.95(0.39-2.29) \\
2: \mathrm{HR}=1.00(\mathrm{REF}) \\
\mathrm{p}=0.0078\end{array}$ & 32 & $\begin{array}{l}n=319 \\
d=58\end{array}$ & $\begin{array}{l}0: 51.84 \% \\
1: 32.14 \%\end{array}$ & -- & -- \\
\hline 36 & $\begin{array}{l}\text { Model } 1+\text { Education + Tumor Size + Tamoxifen Use + } \\
\text { Physical Activity }\end{array}$ & $\begin{array}{l}0: \mathrm{HR}=2.65(1.22-5.72) \\
1: \mathrm{HR}=0.94(0.39-2.27) \\
2: \mathrm{HR}=1.00(\mathrm{REF}) \\
\mathrm{p}=0.0024\end{array}$ & 32 & $\begin{array}{l}n=319 \\
d=58\end{array}$ & $\begin{array}{l}0: 45.70 \% \\
1: 32.86 \%\end{array}$ & $\begin{array}{l}\mathbf{0 :} \mathbf{1 2 . 7 7 \%} \\
1: 1.05 \%\end{array}$ & -- \\
\hline 37 & $\begin{array}{l}\text { Model } 1+\text { Education }+ \text { Tumor Size + Tamoxifen Use + } \\
\text { Physical Activity + Race/Ethnicity }\end{array}$ & $\begin{array}{l}0: \mathrm{HR}=2.64(1.22-5.71) \\
1: \mathrm{HR}=0.94(0.39-2.26) \\
2: \mathrm{HR}=1.00(\mathrm{REF}) \\
\mathrm{p}=0.0025\end{array}$ & 32 & $\begin{array}{l}\mathrm{n}=319 \\
\mathrm{~d}=58\end{array}$ & $\begin{array}{l}0: 45.90 \% \\
1: 32.86 \%\end{array}$ & $\begin{array}{l}\mathbf{0 :} \mathbf{1 2 . 3 4 \%} \\
1: 1.05 \%\end{array}$ & $\begin{array}{l}0: 0.38 \% \\
1: 0.00 \%\end{array}$ \\
\hline 38 & $\begin{array}{l}\text { Model } 1+\text { Education }+ \text { Tumor Size }+ \text { Tamoxifen Use + } \\
\text { Physical Activity + Race/Ethnicity + Treatment Type }\end{array}$ & $\begin{array}{l}0: \mathrm{HR}=2.52(1.17-5.44) \\
1: \mathrm{HR}=0.89(0.37-2.17) \\
2: \mathrm{HR}=1.00(\mathrm{REF}) \\
\mathrm{p}=0.0029\end{array}$ & 32 & $\begin{array}{l}\mathrm{n}=319 \\
\mathrm{~d}=58\end{array}$ & $\begin{array}{l}0: 48.36 \% \\
1: 36.43 \%\end{array}$ & $\begin{array}{l}0: 7.23 \% \\
1: 6.32 \%\end{array}$ & $\begin{array}{l}0: 4.55 \% \\
1: 5.32 \%\end{array}$ \\
\hline 39 & $\begin{array}{l}\text { Model } 1+\text { Education }+ \text { Tumor Size }+ \text { Tamoxifen Use + } \\
\text { Physical Activity }+ \text { Race/Ethnicity + Treatment Type + } \\
\text { Current Lymphedema }\end{array}$ & $\begin{array}{l}0: \mathrm{HR}=2.61(1.20-5.67) \\
1: \mathrm{HR}=0.91(0.37-2.21) \\
2: \mathrm{HR}=1.00(\mathrm{REF}) \\
\mathrm{p}=0.0024\end{array}$ & 32 & $\begin{array}{l}\mathrm{n}=319 \\
\mathrm{~d}=58\end{array}$ & $\begin{array}{l}0: 46.52 \% \\
1: 35.00 \%\end{array}$ & $\begin{array}{l}\mathbf{0 :} \mathbf{1 1 . 0 6 \%} \\
1: 4.21 \%\end{array}$ & $\begin{array}{l}0: 3.57 \% \\
1: 2.25 \%\end{array}$ \\
\hline
\end{tabular}




\begin{tabular}{|c|c|c|c|c|c|c|c|}
\hline Model & Variable(s) in model & $\begin{array}{l}\text { Physical Component } \\
\text { Summary Score (PCS) HR } \\
(95 \% \mathrm{CI})\end{array}$ & $\begin{array}{l}\text { Difference in } \\
\text { ' } \mathrm{N} \text { ' }\end{array}$ & $\begin{array}{l}\text { Total in model } \\
\text { (n) and total } \\
\text { dead (d) }\end{array}$ & $\begin{array}{l}\% \text { change } \\
\text { from Crude }\end{array}$ & $\begin{array}{l}\% \text { change } \\
\text { from model } \\
1\end{array}$ & $\begin{array}{l}\text { \% change } \\
\text { from } \\
\text { previous } \\
\text { model }\end{array}$ \\
\hline 40 & $\begin{array}{l}\text { Model } 1+\text { Education + Tumor Size + Tamoxifen Use + } \\
\text { Physical Activity + Race/Ethnicity + Treatment Type + } \\
\text { Current Lymphedema + Optimism }\end{array}$ & $\begin{array}{l}0: H R=2.58(1.18-5.60) \\
1: H R=0.89(0.36-2.19) \\
2: H R=1.00(\mathrm{REF}) \\
\mathrm{p}=0.0026\end{array}$ & 32 & $\begin{array}{l}\mathrm{n}=319 \\
\mathrm{~d}=58\end{array}$ & $\begin{array}{l}0: 47.13 \% \\
1: 36.43 \%\end{array}$ & $\begin{array}{l}0: 9.79 \% \\
1: 6.32 \%\end{array}$ & $\begin{array}{l}0: 1.15 \% \\
1: 2.20 \%\end{array}$ \\
\hline 41 & $\begin{array}{l}\text { Model } 1 \text { + Education + Tumor Size + Tamoxifen Use + } \\
\text { Physical Activity + Race/Ethnicity + Treatment Type + } \\
\text { Current Lymphedema + Optimism + Confide }\end{array}$ & $\begin{array}{l}0: \mathrm{HR}=2.67(1.21-5.87) \\
1: \mathrm{HR}=0.94(0.38-2.34) \\
2: \mathrm{HR}=1.00(\mathrm{REF}) \\
\mathrm{p}=0.0024\end{array}$ & 32 & $\begin{array}{l}\mathrm{n}=319 \\
\mathrm{~d}=58\end{array}$ & $\begin{array}{l}0: 45.29 \% \\
1: 32.86 \%\end{array}$ & $\begin{array}{l}\mathbf{0 :} \mathbf{1 3 . 6 2 \%} \\
1: 1.05 \%\end{array}$ & $\begin{array}{l}0: 3.49 \% \\
1: 5.62 \%\end{array}$ \\
\hline 42 & $\begin{array}{l}\text { Model } 1+\text { Education }+ \text { Tumor Size + Tamoxifen Use }+ \\
\text { Physical Activity + Race/Ethnicity + Treatment Type + } \\
\text { Current Lymphedema + Optimism + Confide + Fear of } \\
\text { Recurrence }\end{array}$ & $\begin{array}{l}0: \mathrm{HR}=2.66(1.21-5.85) \\
1: \mathrm{HR}=0.95(0.38-2.38) \\
2: \mathrm{HR}=1.00(\mathrm{REF}) \\
\mathrm{p}=0.0027\end{array}$ & 32 & $\begin{array}{l}\mathrm{n}=319 \\
\mathrm{~d}=58\end{array}$ & $\begin{array}{l}0: 45.49 \% \\
1: 32.14 \%\end{array}$ & $\begin{array}{l}\mathbf{0 :} \mathbf{1 3 . 1 9 \%} \\
1: 0.00 \%\end{array}$ & $\begin{array}{l}0: 0.37 \% \\
1: 1.06 \%\end{array}$ \\
\hline \multicolumn{8}{|c|}{ Subset--Restricted to participants with BMI variable } \\
\hline Crude & Physical Component Summary Score (PCS) & $\begin{array}{l}0: H R=5.09(2.36-10.99) \\
1: H R=1.41(0.57-3.51) \\
2: H R=1.00(R E F) \\
p=<0.0001\end{array}$ & 27 & $\begin{array}{l}\mathrm{n}=324 \\
\mathrm{~d}=54\end{array}$ & -- & -- & -- \\
\hline 1 & Age, Marital Status, \& Tumor Stage & $\begin{array}{l}0: \mathrm{HR}=2.41(1.07-5.41) \\
1: \mathrm{HR}=1.00(0.39-2.52) \\
2: \mathrm{HR}=1.00(\mathrm{REF}) \\
\mathrm{p}=0.0129\end{array}$ & 27 & $\begin{array}{l}\mathrm{n}=324 \\
\mathrm{~d}=54\end{array}$ & $\begin{array}{l}0: 52.65 \% \\
1: 29.08 \%\end{array}$ & -- & -- \\
\hline
\end{tabular}




\begin{tabular}{|c|c|c|c|c|c|c|c|}
\hline Model & Variable(s) in model & $\begin{array}{l}\text { Physical Component } \\
\text { Summary Score (PCS) HR } \\
(95 \% \mathrm{CI})\end{array}$ & $\begin{array}{l}\text { Difference in } \\
\text { ' }{ }^{\prime} \text { ' }\end{array}$ & $\begin{array}{l}\text { Total in model } \\
\text { (n) and total } \\
\text { dead (d) }\end{array}$ & $\begin{array}{l}\% \text { change } \\
\text { from Crude }\end{array}$ & $\begin{array}{l}\% \text { change } \\
\text { from model } \\
1\end{array}$ & $\begin{array}{l}\% \text { change } \\
\text { from } \\
\text { previous } \\
\text { model } \\
\end{array}$ \\
\hline 43 & Model $1+$ BMI & $\begin{array}{l}0: \mathrm{HR}=2.54(1.11-5.83) \\
1: \mathrm{HR}=1.07(0.42-2.72) \\
2: \mathrm{HR}=1.00(\mathrm{REF}) \\
\mathrm{p}=0.0147\end{array}$ & 27 & $\begin{array}{l}\mathrm{n}=324 \\
\mathrm{~d}=54\end{array}$ & $\begin{array}{l}0: 50.10 \% \\
1: 24.11 \%\end{array}$ & $\begin{array}{l}0: 5.39 \% \\
1: 7.00 \%\end{array}$ & -- \\
\hline 44 & Model $1+$ BMI + Race/Ethnicity & $\begin{array}{l}0: \mathrm{HR}=2.54(1.11-5.82) \\
1: \mathrm{HR}=1.07(0.42-2.71) \\
\text { 2: } \mathrm{HR}=1.00(\mathrm{REF}) \\
\mathrm{p}=0.0150\end{array}$ & 27 & $\begin{array}{l}n=324 \\
d=54\end{array}$ & $\begin{array}{l}0: 50.10 \% \\
1: 24.11 \%\end{array}$ & $\begin{array}{l}0: 5.39 \% \\
1: 7.00 \%\end{array}$ & $\begin{array}{l}0: 0.00 \% \\
1: 0.00 \%\end{array}$ \\
\hline 45 & Model 1 + BMI + Race/Ethnicity + Treatment Type & $\begin{array}{l}0: \mathrm{HR}=2.42(1.05-5.57) \\
1: \mathrm{HR}=1.03(0.41-2.63) \\
2: \mathrm{HR}=1.00(\mathrm{REF}) \\
\mathrm{p}=0.0184\end{array}$ & 27 & $\begin{array}{l}n=324 \\
d=54\end{array}$ & $\begin{array}{l}0: 52.46 \% \\
1: 26.95 \%\end{array}$ & $\begin{array}{l}0: 0.41 \% \\
1: 3.00 \%\end{array}$ & $\begin{array}{l}0: 4.72 \% \\
1: 3.74 \%\end{array}$ \\
\hline 46 & $\begin{array}{l}\text { Model } 1+\text { BMI + Race/Ethnicity + Treatment Type + } \\
\text { Current Lymphedema }\end{array}$ & $\begin{array}{l}0: H R=2.50(1.08-5.78) \\
1: H R=1.06(0.41-2.70) \\
2: H R=1.00(\mathrm{REF}) \\
\mathrm{p}=0.0160\end{array}$ & 27 & $\begin{array}{l}n=324 \\
d=54\end{array}$ & $\begin{array}{l}0: 50.88 \% \\
1: 24.82 \%\end{array}$ & $\begin{array}{l}0: 3.73 \% \\
1: 6.00 \%\end{array}$ & $\begin{array}{l}0: 3.31 \% \\
1: 2.91 \%\end{array}$ \\
\hline 47 & $\begin{array}{l}\text { Model } 1 \text { + BMI + Race/Ethnicity + Treatment Type + } \\
\text { Current Lymphedema + Optimism }\end{array}$ & $\begin{array}{l}0: \mathrm{HR}=2.37(1.03-5.50) \\
1: \mathrm{HR}=0.99(0.39-2.56) \\
2: \mathrm{HR}=1.00(\mathrm{REF}) \\
\mathrm{p}=0.0187\end{array}$ & 27 & $\begin{array}{l}n=324 \\
d=54\end{array}$ & $\begin{array}{l}0: 53.44 \% \\
1: 29.79 \%\end{array}$ & $\begin{array}{l}0: 1.66 \% \\
1: 1.00 \%\end{array}$ & $\begin{array}{l}0: 5.20 \% \\
1: 6.60 \%\end{array}$ \\
\hline
\end{tabular}




\begin{tabular}{|c|c|c|c|c|c|c|c|}
\hline Model & Variable(s) in model & $\begin{array}{l}\text { Physical Component } \\
\text { Summary Score (PCS) HR } \\
(95 \% \mathrm{CI})\end{array}$ & $\begin{array}{l}\text { Difference in } \\
\text { ' } \mathrm{N} \text { ' }\end{array}$ & $\begin{array}{l}\text { Total in model } \\
\text { (n) and total } \\
\text { dead (d) }\end{array}$ & $\begin{array}{l}\% \text { change } \\
\text { from Crude }\end{array}$ & $\begin{array}{l}\% \text { change } \\
\text { from model } \\
1\end{array}$ & $\begin{array}{l}\% \text { change } \\
\text { from } \\
\text { previous } \\
\text { model } \\
\end{array}$ \\
\hline 48 & $\begin{array}{l}\text { Model } 1 \text { + BMI + Race/Ethnicity + Treatment Type + } \\
\text { Current Lymphedema + Optimism + Confide }\end{array}$ & $\begin{array}{l}0: \mathrm{HR}=2.59(1.11-6.02) \\
1: \mathrm{HR}=1.08(0.42-2.78) \\
2: \mathrm{HR}=1.00(\mathrm{REF}) \\
\mathrm{p}=0.0150\end{array}$ & 27 & $\begin{array}{l}n=324 \\
d=54\end{array}$ & $\begin{array}{l}0: 49.12 \% \\
1: 23.40 \%\end{array}$ & $\begin{array}{l}0: 7.47 \% \\
1: 8.00 \%\end{array}$ & $\begin{array}{l}0: 9.28 \% \\
1: 9.09 \%\end{array}$ \\
\hline 49 & $\begin{array}{l}\text { Model } 1+\text { BMI }+ \text { Race/Ethnicity + Treatment Type }+ \\
\text { Current Lymphedema + Optimism + Confide + Fear of } \\
\text { Recurrence }\end{array}$ & $\begin{array}{l}0: \mathrm{HR}=2.54(1.09-5.89) \\
1: \mathrm{HR}=1.08(0.42-2.78) \\
2: \mathrm{HR}=1.00(\mathrm{REF}) \\
\mathrm{p}=0.0174\end{array}$ & 27 & $\begin{array}{l}n=324 \\
d=54\end{array}$ & $\begin{array}{l}0: 50.10 \% \\
1: 23.40 \%\end{array}$ & $\begin{array}{l}0: 5.39 \% \\
1: 8.00 \%\end{array}$ & $\begin{array}{l}0: 1.93 \% \\
1: 0.00 \%\end{array}$ \\
\hline \multicolumn{8}{|c|}{ Subset--Restricted to participants with Education, Tumor Size, Tamoxifen Use, Physical Activity, \& BMI variables } \\
\hline Crude & Physical Component Summary Score (PCS) & $\begin{array}{l}0: \mathrm{HR}=4.42(2.03-9.65) \\
1: \mathrm{HR}=1.40(0.56-3.47) \\
2: \mathrm{HR}=1.00(\mathrm{REF}) \\
\mathrm{p}=<0.0001\end{array}$ & 56 & $\begin{array}{l}n=295 \\
d=49\end{array}$ & -- & -- & -- \\
\hline 1 & Age, Marital Status, \& Tumor Stage & $\begin{array}{l}0: \mathrm{HR}=2.32(1.02-5.25) \\
1: \mathrm{HR}=1.01(0.40-2.56) \\
2: \mathrm{HR}=1.00(\mathrm{REF}) \\
\mathrm{p}=0.0231\end{array}$ & 56 & $\begin{array}{l}\mathrm{n}=295 \\
\mathrm{~d}=49\end{array}$ & $\begin{array}{l}0: 47.51 \% \\
1: 27.86 \%\end{array}$ & -- & -- \\
\hline 50 & $\begin{array}{l}\text { Model } 1+\text { Education + Tumor Size + Tamoxifen Use + } \\
\text { Physical Activity + BMI }\end{array}$ & $\begin{array}{l}0: \mathrm{HR}=2.88(1.23-6.72) \\
1: \mathrm{HR}=1.06(0.42-2.68) \\
2: \mathrm{HR}=1.00(\mathrm{REF}) \\
\mathrm{p}=0.0068\end{array}$ & 56 & $\begin{array}{l}\mathrm{n}=295 \\
\mathrm{~d}=49\end{array}$ & $\begin{array}{l}0: 34.84 \% \\
1: 24.29 \%\end{array}$ & $\begin{array}{l}\mathbf{0 :} \mathbf{2 4 . 1 4 \%} \\
1: 4.95 \%\end{array}$ & -- \\
\hline
\end{tabular}




\begin{tabular}{|c|c|c|c|c|c|c|c|}
\hline Model & Variable(s) in model & $\begin{array}{l}\text { Physical Component } \\
\text { Summary Score (PCS) HR } \\
(95 \% \text { CI) }\end{array}$ & $\begin{array}{l}\text { Difference in } \\
\text { ' }{ }^{\prime} \text { ' }\end{array}$ & $\begin{array}{l}\text { Total in model } \\
\text { (n) and total } \\
\text { dead (d) }\end{array}$ & $\begin{array}{l}\% \text { change } \\
\text { from Crude }\end{array}$ & $\begin{array}{l}\% \text { change } \\
\text { from model } \\
1\end{array}$ & $\begin{array}{l}\% \text { change } \\
\text { from } \\
\text { previous } \\
\text { model }\end{array}$ \\
\hline 51 & $\begin{array}{l}\text { Model } 1+\text { Education }+ \text { Tumor Size }+ \text { Tamoxifen Use + } \\
\text { Physical Activity + BMI + Race/Ethnicity }\end{array}$ & $\begin{array}{l}0: \mathrm{HR}=2.87(1.23-6.70) \\
1: \mathrm{HR}=1.05(0.42-2.67) \\
2: \mathrm{HR}=1.00(\mathrm{REF}) \\
\mathrm{p}=0.0069\end{array}$ & 56 & $\begin{array}{l}\mathrm{n}=295 \\
\mathrm{~d}=49\end{array}$ & $\begin{array}{l}0: 35.07 \% \\
1: 25.00 \%\end{array}$ & $\begin{array}{l}\mathbf{0 :} \mathbf{2 3 . 7 1 \%} \\
1: 3.96 \%\end{array}$ & $\begin{array}{l}0: 0.35 \% \\
1: 0.94 \%\end{array}$ \\
\hline 52 & $\begin{array}{l}\text { Model } 1+\text { Education + Tumor Size + Tamoxifen Use + } \\
\text { Physical Activity + BMI + Race/Ethnicity + Treatment } \\
\text { Type }\end{array}$ & $\begin{array}{l}0: \mathrm{HR}=2.63(1.13-6.14) \\
1: \mathrm{HR}=1.02(0.40-2.61) \\
2: \mathrm{HR}=1.00(\mathrm{REF}) \\
\mathrm{p}=0.0139\end{array}$ & 56 & $\begin{array}{l}\mathrm{n}=295 \\
\mathrm{~d}=49\end{array}$ & $\begin{array}{l}0: 40.50 \% \\
1: 27.14 \%\end{array}$ & $\begin{array}{l}\mathbf{0 :} \mathbf{1 3 . 3 6 \%} \\
1: 0.99 \%\end{array}$ & $\begin{array}{l}0: 8.36 \% \\
1: 2.86 \%\end{array}$ \\
\hline 53 & $\begin{array}{l}\text { Model } 1+\text { Education + Tumor Size + Tamoxifen Use + } \\
\text { Physical Activity + BMI + Race/Ethnicity + Treatment } \\
\text { Type + Current Lymphedema }\end{array}$ & $\begin{array}{l}0: \mathrm{HR}=2.60(1.10-6.11) \\
1: \mathrm{HR}=1.03(0.40-2.63) \\
2: \mathrm{HR}=1.00(\mathrm{REF}) \\
\mathrm{p}=0.0178\end{array}$ & 56 & $\begin{array}{l}\mathrm{n}=295 \\
\mathrm{~d}=49\end{array}$ & $\begin{array}{l}0: 41.18 \% \\
1: 26.43 \%\end{array}$ & $\begin{array}{l}\text { 0: } \mathbf{1 2 . 0 7 \%} \\
1: 1.98 \%\end{array}$ & $\begin{array}{l}0: 1.14 \% \\
1: 0.98 \%\end{array}$ \\
\hline 54 & $\begin{array}{l}\text { Model } 1+\text { Education + Tumor Size + Tamoxifen Use + } \\
\text { Physical Activity + BMI + Race/Ethnicity + Treatment } \\
\text { Type + Current Lymphedema + Optimism }\end{array}$ & $\begin{array}{l}0: H R=2.55(1.08-6.02) \\
1: H R=0.99(0.38-2.57) \\
\text { 2: } H R=1.00(\mathrm{REF}) \\
\mathrm{p}=0.0169\end{array}$ & 56 & $\begin{array}{l}\mathrm{n}=295 \\
\mathrm{~d}=49\end{array}$ & $\begin{array}{l}0: 42.31 \% \\
1: 29.29 \%\end{array}$ & $\begin{array}{l}0: 9.91 \% \\
1: 1.98 \%\end{array}$ & $\begin{array}{l}0: 1.92 \% \\
1: 3.88 \%\end{array}$ \\
\hline 55 & $\begin{array}{l}\text { Model } 1+\text { Education + Tumor Size + Tamoxifen Use + } \\
\text { Physical Activity + BMI + Race/Ethnicity + Treatment } \\
\text { Type + Current Lymphedema + Optimism + Confide }\end{array}$ & $\begin{array}{l}0: \mathrm{HR}=2.65(1.11-6.29) \\
1: \mathrm{HR}=1.04(0.40-2.74) \\
2: \mathrm{HR}=1.00(\mathrm{REF}) \\
\mathrm{p}=0.0158\end{array}$ & 56 & $\begin{array}{l}\mathrm{n}=295 \\
\mathrm{~d}=49\end{array}$ & $\begin{array}{l}0: 40.06 \% \\
1: 25.71 \%\end{array}$ & $\begin{array}{l}\mathbf{0 :} \mathbf{1 4 . 2 2 \%} \\
1: 2.97 \%\end{array}$ & $\begin{array}{l}0: 3.92 \% \\
1: 5.05 \%\end{array}$ \\
\hline
\end{tabular}




\begin{tabular}{|c|c|c|c|c|c|c|c|}
\hline Model & Variable(s) in model & $\begin{array}{l}\text { Physical Component } \\
\text { Summary Score (PCS) HR } \\
(95 \% \mathrm{CI})\end{array}$ & $\begin{array}{l}\text { Difference in } \\
\text { ' } \mathrm{N} \text { ' }\end{array}$ & $\begin{array}{l}\text { Total in model } \\
\text { (n) and total } \\
\text { dead (d) }\end{array}$ & $\begin{array}{l}\% \text { change } \\
\text { from Crude }\end{array}$ & $\begin{array}{l}\% \text { change } \\
\text { from model } \\
1\end{array}$ & $\begin{array}{l}\% \text { change } \\
\text { from } \\
\text { previous } \\
\text { model }\end{array}$ \\
\hline 56 & $\begin{array}{l}\text { Model } 1+\text { Education + Tumor Size + Tamoxifen Use + } \\
\text { Physical Activity + BMI + Race/Ethnicity + Treatment } \\
\text { Type + Current Lymphedema + Optimism + Confide + } \\
\text { Fear of Recurrence }\end{array}$ & $\begin{array}{l}0: \mathrm{HR}=2.56(1.07-6.11) \\
1: \mathrm{HR}=1.05(0.40-2.76) \\
2: \mathrm{HR}=1.00(\mathrm{REF}) \\
\mathrm{p}=0.0226\end{array}$ & 56 & $\begin{array}{l}\mathrm{n}=295 \\
\mathrm{~d}=49\end{array}$ & $\begin{array}{l}0: 42.08 \% \\
1: 25.00 \%\end{array}$ & $\begin{array}{l}\mathbf{0 :} \mathbf{1 0 . 3 4 \%} \\
1: 3.96 \%\end{array}$ & $\begin{array}{l}0: 3.40 \% \\
1: 0.96 \%\end{array}$ \\
\hline
\end{tabular}


Appendix M. Mental Component Summary Score Univariate HR Analysis and Percent Change for Non-Cancer Mortality when Assessing for Potential Confounders $(N=351)$

\begin{tabular}{|c|c|c|c|c|c|c|c|c|c|}
\hline Model & Variable(s) in model & Categories & $\begin{array}{l}\text { Total in } \\
\text { categories } \\
\text { (n) }\end{array}$ & $\begin{array}{l}\text { Total } \\
\text { in } \\
\text { model } \\
(\mathrm{n}) ; \\
\text { dead } \\
\text { (d) } \\
\end{array}$ & Missing & Univariate-Cox HR (95\% CI) & p-values* & $\begin{array}{l}\text { MCS HR }(95 \% \mathrm{CI}) \text { and p- } \\
\text { values }\end{array}$ & $\begin{array}{l}\% \text { change } \\
\text { from crude } \\
\text { model }\end{array}$ \\
\hline Crude & $\begin{array}{l}\text { Mental Component } \\
\text { Summary Score (MCS) }\end{array}$ & $\begin{array}{l}0: \leq 45.12 \\
1:>45.12 \& \leq 54.40 \\
2:>54.40(\mathrm{REF})\end{array}$ & $\begin{array}{l}0: 117 \\
1: 117 \\
2: 117\end{array}$ & $\begin{array}{l}n=351 \\
d=64\end{array}$ & 0 & $\begin{array}{l}0: \mathrm{HR}=1.45(0.78-2.72) \\
1: \mathrm{HR}=1.42(0.76-2.64)\end{array}$ & $\mathrm{p}=0.4424$ & $\begin{array}{l}0: H R=1.45(0.78-2.72) \\
p(M C S)=0.2439 \\
1: H R=1.42(0.76-2.64) \\
p(M C S)=0.2705\end{array}$ & -- \\
\hline 1 & Age & Continuous & -- & $\begin{array}{l}n=351 \\
d=64\end{array}$ & 0 & $\mathrm{HR}=1.11(1.08-1.14)$ & $\mathrm{p}=<0.0001$ & $\begin{array}{l}0: \mathrm{HR}=1.83(0.98-3.44) \\
\mathrm{p}(\mathrm{MCS})=0.0596 \\
1: \mathrm{HR}=1.44(0.77-2.69) \\
\mathrm{p}(\mathrm{MCS})=0.2576 \\
\mathrm{p}(\mathrm{Age})=<0.0001\end{array}$ & $\begin{array}{l}\mathbf{0}: \mathbf{2 6 . 2 1 \%} \\
1: 1.41 \%\end{array}$ \\
\hline 2 & Race/Ethnicity & $\begin{array}{l}\text { 0: Non-Hispanic } \\
\text { White (REF) } \\
\text { Hispanic }\end{array}$ & $\begin{array}{l}0: 273 \\
1: 78\end{array}$ & $\begin{array}{l}n=351 \\
d=64\end{array}$ & 0 & $\begin{array}{l}0: \mathrm{HR}=1.00 \\
1: \mathrm{HR}=0.53(0.26-1.07)\end{array}$ & $p=0.0774$ & $\begin{array}{l}0: \mathrm{HR}=1.52(0.81-2.85) \\
\mathrm{p}(\mathrm{MCS})=0.1917 \\
1: \mathrm{HR}=1.46(0.78-2.72) \\
\mathrm{p}(\mathrm{MCS})=0.2331 \\
\mathrm{p}(\text { Ethnicity })=0.0774\end{array}$ & $\begin{array}{l}0: 4.83 \% \\
1: 2.82 \%\end{array}$ \\
\hline 3 & Marital Status & $\begin{array}{l}0 \text { : Single } \\
\text { 1: Married (REF) }\end{array}$ & $\begin{array}{l}0: 160 \\
1: 191\end{array}$ & $\begin{array}{l}n=351 \\
d=64\end{array}$ & 0 & $\begin{array}{l}0: \mathrm{HR}=2.65(1.57-4.48) \\
1: \mathrm{HR}=1.00\end{array}$ & $\mathrm{p}=\mathbf{0 . 0 0 0 3}$ & $\begin{array}{l}0: \mathrm{HR}=1.44(0.77-2.69) \\
\mathrm{p}(\mathrm{MCS})=0.2574 \\
1: \mathrm{HR}=1.48(0.79-2.75) \\
\mathrm{p}(\mathrm{MCS})=0.2207 \\
\text { p(Marital) }=0.0003\end{array}$ & $\begin{array}{l}0: 0.69 \% \\
1: 4.23 \%\end{array}$ \\
\hline
\end{tabular}




\begin{tabular}{|c|c|c|c|c|c|c|c|c|c|}
\hline Model & Variable(s) in model & Categories & $\begin{array}{l}\text { Total in } \\
\text { categories } \\
\text { (n) }\end{array}$ & $\begin{array}{l}\text { Total } \\
\text { in } \\
\text { model } \\
\text { (n); } \\
\text { dead } \\
\text { (d) } \\
\end{array}$ & Missing & Univariate-Cox HR (95\% CI) & p-values* & $\begin{array}{l}\text { MCS HR }(95 \% \mathrm{CI}) \text { and p- } \\
\text { values }\end{array}$ & $\begin{array}{l}\% \text { change } \\
\text { from crude } \\
\text { model }\end{array}$ \\
\hline 4 & Tumor Stage & $\begin{array}{l}\text { 0: Localized (I) } \\
\text { 1: Regional (II-IIIa) }\end{array}$ & $\begin{array}{l}0: 276 \\
1: 75\end{array}$ & $\begin{array}{l}\mathrm{n}=351 \\
\mathrm{~d}=64\end{array}$ & 0 & $\begin{array}{l}0: \mathrm{HR}=1.00 \\
1: \mathrm{HR}=0.77(0.40-1.48)\end{array}$ & $\mathrm{p}=0.4351$ & $\begin{array}{l}0: \mathrm{HR}=1.43(0.76-2.68) \\
\mathrm{p}(\mathrm{MCS})=0.2630 \\
1: \mathrm{HR}=1.41(0.76-2.63) \\
\mathrm{p}(\mathrm{MCS})=0.2781 \\
\mathrm{p}(\text { Stage })=0.4351\end{array}$ & $\begin{array}{l}0: 1.38 \% \\
1: 0.70 \%\end{array}$ \\
\hline 5 & $\begin{array}{l}\text { Breast Cancer Treatment } \\
\text { Type }\end{array}$ & $\begin{array}{l}0: \text { Surgery only (REF) } \\
\text { 1: Any chemotherapy } \\
\text { 2: Surgery and } \\
\text { radiation }\end{array}$ & $\begin{array}{l}0: 98 \\
1: 109 \\
2: 144\end{array}$ & $\begin{array}{l}\mathrm{n}=351 \\
\mathrm{~d}=64\end{array}$ & 0 & $\begin{array}{l}0: H R=1.00 \\
1: H R=0.36(0.18-0.72) \\
2: H R=0.66(0.39-1.13)\end{array}$ & $p=0.0154$ & $\begin{array}{l}0: \mathrm{HR}=1.51(0.81-2.84) \\
\mathrm{p}(\mathrm{MCS})=0.1956 \\
1: \mathrm{HR}=1.45(0.78-2.70) \\
\mathrm{p}(\mathrm{MCS})=0.2441 \\
\mathrm{p}(\text { Treatment } 1)=0.0043 \\
\mathrm{p}(\text { Treatment } 2)=0.1312\end{array}$ & $\begin{array}{l}0: 4.14 \% \\
1: 2.11 \%\end{array}$ \\
\hline 6 & Comorbidities & $\begin{array}{l}0: \text { Zero (REF) } \\
1: \text { One or more }\end{array}$ & $\begin{array}{l}0: 298 \\
1: 53\end{array}$ & $\begin{array}{l}\mathrm{n}=351 \\
\mathrm{~d}=64\end{array}$ & 0 & $\begin{array}{l}0: \mathrm{HR}=1.00 \\
1: \mathrm{HR}=1.86(1.02-3.39)\end{array}$ & $p=0.0442$ & $\begin{array}{l}0: \mathrm{HR}=1.34(0.71-2.53) \\
\mathrm{p}(\mathrm{MCS})=0.3636 \\
1: \mathrm{HR}=1.40(0.75-2.60) \\
\mathrm{p}(\mathrm{MCS})=0.2903 \\
\mathrm{p}(\text { Comorbidities })=0.0442\end{array}$ & $\begin{array}{l}0: 7.59 \% \\
1: 1.41 \%\end{array}$ \\
\hline 7 & Current Lymphedema & $\begin{array}{l}0: \text { No (REF) } \\
\text { 1: Yes }\end{array}$ & $\begin{array}{l}0: 307 \\
1: 44\end{array}$ & $\begin{array}{l}n=351 \\
d=64\end{array}$ & 0 & $\begin{array}{l}0: \mathrm{HR}=1.00 \\
1: \mathrm{HR}=0.62(0.26-1.44)\end{array}$ & $\mathrm{p}=0.2624$ & $\begin{array}{l}0: \mathrm{HR}=1.53(0.81-2.87) \\
\mathrm{p}(\mathrm{MCS})=0.1902 \\
1: \mathrm{HR}=1.45(0.78-2.69) \\
\mathrm{p}(\mathrm{MCS})=0.2465 \\
\mathrm{p}(\text { Lymphedema })=0.2624\end{array}$ & $\begin{array}{l}0: 5.52 \% \\
1: 2.11 \%\end{array}$ \\
\hline
\end{tabular}




\begin{tabular}{|c|c|c|c|c|c|c|c|c|c|}
\hline Model & Variable(s) in model & Categories & $\begin{array}{l}\text { Total in } \\
\text { categories } \\
\text { (n) }\end{array}$ & $\begin{array}{l}\text { Total } \\
\text { in } \\
\text { model } \\
\text { (n); } \\
\text { dead } \\
\text { (d) } \\
\end{array}$ & Missing & Univariate-Cox HR $(95 \%$ CI) & p-values* & $\begin{array}{l}\text { MCS HR }(95 \% \mathrm{CI}) \text { and } \mathrm{p}- \\
\text { values }\end{array}$ & $\begin{array}{l}\% \text { change } \\
\text { from crude } \\
\text { model }\end{array}$ \\
\hline 8 & Perceived Optimism & $\begin{array}{l}0: \leq 10 \\
1:>10 \text { (REF) }\end{array}$ & $\begin{array}{l}0: 83 \\
1: 268\end{array}$ & $\begin{array}{l}n=351 \\
d=64\end{array}$ & 0 & $\begin{array}{l}0: \mathrm{HR}=2.08(1.23-3.53) \\
1: \mathrm{HR}=1.00\end{array}$ & $p=0.0066$ & $\begin{array}{l}0: H R=1.16(0.60-2.23) \\
\mathrm{p}(\mathrm{MCS})=0.6636 \\
1: \mathrm{HR}=1.26(0.67-2.36) \\
\mathrm{p}(\mathrm{MCS})=0.4759 \\
\mathrm{p}(\text { Optimism })=0.0066\end{array}$ & $\begin{array}{l}0: 20.00 \% \\
1: 11.27 \%\end{array}$ \\
\hline 9 & Perceived Pessimism & $\begin{array}{l}0: \leq 10(\mathrm{REF}) \\
1:>10\end{array}$ & $\begin{array}{l}0: 255 \\
1: 96\end{array}$ & $\begin{array}{l}n=351 \\
d=64\end{array}$ & 0 & $\begin{array}{l}0: \mathrm{HR}=1.00 \\
1: \mathrm{HR}=1.80(1.07-3.04)\end{array}$ & $\mathrm{p}=\mathbf{0 . 0 2 6 4}$ & $\begin{array}{l}0: H R=1.25(0.66-2.38) \\
p(M C S)=0.5018 \\
1: H R=1.32(0.71-2.47) \\
p(M C S)=0.3831 \\
p(\text { Pessimism })=0.0264\end{array}$ & $\begin{array}{l}\mathbf{0 : 1 3 . 7 9 \%} \\
1: 7.04 \%\end{array}$ \\
\hline 10 & Current Fatigue & $\begin{array}{l}0: \text { No (REF) } \\
1: \text { Yes }\end{array}$ & $\begin{array}{l}0: 136 \\
1: 215\end{array}$ & $\begin{array}{l}n=351 \\
d=64\end{array}$ & 0 & $\begin{array}{l}0: \mathrm{HR}=1.00 \\
\text { 1: } \mathrm{HR}=1.03(0.58-1.82)\end{array}$ & $\mathrm{p}=0.9171$ & $\begin{array}{l}0: H R=1.43(0.72-2.85) \\
\mathrm{p}(\mathrm{MCS})=0.3081 \\
1: \mathrm{HR}=1.41(0.75-2.65) \\
\mathrm{p}(\mathrm{MCS})=0.2870 \\
\mathrm{p}(\text { Fatigue })=0.9171\end{array}$ & $\begin{array}{l}0: 1.38 \% \\
1: 0.70 \%\end{array}$ \\
\hline 11 & Fear of Recurrence & $\begin{array}{l}0: \text { No (REF) } \\
1: \text { Yes }\end{array}$ & $\begin{array}{l}0: 154 \\
1: 197\end{array}$ & $\begin{array}{l}n=351 \\
d=64\end{array}$ & 0 & $\begin{array}{l}0: \mathrm{HR}=1.00 \\
1: \mathrm{HR}=0.45(0.27-0.74)\end{array}$ & $\mathrm{p}=\mathbf{0 . 0 0 1 9}$ & $\begin{array}{l}0: \mathrm{HR}=1.72(0.91-3.24) \\
\mathrm{p}(\mathrm{MCS})=0.0961 \\
1: \mathrm{HR}=1.60(0.86-3.00) \\
\mathrm{p}(\mathrm{MCS})=0.1396 \\
\mathrm{p}(\mathrm{Fear})=0.0019\end{array}$ & $\begin{array}{l}0: 18.62 \% \\
1: 12.68 \%\end{array}$ \\
\hline
\end{tabular}




\begin{tabular}{|c|c|c|c|c|c|c|c|c|c|}
\hline Model & Variable(s) in model & Categories & $\begin{array}{l}\text { Total in } \\
\text { categories } \\
\text { (n) }\end{array}$ & $\begin{array}{l}\text { Total } \\
\text { in } \\
\text { model } \\
\text { (n); } \\
\text { dead } \\
\text { (d) } \\
\end{array}$ & Missing & Univariate-Cox HR (95\% CI) & p-values* & $\begin{array}{l}\text { MCS HR }(95 \% \mathrm{CI}) \text { and p- } \\
\text { values }\end{array}$ & $\begin{array}{l}\% \text { change } \\
\text { from crude } \\
\text { model }\end{array}$ \\
\hline 12 & $\begin{array}{l}\text { Number of Types of } \\
\text { Confidants }\end{array}$ & $\begin{array}{l}0:<3 \\
1: 4-5 \\
2:>5 \text { (REF) }\end{array}$ & $\begin{array}{l}0: 66 \\
1: 172 \\
2: 113\end{array}$ & $\begin{array}{l}n=351 \\
d=64\end{array}$ & 0 & $\begin{array}{l}0: \mathrm{HR}=2.86(1.42-5.75) \\
1: \mathrm{HR}=1.60(0.84-3.06) \\
2: \mathrm{HR}=1.00\end{array}$ & $p=0.0105$ & $\begin{array}{l}0: \mathrm{HR}=1.44(0.77-2.69) \\
\mathrm{p}(\mathrm{MCS})=0.2591 \\
1: \mathrm{HR}=1.44(0.77-2.68) \\
\mathrm{p}(\mathrm{MCS})=0.2529 \\
\mathrm{p}(\text { Confidant } 0)=0.0032 \\
\mathrm{p}(\text { Confidant } 1)=0.1565\end{array}$ & $\begin{array}{l}0: 0.69 \% \\
1: 1.41 \%\end{array}$ \\
\hline 13 & Bodily Pain & $\begin{array}{l}0: \text { No Pain } \\
\text { 1: Experienced Pain } \\
\text { (REF) }\end{array}$ & $\begin{array}{l}0: 180 \\
1: 171\end{array}$ & $\begin{array}{l}n=351 \\
d=64\end{array}$ & 0 & $\begin{array}{l}0: \mathrm{HR}=1.00 \\
1: \mathrm{HR}=1.51(0.80-2.85)\end{array}$ & $\mathrm{p}=\mathbf{0 . 2 0 0 6}$ & $\begin{array}{l}0: \mathrm{HR}=1.37(0.73-2.58) \\
\mathrm{p}(\mathrm{MCS})=0.3285 \\
1: \mathrm{HR}=1.39(0.74-2.58) \\
\mathrm{p}(\mathrm{MCS})=0.3053 \\
\mathrm{p}(\mathrm{Pain})=0.2006\end{array}$ & $\begin{array}{l}0: 5.52 \% \\
1: 2.11 \%\end{array}$ \\
\hline 14 & $\begin{array}{l}\text { Perceived General } \\
\text { Health }\end{array}$ & $\begin{array}{l}\text { 0: "Poor" \& "Fair" } \\
\text { 1: "Good", "Very } \\
\text { Good", \& "Excellent" } \\
\text { (REF) }\end{array}$ & $\begin{array}{l}0: 54 \\
1: 297\end{array}$ & $\begin{array}{l}n=351 \\
d=64\end{array}$ & 0 & $\begin{array}{l}0: \mathrm{HR}=2.84(1.62-4.97) \\
1: \mathrm{HR}=1.00\end{array}$ & $p=0.0003$ & $\begin{array}{l}0: \mathrm{HR}=1.08(0.56-2.09) \\
\mathrm{p}(\mathrm{MCS})=0.8160 \\
1: \mathrm{HR}=1.36(0.73-2.53) \\
\mathrm{p}(\mathrm{MCS})=0.3391 \\
\mathrm{p}(\text { Health })=0.0003\end{array}$ & $\begin{array}{l}\mathbf{0}: \mathbf{2 5 . 5 2 \%} \\
1: 4.23 \%\end{array}$ \\
\hline Crude & $\begin{array}{l}\text { MCS (restricted to those } \\
\text { with education) }\end{array}$ & & $\begin{array}{l}0: 117 \\
1: 116 \\
2: 117\end{array}$ & $\begin{array}{l}n=350 \\
d=63\end{array}$ & & $\begin{array}{l}0: \mathrm{HR}=1.45(0.78-2.72) \\
1: \mathrm{HR}=1.36(0.73-2.55)\end{array}$ & $\mathrm{p}=0.4697$ & $\begin{array}{l}0: \mathrm{HR}=1.45(0.78-2.72) \\
\mathrm{p}(\mathrm{MCS})=0.2438 \\
1: \mathrm{HR}=1.36(0.73-2.55) \\
\mathrm{p}(\mathrm{MCS})=0.3346\end{array}$ & -- \\
\hline
\end{tabular}




\begin{tabular}{|c|c|c|c|c|c|c|c|c|c|}
\hline Model & Variable(s) in model & Categories & $\begin{array}{l}\text { Total in } \\
\text { categories } \\
\text { (n) }\end{array}$ & $\begin{array}{l}\text { Total } \\
\text { in } \\
\text { model } \\
\text { (n); } \\
\text { dead } \\
\text { (d) } \\
\end{array}$ & Missing & Univariate-Cox HR (95\% CI) & p-values* & $\begin{array}{l}\text { MCS HR }(95 \% \mathrm{CI}) \text { and p- } \\
\text { values }\end{array}$ & $\begin{array}{l}\% \text { change } \\
\text { from crude } \\
\text { model }\end{array}$ \\
\hline 15 & Education & $\begin{array}{l}\text { 0: High school or less } \\
\text { 1: Some college } \\
\text { 2: College graduate } \\
\text { 3: Graduate school } \\
\text { (REF) }\end{array}$ & $\begin{array}{l}0: 92 \\
1: 114 \\
2: 70 \\
3: 74\end{array}$ & $\begin{array}{l}n=350 \\
d=63\end{array}$ & 1 & $\begin{array}{l}0: \mathrm{HR}=2.88(1.22-6.85) \\
1: \mathrm{HR}=2.24(0.96-5.19) \\
2: \mathrm{HR}=1.85(0.73-4.70) \\
3: \mathrm{HR}=1.00\end{array}$ & $p=0.1075$ & $\begin{array}{l}0: \mathrm{HR}=1.46(0.78-2.75) \\
\mathrm{p}(\mathrm{MCS})=0.2356 \\
1: \mathrm{HR}=1.44(0.77-2.71) \\
\mathrm{p}(\mathrm{MCS})=0.2356 \\
\mathrm{p}(\text { Education} 0)=0.0163 \\
\mathrm{p}(\text { Education } 1)=0.0612 \\
\mathrm{p}(\text { Education2) }=0.1989\end{array}$ & $\begin{array}{l}0: 0.69 \% \\
1: 5.88 \%\end{array}$ \\
\hline Crude & $\begin{array}{l}\text { MCS (restricted to those } \\
\text { with tumor size) }\end{array}$ & & $\begin{array}{l}0: 113 \\
1: 114 \\
2: 114\end{array}$ & $\begin{array}{l}n=341 \\
d=64\end{array}$ & & $\begin{array}{l}0: \mathrm{HR}=1.48(0.79-2.77) \\
1: \mathrm{HR}=1.43(0.77-2.67)\end{array}$ & $\mathrm{p}=0.4136$ & $\begin{array}{l}0: \mathrm{HR}=1.48(0.79-2.77) \\
\mathrm{p}(\mathrm{MCS})=0.2216 \\
1: \mathrm{HR}=1.43(0.77-2.67) \\
\mathrm{p}(\mathrm{MCS})=0.2569\end{array}$ & -- \\
\hline 16 & Tumor Size & $\begin{array}{l}0:<3 \mathrm{~cm}(\mathrm{REF}) \\
1: \geq 3 \mathrm{~cm}\end{array}$ & $\begin{array}{l}0: 304 \\
1: 37\end{array}$ & $\begin{array}{l}n=341 \\
d=64\end{array}$ & 10 & $\begin{array}{l}0: \mathrm{HR}=1.00 \\
1: \mathrm{HR}=0.43(0.14-1.38)\end{array}$ & $p=0.1574$ & $\begin{array}{l}0: \mathrm{HR}=1.50(0.80-2.80) \\
\mathrm{p}(\mathrm{MCS})=0.2095 \\
1: \mathrm{HR}=1.42(0.76-2.64) \\
\mathrm{p}(\mathrm{MCS})=0.2702 \\
\mathrm{p}(\text { Size })=0.1574\end{array}$ & $\begin{array}{l}0: 1.35 \% \\
1: 0.70 \%\end{array}$ \\
\hline Crude & $\begin{array}{l}\text { MCS (restricted to those } \\
\text { with lymph node } \\
\text { involvement) }\end{array}$ & & $\begin{array}{l}0: 112 \\
1: 114 \\
2: 115\end{array}$ & $\begin{array}{l}n=341 \\
d=59\end{array}$ & & $\begin{array}{l}0: \mathrm{HR}=1.26(0.66-2.41) \\
1: \mathrm{HR}=1.31(0.70-2.47)\end{array}$ & $\mathrm{p}=0.6737$ & $\begin{array}{l}0: H R=1.26(0.66-2.41) \\
p(M C S)=0.4803 \\
1: H R=1.31(0.70-2.47) \\
p(M C S)=0.4008\end{array}$ & -- \\
\hline
\end{tabular}




\begin{tabular}{|c|c|c|c|c|c|c|c|c|c|}
\hline Model & Variable(s) in model & Categories & $\begin{array}{l}\text { Total in } \\
\text { categories } \\
\text { (n) }\end{array}$ & $\begin{array}{l}\text { Total } \\
\text { in } \\
\text { model } \\
(\mathrm{n}) ; \\
\text { dead } \\
\text { (d) } \\
\end{array}$ & Missing & Univariate-Cox HR $(95 \% \mathrm{CI})$ & p-values* & $\begin{array}{l}\text { MCS HR }(95 \% \mathrm{CI}) \text { and } \mathrm{p}- \\
\text { values }\end{array}$ & $\begin{array}{l}\% \text { change } \\
\text { from crude } \\
\text { model }\end{array}$ \\
\hline 17 & $\begin{array}{l}\text { Lymph Node } \\
\text { Involvement }\end{array}$ & $\begin{array}{l}0: \text { None }(\mathrm{REF}) \\
1: \geq 1 \text { lymph node } \\
\text { involved }\end{array}$ & $\begin{array}{l}0: 264 \\
1: 77\end{array}$ & $\begin{array}{l}\mathrm{n}=341 \\
\mathrm{~d}=59\end{array}$ & 10 & $\begin{array}{l}0: \mathrm{HR}=1.00 \\
1: \mathrm{HR}=0.81(0.42-1.56)\end{array}$ & $\mathrm{p}=0.5276$ & $\begin{array}{l}0: \mathrm{HR}=1.25(0.65-2.39) \\
\mathrm{p}(\mathrm{MCS})=0.4997 \\
1: \mathrm{HR}=1.31(0.70-2.47) \\
\mathrm{p}(\mathrm{MCS})=0.4055 \\
\mathrm{p}(\text { Lymph node })=0.5276\end{array}$ & $\begin{array}{l}0: 0.79 \% \\
1: 0.00 \%\end{array}$ \\
\hline Crude & $\begin{array}{l}\text { MCS (restricted to those } \\
\text { with Tamoxifen use, } \\
\text { smoking status, and } \\
\text { physical activity) }\end{array}$ & & $\begin{array}{l}0: 110 \\
1: 109 \\
2: 111\end{array}$ & $\begin{array}{l}\mathrm{n}=330 \\
\mathrm{~d}=59\end{array}$ & & $\begin{array}{l}0: \mathrm{HR}=1.52(0.80-2.89) \\
1: \mathrm{HR}=1.33(0.70-2.56)\end{array}$ & $\mathrm{p}=0.4430$ & $\begin{array}{l}0: \mathrm{HR}=1.52(0.80-2.89) \\
\mathrm{p}(\mathrm{MCS})=0.2060 \\
1: \mathrm{HR}=1.33(0.70-2.56) \\
\mathrm{p}(\mathrm{MCS})=0.3870\end{array}$ & -- \\
\hline 18 & Tamoxifen Use & $\begin{array}{l}0: \text { No } \\
1: \text { Yes (REF) }\end{array}$ & $\begin{array}{l}0: 160 \\
1: 170\end{array}$ & $\begin{array}{l}\mathrm{n}=330 \\
\mathrm{~d}=59\end{array}$ & 21 & $\begin{array}{l}0: H R=1.25(0.75-2.09) \\
1: H R=1.00\end{array}$ & $\mathrm{p}=0.3983$ & $\begin{array}{l}0: \text { HR }=1.49(0.78-2.85) \\
p(\text { MCS })=0.2227 \\
1: \text { HR }=1.31(0.68-2.51) \\
p(\text { MCS })=0.4239 \\
p(\text { Tamoxifen })=0.3983\end{array}$ & $\begin{array}{l}0: 1.49 \% \\
1: 1.50 \%\end{array}$ \\
\hline 19 & Smoking Status & $\begin{array}{l}0: \text { Never (REF) } \\
\text { 1: Former } \\
2 \text { : Current }\end{array}$ & $\begin{array}{l}0: 145 \\
1: 144 \\
2: 41\end{array}$ & $\begin{array}{l}\mathrm{n}=330 \\
\mathrm{~d}=59\end{array}$ & 21 & $\begin{array}{l}0: \mathrm{HR}=1.00 \\
1: \mathrm{HR}=1.00(0.58-1.73) \\
2: \mathrm{HR}=1.25(0.56-2.78)\end{array}$ & $\mathrm{p}=0.8476$ & $\begin{array}{l}0: \text { HR }=1.49(0.78-2.85) \\
\mathrm{p}(\mathrm{MCS})=0.2289 \\
1: \mathrm{HR}=1.33(0.69-2.55) \\
\mathrm{p}(\mathrm{MCS})=0.3925 \\
\mathrm{p}(\text { Smoker1 })=0.9984 \\
\mathrm{p}(\text { Smoker2) }=0.5901\end{array}$ & $\begin{array}{l}0: 1.49 \% \\
1: 0.00 \%\end{array}$ \\
\hline
\end{tabular}




\begin{tabular}{|c|c|c|c|c|c|c|c|c|c|}
\hline Model & Variable(s) in model & Categories & $\begin{array}{l}\text { Total in } \\
\text { categories } \\
\text { (n) }\end{array}$ & $\begin{array}{l}\text { Total } \\
\text { in } \\
\text { model } \\
\text { (n); } \\
\text { dead } \\
\text { (d) } \\
\end{array}$ & Missing & Univariate-Cox HR (95\% CI) & p-values* & $\begin{array}{l}\text { MCS HR }(95 \% \mathrm{CI}) \text { and p- } \\
\text { values }\end{array}$ & $\begin{array}{l}\% \text { change } \\
\text { from crude } \\
\text { model }\end{array}$ \\
\hline 20 & Physical Activity & $\begin{array}{l}0: \text { None } \\
\text { 1: Low } \\
\text { 2: Moderate/Vigorous } \\
\text { (REF) }\end{array}$ & $\begin{array}{l}0: 185 \\
1: 59 \\
2: 86\end{array}$ & $\begin{array}{l}\mathrm{n}=330 \\
\mathrm{~d}=59\end{array}$ & 21 & $\begin{array}{l}0: \mathrm{HR}=2.24(1.15-4.36) \\
1: \mathrm{HR}=0.54(0.17-1.71) \\
2: \mathrm{HR}=1.00\end{array}$ & $p=0.0033$ & $\begin{array}{l}0: \mathrm{HR}=1.70(0.89-3.25) \\
\mathrm{p}(\mathrm{MCS})=0.1089 \\
1: \mathrm{HR}=1.54(0.80-2.97) \\
\mathrm{p}(\mathrm{MCS})=0.1966 \\
\mathrm{p}(\mathrm{PA} 0)=0.0176 \\
\mathrm{p}(\mathrm{PA} 1)=0.2974\end{array}$ & $\begin{array}{l}0: 11.84 \% \\
1: 15.79 \%\end{array}$ \\
\hline Crude & $\begin{array}{l}\text { MCS (restricted to those } \\
\text { with BMI) }\end{array}$ & & $\begin{array}{l}0: 110 \\
1: 108 \\
2: 106\end{array}$ & $\begin{array}{l}n=324 \\
d=54\end{array}$ & & $\begin{array}{l}0: \mathrm{HR}=1.31(0.67-2.58) \\
1: \mathrm{HR}=1.29(0.66-2.52)\end{array}$ & $\mathrm{p}=0.6886$ & $\begin{array}{l}0: H R=1.31(0.67-2.58) \\
p(M C S)=0.1963 \\
1: H R=1.29(0.66-2.52) \\
p(M C S)=0.4547\end{array}$ & -- \\
\hline 21 & Body Mass Index (BMI) & $\begin{array}{l}0:<25(\mathrm{REF}) \\
1: 25-29 \\
2: \geq 30\end{array}$ & $\begin{array}{l}0: 161 \\
1: 99 \\
2: 64\end{array}$ & $\begin{array}{l}\mathrm{n}=324 \\
\mathrm{~d}=54\end{array}$ & 27 & $\begin{array}{l}0: H R=1.00 \\
1: H R=0.61(0.31-1.24) \\
2: H R=1.53(0.80-2.91)\end{array}$ & $p=0.0755$ & $\begin{array}{l}0: \mathrm{HR}=1.31(0.66-2.57) \\
\mathrm{p}(\mathrm{MCS})=0.4383 \\
1: \mathrm{HR}=1.38(0.70-2.72) \\
\mathrm{p}(\mathrm{MCS})=0.3556 \\
\mathrm{p}(\mathrm{BMI})=0.1727 \\
\mathrm{p}(\mathrm{BMI})=0.1972\end{array}$ & $\begin{array}{l}0: 0.00 \% \\
1: 6.98 \%\end{array}$ \\
\hline Crude & $\begin{array}{l}\text { MCS (restricted to those } \\
\text { tumor subtype) }\end{array}$ & & $\begin{array}{l}0: 99 \\
1: 99 \\
2: 102\end{array}$ & $\begin{array}{l}n=300 \\
d=56\end{array}$ & & $\begin{array}{l}0: \mathrm{HR}=1.16(0.60-2.26) \\
1: \mathrm{HR}=1.27(0.67-2.40)\end{array}$ & $\mathrm{p}=0.7681$ & $\begin{array}{l}0: H R=1.16(0.60-2.26) \\
p(M C S)=0.6573 \\
1: H R=1.27(0.67-2.40) \\
p(M C S)=0.4695\end{array}$ & -- \\
\hline
\end{tabular}




\begin{tabular}{|c|c|c|c|c|c|c|c|c|c|}
\hline Model & Variable(s) in model & Categories & $\begin{array}{l}\text { Total in } \\
\text { categories } \\
\text { (n) }\end{array}$ & $\begin{array}{l}\text { Total } \\
\text { in } \\
\text { model } \\
\text { (n); } \\
\text { dead } \\
\text { (d) } \\
\end{array}$ & Missing & Univariate-Cox HR $(95 \%$ CI) & p-values* & $\begin{array}{l}\text { MCS HR }(95 \% \mathrm{CI}) \text { and } \mathrm{p}- \\
\text { values }\end{array}$ & $\begin{array}{l}\% \text { change } \\
\text { from crude } \\
\text { model }\end{array}$ \\
\hline 22 & Tumor Subtype & $\begin{array}{l}\text { 0: } \mathrm{ER}+(\mathrm{REF}) \\
\text { 1: ER- }\end{array}$ & $\begin{array}{l}0: 251 \\
1: 49\end{array}$ & $\begin{array}{l}n=300 \\
d=56\end{array}$ & 51 & $\begin{array}{l}0: \mathrm{HR}=1.00 \\
1: \mathrm{HR}=1.24(0.64-2.41)\end{array}$ & $\mathrm{p}=0.5186$ & $\begin{array}{l}0: \mathrm{HR}=1.15(0.59-2.24) \\
\mathrm{p}(\mathrm{MCS})=0.6747 \\
1: \mathrm{HR}=1.25(0.66-2.37) \\
\mathrm{p}(\mathrm{MCS})=0.5025 \\
\mathrm{p}(\text { Subtype })=0.5186\end{array}$ & $\begin{array}{l}0: 0.86 \% \\
1: 1.57 \%\end{array}$ \\
\hline
\end{tabular}


Appendix N. Percent Change from Crude and Model 1 with Each Potential Confounder (MCS \& Non-Cancer Mortality) (N = 351)

\begin{tabular}{|c|c|c|c|c|c|c|}
\hline Model & Variable(s) in model & $\begin{array}{l}\text { Mental Component Summary } \\
\text { Score (MCS) }(95 \% \text { CI })\end{array}$ & $\begin{array}{l}\text { Difference in } \\
\text { ' } \mathrm{N} \text { ' }\end{array}$ & $\begin{array}{l}\text { Total in model (n) } \\
\text { and total dead (d) }\end{array}$ & $\begin{array}{l}\% \text { change from } \\
\text { Crude }\end{array}$ & $\begin{array}{l}\% \text { change from } \\
\text { model } 1\end{array}$ \\
\hline \multicolumn{7}{|c|}{ Dataset restricted to those with full HRQOL data and baseline covariates } \\
\hline Crude & Mental Component Summary Score (MCS) & $\begin{array}{l}0: \mathrm{HR}=1.45(0.78-2.72) \\
1: \mathrm{HR}=1.42(0.76-2.64) \\
2: \mathrm{HR}=1.00(\mathrm{REF}) \\
\mathrm{p}=0.4424\end{array}$ & 0 & $\begin{array}{l}\mathrm{n}=351 \\
\mathrm{~d}=64\end{array}$ & -- & -- \\
\hline 1 & Age, Marital Status, \& Tumor Stage & $\begin{array}{l}0: \mathrm{HR}=1.73(0.92-3.25) \\
1: \mathrm{HR}=1.46(0.78-2.72) \\
2: \mathrm{HR}=1.00(\mathrm{REF}) \\
\mathrm{p}=0.2327\end{array}$ & 0 & $\begin{array}{l}\mathrm{n}=351 \\
\mathrm{~d}=64\end{array}$ & $\begin{array}{l}\mathbf{0 :} \mathbf{1 9 . 3 1 \%} \\
1: 2.82 \%\end{array}$ & -- \\
\hline 2 & Model 1 + Race/Ethnicity & $\begin{array}{l}0: \mathrm{HR}=1.73(0.92-3.27) \\
1: \mathrm{HR}=1.45(0.78-2.72) \\
2: \mathrm{HR}=1.00(\mathrm{REF}) \\
\mathrm{p}=0.2293\end{array}$ & 0 & $\begin{array}{l}\mathrm{n}=351 \\
\mathrm{~d}=64\end{array}$ & $\begin{array}{l}\mathbf{0 :} \mathbf{1 9 . 3 1 \%} \\
1: 2.11 \%\end{array}$ & $\begin{array}{l}0: 0.00 \% \\
1: 0.68 \%\end{array}$ \\
\hline 3 & Model $1+$ Treatment Type & $\begin{array}{l}0: \mathrm{HR}=1.73(0.92-3.26) \\
1: \mathrm{HR}=1.40(0.74-2.64) \\
2: \mathrm{HR}=1.00(\mathrm{REF}) \\
\mathrm{p}=0.2395\end{array}$ & 0 & $\begin{array}{l}\mathrm{n}=351 \\
\mathrm{~d}=64\end{array}$ & $\begin{array}{l}\mathbf{0 :} \mathbf{1 9 . 3 1 \%} \\
1: 1.41 \%\end{array}$ & $\begin{array}{l}0: 0.00 \% \\
1: 4.11 \%\end{array}$ \\
\hline
\end{tabular}




\begin{tabular}{|c|c|c|c|c|c|c|}
\hline Model & Variable(s) in model & $\begin{array}{l}\text { Mental Component Summary } \\
\text { Score (MCS) }(95 \% \text { CI) }\end{array}$ & $\begin{array}{l}\text { Difference in } \\
\text { ' } \mathrm{N} \text { ' }\end{array}$ & $\begin{array}{l}\text { Total in model (n) } \\
\text { and total dead (d) }\end{array}$ & $\begin{array}{l}\% \text { change from } \\
\text { Crude }\end{array}$ & $\begin{array}{l}\% \text { change from } \\
\text { model } 1\end{array}$ \\
\hline 4 & Model 1 + Comorbidities & $\begin{array}{l}0: \mathrm{HR}=1.64(0.85-3.15) \\
1: \mathrm{HR}=1.47(0.78-2.74) \\
2: \mathrm{HR}=1.00(\mathrm{REF}) \\
\mathrm{p}=0.3020\end{array}$ & 0 & $\begin{array}{l}\mathrm{n}=351 \\
\mathrm{~d}=64\end{array}$ & $\begin{array}{l}\mathbf{0 :} \mathbf{1 3 . 1 0 \%} \\
1: 3.52 \%\end{array}$ & $\begin{array}{l}0: 5.20 \% \\
1: 0.68 \%\end{array}$ \\
\hline 5 & Model $1+$ Current Lymphedema & $\begin{array}{l}0: \mathrm{HR}=1.74(0.92-3.30) \\
1: \mathrm{HR}=1.46(0.78-2.73) \\
2: \mathrm{HR}=1.00(\mathrm{REF}) \\
\mathrm{p}=0.2310\end{array}$ & 0 & $\begin{array}{l}\mathrm{n}=351 \\
\mathrm{~d}=64\end{array}$ & $\begin{array}{l}\mathbf{0 :} \mathbf{2 0 . 0 0 \%} \\
1: 2.82 \%\end{array}$ & $\begin{array}{l}0: 0.58 \% \\
1: 0.00 \%\end{array}$ \\
\hline 6 & Model $1+$ Optimism & $\begin{array}{l}0: \mathrm{HR}=1.60(0.83-3.06) \\
1: \mathrm{HR}=1.35(0.71-2.56) \\
2: \mathrm{HR}=1.00(\mathrm{REF}) \\
\mathrm{p}=0.3678\end{array}$ & 0 & $\begin{array}{l}\mathrm{n}=351 \\
\mathrm{~d}=64\end{array}$ & $\begin{array}{l}\mathbf{0 : 1 0 . 3 4 \%} \\
1: 4.93 \%\end{array}$ & $\begin{array}{l}0: 7.51 \% \\
1: 7.53 \%\end{array}$ \\
\hline 7 & Model $1+$ Pessimism & $\begin{array}{l}0: \mathrm{HR}=1.52(0.79-2.91) \\
1: \mathrm{HR}=1.39(0.74-2.61) \\
2: \mathrm{HR}=1.00 \text { (REF) } \\
\mathrm{p}=0.4252\end{array}$ & 0 & $\begin{array}{l}\mathrm{n}=351 \\
\mathrm{~d}=64\end{array}$ & $\begin{array}{l}0: 4.83 \% \\
1: 2.11 \%\end{array}$ & $\begin{array}{l}\mathbf{0 :} \mathbf{1 2 . 1 4 \%} \\
1: 4.79 \%\end{array}$ \\
\hline 9 & Model $1+$ Current Fatigue & $\begin{array}{l}0: \mathrm{HR}=1.58(0.76-3.29) \\
1: \mathrm{HR}=1.41(0.74-2.67) \\
2: \mathrm{HR}=1.00(\mathrm{REF}) \\
\mathrm{p}=0.4371\end{array}$ & 0 & $\begin{array}{l}\mathrm{n}=351 \\
\mathrm{~d}=64\end{array}$ & $\begin{array}{l}0: 8.97 \% \\
1: 0.70 \%\end{array}$ & $\begin{array}{l}0: 8.67 \% \\
1: 3.42 \%\end{array}$ \\
\hline
\end{tabular}




\begin{tabular}{|c|c|c|c|c|c|c|}
\hline Model & Variable(s) in model & $\begin{array}{l}\text { Mental Component Summary } \\
\text { Score (MCS) }(95 \% \mathrm{Cl})\end{array}$ & $\begin{array}{l}\text { Difference in } \\
\text { ' } \mathrm{N} \text { ' }\end{array}$ & $\begin{array}{l}\text { Total in model (n) } \\
\text { and total dead (d) }\end{array}$ & $\begin{array}{l}\% \text { change from } \\
\text { Crude }\end{array}$ & $\begin{array}{l}\% \text { change from } \\
\text { model } 1\end{array}$ \\
\hline 10 & Model $1+$ Fear of Recurrence & $\begin{array}{l}0: H R=1.83(0.96-3.46) \\
1: H R=1.52(0.81-2.84) \\
2: H R=1.00(R E F) \\
p=0.1739\end{array}$ & 0 & $\begin{array}{l}\mathrm{n}=351 \\
\mathrm{~d}=64\end{array}$ & $\begin{array}{l}\mathbf{0 :} \mathbf{2 6 . 2 1 \%} \\
1: 7.04 \%\end{array}$ & $\begin{array}{l}0: 5.78 \% \\
1: 4.11 \%\end{array}$ \\
\hline 11 & Model $1+$ Number of Types of Confidants & $\begin{array}{l}0: \mathrm{HR}=1.75(0.93-3.31) \\
1: \mathrm{HR}=1.53(0.82-2.88) \\
2: \mathrm{HR}=1.00(\mathrm{REF}) \\
\mathrm{p}=0.2085\end{array}$ & 0 & $\begin{array}{l}\mathrm{n}=351 \\
\mathrm{~d}=64\end{array}$ & $\begin{array}{l}\mathbf{0 :} \mathbf{2 0 . 6 9 \%} \\
1: 7.75 \%\end{array}$ & $\begin{array}{l}0: 1.16 \% \\
1: 4.79 \%\end{array}$ \\
\hline 12 & Model 1 + Bodily Pain & $\begin{array}{l}0: \mathrm{HR}=1.69(0.89-3.21) \\
1: \mathrm{HR}=1.44(0.77-2.70) \\
2: \mathrm{HR}=1.00(\mathrm{REF}) \\
\mathrm{p}=0.2679\end{array}$ & 0 & $\begin{array}{l}\mathrm{n}=351 \\
\mathrm{~d}=64\end{array}$ & $\begin{array}{l}\mathbf{0 :} \mathbf{1 6 . 5 5 \%} \\
1: 1.41 \%\end{array}$ & $\begin{array}{l}0: 2.31 \% \\
1: 1.37 \%\end{array}$ \\
\hline 13 & Model 1 + Perceived General Health & $\begin{array}{l}0: \mathrm{HR}=1.41(0.72-2.74) \\
1: \mathrm{HR}=1.49(0.79-2.79) \\
2: \mathrm{HR}=1.00(\mathrm{REF}) \\
\mathrm{p}=0.4240\end{array}$ & 0 & $\begin{array}{l}\mathrm{n}=351 \\
\mathrm{~d}=64\end{array}$ & $\begin{array}{l}0: 2.76 \% \\
1: 4.93 \%\end{array}$ & $\begin{array}{l}\mathbf{0 :} \mathbf{1 8 . 5 0 \%} \\
1: 2.05 \%\end{array}$ \\
\hline & & stricted to participants with $\mathrm{Ed}$ & in variable & & & \\
\hline
\end{tabular}




\begin{tabular}{|c|c|c|c|c|c|c|}
\hline Model & Variable(s) in model & $\begin{array}{l}\text { Mental Component Summary } \\
\text { Score (MCS) }(95 \% \text { CI) }\end{array}$ & $\begin{array}{l}\text { Difference in } \\
\text { ' } \mathrm{N} \text { ' }\end{array}$ & $\begin{array}{l}\text { Total in model (n) } \\
\text { and total dead (d) }\end{array}$ & $\begin{array}{l}\% \text { change from } \\
\text { Crude }\end{array}$ & $\begin{array}{l}\% \text { change from } \\
\text { model } 1\end{array}$ \\
\hline Crude & Mental Component Summary Score (MCS) & $\begin{array}{l}0: \mathrm{HR}=1.45(0.78-2.72) \\
1: \mathrm{HR}=1.36(0.73-2.55) \\
2: \mathrm{HR}=1.00(\mathrm{REF}) \\
\mathrm{p}=0.4751\end{array}$ & 1 & $\begin{array}{l}n=350 \\
d=63\end{array}$ & -- & -- \\
\hline 1 & Age, Marital Status, \& Tumor Stage & $\begin{array}{l}0: H R=1.76(0.94-3.30) \\
1: H R=1.39(0.74-2.61) \\
2: H R=1.00(\mathrm{REF}) \\
\mathrm{p}=0.2145\end{array}$ & 1 & $\begin{array}{l}n=350 \\
d=63\end{array}$ & $\begin{array}{l}\mathbf{0 :} \mathbf{2 1 . 3 8 \%} \\
1: 2.21 \%\end{array}$ & -- \\
\hline 14 & Model $1+$ Education & $\begin{array}{l}0: \mathrm{HR}=1.72(0.91-3.25) \\
1: \mathrm{HR}=1.54(0.81-2.94) \\
\text { 2: } \mathrm{HR}=1.00(\mathrm{REF}) \\
\mathrm{p}=0.2187\end{array}$ & 1 & $\begin{array}{l}n=350 \\
d=63\end{array}$ & $\begin{array}{l}0: 18.62 \% \\
1: 13.24 \%\end{array}$ & $\begin{array}{l}0: 2.27 \% \\
\mathbf{1}: \mathbf{1 0 . 7 9 \%}\end{array}$ \\
\hline \multicolumn{7}{|c|}{ Subset--Restricted to participants with the Tumor Size variable } \\
\hline Crude & Mental Component Summary Score (MCS) & $\begin{array}{l}0: H R=1.48(0.79-2.77) \\
1: H R=1.43(0.77-2.67) \\
2: H R=1.00(\mathrm{REF}) \\
\mathrm{p}=0.4136\end{array}$ & 10 & $\begin{array}{l}n=341 \\
d=64\end{array}$ & -- & -- \\
\hline
\end{tabular}




\begin{tabular}{|c|c|c|c|c|c|c|}
\hline Model & Variable(s) in model & $\begin{array}{l}\text { Mental Component Summary } \\
\text { Score (MCS) }(95 \% \text { Cl) }\end{array}$ & $\begin{array}{l}\text { Difference in } \\
\text { ' } \mathrm{N} \text { ' }\end{array}$ & $\begin{array}{l}\text { Total in model (n) } \\
\text { and total dead (d) }\end{array}$ & $\begin{array}{l}\% \text { change from } \\
\text { Crude }\end{array}$ & $\begin{array}{l}\% \text { change from } \\
\text { model } 1\end{array}$ \\
\hline 1 & Age, Marital Status, \& Tumor Stage & $\begin{array}{l}0: \mathrm{HR}=1.71(0.91-3.22) \\
1: \mathrm{HR}=1.45(0.78-2.72) \\
2: \mathrm{HR}=1.00(\mathrm{REF}) \\
\mathrm{p}=0.2438\end{array}$ & 10 & $\begin{array}{l}\mathrm{n}=341 \\
\mathrm{~d}=64\end{array}$ & $\begin{array}{l}\mathbf{0 :} \mathbf{1 5 . 5 4 \%} \\
1: 1.40 \%\end{array}$ & -- \\
\hline 15 & Model $1+$ Tumor Size & $\begin{array}{l}0: \mathrm{HR}=1.71(0.91-3.22) \\
1: \mathrm{HR}=1.46(0.78-2.74) \\
2: \mathrm{HR}=1.00(\mathrm{REF}) \\
\mathrm{p}=0.2433\end{array}$ & 10 & $\begin{array}{l}\mathrm{n}=341 \\
\mathrm{~d}=64\end{array}$ & $\begin{array}{l}\mathbf{0 :} \mathbf{1 5 . 5 4 \%} \\
1: 2.10 \%\end{array}$ & $\begin{array}{l}0: 0.00 \% \\
1: 0.69 \%\end{array}$ \\
\hline \multicolumn{7}{|c|}{ Subset--Restricted to participants with Lymph Node Involvement variable } \\
\hline Crude & Mental Component Summary Score (MCS) & $\begin{array}{l}0: H R=1.26(0.66-2.41) \\
1: H R=1.31(0.70-2.47) \\
2: H R=1.00(\mathrm{REF}) \\
\mathrm{p}=0.6737\end{array}$ & 10 & $\begin{array}{l}\mathrm{n}=341 \\
\mathrm{~d}=59\end{array}$ & -- & -- \\
\hline 1 & Age, Marital Status, \& Tumor Stage & $\begin{array}{l}0: \mathrm{HR}=1.55(0.81-2.98) \\
\text { 1: } \mathrm{HR}=1.53(0.81-2.91) \\
\text { 2: } \mathrm{HR}=1.00 \text { (REF) } \\
\mathrm{p}=0.3260\end{array}$ & 10 & $\begin{array}{l}\mathrm{n}=341 \\
\mathrm{~d}=59\end{array}$ & $\begin{array}{l}0: 23.02 \% \\
1: 16.79 \%\end{array}$ & -- \\
\hline
\end{tabular}




\begin{tabular}{|c|c|c|c|c|c|c|}
\hline Model & Variable(s) in model & $\begin{array}{l}\text { Mental Component Summary } \\
\text { Score (MCS) }(95 \% \text { CI) }\end{array}$ & $\begin{array}{l}\text { Difference in } \\
\text { ' } \mathrm{N} \text { ' }\end{array}$ & $\begin{array}{l}\text { Total in model (n) } \\
\text { and total dead (d) }\end{array}$ & $\begin{array}{l}\% \text { change from } \\
\text { Crude }\end{array}$ & $\begin{array}{l}\% \text { change from } \\
\text { model } 1\end{array}$ \\
\hline 16 & Model $1+$ Lymph Node Involvement & $\begin{array}{l}0: \mathrm{HR}=1.53(0.80-2.96) \\
1: \mathrm{HR}=1.52(0.80-2.89) \\
2: \mathrm{HR}=1.00(\mathrm{REF}) \\
\mathrm{p}=0.3480\end{array}$ & 10 & $\begin{array}{l}\mathrm{n}=341 \\
\mathrm{~d}=59\end{array}$ & $\begin{array}{l}0: 21.43 \% \\
1: 16.03 \%\end{array}$ & $\begin{array}{l}0: 1.29 \% \\
1: 0.65 \%\end{array}$ \\
\hline \multicolumn{7}{|c|}{ Subset--Restricted to participants with Tamoxifen Use, Smoking Status, \& Physical Activity variables (24-month follow-up) } \\
\hline Crude & Mental Component Summary Score (MCS) & $\begin{array}{l}0: \mathrm{HR}=1.52(0.80-2.89) \\
1: \mathrm{HR}=1.33(0.70-2.56) \\
2: \mathrm{HR}=1.00(\mathrm{REF}) \\
\mathrm{p}=0.4430\end{array}$ & 21 & $\begin{array}{l}n=330 \\
d=59\end{array}$ & -- & -- \\
\hline 1 & Age, Marital Status, \& Tumor Stage & $\begin{array}{l}0: H R=1.75(0.91-3.37) \\
1: H R=1.39(0.72-2.68) \\
2: H R=1.00(\mathrm{REF}) \\
\mathrm{p}=0.2429\end{array}$ & 21 & $\begin{array}{l}\mathrm{n}=330 \\
\mathrm{~d}=59\end{array}$ & $\begin{array}{l}\mathbf{0 :} \mathbf{1 5 . 1 3 \%} \\
1: 4.51 \%\end{array}$ & -- \\
\hline 17 & Model $1+$ Tamoxifen Use & $\begin{array}{l}0: \mathrm{HR}=1.89(0.98-3.64) \\
1: \mathrm{HR}=1.32(0.68-2.55) \\
2: \mathrm{HR}=1.00(\mathrm{REF}) \\
\mathrm{p}=0.1597\end{array}$ & 21 & $\begin{array}{l}\mathrm{n}=330 \\
\mathrm{~d}=59\end{array}$ & $\begin{array}{l}\mathbf{0 :} \mathbf{2 4 . 3 4 \%} \\
1: 0.75 \%\end{array}$ & $\begin{array}{l}0: 8.00 \% \\
1: 5.04 \%\end{array}$ \\
\hline
\end{tabular}




\begin{tabular}{|c|c|c|c|c|c|c|}
\hline Model & Variable(s) in model & $\begin{array}{l}\text { Mental Component Summary } \\
\text { Score (MCS) }(95 \% \text { CI) }\end{array}$ & $\begin{array}{l}\text { Difference in } \\
\text { ' } \mathrm{N} \text { ' }\end{array}$ & $\begin{array}{l}\text { Total in model (n) } \\
\text { and total dead (d) }\end{array}$ & $\begin{array}{l}\% \text { change from } \\
\text { Crude }\end{array}$ & $\begin{array}{l}\% \text { change from } \\
\text { model } 1\end{array}$ \\
\hline 18 & Model $1+$ Smoking Status & $\begin{array}{l}0: \mathrm{HR}=1.69(0.87-3.26) \\
1: \mathrm{HR}=1.40(0.72-2.69) \\
2: \mathrm{HR}=1.00(\mathrm{REF}) \\
\mathrm{p}=0.2992\end{array}$ & 21 & $\begin{array}{l}\mathrm{n}=330 \\
\mathrm{~d}=59\end{array}$ & $\begin{array}{l}\mathbf{0 :} \mathbf{1 1 . 1 8 \%} \\
1: 5.26 \%\end{array}$ & $\begin{array}{l}0: 3.43 \% \\
1: 0.72 \%\end{array}$ \\
\hline 19 & Model $1+$ Physical Activity & $\begin{array}{l}0: \mathrm{HR}=1.75(0.91-3.38) \\
1: \mathrm{HR}=1.48(0.76-2.89) \\
2: \mathrm{HR}=1.00(\mathrm{REF}) \\
\mathrm{p}=0.2387\end{array}$ & 21 & $\begin{array}{l}\mathrm{n}=330 \\
\mathrm{~d}=59\end{array}$ & $\begin{array}{l}0: 15.13 \% \\
1: 11.28 \%\end{array}$ & $\begin{array}{l}0: 0.00 \% \\
1: 6.47 \%\end{array}$ \\
\hline \multicolumn{7}{|c|}{ Subset--Restricted to participants with BMI variable } \\
\hline Crude & Mental Component Summary Score (MCS) & $\begin{array}{l}0: H R=1.31(0.67-2.58) \\
1: H R=1.29(0.66-2.52) \\
2: H R=1.00(\mathrm{REF}) \\
\mathrm{p}=0.6886\end{array}$ & 27 & $\begin{array}{l}\mathrm{n}=324 \\
\mathrm{~d}=54\end{array}$ & -- & -- \\
\hline 1 & Age, Marital Status, \& Tumor Stage & $\begin{array}{l}0: H R=1.46(0.74-2.90) \\
1: H R=1.19(0.60-2.35) \\
2: H R=1.00(R E F) \\
p=0.5524\end{array}$ & 27 & $\begin{array}{l}\mathrm{n}=324 \\
\mathrm{~d}=54\end{array}$ & $\begin{array}{l}\mathbf{0 :} \mathbf{1 1 . 4 5 \%} \\
1: 7.75 \%\end{array}$ & -- \\
\hline
\end{tabular}




\begin{tabular}{|c|c|c|c|c|c|c|}
\hline Model & Variable(s) in model & $\begin{array}{l}\text { Mental Component Summary } \\
\text { Score (MCS) }(95 \% \text { CI) }\end{array}$ & $\begin{array}{l}\text { Difference in } \\
\text { ' } \mathrm{N} \text { ' }\end{array}$ & $\begin{array}{l}\text { Total in model (n) } \\
\text { and total dead (d) }\end{array}$ & $\begin{array}{l}\% \text { change from } \\
\text { Crude }\end{array}$ & $\begin{array}{l}\% \text { change from } \\
\text { model } 1\end{array}$ \\
\hline 20 & Model $1+$ BMI & $\begin{array}{l}0: \mathrm{HR}=1.49(0.74-2.97) \\
1: \mathrm{HR}=1.24(0.63-2.45) \\
2: \mathrm{HR}=1.00(\mathrm{REF}) \\
\mathrm{p}=0.5325\end{array}$ & 27 & $\begin{array}{l}\mathrm{n}=324 \\
\mathrm{~d}=54\end{array}$ & $\begin{array}{l}\mathbf{0 :} \mathbf{1 3 . 7 4 \%} \\
1: 3.88 \%\end{array}$ & $\begin{array}{l}0: 2.05 \% \\
1: 4.20 \%\end{array}$ \\
\hline \multicolumn{7}{|c|}{ Subset--Restricted to participants with Tumor Subtype variable } \\
\hline Crude & Mental Component Summary Score (MCS) & $\begin{array}{l}0: \mathrm{HR}=1.16(0.60-2.26) \\
1: \mathrm{HR}=1.27(0.67-2.40) \\
2: \mathrm{HR}=1.00(\mathrm{REF}) \\
\mathrm{p}=0.7681\end{array}$ & 51 & $\begin{array}{l}\mathrm{n}=300 \\
\mathrm{~d}=56\end{array}$ & -- & -- \\
\hline 1 & Age, Marital Status, \& Tumor Stage & $\begin{array}{l}0: \mathrm{HR}=1.36(0.70-2.65) \\
1: \mathrm{HR}=1.34(0.70-2.55) \\
2: \mathrm{HR}=1.00 \text { (REF) } \\
\mathrm{p}=0.5966\end{array}$ & 51 & $\begin{array}{l}\mathrm{n}=300 \\
\mathrm{~d}=56\end{array}$ & $\begin{array}{l}\mathbf{0 :} \mathbf{1 7 . 2 4 \%} \\
1: 5.51 \%\end{array}$ & -- \\
\hline 21 & Model $1+$ Tumor Subtype & $\begin{array}{l}0: \mathrm{HR}=1.47(0.75-2.89) \\
1: \mathrm{HR}=1.37(0.72-2.62) \\
2: \mathrm{HR}=1.00 \text { (REF) } \\
\mathrm{p}=0.4811\end{array}$ & 51 & $\begin{array}{l}\mathrm{n}=300 \\
\mathrm{~d}=56\end{array}$ & $\begin{array}{l}\mathbf{0 :} \mathbf{2 6 . 7 2 \%} \\
1: 7.87 \%\end{array}$ & $\begin{array}{l}0: 8.09 \% \\
1: 2.24 \%\end{array}$ \\
\hline
\end{tabular}


Appendix O. Multivariable Modeling with Mental Component Score as the Predictor and Non-Cancer Mortality as the Outcome $(N=351)$

\begin{tabular}{|c|c|c|c|c|c|c|c|}
\hline Model & Variable(s) in model & $\begin{array}{l}\text { Mental Component Summary } \\
\text { Score (MCS) HR }(95 \% \text { CI) }\end{array}$ & $\begin{array}{l}\text { Difference in } \\
\text { ' } \mathrm{N} \text { ' }\end{array}$ & $\begin{array}{l}\text { Total in model } \\
\text { (n) and total } \\
\text { dead (d) }\end{array}$ & $\begin{array}{l}\% \text { change } \\
\text { from Crude }\end{array}$ & $\begin{array}{l}\% \text { change } \\
\text { from model } \\
1\end{array}$ & $\begin{array}{l}\% \text { change } \\
\text { from } \\
\text { previous } \\
\text { model }\end{array}$ \\
\hline Crude & Mental Component Summary Score (MCS) & $\begin{array}{l}0: \mathrm{HR}=1.45(0.78-2.72) \\
1: \mathrm{HR}=1.42(0.76-2.64) \\
2: \mathrm{HR}=1.00(\mathrm{REF}) \\
\mathrm{p}=0.4424\end{array}$ & 0 & $\begin{array}{l}n=351 \\
d=64\end{array}$ & -- & -- & -- \\
\hline 1 & Age, Marital Status, \& Tumor Stage & $\begin{array}{l}0: \mathrm{HR}=1.73(0.92-3.25) \\
1: \mathrm{HR}=1.46(0.78-2.72) \\
2: \mathrm{HR}=1.00(\mathrm{REF}) \\
\mathrm{p}=0.2327\end{array}$ & 0 & $\begin{array}{l}n=351 \\
d=64\end{array}$ & $\begin{array}{l}\mathbf{0}: \mathbf{1 9 . 3 1 \%} \\
1: 2.82 \%\end{array}$ & -- & -- \\
\hline 2 & Model $1+$ Race/Ethnicity & $\begin{array}{l}0: \mathrm{HR}=1.73(0.92-3.27) \\
1: \mathrm{HR}=1.45(0.78-2.72) \\
2: \mathrm{HR}=1.00(\mathrm{REF}) \\
\mathrm{p}=0.2293\end{array}$ & 0 & $\begin{array}{l}n=351 \\
d=64\end{array}$ & $\begin{array}{l}\mathbf{0 :} \mathbf{1 9 . 3 1 \%} \\
1: 2.11 \%\end{array}$ & $\begin{array}{l}0: 0.00 \% \\
1: 0.68 \%\end{array}$ & -- \\
\hline 3 & Model $1+$ Race/Ethnicity + Treatment Type & $\begin{array}{l}0: \mathrm{HR}=1.73(0.92-3.26) \\
1: \mathrm{HR}=1.39(0.74-2.63) \\
2: \mathrm{HR}=1.00(\mathrm{REF}) \\
\mathrm{p}=0.2377\end{array}$ & 0 & $\begin{array}{l}\mathrm{n}=351 \\
\mathrm{~d}=64\end{array}$ & $\begin{array}{l}\mathbf{0 :} \mathbf{1 9 . 3 1 \%} \\
1: 2.11 \%\end{array}$ & $\begin{array}{l}0: 0.00 \% \\
1: 4.79 \%\end{array}$ & $\begin{array}{l}0: 0.00 \% \\
1: 4.14 \%\end{array}$ \\
\hline 4 & $\begin{array}{l}\text { Model } 1+\text { Race/Ethnicity }+ \text { Treatment Type }+ \\
\text { Comorbidities }\end{array}$ & $\begin{array}{l}0: \mathrm{HR}=1.63(0.84-3.14) \\
1: \mathrm{HR}=1.40(0.74-2.64) \\
2: \mathrm{HR}=1.00(\mathrm{REF}) \\
\mathrm{p}=0.3328\end{array}$ & 0 & $\begin{array}{l}\mathrm{n}=351 \\
\mathrm{~d}=64\end{array}$ & $\begin{array}{l}\mathbf{0 :} \mathbf{1 2 . 4 1 \%} \\
1: 1.41 \%\end{array}$ & $\begin{array}{l}0: 5.78 \% \\
1: 4.11 \%\end{array}$ & $\begin{array}{l}0: 5.78 \% \\
1: 0.72 \%\end{array}$ \\
\hline
\end{tabular}




\begin{tabular}{|c|c|c|c|c|c|c|c|}
\hline Model & Variable(s) in model & $\begin{array}{l}\text { Mental Component Summary } \\
\text { Score (MCS) HR }(95 \% \text { CI) }\end{array}$ & $\begin{array}{l}\text { Difference in } \\
\text { ' } \mathrm{N} \text { ' }\end{array}$ & $\begin{array}{l}\text { Total in model } \\
\text { (n) and total } \\
\text { dead (d) }\end{array}$ & $\begin{array}{l}\% \text { change } \\
\text { from Crude }\end{array}$ & $\begin{array}{l}\% \text { change } \\
\text { from model } \\
1\end{array}$ & $\begin{array}{l}\% \text { change } \\
\text { from } \\
\text { previous } \\
\text { model }\end{array}$ \\
\hline 5 & $\begin{array}{l}\text { Model } 1+\text { Race/Ethnicity + Treatment Type + } \\
\text { Comorbidities + Optimism }\end{array}$ & $\begin{array}{l}0: \mathrm{HR}=1.51(0.77-2.96) \\
1: \mathrm{HR}=1.31(0.69-2.49) \\
2: \mathrm{HR}=1.00(\mathrm{REF}) \\
\mathrm{p}=0.4828\end{array}$ & 0 & $\begin{array}{l}n=351 \\
d=64\end{array}$ & $\begin{array}{l}0: 4.14 \% \\
1: 7.75 \%\end{array}$ & $\begin{array}{l}\text { 0: } 12.72 \% \\
1: 10.27 \%\end{array}$ & $\begin{array}{l}0: 7.36 \% \\
1: 6.43 \%\end{array}$ \\
\hline 6 & $\begin{array}{l}\text { Model } 1+\text { Race/Ethnicity + Treatment Type + } \\
\text { Comorbidities + Optimism + Fear of Recurrence }\end{array}$ & $\begin{array}{l}0: \mathrm{HR}=1.58(0.80-3.10) \\
1: \mathrm{HR}=1.37(0.72-2.61) \\
2: \mathrm{HR}=1.00(\mathrm{REF}) \\
\mathrm{p}=0.4022\end{array}$ & 0 & $\begin{array}{l}n=351 \\
d=64\end{array}$ & $\begin{array}{l}0: 8.97 \% \\
1: 3.52 \%\end{array}$ & $\begin{array}{l}0: 8.67 \% \\
1: 6.16 \%\end{array}$ & $\begin{array}{l}0: 4.64 \% \\
1: 4.58 \%\end{array}$ \\
\hline 7 & $\begin{array}{l}\text { Model } 1+\text { Race/Ethnicity }+ \text { Treatment Type }+ \\
\text { Comorbidities }+ \text { Optimism }+ \text { Fear of Recurrence }+ \\
\text { Number of Types of Confidants (Confide) }\end{array}$ & $\begin{array}{l}0: \mathrm{HR}=1.62(0.82-3.20) \\
1: \mathrm{HR}=1.46(0.76-2.80) \\
\text { 2: } \mathrm{HR}=1.00(\mathrm{REF}) \\
\mathrm{p}=0.3513\end{array}$ & 0 & $\begin{array}{l}n=351 \\
d=64\end{array}$ & $\begin{array}{l}\mathbf{0 :} \mathbf{1 1 . 7 2 \%} \\
1: 2.82 \%\end{array}$ & $\begin{array}{l}0: 6.36 \% \\
1: 0.00 \%\end{array}$ & $\begin{array}{l}0: 2.53 \% \\
1: 6.57 \%\end{array}$ \\
\hline 8 & $\begin{array}{l}\text { Model } 1+\text { Race/Ethnicity + Treatment Type + } \\
\text { Comorbidities + Optimism + Fear of Recurrence + } \\
\text { Confide + Bodily Pain }\end{array}$ & $\begin{array}{l}0: H R=1.58(0.79-3.14) \\
1: H R=1.44(0.75-2.78) \\
2: H R=1.00(\mathrm{REF}) \\
\mathrm{p}=0.3822\end{array}$ & 0 & $\begin{array}{l}n=351 \\
d=64\end{array}$ & $\begin{array}{l}0: 8.97 \% \\
1: 1.41 \%\end{array}$ & $\begin{array}{l}0: 8.67 \% \\
1: 1.37 \%\end{array}$ & $\begin{array}{l}0: 2.47 \% \\
1: 1.37 \%\end{array}$ \\
\hline 9 & $\begin{array}{l}\text { Model } 1+\text { Race/Ethnicity + Treatment Type }+ \\
\text { Comorbidities + Optimism + Fear of Recurrence + } \\
\text { Confide + Bodily Pain + Perceived General Health }\end{array}$ & $\begin{array}{l}0: \mathrm{HR}=1.40(0.69-2.85) \\
1: \mathrm{HR}=1.47(0.76-2.83) \\
2: \mathrm{HR}=1.00(\mathrm{REF}) \\
\mathrm{p}=0.4814\end{array}$ & 0 & $\begin{array}{l}n=351 \\
d=64\end{array}$ & $\begin{array}{l}0: 3.45 \% \\
1: 3.52 \%\end{array}$ & $\begin{array}{l}\text { 0: } \mathbf{1 9 . 0 8 \%} \\
1: 0.68 \%\end{array}$ & $\begin{array}{l}\mathbf{0 :} \mathbf{1 1 . 3 9 \%} \\
1: 2.08 \%\end{array}$ \\
\hline
\end{tabular}




\begin{tabular}{|c|c|c|c|c|c|c|c|}
\hline Model & Variable(s) in model & $\begin{array}{l}\text { Mental Component Summary } \\
\text { Score (MCS) HR }(95 \% \text { CI) }\end{array}$ & $\begin{array}{l}\text { Difference in } \\
\text { ' } \mathrm{N}^{\prime}\end{array}$ & $\begin{array}{l}\text { Total in model } \\
\text { (n) and total } \\
\text { dead (d) }\end{array}$ & $\begin{array}{l}\% \text { change } \\
\text { from Crude }\end{array}$ & $\begin{array}{l}\% \text { change } \\
\text { from model } \\
1\end{array}$ & $\begin{array}{l}\text { \% change } \\
\text { from } \\
\text { previous } \\
\text { model }\end{array}$ \\
\hline \multicolumn{8}{|c|}{ Subset--Restricted to participants with Education variable } \\
\hline Crude & Mental Component Summary Score (MCS) & $\begin{array}{l}0: H R=1.45(0.78-2.72) \\
1: H R=1.36(0.73-2.55) \\
2: H R=1.00(\text { REF }) \\
p=0.4751\end{array}$ & 1 & $\begin{array}{l}\mathrm{n}=350 \\
\mathrm{~d}=63\end{array}$ & -- & -- & -- \\
\hline 1 & Age, Marital Status, \& Tumor Stage & $\begin{array}{l}0: \mathrm{HR}=1.72(0.91-3.23) \\
1: \mathrm{HR}=1.41(0.75-2.65) \\
2: \mathrm{HR}=1.00(\mathrm{REF}) \\
\mathrm{p}=0.2464\end{array}$ & 1 & $\begin{array}{l}\mathrm{n}=350 \\
\mathrm{~d}=63\end{array}$ & $\begin{array}{l}\mathbf{0 :} \mathbf{1 8 . 6 2 \%} \\
1: 3.68 \%\end{array}$ & -- & -- \\
\hline 10 & Model $1+$ Education & $\begin{array}{l}0: \mathrm{HR}=1.72(0.91-3.25) \\
1: \mathrm{HR}=1.54(0.81-2.94) \\
2: \mathrm{HR}=1.00(\mathrm{REF}) \\
\mathrm{p}=0.2187\end{array}$ & 1 & $\begin{array}{l}\mathrm{n}=350 \\
\mathrm{~d}=63\end{array}$ & $\begin{array}{l}0: 18.62 \% \\
1: 13.24 \%\end{array}$ & $\begin{array}{l}0: 0.00 \% \\
1: 9.22 \%\end{array}$ & -- \\
\hline 11 & Model $1+$ Education + Race/Ethnicity & $\begin{array}{l}0: H R=1.73(0.92-3.26) \\
1: H R=1.55(0.81-2.97) \\
2: H R=1.00(\mathrm{REF}) \\
\mathrm{p}=0.2119\end{array}$ & 1 & $\begin{array}{l}\mathrm{n}=350 \\
\mathrm{~d}=63\end{array}$ & $\begin{array}{l}0: 19.31 \% \\
1: 13.97 \%\end{array}$ & $\begin{array}{l}0: 0.58 \% \\
1: 9.93 \%\end{array}$ & $\begin{array}{l}0: 0.58 \% \\
1: 0.65 \%\end{array}$ \\
\hline 12 & Model $1+$ Education + Race/Ethnicity + Treatment Type & $\begin{array}{l}0: \mathrm{HR}=1.72(0.91-3.25) \\
1: \mathrm{HR}=1.48(0.77-2.85) \\
2: \mathrm{HR}=1.00(\mathrm{REF}) \\
\mathrm{p}=0.2310\end{array}$ & 1 & $\begin{array}{l}\mathrm{n}=350 \\
\mathrm{~d}=63\end{array}$ & $\begin{array}{l}\mathbf{0 :} \mathbf{1 8 . 6 2 \%} \\
1: 8.82 \%\end{array}$ & $\begin{array}{l}0: 0.00 \% \\
1: 4.96 \%\end{array}$ & $\begin{array}{l}0: 0.58 \% \\
1: 4.52 \%\end{array}$ \\
\hline
\end{tabular}




\begin{tabular}{|c|c|c|c|c|c|c|c|}
\hline Model & Variable(s) in model & $\begin{array}{l}\text { Mental Component Summary } \\
\text { Score (MCS) HR }(95 \% \text { CI) }\end{array}$ & $\begin{array}{l}\text { Difference in } \\
\text { ' }{ }^{\prime} \text { ' }\end{array}$ & $\begin{array}{l}\text { Total in model } \\
\text { (n) and total } \\
\text { dead (d) }\end{array}$ & $\begin{array}{l}\% \text { change } \\
\text { from Crude }\end{array}$ & $\begin{array}{l}\% \text { change } \\
\text { from model } \\
1\end{array}$ & $\begin{array}{l}\% \text { change } \\
\text { from } \\
\text { previous } \\
\text { model }\end{array}$ \\
\hline 13 & $\begin{array}{l}\text { Model } 1 \text { + Education + Race/Ethnicity + Treatment Type } \\
+ \text { Comorbidities }\end{array}$ & $\begin{array}{l}0: \mathrm{HR}=1.64(0.85-3.17) \\
1: \mathrm{HR}=1.47(0.76-2.84) \\
2: \mathrm{HR}=1.00(\mathrm{REF}) \\
\mathrm{p}=0.3079\end{array}$ & 1 & $\begin{array}{l}n=350 \\
d=63\end{array}$ & $\begin{array}{l}\mathbf{0 : 1 3 . 1 0 \%} \\
1: 8.09 \%\end{array}$ & $\begin{array}{l}0: 4.56 \% \\
1: 4.26 \%\end{array}$ & $\begin{array}{l}0: 4.65 \% \\
1: 0.68 \%\end{array}$ \\
\hline 14 & $\begin{array}{l}\text { Model } 1+\text { Education + Race/Ethnicity + Treatment Type } \\
+ \text { Comorbidities + Optimism }\end{array}$ & $\begin{array}{l}0: \mathrm{HR}=1.54(0.78-3.02) \\
1: \mathrm{HR}=1.39(0.71-2.71) \\
2: \mathrm{HR}=1.00(\mathrm{REF}) \\
\mathrm{p}=0.4303\end{array}$ & 1 & $\begin{array}{l}n=350 \\
d=63\end{array}$ & $\begin{array}{l}0: 6.21 \% \\
1: 2.21 \%\end{array}$ & $\begin{array}{l}\mathbf{0 :} \mathbf{1 0 . 4 7 \%} \\
1: 1.42 \%\end{array}$ & $\begin{array}{l}0: 6.10 \% \\
1: 5.44 \%\end{array}$ \\
\hline 15 & $\begin{array}{l}\text { Model } 1+\text { Education + Race/Ethnicity + Treatment Type } \\
+ \text { Comorbidities + Optimism + Fear of Recurrence }\end{array}$ & $\begin{array}{l}0: H R=1.63(0.83-3.20) \\
1: H R=1.49(0.76-2.93) \\
\text { 2: } H R=1.00(R E F) \\
p=0.3310\end{array}$ & 1 & $\begin{array}{l}n=350 \\
d=63\end{array}$ & $\begin{array}{l}\mathbf{0 :} \mathbf{1 2 . 4 1 \%} \\
1: 9.56 \%\end{array}$ & $\begin{array}{l}0: 5.23 \% \\
1: 5.67 \%\end{array}$ & $\begin{array}{l}0: 5.84 \% \\
1: 7.19 \%\end{array}$ \\
\hline 16 & $\begin{array}{l}\text { Model } 1+\text { Education + Race/Ethnicity + Treatment Type } \\
+ \text { Comorbidities + Optimism + Fear of Recurrence + } \\
\text { Confide }\end{array}$ & $\begin{array}{l}0: \mathrm{HR}=1.66(0.84-3.27) \\
1: \mathrm{HR}=1.57(0.80-3.09) \\
2: \mathrm{HR}=1.00(\mathrm{REF}) \\
\mathrm{p}=0.2923\end{array}$ & 1 & $\begin{array}{l}n=350 \\
d=63\end{array}$ & $\begin{array}{l}0: 14.48 \% \\
1: 15.44 \%\end{array}$ & $\begin{array}{l}0: 3.49 \% \\
1: 11.35 \%\end{array}$ & $\begin{array}{l}0: 1.84 \% \\
1: 5.37 \%\end{array}$ \\
\hline 17 & $\begin{array}{l}\text { Model } 1 \text { + Education + Race/Ethnicity + Treatment Type } \\
+ \text { Comorbidities + Optimism + Fear of Recurrence + } \\
\text { Confide + Bodily Pain }\end{array}$ & $\begin{array}{l}0: \mathrm{HR}=1.62(0.81-3.21) \\
1: \mathrm{HR}=1.56(0.79-3.07) \\
2: \mathrm{HR}=1.00(\mathrm{REF}) \\
\mathrm{p}=0.3205\end{array}$ & 1 & $\begin{array}{l}n=350 \\
d=63\end{array}$ & $\begin{array}{l}0: 11.72 \% \\
1: 14.71 \%\end{array}$ & $\begin{array}{l}0: 5.81 \% \\
1: 10.64 \%\end{array}$ & $\begin{array}{l}0: 2.41 \% \\
1: 0.64 \%\end{array}$ \\
\hline
\end{tabular}




\begin{tabular}{|c|c|c|c|c|c|c|c|}
\hline Model & Variable(s) in model & $\begin{array}{l}\text { Mental Component Summary } \\
\text { Score (MCS) HR }(95 \% \mathrm{CI})\end{array}$ & $\begin{array}{l}\text { Difference in } \\
\text { ' } \mathrm{N} \text { ' }\end{array}$ & $\begin{array}{l}\text { Total in model } \\
\text { (n) and total } \\
\text { dead (d) }\end{array}$ & $\begin{array}{l}\% \text { change } \\
\text { from Crude }\end{array}$ & $\begin{array}{l}\% \text { change } \\
\text { from model } \\
1\end{array}$ & $\begin{array}{l}\% \text { change } \\
\text { from } \\
\text { previous } \\
\text { model }\end{array}$ \\
\hline 18 & $\begin{array}{l}\text { Model } 1+\text { Education }+ \text { Race/Ethnicity }+ \text { Treatment Type } \\
+ \text { Comorbidities + Optimism + Fear of Recurrence }+ \\
\text { Confide + Bodily Pain + Perceived General Health }\end{array}$ & $\begin{array}{l}0: \mathrm{HR}=1.46(0.72-2.96) \\
1: \mathrm{HR}=1.58(0.80-3.13) \\
2: \mathrm{HR}=1.00(\mathrm{REF}) \\
\mathrm{p}=0.3839\end{array}$ & 1 & $\begin{array}{l}n=350 \\
d=63\end{array}$ & $\begin{array}{l}0: 0.69 \% \\
\mathbf{1 :} \mathbf{1 6 . 1 8 \%}\end{array}$ & $\begin{array}{l}0: 15.12 \% \\
1: 12.06 \%\end{array}$ & $\begin{array}{l}0: 9.88 \% \\
1: 1.28 \%\end{array}$ \\
\hline \multicolumn{8}{|c|}{ Subset--Restricted to participants with Tumor Size variable } \\
\hline Crude & Mental Component Summary Score (MCS) & $\begin{array}{l}0: \mathrm{HR}=1.48(0.79-2.77) \\
1: \mathrm{HR}=1.43(0.77-2.67) \\
2: \mathrm{HR}=1.00(\mathrm{REF}) \\
\mathrm{p}=0.4136\end{array}$ & 10 & $\begin{array}{l}n=341 \\
d=64\end{array}$ & -- & -- & -- \\
\hline 1 & Age, Marital Status, \& Tumor Stage & $\begin{array}{l}0: \mathrm{HR}=1.71(0.91-3.22) \\
1: \mathrm{HR}=1.45(0.78-2.72) \\
2: \mathrm{HR}=1.00(\mathrm{REF}) \\
\mathrm{p}=0.2438\end{array}$ & 10 & $\begin{array}{l}\mathrm{n}=341 \\
\mathrm{~d}=64\end{array}$ & $\begin{array}{l}\mathbf{0 :} \mathbf{1 5 . 5 4 \%} \\
1: 1.40 \%\end{array}$ & -- & -- \\
\hline 19 & Model $1+$ Tumor Size & $\begin{array}{l}0: \mathrm{HR}=1.71(0.91-3.22) \\
1: \mathrm{HR}=1.46(0.78-2.74) \\
2: \mathrm{HR}=1.00(\mathrm{REF}) \\
\mathrm{p}=0.2433\end{array}$ & 10 & $\begin{array}{l}\mathrm{n}=341 \\
\mathrm{~d}=64\end{array}$ & $\begin{array}{l}\mathbf{0 :} \mathbf{1 5 . 5 4 \%} \\
1: 2.10 \%\end{array}$ & $\begin{array}{l}0: 0.00 \% \\
1: 0.69 \%\end{array}$ & -- \\
\hline
\end{tabular}




\begin{tabular}{|c|c|c|c|c|c|c|c|}
\hline Model & Variable(s) in model & $\begin{array}{l}\text { Mental Component Summary } \\
\text { Score (MCS) HR ( } 95 \% \text { CI) }\end{array}$ & $\begin{array}{l}\text { Difference in } \\
\text { ' } \mathrm{N} \text { ' }\end{array}$ & $\begin{array}{l}\text { Total in model } \\
\text { (n) and total } \\
\text { dead (d) }\end{array}$ & $\begin{array}{l}\% \text { change } \\
\text { from Crude }\end{array}$ & $\begin{array}{l}\% \text { change } \\
\text { from model } \\
1\end{array}$ & $\begin{array}{l}\% \text { change } \\
\text { from } \\
\text { previous } \\
\text { model }\end{array}$ \\
\hline 20 & Model $1+$ Tumor Size + Race/Ethnicity & $\begin{array}{l}0: \mathrm{HR}=1.72(0.91-3.24) \\
1: \mathrm{HR}=1.46(0.78-2.74) \\
\text { 2: } \mathrm{HR}=1.00(\mathrm{REF}) \\
\mathrm{p}=0.2394\end{array}$ & 10 & $\begin{array}{l}\mathrm{n}=341 \\
\mathrm{~d}=64\end{array}$ & $\begin{array}{l}\mathbf{0 :} \mathbf{1 6 . 2 2 \%} \\
1: 2.10 \%\end{array}$ & $\begin{array}{l}0: 0.58 \% \\
1: 0.69 \%\end{array}$ & $\begin{array}{l}0: 0.58 \% \\
1: 0.00 \%\end{array}$ \\
\hline 21 & Model $1+$ Tumor Size + Race/Ethnicity + Treatment Type & $\begin{array}{l}0: \mathrm{HR}=1.72(0.91-3.24) \\
1: \mathrm{HR}=1.40(0.74-2.63) \\
2: \mathrm{HR}=1.00(\mathrm{REF}) \\
\mathrm{p}=0.2476\end{array}$ & 10 & $\begin{array}{l}\mathrm{n}=341 \\
\mathrm{~d}=64\end{array}$ & $\begin{array}{l}\mathbf{0 :} \mathbf{1 6 . 2 2} \% \\
1: 2.10 \%\end{array}$ & $\begin{array}{l}0: 0.58 \% \\
1: 3.45 \%\end{array}$ & $\begin{array}{l}0: 0.00 \% \\
1: 4.11 \%\end{array}$ \\
\hline 22 & $\begin{array}{l}\text { Model } 1+\text { Tumor Size }+ \text { Race/Ethnicity }+ \text { Treatment Type } \\
+ \text { Comorbidities }\end{array}$ & $\begin{array}{l}0: \mathrm{HR}=1.62(0.84-3.12) \\
1: \mathrm{HR}=1.40(0.74-2.65) \\
2: \mathrm{HR}=1.00(\mathrm{REF}) \\
\mathrm{p}=0.3409\end{array}$ & 10 & $\begin{array}{l}\mathrm{n}=341 \\
\mathrm{~d}=64\end{array}$ & $\begin{array}{l}0: 9.46 \% \\
1: 2.10 \%\end{array}$ & $\begin{array}{l}0: 5.26 \% \\
1: 3.45 \%\end{array}$ & $\begin{array}{l}0: 5.81 \% \\
1: 0.00 \%\end{array}$ \\
\hline 23 & $\begin{array}{l}\text { Model } 1+\text { Tumor Size }+ \text { Race/Ethnicity }+ \text { Treatment Type } \\
+ \text { Comorbidities + Optimism }\end{array}$ & $\begin{array}{l}0: \mathrm{HR}=1.50(0.77-2.95) \\
1: \mathrm{HR}=1.31(0.68-2.50) \\
\text { 2: } \mathrm{HR}=1.00(\mathrm{REF}) \\
\mathrm{p}=0.4875\end{array}$ & 10 & $\begin{array}{l}\mathrm{n}=341 \\
\mathrm{~d}=64\end{array}$ & $\begin{array}{l}0: 1.35 \% \\
1: 8.39 \%\end{array}$ & $\begin{array}{l}\mathbf{0 : 1 2 . 2 8 \%} \\
1: 9.66 \%\end{array}$ & $\begin{array}{l}0: 7.41 \% \\
1: 6.43 \%\end{array}$ \\
\hline 24 & $\begin{array}{l}\text { Model } 1+\text { Tumor Size }+ \text { Race/Ethnicity }+ \text { Treatment Type } \\
+ \text { Comorbidities }+ \text { Optimism }+ \text { Fear of Recurrence }\end{array}$ & $\begin{array}{l}0: \mathrm{HR}=1.58(0.80-3.10) \\
1: \mathrm{HR}=1.38(0.72-2.64) \\
2: \mathrm{HR}=1.00(\mathrm{REF}) \\
\mathrm{p}=0.3992\end{array}$ & 10 & $\begin{array}{l}\mathrm{n}=341 \\
\mathrm{~d}=64\end{array}$ & $\begin{array}{l}0: 6.76 \% \\
1: 3.50 \%\end{array}$ & $\begin{array}{l}0: 7.60 \% \\
1: 4.83 \%\end{array}$ & $\begin{array}{l}0: 5.33 \% \\
1: 5.34 \%\end{array}$ \\
\hline
\end{tabular}




\begin{tabular}{|c|c|c|c|c|c|c|c|}
\hline Model & Variable(s) in model & $\begin{array}{l}\text { Mental Component Summary } \\
\text { Score (MCS) HR }(95 \% \mathrm{Cl})\end{array}$ & $\begin{array}{l}\text { Difference in } \\
\text { ' } \mathrm{N} \text { ' }\end{array}$ & $\begin{array}{l}\text { Total in model } \\
\text { (n) and total } \\
\text { dead (d) }\end{array}$ & $\begin{array}{l}\% \text { change } \\
\text { from Crude }\end{array}$ & $\begin{array}{l}\% \text { change } \\
\text { from model } \\
1\end{array}$ & $\begin{array}{l}\% \text { change } \\
\text { from } \\
\text { previous } \\
\text { model }\end{array}$ \\
\hline 25 & $\begin{array}{l}\text { Model } 1+\text { Tumor Size }+ \text { Race/Ethnicity }+ \text { Treatment Type } \\
+ \text { Comorbidities }+ \text { Optimism + Fear of Recurrence }+ \\
\text { Confide }\end{array}$ & $\begin{array}{l}0: \mathrm{HR}=1.62(0.82-3.20) \\
1: \mathrm{HR}=1.48(0.77-2.85) \\
\text { 2: } \mathrm{HR}=1.00(\mathrm{REF}) \\
\mathrm{p}=0.3443\end{array}$ & 10 & $\begin{array}{l}\mathrm{n}=341 \\
\mathrm{~d}=64\end{array}$ & $\begin{array}{l}0: 9.46 \% \\
1: 3.50 \%\end{array}$ & $\begin{array}{l}0: 5.26 \% \\
1: 2.07 \%\end{array}$ & $\begin{array}{l}0: 2.53 \% \\
1: 7.25 \%\end{array}$ \\
\hline 26 & $\begin{array}{l}\text { Model } 1+\text { Tumor Size + Race/Ethnicity + Treatment Type } \\
+ \text { Comorbidities + Optimism + Fear of Recurrence + } \\
\text { Confide + Bodily Pain }\end{array}$ & $\begin{array}{l}0: \mathrm{HR}=1.58(0.80-3.15) \\
1: \mathrm{HR}=1.47(0.76-2.84) \\
\text { 2: } \mathrm{HR}=1.00(\mathrm{REF}) \\
\mathrm{p}=0.3747\end{array}$ & 10 & $\begin{array}{l}\mathrm{n}=341 \\
\mathrm{~d}=64\end{array}$ & $\begin{array}{l}0: 6.76 \% \\
1: 2.80 \%\end{array}$ & $\begin{array}{l}0: 7.60 \% \\
1: 1.38 \%\end{array}$ & $\begin{array}{l}0: 2.47 \% \\
1: 0.68 \%\end{array}$ \\
\hline 27 & $\begin{array}{l}\text { Model } 1+\text { Tumor Size + Race/Ethnicity + Treatment Type } \\
+ \text { Comorbidities + Optimism + Fear of Recurrence + } \\
\text { Confide+ Bodily Pain + Perceived General Health }\end{array}$ & $\begin{array}{l}0: \mathrm{HR}=1.40(0.69-2.85) \\
1: \mathrm{HR}=1.49(0.77-2.88) \\
\text { 2: } \mathrm{HR}=1.00(\mathrm{REF}) \\
\mathrm{p}=0.4631\end{array}$ & 10 & $\begin{array}{l}\mathrm{n}=341 \\
\mathrm{~d}=64\end{array}$ & $\begin{array}{l}0: 5.41 \% \\
1: 4.20 \%\end{array}$ & $\begin{array}{l}\mathbf{0 :} \mathbf{1 8 . 1 3 \%} \\
1: 2.76 \%\end{array}$ & $\begin{array}{l}\mathbf{0 :} \mathbf{1 1 . 3 9 \%} \\
1: 1.36 \%\end{array}$ \\
\hline \multicolumn{8}{|c|}{ Subset--Restricted to participants with Education and Tumor Size variables } \\
\hline Crude & Mental Component Summary Score (MCS) & $\begin{array}{l}0: \mathrm{HR}=1.48(0.79-2.77) \\
1: \mathrm{HR}=1.38(0.74-2.78) \\
2: \mathrm{HR}=1.00(\mathrm{REF}) \\
\mathrm{p}=0.4439\end{array}$ & 11 & $\begin{array}{l}\mathrm{n}=340 \\
\mathrm{~d}=63\end{array}$ & -- & -- & -- \\
\hline
\end{tabular}




\begin{tabular}{|c|c|c|c|c|c|c|c|}
\hline Model & Variable(s) in model & $\begin{array}{l}\text { Mental Component Summary } \\
\text { Score (MCS) HR }(95 \% \text { CI) }\end{array}$ & $\begin{array}{l}\text { Difference in } \\
\text { ' } \mathrm{N} \text { ' }\end{array}$ & $\begin{array}{l}\text { Total in model } \\
\text { (n) and total } \\
\text { dead (d) }\end{array}$ & $\begin{array}{l}\% \text { change } \\
\text { from Crude }\end{array}$ & $\begin{array}{l}\% \text { change } \\
\text { from model } \\
1\end{array}$ & $\begin{array}{l}\% \text { change } \\
\text { from } \\
\text { previous } \\
\text { model }\end{array}$ \\
\hline 1 & Age, Marital Status, \& Tumor Stage & $\begin{array}{l}0: \mathrm{HR}=1.70(0.90-3.20) \\
1: \mathrm{HR}=1.41(0.75-2.65) \\
2: \mathrm{HR}=1.00(\mathrm{REF}) \\
\mathrm{p}=0.2587\end{array}$ & 11 & $\begin{array}{l}n=340 \\
d=63\end{array}$ & $\begin{array}{l}0: 14.86 \% \\
1: 2.17 \%\end{array}$ & -- & -- \\
\hline 28 & Model 1 + Education + Tumor Size & $\begin{array}{l}0: \mathrm{HR}=1.70(0.90-3.21) \\
1: \mathrm{HR}=1.52(0.80-2.90) \\
2: \mathrm{HR}=1.00(\mathrm{REF}) \\
\mathrm{p}=0.2355\end{array}$ & 11 & $\begin{array}{l}n=340 \\
d=63\end{array}$ & $\begin{array}{l}0: 14.86 \% \\
1: 10.14 \%\end{array}$ & $\begin{array}{l}0: 0.00 \% \\
1: 7.80 \%\end{array}$ & -- \\
\hline 29 & Model $1+$ Education + Tumor Size + Race/Ethnicity & $\begin{array}{l}0: \mathrm{HR}=1.71(0.91-3.23) \\
1: \mathrm{HR}=1.54(0.80-2.94) \\
2: \mathrm{HR}=1.00(\mathrm{REF}) \\
\mathrm{p}=0.2259\end{array}$ & 11 & $\begin{array}{l}n=340 \\
d=63\end{array}$ & $\begin{array}{l}0: 15.54 \% \\
1: 11.59 \%\end{array}$ & $\begin{array}{l}0: 0.59 \% \\
1: 9.22 \%\end{array}$ & $\begin{array}{l}0: 0.59 \% \\
1: 1.32 \%\end{array}$ \\
\hline 30 & $\begin{array}{l}\text { Model } 1+\text { Education }+ \text { Tumor Size }+ \text { Race/Ethnicity }+ \\
\text { Treatment Type }\end{array}$ & $\begin{array}{l}0: \mathrm{HR}=1.71(0.91-3.22) \\
1: \mathrm{HR}=1.46(0.76-2.81) \\
2: \mathrm{HR}=1.00(\mathrm{REF}) \\
\mathrm{p}=0.2449\end{array}$ & 11 & $\begin{array}{l}n=340 \\
d=63\end{array}$ & $\begin{array}{l}\mathbf{0 :} \mathbf{1 5 . 5 4 \%} \\
1: 5.80 \%\end{array}$ & $\begin{array}{l}0: 0.59 \% \\
1: 3.55 \%\end{array}$ & $\begin{array}{l}0: 0.00 \% \\
1: 5.19 \%\end{array}$ \\
\hline 31 & $\begin{array}{l}\text { Model } 1+\text { Education }+ \text { Tumor Size + Race/Ethnicity }+ \\
\text { Treatment Type }+ \text { Comorbidities }\end{array}$ & $\begin{array}{l}0: \mathrm{HR}=1.63(0.84-3.14) \\
1: \mathrm{HR}=1.44(0.74-2.78) \\
2: \mathrm{HR}=1.00(\mathrm{REF}) \\
\mathrm{p}=0.3266\end{array}$ & 11 & $\begin{array}{l}n=340 \\
d=63\end{array}$ & $\begin{array}{l}\mathbf{0 :} \mathbf{1 0 . 1 4 \%} \\
1: 4.35 \%\end{array}$ & $\begin{array}{l}0: 4.12 \% \\
1: 2.13 \%\end{array}$ & $\begin{array}{l}0: 4.68 \% \\
1: 1.37 \%\end{array}$ \\
\hline
\end{tabular}




\begin{tabular}{|c|c|c|c|c|c|c|c|}
\hline Model & Variable(s) in model & $\begin{array}{l}\text { Mental Component Summary } \\
\text { Score (MCS) HR }(95 \% \text { CI) }\end{array}$ & $\begin{array}{l}\text { Difference in } \\
\text { ' } \mathrm{N} \text { ' }\end{array}$ & $\begin{array}{l}\text { Total in model } \\
\text { (n) and total } \\
\text { dead (d) }\end{array}$ & $\begin{array}{l}\% \text { change } \\
\text { from Crude }\end{array}$ & $\begin{array}{l}\% \text { change } \\
\text { from model } \\
1\end{array}$ & $\begin{array}{l}\% \text { change } \\
\text { from } \\
\text { previous } \\
\text { model }\end{array}$ \\
\hline 32 & $\begin{array}{l}\text { Model } 1+\text { Education }+ \text { Tumor Size + Race/Ethnicity + } \\
\text { Treatment Type + Comorbidities + Optimism }\end{array}$ & $\begin{array}{l}0: \mathrm{HR}=1.53(0.78-3.01) \\
1: \mathrm{HR}=1.36(0.70-2.66) \\
2: \mathrm{HR}=1.00(\mathrm{REF}) \\
\mathrm{p}=0.4431\end{array}$ & 11 & $\begin{array}{l}n=340 \\
d=63\end{array}$ & $\begin{array}{l}0: 3.38 \% \\
1: 1.45 \%\end{array}$ & $\begin{array}{l}\mathbf{0 :} \mathbf{1 0 . 0 0 \%} \\
1: 3.55 \%\end{array}$ & $\begin{array}{l}0: 6.13 \% \\
1: 5.56 \%\end{array}$ \\
\hline 33 & $\begin{array}{l}\text { Model } 1 \text { + Education + Tumor Size + Race/Ethnicity + } \\
\text { Treatment Type + Comorbidities + Optimism + Fear of } \\
\text { Recurrence }\end{array}$ & $\begin{array}{l}0: \mathrm{HR}=1.63(0.83-3.19) \\
1: \mathrm{HR}=1.47(0.75-2.91) \\
2: \mathrm{HR}=1.00(\mathrm{REF}) \\
\mathrm{p}=0.3372\end{array}$ & 11 & $\begin{array}{l}\mathrm{n}=340 \\
\mathrm{~d}=63\end{array}$ & $\begin{array}{l}\mathbf{0 :} \mathbf{1 0 . 1 4 \%} \\
1: 6.52 \%\end{array}$ & $\begin{array}{l}0: 4.12 \% \\
1: 4.26 \%\end{array}$ & $\begin{array}{l}0: 6.54 \% \\
1: 8.09 \%\end{array}$ \\
\hline 34 & $\begin{array}{l}\text { Model } 1 \text { + Education + Tumor Size + Race/Ethnicity + } \\
\text { Treatment Type + Comorbidities + Optimism + Fear of } \\
\text { Recurrence + Confide }\end{array}$ & $\begin{array}{l}0: H R=1.66(0.84-3.27) \\
1: H R=1.56(0.79-3.08) \\
2: H R=1.00(\mathrm{REF}) \\
\mathrm{p}=0.2949\end{array}$ & 11 & $\begin{array}{l}\mathrm{n}=340 \\
\mathrm{~d}=63\end{array}$ & $\begin{array}{l}0: 12.16 \% \\
1: 13.04 \%\end{array}$ & $\begin{array}{l}0: 2.35 \% \\
1: 10.64 \%\end{array}$ & $\begin{array}{l}0: 1.84 \% \\
1: 6.12 \%\end{array}$ \\
\hline 35 & $\begin{array}{l}\text { Model } 1 \text { + Education + Tumor Size + Race/Ethnicity + } \\
\text { Treatment Type + Comorbidities + Optimism + Fear of } \\
\text { Recurrence + Confide + Bodily Pain }\end{array}$ & $\begin{array}{l}0: H R=1.63(0.82-3.24) \\
1: H R=1.56(0.79-3.09) \\
2: H R=1.00(\mathrm{REF}) \\
\mathrm{p}=0.3136\end{array}$ & 11 & $\begin{array}{l}\mathrm{n}=340 \\
\mathrm{~d}=63\end{array}$ & $\begin{array}{l}0: 10.14 \% \\
1: 13.04 \%\end{array}$ & $\begin{array}{l}0: 4.12 \% \\
1: 10.64 \%\end{array}$ & $\begin{array}{l}0: 1.81 \% \\
1: 0.00 \%\end{array}$ \\
\hline 36 & $\begin{array}{l}\text { Model } 1+\text { Education }+ \text { Tumor Size + Race/Ethnicity }+ \\
\text { Treatment Type + Comorbidities + Optimism + Fear of } \\
\text { Recurrence + Confide + Bodily Pain + Perceived General } \\
\text { Health }\end{array}$ & $\begin{array}{l}0: \mathrm{HR}=1.47(0.73-2.98) \\
1: \mathrm{HR}=1.57(0.79-3.12) \\
\text { 2: } \mathrm{HR}=1.00(\mathrm{REF}) \\
\mathrm{p}=0.3889\end{array}$ & 11 & $\begin{array}{l}\mathrm{n}=340 \\
\mathrm{~d}=63\end{array}$ & $\begin{array}{l}0: 0.68 \% \\
1: 13.77 \%\end{array}$ & $\begin{array}{l}0: 13.53 \% \\
1: 11.35 \%\end{array}$ & $\begin{array}{l}0: 9.82 \% \\
1: 0.64 \%\end{array}$ \\
\hline
\end{tabular}




\begin{tabular}{|c|c|c|c|c|c|c|c|}
\hline Model & Variable(s) in model & $\begin{array}{l}\text { Mental Component Summary } \\
\text { Score (MCS) HR }(95 \% \text { CI) }\end{array}$ & $\begin{array}{l}\text { Difference in } \\
\text { ' } \mathrm{N} \text { ' }\end{array}$ & $\begin{array}{l}\text { Total in model } \\
\text { (n) and total } \\
\text { dead (d) }\end{array}$ & $\begin{array}{l}\% \text { change } \\
\text { from Crude }\end{array}$ & $\begin{array}{l}\% \text { change } \\
\text { from model } \\
1\end{array}$ & $\begin{array}{l}\% \text { change } \\
\text { from } \\
\text { previous } \\
\text { model } \\
\end{array}$ \\
\hline \multicolumn{8}{|c|}{ Subset--Restricted to participants with Physical Activity variable (24-month follow-up) } \\
\hline Crude & Mental Component Summary Score (MCS) & $\begin{array}{l}0: H R=1.52(0.80-2.89) \\
1: H R=1.33(0.70-2.56) \\
2: H R=1.00(R E F) \\
p=0.4430\end{array}$ & 21 & $\begin{array}{l}\mathrm{n}=330 \\
\mathrm{~d}=59\end{array}$ & -- & -- & -- \\
\hline 1 & Age, Marital Status, \& Tumor Stage & $\begin{array}{l}0: \mathrm{HR}=1.75(0.91-3 / 37) \\
1: \mathrm{HR}=1.39(0.72-2.68) \\
2: \mathrm{HR}=1.00(\mathrm{REF}) \\
\mathrm{p}=0.2429\end{array}$ & 21 & $\begin{array}{l}\mathrm{n}=330 \\
\mathrm{~d}=59\end{array}$ & $\begin{array}{l}\mathbf{0 :} \mathbf{1 5 . 1 3 \%} \\
1: 4.51 \%\end{array}$ & -- & -- \\
\hline 37 & Model $1+$ Physical Activity & $\begin{array}{l}0: \mathrm{HR}=1.75(0.91-3.38) \\
1: \mathrm{HR}=1.48(0.76-2.89) \\
2: \mathrm{HR}=1.00(\mathrm{REF}) \\
\mathrm{p}=0.2387\end{array}$ & 21 & $\begin{array}{l}\mathrm{n}=330 \\
\mathrm{~d}=59\end{array}$ & $\begin{array}{l}0: 15.13 \% \\
1: 11.28 \%\end{array}$ & $\begin{array}{l}0: 0.00 \% \\
1: 6.47 \%\end{array}$ & -- \\
\hline 38 & Model $1+$ Physical Activity + Race/Ethnicity & $\begin{array}{l}0: H R=1.75(0.91-3.39) \\
1: H R=1.48(0.76-2.88) \\
2: H R=1.00(\mathrm{REF}) \\
\mathrm{p}=0.2369\end{array}$ & 21 & $\begin{array}{l}\mathrm{n}=330 \\
\mathrm{~d}=59\end{array}$ & $\begin{array}{l}0: 15.13 \% \\
1: 11.28 \%\end{array}$ & $\begin{array}{l}0: 0.00 \% \\
1: 6.47 \%\end{array}$ & $\begin{array}{l}0: 0.00 \% \\
1: 0.00 \%\end{array}$ \\
\hline 39 & $\begin{array}{l}\text { Model } 1+\text { Physical Activity }+ \text { Race/Ethnicity }+ \text { Treatment } \\
\text { Type }\end{array}$ & $\begin{array}{l}0: \mathrm{HR}=1.76(0.91-3.39) \\
1: \mathrm{HR}=1.40(0.71-2.76) \\
2: \mathrm{HR}=1.00(\mathrm{REF}) \\
\mathrm{p}=0.2434\end{array}$ & 21 & $\begin{array}{l}\mathrm{n}=330 \\
\mathrm{~d}=59\end{array}$ & $\begin{array}{l}\mathbf{0 :} \mathbf{1 5 . 7 9 \%} \\
1: 5.26 \%\end{array}$ & $\begin{array}{l}0: 0.57 \% \\
1: 0.72 \%\end{array}$ & $\begin{array}{l}0: 0.57 \% \\
1: 5.41 \%\end{array}$ \\
\hline
\end{tabular}




\begin{tabular}{|c|c|c|c|c|c|c|c|}
\hline Model & Variable(s) in model & $\begin{array}{l}\text { Mental Component Summary } \\
\text { Score (MCS) HR }(95 \% \text { CI) }\end{array}$ & $\begin{array}{l}\text { Difference in } \\
\text { ' } \mathrm{N} \text { ' }\end{array}$ & $\begin{array}{l}\text { Total in model } \\
\text { (n) and total } \\
\text { dead (d) }\end{array}$ & $\begin{array}{l}\% \text { change } \\
\text { from Crude }\end{array}$ & $\begin{array}{l}\% \text { change } \\
\text { from model } \\
1\end{array}$ & $\begin{array}{l}\% \text { change } \\
\text { from } \\
\text { previous } \\
\text { model }\end{array}$ \\
\hline 40 & $\begin{array}{l}\text { Model } 1+\text { Physical Activity }+ \text { Race/Ethnicity }+ \text { Treatment } \\
\text { Type }+ \text { Comorbidities }\end{array}$ & $\begin{array}{l}0: \mathrm{HR}=1.64(0.83-3.22) \\
\text { 1: } \mathrm{HR}=1.41(0.72-2.78) \\
\text { 2: } \mathrm{HR}=1.00(\mathrm{REF}) \\
\mathrm{p}=0.3495\end{array}$ & 21 & $\begin{array}{l}\mathrm{n}=330 \\
\mathrm{~d}=59\end{array}$ & $\begin{array}{l}0: 7.89 \% \\
1: 6.02 \%\end{array}$ & $\begin{array}{l}0: 6.29 \% \\
1: 1.44 \%\end{array}$ & $\begin{array}{l}0: 6.82 \% \\
1: 0.72 \%\end{array}$ \\
\hline 41 & $\begin{array}{l}\text { Model } 1+\text { Physical Activity + Race/Ethnicity + Treatment } \\
\text { Type + Comorbidities + Optimism }\end{array}$ & $\begin{array}{l}0: \mathrm{HR}=1.49(0.75-2.98) \\
\text { 1: } \mathrm{HR}=1.34(0.68-2.66) \\
\text { 2: } \mathrm{HR}=1.00 \text { (REF) } \\
\mathrm{p}=0.5063\end{array}$ & 21 & $\begin{array}{l}\mathrm{n}=330 \\
\mathrm{~d}=59\end{array}$ & $\begin{array}{l}0: 1.97 \% \\
1: 0.75 \%\end{array}$ & $\begin{array}{l}\mathbf{0 :} \mathbf{1 4 . 8 6 \%} \\
1: 3.60 \%\end{array}$ & $\begin{array}{l}0: 9.15 \% \\
1: 4.96 \%\end{array}$ \\
\hline 42 & $\begin{array}{l}\text { Model } 1+\text { Physical Activity }+ \text { Race/Ethnicity }+ \text { Treatment } \\
\text { Type }+ \text { Comorbidities }+ \text { Optimism }+ \text { Fear of Recurrence }\end{array}$ & $\begin{array}{l}0: \mathrm{HR}=1.57(0.78-3.13) \\
1: \mathrm{HR}=1.39(0.70-2.76) \\
2: \mathrm{HR}=1.00(\mathrm{REF}) \\
\mathrm{p}=0.4278\end{array}$ & 21 & $\begin{array}{l}\mathrm{n}=330 \\
\mathrm{~d}=59\end{array}$ & $\begin{array}{l}0: 3.29 \% \\
1: 4.51 \%\end{array}$ & $\begin{array}{l}\mathbf{0 :} \mathbf{1 0 . 2 9 \%} \\
1: 0.00 \%\end{array}$ & $\begin{array}{l}0: 5.37 \% \\
1: 3.73 \%\end{array}$ \\
\hline 43 & $\begin{array}{l}\text { Model } 1+\text { Physical Activity + Race/Ethnicity }+ \text { Treatment } \\
\text { Type }+ \text { Comorbidities + Optimism + Fear of Recurrence }+ \\
\text { Confide }\end{array}$ & $\begin{array}{l}0: H R=1.64(0.80-3.33) \\
\text { 1: } \mathrm{HR}=1.44(0.72-2.88) \\
\text { 2: } \mathrm{HR}=1.00 \text { (REF) } \\
\mathrm{p}=0.3760\end{array}$ & 21 & $\begin{array}{l}\mathrm{n}=330 \\
\mathrm{~d}=59\end{array}$ & $\begin{array}{l}0: 7.89 \% \\
1: 8.27 \%\end{array}$ & $\begin{array}{l}0: 6.29 \% \\
1: 3.60 \%\end{array}$ & $\begin{array}{l}0: 4.46 \% \\
1: 3.60 \%\end{array}$ \\
\hline 44 & $\begin{array}{l}\text { Model } 1+\text { Physical Activity + Race/Ethnicity + Treatment } \\
\text { Type + Comorbidities + Optimism + Fear of Recurrence + } \\
\text { Confide + Bodily Pain }\end{array}$ & $\begin{array}{l}0: \mathrm{HR}=1.57(0.76-3.24) \\
\text { 1: } \mathrm{HR}=1.42(0.71-2.85) \\
\text { 2: } \mathrm{HR}=1.00(\mathrm{REF}) \\
\mathrm{p}=0.4457\end{array}$ & 21 & $\begin{array}{l}\mathrm{n}=330 \\
\mathrm{~d}=59\end{array}$ & $\begin{array}{l}0: 3.29 \% \\
1: 6.77 \%\end{array}$ & $\begin{array}{l}\mathbf{0 :} \mathbf{1 0 . 2 9 \%} \\
1: 2.16 \%\end{array}$ & $\begin{array}{l}0: 4.27 \% \\
1: 1.39 \%\end{array}$ \\
\hline
\end{tabular}




\begin{tabular}{|c|c|c|c|c|c|c|c|}
\hline Model & Variable(s) in model & $\begin{array}{l}\text { Mental Component Summary } \\
\text { Score (MCS) HR }(95 \% \mathrm{CI})\end{array}$ & $\begin{array}{l}\text { Difference in } \\
\text { ' } \mathrm{N}^{\prime}\end{array}$ & $\begin{array}{l}\text { Total in model } \\
\text { (n) and total } \\
\text { dead (d) }\end{array}$ & $\begin{array}{l}\% \text { change } \\
\text { from Crude }\end{array}$ & $\begin{array}{l}\% \text { change } \\
\text { from model } \\
1\end{array}$ & $\begin{array}{l}\text { \% change } \\
\text { from } \\
\text { previous } \\
\text { model }\end{array}$ \\
\hline 45 & $\begin{array}{l}\text { Model } 1+\text { Physical Activity }+ \text { Race/Ethnicity }+ \text { Treatment } \\
\text { Type }+ \text { Comorbidities }+ \text { Optimism }+ \text { Fear of Recurrence }+ \\
\text { Confide + Bodily Pain + Perceived General Health }\end{array}$ & $\begin{array}{l}0: \mathrm{HR}=1.36(0.64-2.92) \\
1: \mathrm{HR}=1.40(0.70-2.80) \\
2: \mathrm{HR}=1.00(\mathrm{REF}) \\
\mathrm{p}=0.6065\end{array}$ & 21 & $\begin{array}{l}\mathrm{n}=330 \\
\mathrm{~d}=59\end{array}$ & $\begin{array}{l}0: 10.53 \% \\
1: 5.26 \%\end{array}$ & $\begin{array}{l}\mathbf{0}: \mathbf{2 2 . 2 9 \%} \\
1: 0.72 \%\end{array}$ & $\begin{array}{l}\mathbf{0 :} \mathbf{1 3 . 3 8 \%} \\
1: 1.41 \%\end{array}$ \\
\hline \multicolumn{8}{|c|}{ Subset--Restricted to participants with Education, Tumor Size, and Physical Activity variables } \\
\hline Crude & Mental Component Summary Score (MCS) & $\begin{array}{l}0: \mathrm{HR}=1.55(0.81-2.95) \\
1: \mathrm{HR}=1.29(0.67-2.48) \\
2: \mathrm{HR}=1.00(\mathrm{REF}) \\
\mathrm{p}=0.4139\end{array}$ & 32 & $\begin{array}{l}\mathrm{n}=319 \\
\mathrm{~d}=58\end{array}$ & -- & -- & -- \\
\hline 1 & Age, Marital Status, \& Tumor Stage & $\begin{array}{l}0: \mathrm{HR}=1.72(0.90-3.31) \\
1: \mathrm{HR}=1.34(0.69-2.59) \\
2: \mathrm{HR}=1.00(\mathrm{REF}) \\
\mathrm{p}=0.2645\end{array}$ & 32 & $\begin{array}{l}\mathrm{n}=319 \\
\mathrm{~d}=58\end{array}$ & $\begin{array}{l}\mathbf{0}: \mathbf{1 0 . 9 7 \%} \\
1: 3.88 \%\end{array}$ & -- & -- \\
\hline 46 & Model $1+$ Education + Tumor Size + Physical Activity & $\begin{array}{l}0: \mathrm{HR}=1.69(0.87-3.27) \\
1: \mathrm{HR}=1.47(0.74-2.91) \\
2: \mathrm{HR}=1.00(\mathrm{REF}) \\
\mathrm{p}=0.2818\end{array}$ & 32 & $\begin{array}{l}\mathrm{n}=319 \\
\mathrm{~d}=58\end{array}$ & $\begin{array}{l}0: 9.03 \% \\
1: \mathbf{1 3 . 9 5 \%}\end{array}$ & $\begin{array}{l}0: 1.74 \% \\
1: 9.70 \%\end{array}$ & -- \\
\hline
\end{tabular}




\begin{tabular}{|c|c|c|c|c|c|c|c|}
\hline Model & Variable(s) in model & $\begin{array}{l}\text { Mental Component Summary } \\
\text { Score (MCS) HR }(95 \% \text { CI) }\end{array}$ & $\begin{array}{l}\text { Difference in } \\
\text { ' } \mathrm{N} \text { ' }\end{array}$ & $\begin{array}{l}\text { Total in model } \\
\text { (n) and total } \\
\text { dead (d) }\end{array}$ & $\begin{array}{l}\% \text { change } \\
\text { from Crude }\end{array}$ & $\begin{array}{l}\% \text { change } \\
\text { from model } \\
1\end{array}$ & $\begin{array}{l}\% \text { change } \\
\text { from } \\
\text { previous } \\
\text { model }\end{array}$ \\
\hline 47 & $\begin{array}{l}\text { Model } 1+\text { Education + Tumor Size + Physical Activity }+ \\
\text { Race/Ethnicity }\end{array}$ & $\begin{array}{l}0: \mathrm{HR}=1.69(0.88-3.28) \\
1: \mathrm{HR}=1.47(0.74-2.91) \\
2: \mathrm{HR}=1.00(\mathrm{REF}) \\
\mathrm{p}=0.2787\end{array}$ & 32 & $\begin{array}{l}\mathrm{n}=319 \\
\mathrm{~d}=58\end{array}$ & $\begin{array}{l}0: 9.03 \% \\
1: 13.95 \%\end{array}$ & $\begin{array}{l}0: 1.74 \% \\
1: 9.70 \%\end{array}$ & $\begin{array}{l}0: 0.00 \% \\
1: 0.00 \%\end{array}$ \\
\hline 48 & $\begin{array}{l}\text { Model } 1+\text { Education + Tumor Size + Physical Activity }+ \\
\text { Race/Ethnicity + Treatment Type }\end{array}$ & $\begin{array}{l}0: H R=1.68(0.87-3.24) \\
1: H R=1.37(0.68-2.76) \\
2: H R=1.00(R E F) \\
p=0.3048\end{array}$ & 32 & $\begin{array}{l}n=319 \\
d=58\end{array}$ & $\begin{array}{l}0: 8.39 \% \\
1: 6.20 \%\end{array}$ & $\begin{array}{l}0: 2.33 \% \\
1: 2.24 \%\end{array}$ & $\begin{array}{l}0: 0.59 \% \\
1: 6.80 \%\end{array}$ \\
\hline 49 & $\begin{array}{l}\text { Model } 1+\text { Education }+ \text { Tumor Size }+ \text { Physical Activity }+ \\
\text { Race/Ethnicity }+ \text { Treatment Type }+ \text { Comorbidities }\end{array}$ & $\begin{array}{l}0: \mathrm{HR}=1.59(0.81-3.15) \\
1: \mathrm{HR}=1.36(0.67-2.73) \\
2: \mathrm{HR}=1.00(\mathrm{REF}) \\
\mathrm{p}=0.3975\end{array}$ & 32 & $\begin{array}{l}\mathrm{n}=319 \\
\mathrm{~d}=58\end{array}$ & $\begin{array}{l}0: 2.58 \% \\
1: 5.43 \%\end{array}$ & $\begin{array}{l}0: 7.56 \% \\
1: 1.49 \%\end{array}$ & $\begin{array}{l}0: 5.36 \% \\
1: 0.73 \%\end{array}$ \\
\hline 50 & $\begin{array}{l}\text { Model } 1+\text { Education + Tumor Size + Physical Activity + } \\
\text { Race/Ethnicity + Treatment Type + Comorbidities }+ \\
\text { Optimism }\end{array}$ & $\begin{array}{l}0: \mathrm{HR}=1.49(0.74-2.98) \\
1: \mathrm{HR}=1.29(0.64-2.61) \\
\text { 2: } \mathrm{HR}=1.00(\mathrm{REF}) \\
\mathrm{p}=0.5232\end{array}$ & 32 & $\begin{array}{l}n=319 \\
d=58\end{array}$ & $\begin{array}{l}0: 3.87 \% \\
1: 0.00 \%\end{array}$ & $\begin{array}{l}\mathbf{0 :} \mathbf{1 3 . 3 7 \%} \\
1: 3.73 \%\end{array}$ & $\begin{array}{l}0: 6.29 \% \\
1: 5.15 \%\end{array}$ \\
\hline 51 & $\begin{array}{l}\text { Model } 1+\text { Education + Tumor Size + Physical Activity + } \\
\text { Race/Ethnicity + Treatment Type + Comorbidities }+ \\
\text { Optimism + Fear of Recurrence }\end{array}$ & $\begin{array}{l}0: \mathrm{HR}=1.59(0.79-3.19) \\
1: \mathrm{HR}=1.37(0.67-2.77) \\
2: \mathrm{HR}=1.00(\mathrm{REF}) \\
\mathrm{p}=0.4176\end{array}$ & 32 & $\begin{array}{l}\mathrm{n}=319 \\
\mathrm{~d}=58\end{array}$ & $\begin{array}{l}0: 2.58 \% \\
1: 6.20 \%\end{array}$ & $\begin{array}{l}0: 7.56 \% \\
1: 2.24 \%\end{array}$ & $\begin{array}{l}0: 6.71 \% \\
1: 6.20 \%\end{array}$ \\
\hline
\end{tabular}




\begin{tabular}{|c|c|c|c|c|c|c|c|}
\hline Model & Variable(s) in model & $\begin{array}{l}\text { Mental Component Summary } \\
\text { Score (MCS) HR }(95 \% \text { CI) }\end{array}$ & $\begin{array}{l}\text { Difference in } \\
\text { ' } \mathrm{N} \text { ' }\end{array}$ & $\begin{array}{l}\text { Total in model } \\
\text { (n) and total } \\
\text { dead (d) }\end{array}$ & $\begin{array}{l}\% \text { change } \\
\text { from Crude }\end{array}$ & $\begin{array}{l}\% \text { change } \\
\text { from model } \\
1\end{array}$ & $\begin{array}{l}\% \text { change } \\
\text { from } \\
\text { previous } \\
\text { model }\end{array}$ \\
\hline 52 & $\begin{array}{l}\text { Model } 1+\text { Education + Tumor Size + Physical Activity + } \\
\text { Race/Ethnicity + Treatment Type + Comorbidities }+ \\
\text { Optimism + Fear of Recurrence + Confide }\end{array}$ & $\begin{array}{l}0: \mathrm{HR}=1.64(0.81-3.36) \\
1: \mathrm{HR}=1.41(0.69-2.88) \\
2: \mathrm{HR}=1.00(\mathrm{REF}) \\
\mathrm{p}=0.3824\end{array}$ & 32 & $\begin{array}{l}\mathrm{n}=319 \\
\mathrm{~d}=58\end{array}$ & $\begin{array}{l}0: 5.81 \% \\
1: 9.30 \%\end{array}$ & $\begin{array}{l}0: 4.65 \% \\
1: 5.22 \%\end{array}$ & $\begin{array}{l}0: 3.14 \% \\
1: 2.92 \%\end{array}$ \\
\hline 53 & $\begin{array}{l}\text { Model } 1+\text { Education + Tumor Size + Physical Activity + } \\
\text { Race/Ethnicity + Treatment Type + Comorbidities + } \\
\text { Optimism + Fear of Recurrence + Confide + Bodily Pain }\end{array}$ & $\begin{array}{l}0: \mathrm{HR}=1.61(0.77-3.35) \\
1: \mathrm{HR}=1.40(0.68-2.87) \\
2: \mathrm{HR}=1.00(\mathrm{REF}) \\
\mathrm{p}=0.4303\end{array}$ & 32 & $\begin{array}{l}n=319 \\
d=58\end{array}$ & $\begin{array}{l}0: 3.87 \% \\
1: 8.53 \%\end{array}$ & $\begin{array}{l}0: 6.40 \% \\
1: 4.48 \%\end{array}$ & $\begin{array}{l}0: 1.83 \% \\
1: 0.71 \%\end{array}$ \\
\hline 54 & $\begin{array}{l}\text { Model } 1+\text { Education }+ \text { Tumor Size }+ \text { Physical Activity }+ \\
\text { Race/Ethnicity + Treatment Type + Comorbidities }+ \\
\text { Optimism + Fear of Recurrence + Confide + Bodily Pain + } \\
\text { Perceived General Health }\end{array}$ & $\begin{array}{l}0: \mathrm{HR}=1.44(0.67-3.09) \\
1: \mathrm{HR}=1.73(0.67-2.83) \\
\text { 2: } \mathrm{HR}=1.00(\mathrm{REF}) \\
\mathrm{p}=0.5886\end{array}$ & 32 & $\begin{array}{l}\mathrm{n}=319 \\
\mathrm{~d}=58\end{array}$ & $\begin{array}{l}0: 7.10 \% \\
\mathbf{1}: \mathbf{3 4 . 1 1} \%\end{array}$ & $\begin{array}{l}0: 16.28 \% \\
1: 29.10 \%\end{array}$ & $\begin{array}{l}0: 10.56 \% \\
1: 23.57 \%\end{array}$ \\
\hline \multicolumn{8}{|c|}{ Subset--Restricted to participants with BMI variable } \\
\hline Crude & Mental Component Summary Score (MCS) & $\begin{array}{l}0: \mathrm{HR}=1.31(0.67-2.58) \\
\text { 1: } \mathrm{HR}=1.29(0.66-2.52) \\
\text { 2: } \mathrm{HR}=1.00(\mathrm{REF}) \\
\mathrm{p}=0.6886\end{array}$ & 27 & $\begin{array}{l}n=324 \\
d=54\end{array}$ & -- & -- & -- \\
\hline
\end{tabular}




\begin{tabular}{|c|c|c|c|c|c|c|c|}
\hline Model & Variable(s) in model & $\begin{array}{l}\text { Mental Component Summary } \\
\text { Score (MCS) HR }(95 \% \text { CI) }\end{array}$ & $\begin{array}{l}\text { Difference in } \\
\text { ' } \mathrm{N} \text { ' }\end{array}$ & $\begin{array}{l}\text { Total in model } \\
\text { (n) and total } \\
\text { dead (d) }\end{array}$ & $\begin{array}{l}\% \text { change } \\
\text { from Crude }\end{array}$ & $\begin{array}{l}\% \text { change } \\
\text { from model } \\
1\end{array}$ & $\begin{array}{l}\% \text { change } \\
\text { from } \\
\text { previous } \\
\text { model }\end{array}$ \\
\hline 1 & Age, Marital Status, \& Tumor Stage & $\begin{array}{l}0: \mathrm{HR}=1.46(0.74-2.90) \\
\text { 1: } \mathrm{HR}=1.19(0.60-2.35) \\
\text { 2: } \mathrm{HR}=1.00 \text { (REF) } \\
\mathrm{p}=0.5524\end{array}$ & 27 & $\begin{array}{l}\mathrm{n}=324 \\
\mathrm{~d}=54\end{array}$ & $\begin{array}{l}\text { 0: } 11.45 \% \\
1: 7.75 \%\end{array}$ & -- & -- \\
\hline 55 & Model $1+$ BMI & $\begin{array}{l}0: \mathrm{HR}=1.49(0.74-2.97) \\
\text { 1: } \mathrm{HR}=1.24 \text { (0.63-2.45) } \\
\text { 2: } \mathrm{HR}=1.00 \text { (REF) } \\
\mathrm{p}=0.5325\end{array}$ & 27 & $\begin{array}{l}\mathrm{n}=324 \\
\mathrm{~d}=54\end{array}$ & $\begin{array}{l}\mathbf{0 :} \mathbf{1 3 . 7 4 \%} \\
1: 3.88 \%\end{array}$ & $\begin{array}{l}0: 2.05 \% \\
1: 4.20 \%\end{array}$ & -- \\
\hline 56 & Model 1 + BMI + Race/Ethnicity & $\begin{array}{l}0: \mathrm{HR}=1.48(0.74-2.97) \\
1: \mathrm{HR}=1.24(0.62-2.45) \\
\text { 2: } \mathrm{HR}=1.00 \text { (REF) } \\
\mathrm{p}=0.5416\end{array}$ & 27 & $\begin{array}{l}\mathrm{n}=324 \\
\mathrm{~d}=54\end{array}$ & $\begin{array}{l}\mathbf{0 :} \mathbf{1 2 . 9 8 \%} \\
1: 3.88 \%\end{array}$ & $\begin{array}{l}0: 1.37 \% \\
1: 4.20 \%\end{array}$ & $\begin{array}{l}0: 0.67 \% \\
1: 0.00 \%\end{array}$ \\
\hline 57 & Model 1 + BMI + Race/Ethnicity + Treatment Type & $\begin{array}{l}0: \mathrm{HR}=1.45(0.72-2.91) \\
\text { 1: } \mathrm{HR}=1.14(0.57-2.29) \\
\text { 2: } \mathrm{HR}=1.00 \text { (REF) } \\
\mathrm{p}=0.5686\end{array}$ & 27 & $\begin{array}{l}\mathrm{n}=324 \\
\mathrm{~d}=54\end{array}$ & $\begin{array}{l}0: 10.69 \% \\
1: 11.63 \%\end{array}$ & $\begin{array}{l}0: 0.68 \% \\
1: 0.00 \%\end{array}$ & $\begin{array}{l}0: 2.03 \% \\
1: 8.06 \%\end{array}$ \\
\hline 58 & $\begin{array}{l}\text { Model } 1 \text { + BMI + Race/Ethnicity + Treatment Type + } \\
\text { Comorbidities }\end{array}$ & $\begin{array}{l}0: \mathrm{HR}=1.43(0.70-2.92) \\
\text { 1: } \mathrm{HR}=1.14 \text { (0.57-2.28) } \\
\text { 2: } \mathrm{HR}=1.00 \text { (REF) } \\
\mathrm{p}=0.6182\end{array}$ & 27 & $\begin{array}{l}\mathrm{n}=324 \\
\mathrm{~d}=54\end{array}$ & $\begin{array}{l}0: 9.16 \% \\
1: 11.63 \%\end{array}$ & $\begin{array}{l}0: 2.05 \% \\
1: 4.20 \%\end{array}$ & $\begin{array}{l}0: 1.38 \% \\
1: 0.00 \%\end{array}$ \\
\hline
\end{tabular}




\begin{tabular}{|c|c|c|c|c|c|c|c|}
\hline Model & Variable(s) in model & $\begin{array}{l}\text { Mental Component Summary } \\
\text { Score (MCS) HR }(95 \% \mathrm{Cl})\end{array}$ & $\begin{array}{l}\text { Difference in } \\
\text { ' } \mathrm{N} \text { ' }\end{array}$ & $\begin{array}{l}\text { Total in model } \\
\text { (n) and total } \\
\text { dead (d) }\end{array}$ & $\begin{array}{l}\% \text { change } \\
\text { from Crude }\end{array}$ & $\begin{array}{l}\% \text { change } \\
\text { from model } \\
1\end{array}$ & $\begin{array}{l}\% \text { change } \\
\text { from } \\
\text { previous } \\
\text { model }\end{array}$ \\
\hline 59 & $\begin{array}{l}\text { Model } 1+\text { BMI + Race/Ethnicity + Treatment Type + } \\
\text { Comorbidities + Optimism }\end{array}$ & $\begin{array}{l}0: H R=1.30(0.63-2.71) \\
\text { 1: } \mathrm{HR}=1.03(0.51-2.09) \\
\text { 2: } \mathrm{HR}=1.00 \text { (REF) } \\
\mathrm{p}=0.7401\end{array}$ & 27 & $\begin{array}{l}\mathrm{n}=324 \\
\mathrm{~d}=54\end{array}$ & $\begin{array}{l}0: 0.76 \% \\
1: 20.16 \%\end{array}$ & $\begin{array}{l}0: 10.96 \% \\
1: 13.45 \%\end{array}$ & $\begin{array}{l}0: 9.09 \% \\
1: 9.65 \%\end{array}$ \\
\hline 60 & $\begin{array}{l}\text { Model } 1+\text { BMI + Race/Ethnicity + Treatment Type + } \\
\text { Comorbidities + Optimism + Fear of Recurrence }\end{array}$ & $\begin{array}{l}0: \mathrm{HR}=1.38(0.66-2.87) \\
1: \mathrm{HR}=1.13(0.56-2.28) \\
\text { 2: } \mathrm{HR}=1.00(\mathrm{REF}) \\
\mathrm{p}=0.6824\end{array}$ & 27 & $\begin{array}{l}\mathrm{n}=324 \\
\mathrm{~d}=54\end{array}$ & $\begin{array}{l}0: 5.34 \% \\
1: 12.40 \%\end{array}$ & $\begin{array}{l}0: 5.48 \% \\
1: 5.04 \%\end{array}$ & $\begin{array}{l}0: 6.15 \% \\
1: 9.71 \%\end{array}$ \\
\hline 61 & $\begin{array}{l}\text { Model } 1 \text { + BMI + Race/Ethnicity + Treatment Type + } \\
\text { Comorbidities + Optimism + Fear of Recurrence }+ \\
\text { Confide }\end{array}$ & $\begin{array}{l}0: \mathrm{HR}=1.39(0.67-2.89) \\
\text { 1: } \mathrm{HR}=1.14(0.57-2.31) \\
\text { 2: } \mathrm{HR}=1.00(\mathrm{REF}) \\
\mathrm{p}=0.6816\end{array}$ & 27 & $\begin{array}{l}\mathrm{n}=324 \\
\mathrm{~d}=54\end{array}$ & $\begin{array}{l}0: 6.11 \% \\
1: 11.63 \%\end{array}$ & $\begin{array}{l}0: 4.79 \% \\
1: 6.72 \%\end{array}$ & $\begin{array}{l}0: 0.72 \% \\
1: 0.88 \%\end{array}$ \\
\hline 62 & $\begin{array}{l}\text { Model } 1 \text { + BMI + Race/Ethnicity + Treatment Type + } \\
\text { Comorbidities + Optimism + Fear of Recurrence + } \\
\text { Confide + Bodily Pain }\end{array}$ & $\begin{array}{l}0: \mathrm{HR}=1.35(0.64-2.83) \\
1: \mathrm{HR}=1.12(0.55-2.28) \\
\text { 2: } \mathrm{HR}=1.00(\mathrm{REF}) \\
\mathrm{p}=0.7242\end{array}$ & 27 & $\begin{array}{l}\mathrm{n}=324 \\
\mathrm{~d}=54\end{array}$ & $\begin{array}{l}0: 3.05 \% \\
\mathbf{1}: \mathbf{1 3 . 1 8} \%\end{array}$ & $\begin{array}{l}0: 7.53 \% \\
1: 5.88 \%\end{array}$ & $\begin{array}{l}0: 2.88 \% \\
1: 1.75 \%\end{array}$ \\
\hline 63 & $\begin{array}{l}\text { Model } 1 \text { + BMI + Race/Ethnicity + Treatment Type + } \\
\text { Comorbidities + Optimism + Fear of Recurrence + } \\
\text { Confide + Bodily Pain + Perceived General Health }\end{array}$ & $\begin{array}{l}0: \mathrm{HR}=1.17(0.54-2.51) \\
\text { 1: } \mathrm{HR}=1.10(0.54-2.23) \\
\text { 2: } \mathrm{HR}=1.00(\mathrm{REF}) \\
\mathrm{p}=0.9232\end{array}$ & 27 & $\begin{array}{l}n=324 \\
d=54\end{array}$ & $\begin{array}{l}0: 10.69 \% \\
1: 14.73 \%\end{array}$ & $\begin{array}{l}\mathbf{0 :} \mathbf{1 9 . 8 6 \%} \\
1: 7.56 \%\end{array}$ & $\begin{array}{l}\mathbf{0 :} \mathbf{1 3 . 3 3 \%} \\
1: 1.79 \%\end{array}$ \\
\hline
\end{tabular}




\begin{tabular}{|c|c|c|c|c|c|c|c|}
\hline Model & Variable(s) in model & $\begin{array}{l}\text { Mental Component Summary } \\
\text { Score (MCS) HR ( } 95 \% \text { CI) }\end{array}$ & $\begin{array}{l}\text { Difference in } \\
\text { ' } \mathrm{N} \text { ' }\end{array}$ & $\begin{array}{l}\text { Total in model } \\
\text { (n) and total } \\
\text { dead (d) }\end{array}$ & $\begin{array}{l}\% \text { change } \\
\text { from Crude }\end{array}$ & $\begin{array}{l}\% \text { change } \\
\text { from model } \\
1\end{array}$ & $\begin{array}{l}\% \text { change } \\
\text { from } \\
\text { previous } \\
\text { model }\end{array}$ \\
\hline \multicolumn{8}{|c|}{ Subset--Restricted to participants with Education, Tumor Size, Physical Activity, and BMI variables } \\
\hline Crude & Mental Component Summary Score (MCS) & $\begin{array}{l}0: \mathrm{HR}=1.41(0.70-2.84) \\
1: \mathrm{HR}=1.20(0.59-2.43) \\
2: \mathrm{HR}=1.00(\mathrm{REF}) \\
\mathrm{p}=0.6282\end{array}$ & 56 & $\begin{array}{l}\mathrm{n}=246 \\
\mathrm{~d}=49\end{array}$ & -- & -- & -- \\
\hline 1 & Age, Marital Status, \& Tumor Stage & $\begin{array}{l}0: \mathrm{HR}=1.59(0.78-3.23) \\
1: \mathrm{HR}=1.20(0.59-2.44) \\
2: \mathrm{HR}=1.00(\mathrm{REF}) \\
\mathrm{p}=0.4238\end{array}$ & 56 & $\begin{array}{l}\mathrm{n}=246 \\
\mathrm{~d}=49\end{array}$ & $\begin{array}{l}\mathbf{0 :} \mathbf{1 2 . 7 7 \%} \\
1: 0.00 \%\end{array}$ & -- & -- \\
\hline 64 & $\begin{array}{l}\text { Model } 1 \text { + Education + Tumor Size + Physical Activity + } \\
\text { BMI }\end{array}$ & $\begin{array}{l}0: H R=1.54(0.75-3.17) \\
1: H R=1.28(0.61-2.68) \\
2: H R=1.00(R E F) \\
p=0.5037\end{array}$ & 56 & $\begin{array}{l}\mathrm{n}=246 \\
\mathrm{~d}=49\end{array}$ & $\begin{array}{l}0: 9.22 \% \\
1: 6.67 \%\end{array}$ & $\begin{array}{l}0: 3.14 \% \\
1: 6.67 \%\end{array}$ & -- \\
\hline 65 & $\begin{array}{l}\text { Model } 1 \text { + Education + Tumor Size + Physical Activity + } \\
\text { BMI + Race/Ethnicity }\end{array}$ & $\begin{array}{l}0: H R=1.54(0.75-3.19) \\
1: H R=1.28(0.61-2.69) \\
2: H R=1.00(R E F) \\
p=0.5055\end{array}$ & 56 & $\begin{array}{l}\mathrm{n}=246 \\
\mathrm{~d}=49\end{array}$ & $\begin{array}{l}0: 9.22 \% \\
1: 6.67 \%\end{array}$ & $\begin{array}{l}0: 3.14 \% \\
1: 6.67 \%\end{array}$ & $\begin{array}{l}0: 0.00 \% \\
1: 0.00 \%\end{array}$ \\
\hline 66 & $\begin{array}{l}\text { Model } 1+\text { Education + Tumor Size + Physical Activity + } \\
\text { BMI + Race/Ethnicity + Treatment Type }\end{array}$ & $\begin{array}{l}0: \mathrm{HR}=1.52(0.74-3.15) \\
1: \mathrm{HR}=1.15(0.54-2.44) \\
2: \mathrm{HR}=1.00(\mathrm{REF}) \\
\mathrm{p}=0.5136\end{array}$ & 56 & $\begin{array}{l}\mathrm{n}=246 \\
\mathrm{~d}=49\end{array}$ & $\begin{array}{l}0: 7.80 \% \\
1: 4.17 \%\end{array}$ & $\begin{array}{l}0: 4.40 \% \\
1: 4.17 \%\end{array}$ & $\begin{array}{l}0: 1.30 \% \\
1: 10.16 \%\end{array}$ \\
\hline
\end{tabular}




\begin{tabular}{|c|c|c|c|c|c|c|c|}
\hline Model & Variable(s) in model & $\begin{array}{l}\text { Mental Component Summary } \\
\text { Score (MCS) HR }(95 \% \text { CI) }\end{array}$ & $\begin{array}{l}\text { Difference in } \\
\text { ' } \mathrm{N} \text { ' }\end{array}$ & $\begin{array}{l}\text { Total in model } \\
\text { (n) and total } \\
\text { dead (d) }\end{array}$ & $\begin{array}{l}\% \text { change } \\
\text { from Crude }\end{array}$ & $\begin{array}{l}\% \text { change } \\
\text { from model } \\
1\end{array}$ & $\begin{array}{l}\% \text { change } \\
\text { from } \\
\text { previous } \\
\text { model }\end{array}$ \\
\hline 67 & $\begin{array}{l}\text { Model } 1+\text { Education + Tumor Size + Physical Activity + } \\
\text { BMI + Race/Ethnicity + Treatment Type + Comorbidities }\end{array}$ & $\begin{array}{l}0: \mathrm{HR}=1.46(0.69-3.07) \\
1: \mathrm{HR}=1.17(0.55-2.49) \\
2: \mathrm{HR}=1.00(\mathrm{REF}) \\
\mathrm{p}=0.6101\end{array}$ & 56 & $\begin{array}{l}\mathrm{n}=246 \\
\mathrm{~d}=49\end{array}$ & $\begin{array}{l}0: 3.55 \% \\
1: 2.50 \%\end{array}$ & $\begin{array}{l}0: 8.18 \% \\
1: 2.50 \%\end{array}$ & $\begin{array}{l}0: 3.95 \% \\
1: 1.74 \%\end{array}$ \\
\hline 68 & $\begin{array}{l}\text { Model } 1 \text { + Education + Tumor Size + Physical Activity + } \\
\text { BMI + Race/Ethnicity + Treatment Type + Comorbidities } \\
+ \text { Optimism }\end{array}$ & $\begin{array}{l}0: H R=1.30(0.61-2.80) \\
1: H R=1.09(0.51-2.32) \\
\text { 2: } H R=1.00(\mathrm{REF}) \\
\mathrm{p}=0.7921\end{array}$ & 56 & $\begin{array}{l}\mathrm{n}=246 \\
\mathrm{~d}=49\end{array}$ & $\begin{array}{l}0: 7.80 \% \\
1: 9.17 \%\end{array}$ & $\begin{array}{l}\text { 0: } \mathbf{1 8 . 2 4} \% \\
1: 9.17 \%\end{array}$ & $\begin{array}{l}\mathbf{0 :} \mathbf{1 0 . 9 6 \%} \\
1: 6.84 \%\end{array}$ \\
\hline 69 & $\begin{array}{l}\text { Model } 1 \text { + Education + Tumor Size + Physical Activity + } \\
\text { BMI + Race/Ethnicity + Treatment Type + Comorbidities } \\
+ \text { Optimism + Fear of Recurrence }\end{array}$ & $\begin{array}{l}0: H R=1.39(0.64-3.01) \\
1: H R=1.17(0.54-2.50) \\
\text { 2: } H R=1.00(R E F) \\
p=0.7031\end{array}$ & 56 & $\begin{array}{l}\mathrm{n}=246 \\
\mathrm{~d}=49\end{array}$ & $\begin{array}{l}0: 1.42 \% \\
1: 2.50 \%\end{array}$ & $\begin{array}{l}\mathbf{0 :} \mathbf{1 2 . 5 8} \% \\
1: 2.50 \%\end{array}$ & $\begin{array}{l}0: 6.92 \% \\
1: 7.34 \%\end{array}$ \\
\hline 70 & $\begin{array}{l}\text { Model } 1+\text { Education + Tumor Size + Physical Activity + } \\
\text { BMI + Race/Ethnicity + Treatment Type + Comorbidities } \\
+ \text { Optimism + Fear of Recurrence + Confide }\end{array}$ & $\begin{array}{l}0: \mathrm{HR}=1.41(0.65-3.06) \\
1: \mathrm{HR}=1.17(0.55-2.51) \\
2: \mathrm{HR}=1.00(\mathrm{REF}) \\
\mathrm{p}=0.6880\end{array}$ & 56 & $\begin{array}{l}\mathrm{n}=246 \\
\mathrm{~d}=49\end{array}$ & $\begin{array}{l}0: 0.00 \% \\
1: 2.50 \%\end{array}$ & $\begin{array}{l}\mathbf{0 :} \mathbf{1 1 . 3 2} \% \\
1: 2.50 \%\end{array}$ & $\begin{array}{l}0: 1.44 \% \\
1: 0.00 \%\end{array}$ \\
\hline 71 & $\begin{array}{l}\text { Model } 1+\text { Education + Tumor Size + Physical Activity + } \\
\text { BMI + Race/Ethnicity + Treatment Type + Comorbidities } \\
+ \text { Optimism + Fear of Recurrence + Confide + Bodily Pain }\end{array}$ & $\begin{array}{l}0: H R=1.36(0.61-2.99) \\
1: H R=1.17(0.54-2.52) \\
\text { 2: } H R=1.00(R E F) \\
p=0.7533\end{array}$ & 56 & $\begin{array}{l}\mathrm{n}=246 \\
\mathrm{~d}=49\end{array}$ & $\begin{array}{l}0: 3.55 \% \\
1: 2.50 \%\end{array}$ & $\begin{array}{l}\mathbf{0 :} \mathbf{1 4 . 4 7 \%} \\
1: 2.50 \%\end{array}$ & $\begin{array}{l}0: 3.55 \% \\
1: 0.00 \%\end{array}$ \\
\hline
\end{tabular}




\begin{tabular}{|c|c|c|c|c|c|c|c|}
\hline Model & Variable(s) in model & $\begin{array}{l}\text { Mental Component Summary } \\
\text { Score (MCS) HR }(95 \% \text { CI) }\end{array}$ & $\begin{array}{l}\text { Difference in } \\
\text { ' } \mathrm{N} \text { ' }\end{array}$ & $\begin{array}{l}\text { Total in model } \\
\text { (n) and total } \\
\text { dead (d) }\end{array}$ & $\begin{array}{l}\% \text { change } \\
\text { from Crude }\end{array}$ & $\begin{array}{l}\% \text { change } \\
\text { from model } \\
1\end{array}$ & $\begin{array}{l}\text { \% change } \\
\text { from } \\
\text { previous } \\
\text { model }\end{array}$ \\
\hline 72 & $\begin{array}{l}\text { Model } 1 \text { + Education + Tumor Size + Physical Activity + } \\
\text { BMI + Race/Ethnicity + Treatment Type + Comorbidities } \\
\text { + Optimism + Fear of Recurrence + Confide + Bodily Pain } \\
\text { + Perceived General Health }\end{array}$ & $\begin{array}{l}0: \mathrm{HR}=1.17(0.52-2.67) \\
1: \mathrm{HR}=1.10(0.51-2.38) \\
2: \mathrm{HR}=1.00(\mathrm{REF}) \\
\mathrm{p}=0.9274\end{array}$ & 56 & $\begin{array}{l}\mathrm{n}=246 \\
\mathrm{~d}=49\end{array}$ & $\begin{array}{l}\mathbf{0 :} \mathbf{1 7 . 0 2 \%} \\
1: 8.33 \%\end{array}$ & $\begin{array}{l}\mathbf{0 :} \mathbf{2 6 . 4 2 \%} \\
1: 8.33 \%\end{array}$ & $\begin{array}{l}\mathbf{0 :} \mathbf{1 3 . 9 7 \%} \\
1: 5.98 \%\end{array}$ \\
\hline
\end{tabular}


Appendix P: Kaplan-Meier Curves: (All-Cause) Survival Probability Estimates for Ethnicity

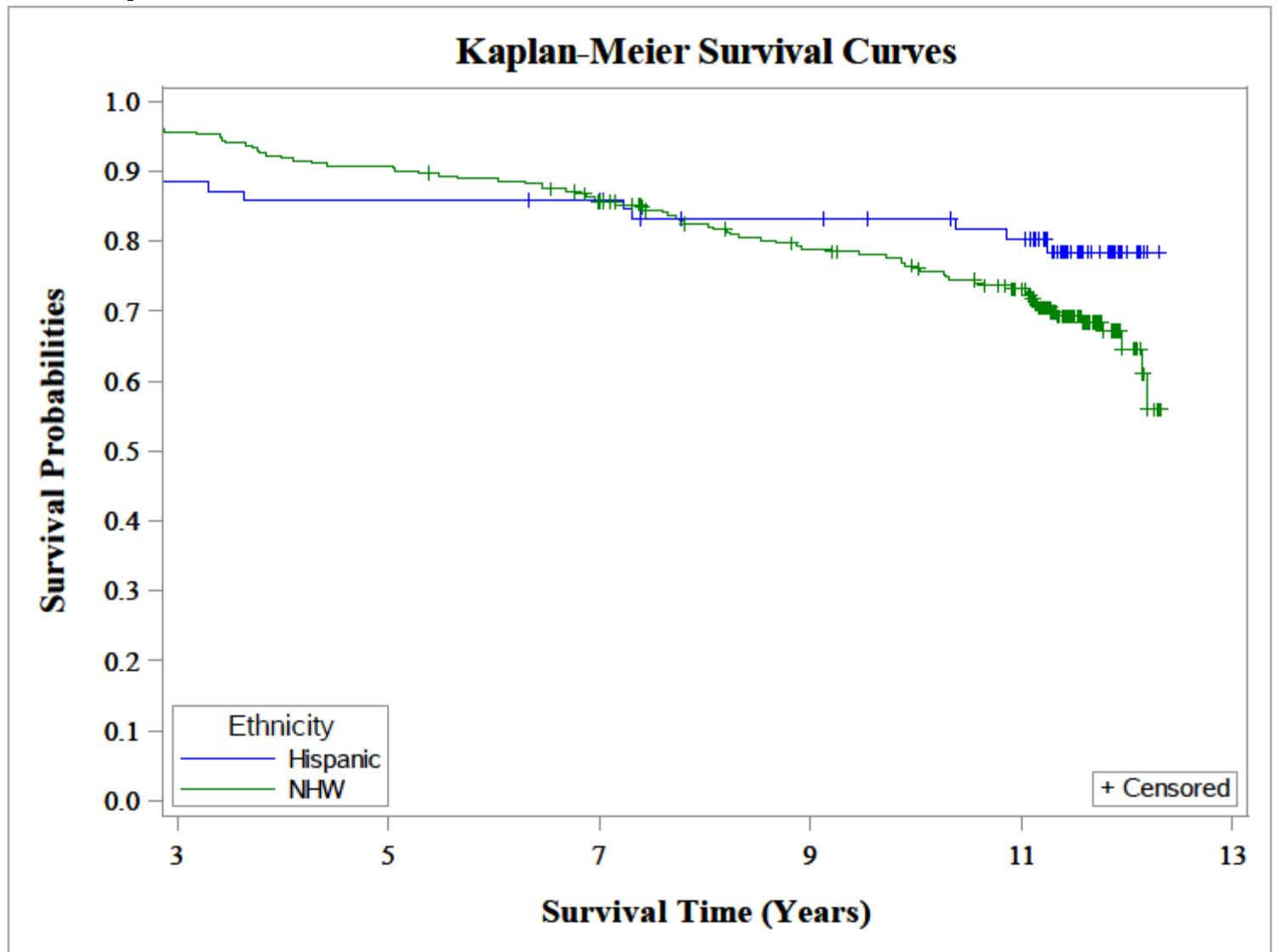


Appendix Q: Kaplan-Meier Curves: (BCS) Survival Probability Estimates for PCS Tertiles

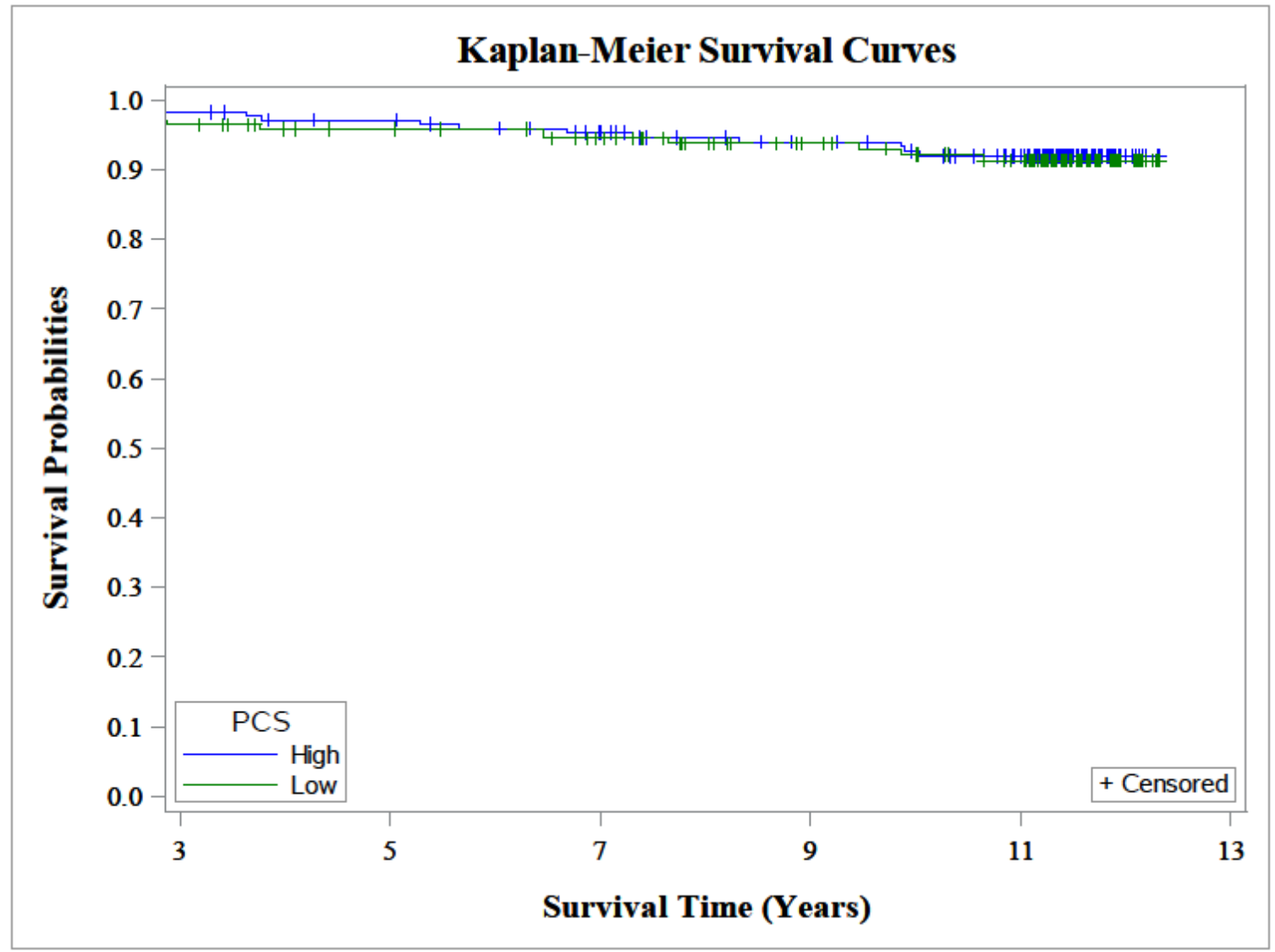


Appendix R: Kaplan-Meier Curves: (BCS) Survival Probability Estimates for MCS Tertiles

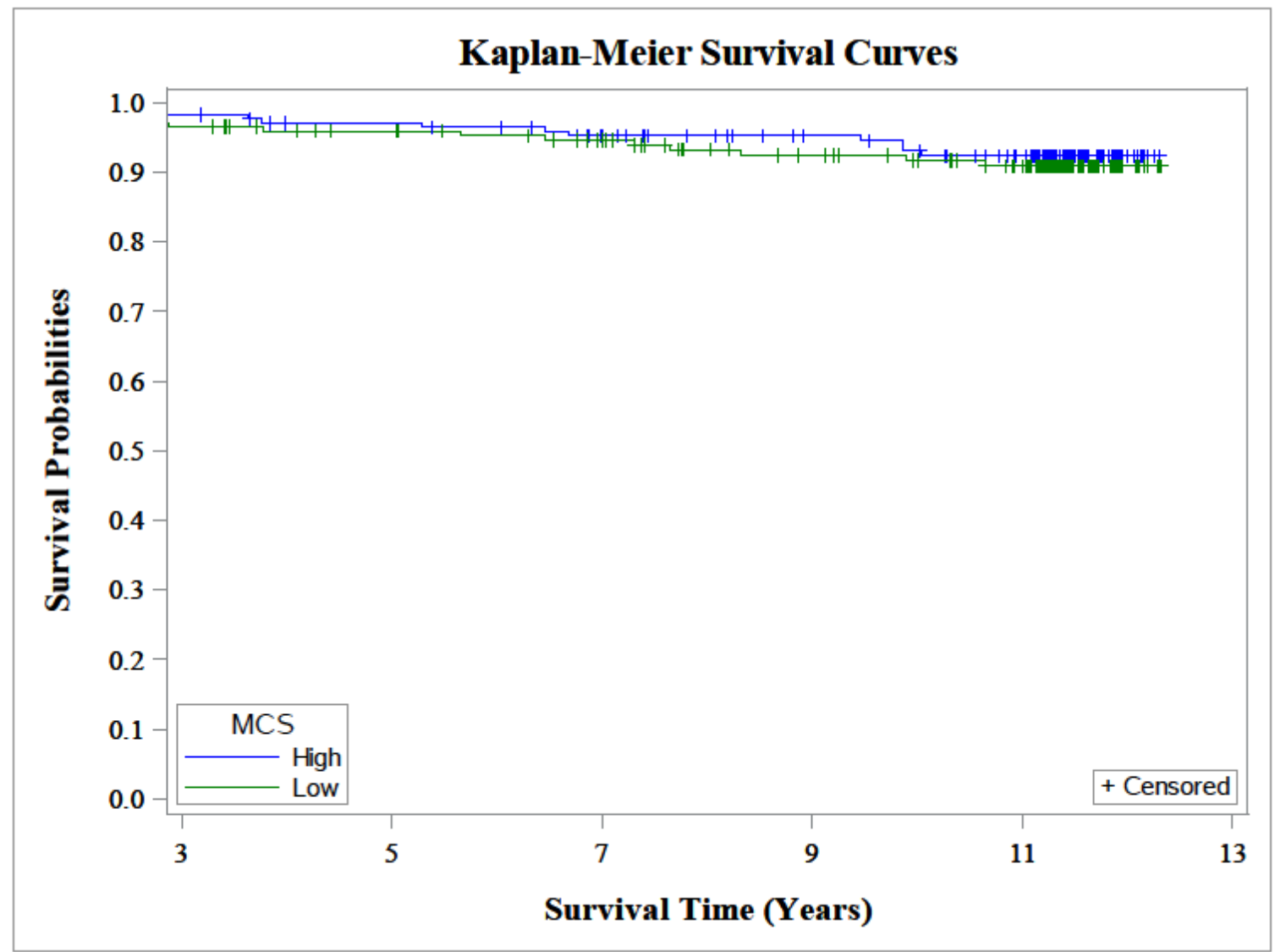


Appendix S: Kaplan-Meier Curves: (BCS) Survival Probability Estimates for Ethnicity

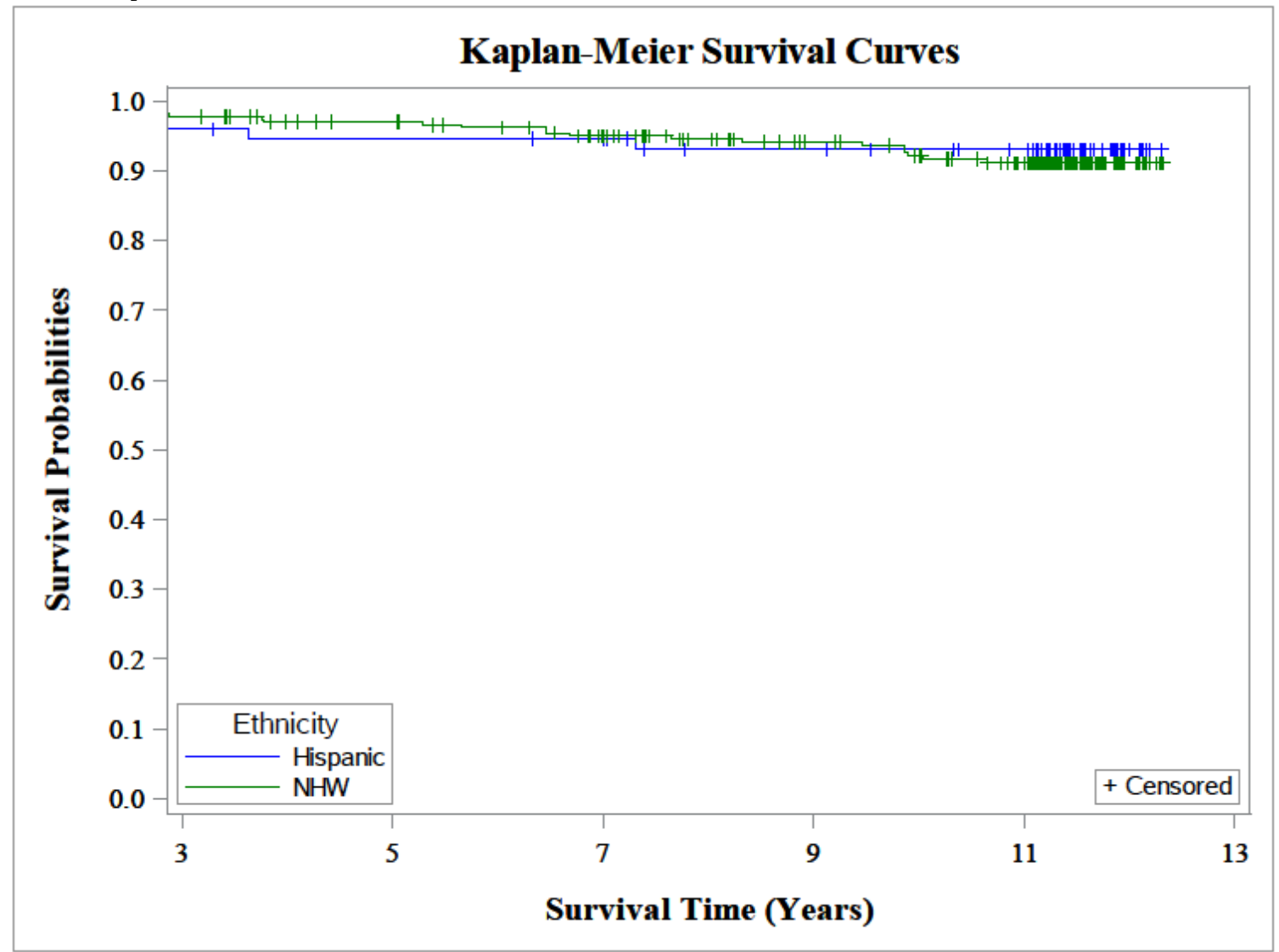


Appendix T: Kaplan-Meier Curves (Non-Cancer) Survival Probability Estimates for PCS Tertiles

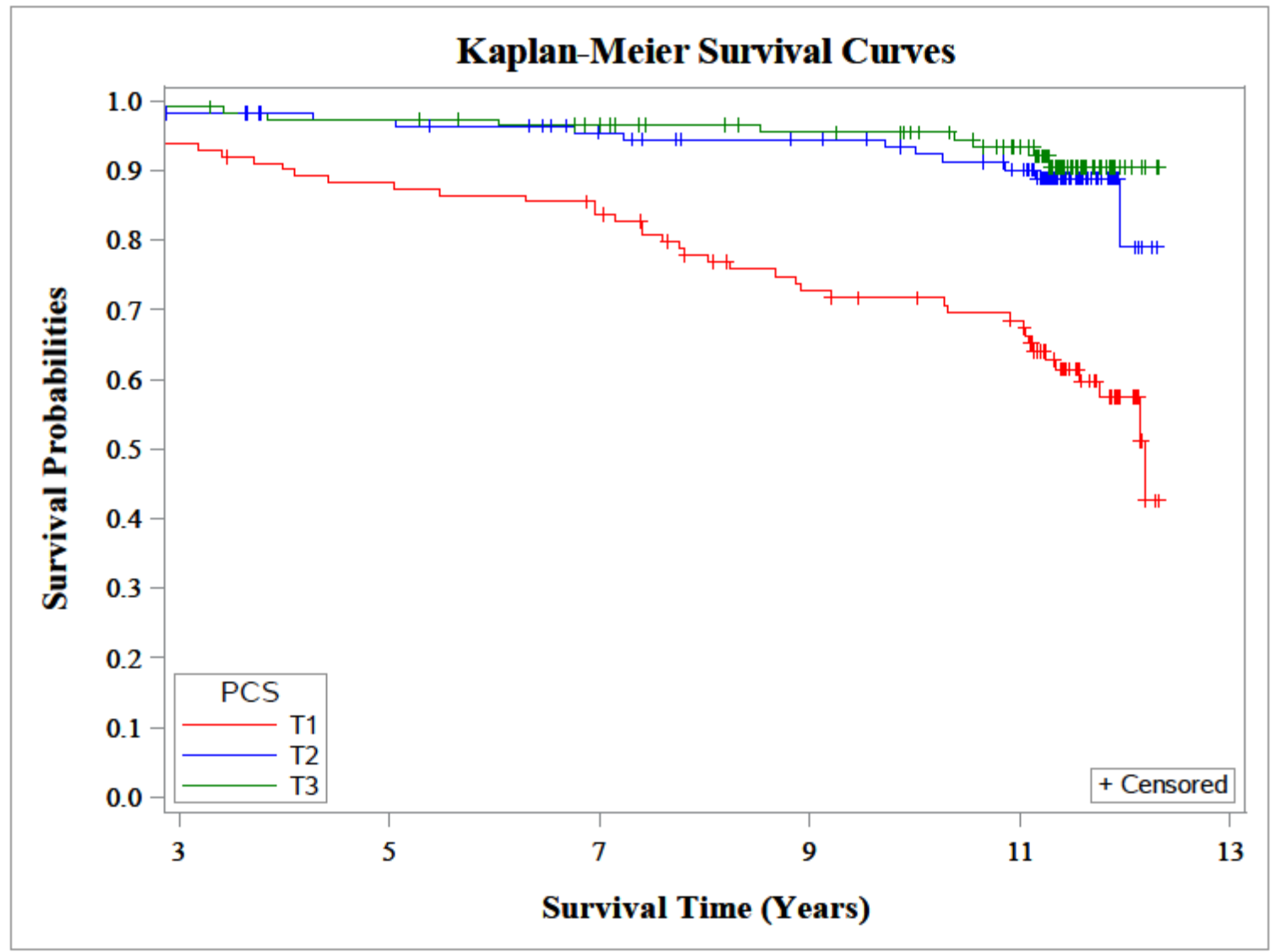


Appendix U: Kaplan-Meier Curves: (Non-Cancer) Survival Probability Estimates for MCS Tertiles

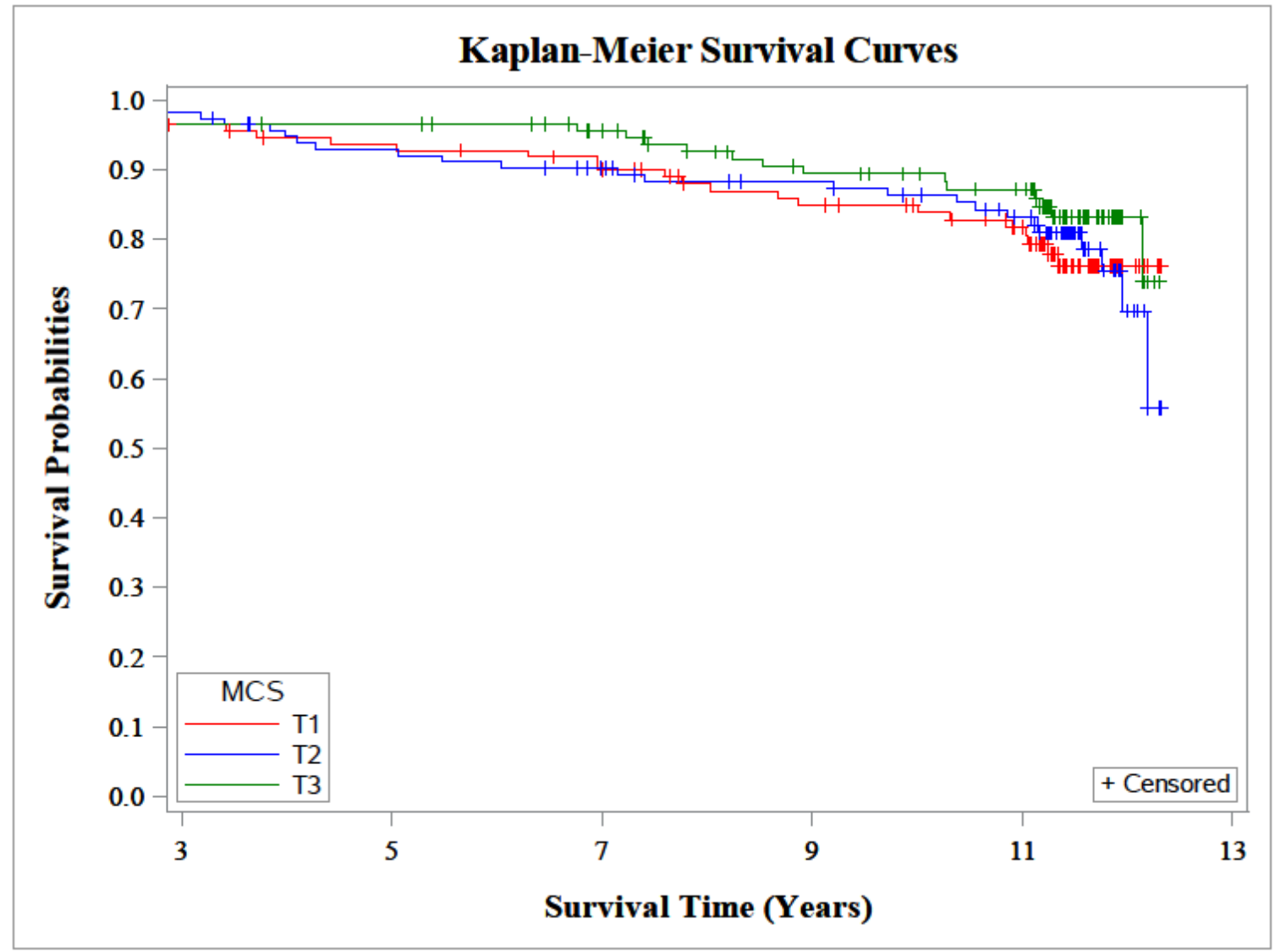


Appendix V: Kaplan-Meier Curves: (Non-Cancer) Survival Probability Estimates for Ethnicity

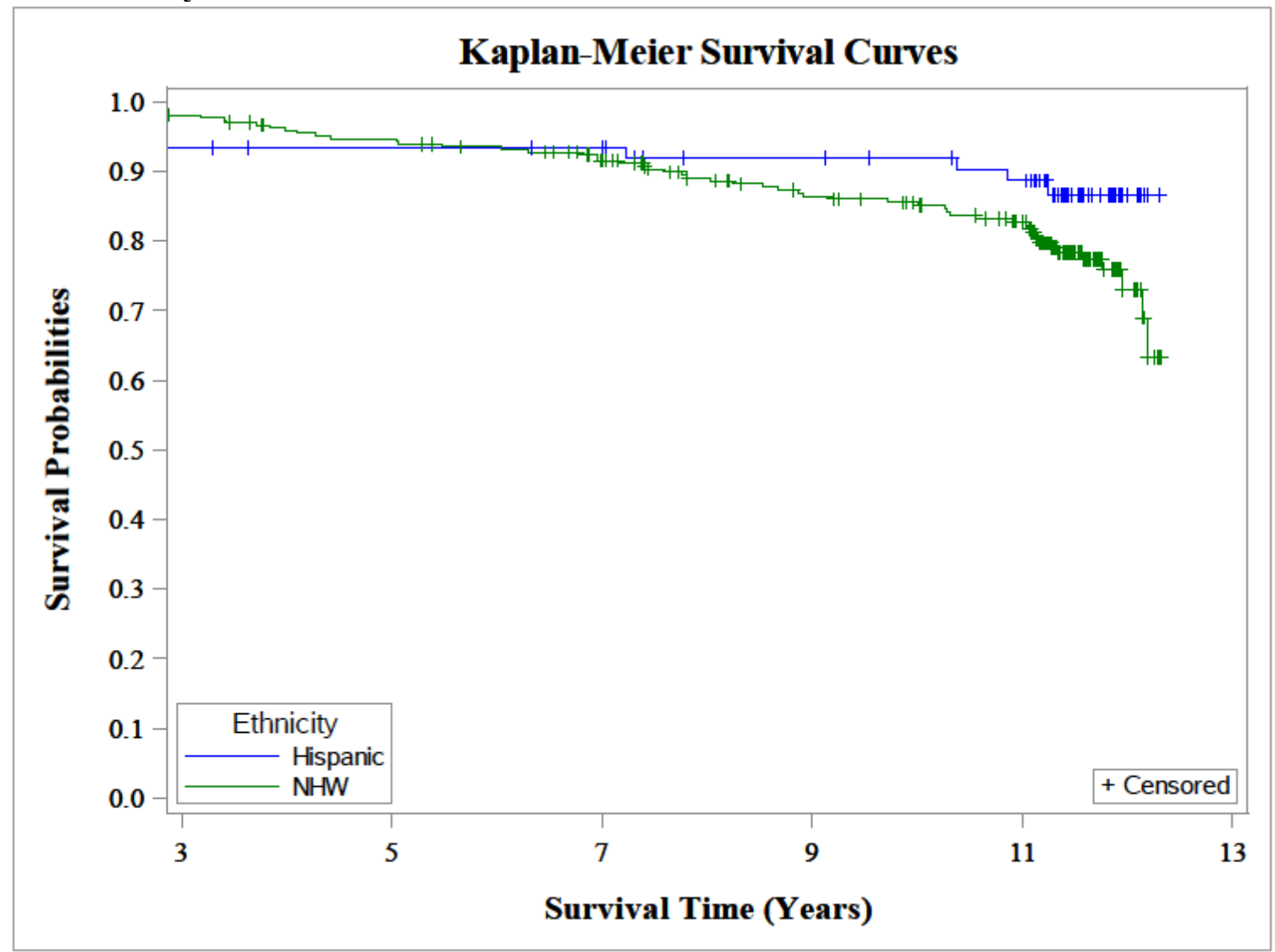


Appendix W: Kaplan-Meier Curves: (All-Cause) Survival Probability Estimates for MCS Tertiles by Ethnicity (NHW Women)

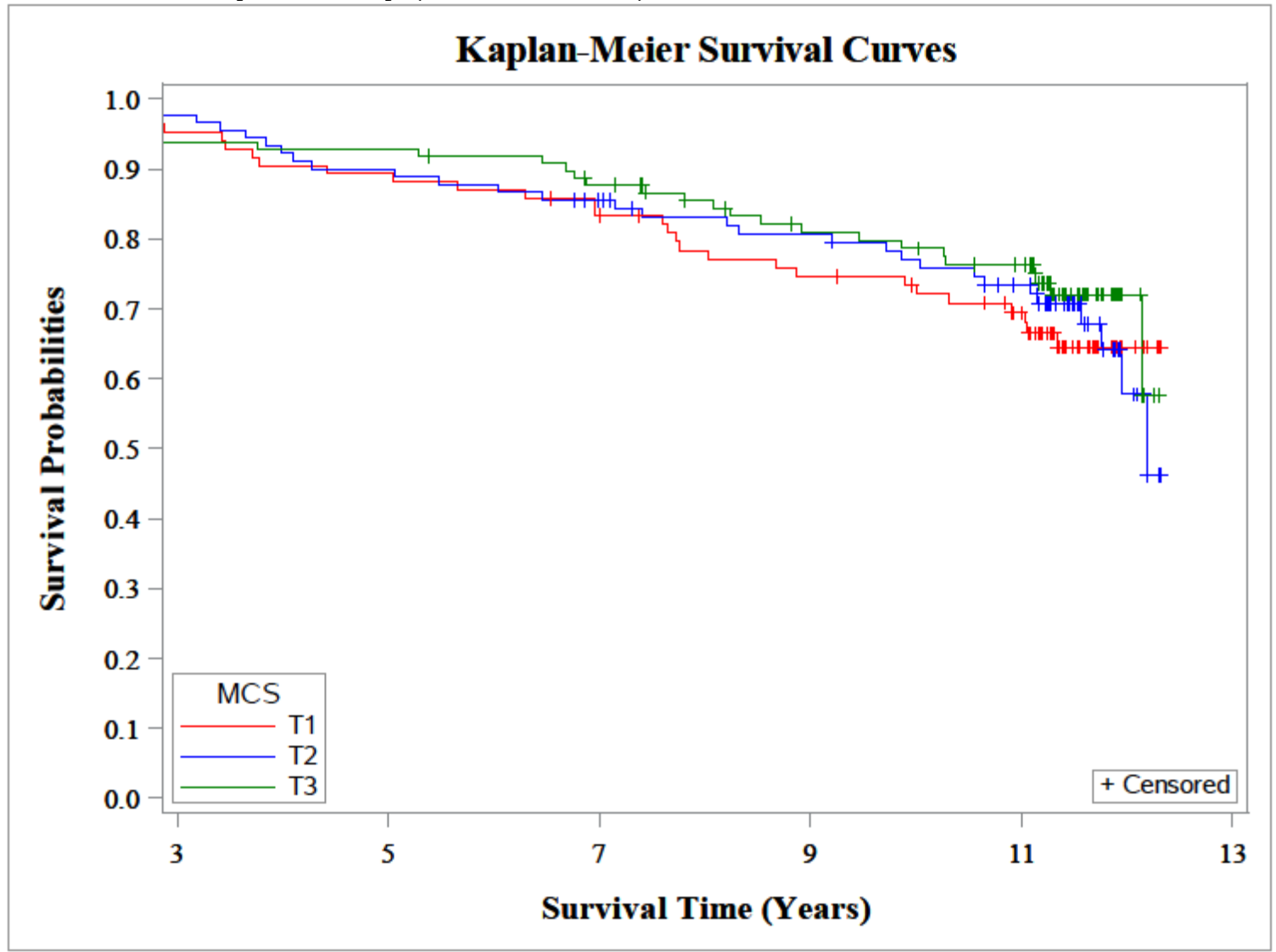


Appendix X: Kaplan-Meier Curves: (All-Cause) Survival Probability Estimates for MCS Tertiles by Ethnicity (Hispanic Women)

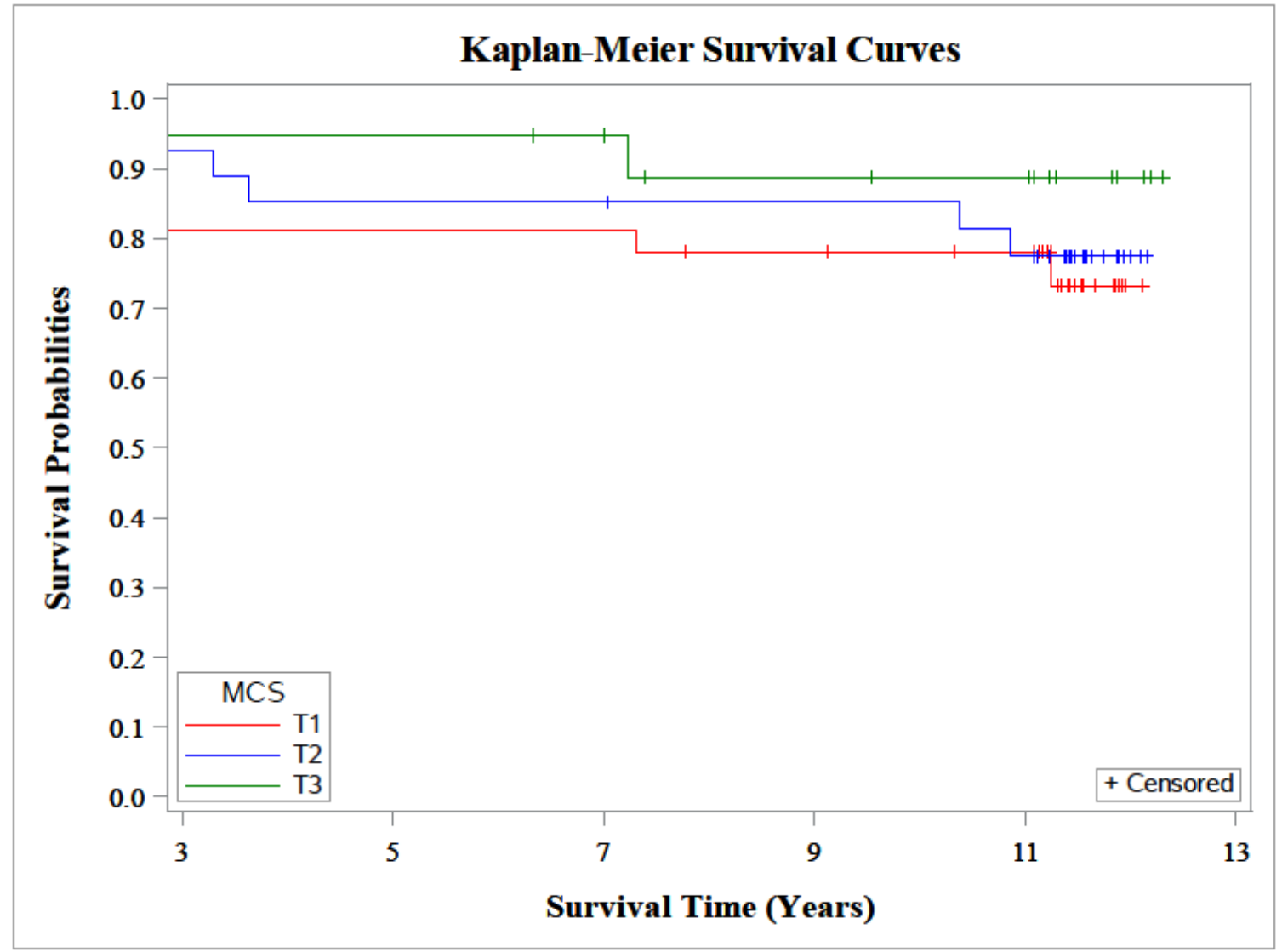


Appendix Y: Kaplan-Meier Curves: (Non-Cancer) Survival Probability Estimates for MCS Tertiles by Ethnicity (NHW Women)

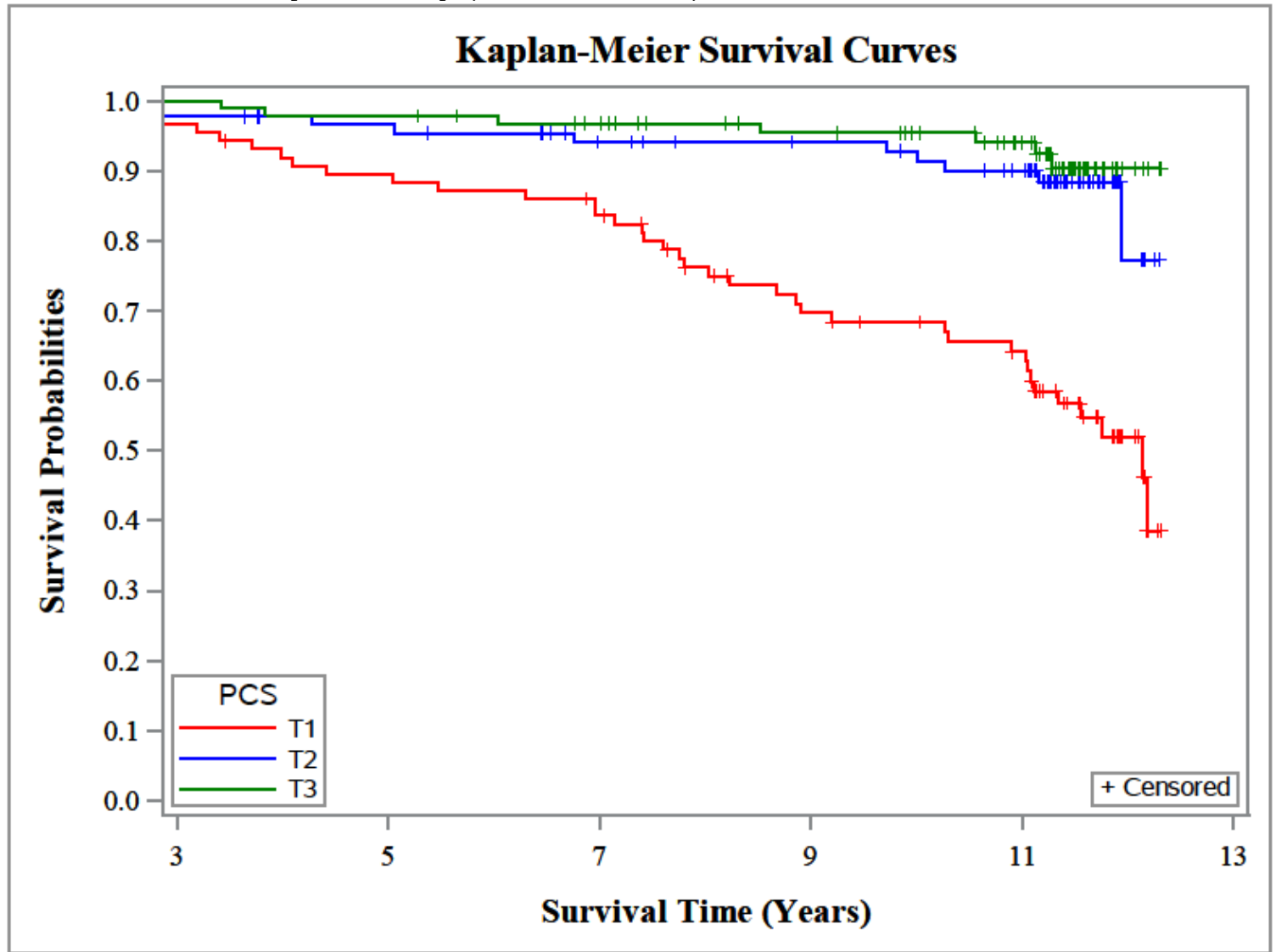


Appendix Z: Kaplan-Meier Curves: (Non-Cancer) Survival Probability Estimates for MCS Tertiles by Ethnicity (Hispanic Women)

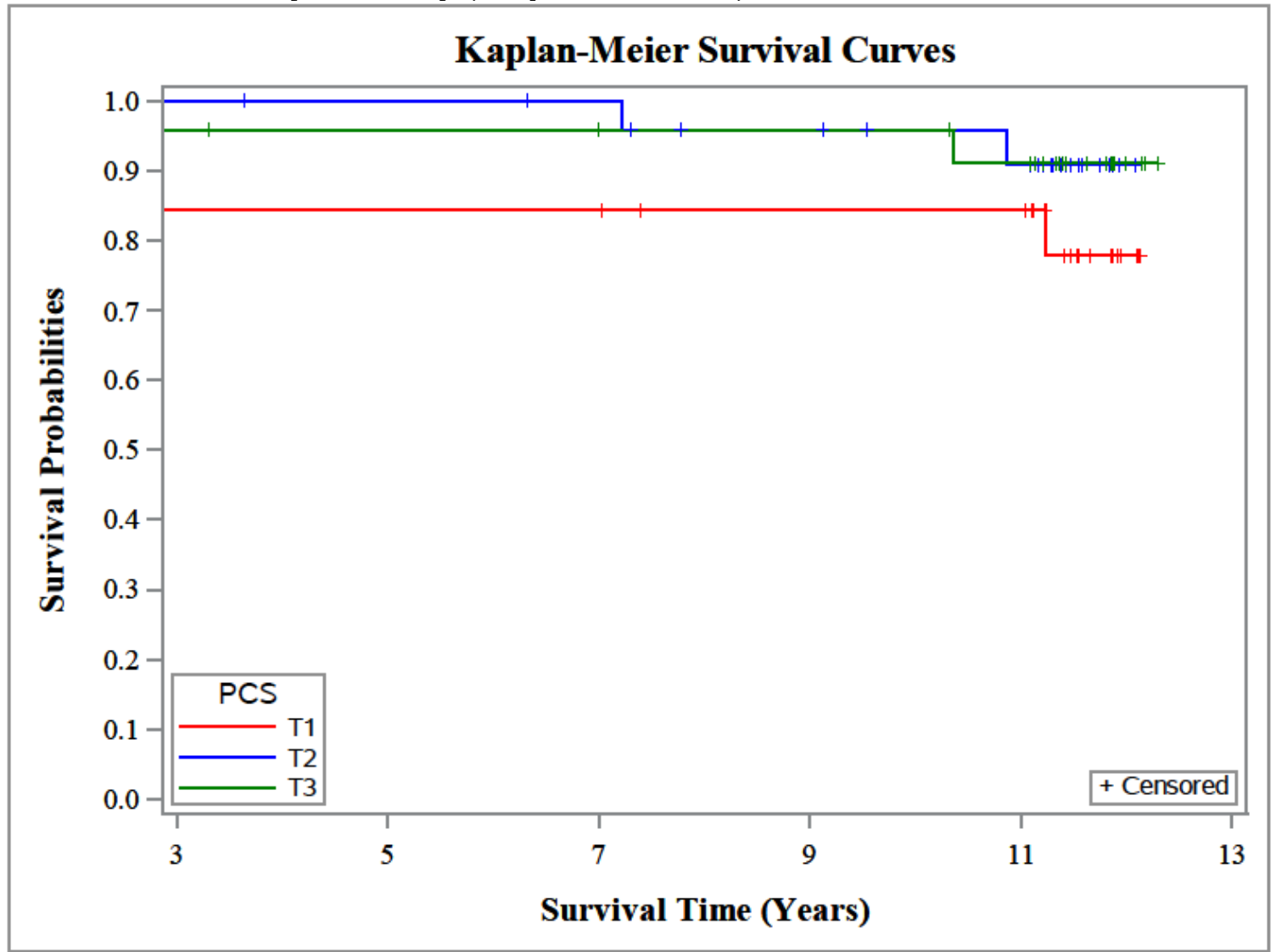




\section{CURRICULUM VITAE}

Delvon T. Mattingly

University of Louisville

Department of Epidemiology and Population Health

485 E Gray St.

Louisville, KY 40202

(502) - 500 - 3974

Delvon.mattingly@louisville.edu

\section{EDUCATION}

Master's of Science, Epidemiology, Expected: August 2018

University of Louisville, Louisville, KY

Advisor: Dr. Stephanie Boone

Bachelor's of Science, Public Health

University of Louisville, Louisville, KY

Summa cum laude

\section{PROFESSIONAL EXPERIENCE}

2017- Robertson, R. M., Bhatnagar, A. (PIs), et al.; AHA Tobacco Regulation and Addiction Center (A-TRAC) (three project areas-1. Cardiovascular Toxicity of Tobacco Products, 2. Cardiovascular Injury Due to Tobacco Use, and 3. Perception of Tobacco Use in Vulnerable Populations). Graduate Assistant for Project 3. National Institutes of Health (NIH) and Food and Drug Administration (FDA), \$19.6 million, 2013-2018, Term: February 2017 Present.

2017-18 Graduate Research Assistant, Department of Environmental and Occupational Health Sciences, University of Louisville, Term: August 2017 - January 2018.

2018-18 Graduate Research Assistant on a National Institutes of Health (NIH) funded grant (1R15ES028440-01) for the "Developmental CSE: Impact of Intestinal Bacterial Community Development”, Term: January 2017 March 2018. 
2018- Volunteer Research Assistant, Department of Communications, University of Louisville, Term: May 2018 - Present.

\section{PUBLICATIONS}

\section{Manuscript Published}

2018

Hart, J. L., Walker, K. L., Sears, C. G., Tompkins, L. K., Lee, A. S., Mattingly, D. T., Groom, A., Landry, R., Giachello, A. L., Payne, T. J., Kesh, A., Siu, A., Smith, C., Robertson, R. M. (2018, January). "The 'State' of Tobacco: Perceptions of Tobacco among Appalachian Youth in Kentucky". Tobacco Prevention \& Cessation.

\section{Manuscripts in Submission}

2018 Sims, M., Glover L. M., Ma, J., Kesh, A., Tompkins, L., Hart, J. L., Mattingly, D. T., Walker, K., Robertson R. M., Payne, T. J. (2018, February). "The Social Patterning of Electronic Nicotine Delivery System Use among US Adults". Preventive Medicine. Manuscript Submitted.

2018 Ma, J., Hart, J., Walker, K., Giachello, A., Groom, A., Landry, R., Tompkins, L., Vu, T-H., Mattingly, D., Sears, C., Kesh, A., Hall, M., Robertson, R. M., Payne, T. (2018, April). "Perceived Health Risks of Electronic Nicotine Delivery Systems (ENDS) Users: The Role of Cigarette Smoking Status". Addictive Behaviors. Manuscript Submitted.

2018 Landry, R., Groom, A., Vu, T-H., Stokes, A., Berry K., Kesh, A., Hart, J., Walker, K., Giachello, A., Sears, C., McGlasson, K., Tompkins, L., Mattingly, D., Robertson, R., Payne, T. (2018, June). "The Role of Flavors in Electronic Cigarette Initiation and Use Patterns among U.S. Adults". Tobacco Control. Manuscript Submitted.

\section{Manuscripts in Preparation}

2018

Mattingly, D. T., Tompkins, L. K., Rai, J., Sears, C. G., Walker, K. L., \& Hart, J. L. (2018, January). "Tobacco Use and Harm Perceptions among Appalachian Youth". Manuscript to be submitted in August.

Mattingly, D. T., Tompkins, L. K., Rai, J., Sears, C. G., Walker, K. L., \& Hart, J. L. (2018, January). "Tobacco Use and Communication Channel Preferences among Appalachian Youth". Manuscript to be submitted in August. 


\section{Presentations and Papers}

2016

2016

Mattingly, D. T., Boone, S. D., Heitz, A. E., Baumgartner, K. B., \& Baumgartner, R. N., (2016, October). "Health Behaviors and Breast Cancer Risk in Non-Hispanic White \& Hispanic Women". Paper presented at the University of Louisville "Research!Louisville" conference, Louisville, KY.

Heitz, A. E., Boone, S. D., Mattingly D. T., Baumgartner, R. N. \& Baumgartner, K. B., (2016, March). "Healthy Lifestyle Impact on Breast Cancer-Specific and All-Cause Mortality". Paper presented at the University of Louisville "Research!Louisville" conference, Louisville, KY.

Heitz, A. E., Boone, S. D., Mattingly D. T., Baumgartner, R. N. \& Baumgartner, K. B., (2016, March). "Healthy Lifestyle Impact on Breast Cancer-Specific and All-Cause Mortality". Paper presented at the Postersat-the-Capitol conference, Frankfort, KY.

Mattingly, D. T., Tompkins, L. K., Sears, C. G., Walker, K. L., \& Hart, J. L. (2017, September). "Tobacco Communication, Tobacco Culture:

Celebrating Successes and Examining Shortcomings". Paper presented at the annual meeting of the Kentucky Communication Association, Carrollton, KY.

Ma, J. Z., Hart, J. L., Walker, K. L., Giachello, A. L., Groom, A., Landry, R. L., Tompkins, L. K., Vu, T-H., Mattingly, D. T., Sears, C. G., Kesh, A., Robertson, R. M., \& Payne, T. J. (2017, October). "Characterization of Current Adult ENDS Users by Cigarette Smoking Status". Paper presented at the NIH Tobacco Regulatory Science Conference, Bethesda, Maryland.

Mattingly, D. T., Tompkins, L. K., Sears, C. G., Walker, K. L., \& Hart, J. L. (2017, October). "Tobacco Use and Harm Perceptions among Appalachian Youth". Paper presented at the NIH Tobacco Regulatory Science Conference, Bethesda, Maryland.

Stokes, A., McGlasson, K. L., Groom, A., Landry, R. L., Vu, T-H., Hart, J. L., Walker, K. L., Payne, T. J., Giachello, A. L., Sears, C. G., Kesh, A., Tompkins, L., K., Mattingly, D. T., \& Rose Marie Robertson, R. M. (2017, October). "The Role of Flavors in E-cigarette Uptake and Use Patterns: Results from a Survey of US Adults". Paper presented at the NIH Tobacco Regulatory Science Conference, Bethesda, Maryland.

Vu, T-H., Hart, J. L., Walker, K. L., Landry, R., Groom, A., Sears, C. G., Tompkins, L. K., Mattingly'D. T., \& Anshula Kesh' A. (2017, October). "Age Differences in Patterns of Use, Health Knowledge, Perception of E- 
cigarettes and Intention to Quit among Current E-cigarette Users". Paper presented at the NIH Tobacco Regulatory Science Conference, Bethesda, Maryland.

Hart, J. L., Walker, K. L., Sears, C. G., Tompkins, L. K., Mattingly, D. T., Groom, A., Landry, R., Giachello, A. L., Payne, T. J., Lee, A. S., Kesh, A., Siu, A., Smith, C., \& Robertson, R. M. (2018, February). The "state" of tobacco: Perceptions of tobacco among Appalachian youth in Kentucky. Paper presented at the annual meeting of the Society for Research on Nicotine \& Tobacco, Baltimore, Maryland.

2018 Ma, J. Z., Hart, J. L., Walker, K. L., Giachello, A. L., Groom, A., Landry, R. L., Tompkins, L. K., Vu, T-H., Mattingly, D. T., Sears, C. G., Kesh, A., Robertson, R. M., \& Payne, T. J. (2018, February). "Characterization of Current Adult ENDS Users by Cigarette Smoking Status". Paper presented at the annual meeting of the Society for Research on Nicotine \& Tobacco, Baltimore, Maryland.

2018 Tompkins, L. K., Sears, C. G., Walker, K. L., Mattingly, D. T., \& Hart, J. L. (2018, March). "Knowledge of Tobacco-Related Cardiovascular Disease Risks: A Study of Appalachian Youth". Paper presented at the 2018 American Academy of Health Behavior, Portland, Oregon.

Mattingly, D. T., Chea T., Cockrell, R., Farley G., Christian C., \& Neal, R. E. (2018, March). "Prevalence and Correlates of Tobacco and ENDS Product Use among Young Adult, University Students of Louisville, Kentucky: the 2017 SPOTS Survey". Paper presented at the Graduate Student Regional Research Conference, Louisville, Kentucky.

Mattingly, D. T., Tompkins, L. K., Sears, C. G., Walker, K. L., \& Hart, J. L. (2018, March). "Youth Tobacco Users Perceive Less E-cig Harm". Circulation, 137, AP087. Paper presented at the EPI Lifestyle Scientific Sessions, New Orleans, Louisiana.

Vu, T-H. T., Hart, J. L., Walker, K. L., Landry, R., Groom, A., Sears, C. G., Tompkins, L. K., Mattingly, D.T., Kesh, A., Giachello, A. L., \& Payne, T. J. (2018). Age Differences in Patterns of Use, Health Knowledge, Perceptions, and Intention to Quit Among Current E-cigarette Users. Circulation, 137, AP103. Paper presented at the EPI Lifestyle Scientific Sessions, New Orleans, Louisiana.

Mattingly, D. T., Tompkins, L. K., Rai, J., Sears, C. G., Walker, K. L., \& Hart, J. L. (2018, June). "Tobacco Use and Communication Channel Preferences Among Appalachian Youth". Paper presented at the Society for Pediatric and Perinatal Epidemiologic Research Annual Conference, Baltimore, Maryland. 

Hart, J. L. (2018, June). "Tobacco Use and Communication Channel Preferences Among Appalachian Youth". Paper presented at the Society for Epidemiologic Research Annual Conference, Baltimore, Marlyand.

Mattingly, D. T., Tompkins, L. K., Rai, J., Sears, C. G., Walker, K. L., \& Hart, J. L. (2018, June). "Tobacco Use and Communication Channel Preferences Among Appalachian Youth". Paper presented at the 2018 NIH Tobacco Regulatory Science Meeting, Baltimore, Marlyand.

Hart, J. L., Walker, K. L., Tompkins, L. K., Zachary, A., Wood, L., Mattingly, D. T., Pfeiffer, J. (2018, September). "Environmental Health: Engaging a Community in Research, Partnership, and Practice". Paper to be presented at the Kentucky Communication Association Conference, Prestonsburg, Kentucky.

\section{CONFERENCE PARTICIPATION}

2017

2017

2017

2017

2017

2018

2018

2018

2018
AHA Tobacco Regulation and Addiction Center (A-TRAC) Annual Meeting, Louisville, Kentucky (2017, March).

American College of Epidemiology Annual Meeting, New Orleans, Louisiana (2017, September).

IdeaFestival, Louisville, Kentucky (2017, September).

The Root Cause Coalition's Second Annual Summit on the Social Determinants of Health, Louisville, Kentucky (volunteer \& attendee) (2017, October).

National Institutes of Health (NIH) Tobacco Regulatory Science Conference, Bethesda, Maryland (2017, October).

Graduate Student Regional Research Conference (GSRRC), Louisville, Kentucky (2018, March).

EPI Lifestyle 2018 Scientific Session, New Orleans, Louisiana (2018, March).

Society for Pediatric and Perinatal Epidemiologic Research Annual Conference, Baltimore, Maryland (2018, June).

Society for Epidemiologic Research Annual Conference, Baltimore, Maryland (2018, June).

\section{MEDIA APPEARANCES}

2018

Heflin, J., (2018, June). "Public Health Student Discusses Unique Research Program, Epidemiology Interests". UofL News. Article. Louisville, Kentucky. 
School of Public Health \& Information Sciences Website. Article. Louisville, Kentucky.

2018 Hebert M., (2018, July). "Cancer Education Program; Grawemeyer Winner; Sayed Akhlaq — Scholar at Risk". UofL Today with Mark Hebert. Radio Talk. Louisville, Kentucky.

\section{HONORS}

Public Health John Snow Scholarship, University of Louisville, Louisville, KY

2015 Public Health Merit Scholarship, University of Louisville, Louisville, KY

2016 Outstanding Capstone Project Award, University of Louisville, Louisville, $\mathrm{KY}$

2016 Undergraduate Summa Cum Laude Award, University of Louisville, Louisville, KY

2016 Department of Epidemiology \& Population Health Scholarship, University of Louisville, Louisville, KY

2016 NCI R25 Cancer Education Program Grant, University of Louisville, Louisville, $\mathrm{KY}$

2016 NCI R25 Cancer Education Program $1^{\text {st }}$ Place Award for best research and presentation, University of Louisville, Louisville, KY

2017 IdeaFestival Fellowship, University of Louisville, Louisville, KY

2018 University of Louisville School of Public Health \& Information Sciences Travel Scholarship Recipient, University of Louisville, Louisville, KY

\section{PROFESSIONAL MEMBERSHIP}

2017- Member, American Heart Association Tobacco Regulation and Addiction Center (A-TRAC)

2018- $\quad$ Member, Society for Epidemiologic Research (SER)

2018- Member, Society for Pediatric and Perinatal Epidemiologic Research (SPER)

\section{CERTIFICATIONS}

Teaching English as a Foreign Language (TEFL) Certification (150 Hours)

University of Toronto, Toronto, Canada

\section{FICTION PUBLICATIONS}

\section{Fiction in Periodicals}


Mattingly, D.T., (2018, May). "Perfect Match”. The Fiction Pool: online. Mattingly, D.T., (2018, May). "Ana and the Window". Scrutiny Journal: online.

2018 Mattingly, D.T., (2018, June). "Neither of Us Are Boyfriends". Literally Stories: online.

2018 Mattingly, D.T., (2018, July). "Behind the Pancakes". Scarlet Leaf Review: print.

Mattingly, D.T., (2018, July). "Move On, Irene”. Corvus Review: online.

2018 Mattingly, D.T., (2018, August). "A Final Moment in 1911”. The Cabinet of Heed Literary Journal: online

2018 Mattingly, D.T., (2018, August). “Sometimes Heroes Can't Wear Brown Skin". X-R-A-Y Literary Magazine: online.

2018 Mattingly, D.T., (2018, September). "Your Kind of Thing". STORGY Magazine (Forthcoming): online.

2018 Mattingly, D.T., (2018, September). "Nobody Cares”. MoonPark Review (Forthcoming): online.

2019 Mattingly, D.T., (2019, January). “A Little Bit of Everything”. Red Queen Literary Magazine (Forthcoming): online.

2019 Mattingly, D.T., (2019, January). "Even the Decent Ones Are Brutal". Red Queen Literary Magazine (Forthcoming): online.

2019 Mattingly, D.T., (2019, April). "Poems for the Devil". Riggwelter (Forthcoming): online.

\section{Drabbles in Periodicals}

2018

2018
Mattingly, D.T., (2018, February). "Try Again”. The Drabble: online. Mattingly, D.T., (2018, June). "Knots That Matter". 101 Words: online. 